\title{
Manual of Plant
}

\section{Species Suitability for}

\section{Reclamation in Alberta}

\section{-- 2nd Edition}

\section{Recreation, Parks and}

Wildlife Foundation

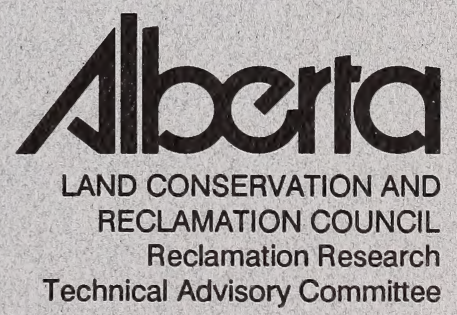




\section{Alberta's Reclamation Research Program}

Regulating surface disturbances in Alberta is the responsibility of the Land Conservation and Reclamation Council. The Council executive consists of a Chairman from Alberta Environment and two Deputy Chairmen from Alberta Forestry, Lands and Wildlife. The Council oversees a reclamation research program, established in 1978 , to identify the most efficient methods for achieving acceptable reclamation in the province. Funding for the research program is provided by Alberta's Heritage Savings Trust Fund, Land Reclamation Program.

To assist with the development and administration of the research program, the Council appointed the inter-departmental Reclamation Research Technical Advisory Committee (RRTAC). The Committee consists of eight members representing the Alberta Departments of Agriculture, Energy, Forestry, Lands and Wildlife, and Environment, and the Alberta Research Council. The Committee updates research priorities, reviews research proposals, organizes workshops, and otherwise acts as the coordinating body for reclamation research in Alberta.

Additional information on the Reclamation Research Program may be obtained by contacting.

Chris Powter, Chairman

Reclamation Research Technical Advisory Committee

Alberta Environment

3rd Floor, Oxbridge Place

9820 - 106 Street

Edmonton, Alberta T5K 2J6

(403) $427-4147$

Additional copies of this report may be obtained from:

Publications Services

Queen's Printer

11510 Kingsway Avenue

Edmonton, Alberta T5G 2 Y5

(403) $427-4952$

This report may be cited as:

Hardy BBT Limited 1989. Manual of plant species suitability for reclamation in Alberta - 2nd Edition. Alberta Land Conservation and Reclamation Council Report No. RRTAC 89-4.

$436 \mathrm{pp}$. 


\section{MANUAL OF PLANT SPECIES}

\section{SUITABILITY FOR RECLAMATION}

\section{IN ALBERTA}

-- 2ND EDITION

by

Hardy BBT Limited

Prepared for

ALBERTA LAND CONSERVATION AND RECLAMATION COUNCIL (Reclamation Research Technical Advisory Committee) 
Digitized by the Internet Archive in 2015 


\section{Reclamation Research Technical Advisory Committee}
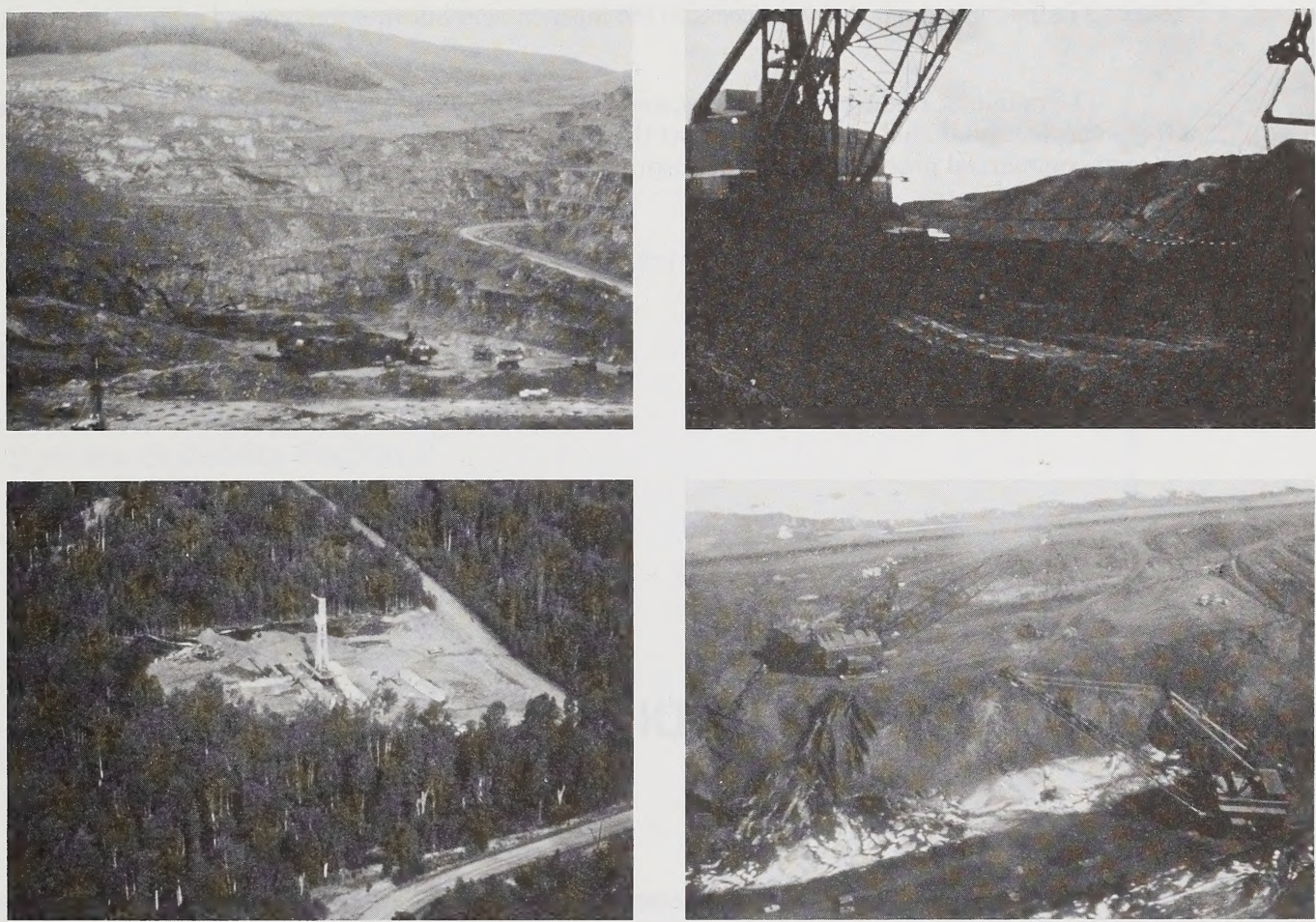

Mission: To coordinate and foster reclamation research in Alberta.

Members: Chris Powter (Chairman) - Alberta Environment; Sharon Guenette (Secretary) - Alberta Forestry, Lands and Wildlife; Leon Marciak Alberta Agriculture; Reinhard Hermesh - Alberta Environmental Centre; David Lloyd - Alberta Forestry, Lands and Wildlife; Sam Takyi - Alberta Forestry, Lands and Wildlife; Hugh Wollis - Alberta Forestry, Lands and Wildlife; Harry Sahay - Alberta Energy; Stephen Moran - Alberta Research Council. 


\section{DISCLAIMER}

This report is intended to provide government and industry staff with up-to-date technical information to assist in the preparation and review of Development and Reclamation Approvals, and development of guidelines and operating procedures. This report is also available to the public so that interested individuals similarly have access to the most current information on land reclamation topics.

The opinions, findings, conclusions, and recommendations expressed in this report are those of the author(s) and do not necessarily reflect the views of government or industry. Mention of trade names or commercial products does not constitute endorsement, or recommendation for use, by government or industry.

\section{CO-FUNDING AGENCIES}

RRTAC would like to thank the Recreation, Parks and Wildlife Foundation for their support in preparing this manual. 


\section{TABLE OF CONTENTS}

Page

ACKNOWLEDGEMENTS

$\begin{array}{lr}\text { INTRODUCTION } & 1\end{array}$

$\begin{array}{ll}\text { Reclamation Planning } & 1\end{array}$

HOW TO USE THE MANUAL 2

Combined Performance Chart 2

Species Suitability Maps 2

Summary Table 2

Species Information 2

Example of How to Select Plant Species for a Particular Site 3

SPECIES SUITABILITY REGIONS

Species Suitability Region $1 \quad 5$

Species Suitability Region $2 \quad 5$

Species Suitability Region $3 \quad 5$

Species Suitability Region $4 \quad 8$

Species Suitability Region $5 \quad 8$

Species Suitability Region $6 \quad 9$

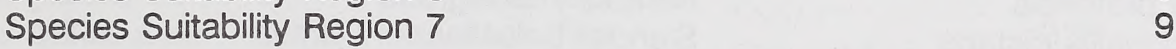

\section{SPECIES INFORMATION - GRASSES}

Combined Performance Chart - Grasses 13

Agropyron dasystachyum . . . . Northern Wheatgrass $\quad 14$

Agropyron elongatum ..... . Tall Wheatgrass 18

Agropyron intermedium ..... Intermediate Wheatgrass 22

Agropyron pectiniforme ..... Crested Wheatgrass 26

Agropyron riparium ....... Streambank Wheatgrass 32

Agropyron smithii ........ Western Wheatgrass 36

Agropyron spicatum ....... Bluebunch Wheatgrass 40

Agropyron subsecundum .... Bearded Wheatgrass 44

Agropyron trachycaulum .... Slender Wheatgrass 48

Agropyron trichophorum .... Pubescent Wheatgrass 54

Agrostis alba .......... Redtop 58

Agrostis scabra ......... Hair Grass 62

Alopecurus arundinaceus .... Creeping Foxtail 66

Arctagrostis arundinacea .... Reed Polar Grass

Bromus inermis .......... Smooth Brome 74

Bromus marginatus ........ Mountain Brome 78 
Page

Calamagrostis canadensis ... Bluejoint 82

Calamagrostis purpurescens . Purple Reed Grass 86

Calamovilfa longifolia ....... Sand Grass 90

Carex atherodes ......... Awned Sedge 94

Carex rossii . . . . . . . . . . . Ross's Sedge 98

Dactylis glomerata . . . . . . . O Orchardgrass 102

Deschampsia caespitosa . . . . Tufted Hair Grass 106

Distichlis stricta ......... Saltgrass 110

Elymus innovatus ........ Hairy Wild Rye 114

Elymus junceus . . . . . . . . Russian Wild Ryegrass 118

Festuca arundinacea . . . . . . Tall Fescue 122

Festuca ovina .......... Sheep Fescue 126

Festuca rubra .......... Red Fescue 130

Hierochloe alpina . . . . . . . . Sweetgrass 134

Hordeum jubatum ........ Foxtail Barley 138

Koeleria macrantha . . . . . . . . June Grass 142

Lolium perenne ... . . . . . . Perennial Ryegrass 146

Muhlenbergia asperifolia . . . . . Scratch Grass 150

Oryzopsis hymenoides . . . . . . Rice Grass 154

Phalaris arundinacea ...... Reed Canarygrass 158

Phleum alpinum .......... Alpine Timothy 162

Phleum pratense ........ Timothy 166

Poa alpina ........... Alpine Bluegrass 170

Poa compressa ......... Canada Bluegrass 174

Poa pratensis .......... Kentucky Bluegrass 178

Puccinellia distans . . . . . . . . Slender Salt-Meadow Grass 182

Stipa viridula . . . . . . . . . . . Green Needle Grass 186

Trisetum spicatum . . . . . . . Spike Trisetum 190

\section{SPECIES INFORMATION - FORBS}

Combined Performance Chart - Forbs 195

Astragalus cicer . . . . . . . . . Cicer Milk Vetch 196

Epilobium spp. . . . . . . . . Fireweed 200

Hedysarum spp. . . . . . . . Hedysarum 204

Lathyrus ochroleucus . . . . . . . Pea Vine 208

Lotus corniculatus . . . . . . . Birdsfoot Trefoil 212

Lupinus argenteus . . . . . . . Silvery Lupine 216

Medicago spp. . . . . . . . Alfalfa 220

Melilotus alba .......... Sweetclover 226

Onobrychis viciifolia ........ Common Sainfoin 230

Oxytropis spp. . . . . . . . . L Loco-weed 234

Trifolium hybridum . . . . . . . Alsike Clover 238

Trifolium pratense ....... Red Clover 242 
Trifolium repens ......... White Clover

Vicia americana ......... Wild Vetch

250

\section{SPECIES INFORMATION - SHRUBS AND TREES}

Combined Performance Chart - Shrubs and Trees 255

Abies lasiocarpa ........ Alpine Fir 256

Acer negundo .......... Manitoba Maple 260

Alnus crispa ........... Green Alder 264

Alnus sinuata . . . . . . . Sitka Alder 268

Alnus tenuifolia .......... River Alder 272

Amelanchier alnifolia ...... Saskatoon-berry 276

Arctostaphylos rubra ....... Red Fruit Bearberry 280

Arctostaphylos uva-ursi ..... Bearberry 284

Betula papyrifera ........ Paper Birch 288

Ceanothus velutinus ....... Snow Brush 292

Cornus stolonifera . . . . . . . Red Osier 296

Dryas drummondii ........ Yellow Dryad $\quad 300$

Dryas octopetala ......... White Dryad 304

Elaeagnus commutata ..... Silverberry 308

Juniperus communis . . . . . . Common Juniper 312

Juniperus horizontalis . . . . . Creeping Juniper 316

Larix laricina . . . . . . . Tamarack 320

Picea glauca ........... White Spruce 324

Pinus banksiana ......... Jack Pine 328

Pinus contorta . . . . . . . . . Lodgepole Pine 332

Populus balsamifera . . . . . . . Balsam Poplar 336

Populus tremuloides ....... Trembling Aspen 340

Potentilla fruticosa . . . . . . . Shrubby Cinquefoil 344

Prunus virginiana . . . . . . . Choke Cherry 348

Rosa acicularis ......... Prickly Rose 352

Rosa woodsii .......... Common Wild Rose 356

Rubus idaeus .......... Wild Red Raspberry 360

Salix arctica . . . . . . . . . Arctic Willow 364

Salix bebbiana .......... Beaked Willow 368

Salix glauca ............ Grayleaf Willow 372

Salix scouleriana ......... Scouler Willow 376

Shepherdia canadensis ..... Buffaloberry 380

Spiraea betulifolia . . . . . . . White Meadow Sweet 384

Symphoricarpos albus ...... Snowberry 388

Symphoricarpos occidentalis . Buckbrush 392 


\section{ACKNOWLEDGEMENTS}

\section{Second Printing}

This document was prepared by Hardy BBT Limited through the efforts of a number of individuals over the course of the project. Major contributions were made by Harvey Martens, Ross Parker, Carl Warner, David Reid and Michael Saretsky. Special thanks are due to Evelyn Martens for typing the first draft, and to Cheryle Paterson for completing the final document.

The authors wish to thank Chris Powter, Land Reclamation Division, Alberta Environment, for directing and supporting the project, assisting in the editing, and for providing numerous bibliographic materials and published references.

On behalf of the Reclamation Research Technical Advisory Committee, the authors of this updated manual wish to acknowledge the Recreation, Parks and Wildlife Foundation for co-funding the project.

We also wish to thank the following organizations for their cooperation in granting permission to reproduce the species illustrations that were added to the manual:

1. Agriculture Canada for illustrations in:

111 Range and Forage Plants of the Canadaian Prairies, Publication No. 1751 , by J. Looman. (1983).

Prairie Grasses Identified and Described by Vegetative Characters, Publication No. 413, by K.F. Best, J. Looman and J.B. Campbell (1971).

Wild Plants of the Canadian Prairies, Publication No. 965, by A.C. Budd and K.F. Best (1969).

2. Industrial Vegetation Management Association of Alberta for illustrations in:

Tree and Shrub Identification Guide, by D.G. Blackmore, W. Inkpen, M.S. Allan and G.R. Barth (1980).

3. National Museum of Natural Sciences, Ottawa, Canada, for illustrations in:

Rocky Mountain Wild Flowers, by A.E. Porsild (Ottawa, 1986).
Vascular Plants of Continental Northwestern Territories, by A.E. Porsild and W.J. Cody (Ottawa, 1980).

4. Royal British Columbia Museum for illustrations in:

The Pea Family of British Columbia, Handbook No. 32, by T.M.C. Taylor (1974).

5. Saskatchewan Museum of Natural History for illustrations in:

Saskatchewan Wildflowers: Western Area, by L.T. Carmichael (1967).

6. United States Government, Superintendent of Documents for illustrations in:

Manual of the Grasses of the United States. Miscellaneous Publication No. 200, by A.S. Hitchcock (1950).

\section{First Printing}

The authors wish to express their gratitude to the following individuals and agencies for their invaluable assistance in the preparation of the Manual of Plant Species Suitability for Reclamation in Alberta:

- Mr. Henry Thiessen and the Land Conservation and Reclamation Council for funding this compilation and supporting its aspirations.

- Dr. Paul Ziemkiewicz and the Reclamation Research Technical Advisory Committee for thoughtfully and conscientiously developing the terms of reference for this Manual, after much feedback and discussion with their various departments and the consultants, and for guiding its course over the research term.

- Dr. Percy Sims, Research Management Division, Alberta Environment, for providing considerable early encouragement, guidance and support, and for generously providing bibliographic materials and published references for use in this project. 
- Representatives of numerous private and government agencies for unreservedly opening their files and resources to the authors, so that the many details of the accounts could be developed in a systematic manner. These include:

Messrs. C. Leary, P. King, J. Sherstabetoff and Dr. S. Takyi of the Reforestation and Reclamation Branch, Alberta Forest Service; Mr. G. Wheeler of the Plant Industry Laboratory, Alberta Agriculture; Dr. Ali Khan of the Alberta Oil Sands Environmental Research Program, Department of Genetics, University of Alberta; Mr. J.A.G. Howe of the Tree Nursery Division, Prairie Farm Rehabilitation Administration; Mr. G. Grainger of the Provincial Tree Nursery, Alberta Agriculture; Mr. J. Dick of the Environment and Land Use Committee, Government of British Columbia; Dr. A. Fedkenheuer of Syncrude Canada Ltd.; Mr. D. Klym of Suncor Inc.; Messrs. R. Logan and R. Ferster of Luscar-Sterco (1976) Ltd.; Mr. K. Wallace of Alberta Gas Trunk Line Company Limited; Dr. J. Railton of Calgary Power Ltd.; Mr. M. Vaartnou of Vaartnou and Sons Enterprises Ltd.; and Mr. P. Lulman of LGL Limited.

- The many respondents to our questionnaire regarding current reclamation research and operations, who offered and provided invaluable guidance in outlining the scope of the project, and in identifying information sources (list of respondents appended).

- The Library, Alberta Environment for providing access to numerous references and resources.

- Mr. Bernd Martens, for his energetic assistance in documenting contents of references, preparing accounts and providing specialized knowledge of wildlife utilization.

- Ms. Jennifer Hansen, who carefully and systematically documented reference materials and made major contributions to the introductory chapter.

- Ms. Sonia Jung, who coordinated and carried most of the burden of typing this manuscript and whose patience and attention to detail have made the Manual both attractive and correct.

- And finally, to the many, many concerned reclamationists throughout Canada and the United States, who provided encouragement and guidance in our attempt to make this effort meaningful to researchers, operations people and other practitioners in Alberta and elsewhere in North America.

Without this level of support, enthusiasm and concern, such an ambitious undertaking could not have been possible. The authors truly hope that the contents will be useful into the future, and will provide a core of data upon which to build in years to come. 


\section{INTRODUCTION}

In 1980 RRTAC published RRTAC Report No. 80-5: Manual of Plant Species Suitability for Reclamation in Alberta to provide users with information on a variety of plant species suitable for use in reclamation programs in Alberta. The manual was well received and went out of print in late 1988. An "updated" manual was prepared in 1989. The "update" added new information on the species in the manual which had become available through operational and research activities, primarily in Alberta. Performance data on new varieties tested in Alberta and new species (Pinus banksiana and Agropyron dasystachyum) were also added to the manual. With the addition of the new species the manual includes information on forty-four grasses, fourteen forbs and thirty-five trees and shrubs.

The objectives of the "update" were:

1. to reprint original information in RRTAC Report 80-5: Manual of Plant Species Suitability for Reclamation in Alberta, and

2. to add new information to the manual.

Prior to reprinting, the species information was reorganized under several major headings: Species Biology, Species Tolerances and Reclamation Considerations. In order to further improve the accessibility of the information contained in the manual, a summary page with a suitability map was prepared for each species. The summary, presented in tabular form, provides, for key reclamation parameters, a rating of the performance of each species. A Species Suitability Map for each species identifies the ecoregion(s) of Alberta where the species is best suited, based upon information from field test results and natural occurrence of the species in Alberta.

A Combined Performance Chart was also prepared for each of the grass, forb and tree/shrub groups, rating each species for selected key reclamation parameters.

\section{Reclamation Planning}

Effective reclamation of disturbed lands is very much dependent on good planning. The main constituents of a reclamation plan are:

description of existing site conditions

choice of final land use

establishment of final landform

water management and erosion control

soil reconstruction, and

revegetation
Detailed information on the existing site conditions is an important component of reclamation planning. This baseline information includes data on slopes, elevations, aspects, drainage patterns, vegetation and soil conditions. Soils information can be used to determine the need for amendment or to select soils suitable for salvage. Description of vegetation provides information on plant species adapted to local climatic and soil conditions. An examination of species colonizing nearby disturbed areas is also beneficial as this is valuable in understanding natural plant succession. This will also provide information on local sources of plant materials for use in revegetation.

The choice of final land use should be determined at an early stage in the planning process, so that the economics and practicality of various reclamation options can be assessed. The appropriate land use should be chosen after discussion between the landowner(s), developer and various regulatory agencies.

The post-development landform should be compatible with the post-development land use objective and drainage regime. A critical feature of reclamation planning is to prevent erosion of the disturbed area, and to protect off-site water quality conditions.

A prerequisite to successful reclamation is the preparation of a suitable soil for plant growth. Where soil conditions are marginal because of some adverse physical or chemical properties, the chance of successful reclamation will be greatly enhanced by ameliorating these properties to acceptable levels for plant growth, especially if climatic conditions are extreme.

The revegetation phase of reclamation should be viewed as a land management process, rather than a "one-time" task. It involves obtaining suitable seed, determination of plant nutrient requirements, propagation of plant material, planting (often in stages), monitoring success and on-going maintenance.

This plant species manual has been prepared to aid in selection of plant species suitable for reclamation in Alberta. It is designed to enable the user to select appropriate plant species that are adapted to specific site conditions. Where sites to be reclaimed are extensive, variability between microsites should be considered. Differences in microsite characteristics may result in a decision to plant different species in different locations within the disturbance site. 
HOW TO USE THE MANUAL

To select appropriate species using this manual, the following procedure should be followed:

1. Refer to the combined performance chart at the head of each section dealing with grasses, forbs, trees and shrubs.

2. Next, use the Species Suitability Map to determine if the species is adapted to growing in your area of interest.

3. Refer to the Summary Table which provides information on individual species tolerances and preferences. Use this information to refine your choice to those species most adapted to the site conditions.

4. Finally, review the species description to confirm final species selection.

\section{Combined Performance Chart}

The combined performance chart at the head of each major section rates the preference of each species according to a number of key parameters critical to reclamation success, i.e., cold tolerance, drought tolerance, $\mathrm{pH}$ tolerance, salt tolerance, textural preference. Using this chart a number of potentially suitable species may be identified.

The next step is to turn to each of these species within the manual. The summary page for each species, always situated at the beginning of each new species and on the left hand page, provides a map showing the region in Alberta where the species is expected to do best. It may also grow elsewhere, but it is likely that other available species will perform better in those areas.

\section{Species Suitability Maps}

The ecoregion map of Alberta, as developed by Strong and Leggat (1981), was used as the basis for delineating regions within Alberta which are most suitable for the reclamation species. These are described in the section "Species Suitability Regions." The basic assumption in using this approach is that a revegetation species tested on a typical site within an ecoregion will most likely be adapted to the normal range of sites within that entire ecoregion. The recommended area for a given species corresponds to the ecoregion where there is a good probability of success on the normal range of sites. The conditional area refers to ecoregions where the species may be expected to perform well but it has not been tested in the ecoregion, or it may perform well on particular sites or with special management.
Strong and Leggat recognized twelve ecoregions with distinctive climatic conditions and vegetation. For the purpose of this manual some of these ecoregions have been combined into one. The reasons for this are several: in some cases performance data of the revegetation species are not precise enough to distinguish between ecoregions or, as in the case of the Cordilleran ecoregion, it was impossible to indicate on the small map whether the species was suited to alpine, subalpine or montane. In this case, if a species is adapted to any one of these three ecoregions, the entire Cordilleran ecoregion will be shaded. Adaptability of the species to this diverse region can be determined from the Summary Table below the species suitability map. A species with very high winter hardiness would be adapted to alpine ecoregions, a high winter hardiness would indicate adaptation to the subalpine ecoregion but not the alpine, and a moderate rating would indicate that the species is adapted to the montane, but not the alpine or subalpine regions. It should be noted that Canada Parks Service has strict rules regarding plant species that may be used within National Park boundaries. These rules should be checked as part of the species selection process.

\section{Summary Table}

The Summary Table includes the information in the combined performance chart plus information on several other key tolerances and preferences. Tolerances and preferences summarized in this table are based on information contained in the species descriptions. When different tolerances are reported, they are given as a range. Where a particular value (eg. $\mathrm{pH}$ ) has been reported, this value is included in the Summary Table. Some species may be eliminated after considering the summary information. For those species still in the running, the information contained within the Manual should be considered carefully to be assured that the species is adapted to the site and will provide the desired plant cover.

\section{Species Information}

Information about the species covers a wide range of topics. This is presented in a quantitative form where such information is available. It is also presented in a qualitative form as described in the original reference or where a rating could be inferred from habitat observations. Various adjectives used in the literature have been converted to standardized ratings summarized in the combined performance charts. Examples of 
these adjectives (with the standardized version in brackets) are given below:

moderate (medium), extremely (very high or none), good (medium), very good (high), best (very high), tolerant (high), very tolerant (very high), excellent (high), relatively (medium), some (medium), long-lived (very high), poor (low), fair (low), mildly (low), strongly (high), performed well (high), heavy grazing (high).

In general, if equally reliable information sources provided contradictory data on the tolerances, preferences or characteristics of a species, the divergent facts were presented. In some cases, recommendations or data from the literature were very case or site specific These were not presented if it was considered to be misleading to the user.

In describing the taxonomy of each species the nomenclature of Moss (1983) has been adopted. Where a species was not contained in Moss (1983), the reference has been cited.

An important feature of this Manual is that all sources of information have been cited. Identifying numbers for references from which information was drawn have been provided following each statement. Where the user finds unreferenced statements, information has been supplied by the authors based on their observations, or professional judgements. It was considered important to address every parameter unless the information required was highly specific and/or no indications whatsoever emerged.

Some of the parameters addressed in the species accounts are straightforward. Several, however, are variable in their detail and scope:

Ecological Setting - This parameter includes commonly associated species under natural conditions, habitat, preferred ecological zone, precipitation requirements, favored microsite conditions and elevational preferences (where these are known).

Soll Preferences - This describes not only moisture (drainage) and textural considerations, but soil orders of common occurrence, preferred soil depth, optimum slope and exposure, and known success under specific artificial soil conditions.

Seed or Planting Stock Availability - Included here is not only commercial availability of seed, but details of licensing and experimental cultivars.

Methods and Ease of Establishment - This covers a wide range of topics associated with seeding and transplanting methods and success, including fertilizer and equipment requirements, ease of establishment, germination, early survival, seed purity and viability, and seasonality of collections, storage, seed preparation and planting. Reliable details were not available in all cases. It should be kept in mind that adapted ecotypes are usually preferable. Selection of the proper commercial cultivar should also be carefully considered (Lowen and Walker 1989). In many cases, seed merchants or seed catalogues are very helpful. Where seeding rates and dates have been given it must be kept in mind that these are only for general reference - the reader should always evaluate local conditions and requirements before selecting a seeding rate and time.

Current Status for Reclamation - This is the broadest of all the sections. It includes experimental and operational experiences in Alberta through 1988, elsewhere in Canada, and in the United States. It attempts to cover the recommended types of industrial and agricultural uses and, if not in use, where promising situations exist. Usually, a brief summation of the species' chief advantages and disadvantages for reclamation under Alberta conditions is also provided.

Should the manual not provide the level of information or the detail required, references in the bibliography should be consulted.

\section{Example of How to Select Plant Species for a Particular Site}

An example is given here to illustrate use of the Plant Species Manual for determining a list of appropriate plant species. Assume that there is a site disturbed by pipeline construction near Lethbridge. The soils have a loam to sandy loam texture and are moderately saline (electrical conductivity values range from 6 to $10 \mathrm{mS} / \mathrm{cm}$ ). The site is well to moderately well drained with moderate (10 to $15 \%$ ) slopes and is presently used for grazing cattle. Plant species (grasses and legumes) suitable for use will therefore need to have the following attributes: drought tolerance, salt tolerance, palatability, persistence and capability for providing an erosion controlling cover.

\section{STEP 1}

Refer to the Combined Performance Charts for grasses and forbs (Tables 2 and 3) to obtain a list of potentially suitable species. Those species with ratings of medium or better for each of the desired attributes are considered suitable. These include: 
Agropyron dasystachyum

Agropyron intermedium

Agropyron smithii

Agropyron trachycaulum

Agropyron trichophorum

Bromus inermis

Elymus junceus

Festuca arundinacea

Festuca rubra

Oryzopsis hymenoides

Poa compressa

Pucinella distans

Lotus corniculatus

Medicago spp.

\section{STEP 2}

Refer to Figure 1 and to the Species Suitability Maps for each species to determine if each species is adapted to growing in the appropriate Species Suitability Region (2). Eliminate those species that are not recommended for this Species Suitability Region. In this example Lotus corniculatus was eliminated.

\section{STEP 3}

Refer to the Summary Table (below the Species Suitability Map) which provides further information on individual species tolerances and preferences. Features which are considered here are soil moisture preferences (moist to dry), soil texture preferences (medium to coarse textured), browse tolerance, and availability of seed. The resulting list of species now includes:

Agropyron dasystachyum

Agropyron intermedium

Agropyron trachycaulum

Agropyron trichophorum

Bromus inermis

Elymus junceus

Oryzopsis hymenoides

Poa compressa

Medicago spp.

\section{STEP 4}

Review the species descriptions to confirm final species selection. Features which can be considered include nutrient requirements, susceptibility to disease and insect damage, soil building capability, competitive ability and methods and ease of establishment. Bromus inermis was eliminated because of its tendency to dominate other grasses in a mixture. Agropyron trachycaulum and Oryzopsis hymenoides were eliminated because they do best on moist sites. The final list of species includes:

Agropyron dasystachyum

Agropyron intermedium

Agropyron trichophorum

Elymus junceus

Poa compressa

Medicago spp.

These species are well adapted to the climatic conditions of the area, and will provide an erosion controlling cover that is self-sustaining. They are also salt tolerant and will also produce a high yielding pasture.

Information on availability of appropriate commercial cultivars and assistance with formulation of the seed mix can be obtained form local seed merchants. 


\section{SPECIES SUITABILITY REGIONS}

The seven regions of species suitability are described in Table 1 and their distribution is shown on Figure 1. The twelve ecoregions recognized by Strong and Leggat (1981) have been maintained and where several ecoregions have been combined, a range of vegetation, soil and climatic conditions are indicated.

\section{Species Suitability Region 1}

This corresponds to the Short Grass Ecoregion (Table 1) and is located in the southeastern corner of Alberta. The Short Grass Ecoregion has the lowest mean summer precipitation $(210 \mathrm{~mm})$ of any ecoregion in Alberta. The mean yearly precipitation is $340 \mathrm{~mm}$ with a range of 260 to $380 \mathrm{~mm}$. The mean May to September temperature is $15.0^{\circ} \mathrm{C}$ with a range from $14.5^{\circ}$ to $16.0^{\circ} \mathrm{C}$. The warmest month is July with a mean temperature of $18.5^{\circ} \mathrm{C}$ and a range of 17.5 to $20.0^{\circ} \mathrm{C}$, the warmest summer conditions of any ecoregion in the province.

The high summer temperatures, low precipitation, strong winds, and high insolation combine to produce high potential evapotranspiration values and a large climatic moisture deficit (260 to $350 \mathrm{~mm}$ ). This moisture deficit is a severe limiting factor for many plants.

Snow depths are shallow with relatively few days with continuous snow cover. This ecoregion has the lowest mean October to April precipitation. The cold mean winter (December to February) temperatures $\left(-10.5^{\circ} \mathrm{C}\right)$ coupled with shallow snow cover lead to very harsh winter conditions for vegetation.

The southwest corner of this ecoregion receives an average of 35 chinook days per year, but the remaining area receives 10 to 20 chinook days. (A chinook day is defined as one with the daily maximum temperature above $4^{\circ} \mathrm{C}$ from December to February).

The plant species of this ecoregion reflect the severe deficit that occurs during mid to late summer. Grama grass is the dominant species with significant amounts of spear grass. During wetter periods of climatic cycles, spear grass increases in cover. Modal soils within this ecoregion are medium textured, well to moderately well drained Brown Chernozems.

\section{Species Suitability Region 2}

This corresponds to the Mixed Grass Ecoregion which is situated adjacent to the Short Grass Ecoregion. The Mixed Grass Ecoregion receives between 200 and $290 \mathrm{~mm}$ of precipitation during the May to September period. This is approximately $50 \mathrm{~mm}$ higher than for the Short Grass Ecoregion. The slightly lower summer temperatures (range 13.5 to $15.0^{\circ}$ C) result in lower potential evapotranspiration. The climatic moisture deficit in the Mixed Grass Ecoregion ranges from 200 to $300 \mathrm{~mm}$ with a mean of $240 \mathrm{~mm} ; 60 \mathrm{~mm}$ less than for the Short Grass Ecoregion.

In comparison with the Short Grass, the Mixed Grass Ecoregion has similar winter temperatures, a deeper snow cover, and the snow remains on the ground longer, however these differences are small. The southern portions of this ecoregion receive about 30 chinook days per year, while the northern portions receive less than 10 chinook days.

The modal vegetation is dominated by spear grass with secondary quantities of grama grass and wheat grass. Shrubs (buck brush and wolf willow) and trees (aspen) occur where moisture is locally available throughout most of the growing season. Mixed Grass sites that are drier than the modal conditions have vegetation more typical of the Short Grass Ecoregion. Modal soils in this ecoregion are moderately well drained Dark Brown Chernozemic soils.

\section{Species Suitability Region 3}

This Species Suitability Region comprises two ecoregions: The Fescue Grass and Aspen Parkland Ecoregions. The Fescue Grass Ecoregion lies west of the Mixed Grass Ecoregion and is the smallest grassland ecoregion. The Aspen Parkland Ecoregion is located north of the Mixed Grass and west of the Fescue Grass Ecoregions. The Aspen Parkland and Fescue Grassland receive nearly equal amounts of summer precipitation; however, precipitation occurs early in the summer within the Fescue Grassland which produces a significant late summer moisture deficit.

Mean yearly precipitation in the Aspen Parkland is $450 \mathrm{~mm}, 50 \mathrm{~mm}$ more than the Mixed Grass Ecoregion. Mean annual precipitation ranges from $390 \mathrm{~mm}$ at Camrose to $720 \mathrm{~mm}$ at Mountain ViewBirdseye, a zone of high precipitation restricted to 


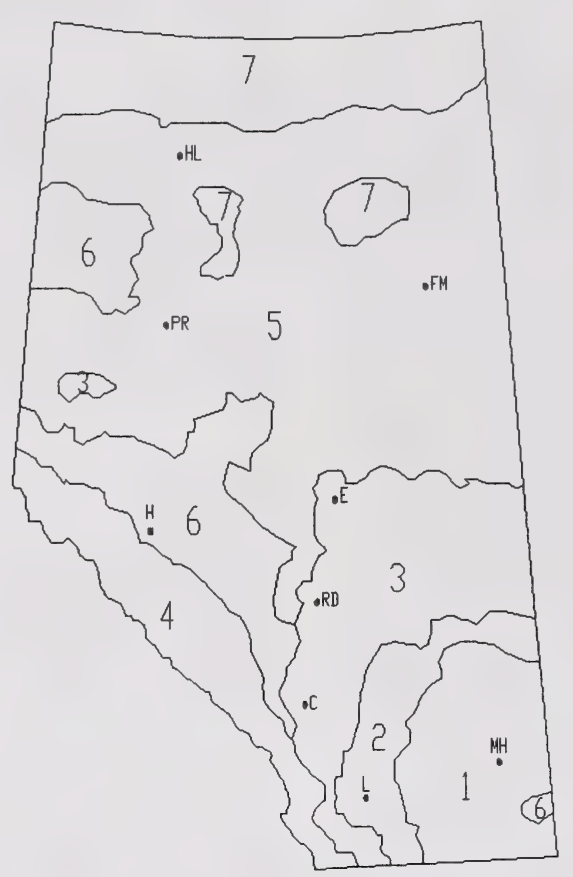
1. Short Grass
2. Mixed Grass
3. Aspen Parkland - Fescue
4. Subalpine - Montane - Alpine
5. Boreal Mixedwood
6. Boreal Foothills - Uplands
7. Boreal Northlands - Subarctic

Figure 1. Species Suitability Regions 


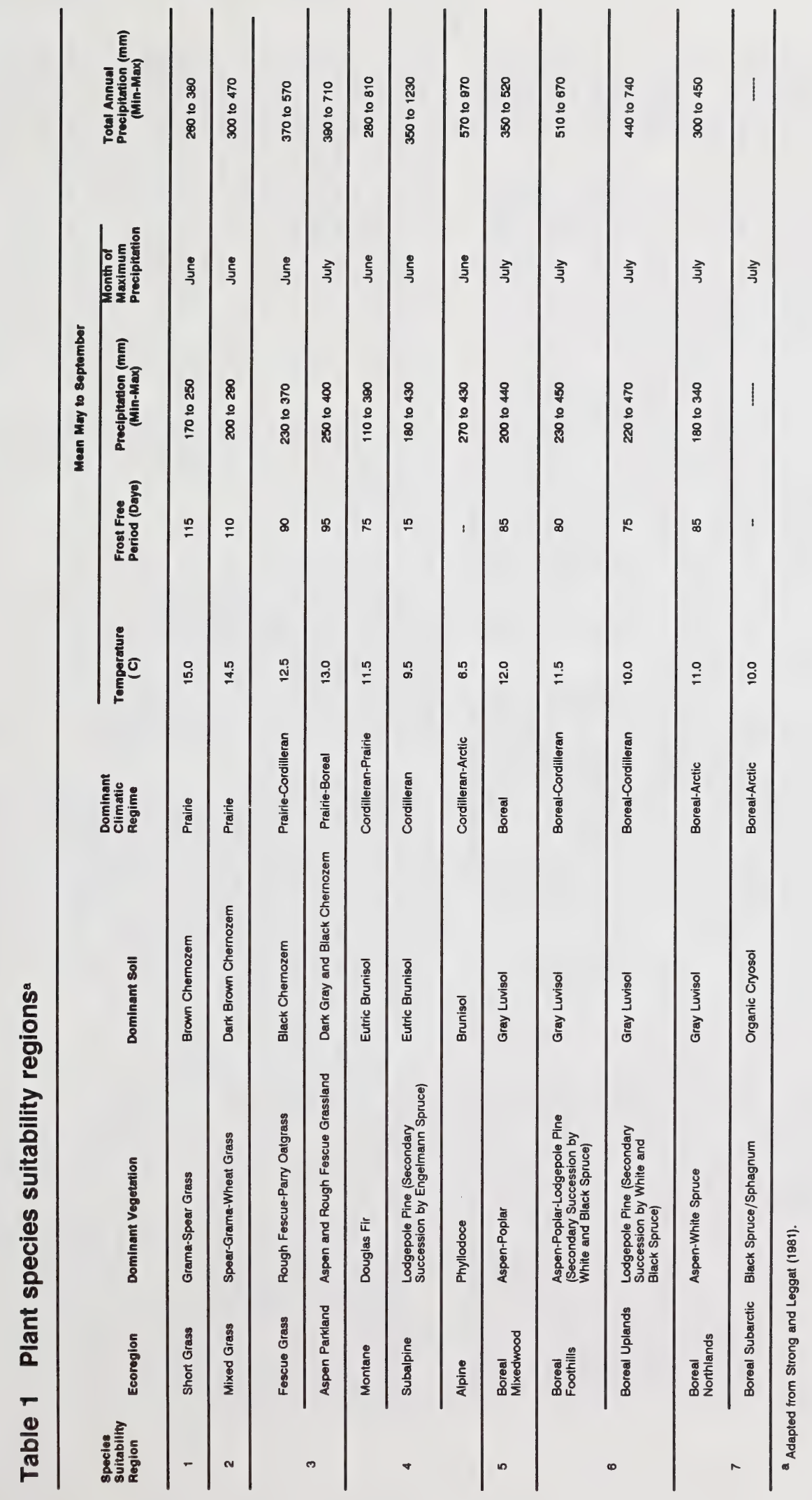


the foothills. Although the range of mean May to September temperatures in the Aspen Parkland is greater than in the Fescue Grassland, the mean values for the two regions are similar.

The Aspen Parkland was delineated on the basis of co-existent Chernozemic soils (Black and Dark Brown) and aspen/grassland vegetation. Black Chernozems are the common soils within the Fescue Grassland. They have been refered to as "shallow" (less than $30 \mathrm{~cm}$ ) Black Chernozems as opposed to "deep" Black Chernozems which are characteristic of the Aspen Parkland.

Dominant vegetation in the Fescue Grassland is rough fescue with secondary quantities of Parry oat grass. Shrub communities become increasingly important as moisture increases. The Aspen Parkland is a transition zone between boreal forest and prairie grasslands. Plant cover varies from clumps of aspen comprising $15 \%$ cover within fescue grassland and shrub communities, to extensive stands of aspen with patches of grassland.

\section{Species Suitability Region 4}

This Species Suitability Region comprises three ecoregions: the Montane Ecoregion, Subalpine Ecoregion and the Alpine Ecoregion. The Montane Ecoregion is restricted to the foothills and major valleys of the Rocky Mountains. The main occurrances are in the vicinity of the Porcupine Hills, Crowsnest Pass and foothills north of Waterton Lakes National Park. The Bow, Saskatchewan and Athabasca River Valleys also contain Montane Vegetation.

Ecological conditions are highly variable, however the Montane has the warmest December to February temperature (mean of $-7.5^{\circ} \mathrm{C}$ ) of any ecoregion in Alberta. The Montane Ecoregion is distinguished by open stands of Douglas fir on shallow, moderately well drained Eutric Brunisols. In cooler areas, the Douglas fir occupies sites which have well drained soils and/or steep south aspects where solar insolation is increased. Limber pine is largely confined to rapidly drained sandstone outcrops. Grasslands may also be found on steep south-facing slopes or coarse textured soils.

The Subalpine Ecoregion is an altitudinal vegetation zone with the upper boundary formed by the Alpine Ecoregion and the lower boundary abutting the Montane, Aspen Parkland and the Boreal Uplands Ecoregions. It occurs from 1520 to $2135 \mathrm{~m}$ south of the Bow River, 1620 to $2135 \mathrm{~m}$ north of the Bow River, and 1490 to $1975 \mathrm{~m}$ in the vicinity of Grande
Cache. This ecoregion is characterized by snowy cold winters and showery cool summers. Below freezing temperatures in the subalpine are common during all months with the lowest frequency during July and August. The lowest elevations of the Subalpine Ecoregion are characterized bylodgepole pine which shows little evidence of succession to Englemann spruce and/or alpine fir in the first 200 years of stand growth. Soils are typically shallow, poorly developed Eutric Brunisols. Higher elevation sites above the lodgepole pine zone are characterized by Engelmann spruce-alpine fir forests. Spruce is usually much more abundant. Soils are predominantly Eutric Brunisols. At the upper limit of the Subalpine Ecoregion, typical species are dwarfed Englemann spruce, alpine fir and whitebark pine, and open stands of alpine larch. Plant growth is restricted because of low temperatures, high wind, moisture stress, and the short growing season.

The Alpine Ecoregion occurs above the climatic forest-line in the Rocky Mountains. It is characterized by strong winds, long winters and summer coolness. Below freezing temperatures are common even during the warmest months. The Alpine Ecoregion is found above $2135 \mathrm{~m}$ in southern Alberta but declines to about $1980 \mathrm{~m}$ in the northern portions. The mean May to September precipitation is $360 \mathrm{~mm}$ which is $40 \mathrm{~mm}$ higher than in the Subalpine Ecoregion.

Plant communities within the Alpine Ecoregion are characterized by low-growing vegetation whose distribution is strongly influenced by snow cover. Red heather communities are commonly found on moderately well drained sites with white heather communities dominant on mesic to wet sites. Willow communities are found on imperfectly to poorly drained sites resulting from later summer snowmelt and alongside streams.

\section{Species Suitability Region $\mathbf{5}$}

This corresponds to the Boreal Mixedwood Ecoregion which comprises approximately $43 \%$ of the province. This ecoregion has a low energy climate with short winter days and long summer days. Despite the length of summer days, potential solar energy available at the ground surface is lower than ecoregions at lower latitudes. More than $70 \%$ of the total precipitation occurs during the summer with July being the wettest month. Mean annual precipitation is about $440 \mathrm{~mm}$ with a range of 350 to over $600 \mathrm{~mm}$. The Boreal Mixedwood Ecoregion has the coldest mean winter temperature, and the largest range between the mean winter and summer temperatures of all the ecoregions. The mean 
December to February temperature is $-15.5^{\circ} \mathrm{C}$ with a range of -11.5 to $-23.5^{\circ} \mathrm{C}$. The mean frost free period is 85 days, 10 days shorter than for the Aspen Parkland.

The Boreal Mixedwood Ecoregion is primarily composed of deciduous forests dominated by trembling aspen with secondary amounts of balsam poplar. White spruce and balsam fir are the potential climax species on mesic sites. The understory vegetation is varied and includes such species as reed grass, wild rye, pea vine, vetch, roses, dogwood, willows and Saskatoon berry. Soils are predominantly Gray Luvisols.

Jack pine communities developed on sandy parent materials are also common within the Mixedwood Ecoregion. The largest concentration of this vegetation type lies south of Lake Athabasca. Blueberry, bearberry and lichens are major understory components. Soils are primarily Eutric and Dystric Brunsols.

Poorly drained sites within the Mixedwood Ecoregion support black spruce communities, with an understory of Labrador tea, cowberry and mosses.

\section{Species Suitability Region 6}

Species Suitability Region 6 comprises the Boreal Foothills Ecoregion and the Boreal Uplands Ecoregion. The Boreal Foothills Ecoregion lies on the west side of the Boreal Mixedwood Ecoregion and parallel to the Rocky Mountains from Turner Valley northward to the British Columbia border southwest of Grande Prairie. Outliers of this ecoregion occur in the Clear and Saddle Hills, Pelican Mountains, Pushwaskau Hills and Cypress Hills. The mean yearly precipitation is $570 \mathrm{~mm}$ with a range of 510 to $670 \mathrm{~mm}$. Summer precipitation totals vary from 230 to $450 \mathrm{~mm}$ with the outliers receiving less than $300 \mathrm{~mm}$. The mean May to September temperature in the Boreal Foothills is $11.5^{\circ} \mathrm{C}$ with a range of 10.0 to $12.5^{\circ} \mathrm{C}$. Winter temperatures are relatively warm, the mean December to February temperature is $5.0^{\circ} \mathrm{C}$ higher than the Boreal Mixedwood Ecoregion.

This ecoregion is characterized by the codominance of aspen, balsam poplar and lodgepole pine. Paper birch, white spruce, black spruce and fir are also common associates on moderately well drained sites. Both white and black spruce can be successional and potential climax species on the same site. The mixture of species on a given site is dependent on site conditions, geographical location and fire history. In general the deciduous components dominate. The understory vegetation comprises Labrador tea, roses, wild rye, willows, fireweed and wintergreen. Modal soils are Gray Luvisols.

The Boreal Uplands Ecoregion occurs north of the Bow River to the Grande Cache area with outliers occurring in the Clear and Swan Hills. It is associated with both mountain and foothills. The mean annual precipitation is similar to the Boreal Foothills at $570 \mathrm{~mm}$. Summer precipitation varies from 290 to $470 \mathrm{~mm}$ with a mean of $380 \mathrm{~mm}$. The Boreal Uplands has cool summer temperatures with a mean of $10.0^{\circ} \mathrm{C}$ and a range of 8.5 to $11.5^{\circ} \mathrm{C}$. Mean winter temperature $\left(-10.0^{\circ} \mathrm{C}\right)$ is similar to the Boreal Foothills. Lodgepole pine is the prevalent tree species on moderately well drained sites with succession to white spruce, or black spruce on imperfectly drained sites. The understory is less diverse than the Boreal Foothills Ecoregion but includes such species as alder, wintergreen, aster, mosses, twinflower and wild rye. Soils are predominantly Brunisols and Luvisols. Organic and Gleysolic soils are found in poorly drained depressional areas dominated by black spruce.

\section{Species Suitability Region 7}

This region comprises the Boreal Northlands and Boreal Subarctic Ecoregions. The Boreal Northlands Ecoregion is found north of the Boreal Mixedwood with outliers at the upper elevations of the Buffalo Head Hills and Birch Mountains. Mean annual precipitation ranges from 300 to $450 \mathrm{~mm}$. Mean summer temperature is $11.0^{\circ} \mathrm{C}$, and the mean frost free period is approximately 85 days. The mean length of snow cover is 185 days, which is much longer than for any ecoregion except parts of the Subalpine and Alpine.

Mixed aspen and white spruce forests dominate well drained sites within the Boreal Northlands Ecoregion. This ecoregion is distinguished from the adjacent Boreal Mixedwood Ecoregion by the increased abundance of white spruce. Understory species include buffaloberry, wild rose, cowberry, willows, fireweed, blueberry, wild rye, twinflower and mosses. Jackpine stands dominate rapidly to well drained sites. Imperfectly drained sites are dominated by white spruce with secondary quantities of black spruce, while black spruce dominates poorly drained sites.

Luvisolic soils are typical on moderately well drained sites with Dystric Brunisols on well to rapidly drained sites. Gleysolic and Organic soils are found on the imperfectly to poorly drained sites. 
The Boreal Subarctic Ecoregion is limited in extent and is composed of the Cameron Hills, Caribou Mountains and Buffalo Head Hills of northern Alberta. It has wet summers with low energy input which does not allow the soil to warm above freezing. This ecoregion is characterized by the presence of discontinuous permafrost and a sparse forest cover. Open black spruce stands developed on Organic Cryosols are typical with an understory of sphagnum mosses, cloudberry and lichens. Poorly drained sites lack tree cover but have similar ground vegetation.

\section{REFERENCES CITED}

Lowen, K. and D.G. Walker. 1989, Buying seed: The pitfalls and blunders and how to avoid them. IN: Alberta Conservation and Reclamation Conference '88. C.B. Powter (compiler). Proceedings of a conference sponsored by the Alberta chapters of the Canadian Land Reclamation Association and the Soil and Water Conservation Society. Pages 139 - 144.

Moss, E.H. 1983. Flora of Alberta. 2nd Edition revised by J.G. Packer. University of Toronto Press. Toronto, Ontario.

Strong, W.L., and K.R. Leggat. 1981. Ecoregions of Alberta. Alberta Energy and Natural Resources, Resource Evaluation and Planning Division. ENR Technical Report Number: T/4. Edmonton, Alberta. 


\section{SPECIES INFORMATION - GRASSES}

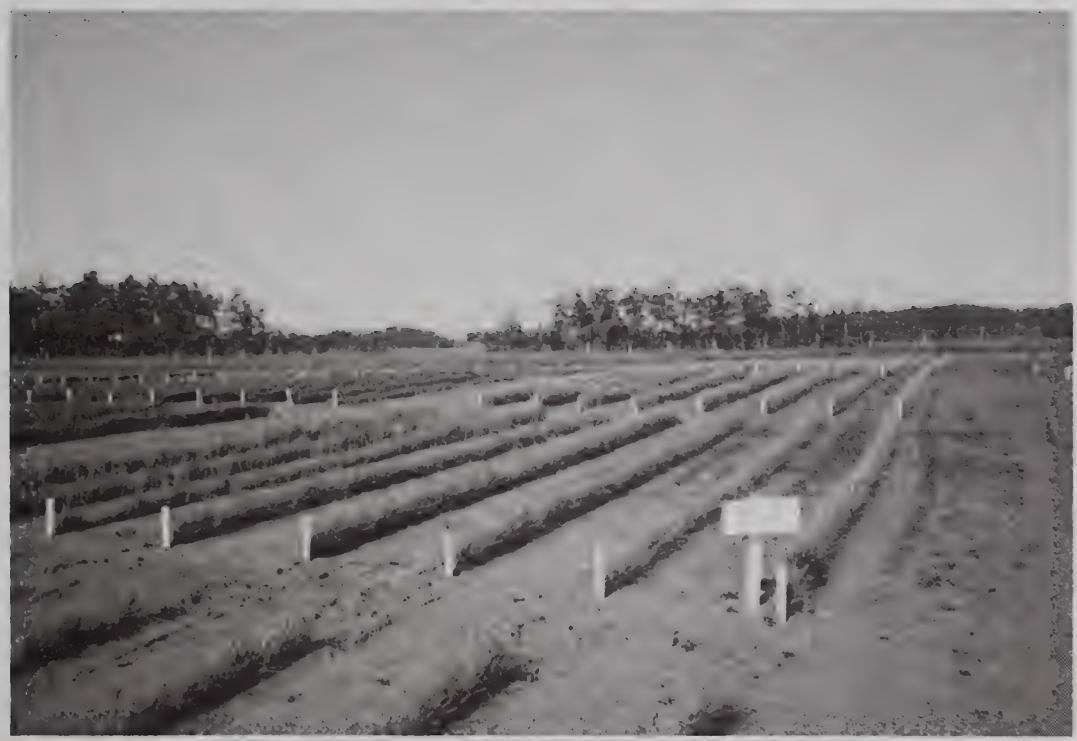




\section{Species}

Reclamation Suitability Criteria

\begin{tabular}{ccccc}
\hline $\begin{array}{c}\text { Drought } \\
\text { Tolerance }\end{array}$ & $\begin{array}{c}\text { Saht } \\
\text { Tolerance }\end{array}$ & $\begin{array}{c}\text { Winter } \\
\text { Hardinese }\end{array}$ & $\begin{array}{l}\text { Soil Reaction } \\
\text { Tolerance }\end{array}$ & $\begin{array}{c}\text { Erosion } \\
\text { Control }\end{array}$ \\
\end{tabular}

Agropyron dasystachyum Agropyron elongatum Agropyron intermedium Agropyron pectiniforme Agropyron riparium Agropyron smithii Agropyron spicatum Agropyron subsecundum Agropyron trachycaulum Agropyron trichophorum Agrostis alba Agrostis scabra Alopecurus arundinaceus Arctagrostis latifolia Bromus inermis Bromus marginatus Calamagrostis canadensis Calamagrostis purpurasecens Calamovilfa longifolia Carex atherodes

Carex rossii

Dactylis glomerata

Deschampsia caespitosa

Distichlis stricta

Elymus innovatus

Elymus junceus

Festuca arundinacea

Festuca ovina

Festuca rubra

Hierochloe alpina

Hordeum jubatum

Koeleria macrantha

Lolium perenne

Muhlenbergia asperifolia

Oryzopsis hymeroides

Phalaris arundinacea

Phleum alpinum

Phleum pratense

Poa alpina

Poa compressa

Poa pratensis

Pucinellia distans

Stipa viridula

Trisetum spicatum

$\begin{array}{lllll}\text { VH } & M & M & M & H \\ H & V H & M & U & V H-H \\ M & M & M & L & M-L \\ H & M-L & V H & U & M \\ H & M & H-M & M & M \\ H-M & H-M & M & M & M \\ H & L & M-L & L & M \\ H-M & M-L & H-M & L & M \\ M & H-M & H & U & H \\ H-M & M & M & M-L & M \\ M-L & L & H-M & H & L \\ M & L & V H & H & U \\ M-L & L & V H-H & H & L \\ L & L & V H & V H & U \\ H-M & M & H-M & M & M \\ M & L & H & L & M \\ H & M & V H & V H & U \\ M & L & H & U & M \\ H & N & M & L & M \\ M & L & M & L & M \\ \text { VH } & L & H & M & L \\ M & L & H-M & M & L \\ M-L & M-L & V H & H & M \\ M & V H & M & U & H \\ L & L & H-M & L & L \\ H-M & H & M & L & M \\ M & H & M & H & M \\ H-M & L & V H & M & L \\ H-M & H-M & V H-H & H & M \\ M-L & M & V H & L & L \\ M & V H & H & N & M \\ H-M & L & H & L & M \\ L & M & H & H & L \\ L & H & M & U & H \\ \text { VH-H } & M & H & L & M \\ M-L & H-L & M & H-M & M \\ H & M & V H & M & M \\ L & L & M & V H & L \\ M & L & V H & H & U \\ H-M & M & H & H & M \\ M-L & L & V H-H & M & M \\ M & V H-H & M & L & H \\ M & L & M & U & M \\ \text { VH-M } & L & V H & M & M \\ & L & & & \end{array}$

H

VH

$\mathrm{H} \quad \mathrm{H}$

VH-H VH

VH-H VH

$\mathrm{H} \quad \mathrm{VH}$

VH $\quad H$

H M

H M

H H-M

M H

$\mathrm{H}$

H

$\mathrm{H}$

H-M

$\mathrm{H}$

M VH-H

H-M

$\mathrm{H}$

$\mathrm{H}$

$\mathrm{H}-\mathrm{M}$

M

H-M

VH

$\mathrm{H}-\mathrm{M}$

M

H

$\mathrm{H}$

H

$\mathrm{H}$

H

M

M

H

$\mathrm{H}-\mathrm{M}$

$\mathrm{H}$

M-L

M

M

H

VH

H

M

M
M

M-L

$\mathrm{H}$

H

L

H-M

$\mathrm{H}$

H-M

$M$

$M$

M-L

$M$

H-M

$M$

$\mathrm{VH}-\mathrm{H}$

$\mathrm{H}$

M-L

L

$M-L$

$M$

H-M

$\mathrm{H}$

M-L

L

H-L

$\mathrm{VH}-\mathrm{H}$

$\mathrm{H}-\mathrm{L}$

H-L

$\mathrm{VH}$

L

M-L

$\mathrm{H}$

$\mathrm{H}$

M-L

$\mathrm{H}$

M-L

$\mathrm{H}$

$\mathrm{H}$

$\mathrm{H}$

$\mathrm{H}$

H-M

$M$

H-M

- very high

- high

- medium

- low

- none

- unknown 
SPECIES SUITABILITY MAP AND SUMMARY TABLE

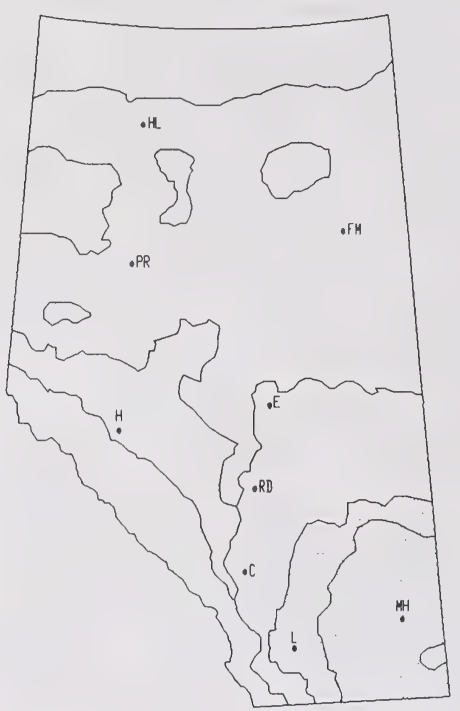

Recommended Area

Commercially Available: Yes $\mathrm{X}$ No

\begin{tabular}{|c|c|c|c|c|c|}
\hline \multirow{2}{*}{$\begin{array}{l}\text { RECLAMATION SUITABILITY } \\
\text { CRITERIA }\end{array}$} & \multicolumn{5}{|c|}{ SUITABILITY RATING } \\
\hline & Very High & High & Medium & Low & None \\
\hline Drought Tolerance & $x$ & $x$ & & & \\
\hline Salt Tolerance & & & $x$ & & \\
\hline Acid & & & 6.0 & & \\
\hline Tolerance Base & & 9.5 & & & \\
\hline Winter Hardiness & & & $x$ & & \\
\hline Erosion Control & & $x$ & & & \\
\hline Persistence & $x$ & & & & \\
\hline Palatability & & & $x$ & & \\
\hline Browse Tolerance & & $x$ & & & \\
\hline Moisture Preference & Moist & dry, w & stands $\mathrm{mc}$ & te $\mathrm{fl}$ & \\
\hline Soil Preference & Mediun & codrs & . & & \\
\hline
\end{tabular}


Agropyron dasystachyum (Hook.) Scribn.

\section{SPECIES BIOLOGY}

Taxonomy - Northern Wheatgrass

Cultivars Elbee and Critana $(709,720)$; thickspike wheatgrass (639).

Interspecific hybrids between northern wheatgrass and slender wheatgrass; and northern wheatgrass and streambank wheatgrass occur naturally in native stands (720).

\section{Origin and Range}

Native. It is widely distributed throughout the prairies. Northern wheatgrass extends from British Columbia east to Michigan, south to Colorado and Illinois.

\section{Growth Habit}

Resembles western wheatgrass but is greener (725). Northern wheatgrass is a cool season perennial, strongly rhizomatous, creeping, aggressive sod forming root system. It will form a tight sod under dryland conditions $(720,727)$. Elbee has a threeway rooting system: creeping underground rootstalks which spread and reproduce, a very shallow fiberous root system, and deep roots which penetrate to at least $60 \mathrm{~cm}$. The plants are tufted with erect leaves and stems 45 to $75 \mathrm{~cm}$ tall.

Nitrogen Fixing - None

\section{Longevity}

"Elbee" is a hardy long-lived perennial.

\section{Self Propogation}

It is a cross-pollinated species (605). High seed yield (716). Strongly rhizomatous (709).

\section{Ecological Setting}

Common to northern parts of the Great Plains and intermountain area (725). Common to both brown and dark brown soil zones, preferring dry areas. Found throughout mixed prairie and parklands (78). Found in varied habitats ranging from heavy soils at valley bottoms to lighter soils on hillsides (627). Critana is adapted to a mean annual precipitation zone of 25 to $40 \mathrm{~cm}$. Requires $20 \mathrm{~cm}$ minimum (639). In areas with mean annual precipitation greater than $46 \mathrm{~cm}$ it is out performed by other species.

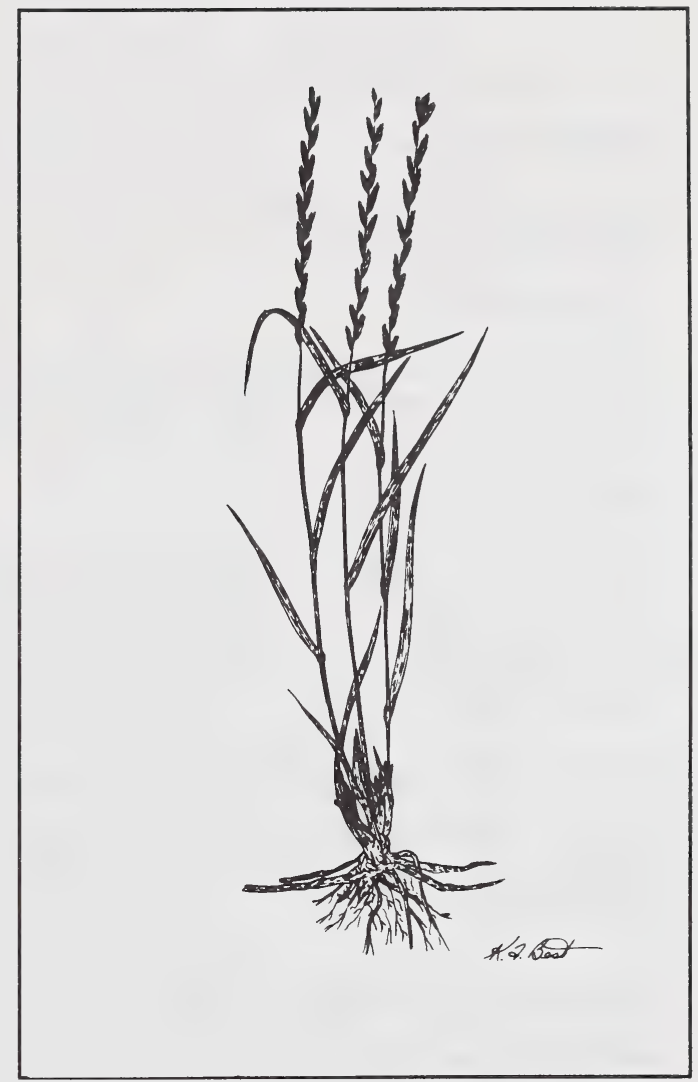

\section{TOLERANCES}

\section{Soil Preferences}

It is adapted to a wide range of soil conditions, but prefers dry medium to coarse textured soils and performs well on sandy soils or shaley clays $(720$, 727). Adapted to coarser textured soils than western wheatgrass (725).

\section{Nutrient Requirements}

It can be inferred from the ability of northern wheatgrass to establish itself on mine spoils, depleted rangeland conditions and eroded areas that its nutrient requirements may be low.

\section{Soil Reaction}

Elbee has been reported to tolerate a range of soil reaction ( $\mathrm{pH} 6.0$ to 9.5) and it tolerates considerable alkalinity (727). 
Soil Salinity

It has moderate tolerance to salinity.

\section{Drought Tolerance}

It has excellent drought tolerance; More so than western wheatgrass (725).

\section{Shade Tolerance}

No specific references in the literature, but may be inferred to be relatively intolerant because of its range.

\section{Grazing or Mowing Tolerance}

It produces good quality hay, but is better suited for pasture as the plants cure on the stem and retain their nutrients over winter and the long creeping roots enable the plants to withstand heavy grazing and considerable trampling $(720,725)$.

\section{Susceptibility to Disease and Insect Damage}

Northern wheatgrass is susceptible to leaf stem rust especially under irrigation, but not under dryland conditions (720).

\section{RECLAMATION CONSIDERATIONS}

\section{Soil Building and Erosion Control Capability}

Has strong sod forming ability. Provides excellent erosion control because of its aggressive creeping rhizomes and relatively deep roots which bind the soil (605). Can be used alone in erosion control plantings (725).

\section{Adaption to Disturbance}

It has good adaption to disturbance as attested to its successful use in ecological repair and vegetation of industrial disturbed areas and depleted rangelands.

\section{Competitive Ability}

It is considered to be compatable with other species because of its wide adaption and because it is suitable for planting in mixtures with other forbs, grasses and shrubs.

\section{Commercial Value}

Suitable for rehabilitation of rangelands and erosion control. It is valued more for its special purpose applications than for its productivity as forage grass (605). Has yielded over $500 \mathrm{~kg} / \mathrm{ha}$ under irrigation (720). Forage yield less than western wheatgrass (725). Elbee northern wheatgrass is well adapted for pasture and hay production in Brown, Dark Brown and Black soil zones in the prairies (716). Elbee is more productive in forage and seed than Critana in trials in Alberta and Saskatchewan but produced about $45 \%$ less forage than crested wheatgrass (716).

\section{Palatability and Nutritive Value}

Northern wheatgrass is considered to have good forage value for cattle.

\section{Seed and Planting Stock Availability}

Elbee (released 1980) is the first variety of northern wheatgrass to be released in Canada (Lethbridge) and seed is readily available. It is tolerant of cold, drought and alkali. Critana (released 1971) is another variety developed in Montana. It is suitable for reclamation of dry sites $(605,720)$. Approximately 154000 seeds/lb (639).

\section{Methods and Ease of Establishment}

Seed holds well and can be combined. It has excellent germination, seedling vigour and early spring growth that suggest it is easy to establish under dryland or irrigation by drilling or broadcast. Establishes more rapidly than Sodar Streambank wheatgrass (720) and Western wheatgrass (725). Fall/spring seeding at a rate of 6 to $8 \mathrm{lbs}$ PLS/ac is recommended (639).

\section{Current Status for Reclamation}

Northern wheatgrass is valued for its special purpose applications. It is used in revegetation of industrially disturbed areas, such as oil and gas well sites, pipeline construction areas, roadside and other construction sites that will receive little or no maintenance. It has been used successfully on mine spoils and in range seedings in Montana and Wyoming (725). May be used for reseeding range sites that are severely eroded and have low fertility (709).

Northern wheatgrass has excellent germination, high seedling vigour and is easy to establish. Its resistance to drought along with its relatively procumbent spreading habit of growth makes it well suited for soil stabilization on dry and alkaline areas. It has also been used successfully on mine spoils and in rangeland rehabilitation. 
SPECIES SUITABILITY MAP AND SUMMARY TABLE

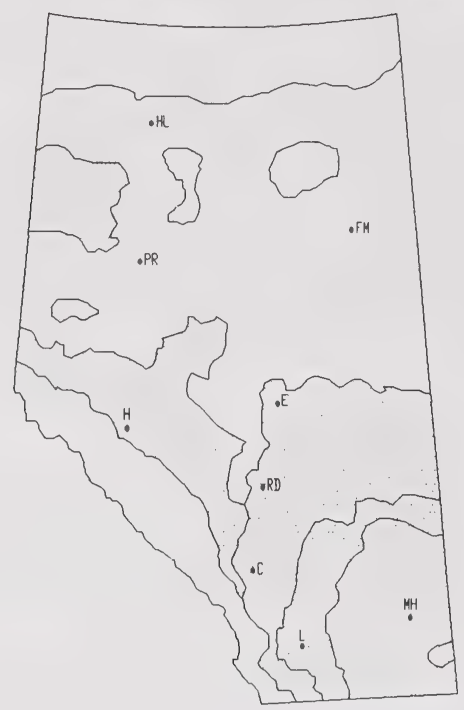

Recommended Area

Commercially Available: Yes $X$ No

\begin{tabular}{|c|c|c|c|c|c|}
\hline \multirow{2}{*}{$\begin{array}{l}\text { RECLAMATION SUITABILITY } \\
\text { CRITERIA }\end{array}$} & \multicolumn{5}{|c|}{ SUITABILITY RATING } \\
\hline & Very High & High & Medium & Low & None \\
\hline Drought Tolerance & & $x$ & & & \\
\hline Salt Tolerance & $x$ & & & & \\
\hline $\mathrm{pH} \quad$ Acid & & & & & \\
\hline Tolerance Base & $x$ & $x$ & & & \\
\hline Winter Hardiness & & & $x$ & & \\
\hline Erosion Control & & & $x$ & & \\
\hline Persistence & $x$ & & & & \\
\hline Palatability & & & $x$ & $x$ & \\
\hline Browse Tolerance & & & $\mathrm{x}$ & & \\
\hline Moisture Preference & Moist & wet, $v$ & tands 3 & eeks & floodin \\
\hline Soil Preference & Well & ed & & & \\
\hline
\end{tabular}


Agropyron elongatum (Host) Beauv.

\section{SPECIES BIOLOGY}

Taxonomy - Tall Wheatgrass

\section{Origin and Range}

Introduced from Eurasia, notably Turkey, Asia Minor and the USSR $(179,426)$. Used throughout western North America especially on the Canadian prairies (47), and the American Great Plains and intermountain region (183).

\section{Growth Habit}

A tall, erect, loosely tufted bunchgrass (47). Typically stemmy, with coarse leaves $(183,179)$. Can be 120 to $180 \mathrm{~cm}$ high $(183,424)$, but the Canadian cultivar "Orbit" is more typically 100 to $110 \mathrm{~cm}$ in height (139). Fibrous root system (47).

Nitrogen Fixing - None

\section{Longevity}

Long-lived, cool season (639) perennial (391), with good overall hardiness (139). The species may be subject to winter killing (391); "Orbit" displays superior winter hardiness $(183,426)$. Late maturing $(183,391,426,179)$.

\section{Self Propagation}

Propagates itself primarily by reseeding (338). Good seed producer, large seeds, and good seedling vigour (183).

\section{Ecological Setting}

Occurs primarily in cultivated stands: hayfields and pastures (47). Also occurs (escaped) on certain dry and/or saline areas (338). Requires a minimum of $20 \mathrm{~cm}$ of precipitation (639).

\section{TOLERANCES}

\section{Soil Preferences}

Adapted to growth on well drained, imperfectly drained and wet soils $(179,391,426,12)$. Specifically adapted to Solonetzic soils, usually where these are in conjunction with brown Chernozems. Also found on Gleysols (179). Often the soils are alluvial, with high water tables and migrating leached salts (179). Does well when water tables are a few centimeters from the surface

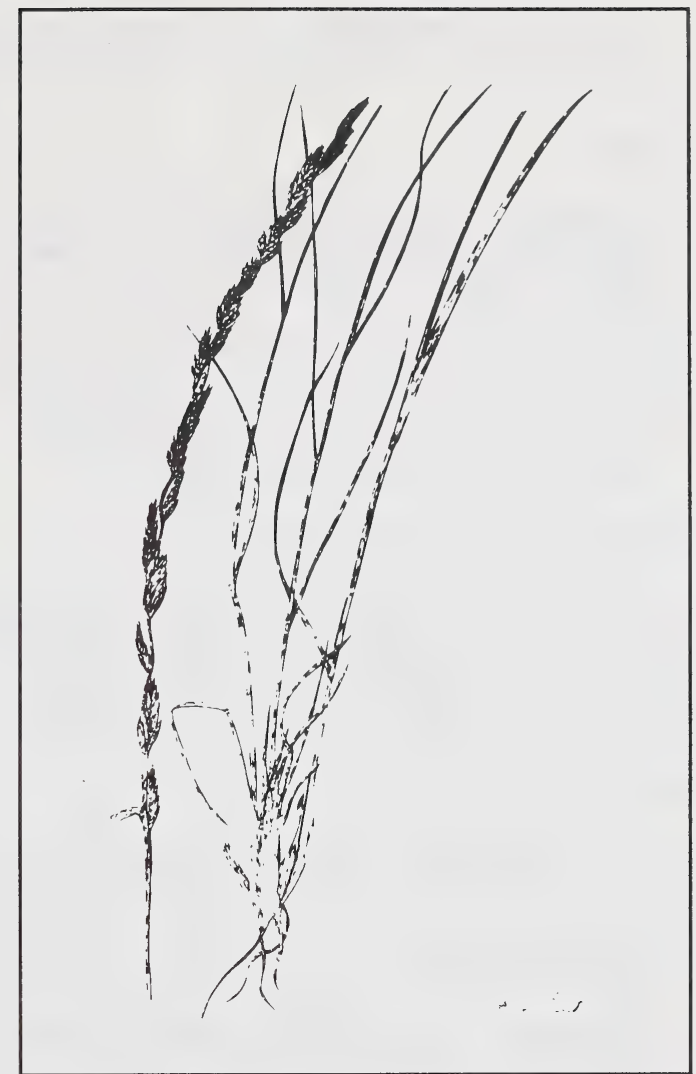

and also when the water table is barely within the rooting zone (340); withstands as much as 3 to 4 weeks of flooding in spring $(391,183)$. All but the most coarse textural classes are acceptable.

\section{Nutrient Requirements}

No specific requirements have been noted, however improved range and pasture lands in the U.S. are supplemented with nitrogen fertilizer annually (179).

\section{Soil Reaction}

Tolerant to very tolerant of alkaline soil conditions $(391,183,179,388,422)$. No $\mathrm{pH}$ ranges have been noted.

\section{Soil Salinity}

Reputed to be "the most salt tolerant of all cultivated grasses" (47). General agreement that the species is highly adapted to saline soil conditions $(391,183$, $422,233,340,179,468$ ) and alkali conditions (639). Grown successfully where as much as $1 \%$ soluble salts occur (340). Variously noted to tolerate 
between 11 and $16 \mathrm{mS} / \mathrm{cm}(468,125)$ and between 8 and $15 \mathrm{mS} / \mathrm{cm}$ (247). May tolerate even higher levels $(422,125)$.

\section{Drought}

A relatively high degree of drought tolerance (391, 340 ), though less drought tolerant than crested wheatgrass or the sod-formers, pubescent and riparian wheatgrass (34). Fared best (with pubescent wheatgrass) under droughty Texas test conditions (375). Its extensive root system reaches down as far as $3 \mathrm{~m}$ in search of water under suitable soil conditions (34). Requires a minimum of $35 \mathrm{~cm}$ of precipitation annually (179).

\section{Heavy Metals and Hydrocarbons}

Tolerant of $5 \%$ soluble boron content of spoil material when grown without amendment; this spoil also had high electrical conductivity $(10 \mathrm{mS} / \mathrm{cm})$ and sodium saturation (30\%) (91). No other tolerances have been specifically noted.

\section{Shade}

May become weak and spindly when growing in shady areas (340).

\section{Grazing or Mowing}

Not as tolerant of heavy grazing as most introduced wheatgrasses; use in the growing stage should not exceed $60 \%$ (340).

\section{Susceptibility to Disease and Insect Damage}

No information located in the literature reviewed.

\section{RECLAMATION CONSIDERATIONS}

\section{Soil Building and Erosion Control Capability}

Extensive fibrous root system produces a high tonnage of residue (179); substantial herbage yields also contribute to accumulation of large amounts of soil organic matter $(183,179)$. Considered a good soil stabilizer (338), although it is not recommended for steep slopes (422).

\section{Adaption to Disturbance}

Relatively well adapted to disturbance (338).

\section{Competitive Ability}

Seems to be a moderately good competitor especially under the extreme soil conditions for which it is adapted. For best hay and pasture however, tall wheatgrass is usually grown alone $(391,179)$.

\section{Commercial Value}

Produces fair hay (391) and its value for pasture is quite high (especially in alkaline-saline areas where high yield forage species usually do poorly), particularly late in summer when it stays green later than most species $(391,179,340)$. Also useful for rehabilitating wet alkaline and saline lands (391) for other crops; with proper cultural methods, drainage, etc., "Alkar" tall wheatgrass (U.S. variety not licensed in Canada) will ameliorate conditions to allow alfalfa and other moderately tolerant species to take over (179). Also used for wildlife plantings $(179,426)$, and for silage $(179,391)$.

\section{Palatability and Nutritive Value}

Generally agreed to be at least moderately palatable for livestock (19) though less so than most other wheatgrasses $(391,183,340)$. Apparently less palatable when found in mixed stands than when occurring in pure stands (340). Late maturity provides increasingly desirable forage into late summer and fall $(391,340)$. There is some evidence however that digestible protein and total digestible nutrients (TDN) are better than for crested wheatgrass (179). Palatability for sheep is equal to tall fescue (Festuca arundinacea), with yields as much as double (179).

\section{Seed or Planting Stock Availability}

Several commercial cultivars are available in the U.S. in quantity, namely "Alkar", "Jose", "Largo" and "Orbit" $(183,139,430)$; Nebraska 98526 is undergoing testing(183). "Orbit" is the only cultivar licensed in Canada (138). Approximately 79000 seeds/lb (639).

\section{Methods and Ease of Establishment}

Very good establishment by both seeding and transplanting (338). Reported to be easily established (391). Recommend planting in pure stands to optimize forage value. Where possible, a deep furrow drill should be used (179). A full season's protection should be provided, and preferably two seasons on dryland (no grazing). Setting seed at least once aids good establishment. Leaving a $15 \mathrm{~cm}$ stubble after cutting will ensure protection from potentially injurious grazing (179). Occasional fertilizations are recommended. A spring seeding at a rate of 8 to $10 \mathrm{lbs}$ PLS/ac has 
been recommended (639).

\section{Current Status For Reclamation}

Widely used to cope with, and combat, saline and alkaline soil problems related to pasture and hay use $(47,391)$. Performed poorly in a grass/legume

mixture at Fort McMurray on amended tailings sand, dying out after 5 to 7 years (645).

Though it has been tested in British Columbia interior on several metal mining refuse substrata, it has fared rather poorly (143); reasons are not readily apparent and more investigation is required.

Tall wheatgrass has a very good performance record at the Decker Coal Mine in Montana, where excess soluble salts and exchangeable sodium are a problem $(117,328)$. Other western U.S. mines are also having encouraging results (90).

Major assets of tall wheatgrass are its tolerance to high levels of alkalinity and salinity, tolerance of boron-containing spoils, tolerance of flooding and high water tables, relative ease of establishment under these conditions, high forage yields and extensive root system. 


\section{SPECIES SUITABILITY MAP AND SUMMARY TABLE}

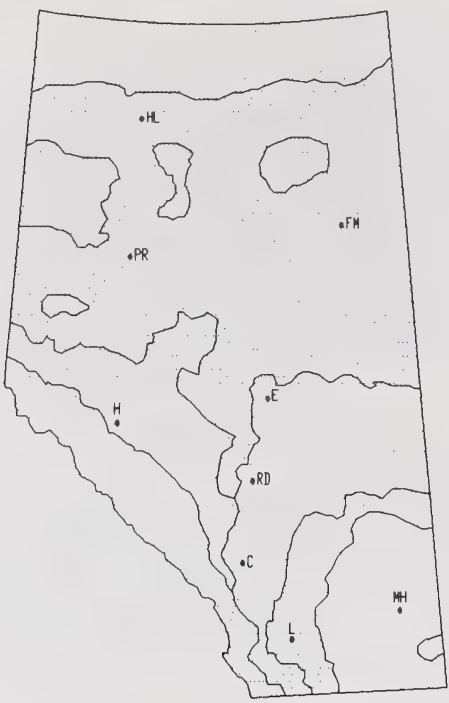

Recommended Area

Commercially Available: Yes $\mathrm{X}$ No

\begin{tabular}{|c|c|c|c|c|c|}
\hline \multirow{2}{*}{$\begin{array}{l}\text { RECLAMATION SUITABILITY } \\
\text { CRITERIA }\end{array}$} & \multicolumn{5}{|c|}{ SUITABILITY RATING } \\
\hline & Very High & High & Medium & Low & None \\
\hline Drought Tolerance & & & $x$ & & \\
\hline Salt Tolerance & & & $x$ & & \\
\hline pH Acid & & & & $x$ & \\
\hline Tolerance Base & & & $x$ & $x$ & \\
\hline Winter Hardiness & & & $x$ & & \\
\hline Erosion Control & & $x$ & & & \\
\hline Persistence & & $x$ & & & \\
\hline Palatability & & $x$ & & & \\
\hline Browse Tolerance & & & $x$ & $x$ & \\
\hline Moisture Preference & Moist. & & & & \\
\hline Soil Preference & Well d & ined, & ile. & & \\
\hline
\end{tabular}


Agropyron intermedium (Host) Beauv.

\section{SPECIES BIOLOGY}

Taxonomy - Intermediate Wheatgrass.

\section{Origin and Range}

Introduced from Eurasia, Turkey the USSR and China $(183,199,340)$. Similar to pubescent wheatgrass (A. trichophorum), except for lack of pubescence on seedheads; the two cross-pollinate and hybridize easily $(179,339)$. Planted throughout western Canada and the western U.S.; common in areas where smooth brome (Bromus inermis) is adapted (391).

\section{Growth Habit}

An erect, leafy sod-forming grass $(183,47)$ which generally attains heights in excess of $100 \mathrm{~cm}(100$ to $120 \mathrm{~cm}$ ) (139). A mild to aggressive sod-former of rhizomatous habit (short rhizomes) $(183,179,47)$ with quick establishment and growth characteristics.

\section{Nitrogen Fixing - None}

\section{Longevity}

Long-lived, cool season (639) perennial, though shorter-lived than crested wheatgrass (A. cristatum) (391). Stands deteriorate rapidly if poorly managed (391). Reasonably good winter hardiness (183). Good pasture is difficult to maintain past 5 years (391).

\section{Self Propagation}

Medium natural reseeding ability and good natural vegetative growth (338). Though rhizomes are usually short, plants spread relatively aggressively under good moisture conditions $(391,179)$.

\section{Ecological Setting}

Primarily occurring in plantations for pastures and range and for revegetated disturbances within its adapted range (199). In Alberta, most common in the aspen parkland (47) and mixed grass prairie. Intermediate wheatgrass prefers moist sites (12) which receive at least 35 to $38 \mathrm{~cm}$ of precipitation annually $(183,639)$. The species is probably restricted to elevations below about $1600 \mathrm{~m} \mathrm{ASL}$, based on research near Sparwood, B.C. $(494,498)$. Northerly and westerly exposures seem to be preferred $(422,498)$. At higher elevations, plants lack vigour and may not set seed (340). Will not persist in the high subalpine (41).

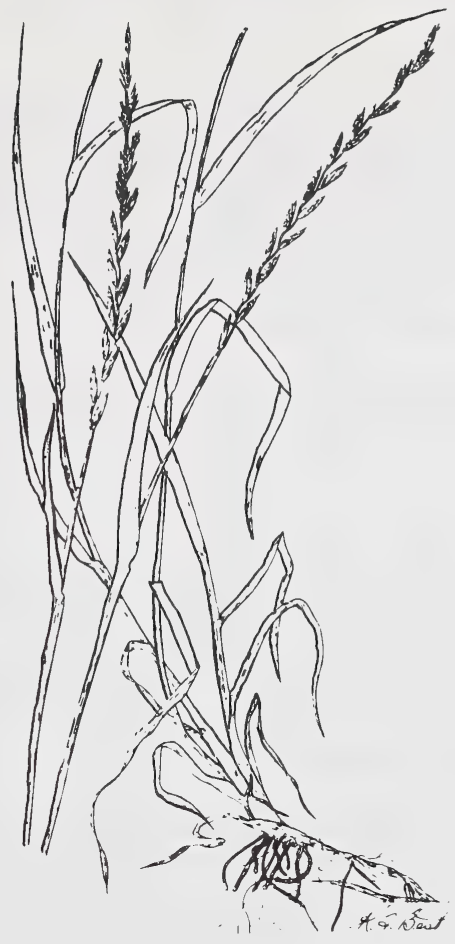

TOLERANCES

\section{Soil Preferences}

Best on well drained, fertile soils that receive ample moisture. Its aggressiveness as a sod-former is enhanced by irrigation (391). Soil classes preferred include the Chernozems and Podzols extending from the better brown soils through to alluvial types (179). Medium textured soils are best (179).

\section{Nutrient Requirements}

May become sod-bound on low fertility lands (340). Requires medium fertility (500).

\section{Soil Reaction}

The species prefers non-alkaline land (179), though it tolerates alkalinity better than acidity (338).

\section{Soil Salinity}

Moderate tolerance to salinity; will withstand electrical conductivities in the range of 5 to 
$10 \mathrm{mS} / \mathrm{cm}(468,125)$. This tolerance is comparable to alfalfa and crested wheatgrass.

\section{Drought}

Intermediate in drought tolerance among the Agropyron group. Superior to slender, bearded, tall and western wheatgrasses, but inferior to crested, streambank, bluebunch and pubescent wheatgrasses (340). It can withstand no less than $28 \mathrm{~cm}$ of precipitation annually (339).

\section{Heavy Metals and Hydrocarbons}

No particular tolerances to heavy metals have been noted from the literature.

\section{Shade}

Not very well adapted to shade (340), but performs well in competitively suppressing undesirable shrubs which in some cases shade it, in Utah. It also withstands high temperatures associated with the arid Utah lowlands (Lower Sonoran zone) (339).

\section{Grazing or Mowing}

Often short-lived when grazed (47). Care should be taken in grazing the stands, even when mixed with alfalfa; moderate rates of grazing produce good results (179). Tolerance is generally excellent (339).

\section{Susceptibility to Disease and Insect Damage}

High tolerance to snow mold (50). Appears to be more resistant to leaf blight than pubescent wheatgrass (A. trichophorum) and is therefore often preferred (340). The "Tegmar" cultivar is more resistant to Banks grass mite than other strains of intermediate wheatgrass (183). Stems are strong and resist lodging (179). Resistance to insects and disease is considered good, relative to other grasses considered for seeding of big game range in Utah (339).

\section{RECLAMATION CONSIDERATIONS}

\section{Soil Building and Erosion Control Capability}

Root production is extremely good. A five year old stand in a mixture with alfalfa produced over $12000 \mathrm{~kg} / \mathrm{ha}$ of roots in the top $20 \mathrm{~cm}$ of soil; about $70 \%$ of this was provided by the grass. Soil structure and resistance to erosion was greatly improved (179). Intermediate wheatgrass is considered an excellent soil stabilizer (338).

\section{Adaptation to Disturbance}

Adaptation to disturbance is good (338).

\section{Competitive Ability}

Its sod-forming habit ensures its good competitive abilities (183). The species is also very compatible with alfalfa for pasture or hay. Phenology is such that the grass is not quite ready to flower when the alfalfa is ready to cut, resulting in excellent quality hay. This practice seems not to affect the longevity of the stand (179). Intermediate wheatgrass is able to competitively suppress shrub growth (339).

\section{Commercial Value}

Chief value is as a pasture and hay crop, though it is also well suited to erosion control including steep slope stabilization (422, 183). Intermediate wheatgrass is often substituted for smooth brome (Bromus inermis) in conservation mixes because of its higher forage production in non-irrigated lands. It is also better suited to the semi-arid brown soils (179). The species can be planted in combination with adapted bunchgrasses (eg. crested wheatgrass) to form a continuous mat (339).

\section{Palatability and Nutritive Value}

Palatable to all classes of livestock (47). Forage value for cattle is considered good (19). More palatable after heading than crested wheatgrass (340). Considered highly palatable on Utah ranges, and preferred forage during critical periods (339). Hay yields are higher than for most other adapted grasses; constitutes excellent pasture, through to late summer (391).

\section{Seed or Planting Stock Availability}

"Clarke" replaces "Chief" as the commercial cultivar available in western Canada. It outyields most grasses in the dark brown soils and under moderately dry conditions "Clarke" will out-produce crested wheatgrass. Five commercial cultivars are available in the U.S. "Amur" originated in China. Though vigorous, it is a slow sod-former with high seed yield. "Greenar" (Reg. No. 3) is an early cultivar which is vigorous, a moderate sod-former, disease resistant, and very productive. It is late maturing, shows good recovery and is widely used for conservation planting. "Oahe" (Reg. No. 5), obtained from the USSR, is tall, vigourous and has high yields of both seed and forage. "Slate" is one of the more strongly spreading cultivars. "Tegmar" is a dwarf strain. It is long-lived, strongly spreading 
and more drought tolerant. It is well suited to waterway planting and erosion control (183). Approximately 88000 seeds/lb (639).

\section{Methods and Ease of Establishment}

Excellent success by both seeding and transplanting (338). Excellent seedling vigour (41). Plantings should be treated similar to pubescent wheatgrass. Seed retains its viability $(70 \%)$ for 6 to 10 years under cool, dry warehouse storage (179). Achieves a very good growth rate (338). A fall/spring seeding at a rate of $8 \mathrm{lbs}$ PLS/ac has been recommended (639).

\section{Current Status for Reclamation}

Widely used in Canada and the U.S. as a pasture and hay species, and to some extent for erosion control along waterways and such areas $(183,179$, 391). Used to reclaim some mine lands in the semiarid intermountain and Great Basin regions(422). Intermediate wheatgrass has been used at three metal minesites in the B.C. interior with moderate success on waste rock and overburden, but poor success on tailings (143). Trial success in the Upper Mackenzie Region of the Boreal Forest was acceptable at latitude $65^{\circ} \mathrm{N}$ (Sans Sault Test Facility) (111) and excellent with "Clarke" after three seasons at latitude $63^{\circ} N(644)$. Encouraging results have been recorded in mine site trials at Grande Cache, Alberta $(268,271)$. Apparently the species is less widely adapted than pubescent wheatgrass (A. trichophorum) (500). 


\section{SPECIES SUITABILITY MAP AND SUMMARY TABLE}

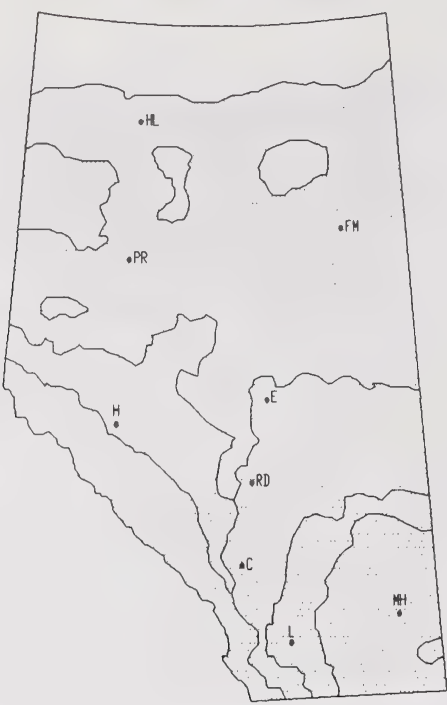

Recommended Area

Commercially Available: Yes $\mathrm{X}$ No

\begin{tabular}{|c|c|c|c|c|c|}
\hline \multirow{2}{*}{$\begin{array}{l}\text { RECLAMATION SUITABILITY } \\
\text { CRITERIA }\end{array}$} & \multicolumn{5}{|c|}{ SUITABILITY RATING } \\
\hline & Very High & High & Medium & Low & None \\
\hline Drought Tolerance & & $x$ & & & \\
\hline Salt Tolerance & & & $x$ & $x$ & \\
\hline Acid & & & & & \\
\hline Tolerance Base & & & $\mathrm{x}$ & & \\
\hline Winter Hardiness & $x$ & & & & \\
\hline Erosion Control & $x$ & $x$ & & & \\
\hline Persistence & $x$ & & & & \\
\hline Palatability & & $\mathrm{x}$ & $x$ & & \\
\hline Browse Tolerance & & $x$ & $x$ & & \\
\hline Moisture Preference & Dry. & & & & \\
\hline Soil Preference & Medium & mod & $1 y$ coarse & cure. & \\
\hline
\end{tabular}


Agropyron pectiniforme Roem. and Schutt.

\section{SPECIES BIOLOGY}

\section{Taxonomy - Crested Wheatgrass}

A. desertorum (Fisch.) Schult.

A. sibiricum (Willd.) Beauv.

A. cristatum (L.) Gaertn.

\section{Origin and Range}

All strains, varieties and species were acquired from the USSR, notably Russia and Siberia $(183,199)$. In the United States, particularly since 1950, the Fairway variety (A. cristatum) has been distinguished from the Standard type (A. desertorum) as a different species (the former is diploid, the latter tetraploid, and apparently little or no natural hybridization occurs) $(183,339)$. Most authors recognize the two as separate, though decidedly similar in habitat, growth habit, and appearance. Some authors, however still treat the two as varieties of A. cristatum (104). Siberian wheatgrass ( $A$. sibericum) is probably also a distinct species, though closely related. A. cristatum predominates in Canada, being widely used in the western provinces, and to some extent used in the American northern Great Plains; Standard crested wheatgrass or desert wheatgrass (A. desertorum) is most common in the United States Great Plains. They both occur in both countries, however (183, 339). Siberian wheatgrass (A. sibericum) is less widely distributed in eastern Europe, and Russia through Siberia. All three have been naturalized and now occur from B.C. and the prairie provinces through Ontario, the Dakotas, Wyoming, Colorado, New Mexico and west to California (199). Their distribution elsewhere in North America is more sporadic, but extends through the mid-western and New England States, Labrador, the Yukon, N.W.T., and Alaska $(214,346)$.

\section{Growth Habit}

The species are all medium height bunchgrasses, and have various spreading abilities. Plants are erect and tufted $(365,348)$. Standard crested wheatgrass is taller than Fairway (about 50 to $75 \mathrm{~cm}$ versus 40 to $60 \mathrm{~cm}$ ), more tufted, has coarser stems and leaves, and is less leafy $(210$, $139,424)$. Siberian wheatgrass more closely resembles standard crested wheatgrass (183), but is reported to be taller (424), and is awnless (179). Standard is a typical bunchgrass; one ecotype is dwarf and tends to be rhizomatous $(339,179)$. Fairway is also a bunchgrass form, but is weakly

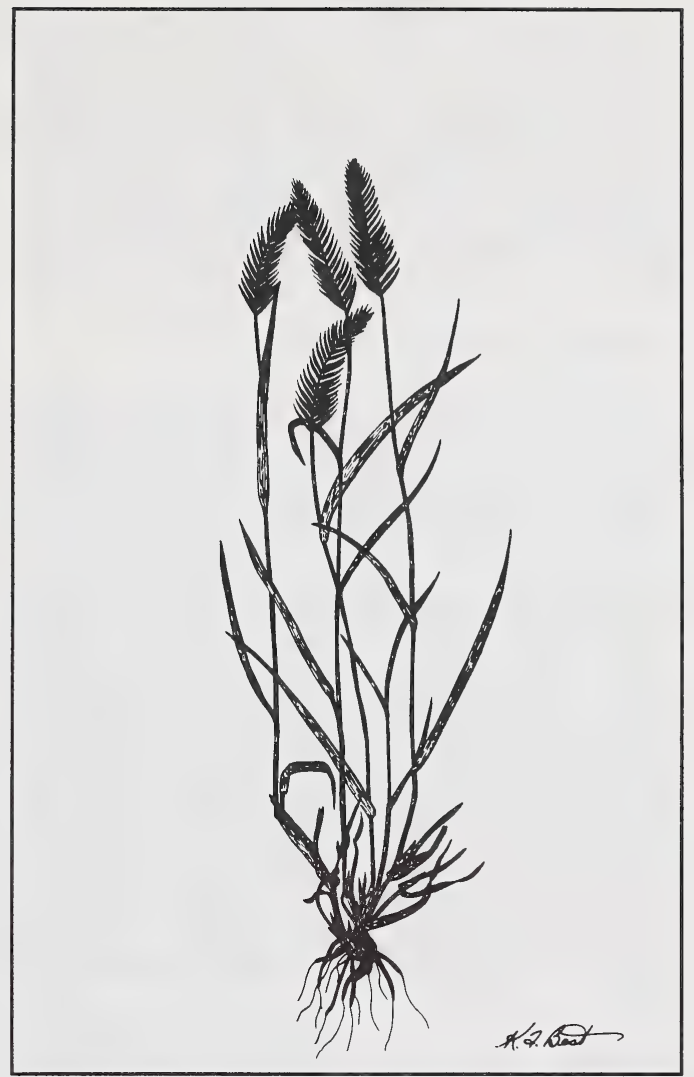

rhizomatous (179) and tillers from the base to produce a persistent, tough sod (339). Siberian is another bunchgrass type.

Nitrogen Fixing - None

\section{Longevity}

Both Fairway and Standard crested wheatgrass are extremely long-lived perennials, often remaining productive for 30 years or more, even under conditions of occasional drought $(286,391,179)$. Mortality is virtually unknown (286) in established stands. Mortality has occasionally occurred where extreme drought took place during a critical phenological stage (286). Crested wheatgrass is a cool season grass (639).

\section{Self Propagation}

The natural reseeding ability of these is considered excellent $(338,339)$. Seed production is generally very high, germination is excellent (339). A. desertorum, in particular, has the ability to germinate on harsh sites under conditions of low 
temperature and intermittent drought (474). Natural vegetative reproduction is less well developed; all species spread somewhat (rated fair) but Fairway crested wheatgrass produces tillers and rhizomes, and is therefore a good sod-former $(338,339,179)$. The ability of Fainway to reproduce vegetatively probably accounts for its greater success at higher elevations where seed is not always able to mature (340).

\section{Ecological Setting}

These forms are all adapted to dry rangeland conditions and are most frequently found in these situations $(391,47,339)$. They prefer at least 23 to $38 \mathrm{~cm}$ of annual precipitation $(426,639)$. They are most common on dry, open plains; Standard is generally limited to these locations, whereas Fairway is also adapted to favorable sites with more moisture, even at higher elevations and in tundra or taiga situations $(391,339,312)$. Siberian wheatgrass is somewhat less adaptable than either of the other forms, and is more restricted in its occurrence (339). Standard crested wheatgrass (A. desertorum) would not reproduce at elevations exceeding about $1600 \mathrm{~m}$ ASL on dry slopes in southeastern B.C. (498), however Fairway is known to occur 300 to $500 \mathrm{~m}$ higher at many locations in Utah, Idaho and Wyoming $(210,340)$. At higher elevations, Fairway is more persistent than Standard (340).

\section{TOLERANCES}

\section{Soil Preferences}

Standard crested wheatgrass is most common on medium and moderately coarse textured soils. These are often Chernozemic, Solonetzic, Regosolic, or extremely shallow soils (179). Growth is also expected to be good on some Brunisols and Luvisols. Suitable soils are normally well drained, and moist or dry $(12,391)$; deep, well-drained loamy soils (639). Siberian wheatgrass is also adapted to light droughty soils $(183,179)$. Fairway wheatgrass (A. cristatum) is a hardy species on these dry soils as well, but it also survives and does well under more moist conditions (339). The species will not withstand prolonged flooding $(183,426)$.

\section{Nutrient Requirements}

Considered to have low to medium fertility requirements $(500)$. The extremely wide adaptations of these species, their persistence on marginal and unfavorable sites, and their common occurrence on normally low nutrient mountain and foothill soils suggest that their nutrient requirements are rather modest.

\section{Soil Reaction}

These species are all adapted to moderately alkaline conditions $(179,339,338)$.

\section{Soil Salinity}

Standard and Fairway crested wheatgrasses are both adapted to at least moderate levels of salinity $(339,422)$. Tolerances in the ranges of 5 to $10 \mathrm{mS} / \mathrm{cm}$ and 8 to $15 \mathrm{mS} / \mathrm{cm}$ have been identified $(247,468,125)$. Emergence in the greenhouse of pregerminated seed and untreated seed was initially highest in $16 \mathrm{mS} / \mathrm{cm}$ solution; however after 17 days emergence was greatest in solutions of 0 and $4 \mathrm{mS} / \mathrm{cm}$ and much lower in solutions of 8 and $16 \mathrm{mS} / \mathrm{cm}$; the pregerminated seed had significantly better emergence after 17 days than the untreated seed (691). Crested wheatgrass seed had better emergence in the $16 \mathrm{mS} / \mathrm{cm}$ solution than Russian wildrye, but poorer than western wheatgrass (691). Standard crested wheatgrass is somewhat less salt tolerant than Fairway (339).

\section{Drought}

These are extremely drought resistant species (391, $183,340,256$ ) surpassing virtually all other wheatgrasses (340).

\section{Heavy Metals and Hydrocarbons}

Fairway crested wheatgrass, simply known as crested wheatgrass (A. cristatum) in Canada, performed satisfactorily on ameliorated ash lagoon material (high in boron) at Wabamun (305). No other sensitivities or tolerances were identified from the literature.

\section{Shade}

Fairway is more shade tolerant than Standard, but both prefer not to be shaded $(391,210)$.

\section{Grazing or Mowing}

Good to very good tolerance to grazing (339). All of these species are very resistant to heavy grazing $(183,286)$. Under dry conditions seedlings are slow to develop, and should be protected from grazing for the first two years (179).

\section{Susceptibility to Disease and Insect Damage}

Some varieties are resistant to leaf and stripe rusts 
(179). Variable resistance to snow mold (50). Susceptible to black grass bug (Labops sp.) in pure plantings ( $\mathrm{P}$. Ziemkiewicz, pers. comm.).

\section{RECLAMATION CONSIDERATIONS}

\section{Soil Building and Erosion Control Capability}

These grasses are among the best erosion controlling bunchgrasses due to the slightly rhizomatous and sometimes tillering habits (339). Fairway, particularly, is important for stabilizing reservoir berms, highway cuts and fills, and for turf purposes $(179,183)$. Both are noted for strong rooting abilities and root biomass production (179). Notably successful on both dry and moist slopes, even where these are steep $(422,498)$. Roots may extend past $2 \mathrm{~m}$ (138).

\section{Adaptation to Disturbance}

Good adaptation to disturbance (338), particularly under droughty conditions.

\section{Competitive Ability}

Crested wheatgrass is considered to have good compatibility with other species and because of its wide adaptation is suitable for planting in mixtures with other grasses, forbs and shrubs (339). Planting in combination with more narrowly adapted species is useful on ranges of varying alkalinity (339); this would undoubtedly be a good technique for variably inundated and eroding sites as well. Planting alone and with alfalfa is common practice (179). Considered a medium aggressor (500). The varying sod forming abilities of both forms of crested wheatgrass and their notably high longevity and persistence, suggest that they are strong competitors under dry rangeland conditions. For this reason crested wheatgrass is not recommended for use where "native prairie" is to be maintained in Alberta (B. Adams, pers. comm.).

\section{Commercial Value}

Suitable for rehabilitation of rangeland in poor condition, conversion of marginal cropland to grass $(179,341)$, pasture and hay, erosion control, dryland lawns and turf (183), and wildlife range (422).

\section{Palatability and Nutritive Value}

A. cristatum is considered to have good forage value for cattle (19). Palatability is moderate to good throughout the year, but the species are much more important in spring due to their earlier emergence, growth and maturity $(339,183)$; they provide forage ahead of the native grasses. This benefits livestock and wildlife alike $(339,183)$. Overall, Fairway is slightly more palatable than Standard (339), but yields of Standard are higher, with Siberian wheatgrass yielding highest of all (179). Siberian also remains green 10 to 15 days longer and is more digestible (less lignin) than Standard crested wheatgrass (179).

\section{Seed or Planting Stock Availability}

Several cultivars of each of these species are available. Though the term "Fairway" is widely used in the U.S. to describe A. cristatum, it is considered a licensed cultivar in Canada $(426,138)$. "Parkway" is also licensed in Canada (138). Other A. cristatum cultivars include "Ruff" (426) and "Musla" (139). A. desertorum is available as the (Standard) cultivar "Nordan" (Reg. No. 2); "Summit" is also licensed in Canada. A dwarf cultivar, which is rhizomatous, favors higher altitudes but is less productive, and is still undergoing testing $(183,139$, $340,500,138)$. There is one cultivar of Siberian wheatgrass available in the U.S., namely "P-27" (179, 183). Other US varieties include Ephraim and Hycrest. There are approximately 200000 seeds/lb (639).

\section{Methods and Ease of Establishment}

A. cristatum is considered to have excellent establishment qualities for direct seeding, transplanting or sod introduction $(339,338)$. Probably because of this establishment flexibility it is considered superior to both $\underline{A}$. desertorum (Standard) and A. siberium (Siberian). All are excellent germinators. All three are acceptably good as transplanting stock (339). Seed of crested wheatgrass can be stored in dry, cool surroundings for as much as 12 years, retaining $70 \%$ viability (179). Crested wheatgrass establishes well through seeding, but prospects improve with improved seedbed preparation. Drilling is preferred to broadcast seeding, and deep furrow drills produce best results (179). Fall and spring seeding at a rate of 10 to $20 \mathrm{lbs}$ PLS/ac is recommended (639).

\section{Current Status for Reclamation}

Both forms of crested wheatgrass (the various Standard and Fairway types) are widely used for range and cropland rehabilitation, erosion control, and for reclamation. Siberian is less widely utilized $(183,339,179)$. The crested wheatgrasses have been used or tested for reclamation of a wide variety of disturbances in western Canada including: tests and operations at Camrose-Ryley (340), and 
Highvale and Whitewood mines at Wabamun (304, 280 ) including ash lagoon revegetation trials (305); encouraging trials at the Cardinal River mine at Luscar (259) and at Grande Cache $(268,354,267)$; high survival and vigour (Fairway) after five years testing in subalpine sites along the Rocky Mountains eastern Slopes (705) and after three years testing at lat. $63^{\circ} \mathrm{N}$ in the Mackenzie River Valley, but performed poorly on tundra sites (644); on mine spoil at Poplar River, Saskatchewan (290), and Estevan (180); encouraging trials on sand at Lesser Slave Lake (249, 257, 258); persisting (Norday) in mixed seedings at Fort McMurray on tailings sand soil mixtures and on overburden on dry sites for 17 years (643) but declining rapidly in tailings sand soil amendment trials on moist sites (704); also performed poorly (Fairway) in grass/legume mix on topsoil and overburden on moist sites at the Judy Creek test mine (646). In B.C., tests and operations are underway at Craigmont Mines (165), at Kaiser (498), and results from 7 metal mines in the B.C. interior indicate excellent success on waste rock and good success on overburden and tailings (rated as the best agronomic for metal mine revegetation in the B.C. interior) (143).

In the U.S., success has been recorded at dry sites in the Alaska interior (298), at high elevations in Colorado (236), at West Decker mine in Montana (117), at Bull Mountains test plots in Montana (129), at the Carter bentonite mine in Montana (328) and at the Bighorn coal mine in Wyoming (328). Numerous tests have been conducted elsewhere regarding such problems as heavy metal uptake (141).

The impressive success and wide use of the two crested wheatgrasses ( $\underline{A}$. cristatum and A. desertorum) can be attributed to exceptional drought tolerance, moderate alkalinity-salinity tolerance, high seed yield, variable sod-forming tendencies, low nutrient requirements, good soil stabilizing abilities, rapid establishment, early maturity, good palatability and extreme longevity. Weak characteristics are few, but may include low tolerance for wet or shady conditions and elevational limitations. Not recommended where "native" prairie is to be maintained. 


\section{SPECIES SUITABILITY MAP AND SUMMARY TABLE}

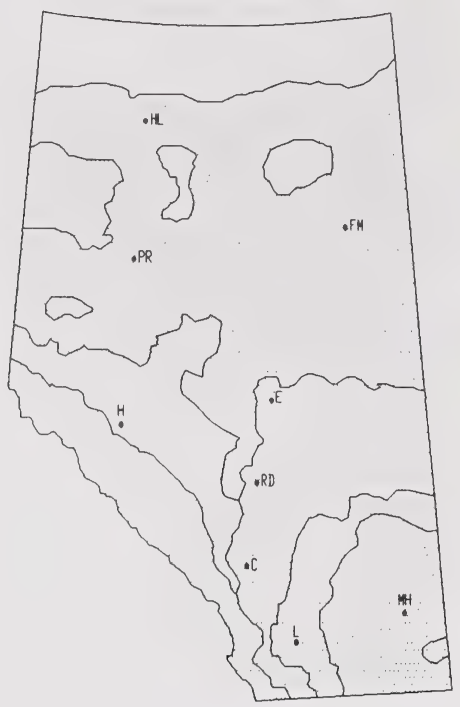

Recommended Area

Commercially Available: Yes $\mathrm{X}$ No

\begin{tabular}{|c|c|c|c|c|c|}
\hline \multirow{2}{*}{$\begin{array}{l}\text { RECLAMATION SUITABILITY } \\
\text { CRITERIA }\end{array}$} & \multicolumn{5}{|c|}{ SUITABILITY RATING } \\
\hline & Very High & High & Medium & Low & None \\
\hline Drought Tolerance & & $x$ & & & \\
\hline Salt Tolerance & & & $x$ & & \\
\hline $\mathrm{pH} \quad$ Acid & & & $x$ & & \\
\hline Tolerance Base & & & $x$ & & \\
\hline Winter Hardiness & & $x$ & $x$ & & \\
\hline Erosion Control & $x$ & $x$ & & & \\
\hline Persistence & $x$ & & & & \\
\hline Palatability & & & & $x$ & \\
\hline Browse Tolerance & & $\mathrm{X}$ & & & \\
\hline Moisture Preference & Moist & dry. & & & \\
\hline Soil Preference & We11 & ed & tolerat & vide & \\
\hline
\end{tabular}


Agropyron riparium Scribn. and Smith

\section{SPECIES BIOLOGY}

Taxonomy - Streambank Wheatgrass.

\section{Origin and Range}

Native to North America. Found in western Canada and the northwestern United States $(199,426)$.

\section{Growth Habit}

Low growing, sod-forming grass $(426,232)$ with stems 30 to $80 \mathrm{~cm}$ high (78). Vigourous rhizomes $(199,179,187)$. Relatively low biomass yield (139) due to short size of plants and narrowness of leaves (391).

Nitrogen Fixing - None

\section{Longevity}

Long-lived, cool season (639) perennial $(391,179)$, showing good winter hardiness (240).

\section{Self Propagation}

Reproduces both by seed and vegetatively through a spreading root system $(338,179,187)$. Low seed yield (139) and rather poor natural reseeding ability (338); this is compensated for by very good spreading by vegetative means $(179,338)$.

\section{Ecological Setting}

Dry or moist meadows and hills (199). Requires minimal precipitation (and soil moisture); where evapotranspiration is high, often at lower elevations, $30 \mathrm{~cm}$ of precipitation is recommended, however only $23 \mathrm{~cm}$ is necessary where water loss is noticeably reduced $(426,179)$. A minimum of $20 \mathrm{~cm}$ rainfall required (639). Native to dry forest (338) and grassland communities. Not regarded as adapted to the higher subalpine (359), although at least three years successful growth noted at $2340 \mathrm{~m}$ in Alberta (D. Walker, pers.comm.). Occurs in both natural and revegetation settings at over 1 $600 \mathrm{~m} \mathrm{ASL}$ in the Alberta foothills $(259,455)$. Growing season requirement is less than 120 frostfree days.

\section{TOLERANCES}

\section{Soil Preferences}

Prefers well drained soils, notably Chernozems

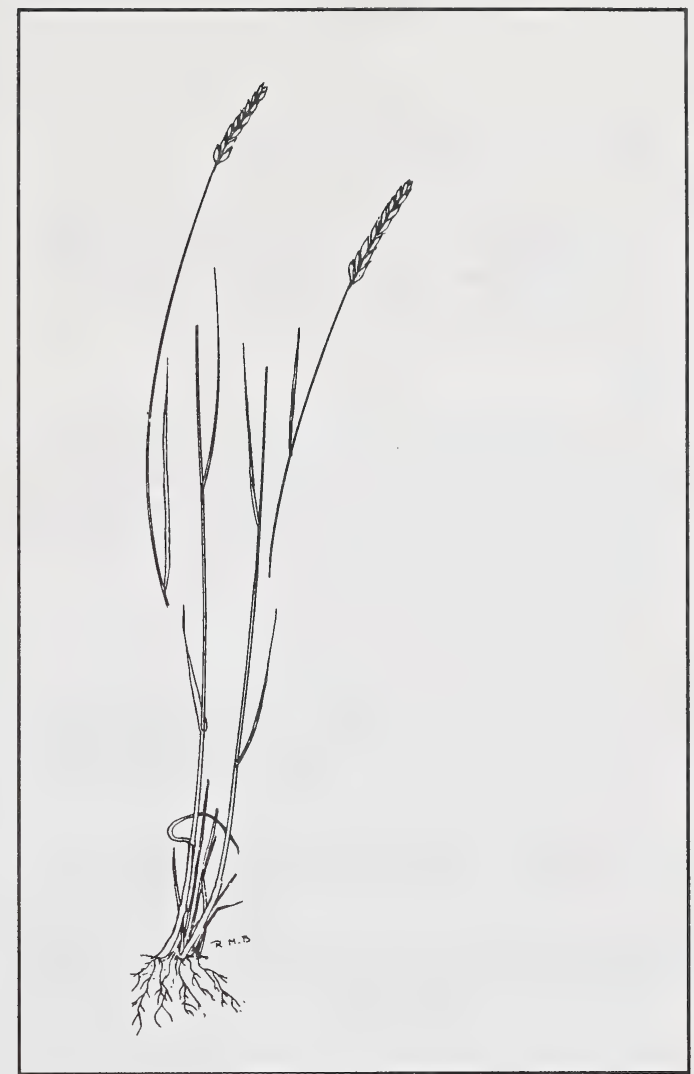

(179). Textural classes can range from sandy to clayey (426). Notably successful emergence on carbonaceous materials, bentonitic clays and gritstone (187). Though emergence was not affected, biomass increased when topsoil was added (187) at Hat Creek, B.C. tests. Is successful in Montana under both low and moderate moisture conditions (422).

\section{Nutrient Requirements}

Maintained better cover, in conjunction with legumes, and in combination with other grasses, when fertilizer applications were only moderate (359).

\section{Soil Reaction}

Tolerant of mildly acid (338), and moderately alkaline conditions $(391,183,179)$.

\section{Soil Salinity}

Moderate tolerance to saline conditions $(424,422)$. 


\section{Drought}

Relatively drought tolerant $(391,183,179,426)$.

\section{Heavy Metals and Hydrocarbons}

No information reviewed points to particular heavy metal tolerances. Appears to have some tolerance to carbonaceous (coaly) materials, at least in the emergence and early growth stages (187).

\section{Shade}

No relevant information reviewed. Presumably has no more than modest tolerance to shade, since the species is most successful in arid environments where its tolerance to drought gives it an advantage over competitors.

\section{Grazing or Mowing}

Low palatability precludes grazing pressure. Apparently the species withstands mowing very well due to its extensive use for lawns and heavy use (traffic, trampling) areas.

\section{Susceptibility to Disease and Insect Damage}

Specific information is generally lacking. Some evidence of powdery mildew and head smut effects in the oil sands area (359).

\section{RECLAMATION CONSIDERATIONS}

\section{Soil Building and Erosion Control Capability}

Provides good protection for soil surfaces and prevents encroachment by weeds $(183,179)$. Particularly well adapted for erosion control, its primary use $(183,391,187)$. Ranked very high for soil stabilization ability $(178,338)$. As with grasses generally, it offers good potential for increasing organic matter content of soils. Successful on steep slopes (422).

\section{Adaptation to Disturbance}

Good adaptation to disturbance (338) attested to by success on such sites as cut and fill slopes, highway margins and parking lots (179).

\section{Competitive Ability}

Highly competitive to weeds and other plants under dryland conditions $(183,179,183)$. Plants are easily crowded out by other grasses, however, if the site is wet (179).

\section{Commercial Value}

Major value is for surface stabilization and erosion control $(391,183,426,187,179)$. Applications of "Sodar" cultivar include cover for highway shoulders, cut and fill slopes, borrow pits and median separators. It is used for grassing runways for small aircraft, and at large airports for stabilizing soils adjacent to runways and hangars. It provides a low, smooth sod suitable for playgrounds, parking lots, lawns and farmyards $(183,179)$. It requires low maintenance and infrequent watering (391). It is also favored for use on the banks of irrigation canals and drainage ditches $(391,183,179)$. Low fire hazard due to low above ground biomass (179).

\section{Palatability and Nutritive Value}

Low palatability $(427,391)$. Low growth and narrow blade indicate low forage yield (391). Low palatability is an asset in highway revegetation and other schemes where animal use is discouraged.

\section{Seed or Planting Stock Availability}

One commercial cultivar is available in Canada and the U.S., namely "Sodar" $(183,138)$. "Sodar" was selected for low seed yield, although this is not necessarily a characteristic of the species. Approximately 156000 seeds/lb (639).

\section{Methods and Ease of Establishment}

Can be established either by seeding or transplanting with good success (338). Relatively easily established (424) due to quick seed germination and good seedling vigour (179). Low maintenance requirements $(391,179)$. A fall/spring seeding at a rate of 6 to $8 \mathrm{lbs}$ PLS/ac has been recommended (639).

\section{Current Status for Reclamation}

Widely used for ground cover and stabilization associated with public use areas such as highways, airports, recreation areas, parking lots and irrigation canals $(391,183,179)$. Streambank wheatgrass is being used with limited success at several metal mine reclamation sites in the southern interior of B.C. (143). It has achieved at least experimental success at several other locations; at Hat Creek (187), Luscar (259), and in Montana (422, 117). "Sodar" was found adequate for short-term (1 to 3 year) performance at Banff at $1390 \mathrm{~m} \mathrm{(732)} \mathrm{and}$ at Fort McMurray it performed as well as other wheatgrasses after five years of testing on amended tailings sand (705). Results have been very discouraging for use in reclamation in the 
western arctic $(111,488)$.

For reclamation, its chief advantages are drought tolerance, moderate alkalinity and salinity tolerance, and its sod-forming habits which achieve very effective erosion control even on steep slopes. The species has low palatability, however, and under dry conditions can crowd out less vigorous competitors. 
Agropyron smithii

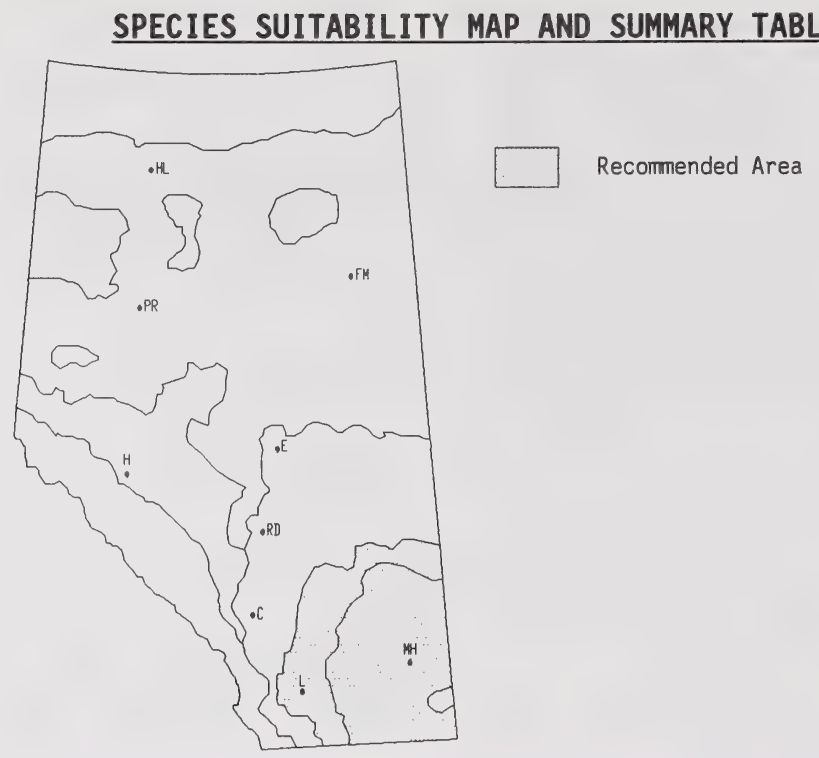

Commercially Available: Yes $\mathrm{X}$ No

\begin{tabular}{|c|c|c|c|c|c|}
\hline \multirow{2}{*}{$\begin{array}{l}\text { RECLAMATION SUITABILITY } \\
\text { CRITERIA }\end{array}$} & \multicolumn{5}{|c|}{ SUITABILITY RATING } \\
\hline & Very High & High & Medium & Low & None \\
\hline Drought Tolerance & & $x$ & $x$ & & \\
\hline Salt Tolerance & & $x$ & $x$ & & \\
\hline Acid & & & 5.0 & & \\
\hline Tolerance Base & & & $x$ & & \\
\hline Winter Hardiness & & & $x$ & & \\
\hline Erosion Control & & $x$ & & & \\
\hline Persistence & $x$ & & & & \\
\hline Palatability & & $x$ & $x$ & & \\
\hline Browse Tolerance & & & $x$ & & \\
\hline Moisture Preference & Moist & dry, & stands s| & floo & \\
\hline Soil Preference & Clay & lay & xture & & \\
\hline
\end{tabular}


Agropyron smithii Rydb.

\section{SPECIES BIOLOGY}

Taxonomy - Western Wheatgrass

Also the variety $\underline{A}$. smithii var. molle (Scribn. and Smith) Jones.

\section{Origin and Range}

Native throughout most of northern North America, but well south of arctic treeline(214). British Columbia and Alberta, east to Ontario, south to New York, Tennessee and Texas, and west again to northern California (199). Introduced to Alaska (214), and in the U.S. east of lowa and Kansas (199). Isolated occurrences in Iceland, Quebec and the Northwest Territories (214).

\section{Growth Habit}

Erect, loosely tufted, low growing sod-forming grass, with long, slender creeping rhizomes (214, 199, 47). Ranges from 30 to $60 \mathrm{~cm}$ in height, sometimes taller (199) and occasionally less $(20 \mathrm{~cm})$ (424). Most strains produce open sod, but tight sod is typical of at least one cultivar (183).

\section{Nitrogen Fixing - None}

\section{Longevity}

Long-lived, cool season (639) perennial (244).

\section{Self Propagation}

Though seed production is often high (183), the species is considered a poor natural re-seeder. During unfavorable years, seed production may be greatly reduced (231). It has excellent capability for vegetative spreading (338). Rapid germination and good seedling vigour (183). Slow to establish from seed (605).

\section{Ecological Setting}

Most common on heavy soils and in swales where moisture collects $(489,47,179)$. Minimum of $25 \mathrm{~cm}$ of rainfall required (639). Survives in mixtures even where annual precipitation is less than $30 \mathrm{~cm}$ (340), though it prefers $35 \mathrm{~cm}$ or more under dryland conditions(429). Usually found on flat to moderately rolling topography (429). A prairie species, losing importance northward in Alberta (455) due to growing season requirements (needs 120 to 150 frost-free days). Collected at Greenville Mountain, Alberta $(1050 \mathrm{~m})$ (455). Often associated with blue

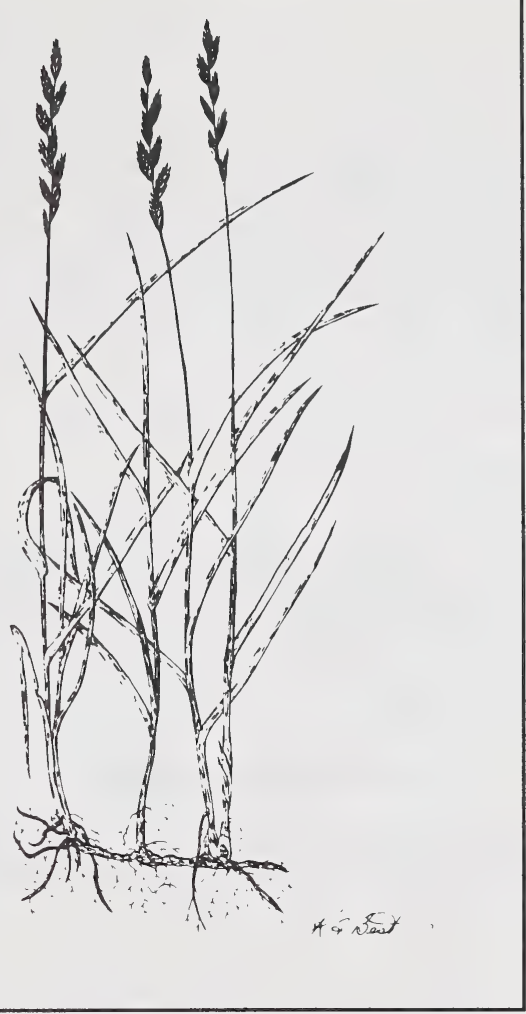

grama and the needlegrasses in the Great Plains (605).

\section{TOLERANCES}

\section{Soil Preferences}

Adapted to fine and medium textured soils (429). Withstands considerable flooding and silt deposition, and fares well in swales where moisture accumulates. Production is lower on the lighter soils (340).

\section{Nutrient Requirements}

Presumably requirements are at least moderate for nutrients due to its affinity for water collection areas.

\section{Soil Reaction}

Tolerance to alkaline soil conditions $(244,422,47)$ is at least moderate (183). Satisfactory survival can also be expected for acidic pH's above 5.0 (228). 


\section{Soil Salinity}

Moderate (424) to very high (361) salt tolerance. "Walsh" performed well on a heavy clay mud-flat with electrical conductivities ranging from 9.1 to $21.2 \mathrm{mS} / \mathrm{cm}$ (717). Emergence in the greenhouse of pregerminated seed and untreated seed was initially highest in $16 \mathrm{mS} / \mathrm{cm}$ solution; however after 17 days emergence was greatest in solutions of 0 and $4 \mathrm{mS} / \mathrm{cm}$ and much lower in solutions of 8 and $16 \mathrm{mS} / \mathrm{cm}$; the pregerminated seed had significantly better emergence after 17 days than the untreated seed (691). Western wheatgrass seed had better emergence in the $16 \mathrm{mS} / \mathrm{cm}$ solution than Russian wildrye and crested wheatgrass (691).

\section{Drought}

Established stands endure long periods of drought (179). Emergence of seed 24 days after sowing was significantly better in soils at field capacity than soils which were "moderately dry" or "dry"; however, there were no effects on root or shoot length or weight (691).

\section{Heavy Metals and Hydrocarbons}

No particular tolerances to heavy metals or hydrocarbons were noted from the literature.

\section{Shade}

Not highly shade tolerant, but does well in an open brush setting (340).

\section{Grazing or Mowing}

Was found to decrease under heavy grazing by sheep (389). It would seem that the species is most sensitive to grazing pressure during its initial establishment period.

\section{Susceptibility to Disease and Insect Damage}

Susceptible to leaf and stem rusts under heavy irrigation, though resistant under dryland conditions (429). Susceptible to "take-all" (Ophiobolis graminis) under irrigation. Periodically infested with clay-backed cutworms (429).

\section{RECLAMATION CONSIDERATIONS}

\section{Soil Building and Erosion Control Capability}

High soil stabilization potential $(244,338)$. Survives satisfactorily on steep slopes if drought, typical of southern exposures, is avoided (422).

\section{Adaptation to Disturbance}

Good adaptation to disturbance (338). Observed to invade disturbed sites and certain mill tailings in the subalpine zone (41).

\section{Competitive Ability}

The aggressive spreading root system is extremely competitive and resists invasion by other species (340).

\section{Commercial Value}

Useful for irrigated and dryland pasture and hay, and stabilization of swales, overflow sites and waterways (429). Other uses include natural range, wildlife habitat, fairly heavy use recreation areas and erosion control (422).

\section{Palatability and Nutritive Value}

"Arriba" is palatable to all forms of livestock (321). Good forage value for cattle and wildlife (381). The young spring growth is most palatable, but the grass becomes coarser and less palatable by early summer $(183,179)$. Authors are not agreed on this latter point, however, sometimes stating the opposite relationship (340). Leaves cure well on the stem, providing a good source of winter grazing (605). Relatively highly digestible, though crude protein content decreases significantly with maturity (231). In mixed stands with native bunchgrasses, the bunchgrasses are generally selected first; continuous early spring grazing of these may result in pure stands of western wheatgrass (179).

\section{Seed or Planting Stock Availability}

One cultivar, "Walsh", is available in Canada since 1983. "Walsh" produced about 5\% more dry matter than "Rosana", a U.S. cultivar, on dryland trials at Lacombe and Lethbridge, Alberta, and Swift Current, Saskatchewan. "Walsh" outyielded "Sodar" streambank, "Revenue" slender, "Nordan" crested, and "Chief" intermediate wheatgrass on a moderately saline, heavy clay mud-flat at Stirling, Alberta (717).

Three cultivars are commercially available in the U.S. "Barton" was developed in Kansas, and is a high yielding, relatively disease resistant strain (183). "Rosanna", best adapted for western Canada, was acquired and tested in Montana, and is very strongly rhizomatous, producing tight sod. It has superior seedling vigour, and good forage and seed yield $(183,430,429)$. "Arriba" is a Colorado strain with high seed yield, good emergence, seedling 
vigour and forage production. It is palatable for livestock, a good soil stabilizer, and average in its tolerance to mites and rust (321). Seed is sometimes in short supply, and can be fairly expensive (132). "Rodan" is also available (639). Approximately 110000 seeds/lb (639).

\section{Methods and Ease of Establishment}

Root systems develop slowly in the seedling stage, and mortality at this time is often high if drought is experienced soon after germination (340). Sometimes difficult to establish in the subalpine (41). Rated as having only fair ease of establishment on moderately dry Colorado ranges (424). Where possible, seed should be drilled to afford extra protection in the early growth stages (321). Modest fertilization (and irrigation where possible) should help to rapidly establish stands. A fall/spring seeding at a rate of $10 \mathrm{lbs}$ PLS/ac has been recommended (639).

\section{Current Status for Reclamation}

The species is well suited for native range, particularly where periodic flooding or poor drainage are expected (water collection areas), and where occasional drought may occur $(179,340)$. In Canada, Cominco has had encouraging experimental results with western wheatgrass on low $\mathrm{pH}$ gypsum waste ameliorated with lime (to $\mathrm{pH} 6.0$ ), and directly on saline/alkaline tailings from their Yellowknife gold operation (163). When seeded on reclaimed coal strip mined areas, "Walsh" showed better establishment and persistence than the other wheatgrasses or the wild ryes (717). Western wheatgrass has been planted with poor results on at least two southern interior B.C. metal mine sites (143). Limited success has been encountered at Tent Mountain as indicated by fifth year survival and production data (723).

In the U.S., western wheatgrass is widely used for minesite reclamation in the arid Great Basin, intermountain region and prairie of the U.S. "Barton" and "Rosana" are predominantly range grasses, while "Arriba" is well adapted to soil stabilization and revegetation after disturbances $(183,321,429)$. Use noted (often "Barton") at the Bridger Coal mine (Montana), Knife River Coal Co. mines at Beulah and Gascoyne (N. Dakota), Wyodak Resources mine (Wyoming), Amax Coal Co. mine at Belle Ayr (Wyoming), Pacific Power and Light Glenrock mine (Wyoming), Decker mine (Montana), Baukal-Noonan Centre mine (N. Dakota) and FMC Carter mine (Montana) $(90,328)$. About $70 \%$ of mines in the Northern Great Plains Coal Province seed western wheatgrass (31). Plug transplants were successful in the face of drought when planted on raw coal mine spoil at the McKinlay mine, in New Mexico (80).

Main assets of the species include an aggressive sodforming habit, tolerance of prolonged flooding and of saline conditions, and moderate drought tolerance. Western wheatgrass is not a strongly superior forage species however, and has only moderate tolerance to grazing. It is also relatively slow to establish and is most vulnerable at that time. 
Agropyron spicatum

SPECIES SUITABILITY MAP AND SUMMARY TABLE

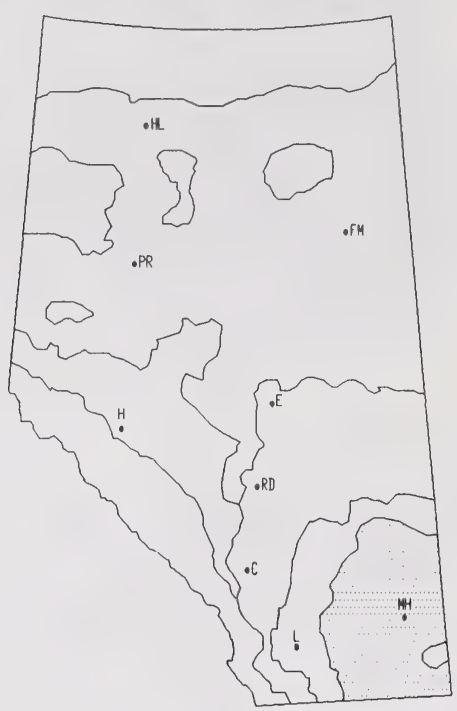

Recommended Area

Commercially Available: Yes No

\begin{tabular}{|c|c|c|c|c|c|}
\hline \multirow{2}{*}{$\begin{array}{l}\text { RECLAMATION SUITABILITY } \\
\text { CRITERIA }\end{array}$} & \multicolumn{5}{|c|}{ SUITABILITY, RAIING. } \\
\hline & Very High & High & Medium & Low & None \\
\hline Drought Tolerance & & $x$ & & & \\
\hline Salt Tolerance & & & & $x$ & \\
\hline $\mathrm{pH} \quad$ Acid & & & & $x$ & \\
\hline Tolerance Base & & & $x$ & & \\
\hline Winter Hardiness & & & $\mathrm{X}$ & $x$ & \\
\hline Erosion Control & $x$ & & & & \\
\hline Persistence & & $x$ & & & \\
\hline Palatability & & $x$ & & & \\
\hline Browse Tolerance & & & & $x$ & \\
\hline Moisture Preference & Moist & dry. & & & \\
\hline Soil Preference & Well & ined, & rates wide & extural & \\
\hline
\end{tabular}


Agropyron spicatum (Pursh) Scribn. and Smith

\section{SPECIES BIOLOGY}

\section{Taxonomy}

Bluebunch Wheatgrass var. Beardless Bluebunch Wheatgrass (430).

Also $\underline{A}$. spicatum var. inerme Heller.

\section{Origin and Range}

Native to western North America $(214,199,340)$. Ranges from Alaska through the interior of British Columbia, east through Alberta to Michigan, and from the Dakotas south to Texas, and including American states westward.

\section{Growth Habit}

Plants densely tufted, often forming large bunches (47). Tall or intermediate height $(60$ to $100 \mathrm{~cm})$ $(424,199)$. Fibrous root system (47), but with short rhizomes (183). A . spicatum displays awned seeds, while $\mathrm{A}$. spicatum var. inerme is the awnless variety $(199,340,179,183)$. Variable ecotypes have been recognized (179).

\section{Nitrogen Fixing - None}

\section{Longevity}

Long-lived, cool season (639) perennial. Winter hardiness is rated from very poor (D. Walker, pers.comm.) to good (183). Growth rate is only moderate (338).

\section{Self Propagation}

Seeds large and heavy. Production high (183). Establishment by natural reseeding is moderate (338). Though stands do spread slowly from short rhizomes (183), vegetative reproduction is considered poor (338).

\section{Ecological Setting}

Native to drier areas such as the southern Canadian prairies, B.C. interior, and U.S. intermountain region $(183,199,47)$. Common on dry slopes, canyons, dry open woods and plains (199). Also common in river valleys in Alaska (214). Though total precipitation in the order of 20 to $35 \mathrm{~cm}$ is satisfactory (639), growth is better above $25 \mathrm{~cm}$ annually $(183,340)$. A small form identified as A. vaseyi occurs in the deserts of the American Great Basin (199). Though the species will grow at

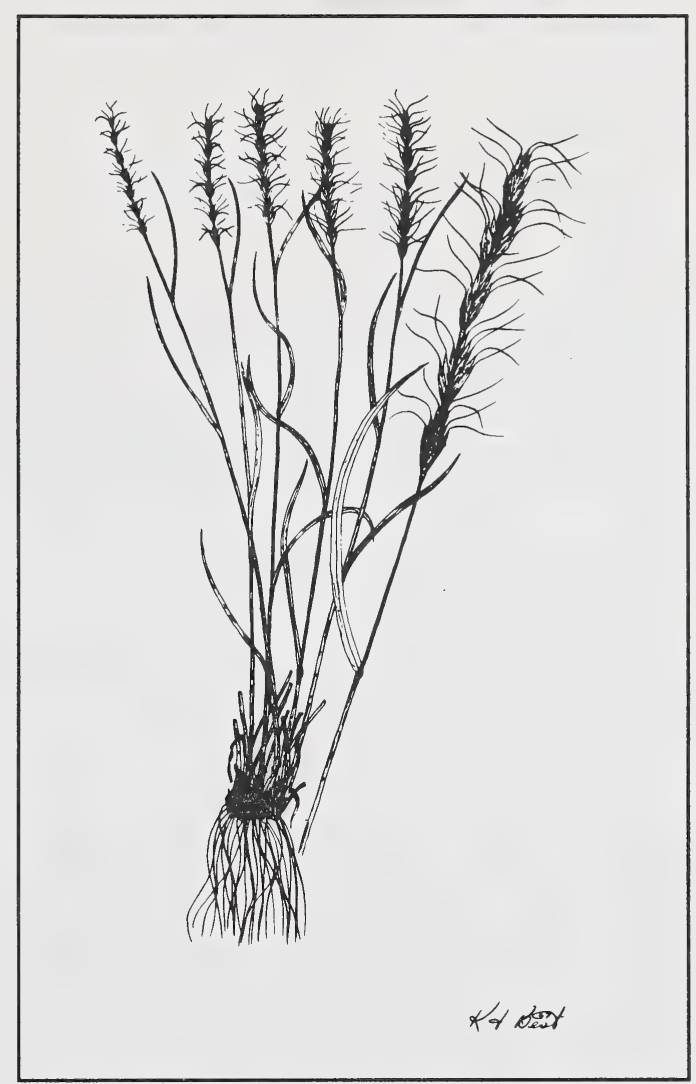

higher elevations, forage production is much lower (340).

\section{TOLERANCES}

\section{Soil Preferences}

Prefers well drained soils (489) which in Alberta and elsewhere would include Chernozems and Brunisols, particularly brown soils (179). Amount of soil moisture retained at depth is important for perpetuating established stands (93). Range of suitable textural classes is apparently broad, though it is considered best on medium to clayey soils (639).

\section{Nutrient Requirements}

Noted to be persistent under adverse conditions (183), presumably including fairly low nutrient levels.

\section{Soil Reaction}

Somewhat more tolerant of alkaline than acid 
conditions (338). Apparently not adapted to extremes.

\section{Soil Salinity}

Only fair tolerance to saline conditions (424).

\section{Drought}

Highly drought resistant, especially in well established stands where roots penetrate into deep soil layers (183, 93, 179). Amongst the wheatgrasses, it is exceeded in drought tolerance only by crested wheatgrass (Agropyron cristatum), and possibly streambank wheatgrass (A. riparium) (340).

\section{Heavy Metals and Hydrocarbons}

No particular tolerances noted from the literature.

Shade - Only slightly shade tolerant (340).

\section{Grazing or Mowing Tolerance}

Inferior to other adapted grasses in grazing tolerance (340). Even light grazing or mowing reduces plant size (114), vigour (314) and cover (287). Heavy grazing has greater impact. Recovery is possible if grazing (or mowing) is discontinued and competition is suppressed $(287,313)$. A rotational-deferred system of grazing is the best practice; not more than $50 \%$ of the current year's growth of stems and leaves should be taken. Three years protection after seeding is recommended (179).

\section{Susceptibility to Disease and Insect Damage}

Seed should be treated with an insecticide to prevent wireworm damage (340). Also susceptible to the soil-borne pathogen Podosporiella verticillata; Seed should be treated with a fungicide (340). Injured less by ground squirrels than crested wheatgrass (A. cristatum) (179).

\section{RECLAMATION CONSIDERATIONS}

\section{Soil Building and Erosion Control Capability}

Root production, at least by the $\mathrm{A}$. inerme variety, is very high (179). Root production over six growing seasons has been measured as almost $25 \%$ higher than that of crested wheatgrass (179). Soil stabilization ability is very high (338). The occurrence of bluebunch wheatgrass on dry slopes and in canyons attests to its usefulness for erodible slopes $(183,119,214)$. The root systems exploit deep soil water through the summer months, consequently soil moisture is likely to be substantially depleted by October (93).

\section{Adaptation to Disturbance}

Considered only moderate, and poorer than all other wheatgrasses (338).

\section{Competitive Ability}

Natural competition severely restricts the growth and vigour of bluebunch wheatgrass (313). This plus susceptibility to grazing pressure lead to the recommended practice of planting in pure stands (340).

\section{Commercial Value}

Valuable as a native range grass where its palatability and drought resistance are important (183).

\section{Palatability and Nutritive Value}

Palatability is considered high (427). Though reducing size of plants, even light grazing improves nutrient content (114) by increasing proportion of leaves above ground. Even when well headed, the coefficient of digestibility is higher than for similar crested wheatgrass stands (179). Retains feed value and palatability late into summer and fall (183).

\section{Seed or Planting Stock Availability}

A. spicatum var. inerme is available in the United States under the cultivar name "Whitmar" (Reg. No. 4). "Secar" is also available in the US (639). Other cultivars not available, but undergoing testing, include "P-739" and "P-6409". "P-739" is somewhat better adapted to moister conditions and higher elevations. "P-6409" is smaller, adapted to droughtier conditions and is more persistent under adverse conditions (183). Considerable variation exists between strains and ecotypes (340). No licensed cultivars are available in Canada (138). Approximately 140000 seeds/lb (639).

\section{Methods and Ease of Establishment}

Ease of establishment by seeding or transplanting is considered good (338). Seed of the awned ecotypes must be processed before they can be cleaned and planted. When seeding "Whitmar", good stands are obtained from spring seeding on well prepared (or summer fallowed) seedbeds; when 
preparation has been less extensive, fall seeding is recommended. Pretreating with insecticides and fungicides should be considered. Deep furrow drills are preferred to other seeders. Grass requires three years of protection prior to grazing (179). Planting in pure stands is recommended to avoid overgrazing, allows grazing rotation, and presents forage to livestock in as palatable a form as possible (340). Seed shatters readily. Binding or swathing in the soft-dough stage is preferable to combining. Germination remains above $70 \%$ during six years of cool, dry warehouse storage(179). A fall/spring seeding at a rate of 6 to $8 \mathrm{lbs}$ PLS/ac has been recommended (639).

\section{Current Status for Reclamation}

Bluebunch wheatgrass and beardless wheatgrass are widely used native grasses, particularly in the interior of British Columbia (114) and in the dry intermountain region of the United States $(183,340$, 179). They are favored for their palatability and drought tolerance, though they are not especially good competitors, nor do they withstand heavy grazing pressure. The species has apparently been used for reclamation (34) in B.C., and has survived after two years on plots at Luscar, Alberta (259). The history of test plot and operational trial data is sparser than for most other wheatgrasses. It has undergone genetic testing on the Alberta east slopes $(455,453)$. 
SPECIES SUITABILITY MAP AND SUMMARY TABLE

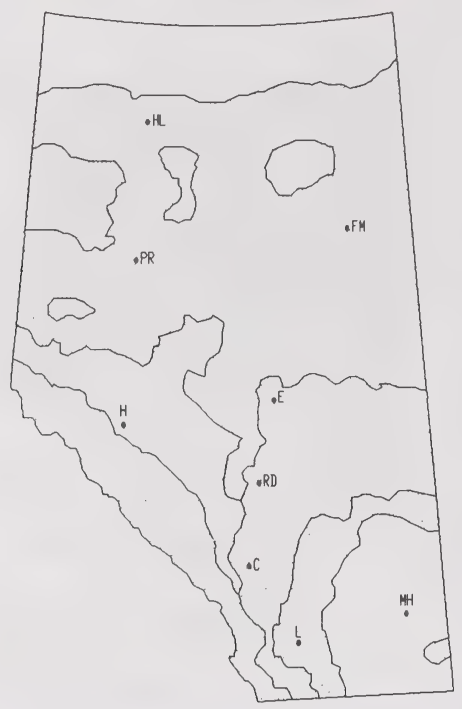

Recommended Area

Commercially Available: Yes No $X$

\begin{tabular}{|c|c|c|c|c|c|}
\hline \multirow{2}{*}{$\begin{array}{l}\text { RECLAMATION SUITABILITY } \\
\text { CRITERIA }\end{array}$} & \multicolumn{5}{|c|}{ SUITABILITY RATING } \\
\hline & Very High & High & Medium & Low & None \\
\hline Drought Tolerance & & $X$ & $x$ & & \\
\hline Salt Tolerance & & & $x$ & $x$ & \\
\hline pH Acid & & & & $x$ & \\
\hline Tolerance Base & & & $\mathrm{X}$ & & \\
\hline Winter Hardiness & & $x$ & $x$ & & \\
\hline Erosion Control & & $x$ & & & \\
\hline Persistence & & & $x$ & & \\
\hline Palatability & & $x$ & $x$ & & \\
\hline Browse Tolerance & & & $x$ & & \\
\hline Moisture Preference & Moist & dry. & & & \\
\hline Soil Preference & Welld & ned. & & & \\
\hline
\end{tabular}


Agropyron subsecundum (Link) Hitchc.

\section{SPECIES BIOLOGY}

Taxonomy - Awned Wheatgrass

Also Agropyron trachycaulum (Link) Malte var. unilaterale (Cass.) Malte.

\section{Origin and Range}

Native to North America. Range extends from Alaska to Labrador; northern extent is about the limit of the open boreal forest (214). Distributed south to New England and along a line linking West Virginia, Missouri, New Mexico and California. Range is very similar to A. trachycaulum (199).

\section{Growth Habit}

An erect, loosely tufted bunchgrass ranging from 50 to $100 \mathrm{~cm}$ in height (199). Fibrous root system (47); without creeping rhizomes (199). Not domesticated (179).

\section{Nitrogen Fixing - None}

\section{Longevity}

Short-lived perennial, though living generally longer than $\underline{A}$. trachycaulum (179).

\section{Self Propagation}

Strong reseeder (340), usually setting seed the first year (179). Produces tillers, but in less abundance than slender wheatgrass (A. trachycaulum) (450). Seedling vigour is excellent (179). At least one ecotype, a USDA accession (P-9115), produces more seed than "Primar" slender wheatgrass (179).

\section{Ecological Setting}

Common in fairly moist meadows and open woods (199) and along forest margins (47). Optimal precipitation level seems to be about $35 \mathrm{~cm}$ per year. Though the species does well throughout the forested mountain areas, only adapted breeds and subspecies will be successful in the high sub-alpine or alpine (340). Plants collected on Kootenay Plains (2 375 m ASL) (379), and Pigeon Mountain (1 830 m ASL) (450). Good plot trial yields were found at Cadomin (1 675 m ASL) (364).

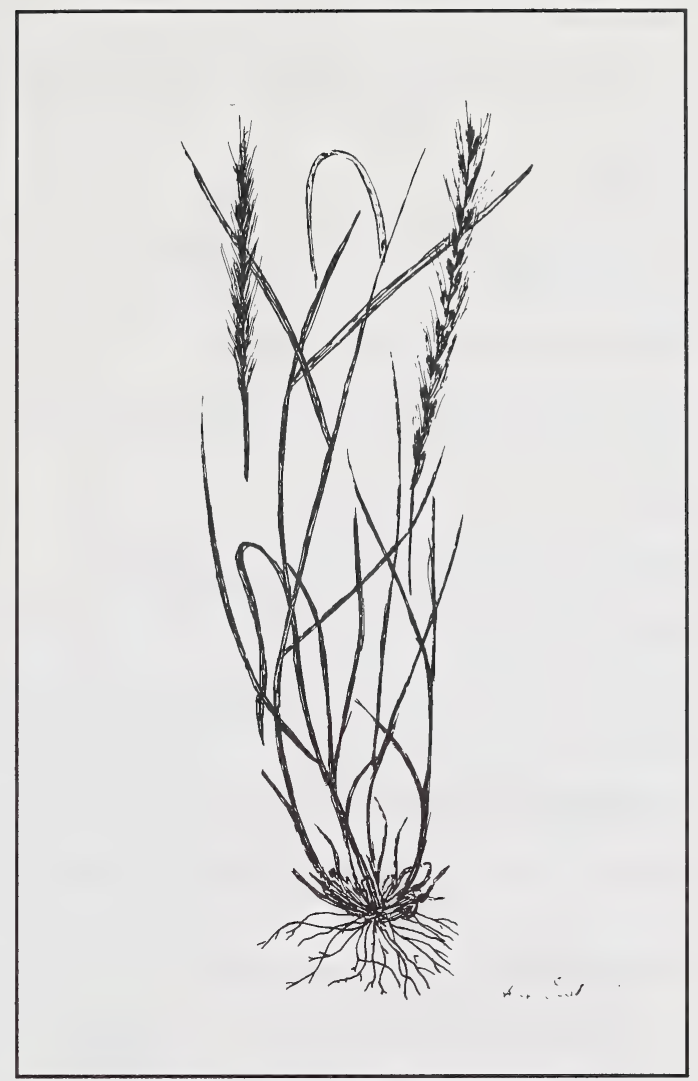

\section{TOLERANCES}

\section{Soil Preferences}

Like A. trachycaulum, it prefers moist to dry soils that are well drained (179). Most common on Chernozemic soils, but occurs on well drained Luvisols and Brunisols as well (179). Fares better on mineral soils than on raw overburden (364).

\section{Nutrient Requirements}

Often occurs naturally under conditions of relatively low nutrient supply, though better conditions are probably favored.

\section{Soil Reaction}

Somewhat more tolerant of alkaline than of acid conditions (338). 
Soil Salinity

Presumably somewhat tolerant of moderate or low salinity.

\section{Drought}

Somewhat more drought tolerant than A. trachycaulum (340).

\section{Heavy Metals and Hydrocarbons}

No specific heavy metal or hydrocarbon tolerances noted.

\section{Shade}

Noted to be relatively shade tolerant (340).

\section{Grazing or Mowing}

Tolerance to grazing is not known, but may be comparable to $\underline{A}$. trachycaulum.

\section{Susceptibility to Disease and Insect Damage}

Resistant to stripe rust (179), otherwise not known.

\section{RECLAMATION CONSIDERATIONS}

\section{Soil Building and Erosion Control Capability}

A good soil stabilizer (338) and, as with most grasses, contributes significant biomass for soil building. Its rapid establishment and high emergence success suggests that it would be a good species for erosion control purposes; better soil stabilization abilities than $\mathrm{A}$. trachycaulum (338).

\section{Adaptation to Disturbance}

Reasonably well adapted to disturbance (338).

\section{Competitive Ability}

Due to its early vigour and rapid establishment, considered a good early competitor (179). Considered aggressive (340). As with certain other wheatgrasses, it apparently fares better competitively with low rates of fertilization (404).

\section{Commercial Value}

Improved and unimproved domestic pasture, wildlife range and short term erosion control $(340,338$, 144).

\section{Palatability and Nutritive Value}

Considered moderately palatable on Colorado ranges between 2000 and $2700 \mathrm{~m}$ ASL (427). High palatability for bighorn sheep and elk, moderate for moose and low for deer (144).

\section{Seed or Planting Stock Availability}

Commercial cultivars apparently nonexistent. Available commercially, but no named cultivars (106). High elevation strains not commercially available, but readily harvested and propagated from native stands (340). Typical genetic variability indicates advisability of local collections where possible (179).

\section{Methods and Ease of Establishment}

Establishment methods the same as A. trachycaulum, except slightly less readily transplantable (though still good) (338). Must be processed to remove short, straight awns prior to drilling $(340,179)$.

\section{Current Status for Reclamation}

The species has undergone study for genetic improvement and propagation $(450,453)$ and for operational field use. It was among the best grasses for subalpine sites in five years of testing on overburden and topsoil at Cadomin (740) and Tent Mountain and was recommended for use in the eastern slopes region (723). At Fort McMurray it performed moderately well in five years of testing on amended tailings sand (705).

Probably because the species is a native, and since commercial seed is scarce (and/or expensive), little use has apparently been made of it on large scale studies or operations. Also, since the species displays most of the same characteristics as A. trachycaulum, but is generally less tolerant of extreme soil conditions (except for superior drought tolerance), less well known, and less readily available, it is being neglected in favor of the closely related slender wheatgrass. 
SPECIES SUITABILITY MAP AND SUMMARY TABLE

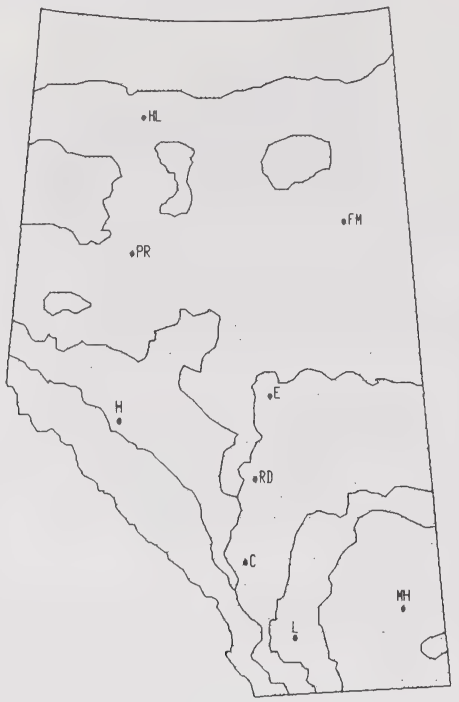

Recommended Area

Commercially Available: Yes X No

\begin{tabular}{|c|c|c|c|c|c|}
\hline \multirow{2}{*}{$\begin{array}{l}\text { RECLAMATION SUITABILITY } \\
\text { CRITERIA }\end{array}$} & \multicolumn{5}{|c|}{ SUITABILITY, RATING } \\
\hline & Very High & High & Medium & Low & None \\
\hline Drought Tolerance & & & $x$ & & \\
\hline Salt Tolerance & & $x$ & $x$ & & \\
\hline pH Acid & & & & & \\
\hline Tolerance Base & & 8.8 & & & \\
\hline Winter Hardiness & & $x$ & & & \\
\hline Erosion Control & & $x$ & & & \\
\hline Persistence & & & $x$ & & \\
\hline Palatability & & & $x$ & & \\
\hline Browse Tolerance & & $x$ & & & \\
\hline Moisture Preference & Moist & 0 dry. & & & \\
\hline Soil Preference & Medium & texture, & 11 drain & & \\
\hline
\end{tabular}


Agropyron trachycaulum (Link) Malte

\section{SPECIES BIOLOGY}

Taxonomy - Slender Wheatgrass

Also A. trachycaulum var. unilateral (Cassidy) Malte, var. glaucum (Pease \& Moore) Malte, and var. trachycaulum (690). Also A. pauciflorum, (Schwein) Hitchc. (214).

Produces hybrids with Hordeum jubatum L. ( $x$ Agrohordeum macounii (Vasey) Lepage), Elymus innovatus Beal (x Argroelymus hirtiflorus (A.S. Hitchc.) Bowden), and possible Elymus canadensis L. (x Argroelymus mossii Lepage) (690).

\section{Origins and Range}

Native to North America, not generally occurring elsewhere (214). Range extends from Labrador to Alaska, south to New Mexico, Missouri and West Virginia. Also in western Mexico (199).

\section{Growth Habit}

A tufted bunchgrass ranging in height from 50 to $100 \mathrm{~cm}$ (341). Cultivated heights are typically $90 \mathrm{~cm}$ erect or somewhat erect at the base. Very short rhizomes are common (47) though the species is considered a domesticated bunchgrass $(41,179)$.

Nitrogen Fixing - None.

\section{Longevity}

A relatively short lived, cool season (639) perennial species $(391,183,331)$ that depends on reseeding to perpetuate a stand (640). Native in the subalpine though stands from commercial seed sources will not set seed at high elevations. Seed from local, subalpine collections may result in stands lasting up to 10 years, with good reseeding (41).

\section{Self propagation}

This species is somewhat rhizomatous (47) and produces considerable productive tillers (450). It is a self-pollinating species $(700)$ noted for its high production of seed $(450,340)$ though not for its vegetative reproduction (338). Seed is relatively easy to thresh and handle (640). Considerable variation has been noted amongst northern ecotypes in both vegetative growth and seed production (700). Seed yield is somewhat higher in the cultivar "Revenue". Seed of the "Primar" cultivar retained $70 \%$ viability over 6 years under cool, dry

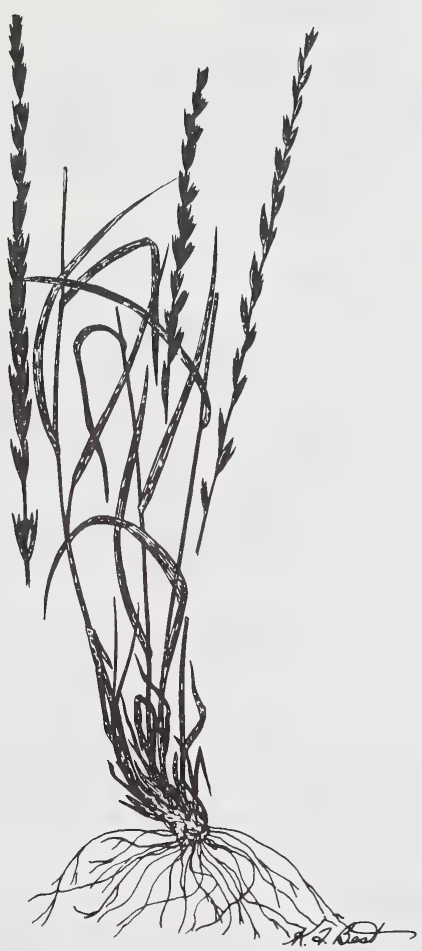

warehouse storage (179). Seeds display high germination rates and seedlings are vigorous. (391, $183,340)$. Commercial cultivars may not set seed at higher elevations (41).

\section{Ecological Setting}

A common species in moist and semi-arid ranges of the United States and Canada (199). Common to open woods, boreal forest to subalpine and subarctic $(214,341,47,312,41)$. Component of saline tall grass prairie $(729,730)$. With such a wide range of adaptability it must have a great number of ecotypes within its population (700). Requires a minimum of $40 \mathrm{~cm}$ of precipitation (639). Where plants occur in the high subalpine, specimens are shorter and denser (199). In Alberta, plant and seed collections have been made at elevations of $1830 \mathrm{~m}$ ASL (Savanna Creek, Pigeon Mountain) and $2600 \mathrm{~m}$ ASL (Ram Mountain) (456). Invasions in BC at elevations of $2200 \mathrm{~m}$ ASL (494) have been noted. In Utah, the species is native to areas at $2800 \mathrm{~m}$ ASL (106). Noted to have good winter hardiness (240). 


\section{TOLERANCES}

\section{Soil Preferences}

The species prefers moist to dry sites (12). Medium textured and well drained soils of the Chernozemic, Solonetzic, Luvisolic and Brunisolic Orders are preferred (179). Requires good soil drainage for survival (609).

\section{Nutrient Requirements}

The species occurs naturally under a variety of nutrient conditions. In reclamation situations it is normally fertilized or grown in combination with legumes (422). In a hydroponic study it was severely affected by $N, P$, and $K$ treatments, with plants being most sensitive to $K$ deficiency. Characteristic deficiency symptoms are as follows:

Nitrogen: Progressive fading of the leaves resulting in dusky brown color followed by tip dying; restricted growth rate leading to very small, tillerless plants.

Phosphorus: Spindly growth; purple pigmentation on older leaves; younger leaves dark green; restricted growth.

Potassium: Extremely reduced plant growth; progressive leaf scorching starting from tips and spreading towards leaf base; the scorched areas of leaves turn ash-white and papery and finally drop off.

Iron: Yellowing and chlorosis of youngest leaves, followed by chlorosis of almost all the leaves except the oldest; growth of plants slightly restricted.

Slender wheatgrass has a low requirement for $\mathrm{Zn}$, (710). It performs best on tailings sand dykes at relatively lower fertilization rates, possibly because of poorer success of other species, and reduced competition (359).

\section{Soil Reaction}

Considered moderately to highly tolerant of alkaline soil conditions $(391,183)$. Successful on coarse textured overburden $(\mathrm{pH} 8.8)$ at Cadomin (364), though not successful on an alkaline tailings pond (pH 9.0) at an asbestos mine in Quebec (where heavy metals may have also been a problem) (310).

Soil Salinity

Displays moderate to high tolerance to soil salinity
$(85,422,426)$. Various tolerance ranges are quoted in the literature: 11 to $16 \mathrm{mS} / \mathrm{cm}$ (468) and 8 to $15 \mathrm{mS} / \mathrm{cm}$ (247). Established readily on a moderately saline clay with electrical conductivity (EC) values ranging from 9 to $21 \mathrm{mS} / \mathrm{cm}$ (717). Moderate growth has been demonstrated in the Alberta oil sands at about $12 \mathrm{mS} / \mathrm{cm}$, though vigour was somewhat reduced (404). In a greenhouse study herbage yield started to decline on soils with EC values greater than $10 \mathrm{mS} / \mathrm{cm}$, with $50 \%$ reduction at EC values about $16 \mathrm{mS} / \mathrm{cm}$. Slender wheatgrass was more tolerant than brome grass and reed canary grass but less tolerant than Russian wild ryegrass, Altai wild ryegrass and tall wheatgrass. Slender wheatgrass salinity tolerance varied with growth stage with germination being the most sensitive (687). Some ecotypes are more salt tolerant than others.

\section{Drought}

Found on relatively moist sites on semi-arid western rangelands (736); considered mesic species. Based on subjective field observations and measurement of turgor pressure responses considered to have low drought resistance (664). Requires the equivalent of $35 \mathrm{~cm}$ of precipitation annually (391, $178,183,426)$ depending on evapotranspiration. Matures later than certain other wheatgrasses, and therefore is more susceptible to the effects of drought (391). Relatively less drought tolerant than crested wheatgrass (391).

\section{Heavy Metals and Hydrocarbons}

The species appears to do acceptably well where boron concentrations are moderately toxic (10 to $22 \mathrm{ppm}$ ) (305). Unsuccessful on alkaline tailings characterized by heavy metal problems (310). There is some evidence to indicate that this species performs satisfactorily on heavy and lean bitumen contaminated materials (404). No other special tolerances have been noted from the literature.

\section{Shade}

Presumably reasonably shade tolerant since its habitat preferences are similar to the shade tolerant A. subsecundum (304).

\section{Grazing or Mowing}

Moderately tolerant to grazing and mowing (P. King, pers. comm.). Reported sharp decrease in cover (most prevalent species to least prevalent) under grazing (734). 


\section{Susceptibility to Disease and Insect Damage}

Moderately resistant to disease and insects (339). Resistant to leaf and stem rust and stripe rust, and with varying resistance to head smut $(183,179$, 618). Occasionally attacked by powdery mildew (35). Somewhat tolerant to grass bug (Labops hesperius) in nursery trials, possible use in reseeding semi-arid rangeland where grass bugs are a problem (658). However, slender wheatgrass was found to be susceptible to grass bugs compared to native grasses in a field trial in Utah (658). Appears to be less heavily grazed by voles and mice than many other native pasture species (111).

\section{RECLAMATION CONSIDERATIONS}

\section{Soil Building and Erosion Control Capability}

Because of its rapid establishment, high emergence success and rapid spreading ability, the species is a good choice for use in a short-term erosion control program $(187,340)$. A moderately good soil stabilizer (338). Possesses a relatively inextensive root system. When used with long lived or slower developing species, it is at first more prominent, but eventually becomes secondary (187). Its high biomass production indicates good soil building potential. The species is often recommended for use on steep slopes, especially in cooler locations $(249,422)$.

\section{Adaptations to Disturbance}

Good colonizer, reasonably well adapted to disturbance (338), often filling in sites where sod has been opened by rodent activity or other disturbance (340). Has been recorded as colonizing various disturbed sites in Alberta, including a droughty exposed site in Jasper National Park (651), a scarified gravel road bed in Banff National Park (652) and abandoned coal mine spoils in the eastern slopes (708).

\section{Competitive Ability}

A relatively good competitor in the first two or three years because of its rapid establishment and early seed production (339). Less competitive than pubescent wheatgrass but more competitive than slower developing Russian Wild ryegrass, crested wheatgrass and Altai wild ryegrass in greenhouse trials (715). When planted with crested wheatgrass declined from $69.5 \%$ to $2.6 \%$ of herbage production after 4 years. When planted in mixture with crested wheatgrass, thickspike wheatgrass, western wheatgrass and green needlegrass; slender wheatgrass was eliminated after 4 years (711).

\section{Commercial Value}

Suitable for hay and forage production under conditions of natural rainfall (674), partly because of its superior biomass production (187). Wildlife range and short term erosion control $(12,144,391,340$, 179).

\section{Palatability and Nutritive Value}

Considered a good quality hay crop species and a fair pasture plant $(391,183)$. Fairly palatable (614). Cattle grazed Altai or Russian wild ryegrass but refused to eat slender wheatgrass grown in association with it (662). Among the preferred foods of bighorn sheep and elk, and of moderate palatability to moose (144). Moderately to highly palatable on Colorado ranges above $2000 \mathrm{~m}$ ASL (427).

\section{Seed or Planting Stock Availability}

At least two commercial cultivars "Primar" and "Revenue" are licenced and available in Canada (138). Revenue has superior establishment ability, salinity tolerance, forage quality and yield compared to Primar (618). "San Luis" is available in the US (639). Native seed is fairly easily collected since seeds are large and the species is common. Because of considerable genetic variability, it is important to collect seed from appropriately adapted local populations (456). Limited quantities of seed of a cultivar adapted to northern conditions may be available from fall 1991 (M. Vaartnou pers. comm). Five lines of slender wheatgrass are presently being tested for potential use in alpine reclamation with the objective of registering successful lines as commercial seed (655). Approximately 159000 seeds/lb (639).

\section{Methods and Ease of Establishment}

Early summer seeding is better than midsummer or fall (655). Fall seeding has also been recommended at a rate of 6 to $8 \mathrm{lbs}$ PLS/ac (639). Slender wheatgrass has excellent seedling vigour and is very productive for the first 1 or 2 years after seeding (616). Adapted to seeding in combination with other pasture grasses and legumes (391), notably with sweet clover (Melilotus spp.) on saline sites (183). Seed mixes containing longer-living, slower establishing and/or earlier ripening species are recommended $(187,340)$. Fertilization at time of planting would likely be advantageous. Topdressing of coaly or contaminated wastes prior to seeding is usually adequate to ensure high rates 
of emergence $(187,364,489)$. Yields are notably higher under relatively dry range conditions, when irrigation is possible. Slender wheatgrass is rated as high for both seed and transplanting establishment (338).

\section{Current Status for Reclamation}

A widely used range and forage species (391) in agricultural and semi-agricultural situations. "Revenue" particularly suitable cultivar for saline soils and short rotations in the Dark Brown, Black, and Eluviated Black soils of Western Canada. Extensive testing over five years along the Eastern Slopes Region $(705,723,732,740)$. Determined that the native species and the cultivar "Revenue" are well suited to the subalpine region on topsoil sites and overburden sites with fertilizer, however, reproduction of "Revenue" was lower that of the native species (740). Native and "Revenue" slender wheatgrass produced good ground cover but failed to set seed in the alpine (740). "Revenue" also performed well in mixed seedings on various terrain on a pipeline right-of-way in the upper MacKenzie Region of the Boreal Forest from Norman Wells, N.W.T., to Zama, Alberta (644) but was short-lived (three years) in tests in arctic tundra in the Mackenzie River Delta. The native species were best species in five years at tests at Fort McMurray on tailings sand (705) but died out after eight years in a grass/legume mixture on similar soils (643). "Revenue" also did poorly in grass/legume test mixes in overburden and topsoil sites at the Judy Creek test mine (646).

Major assets of slender wheatgrass are its tolerance to both highly saline and moderately alkaline soils, its relative ease of establishment, its high biomass production, its colonizing characteristics, its rapid addition of organic matter to disturbed soil and its superior self-propagation success. 
SPECIES SUITABILITY MAP AND SUMMARY TABLE

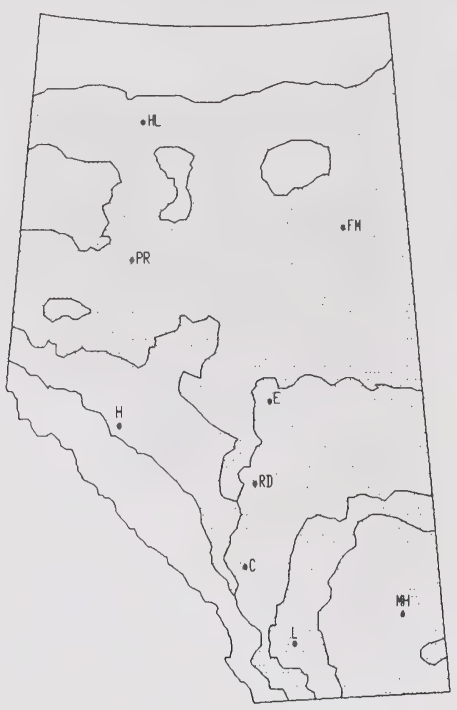

Recommended Area

Commercially Available: Yes $\mathrm{X}$ No

\begin{tabular}{|c|c|c|c|c|c|}
\hline \multirow{2}{*}{$\begin{array}{l}\text { RECLAMATION SUITABILITY } \\
\text { CRITERIA }\end{array}$} & \multicolumn{5}{|c|}{ SUITABILITY RATING } \\
\hline & Very High & High & Medium & Low & None \\
\hline Drought Tolerance & & $x$ & $X$ & & \\
\hline Salt Tolerance & & & $x$ & & \\
\hline Acid & & & $x$ & $x$ & \\
\hline Tolerance Base & & & $\mathrm{X}$ & & \\
\hline Winter Hardiness & & & $x$ & & \\
\hline Erosion Control & & $x$ & & & \\
\hline Persistence & & $x$ & $x$ & & \\
\hline Palatability & & & $x$ & & \\
\hline Browse Tolerance & & $x$ & $x$ & & \\
\hline Moisture Preference & Moist & dry. & & & \\
\hline Soil Preference & Relat & $1 y$ sar & clay w & aine & \\
\hline
\end{tabular}


Agropyron trichophorum (Link) Richt.

\section{SPECIES BIOLOGY}

Taxonomy - Pubescent Wheatgrass

\section{Origin and Range}

Introduced from the USSR and eastern Europe (183, 430, 340). Planted in the northwestern U.S. (199) and in western Canada, generally below arctic and alpine treelines.

\section{Growth Habit}

A tall, erect sod-forming grass $(183,47)$, up to $110 \mathrm{~cm}$ in height depending on site conditions (139). Heights of $75 \mathrm{~cm}$ are common in Colorado (424). Somewhat rhizomatous $(391,232,47)$.

Nitrogen Fixing - None

\section{Longevity}

Long-lived, cool season (639) perennial (391, 426, 179). On dryland, plants may lose vigour after 3 to 5 years, with a resultant drop off in production (391). Has good overall hardiness (139).

\section{Self Propagation}

The species reproduces itself both by seeding and vegetatively through a spreading root system (391, $183,340)$. Natural reseeding ability is rated as medium, while natural vegetative reproduction is considered very good (338). Seed yield is moderate to good (139). Good establishment (179); very good growth rate (338). Seeds are large and seedling vigour is excellent $(179,320)$.

\section{Ecological Setting}

Habitats are nearly the same as for $\underline{A}$. intermedium. Found fairly commonly in hayfields and pastures in the parkland areas (47). Also found in dry, open habitats (338). About 30 to $35 \mathrm{~cm}$ (639) of precipitation is required at lower elevations or where evapotranspiration is relatively high; at lower rates of evapotranspiration, $25 \mathrm{~cm}$ is adequate (179). The "Topar" and "Luna" cultivars are adapted to shallow, low fertility soils, and require 25 to $35 \mathrm{~cm}$ of precipitation $(183,320)$. "Trigo" cultivar has been successful in trials where precipitation was as low as $15 \mathrm{~cm}$ annually (183). "Luna" has reduced seed production at annual precipitation below $45 \mathrm{~cm}$ (320).

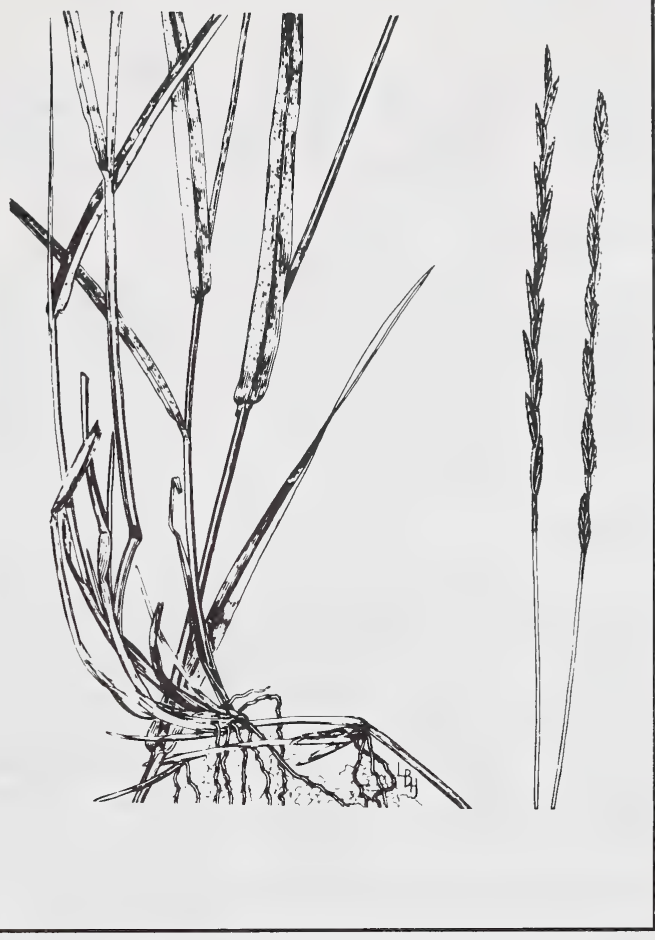

TOLERANCES

\section{Soil Preferences}

Prefers well drained $(179,639)$ but moist soils $(12$, 249). Also achieves good growth under low soil moisture conditions (422). Chernozems, Brunisols, well drained Podzols and Regosols are all suitable substrata. A wide variety of textural classes are suitable, from relatively sandy to fairly clayey (426). Performance of pubescent wheatgrass (cultivars not specified) seeded on waste rock and overburden at several metal mining operations in the southern interior of B.C. was rated as "moderate" (143).

\section{Nutrient Requirements}

Under low fertility conditions, pubescent wheatgrass may become sodbound after 4 to 5 years, resulting in greatly reduced production (340). "Luna" and "Topar" cultivars withstand lower fertility $(183,320)$. Will be successful under conditions of lower fertility than intermediate wheatgrass (426). Like slender 
wheatgrass (Agropyron trachycaulum), it is one of the better companions of legumes at lower fertilization rates (359).

\section{Soil Reaction}

Prefers mildly acid, neutral or mildly alkaline conditions (179). Possibly favoring mildly alkaline conditions (338). Withstands more alkaline conditions than intermediate wheatgrass (426).

\section{Soil Salinity}

Fairly tolerant of soil salinity $(183,424)$, especially the "Greenleaf" cultivar. Rated as having moderate tolerance in the range of 4 to $8 \mathrm{mS} / \mathrm{cm}$ (247). Seeding and planting recommendations in Montana, however, indicate that the species is poorly adapted to saline and alkaline sites (422).

\section{Drought}

Somewhat more drought tolerant than intermediate wheatgrass (A. intermedium) $(391,183,426)$, but less drought tolerant than crested wheatgrass (A. cristatum) (340). Performed very well under dry non-irrigated conditions in Texas (375). Becomes dormant during periods of drought, reviving with the rains. Prefers sites where significant annual moisture is derived from snow (320).

\section{Heavy Metals and Hydrocarbons}

Considered intolerant to boron (5 ppm) when grown directly on spoil materials in California (344).

\section{Shade}

Not very well adapted to shady situations (340).

\section{Grazing or Mowing}

Good persistence under close grazing is attributable to its sod-forming habit (340).

\section{Susceptibility to Disease and Insect Damage}

The species is relatively free of disease (179). Readily infected with leaf blight, causing foliage to become dry and unpalatable (340). Subject to Banks grass mite (Oiiqonychus pratensis Banks), which feeds on leaves; timely application of dusting sulphur or other miticides is effective. Damage is usually not severe in grazed stands. Infestations of Pacific grass bug, which feed on leaf chlorophyll, are generally not serious enough to warrant treatment (179).

\section{RECLAMATION CONSIDERATIONS}

\section{Soil Building and Erosion Control Capability}

Considered a very good soil stabilizer (338) because of its sod-forming habit. Stands spread rapidly $(183,340)$ amidst other species.

\section{Adaptation to Disturbance}

Well adapted to disturbance (338).

\section{Competitive Ability}

Generally a good competitor, spreading rapidly by vegetative means (183). In Nevada, it displayed a rare ability to aggressively invade stands of big sagebrush and wheatgrass (Bromus tectorum), an aggressive, weedy annual range grass $(183,308)$.

\section{Commercial Value}

Can be used for hay or pasture, although its ability to stay green over summer, when moisture supplies are low, suggests that it is an especially good pasture species (391). Also suitable for erosion control (422).

\section{Palatability and Nutritive Value}

More palatable after heading than crested wheatgrass (340). Herbage yield is moderate to high (139). As with other wheatgrasses, highly palatable for bighorn sheep and elk, moderate for moose, but not often used by deer (144). Found to have moderate palatability for a wide range of site conditions (moisture, climate, elevation) (427). Considered to have good forage value for cattle $(320,19)$

\section{Seed or Planting Stock Availability}

Several commercial cultivars are available. "Greenleaf" was developed in Canada at Lethbridge and it is the only cultivar licensed in Canada. "Luna" (Reg. No. 6), "Mandan" and "Topar" are available in the US (639). Other cultivars are still undergoing testing ("Mandan 759" and "Trigo") (183). Local seed collection is relatively easy due to large seed size and general abundance of seed (179). Since seed does not shatter, the crop can be swathed and combined, but it is difficult to thresh because the rachis breaks up and the seeds adhere to segments (179). The rachis segments are difficult to remove when cleaning the seed; therefore the maximum purity of seed is less than $90 \%$ (179). Approximately 100000 seeds/lb (639). 


\section{Methods and Ease of Establishment}

Deep furrow drills are preferred for seeding; the species can be planted in fall (639) or in spring with equally good results (179), presumably due to its tolerance of later summer drought. Can be grown alone or in mixtures including legumes (179). An initial fertilization may be useful, but otherwise stands will do acceptably well under minimal soil fertility conditions. The species does as well as any grass except creeping red fescue (Festuca rubra) and crested wheatgrass on waste rock and overburden in the southern interior of B.C. (143). A seeding rate of 10 to $12 \mathrm{lbs}$ PLS/ac has been recommended (639).

\section{Current Status for Reclamation}

A moderately well used hay and pasture species in western Canada and the northwestern U.S. (391, 199), since it remains green late in the season. Considered a good species for dry reclamation situations, though it may have some elevational limitations in Canada. Currently in use at five metal mines in southern B.C. (143). Performing satisfactorily on top dressed ash lagoons at Wabamum (305). Grew well in initial stages in Grande Cache (269). Showed good experimental survival at Luscar (259). Fair to good results for mine revegetation under a variety of conditions have been recorded $(213,117,90)$. "Greenleaf" performed poorly at Fort McMurray on amended tailings sand, dying out in a grass/legume mix after three years (643).

Major assets are its good drought tolerance, superior forage value (especially in late summer), aggressive sod-forming habit for erosion control, relative vigour, ease of establishment, low nutrient requirements, and longevity. It appears not to have particular tolerances to extreme $\mathrm{pH}$, high salinity, shade, heavy metals or hydrocarbons. 
Agrostis alba

SPECIES SUITABILITY MAP AND SUMMARY TABLE

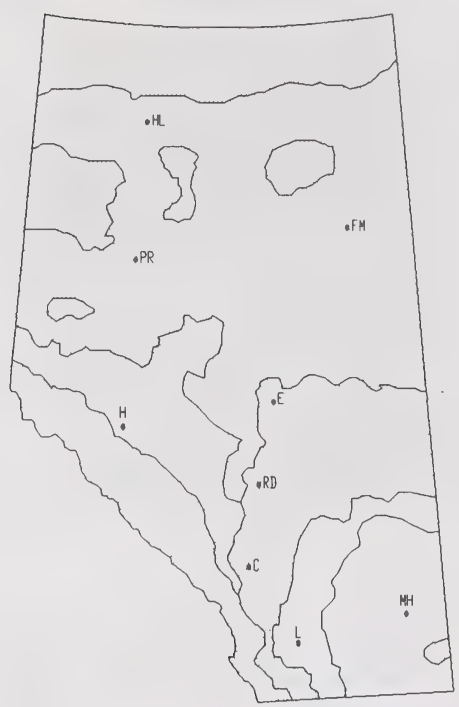

Recommended Area

Commercially Available: Yes $\mathrm{X}$ No

\begin{tabular}{|c|c|c|c|c|c|}
\hline \multirow{2}{*}{$\begin{array}{l}\text { RECLAMATION SUITABILITY } \\
\text { CRITERIA }\end{array}$} & \multicolumn{5}{|c|}{ SUITABILITY RATING } \\
\hline & Very High & High & Medium & Low & None \\
\hline Drought Tolerance & & & $x$ & $x$ & \\
\hline Salt Tolerance & & & & $x$ & \\
\hline $\mathrm{pH} \quad$ Acid & & 4.5 & & & \\
\hline Tolerance Base & & & & $\mathrm{X}$ & \\
\hline Winter Hardiness & & $x$ & $x$ & & \\
\hline Erosion Control & & & $x$ & & \\
\hline Persistence & & $x$ & & & \\
\hline Palatability & & & $x$ & $x$ & \\
\hline Browse Tolerance & & & $x$ & & \\
\hline Moisture Preference & Wet, & hstands & olonged & ng. & \\
\hline Soil Preference & Clay & ured, & rly drai & & \\
\hline
\end{tabular}


Agrostis alba L.

\section{SPECIES BIOLOGY}

Taxonomy - Redtop $(138,47,179)$.

Similar to A. stolonifera L.; also sometimes called A. palustris Huds.

\section{Origin and Range}

Introduced to North America, probably before 1750 (138). Native to Europe $(47,341,138)$. The species is found in the U.S. throughout cooler parts, especially northeast and northcentral areas (183). It is well established wherever moisture supplies are adequate (138). Similarly in Canada, the species is associated with fairly moist forested or partly forested areas.

\section{Growth Habit}

A relatively low growing, erect species which spreads by shallow creeping rootstocks or rhizomes $(38,341,47,391)$. Can achieve heights of 100 to $150 \mathrm{~cm}(47,341)$, but is more typically about $60 \mathrm{~cm}$ (424, 139). Rooting is shallow (138).

\section{Nitrogen Fixing - None}

\section{Longevity}

Long-lived, cool season (639) perennial (138). Only moderate winter hardiness $(70,139,240)$, though in Alaska it is rated as high in this category (5).

\section{Self Propagation}

Seeds are small and generally numerous $(138,257)$, though seed production is considered low in Alaska (5). Plants spread from shallow rhizomes (47). Growth is vigourous $(391,5)$.

\section{Ecological Setting}

Cultivated for meadows, pastures and lawns. Escaped throughout cooler, moister parts of North America (47). Also is found on roadsides and waste places (341). Prefers about $50 \mathrm{~cm}$ of precipitation annually $(179,639)$. Can be used with some success at elevations above about 1500 or 1 $600 \mathrm{~m}$ ASL $(119,70,498)$, though success below treeline is sometimes better (70).

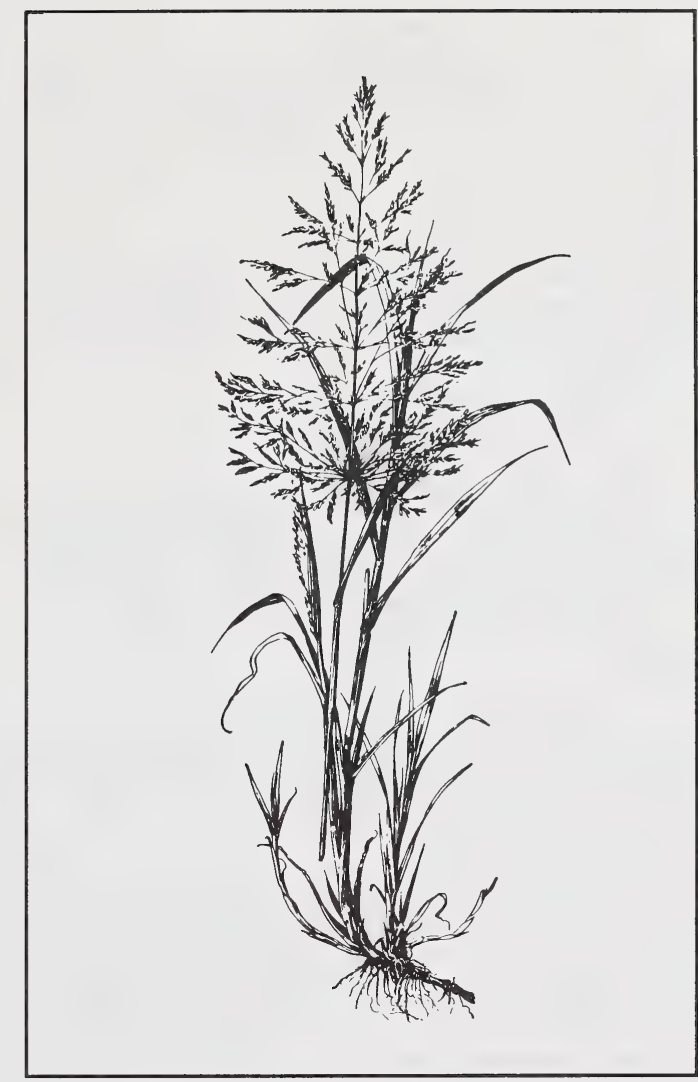

\section{TOLERANCES}

\section{Soil Preferences}

Adapted to poorly drained land, and clay soils (391, 183). High tolerance to wet soil and flooding, even over prolonged periods $(5,361)$.

\section{Nutrient Requirements}

Adapted to low fertility soils $(179,391,361,342)$ though best with moderate fertilizer application (5).

\section{Soil Reaction}

Adapted to neutral, acid or very acid soils $(391,183$, $5,179,38$ ). Good above pH 4.5 (346), though some records exist for occurrences below this level. 


\section{Soil Salinity}

No more than low tolerance to saline soils (247, $361,125)$, notably ones that do not exceed $4 \mathrm{~ms} / \mathrm{cm}$.

\section{Drought}

Redtop has some tolerance to drought $(5,138)$, especially when droughty periods are short (391, 179). Said to have poor resistance to drought in Alaska (5).

\section{Heavy Metals and Hydrocarbons}

Displays several-fold greater tolerance to aluminum than alfalfa (Medicago sativa) or timothy (Phleum pratense) (227). No particular success in revegetation of oil contaminated land (360).

\section{Shade}

Can be used for pasture and hay in timbered areas (179), therefore presumed to be at least moderately adapted to shade.

\section{Grazing or Mowing}

Recovery rate after cutting is moderate (5).

\section{Susceptibility to Disease and Insect Damage}

No information regarding disease or insect damage was located.

\section{RECLAMATION CONSIDERATIONS}

\section{Soil Building and Erosion Control Capability}

Strong rhizomatous habit (47) facilitates good erosion control characteristics. Widely used for erosion control and site stabilization $(391,183,179)$. Commonly occurs on moist roadsides (9). May do well on slopes if moisture is adequate.

\section{Adaptation to Disturbance}

Redtop is known to colonize acid soils at Sudbury (476). Presumed to be well adapted to disturbance due to its strong sod-forming habit, abundant seed production, and preference for reestablishing on bare soil.

\section{Competitive Ability}

Relatively aggressive, though less so than timothy or colonial bentgrass (Agrostis tenuis) $(183,318$,
138). Often grown with alsike clover (Trifolium hybridum) and timothy $(179,391)$. Fairly compatible with other species (5).

\section{Commercial Value}

Used for lawns, pastures, erosion control and occasionally for hay (183). Can be used along waterways, at waterline on irrigation ditches, on moist burned-over areas, or to retard invasion of weedy species $(391,179)$. Little value as a herbaceous species (138).

\section{Palatability and Nutritive Value}

Not as palatable as other wetland species (179, 391). Often considered to have poor palatability (5). Useful to wildlife for the cover, herbage and seed that it provides some species (346).

\section{Seed or Planting Stock Availability}

One cultivar, "Reton", has been identified, but it is no longer licensed in Canada, and seed supplies are short but "common" is available (138). Approximately 4900000 seeds/lb (639).

\section{Methods and Ease of Establishment}

Prefers shallow or broadcast seeding on prepared seedbeds or other bare mineral soil surfaces (179). Ease of establishment is considered good (424). Germination capacity is about $75 \%$ (257). A fall/spring seeding at a rate of $1 \mathrm{lb}$ PLS/ac has been recommended (639).

\section{Current Status for Reclamation}

In Alberta, redtop has been fairly widely tested and used for reclamation purposes. Early test results have been encouraging on various materials at Grande Cache (267), Luscar (259) and Tent Mountain $(380,723)$. In the oil sands area, redtop was among the most successful species on well drained, unimproved tailings sand (257), though certain subsequent trials have been less encouraging (359). In the B.C. interior, moderate success has been recorded on waste rock at two metal mines, but results on overburden and tailings have been poor (143). Redtop has been a volunteer on tailings pond remnants (96) in B.C. trials which are being actively carried out in the Northeast Coal Block $(70)$, as well as in the south $(164,496)$. Many of these results are promising. Good overwintering was found at Yellowknife on moderately saline materials (457), as well as at Prudhoe Bay (284). While establishment was rapid it did not overwinter on the arctic coastal plain, however, it has persisted 
well for ten years in a mixed seeding in the Upper Mackenzie Region of the boreal forest on a pipeline right-of-way at latitude $65^{\circ} \mathrm{N}$ (644). Encouraging success on acidic materials has been recorded for Elliott Lake, Sudbury $(476,318,316)$ and at Timmins, Ontario (408). Success has also been recorded on acidic tailings in Quebec (408) and New Brunswick (2). Success in the United States appears to be somewhat dependent on the moisture available at the reclamation site $(16,275,342,213$, 212).

Major assets include its tolerances of flooding, acidity, certain heavy metals and low fertility levels; its erosion control capability, and its excellent establishment potentials. However, it is not highly palatable, not particularly drought tolerant, and may be somewhat lacking in winter hardiness. 
SPECIES SUITABILITY MAP AND SUMMARY TABLE

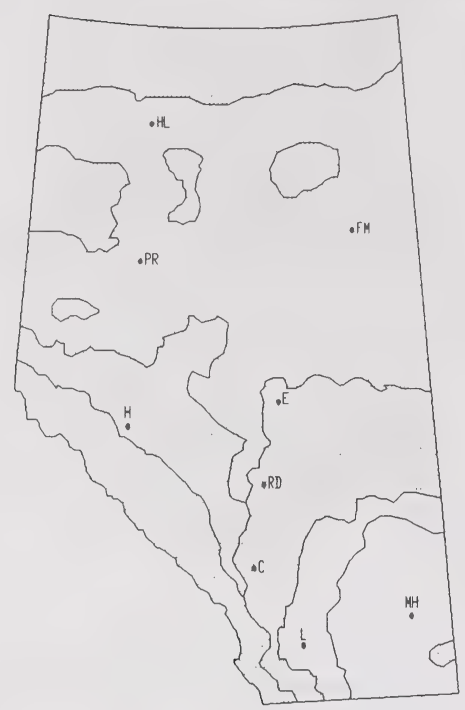

Recommended Area

Commercially Available: Yes No

\begin{tabular}{|c|c|c|c|c|c|}
\hline \multirow{2}{*}{$\begin{array}{l}\text { RECLAMATION SUITABILITY } \\
\text { CRITERIA }\end{array}$} & \multicolumn{5}{|c|}{ SUITABILITY RAIING } \\
\hline & Very High & High & Medium & Low & None \\
\hline Drought Tolerance & & & $x$ & & \\
\hline Salt Tolerance & & & & $x$ & \\
\hline pH Acid & & 4.0 & & & \\
\hline Tolerance Base & & & & & \\
\hline Winter Hardiness & $x$ & & & & \\
\hline Erosion Control & & $x$ & & & \\
\hline Persistence & & & & $x$ & \\
\hline \multicolumn{6}{|l|}{ Palatability } \\
\hline Browse Tolerance & & & $x$ & & \\
\hline Moisture Preference & \multicolumn{5}{|c|}{ Moist to dry. } \\
\hline Soil Preference & Fine & sandy & ured; we & impe & ain \\
\hline
\end{tabular}


Agrostis scabra Wild.

\section{SPECIES BIOLOGY}

\section{Taxonomy}

Hair Grass; Tickle Grass (312); Rough Hair Grass (78).

Includes Agrostis geminata

\section{Origin and Range}

Native. Alaska to Newfoundland and south to all but the southeastern United States. Also in Asia (507). It is a variable species (435). Var. geminata (Trin.) Swallen is also found in Alberta (312).

\section{Growth Habit}

Tufted bunchgrass, 30 to $70 \mathrm{~cm}$ high (312). It forms small, dense tufts (435).

\section{Nitrogen Fixing - None}

Longevity - Perennial (312).

\section{Self Propagation}

At maturity the inflorescence breaks away and is carried off by the wind like a tumbleweed. This facilitates dispersal to areas far removed from the place of origin $(312,78)$.

\section{Ecological Setting}

Hairgrass is found from near sea level to the subalpine (507). It is found on dry, open slopes and alluvial flats (214). It is also found on moist ground in meadows, open woods and abandoned fields even in dry areas $(312,78)$. Var. geminata is found on alpine slopes in Alberta (312). Hair grass has been reported to be found in moist sites from 2000 to $3330 \mathrm{~m}$ in Wyoming (18). Seed has been collected at $2000 \mathrm{~m}$ in Alberta (380).

\section{TOLERANCES}

\section{Soil Preferences}

Hair grass has been successfully established on barren, gravelly, stony and rocky slopes when adequate fertilizer was applied (478).

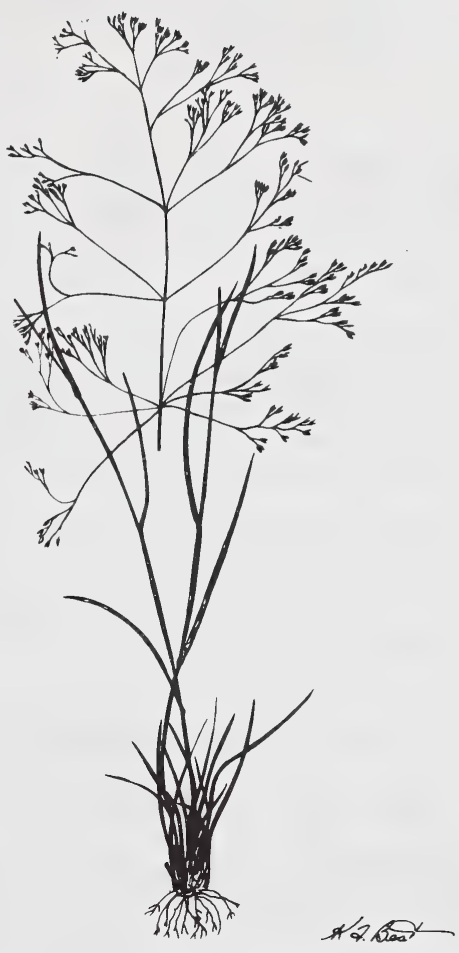

Nutrient Requirements

Hair grass is adapted to soils of low nutrient status (476).

\section{Soil Reaction}

Hair grass can tolerate soils of low $\mathrm{pH}(476)$. It is an early colonizer of barren acid ( $\mathrm{pH} 4.0)$ soils near Coniston, Ontario (478).

\section{Soil Salinity}

Tolerant of mildly saline soils.

\section{Drought}

Drought tolerance is probably moderate since it colonizes bare, sandy soil near Coniston, Ontario (477). It is also found on dry, open slopes in the mountains (214). 


\section{Heavy Metals and Hydrocarbons}

Hair grass has been found growing on soils with total $\mathrm{Cu}$ and $\mathrm{Ni}$ contents of up to $450 \mathrm{ppm}$ and $500 \mathrm{ppm}$ respectively (478).

\section{Shade}

Generally found in open sunny locations, so it is presumed to be relatively shade intolerant.

\section{Grazing or Mowing}

No specific tolerances noted in the literature reviewed, although the habits of this species would suggest that it is reasonably tolerant of grazing. Many Agrostis spp. are used for putting greens of golf courses; tolerant of very close mowing.

\section{Susceptibility to Disease and Insect Damage}

Some ecotypes are resistant to snow mold (Sclerotinia borealis) (435).

\section{RECLAMATION CONSIDERATIONS}

\section{Soil Building and Erosion Control Capability}

Hair grass produces very lush growth the first year, if fertilized. The resulting dense cover provides an effective ground cover to prevent surface erosion (478).

\section{Adaptation to Disturbance}

Hair grass is a common pioneer of abandoned fields throughout the prairies $(145,78)$. It is a pioneer of barren, sandy soil near Coniston, Ontario (478). It is not necessary to seed hair grass in an area where there is a seed source nearby since it is very efficient at seed dispersal by tumbling mechanisms (478). Hair grass has been reported as a pioneer on a relatively dry white spruce area, near Norman Wells, N.W.T. (45). It has been noted as a pioneer of disturbed areas in Alberta (455).

\section{Competitive Ability}

Moderately aggressive in adapted areas.

\section{Commercial Value}

Some Agrostis spp. are used for lawns and golf courses, particularly putting greens where their growth form allows development of a very fine, short turf.

\section{Palatability and Nutritive Value}

No indication of palatability or nutrient value for this species was found in the literature reviewed.

\section{Seed or Planting Stock Availability}

No commercial supply of A. scabra seed is available. Seed for several related species (A. tenuis, A. alba, and A. palustris) is available from commercial suppliers although it is generally very expensive.

\section{Methods and Ease of Establishment}

Primarily by seed although sprigging has been successful for related species.

\section{Current Status for Reclamation}

Seed of hair grass has been collected in Alberta for genetic improvement $(455,453)$. When established on fertilized ground, hair grass produced very lush growth the first year, but it tended to act more as an annual than a perennial. The thick thatch form retarded regrowth in the second year and establishment of other species (378). In a field trial near Tent Mountain in Alberta, hair grass produced greater than $20 \%$ cover on fertilized plots after the first growing season (10).

Hair grass is a variable species found in dry and moist sites from the prairies to the mountains. Var. geminata is found on alpine slopes. The species is tolerant of very acid soils and soils low in nutrients. Some ecotypes are resistant to snow mold. It has good potential for use in reclamation in Alberta. Further research is needed into suitable ecotypes and methods of establishment. 
Alopecurus arundinaceus

SPECIES SUITABILITY MAP AND SUMMARY TABLE

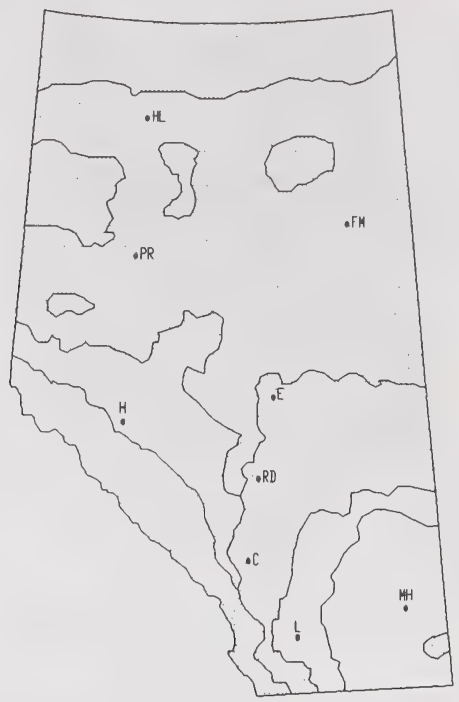

Recommended Area

Commercially Available: Yes $\mathrm{X}$ No

\begin{tabular}{|c|c|c|c|c|c|}
\hline \multirow{2}{*}{$\begin{array}{l}\text { RECLAMATION SUITABILITY } \\
\text { CRITERIA }\end{array}$} & \multicolumn{5}{|c|}{ SUITABILITY RATING. } \\
\hline & Very High & High & Medium & Low & None \\
\hline Drought Tolerance & & & $x$ & $x$ & \\
\hline Salt Tolerance & & & & $x$ & \\
\hline Acid & & $x$ & & & \\
\hline Tolerance Base & & & & $x$ & \\
\hline Winter Hardiness & $x$ & $x$ & & & \\
\hline Erosion Control & & $x$ & & & \\
\hline Persistence & $x$ & & & & \\
\hline Palatability & & $x$ & $x$ & & \\
\hline Browse Tolerance & & $x$ & & & \\
\hline Moisture Preference & Moist & wet, & res cons & le $f$ & \\
\hline Soil Preference & Mediun & o heav & xtured, & dra & \\
\hline
\end{tabular}


Alopecurus arundinaceus Poir.

\section{SPECIES BIOLOGY}

\section{Taxonomy}

Creeping Foxtail $(183,139,179)$, Creeping Meadow Foxtail $(426,5)$

\section{Origin and Range}

Creeping foxtail is native to Eurasia $(183,199)$. The species is variously considered native $(132,500)$ and introduced $(391,183,426)$ in North America. It was apparently brought to the U.S. by homesteaders from eastern Germany or the western USSR, probably around the turn of this century (183). It has since escaped and is now present in many areas of western and northern North America $(183,426)$.

\section{Growth Habit}

A tall, erect sod-forming grass, with strong rhizomes $(183,426)$. It may reach heights of $80 \mathrm{~cm}(139)$ or more under favorable conditions (500). A. pratensis (meadow foxtail) is a related species of similar growth habit $(183,179,500)$.

\section{Nitrogen Fixing - None}

\section{Longevity}

Long-lived, cool season (639) perennial $(179,183$, 426), that shows excellent persistence at high altitudes and in the north $(41,5)$. Good winter hardiness $(240,5)$. Can survive at least 18 years at high elevations (3 $770 \mathrm{~m} \mathrm{ASL}$ ) (213).

\section{Self Propagation}

Natural seed production is low (5). Seedling vigor is described variously as weak to moderate $(41,5$, 179) to excellent (D. Walker, pers.comm.). It is the only commercially available species able to set viable seed in the upper subalpine (41). Principle means of self propagation is by vegetative spreading from the strong rhizomatous root system $(183,391)$.

\section{Ecological Setting}

Performs best in moist situations such as wetland pastures and mountain meadows (183). Requires a minimum of $63 \mathrm{~cm}$ of precipitation (639). Its high tolerance of flooding (5) and cold temperatures ensures its success for very moist situations throughout the area. Suited to both high elevations

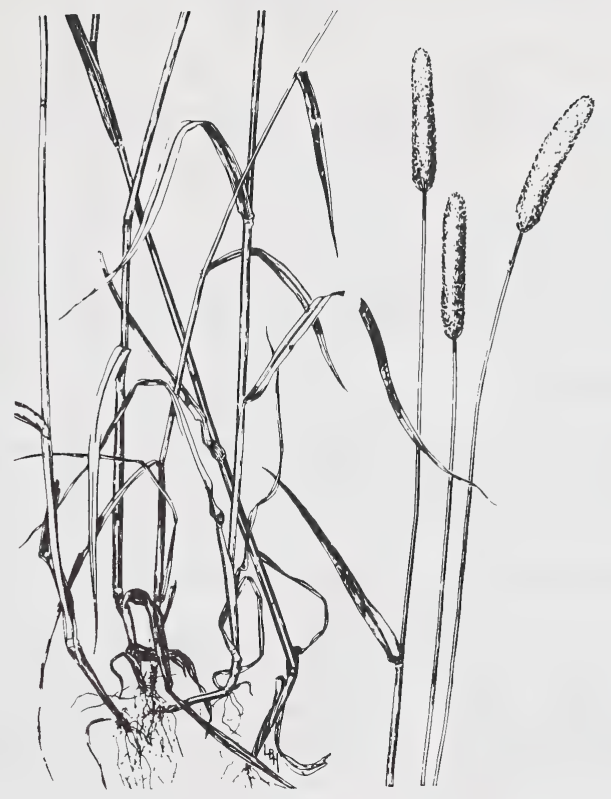

(41) and high latitudes (5). Successful at the Climax molybdenum mine (Colorado) at about $3400 \mathrm{~m} \mathrm{ASL}$ (236) and $2200 \mathrm{~m} \mathrm{ASL}$ at Marmot Basin $\left(65^{\circ}\right.$ latitude) in Alberta (D. Walker, pers.comm.).

\section{TOLERANCES}

\section{Soil Preferences}

Prefers medium and heavy textured soils $(5,500)$ that are poorly drained (179). Creeping foxtail endures considerable flooding (5) and is best adapted to fairly moist conditions (183). Favored soils include saturated or "groundwater" Podzols and humid forest soils such as the poorly aerated, saturated "claypan" soils (179). Gleysols or gleyed Luvisols should also be suitable.

\section{Nutrient Requirements}

Noted to have moderate to high nutrient requirements $(5,426)$. Meadow foxtail ( $A$. pratensis) also requires good fertility $(391,5)$. Good crop management often includes a mid-season nitrogen 
fertilizer application (179). Establishment and early growth is aided by low nitrogen fertilizer applications (179). Phosphorous applications yield particularly good responses (380).

\section{Soil Reaction}

Adapted to strongly acid to neutral soils $(5,179$, 500).

\section{Soil Salinity}

Little indication, though it has been suggested that creeping foxtail may endure slight salinity (500).

\section{Drought}

Moderately tolerant of short droughty periods (500), though overall resistance must be considered poor (5).

\section{Heavy Metals and Hydrocarbons}

Creeping foxtail has performed well on coal overburden spoils (with unknown hydrocarbon content) (380). No other notes of growth on potentially phytotoxic materials have been gathered from the literature.

\section{Shade}

Presumably it tolerates some shade, as does meadow foxtail, and grows well in deciduous forest stands (339).

\section{Grazing or Mowing}

Creeping foxtail has a moderate recovery rate after cutting (5). A. pratensis is noted to have excellent tolerance to grazing (339).

\section{Susceptibility to Disease and Insect Damage}

No particular sensitivities or tolerances to diseases or insect pests have been noted from the literature consulted.

\section{RECLAMATION CONSIDERATIONS}

\section{Soil Building and Erosion Control Capability}

Creeping foxtail is a useful and effective erosion control species $(186,426)$. It has been improved, in part, for use in waterway stabilization (266) and is used for highway turf purposes (298), for ski slopes (236) and for minesite slope stabilization (380), especially at high elevations and in moist situations.
Its vigorous sod-forming habit and wide adaptability may be credited.

\section{Adaptation to Disturbance}

Probably can be considered moderate, at least where it is able to vegetatively invade.

\section{Competitive Ability}

Creeping foxtail is at least a moderately good competitor, reducing the invasion of weedy grass (179). Considered to have medium to strong aggressiveness on moist to wet sites $(500,644)$. Though some report that it has poor compatibility with other species (5), others disagree regarding meadow foxtail (500). It is frequently seeded with alsike or white clover (Trifolium hybridum or I. repens), big trefoil (Lotus uliginosus) or timothy (179).

\section{Commercial Value}

The species is used for pasture, silage and hay purposes (179) and for erosion control (183), including waterways (266), highways (298) and ski slopes (236).

\section{Palatability and Nutritive Value}

Both creeping (Alopecurus arundinaceus) and meadow foxtail (A. pratensis) are moderately to highly palatable. Both green up early and remain palatable throughout the growing season $(41,183$, $391,426,427,339,-179,5)$. In one test, it ranked second only to timothy (Phleum pratense) among 20 grasses tested (179). Deer and elk favor meadow foxtail for its early growth and new shoots throughout the summer. Livestock favor the forage (339). Forage yield is high.

\section{Seed or Planting Stock Availability}

"Garrison" is the only cultivar of creeping foxtail commercially available in Canada and the U.S. Though readily available $(183,426)$, it may be quite expensive (41). It has good yields of high quality forage, and is well adapted to wetland sites (183) or irrigated pastures (426). Approximately 900000 seeds/lb (639). Four cultivars of meadow foxtail (A. pratensis) are available. These include "Dan", "Oregon", "Polano" and "Rhona" (139).

\section{Methods and Ease of Establishment}

Seed is fluffy and it will not distribute at all in common drills (41). Combining with an inert material such as rice hulls, vermiculite or cracked 
corn will ensure that seed is properly delivered (391, $179,41)$. Coated seed is suggested for easier handling (D. Walker, pers. comm.). Seeding in combination with one or more legumes is also advised (179). Fertilization with a low nitrogen product at the time of seeding will aid establishment (179), which is a sensitive period for the species. Unprocessed seed retains $70 \%$ viability over 10 years storage in cool, dry conditions (179). Irrigation would probably be useful if the adequacy of moisture is in question. A fall or spring seeding at a rate of 3 to $4 \mathrm{lbs}$ PLS/ac has been recommended (639).

\section{Current Status for Reclamation}

The species is widely used as a hay, silage and pasture species in the northern great plains, Pacific northwest, the U.S. intermountain region, and in Alaska $(5,183)$. Experimental work at high elevations in Alberta and British Columbia has been encouraging $(380,498)$. It was consistently successful in subalpine and alpine test sites along the eastern slopes region (705), but required fertilization to maintain growth after two years (740). It became the dominant species in mixed seedings on moist to wet sites on a pipeline right-of-way in the Upper Mackenzie Region of the boreal forest (644), but only provided short-term (one to two year) cover in the arctic tundra (644). Noted to be less aggressive than reed canary grass for stabilizing irrigation canals (635).

Creeping foxtail is also commonly used for high elevation reclamation or rehabilitation of disturbances in the western U.S. $(236,213)$.

Major assets include its winter hardiness, tolerance of excessive soil moisture and flooding, acid tolerance and strong rhizomatous habit. It is not a strong reseeder, however, and is very sensitive during its weak seedling stage. 
Arctagrostis arundinacea

SPECIES SUITABILITY MAP AND SUMMARY TABLE

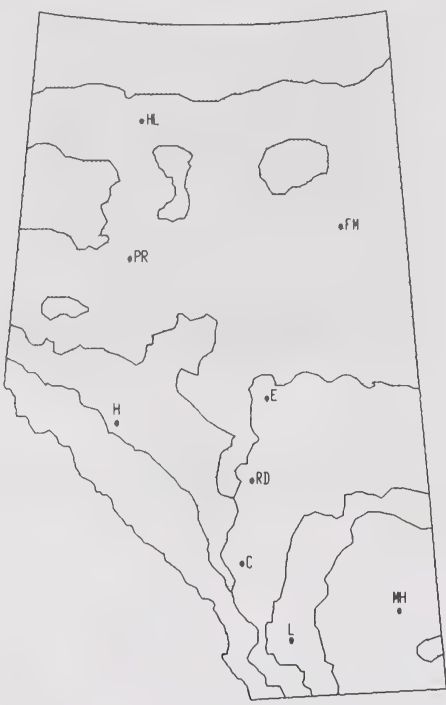

Recommended Area

Commercially Available: Yes

No

\begin{tabular}{|c|c|c|c|c|c|}
\hline \multirow{2}{*}{$\begin{array}{l}\text { RECLAMATION SUITABILITY } \\
\text { CRITERIA }\end{array}$} & \multicolumn{5}{|c|}{ SUITABILITY RAIING } \\
\hline & Very High & High & Medium & Low & None \\
\hline Drought Tolerance & & & & $x$ & \\
\hline Salt Tolerance & & & & $x$ & \\
\hline $\mathrm{pH} \quad$ Acid & $2-3$ & & & & \\
\hline Tolerance Base & & & & & \\
\hline Winter Hardiness & $x$ & & & & \\
\hline Erosion Control & & $x$ & & & \\
\hline Persistence & & & $x$ & & \\
\hline Palatability & & & $x$ & & \\
\hline Browse Tolerance & & & $x$ & & \\
\hline Moisture Preference & Moist, & ithst & flooding & & \\
\hline Soil Preference & Modera & $1 y$ we & imperfe & drair & soil \\
\hline
\end{tabular}


Arctagrostis arundinacea (Trin.) Beal

\section{SPECIES BIOLOGY}

\section{Taxonomy}

Reed Polar Grass (405), Polar Grass (34).

Varieties include A. latifolia var. latifolia, A. latifolia var. arundinacea (Trin.) Griseb. $(405,312)$.

\section{Origin and Range}

Native. In Alberta, its main distribution is in the northern part of the province, particularly the Caribou Mountains (312). Arctagrostis latifolia var. latifolia is the more northern circumpolar form (490). Arctagrostis latifolia has a circumpolar distribution and a north-south range between $55^{\circ}$ and $85^{\circ}$ latitude (490). Arctagrostis is a truly northern genus, having no species occurring below $50^{\circ} \mathrm{N}$ (111).

\section{Growth Habit}

Relatively tall grass reaching 40 to $100 \mathrm{~cm}$ tall (312); var. arundinacea is taller than var. latifolia, being up to $150 \mathrm{~cm}$ tall. Slowly expanding growth by rhizomes produces a dense bunch-like appearance (111).

\section{Nitrogen Fixing - None}

Longevity - Perennial grass (405).

\section{Self Propagation}

Propagation is by seeds as well as by stout rhizomes (490). Relatively few flowering heads are produced in undisturbed plant communities (490). Seeds of Arctagrostis are very light and are easily windborne. Seed maturity occurs late in the growing season with seeds remaining viable over the winter for early spring germination (490).

\section{Ecological Setting}

Wetland plant (405). Var. latifolia is found in wet meadows, along rivers, and on the tundra (214); var. arundinacea is found in meadows and sandbars along rivers (214). Var. latifolia tolerates a wide range of tundra conditions and is found as a common, but minor, member of most tundra plant communities, generally occupying better drained positions (490). Component of early seral stages, at least up to six years following fire in tundra vegetation. Associated with shrubs such as Betula

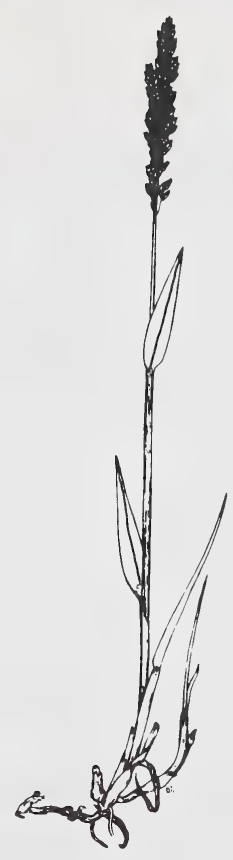

glandulosa, herbs such as Epilobium anqustifolium, and other grasses such as Calamagrostis canadensis (460). In the Mackenzie Delta region, reed polar grass is found on deposited sediments along river channels and lake shores subject to flooding, and associated with willows (Salix spp.) and herbs such as horsetail (Equisetum arvense) (97).

\section{TOLERANCES}

\section{Soil Preferences}

In the arctic tundra, var. latifolia is common on imperfectly to moderately well drained habitats in all topographic positions; most important on imperfectly drained areas, decreasing in importance on dry upland or wet lowland sites. Requires a minimum depth of $35 \mathrm{~cm}$ of active soil and favors areas where mineral soil is covered by only a thin layer of organic matter $(490,111)$. On river alluvium in northern Alaska, it is restricted to areas of deepest sand and silt (52). 


\section{Nutrient Requirements}

Fertilizer application noted to stimulate growth of reed polar grass (110).

\section{Soil Reaction}

Local populations of reed polar grass were found growing in very acid environments in the Northwest Territories (soils with $\mathrm{pH} 2.0$ to 3.0 compared to normal tundra soils $\mathrm{pH} 7.0$ to 7.5 ). Greenhouse and field trials indicated that plants from this stock outperformed other species tested (Deschampsia caespitosa and Hordeum jubatum) on various acid tailings conditions (246); amelioration of tailings increased growth responses.

\section{Soil Salinity}

No specific tolerances noted, but generally not found on saline sites.

\section{Drought}

Low evapotranspiration in areas of favored growth indicates low drought tolerance.

\section{Heavy Metals and Hydrocarbons}

Greenhouse and field trials of reed polar grass on various acid tailings materials indicated tolerance to high levels of $\mathrm{Ni}, \mathrm{Cu}$ and $\mathrm{Zn}$. Grew better than Deschampsia caespitosa and Hordeum jubatum on a wide range of acid tailings conditions, associated with increased solubility of heavy metals (246).

\section{Shade}

Generally not found in excessively shady sites.

\section{Grazing or Mowing}

Can withstand a moderate degree of grazing.

\section{Susceptibility to Disease and Insect Damage}

No specific susceptibilities noted.

\section{RECLAMATION CONSIDERATIONS}

\section{Soil Building and Erosion Control Capability}

Arctagrostis is characterized by penetration of root systems into progressively colder soils, an adaptation to permafrost environments; it produces a root system which is 2 to 3 times larger than that of Calamagrostis canadensis (484). These attributes may be useful for soil stabilization and erosion control. Both species had better root growth than the agronomic species tested (223).

\section{Adaptation to Disturbance}

Rapid growth, rhizomatous spreading ability, and vigorous seed production result in rapid colonization of disturbed moist to dry sites (490), and streamsides as in the Prudhoe Bay area (459). Noted for invasion of mineral backfill in pipeline operations along the Mackenzie River (110). Var. latifolia is an important colonizer of disturbed upland tundra habitats except for those which are very wet (490). Flowering and seed production of plants growing on disturbed sites was greater than on undisturbed sites ( $86 \%$ vs. $29 \%$ ) (490). A. latifolia and other grasses such as Calamagrostis canadensis were observed invading seismic lines in the Mackenzie Delta region, with plant cover and frequency greater than in natural tundra (194). Along with fireweed (Epilobium angustifolium) and Calamagrostis canadensis, A. latifolia is the most dramatic increaser in burned areas in the forest tundra (460).

\section{Competitive Ability}

A. latifolia has cold tolerant roots and is not particularly well adapted to competition for nutrients in the upper, warmer soil horizons where most roots are concentrated (490). The species is slow to establish in an area and seems susceptible to competition during the seedling stage; however, once established, it grows quickly and can flower by the second year (195).

\section{Commercial Value}

Value appears to be primarily for stabilization of soil disturbances and for wildlife forage.

\section{Palatability and Nutritive Value}

Reed polar grass had nitrogen and phosphorus contents of $1.4 \%$ and $0.15 \%$, respectively, in July before flowering and $0.8 \%$ and $0.1 \%$, respectively, in August after flowering. Var. arundinacea grown in fertilized gardens in Alaska had a mean nitrogen content of $2.8 \%(490)$. Used for food by voles (110).

\section{Seed or Planting Stock Availability}

Not known to be available commercially in Canada. Licensed in the United States by W.W. Mitchell (in Alaska); the cultivar is called "Alyeska" (D. Walker, pers.comm.). 


\section{Methods and Ease of Establishment}

Seed of A. latifolia is exceedingly small and difficult to harvest and apply (P. Ziemkiewicz, pers.comm.). Seed is to be applied in two sowings, one-third at the initial seeding, the remaining two-thirds 2 years later, with a booster fertilizer dressing (398). Initial establishment of $\mathbf{A}$. latifolia, after two years on reclamation trials in the Northwest Territories, was inferior to the agronomic species used; after seven years it was many times more successful (34). Unlike many tundra species, the seed of $A$. latifolia var. latifolia germinates over a wide range of temperatures and requires no special pretreatment (490). Germination\%age in the field ranged from 65 to $75 \%(307)$, and 80 to $90 \%$ in non-stratified and cold stratified laboratory tests although in a polar semi-desert situation, it ranged from 0 to $16 \%$ (35). Arctagrostis had higher and more consistent germination\%ages at all temperatures than most other tundra grasses (307) tested. Seed germinates in six days (35).

\section{Current Status for Reclamation}

A. latifolia is best adapted for revegetation of disturbed tundra or boreal forest sites, particularly where permafrost is present. In Alberta, range extends north of $55^{\circ} \mathrm{N}$ latitude, although revegetation research is limited to arctic tundra and Mackenzie Delta locations. Attractive features of this species include aggressiveness once established, low winter kill, and tolerance to cold soils. Further research is warranted on tolerance of polar grass to acid soils and tailings in northern environments. Reed polar grass has been tried on tundra desert (King Christian Island) (3) and elsewhere in the Yukon and Northwest Territories $(490,398,307,160,35)$. Arctagrostis arundinacea has been recommended for revegetation in foothills and mountain areas (435). 
Bromus inermis

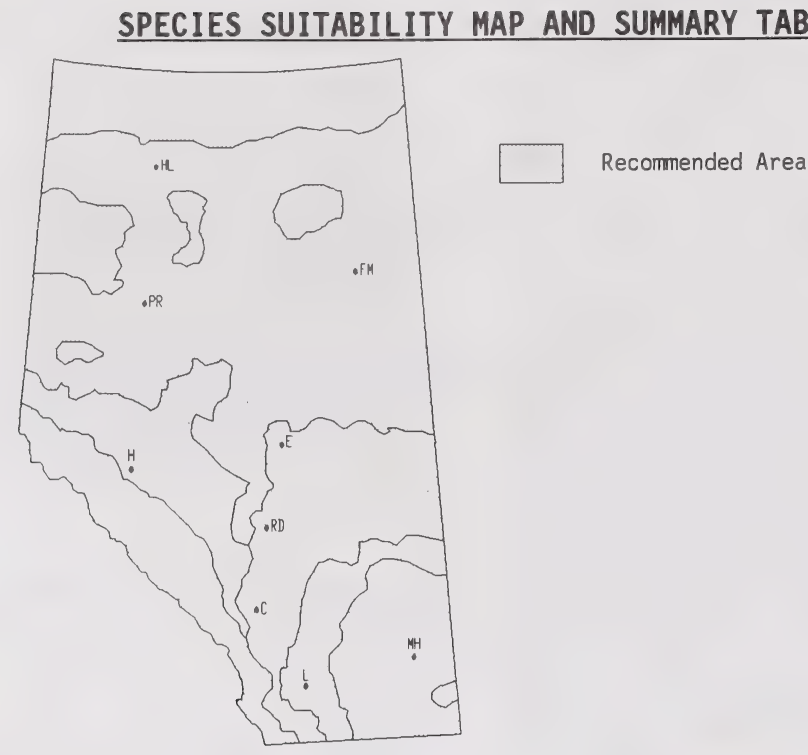

Commercially Available: Yes $\mathrm{X}$ No

\begin{tabular}{|l|c|c|c|c|c|}
\hline \multirow{2}{*}{$\begin{array}{c}\text { RECLAMATION SUITABILITY } \\
\text { CRITERIA }\end{array}$} & Very High & High & Medium & Low & None \\
\hline Drought Tolerance & & $\mathrm{X}$ & $\mathrm{X}$ & & \\
\hline Salt Tolerance & & & $\mathrm{X}$ & & \\
\hline $\begin{array}{l}\text { PH Acid } \\
\text { Tolerance Base }\end{array}$ & & & $\mathrm{X}$ & & \\
\hline $\begin{array}{l}\text { Winter Hardiness } \\
\text { Erosion Control }\end{array}$ & & $\mathrm{X}$ & $\mathrm{X}$ & & \\
\hline Persistence & $\mathrm{X}$ & $\mathrm{X}$ & $\mathrm{X}$ & & \\
\hline $\begin{array}{l}\text { Palatability } \\
\text { Browse Tolerance }\end{array}$ & & $\mathrm{X}$ & & & \\
\hline $\begin{array}{l}\text { Moisture Preference } \\
\text { Soil Preference }\end{array}$ & Loamy to clay, fair on sand. & \\
\hline
\end{tabular}


Bromus inermis Leyss.

\section{SPECIES BIOLOGY}

Taxonomy - Smooth Brome, Awnless Brome

\section{Origin and Range}

Introduced from Europe and Asia (339). Circumboreal distribution. Cultivated in Alaska, and from British Columbia to Newfoundland and south to the Great Lake states and California (214). Smooth brome is the most widely adapted species on western ranges (339). Hybridizes with B. pumpellianus (214). There are two types of smooth brome recognized. The southern type was introduced from France and Hungary into the United States about 1880 , and from there into Canada. The northern type was introduced to Canada from Germany about 1880 (138). A number of varieties of each, as well as intermediate northern-southern types, are licensed in Canada (138).

\section{Growth Habit}

Smooth brome is a tall, leafy, sod-former (138). Northern types are generally weakly rhizomatous and form an open sod (for example, variety "Carlton"), although some grow as bunchgrass; southern types are aggressive sod-formers (rhizomatous) and develop a tight sod (for example, variety "Lincoln") $(138,338)$.

\section{Nitrogen Fixing - None}

\section{Longevity}

Smooth brome is a rapid growing, long-lived, cool season (712) perennial (179). Many plantings in the United States are more than 60 years old (339). "Polar" smooth brome is a variety (a cross between $\underline{B}$. inermis and $\underline{B}$. pumpellianus) developed in Alaska which is particularly winter hardy (4).

\section{Self Propagation}

Primarily by seed. It spreads vegetatively by rhizomes $(2,138)$. Spread by reseeding has been rated moderate, and natural vegetative spread has been rated good (338).

\section{Ecological Setting}

Introduced as a forage crop, smooth brome persists as a weed. It is common along roads and in waste areas throughout the Canadian prairies $(312,78)$. The northern type is apparently more productive

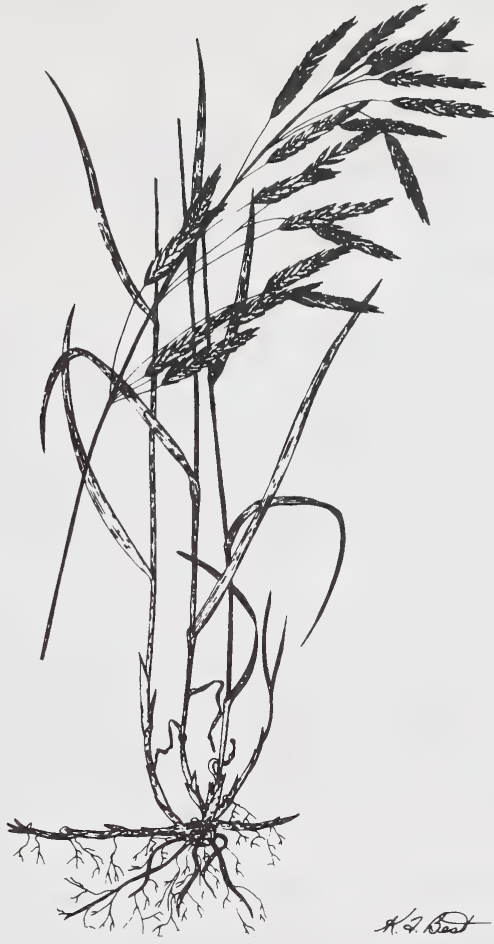

than the southern type in aspen parkland, subalpine and alpine ranges. The southern type is better suited to winter game range areas in Utah (339). The minimum annual precipitation at which smooth brome becomes established and produces well has been reported variously as $28 \mathrm{~cm}$ (339), $38 \mathrm{~cm}$ (179), and 30 to $45 \mathrm{~cm}$ (639). The northern type is better suited to western Canada, while the southern type is best suited to southern British Columbia and eastern Canada (138). The southern type has earlier spring growth while the northern type has even growth throughout the season (179).

\section{TOLERANCES}

\section{Soil Preferences}

Smooth brome is highly adaptable to a wide range of soil conditions (256), although apparently best suited for Chernozemic, Luvisolic, and Podzolic soils (179). It has only a fair tolerance of wetness and flooding (5). Smooth brome can grow on organic soils (436). It is adapted to a moderate range of soil textures (5). Growth on sandy soil is reported 
to be fair, while on loamy and clayey soil growth is good (446). In Alberta, it is more prevalent on fine textured soils than on coarse textured ones (435).

\section{Nutrient Requirements}

Smooth brome is variously reported to have high fertilizer requirements (5) and low nutrient demands (433). It has a high nitrogen requirement (41).

\section{Soil Reaction}

Smooth brome cannot tolerate soils that are more than mildly alkaline (179). Although reported to have poor tolerance of acid soils (5), smooth brome comprises the dominant cover on coal spoil with $\mathrm{pH} 4.5$ at a site in southeastern B.C. (P. Ziemkiewicz, pers.comm.). A lower limit of pH 5.0 has been defined for the eastern US (712).

\section{Soil Salinity}

Smooth brome is fairly saline tolerant (426). Brome is moderately tolerant of salts within the range 5 to $10 \mathrm{mS} / \mathrm{cm}$ (468). Smooth brome did not do well when seeded on sodic soils in Alberta (435).

\section{Drought}

Smooth brome is a drought resistant grass $(256,5)$.

\section{Heavy Metals and Hydrocarbons}

Smooth brome is reported to have good tolerance of oil $(113,5)$.

\section{Shade}

Smooth brome can tolerate shade and for this reason it is desirable on brushy range areas where it can open up brush thickets (339).

\section{Grazing or Mowing}

Smooth brome can maintain itself better than most other grasses under very heavy grazing (339). Recovery of smooth brome after cutting has been rated as moderate (5).

\section{Susceptibility to Disease and Insect Damage}

Some varieties are fairly susceptible to leaf spot (Selenophoma bromigena) and Pyrenophora bromi (138). Smooth brome is also susceptible to damage by pocket gophers, presumably because of the fleshy rhizomes (41).

\section{RECLAMATION CONSIDERATIONS}

\section{Soil Building and Erosion Control Capability}

The northern type tends to have open sod, whereas the southern type is more aggressive and develops a tight sod (339). Smooth brome increased the organic matter content and moisture retaining properties of mine spoils (227). Smooth brome has very good soil stabilizing ability and good growth rate $(338,339)$. Smooth brome was found to improve ground cover and reduce erosion when planted on disturbed areas in the ponderosa pinebunchgrass habitat (302).

\section{Adaptation to Disturbance}

Adaptation of smooth brome to disturbance has been rated as good (338).

\section{Competitive Ability}

Compatibility of smooth brome is high $(5,179)$, but will dominate other grasses if it is fertilized heavily (41).

\section{Commercial Value}

Smooth brome is used with alfalfa for hay and pasture.

\section{Palatability and Nutritive Value}

Smooth brome is palatable to all livestock, and yields of forage and seed are good (179). It is also palatable to game. The northern type is generally preferred because it is more leafy (339).

\section{Seed or Planting Stock Availability}

Varieties licensed for use in Canada include "Baylor", "Beacon", "Blair", "Carlton", "Fischer", "Lincoln", "Magna", "Manchar", "Redpatch", "Saratoga" and "Tempo" (138). Widely available from commercial suppliers. Approximately 125000 seeds/lb (639).

\section{Methods and Ease of Establishment}

Smooth brome has fair (712) to good establishment by seed and excellent establishment by transplanting (338). Seedling vigor is good (5). Typical seed viability and germination is about 92 and $85 \%$, respectively (376). Smooth brome also has rapid emergence and early spring growth (436). Seed is relatively inexpensive and is easy to handle 
(41). A seeding rate of 15 to $20 \mathrm{lbs}$ PLS/ac has been recommended for the eastern US (712), and $8 \mathrm{lbs}$ PLS/ac in a fall/spring seeding for the western US (639). Establishment requirements of smooth brome are low (446). Seedlings and pieces of sod can be transplanted successfully on eroded sites (339).

\section{Current Status for Reclamation}

Smooth brome is one of the most valuable cover species throughout Alberta. It is present, if not the dominant cover type, in every region (435). Performance of "Polar" smooth brome was rated as good after two growing seasons at an alpine site in Alberta. "Baylor" smooth brome did not overwinter well at the same site (377). "Manchar" smooth brome produced acceptable cover at three years on a subalpine site at Tent Mountain and was recommended for use in the eastern slopes region (723). "Carlton" and "Manchar" smooth brome exhibited excellent vigor and survival after three seasons in the Upper Mackenzie region of the boreal forest at latitude $63^{\circ} \mathrm{N}$ (644). At Fort McMurray "Carlton" smooth brome has persisted in mixed stands for 17 years on amended tailings sand on moist sites. Smooth brome had moderate performance above and below the tree line in the northeast coal block of B.C. as well. In the southern interior smooth brome performed well on waste rock, overburden and tailings at 6 mine sites (143).

"Manchar" smooth brome has been recommended for revegetation of critical sites in northwestern Colorado. It is best suited to moist regions and elevations greater than $2670 \mathrm{~m}$ (427). "Manchar" smooth brome was included in a seed mix suitable for use in the subalpine in Colorado (73). Smooth brome seed on coal mine spoils in northwestern Colorado at $2200 \mathrm{~m} \mathrm{ASL}$ was a major component of the plant canopy 4 years after seeding (307). "Manchar" has been used for revegetation at Vail, Colorado both below and above 3300 m ASL (462). It has proved to be persistent in the subalpine largely due to reproduction by rhizomes. "Polar" has been recommended for revegetation of surface disturbances in the permafrost area of Alaska (79).

This species has low establishment requirements, early spring growth and rapid seedling emergence. It also spreads vigorously by rhizomes. Although it does best on moist sites, it is somewhat drought resistant. It is also a long-lived perennial that is moderately tolerant of saline soils. Varieties that are disease resistant and winter hardy would be useful for reclamation throughout the province, especially for providing initial cover and controlling erosion. 
Bromus marginatus

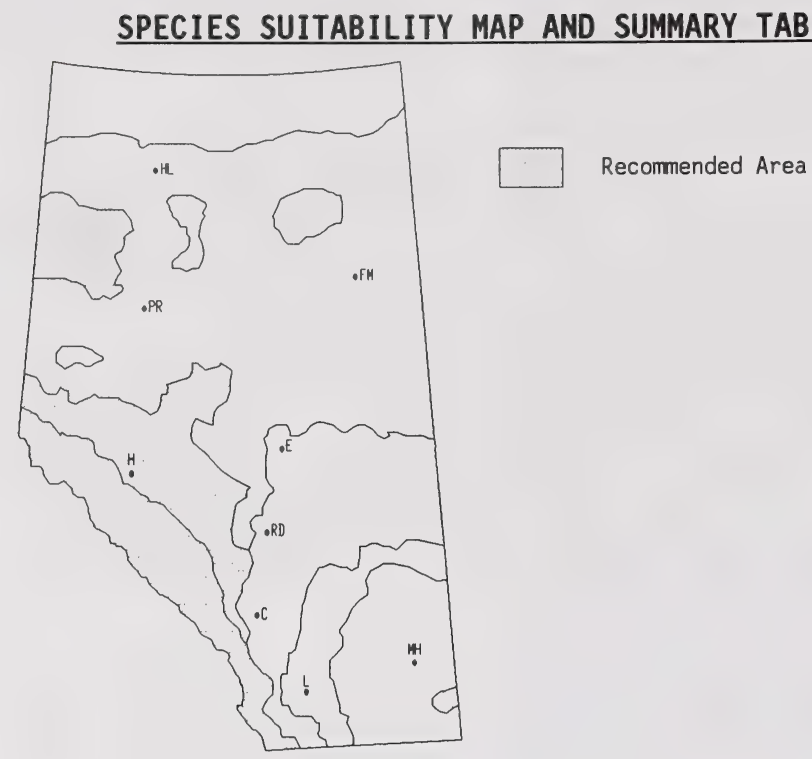

Commercially Available: Yes No $X$

\begin{tabular}{|c|c|c|c|c|c|}
\hline \multirow{2}{*}{$\begin{array}{l}\text { RECLAMATION SUITABILITY } \\
\text { CRITERIA }\end{array}$} & \multicolumn{5}{|c|}{ SUITABILITY RATING } \\
\hline & Very High & High & Medium & Low & None \\
\hline Drought Tolerance & & & $x$ & & \\
\hline Salt Tolerance & & & & $x$ & \\
\hline Acid. & & & & $x$ & \\
\hline Tolerance Base & & & $x$ & & \\
\hline Winter Hardiness & & $x$ & & & \\
\hline Erosion Control & & $x$ & & & \\
\hline Persistence & & & $x$ & & \\
\hline Palatability & & $x$ & $x$ & $x$ & \\
\hline Browse Tolerance & & $x$ & & & \\
\hline Moisture Preference & Moist & tes. & & & \\
\hline Soil Preference & Loamy & lay & & & \\
\hline
\end{tabular}


Bromus marginatus Nees.

\section{SPECIES BIOLOGY}

\section{Taxonomy}

Erect Brome (78), Mountain Brome (183)

\section{Origin and Range}

Native. Mountain brome is found in the northern and central Rocky Mountains, and the northern portion of the intermountain and Pacific coast regions of western North America $(183,214,426)$. In Alberta it is found mainly in the southwest (312), and in the Cypress Hills (78). It is closely related to B. breviaristatus (Hook.) Buckl. and $\underline{B}$. carinatus H. \& A., and it may be treated as a variety of the latter species (312). Some authors consider B. carinatus to be a polymorphic species that includes B. marqinatus (183). "Bromar" mountain brome is a variety developed in the United States (183).

\section{Growth Habit}

Mountain brome is a robust bunchgrass 60 to $120 \mathrm{~cm}$ high (312).

\section{Nitrogen Fixing}

No rhizosheath noted on plants growing on disturbed sites (P. Lulman, pers.comm.). Does not fix atmospheric nitrogen.

\section{Longevity}

Short-lived, cool season (639) perennial $(41,183)$.

Self Propagation - Seed.

\section{Ecological Setting}

Mountain brome is found in woods and open slopes in southwestern Alberta (312). It has been reported in moist habitats between 2230 and $3000 \mathrm{~m}$ in Wyoming (18). Mountain brome is best adapted to areas receiving about $40 \mathrm{~cm}$ (639) to $45 \mathrm{~cm}$ (426) mean annual precipitation.

\section{TOLERANCES}

\section{Soil Preferences}

Mountain brome has been recommended for planting of critical sites on both loamy and clayey

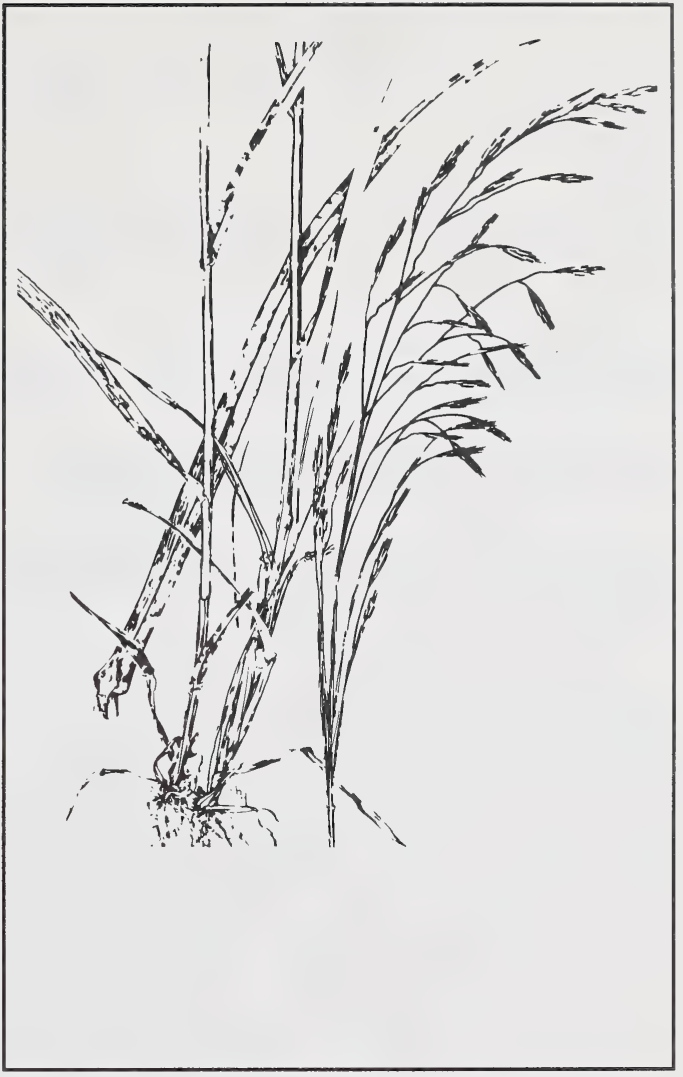

soils (424). It has been used for soil conservation in the Pacific northwest and great basin states on Chernozemic and Luvisolic soils (179). It is therefore adapted to a range of soil types and textures.

\section{Nutrient Requirements}

Good growth on low nutrient sites indicates low requirements.

\section{Soil Reaction}

Tolerant of mildly acidic to moderately alkaline soils. Prefers soils derived from basic parent materials.

\section{Soil Salinity Tolerance}

Bromar mountain brome has only fair salt tolerance (424).

\section{Drought}

Moderately drought tolerant, but prefers moist sites. 


\section{Heavy Metals and Hydrocarbons}

No specific tolerances noted in the literature reviewed.

\section{Shade}

Will tolerate partial shade but prefers full sunlight.

\section{Grazing or Mowing}

Can be heavily grazed on alpine and subalpine ranges with little damage.

\section{Susceptibility to Disease and Insect Damage}

Mountain brome is susceptible to head smut, so seed must be treated with a fungicide before planting (179).

\section{RECLAMATION CONSIDERATIONS}

\section{Soil Building and Erosion Control Capability}

Mountain brome has a deep, well branched root system that is good for erosion control (183). It has a fair rate of spread (424).

\section{Adaptation to Disturbance}

Noted to invade disturbed sites in adapted areas.

\section{Competitive Ability}

Moderately aggressive but compatible with legumes.

\section{Commercial Value}

"Bromar" mountain brome is outstanding in performance in mixtures with sweet clover (Melilotus spp.) or red clover (Trifolium pratense) for pasture or green manure (183).

\section{Palatability and Nutritive Value}

Mountain brome is high in crude protein and digestible carbohydrates (179). Utilization of Bromus spp. has been rated as high for elk, moderate for mule deer, and low for bighorn sheep and moose (144). Mountain brome has been rated as a desirable species for sheep and deer, and a preferred species for cattle and elk (425).

\section{Seed or Planting Stock Availability}

Breeder seed is apparently available in the United States (183). "Bromar" is available in the US (639).
No licensed cultivars are available in Canada. Approximately 90000 seeds/lb (639).

\section{Methods and Ease of Establishment}

The seed of mountain brome shatters, so harvesting must be done carefully (179). Typical seed purity and germination is 90 and $85 \%$ respectively (371). Seed had a viability of $70 \%$ after 3 years of storage (179). Seed is large and seedling vigor is not rated as good. "Bromar" mountain brome has greater seedling vigor than common mountain brome (426, 183). In a greenhouse experiment, 12 out of 40 seeds planted became established on soils collected from high altitude sites (131). Ease of establishment of "Bromar" mountain brome has been rated as excellent. A late spring seeding at a rate of 6 to $8 \mathrm{lbs}$ PLS/ac has been recommended (639).

\section{Current Status for Reclamation}

Mountain brome has been recommended for use in the aspen zone in Colorado (106). It has been tested and recommended for revegetation of roadcuts and other disturbed sites in Utah (336). Mountain brome can be used to stabilize road cuts or mined lands where rapidly developed seedlings are required (426). "Bromar" mountain brome planted at several sites over $3000 \mathrm{~m}$ in Colorado had only fair growth (236). This variety has been recommended for planting in critical areas in Colorado where mean annual precipitation is greater than $40 \mathrm{~cm}(424,427)$.

Mountain brome is a rapidly developing, short-lived bunchgrass. It is only slightly tolerant of saline soils and prefers moist sites. Mountain brome has a high protein content and is highly palatable to livestock. The species has a deep, dense root system ideal for stabilizing erodible slopes. It has potential for use in reclamation and erosion control on moist sites to the subalpine in Alberta. 
Calamagrostis canadensis

SPECIES SUITABILITY MAP AND SUMMARY TABLE

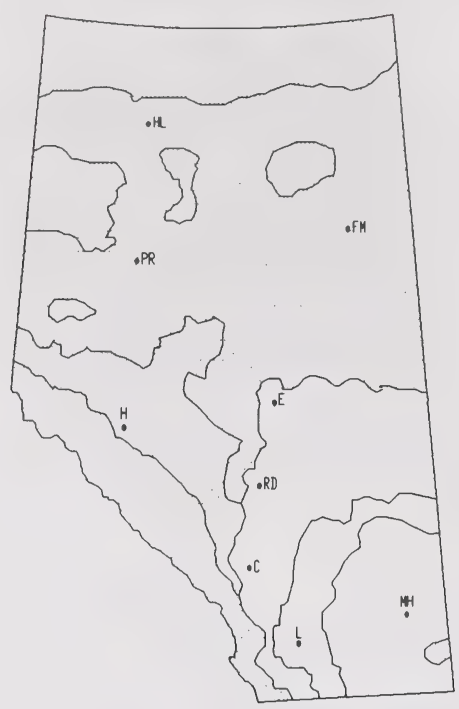

Recommended Area

Commercially Available: Yes No

\begin{tabular}{|c|c|c|c|c|c|}
\hline \multirow{2}{*}{$\begin{array}{l}\text { RECLAMATION SUITABILITY } \\
\text { CRITERIA }\end{array}$} & \multicolumn{5}{|c|}{ SUITABILITY RATING } \\
\hline & Very High & High & Medium & Low & None \\
\hline Drought Tolerance & & $x$ & & & \\
\hline Salt Tolerance & & & $x$ & & \\
\hline pH Acid & 3.5 & & & & \\
\hline Tolerance Base & & & & & \\
\hline Winter Hardiness & $x$ & & & & \\
\hline Erosion Control & & & $x$ & & \\
\hline Persistence & $x$ & $x$ & & & \\
\hline Palatability & & & $x$ & $x$ & \\
\hline Browse Tolerance & & & & $x$ & \\
\hline Moisture Preference & Moist & wet, & toleran & floo & \\
\hline Soil Preference & Wide & m & ely wel & pe & 1 \\
\hline
\end{tabular}


Calamagrostis canadensis (Michx.) Beauv.

\section{SPECIES BIOLOGY}

Taxonomy - Bluejoint, Marsh Reed Grass

Also $\underline{\mathrm{C}}$. canadensis (var. macouniance (Vasey) Stebbins) and ssp. langsdorfii (Link) Hult. (var. scabra (Kunth) (A.S. Hitchc.)

\section{Origin and Range}

Native. Bluejoint occurs throughout the boreal and temperate regions(297). Bluejoint is common in the subarctic and rare in the low arctic (223). Alaska to Quebec, south to all but the southeastern United States (507).

\section{Growth Habit}

Bluejoint is a tall grass, 60 to $120 \mathrm{~cm}$ tall. It has numerous leaves and creeping rhizomes, and forms tussocks $(312,214)$. It is particularly luxuriant in Alaska where it may reach heights of up to $200 \mathrm{~cm}$ within 6 weeks (297).

\section{Nitrogen Fixing - None}

\section{Longevity}

Long-lived perennial $(312,54)$. A well developed stand of bluejoint may persist for long periods, possibly as long as 100 years (4). It is very winter hardy $(5,240)$.

\section{Self Propagation}

Bluejoint spreads by seed and rhizomes. Seed yields are low (5) but seed has high viability (490).

\section{Ecological Setting}

Bluejoint occurs in a wide range of habitats from lowland wet sites to wind swept alpine ridges (490, 507). It is common in moist sites; marshes and moist woodlands throughout the North America prairies $(451,324,78)$. It is often found in lowland hay meadows (347). It has been reported to occur on wet sites from $1670 \mathrm{~m}$ to $4170 \mathrm{~m}$ ASL in Wyoming (18). Bluejoint has been reported as a component of several community types in the Mackenzie Delta Region, N.W.T. (97). It is found in all habitats, except wet depressional, in the arctic tundra, being most prominent in moderately well drained uplands (490). It is the most abundant grass in Alaska and can withstand exposed sites (298).

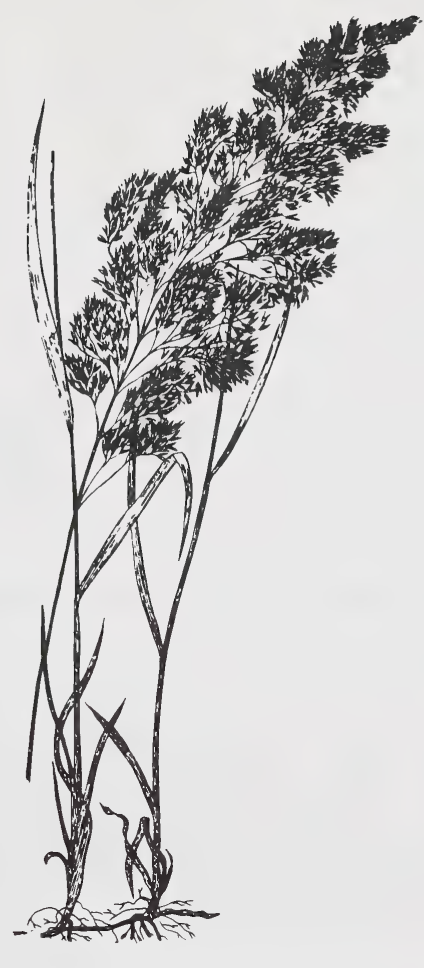

\section{TOLERANCES}

\section{Soil Preferences}

Bluejoint prefers moist sites (180) but can survive on a wide range of moisture regimes from imperfectly to moderately well drained soils. It is found on both peaty and mineral soils, but more often on peat (490). Bluejoint is adapted to a wide range of soil textures. It has good tolerance to wetness and flooding (5).

\section{Nutrient Requirements}

Addition of fertilizer on tundra sites causes a marked stimulation, and an increase in the number of flowering spikes (216). Addition of fertilizer to revegetation plots in the Northwest Territories increased plant vigor and production (195). Bluejoint has moderate fertilizer requirements (5).

\section{Soil Reaction}

Bluejoint is tolerant of extremely acid soils, with $\mathrm{pH}$ 
values as low as 3.5 (298).

\section{Soil Salinity}

Moderately tolerant of saline soils.

\section{Drought}

Bluejoint cannot germinate under droughty conditions (461), although it has very good drought resistance once established (5).

\section{Heavy Metals and Hydrocarbons}

Bluejoint has been noted as a vigorous invader of oil spill sites in the Northwest Territories, and showed rapid recovery after spills (216).

\section{Shade}

Prefers open sites but will tolerate partial shade.

\section{Grazing or Mowing}

Yields of bluejoint were decreased by 15 to $20 \%$ when cut two to four times, by 35 to $45 \%$ when cut five to six times and about $70 \%$ when cut seven times, in relation to plots cut once at the end of the growing season (100). Forage yield potential has been rated as moderate. The recovery rate after cutting is slow (5). It is intolerant of heavy grazing (4).

\section{Susceptibility to Disease and Insect Damage}

Some bluejoint strains are susceptible to white top. This condition is caused by insect or fungal damage of the lower culms. Bluejoint is, in general, not susceptible to snow mold (298).

\section{RECLAMATION CONSIDERATIONS}

\section{Soil Building and Erosion Control Capability}

Bluejoint is a bunchgrass with a creeping growth habit $(5,312)$ and is capable of high ground cover production (436). The species is presumably a good erosion controller.

\section{Adaptation to Disturbance}

Bluejoint has been reported as a pioneer on dry disturbed sites near Norman Wells, N.W.T. (459). The ability of bluejoint to rapidly invade disturbed arctic tundra sites can be attributed to its small but highly viable and early germinating seed, and a root system that is tolerant of low soil temperatures
(490). The seeds are easily wind-borne (242). Bluejoint tends to become established more slowly than commercial species, but by the third season, cover can equal or exceed those species $(209,195)$. Bluejoint has been reported as a pioneer on sand dunes in the Great Lakes region (482). It was found to be an important increaser on burned tundra sites (460). Bluejoint was found to be a better colonizer on disturbed sites in the northern boreal forest than on disturbed tundra sites (195).

\section{Competitive Ability}

Bluejoint was found throughout a wide range of tundra habitats, but in no habitat was it very vigorous or dominant. Bluejoint, however, is a dominant species on disturbed sites (490). This suggests that it has poor competitive ability. Other sources indicate good competitive ability (436) and fair compatibility (5).

\section{Commercial Value}

Bluejoint is an important hay meadow grass in Alberta (298). The species also has erosion control value.

\section{Palatability and Nutritive Value}

Bluejoint is not highly palatable to livestock at any time during the growing season, although it may be grazed in the spring. In general, good hay may be produced if it is cut in mid-summer. The chemical composition of forage is fairly good in comparison to upland grasses (180). Cattle forage value has been rated as fair (19). Palatability has been rated as moderate (5). In Alaska, bluejoint provides good, nutritious forage for cattle early in the season. Protein content is about 15 to $20 \%$ in mid-June, but decreases to 10 to $14 \%$ in early July and to 7 to $9 \%$ by early August (4).

\section{Seed or Planting Stock Availability}

The cultivar "Sourdough" bluejoint has been released for use in Alaska (298). No commercial sources or licensed varieties in Canada.

\section{Methods and Ease of Establishment}

Seed collected from near Inuvik, N.W.T., had a germination rate of $90 \%$ at $20^{\circ} \mathrm{C}$ (35). Cold stratification did not improve the rate of seed germination (490). Seedling vigor has been rated as moderate (5). Seed has been successfully harvested by a modified rasping bar thresher. It is a difficult species to harvest because the seed has many callus hairs which make the seed difficult to 
dislodge from the floret (242). The inflorescense also shatters (298); seed yields are usually low (490).

\section{Current Status for Reclamation}

Bluejoint has been evaluated for revegetation in several trials in tundra and northern boreal forest sites $(209,195)$. It was found to establish slowly, but by the end of the growing season, cover and biomass production equaled or exceeded those of commercial varieties. Annual production at this time was 2 to 8 times that of "Arctared" red fescue (Festuca rubra) and "Nugget" Kentucky bluegrass (Poa pratensis), the two most successful agronomic species used (209). Seed of bluejoint has been collected for revegetation trials in Alberta (209).

Bluejoint is a widely distributed grass that is adapted to a variety of habitats. It is generally found on moist to wet sites and can grow well on organic soils. It is very tolerant of acidic soils and is extremely winter hardy. It is an aggressive pioneer of disturbance sites and spreads by rhizomes. Bluejoint also has good drought tolerance once established. Because it has a high viability, there is potential for selecting populations for revegetation of specific sites in Alberta. Further research is needed into collection of seed, since seed yields are usually low and harvesting of seed is difficult. 
Calamagrostis purpurascens

\section{SPECIES SUITABILITY MAP AND SUMMARY TABLE}

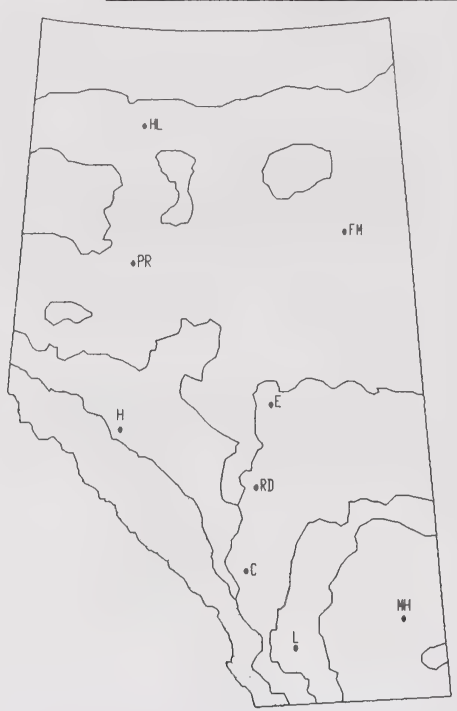

Recommended Area

Commercially Available: Yes No

\begin{tabular}{|c|c|c|c|c|c|}
\hline \multirow{2}{*}{$\begin{array}{l}\text { RECLAMATION SUITABILITY } \\
\text { CRITERIA }\end{array}$} & \multicolumn{5}{|c|}{ SUITABILITY RAIING } \\
\hline & Very High & High & Medium & Low & None \\
\hline Drought Tolerance & & & $x$ & & \\
\hline Salt Tolerance & & & & $x$ & \\
\hline Acid & & & & & \\
\hline Tolerance Base & & & $x$ & & \\
\hline Winter Hardiness & & $x$ & & & \\
\hline Erosion Control & & $x$ & $x$ & & \\
\hline Persistence & & & $x$ & & \\
\hline Palatability & & & & $\mathrm{X}$ & \\
\hline Browse Tolerance & & $x$ & & & \\
\hline Moisture Preference & Dry. & & & & \\
\hline Soil Preference & Rocky, & sandy to & ity loam. & & \\
\hline
\end{tabular}


Calamagrostis purpurascens R.Br.

\section{SPECIES BIOLOGY}

Taxonomy - Purple Reed Grass

\section{Origin and Range}

Native. Alaska south to California in the Olympic and Cascade Mountains. East to Quebec and south to Colorado through the Rocky Mountains, also in South Dakota and Minnesota. Also found in Greenland and throughout Asia (507).

\section{Growth Habit}

A tufted grass 30 to $70 \mathrm{~cm}$ tall. Purple reed grass sometimes has short rhizomes (312). It is characterized by purplish or pinkish compact heads (78).

\section{Nitrogen Fixing - None}

Longevity - Perennial (312).

\section{Self Propagation}

Purple reed grass spreads by seed and a very few genotypes creep (312).

\section{Ecological Setting}

Purple reed grass is found in western and southwestern portions of the Canadian prairies (78). It is mainly found in the Rocky Mountains and the Cypress Hills in Alberta (312). Plants have been collected at Snow Creek Pass in Banff National Park at $2170 \mathrm{~m} \mathrm{ASL}$ (455). Purple reed grass has been reported as the dominant grass on a loose, sandy erosion slope in west Greenland (177). Calamagrostis purpurascens $\mathrm{ssp}$. purpurascens was reported as a component of the Artemisia frigida community found on steep banks of the Mackenzie River, N.W.T. (97).

\section{TOLERANCES}

\section{Soil Preferences}

Purple reed grass is typically found on dry, rocky soil in open areas (507). Soil texture preferences range from sandy to silty loam.

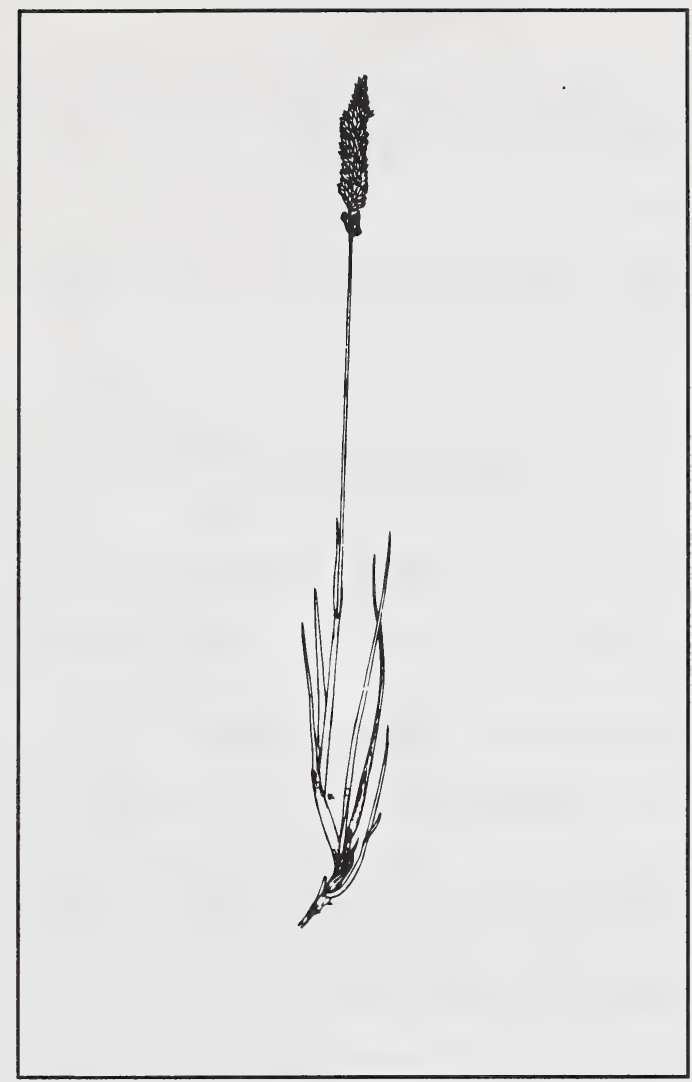

\section{Nutrient Requirements}

Expected to have low nutrient requirements judging by its natural occurrences.

\section{Soil Reaction}

No references to $\mathrm{pH}$ range round in literature reviewed. Generally occurs on basic soils.

\section{Soil Salinity}

Will tolerate mildly saline sites.

\section{Drought}

Will tolerate moderately droughty conditions. 


\section{Heavy Metals and Hydrocarbons}

Purple reed grass recovered well after oil spills and it appeared as a potentially useful species for recolonization of oil spill sites (216).

\section{Shade}

Prefers full sunlight, but will survive at reduced vigour under partial shade.

\section{Grazing or Mowing}

The low palatability of most Calamagrostis spp. generally enables it to maintain its vigor on all but the most seriously overgrazed ranges.

\section{Susceptibility to Disease and Insect Damage}

No susceptibilities noted in the literature reviewed.

\section{RECLAMATION CONSIDERATIONS}

\section{Soil Building and Erosion Control Capability}

Fibrous roots as well as the ability to colonize hostile sites make this species a good soil builder and an effective erosion controller.

\section{Adaptation to Disturbance}

Small pieces of turf eroded from a roadcut in alpine and high subalpine areas in Washington resulted in the establishment of purple reed grass on the cutbank (36).

Competitive Ability - Not highly aggressive.

\section{Commercial Value}

Utilized by wildlife to a limited extent.

Palatability and Nutritive Value

Calamagrostis spp. have a relatively low palatability although purple reed grass is occasionally grazed by bighorn sheep.

\section{Seed or Planting Stock Availability}

Currently being developed, although seed not now commercially available.

\section{Methods and Ease of Establishment}

Generally by seed, although specific treatments have yet to be worked out.

\section{Current Status for Reclamation}

Purple reed grass produced greater cover when planted on overburden topdressed with mineral soil compared to raw overburden at Cadomin (1 $675 \mathrm{~m}$ ASL), Alberta. The seeds of purple reed grass have been collected for selection of strains suitable for revegetation in Alberta (455).

Purple reed grass is found from the foothills to subalpine rocky slopes in Alberta. It is moderately drought tolerant and is a pioneer species on disturbed mountain sites. It has some potential for use in reclamation in the Rocky Mountains in Alberta, but further research is required into genetic variability, seed handling and early management. 
Calamovilfa longifolia

SPECIES SUITABILITY MAP AND SUMMARY TABLE

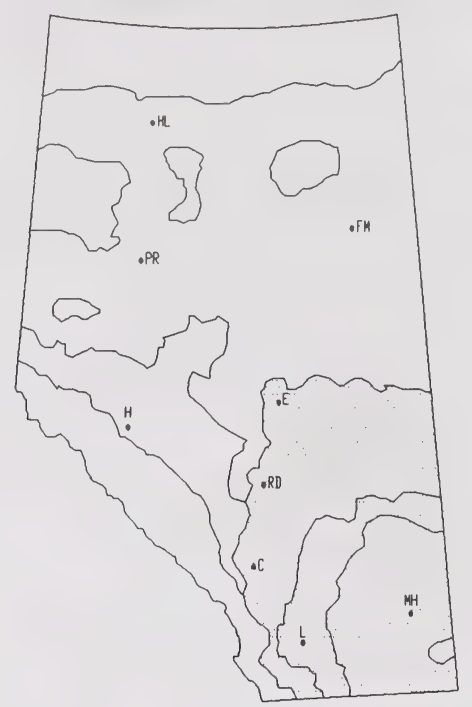

Recommended Area

Commercially Available: Yes

\begin{tabular}{|c|c|c|c|c|c|}
\hline \multirow{2}{*}{$\begin{array}{l}\text { RECLAMATION SUITABILITY } \\
\text { CRITERIA }\end{array}$} & \multicolumn{5}{|c|}{ SUITABILITY RATING. } \\
\hline & Very High & High & Medium & Low & Non \\
\hline Drought Tolerance & & $x$ & & & \\
\hline Salt Tolerance & & & & & $x$ \\
\hline $\mathrm{pH} \quad$ Acid & & & & $x$ & \\
\hline Tolerance Base & & & $\mathrm{x}$ & & \\
\hline Winter Hardiness & & & $x$ & & \\
\hline Erosion Control & & $x$ & & & \\
\hline Persistence & & & $x$ & & \\
\hline Palatability & & & $x$ & $x$ & \\
\hline Browse Tolerance & & & & $x$ & \\
\hline Moisture Preference & Dry. & & & & \\
\hline Soil Preference & Sandy. & & & & \\
\hline
\end{tabular}


Calamovilfa longifolia (Hook.) Scribn.

\section{SPECIES BIOLOGY}

\section{Taxonomy}

Sand Grass, Sand Reed Grass (47), Prairie Sandreed (639).

\section{Origin and Range}

Native (405). Sand grass is the only Canadian representative of the genus Calamovilfa. Its range spreads from the Rocky Mountains east to the Lake Superior region and southward to New Mexico and Kansas (9).

\section{Growth Habit}

Tall, erect sod-forming grass with coarse leafy stems up to $2 \mathrm{~m}$ tall (336) and long stout scaly rhizomes. Roots to a depth of up to $1.5 \mathrm{~m}$ although most are found within $7 \mathrm{~cm}$ of the surface (9). On mixed prairie, it is observed to grow in nearly pure stands or colonies ranging from about $1 \mathrm{~m}$ to $8 \mathrm{~m}$ in diameter (1). Also mildly to strongly rhizomatous $(183,199)$, with large, spreading rhizomes (1).

Nitrogen Fixing - None

\section{Longevity}

Warm season (639) perennial grass (312).

\section{Self Propagation}

Seed production is rated as good; although propagation is predominantly by seed, the rhizomatous roots facilitate good vegetative spreading as well.

\section{Ecological Setting}

Found on sandy prairie sites and in open woods; and commonly on sand dunes (312). In Wyoming, found in areas where topsoil is normally absent and associated with plants such as Oryzopsis hymenoides, Artemisia cana, Chrysothamnus spp., and Yucca glauca (381). On the grasslands of eastern North Dakota, sand grass grows on the excessively drained "high prairie" in association with needle-and-thread (Stipa comata), june grass (Koeleria cristata) and side oats grama (Bouteloua curtipendula) (469). It is well adapted to sites that receive $30 \mathrm{~cm}$ of precipitation annually $(90,639)$, but the range of 25 to $40 \mathrm{~cm}$ seems satisfactory (426).

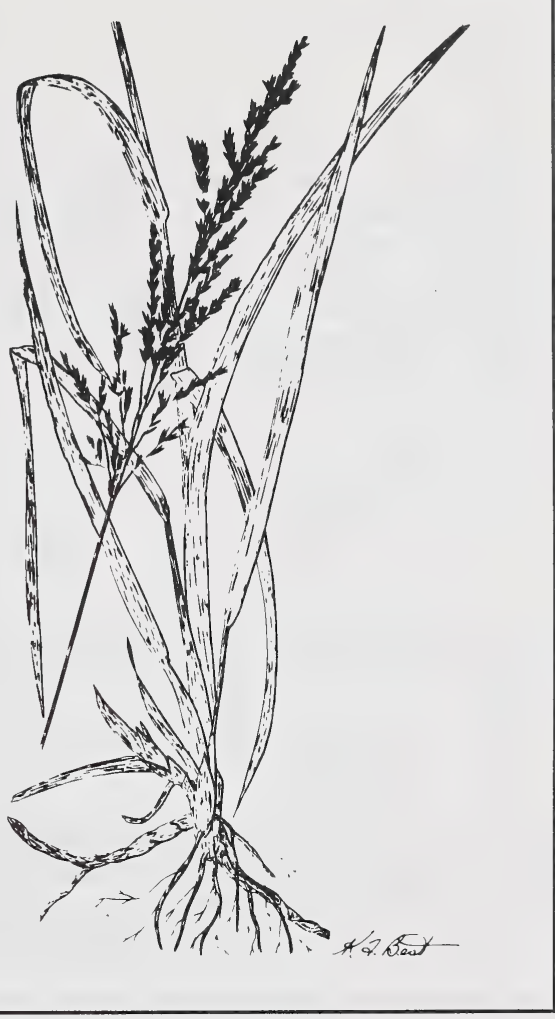

\section{TOLERANCES}

\section{Soil Preferences}

Associated with sandy soil conditions (312). In Montana, sand grass grows on soils of medium to coarse texture (1). In the mountains of Montana and Wyoming, sand grass prefers dry habitat, with an optimum slope of 9 to $30 \%$ and an optimum soil depth of more than $65 \mathrm{~cm}$. Growth is good on sandy soil, fair on loamy soil, and poor on clayey soil.

\section{Nutrient Requirements}

Responds to nitrogen fertilization, but will grow on low fertility soils.

\section{Soil Reaction}

Generally occurs on neutral soils, but will tolerate somewhat alkaline sites. 


\section{Soil Salinity}

Not found on saline soils.

\section{Drought}

Sand grass is rated as drought hardy $(183,426)$. In Montana mixed prairie conditions, field studies indicated greater water infiltration and higher soil water content under sand grass colonies than under surrounding vegetation; greater snow catch has been noted as well (1). It tends to replace sand bluestem (Andropogon hallii) on the American great plains during drought periods.

Heavy Metals and Hydrocarbons

No specific tolerances noted.

\section{Shade}

Sand grass is associated with the relatively unshaded conditions of sand dunes and open prairie.

\section{Grazing or Mowing}

Sandgrass disappears under high grazing intensities and is considered a "decreaser" relative to other range plants (1). The species is therefore considered moderately sensitive to heavy grazing.

\section{Susceptibility to Disease and Insect Damage}

No specific pests noted.

\section{RECLAMATION CONSIDERATIONS}

\section{Soil Building and Erosion Control Capability}

Rated high for erosion control value (405); it is treated as a sand binder (199), effectively stabilizing sand dunes (482). The surface roots are dense and wiry, and are well adapted to holding sandy soil against wind erosion (9).

\section{Adaptation to Disturbance}

Despite its heavy root development, sand grass is susceptible to trampling and will disappear from sites where livestock congregate (9). It is adapted to disturbed or shifting soil conditions (439). Noted to invade sand dunes as a pioneer (482).

\section{Competitive Ability}

Good stands of sand grass ("Goshen") were obtained when grown in mixtures with "Critana" thickspike wheatgrass, "Rosanna" western wheatgrass, green needlegrass or Indian ricegrass (1). It is apparently aggressive, sometimes occurring in pure stands of small size (1).

\section{Commercial Value}

Erosion control (405).

\section{Palatability and Nutritive Value}

Sand grass is palatable for livestock during its first month of growth (in the spring) and after it cures on the stem in the autumn. It is also considered a good winter pasture species. However, stems are rarely eaten if other food is available (9). Sand grass is a high producer (1). Forage value for mule deer and game birds is poor, but for small mammals it is considered fair (447).

\section{Seed or Planting Stock Availability}

Little commercial production; certified seed is apparently not available in Canada at present, although seed of the species has been distributed for field testing (183). "Goshen" is licensed in the U.S. (639) and is available in quantity, though at relatively high cost. 273000 seeds/lb (639).

\section{Methods and Ease of Establishment}

Best establishment would be by seeding, though commercial seed is not yet available in Canada (183). Spring seeding is recommended at a rate of 3 to 4 lbs PLS/ac (639).

\section{Current Status for Reclamation}

Calamovilfa longifolia has been released recently as a licensed variety ("Goshen") by the U.S. Soil Conservation Service for stabilization and range revegetation on sandy soils (456). Sand grass is in limited use in North America, but most work to date is experimental. First year results are available for experimental pipeline berm revegetation in northeastern B.C. Survival of transplanted nursery stock has been about $60 \%$ (431).

The species has been recommended for testing in the Alberta foothills and mountains (435), and would seem to warrant experimentation for tailings sand stabilization in the Alberta oil sands. Its primary assets are its soil binding abilities, its adaptability to sandy soils, its drought tolerance, and its modest nutrient requirements. 


\section{Carex atherodes}

\section{SPECIES SUITABILITY MAP AND SUMMARY TABLE}

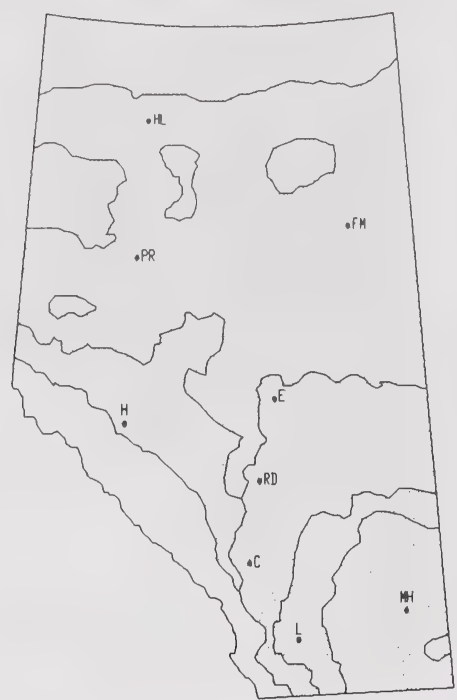

Recommended Area

Commercially Available: Yes No.

\begin{tabular}{|c|c|c|c|c|c|}
\hline \multirow{2}{*}{$\begin{array}{l}\text { RECLAMATION SUITABILITY } \\
\text { CRITERIA }\end{array}$} & \multicolumn{5}{|c|}{ SUITABILITY RATING } \\
\hline & Very High & High & Medium & Low & None \\
\hline Drought Tolerance & & & $x$ & & \\
\hline Salt Tolerance & & & & $x$ & \\
\hline pH Acid & & & & $x$ & \\
\hline Tolerance Base & & & $x$ & & \\
\hline Winter Hardiness & & & $x$ & & \\
\hline Erosion Control & & $x$ & & & \\
\hline Persistence & & $x$ & & & \\
\hline Palatability & & & $x$ & & \\
\hline Browse Tolerance & & & $x$ & & \\
\hline Moisture Preference & Wet to & loist. & & & \\
\hline Soil Preference & Clay $\mathrm{t}$ & clay 1 & & & \\
\hline
\end{tabular}


Carex atherodes Spreng.

\section{SPECIES BIOLOGY}

Taxonomy - Awned Sedge

Also $\underline{\text { C. trichocarpa var. aristata }}$

\section{Origin and Range}

Native. Ontario to the Yukon, south to New York, Indiana, Missouri, Colorado, Utah and Oregon. Also in northern Eurasia (503).

\section{Growth Habit}

A large water sedge which grows in clumps to $100 \mathrm{~cm}$ high. Awned sedge has heavy scaly rhizomes 4 to $6 \mathrm{~mm}$ in diameter (502). It is a very coarse-growing sedge (78); basal sheaths are purplish.

Nitrogen Fixing - None

Longevity - Long-lived perennial.

\section{Self Propagation}

Primarily by rhizomes. Seeds are often sterile.

\section{Ecological Setting}

Awned sedge is a common species in shallow fresh water marshes, sloughs and wet meadows throughout the prairies (312). It is often found growing with beaked sedge (Carex rostrata) in western Colorado (98). In western North America it is usually found between 1670 and $2830 \mathrm{~m} \mathrm{ASL}$ (503). It is abundant in the grassland and parkland zones of the prairies, often forming solid stands in slough bottoms (502).

\section{TOLERANCES}

\section{Soil Preferences}

Awned sedge is characteristic of wetland sites. It has been reported growing in sloughs with soil textures of clay and clay loam. One known site had 30 to $60 \mathrm{~cm}$ of peat over the clay (98).

\section{Nutrient Requirements}

Grows on relatively nutrient rich sites, hence nutrient requirements expected to be moderate to high.

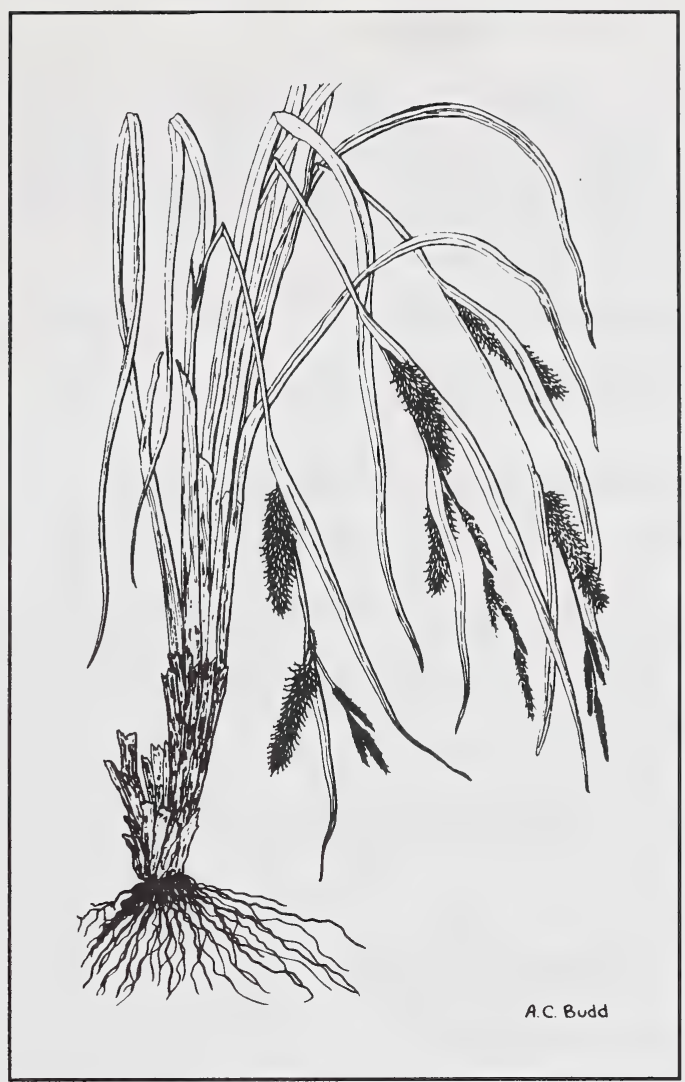

\section{Soil Reaction}

Mildly acidic to moderately alkaline.

\section{Soil Salinity}

Will tolerate moderately saline soils.

\section{Drought}

Awned sedge can apparently tolerate drying up of sloughs more than Carex aquatilis or $\underline{\mathrm{C}}$. rostrata which are more commonly found in continuously wet sites (502).

\section{Heavy Metals and Hydrocarbons}

No specific tolerances noted in the literature reviewed.

Shade - Does not tolerate shade. 


\section{Grazing or Mowing}

Two mowings per year was found to be the optimum for maintaining yield and chemical composition of awned sedge. Mowing six times in one growing season reduced the forage yield of that year and the following year, but it did not alter the chemical composition of the forage (98).

\section{Susceptibility to Disease and Insect Damage}

No pests noted in literature reviewed.

\section{RECLAMATION CONSIDERATIONS}

\section{Soil Building and Erosion Control Capability}

Extensive rhizome system and prolific growth makes awned sedge a good soil stabilizer, and adds significantly to the organic matter of the soil.

\section{Adaptation to Disturbance}

Observed to survive, and seems to thrive on burned sites or sites disturbed by moose.

\section{Competitive Ability}

Very aggressive due to rhizomatous habit.

\section{Commercial Value}

Awned sedge and beaked sedge are valuable species for hay if cut early (98). Used as cover by waterfowl and semi-aquatic mammals.

\section{Palatability and Nutritive Value}

The chemical composition of awned sedge was found to be similar to that of meadow grasses, upland short grass, and mixed prairie species. Seasonal declines in crude protein, phosphorous and carotene were also similar to that of native upland grasses. Crude protein ranged from $18.7 \%$ in May to $8 \%$ in September (98).

\section{Seed or Planting Stock Availability}

No commercially available seed. Awned sedge is abundant and its seed is easily collected. However, low germination rates and the lack of pre-treatment knowledge has hindered the development of seed stocks.

\section{Methods and Ease of Establishment}

Thought to do well from rhizome cuttings or transplanting.

\section{Current Status for Reclamation}

Not currently used for reclamation, although holds promise for revegetation of wetlands and drainage ditch banks. 
Carex rossii

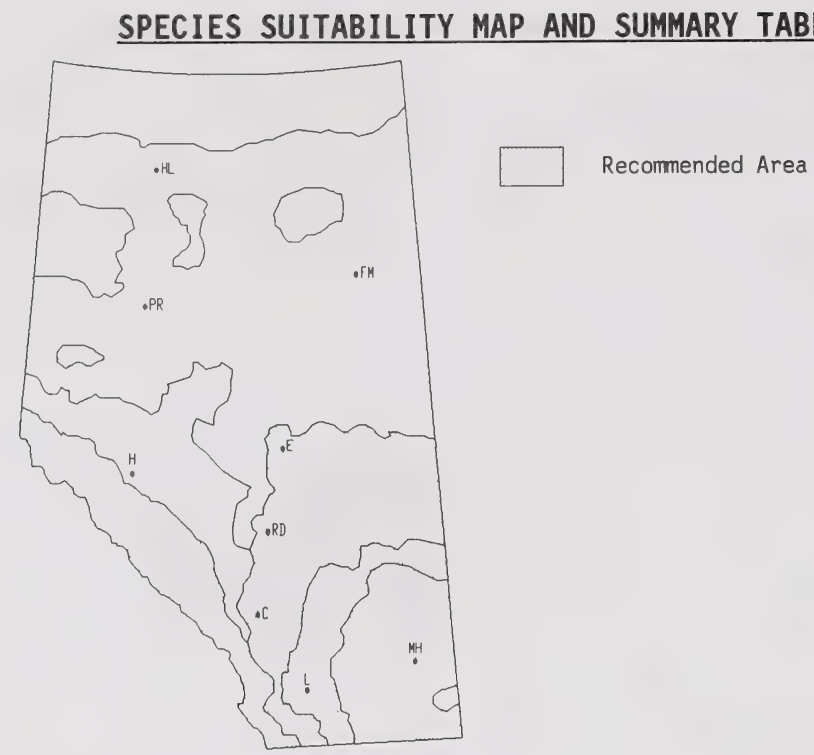

Commercially Available: Yes No

\begin{tabular}{|c|c|c|c|c|c|}
\hline \multirow{2}{*}{$\begin{array}{l}\text { RECLAMATION SUITABILITY } \\
\text { CRITERIA }\end{array}$} & \multicolumn{5}{|c|}{ SUITABILITY RAIING } \\
\hline & Very High & High & Medium & Low & None \\
\hline Drought Tolerance & $x$ & & & & \\
\hline Salt Tolerance & & & & $x$ & \\
\hline pH Acid & & & $x$ & & \\
\hline Tolerance Base & & & & $x$ & \\
\hline Winter Hardiness & & $x$ & & & \\
\hline Erosion Control & & $x$ & $\mathrm{x}$ & & \\
\hline Persistence & & $x$ & & & \\
\hline Palatability & & $x$ & $x$ & & \\
\hline Browse Tolerance & $x$ & $x$ & $\mathrm{x}$ & & \\
\hline Moisture Preference & Dry. & & & & \\
\hline Soil Preference & Sandy & to & loam comf & and & slop \\
\hline
\end{tabular}


Carex rossii Boott.

\section{SPECIES BIOLOGY}

Taxonomy - Ross's Sedge (47)

\section{Origin and Range}

Native. British Columbia and the Yukon, south to South Dakota, Wyoming, Colorado, and Arizona and California (503).

\section{Growth Habit}

A small sedge, usually in dense tufts, 5 to $30 \mathrm{~cm}$ high. This sedge does not have long stolons (502). The rootstocks are ascending, stout and fairly woody (312).

Nitrogen Fixing - None

Longevity - Long-lived perennial.

Self Propagation - By seed and rhizomes.

\section{Ecological Setting}

Carex rossii is a common species in the aspen parkland, grasslands and dry mountain slopes. It is usually found in dry or well drained sites of aspen forests, or in clearings $(502,312)$. It has been reported at between 1600 and $3267 \mathrm{~m} \mathrm{ASL}$, on dry sites in Wyoming (18). It often grows by itself on unstable screes and steep banks.

\section{TOLERANCES}

\section{Soil Preferences}

Found on sandy loam to clay loam soils. Can tolerate excessive soil compaction as well as unstable slopes.

\section{Nutrient Requirements}

Expected to have low nutrient requirements judging by its natural occurrences.

\section{Soil Reaction}

Prefers mildly alkaline to moderately acidic soils.

\section{Soil Salinity}

Will tolerate mildly saline soils.

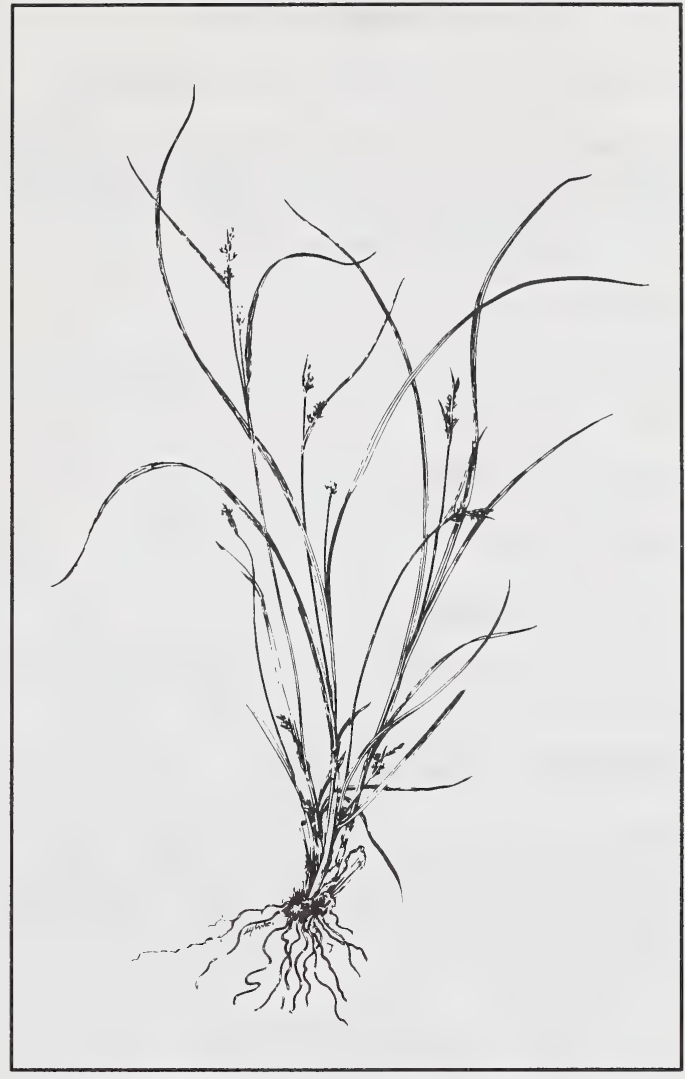

\section{Drought}

Found on sites prone to excessive drought.

\section{Heavy Metals and Hydrocarbons}

No specific tolerances noted in the literature reviewed, but noted to survive on fuel oil saturated soils in southeastern B.C.

Shade - Will tolerate at least partial shade.

\section{Grazing or Mowing}

Grazed by bighorn sheep, elk and deer (144), with little damage. The low matting habit and extensive root system is expected to allow this species to withstand moderate to severe grazing pressure.

\section{Susceptibility to Disease and Insect Damage}

No specific pests or diseases noted from the literature. Observed to be hardy in native sites. 


\section{RECLAMATION CONSIDERATIONS}

\section{Soil Building and Erosion Control Capability}

The extensive root system and the ability to contend with unstable loose material as well as compacted soils makes this species an excellent soil builder with good erosion control capability.

\section{Adaptation to Disturbance}

Invades extremely hostile, disturbed sites in southeastern B.C.

\section{Competitive Ability}

Aggressive as a pioneer of hostile sites.

\section{Commercial Value}

Utilized as domestic sheep forage in the Rocky Mountains and Colorado basin (503).

\section{Palatability and Nutritive Value}

Sedges have been reported to be highly preferred by bighorn sheep and moderately preferred by elk, mule deer and moose (144). Ross's sedge has been rated as having fair to good forage value for sheep (503).

\section{Seed or Planting Stock Availability}

No commercially available sources of propagules.

\section{Methods and Ease of Establishment}

Seed may be difficult to collect and may have low viability. Splitting and transplanting of native clumps may prove an effective means of establishment. Research required to determine most suitable method(s) of establishment.

\section{Current Status for Reclamation}

Not currently employed in revegetation programs in Alberta. Some small scale testing of this species has been conducted in southeastern B.C. 


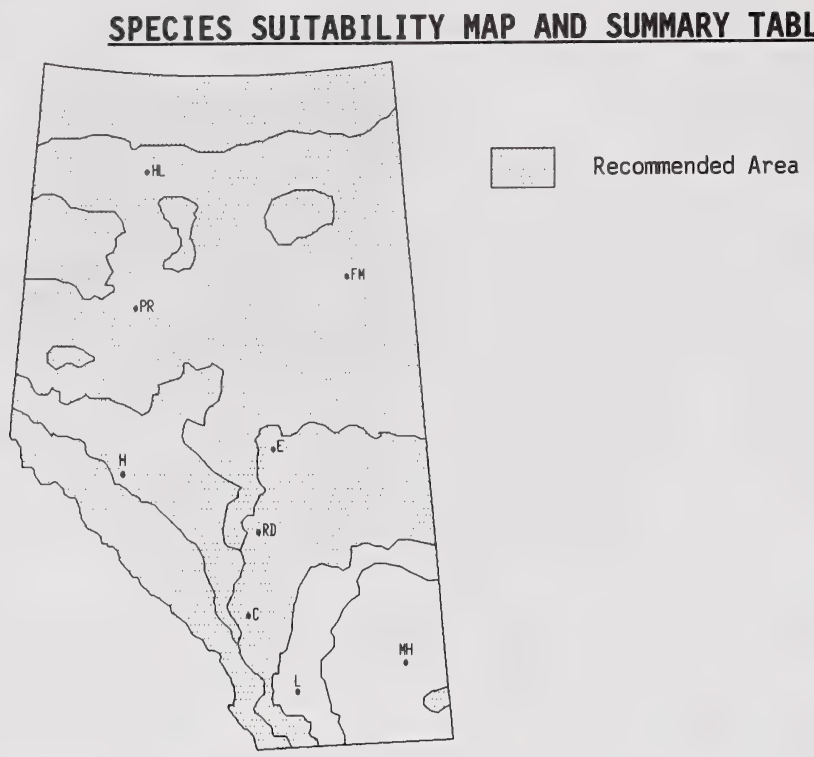

Commercially Available: Yes $\mathrm{X}$ No

\begin{tabular}{|c|c|c|c|c|c|}
\hline \multirow{2}{*}{$\begin{array}{l}\text { RECLAMATION SUITABILITY } \\
\text { CRITERIA }\end{array}$} & \multicolumn{5}{|c|}{ SUITABIL ITY RATING } \\
\hline & Very High & High & Medium & Low & None \\
\hline Drought Tolerance & & & $x$ & & \\
\hline Salt Tolerance & & & & $x$ & \\
\hline Acid & & & $x$ & & \\
\hline Tolerance Base & & & & $x$ & \\
\hline Winter Hardiness & & $x$ & $x$ & & \\
\hline Erosion Control & & & $x$ & & \\
\hline Persistence & $x$ & $x$ & & & \\
\hline Palatability & & $x$ & & & \\
\hline Browse Tolerance & & $x$ & & & \\
\hline Moisture Preference & Moist & wet, & ates so & odin & \\
\hline Soil Preference & M & $\mathrm{CO}$ & mediu & ted & \\
\hline
\end{tabular}


Dactylis glomerata L.

\section{SPECIES BIOLOGY}

Taxonomy - Orchard Grass.

\section{Origin and Range}

Introduced. Originated in Eurasia (199), notably from central and western Europe (183). It has escaped in favorable locations $(47,312)$. In North America, the species is extremely widespread, occurring from Newfoundland to Florida, and California to Alaska (199). It is best adapted to more humid regions such as the eastern edge of the plains (183).

\section{Growth Habit}

This is a tall, tufted bunchgrass, which often occurs in tussocks $(199,47)$. It is coarse and leafy $(312$, 391). Cultivars and varieties vary in height from about $60 \mathrm{~cm}$ to $120 \mathrm{~cm}$ (199); a dwarf variety "Pomar" is usually less than $60 \mathrm{~cm}$ tall (183). Typical heights for locally available cultivars are 65 to 80 or $90 \mathrm{~cm}(139,341)$. Roots are medium sized and fibrous $(179,47)$.

\section{Nitrogen Fixing - None}

\section{Longevity}

Orchardgrass is a long-lived, cool season (712) perennial (179). The species is subject to winterkill, though some cultivars are notably more winter hardy than others $(391,183,139)$. More subject to winterkill than timothy (Phleum pratense), slender wheatgrass (Agropyron trachycaulum), or smooth brome (Bromus inermis) $(183,359)$.

\section{Self Propagation}

Self propagation is primarily by seed, though at least one cultivar spreads vegetatively from abundant tillers $(183,391,339)$. Seeds germinate quickly and seedlings are vigorous (391). Seed production is excellent (339). Plants spread rapidly from seed $(340,339)$.

\section{Ecological Setting}

Occurs in moist or irrigated hay or pasture areas $(341,183)$, as well as under orchard trees $(47,179)$, including on slopes. It is also found in fields, meadows and waste places (199). Adequate moisture is necessary, over 30 to $45 \mathrm{~cm}(179,339)$. It is successful locally in irrigated or higher precipitation areas throughout the mountains and

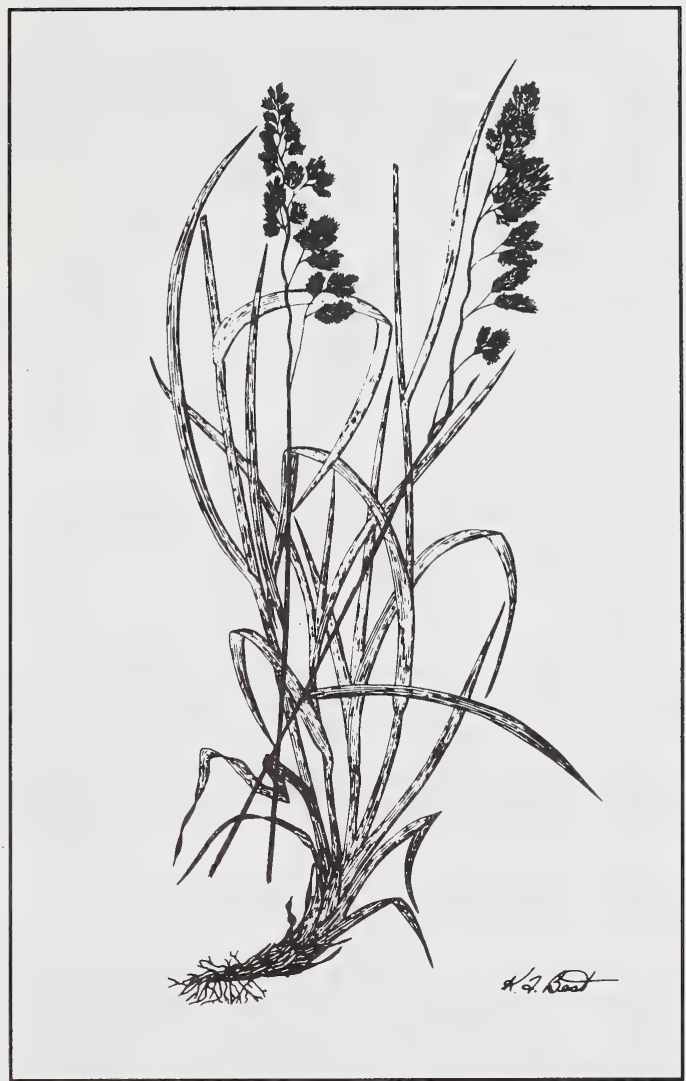

dry intermountain regions (183). Favors subhumid climates (179). Performs well at high elevations (2 000 to $2600 \mathrm{~m} \mathrm{ASL}$ ) in northern Utah; plants remained vigorous and produced an abundance of high quality forage (406). "Latar" appears to do best on protected sites which are snow covered in winter, even at elevations to $3500 \mathrm{~m} \mathrm{ASL}$ in Colorado (357). "Tardus" performed well in trials at Tent Mountain (2 100 m ASL) (29). "Chinook" noted as long-lived (30 years) in the southern foothills of Alberta (D. Walker, pers.comm.).

\section{TOLERANCES}

\section{Soil Preferences}

Orchardgrass is best adapted to medium textured, well drained, fertile soils. Growth may also be good on moderately coarse textured soils (179). The species will tolerate some flooding but not as much as reed canary grass (Phalaris arundinacea). Survives on wet soils (391). 


\section{Nutrient Requirements}

Persists on relatively shallow, infertile soils, but shows good response to improved fertility (500). Reported to prefer fertile soils (179). Does well in combination with leguminous species (179).

\section{Soil Reaction}

Performs well on moderately acid, neutral or mildly alkaline soils (179). A lower limit of $\mathrm{pH} 4.5$ has been suggested for the eastern US (712).

\section{Soil Salinity}

Prefers calcareous soils (179); shows fair tolerance to salts (424), in the range of 4 to $8 \mathrm{mS} / \mathrm{cm}$ (247).

\section{Drought}

More drought tolerant than either timothy or Kentucky bluegrass (Poa pratensis) (391), but cannot be considered better than moderate (340). "Barge", "Dayton", "Napier", "Palestine" (Reg. No. 7), and "Pomar" comprise the more drought resistant cultivars (183).

\section{Heavy Metals and Hydrocarbons}

Reported to be intolerant of toxic boron spoils (5 ppm soluble boron) with an electrical conductivity of $10 \mathrm{mS} / \mathrm{cm}$ and a sodium saturation of $30 \%$ (344). No other tolerances or sensitivities were noted from the literature.

\section{Shade}

Highly shade tolerant, growing very well under deciduous tree cover $(340,339)$.

\section{Grazing or Mowing}

Excellent tolerance to grazing (339).

\section{Susceptibility to Disease and Insect Damage}

Some strains susceptible to leaf disease (Mastigosporium rubricosums (Dearn. and Barth.) Sprague, rust leaf blight and leaf streak. Several resistant cultivars are available (183). Overall resistance to disease and insects is considered excellent (339).

\section{RECLAMATION CONSIDERATIONS}

\section{Adaptation to Disturbance}

Presumably orchardgrass is fairly well adapted to disturbance (in subhumid areas) as it germinates rapidly, has vigorous seedlings and shows excellent natural spreading ability $(391,339)$.

\section{Competitive Ability}

The species is only moderately aggressive and can be considered compatible with others (339). It is often used with smooth brome, or with such legumes as alfalfa (Medicago spp.), white clover (Trifolium repens), and birdsfoot trefoil (Lotus corniculatus) (179).

\section{Commercial Value}

Important for forage, hay and silage (183, 179). "Pomar" is used for cover and erosion control under orchards (forest cover) (179). The variegated form, var. variegata, is used as an ornamental (199). Limited current use in mined land reclamation (426).

\section{Palatability and Nutritive Value}

Excellent palatability $(340,339,19,427)$. Wildlife and livestock seek orchardgrass in all seasons, but it is particularly attractive in spring as the snow recedes, because basal leaves remain green throughout the winter and new leaves appear quickly (339). Hay and forage is high quality, and when planted with legumes (a common practice), hay quality is exceptionally good (179). Nitrogen content remains high through the summer (406).

\section{Seed or Planting Stock Availability}

Numerous commercial cultivars are available. These have been developed in, and are adapted to, many countries and regions including Canada, the U.S., France, Poland, Germany, Denmark, Sweden and Wales $(90,183)$. Canadian-bred cultivars include "Chinook", "Hercules", "Frode", "Kay", and "Rideau" $(139,183)$. These are more winter hardy and are earlier maturing (183). These and "Hallmark", "Ina", "June", "Majestic", "Nordstern", "Pennulate", "Sterling", "Sumas", "S-143", and "Tardus II" are licensed in Canada (138). Approximately 654000 seeds/lb (639). 


\section{Methods and Ease of Establishment}

Establishment is usually by seed, though good transplanting success can be expected (339). Seeding has fairly good expectations for success, since germination is rapid, seedling vigor is good, and growth rate is excellent $(391,339)$. A seeding rate of 10 to $20 \mathrm{lbs}$ PLS/ac has been recommended for the eastern US (712), but only 2 to $3 \mathrm{lbs}$ PLS/ac in a spring seeding for the west (639). Planting in combination with other grasses, and especially with legumes, is recommended since nutrient requirements are moderate and forage quality can be improved in this way (179). The dwarf cultivar "Pomar" has reduced maintenance requirements under orchards due to its shorter stature. Seed retains its viability above $80 \%$ during 12 to 14 years of cool, dry warehouse storage (179). Viability of $29 \%$ has been recorded after 20 years (211).

\section{Current Status for Reclamation}

Orchardgrass has been tested, with good success, on high elevation overburden at Tent Mountain, and on Harmer Ridge near Sparwood, B.C. $(380,498$, 494). Results show that growth is very good between 1500 and $1900 \mathrm{~m}$ ASL in southeastern British Columbia (498). Trials have also been carried out at Luscar, Alberta (144), near Grande Cache (377) and at Inuvik and Tuktoyaktuk, N.W.T. (195). Under the latter cold conditions, germination is good, but overwintering success is poor (195).

Orchardgrass is fairly widely used for rehabilitation work in the United States, particularly in the more humid eastern states. Experimental work has been done at a coal test pit near Roundup, Montana (129), at the Decker mine (with poor success (117)), and on the Beartooth Plateau (74). Experimental and propagation efforts are active in Oregon (130, 266), Idaho (147), Colorado (236, 132), Utah (406), Arizona (354), and Texas (375). Results at high elevations are encouraging, but drought appears to be a major factor limiting success.

Orchardgrass is widely used, in subhumid climates and under irrigation, as a pasture and hay crop. It is also used for erosion control in orchards or under other forest cover (179). It has been used with varying, but generally limited, success for reclamation. Overall, where moisture is adequate prospects are good. Its chief assets are its tolerance to acidic conditions, its ease of establishment through seeding, and its tolerances of shade, grazing and flooding. It is highly palatable and nutritious, long-living and is a good soil builder and stabilizer. It is relatively intolerant of drought, however, and requires moderate fertility. 
Deschampsia caespitosa

SPECIES SUITABILITY MAP AND SUMMARY TABLE

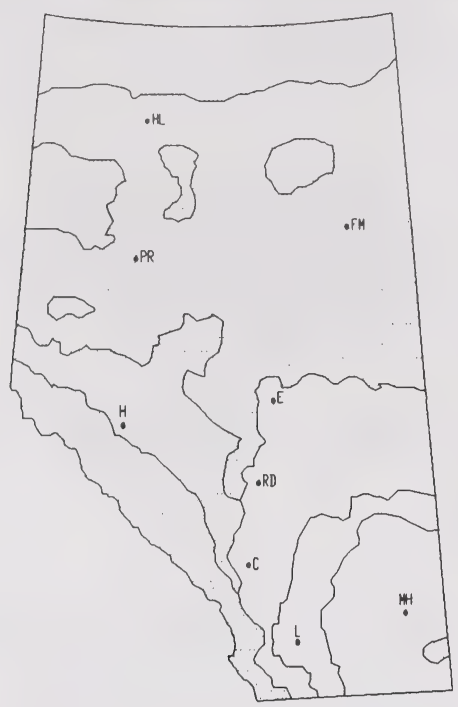

Recommended Area

Commercially Available: Yes No $x$

\begin{tabular}{|c|c|c|c|c|c|}
\hline \multirow{2}{*}{$\begin{array}{l}\text { RECLAMATION SUITABILITY } \\
\text { CRITERIA }\end{array}$} & \multicolumn{5}{|c|}{ SUIIABILITY RATING } \\
\hline & Very High & High & Medium & Low & None \\
\hline Drought Tolerance & & & $x$ & $x$ & \\
\hline Salt Tolerance & & & $x$ & $x$ & \\
\hline Acid & & 3.3 & & & \\
\hline Tolerance Base & & & $x$ & & \\
\hline Winter Hardiness & $x$ & $x$ & & & \\
\hline Erosion Control & & $x$ & X & & \\
\hline Persistence & & & $x$ & & \\
\hline Palatability & & & $x$ & $x$ & \\
\hline Browse Tolerance & & & $x$ & & \\
\hline Moisture Preference & Wet to & moist. & & & \\
\hline Soil Preference & Mediun & to fine & tured, $\mathrm{t}$ & tes wid & range. \\
\hline
\end{tabular}




\section{Deschampsia caespitosa (L.) Beauv.}

\section{SPECIES BIOLOGY}

Taxonomy - Tufted Hair Grass

\section{Origin and Range}

Native. Alaska to Greenland, south through most of the United States and northern Mexico. Also found throughout Eurasia (507). ㅁ. caespitosa forms hybrids with $\underline{D}$. beringensis and $\underline{D}$. brevifolia in Alaska (214). A highly complex and variable species (214). Tufted hair grass is common throughout the prairie and mountain regions of Alberta (312).

\section{Growth Habit}

Tufted hair grass is a tall, densely tufted bunchgrass, (426) 20 to $120 \mathrm{~cm}$ tall. There are apparently large differences between various populations in cold hardiness.

Nitrogen Fixing - None

Longevity - Cool season (639) perennial (426).

\section{Self Propagation}

Propagates itself only by seed.

\section{Ecological Setting}

It is found in sloughs, moist draws, wet meadows and on stream banks $(312,78)$. It occurs on wet or damp sites at elevations of 2300 to $4260 \mathrm{~m} \mathrm{ASL}$ and occasionally as low as $1600 \mathrm{~m}$ in the western United States. It is usually found on moist meadows. Requires $50 \mathrm{~cm}$ of precipitation (639). Ecotypes perform well on dry, windblown disturbed sites at high elevations (426). It has been reported as a dominant species on alpine/subaipine meadows in southwestern Montana (193).

\section{TOLERANCES}

\section{Soil Preferences}

Tufted hair grass is adapted to wet sites, at optimum slopes of 9 to $30 \%$ and optimum soil depth of 30 to $60 \mathrm{~cm}$. Growth on sandy soil is rated as fair, and on loamy and clayey soil as good (446). It has been reported growing on coarse textured river alluvium in northern Alaska (52).

Nutrient Requirements - Unknown

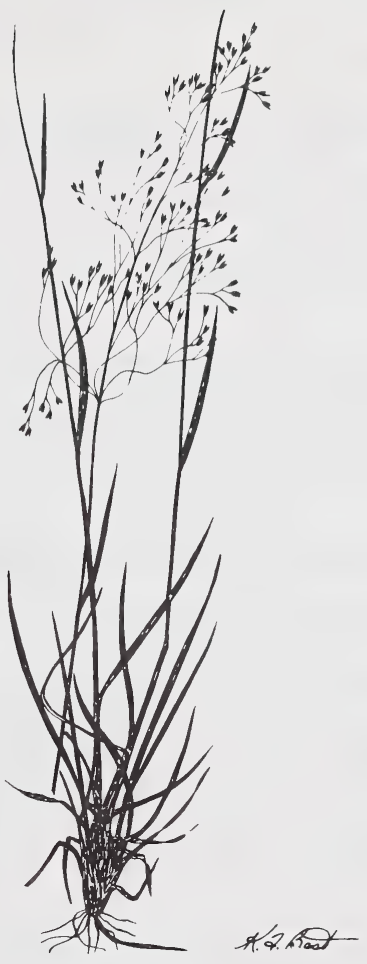

\section{Soil Reaction}

Tufted hair grass has been observed as a dominant colonizer of calcareous mine waste materials (387). It is also a pioneer on acid soils near Sudbury, Ontario. It grew well on tailings of pH 3.3 (246).

\section{Soil Salinity}

Probably not well adapted to very saline sites.

\section{Drought}

Some ecotypes are presumed to be at least moderately drought tolerant, though the species prefers moist locations.

\section{Heavy Metals and Hydrocarbons}

Tufted hair grass is reported to be a pioneer on acid soils with elevated levels of $\mathrm{Ni}, \mathrm{Cu}$ and $\mathrm{Co}$ at Sudbury, Ontario. $\mathrm{Cu}, \mathrm{Ni}$ and $\mathrm{Zn}$ concentrations of 392,290 and $291 \mathrm{ppm}$ respectively were not toxic to tufted hair grass grown on acid tailings ( $\mathrm{pH} 3.3$ ) in a greenhouse experiment. It also grew well on near 
neutral tailings with concentrations of $\mathrm{Pb}$ to $2300 \mathrm{ppm}, \mathrm{Zn}$ to $18000 \mathrm{ppm}, \mathrm{Cd}$ to $114 \mathrm{ppm}, \mathrm{Cu}$ to $1420 \mathrm{ppm}$ and As to $50000 \mathrm{ppm}$ (246).

\section{Shade}

Likely at least moderately tolerant of shady locations

\section{Grazing or Mowing}

Tufted hair grass has moderate tolerance to grazing (639).

\section{Susceptibility to Disease and Insect Damage}

Tufted hair grass is rated as having good resistance to insects and disease (339).

\section{RECLAMATION CONSIDERATIONS}

\section{Soil Building and Erosion Control Capability}

Tufted hair grass has a medium rate of growth but has a poor rate of spread. It is considered fair for soil stabilization (339). Tufted hair grass produces considerable ground cover (436).

\section{Adaptation to Disturbance}

Tufted hair grass has been observed growing in disturbed sites in the alpine in Colorado (177). Tufted hair grass is a pioneer on river alluvium in northern Alaska (52). It also colonizes acid spoils near Sudbury, Ontario (246). Tufted hair grass is occasionally found as a pioneer on dry gravel bars near Golden (1 900 m ASL), B.C. (209).

\section{Competitive Ability}

Tufted hair grass has been rated as having good compatibility (436). It has good competitive ability relative to a number of plant species considered for the Alaska Highway gas pipeline revegetation (223). Based on field observations, it is presumed to be no more than moderately aggressive, in relation to other plants within its range.

\section{Commercial Value}

This grass is a valuable soil stabilizer, especially in wet, acidic locations. It is also important for wildlife forage.

\section{Palatability and Nutritive Value}

Tufted hair grass is a leafy and palatable grass (426, 427). It has been rated as good for providing palatable early spring growth and remains palatable through summer growth (339). Forage value has been rated as fair for mule deer and game birds, and good for small mammals. Cover value has been rated as poor for mule and game birds, but good for small mammals (446). Frequently grazed by bears.

\section{Seed or Planting Stock Availability}

Tufted hair grass is not available from commercial sources (426). Apprxoimately 2500000 seeds/lb (639)

\section{Methods and Ease of Establishment}

In Utah, tufted hair grass is easily established from seed, though seed is not particularly abundant. Germination is fair, but initial establishment is often poor. Ease of transplanting has been rated as good (339). Good seed production from a strain of tufted hair grass (M-926) has been reported (131). Tufted hair grass has been successfully transplanted to disturbed alpine/subalpine sites in Montana (74). Fall seeding is recommended at a rate of 1 to 2 Ibs PLS/ac (639).

\section{Current Status for Reclamation}

This species has potential for use in reclamation in Alberta. When planted at several alpine and subalpine sites in the Rocky Mountains in Alberta, it had excellent survival and cover after five years (723), however performance in mixed seedings was poor after six years (705). Plant cover was significantly higher on overburden topdressed with mineral soil than on raw overburden (364). Survival and vigor was good on medium textured soil and poor on fine-textured soil after three years testing in the Upper Mackenzie region of the boreal forest (latitude $63^{\circ} \mathrm{N}$ ) (644). It was found to be highly tolerant of metal contaminated tailings $(\mathrm{Pb}, \mathrm{Zn}, \mathrm{Cu}$, $\mathrm{Mn}$ ) in the Yukon (611). At Fort McMurray, tufted hair grass had relatively low cover after five years on tailings sand soil mixtures (705).

Three varieties of tufted hair grass (Deschampsia caespitosa/beringensis complex) are currently undergoing seed increase and other testing at Palmer, Alaska (223). Tufted hair grass has been recommended for revegetation of disturbed areas in moderately moist to moist regions in northwestern Colorado (427). It is a promising species for revegetation of bare soil in the alpine in Colorado (323).

This species is adapted to moist to wet sites throughout the prairies, moist mountain meadows 
and somewhat alkaline as well as relatively acidic soils. Some populations are also adapted to growing on spoils with elevated levels of heavy metals. 
Distichlis stricta

\section{SPECIES SUITABILITY MAP AND SUMMARY TABLE}

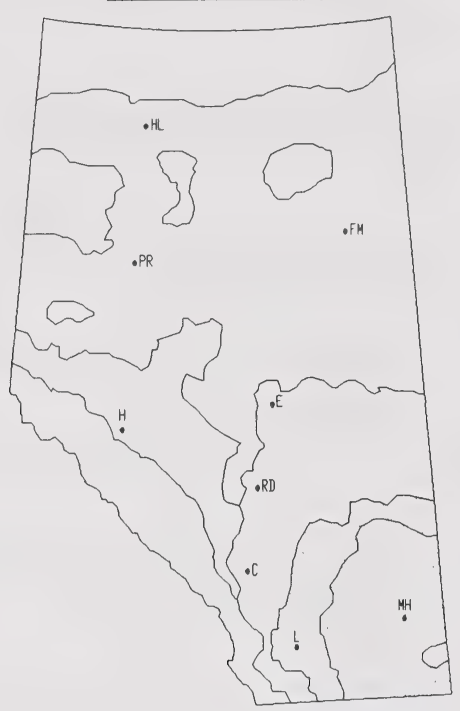

Recommended Area

Commercially Available: Yes No

\begin{tabular}{|c|c|c|c|c|c|}
\hline \multirow{2}{*}{$\begin{array}{l}\text { RECLAMATION SUITABILITY } \\
\text { CRITERIA }\end{array}$} & \multicolumn{5}{|c|}{ SUITABILITY RATING. } \\
\hline & Very High & High & Medium & Low & None \\
\hline Drought Tolerance & & & $x$ & & \\
\hline Salt Tolerance & $x$ & & & & \\
\hline Acid & & & & & \\
\hline Tolerance Base & & $x$ & & & \\
\hline Winter Hardiness & & & $x$ & & \\
\hline Erosion Control & $x$ & & & & \\
\hline Persistence & & $x$ & & & \\
\hline Palatability & & & & $x$ & \\
\hline \multicolumn{6}{|l|}{ Browse Tolerance } \\
\hline Moisture Preference & \multicolumn{5}{|c|}{ 0ccassionally dry. } \\
\hline Soil Preference & \multicolumn{5}{|c|}{ Medium to fine textured, poorly drained. } \\
\hline
\end{tabular}


Distichlis stricta (Torr.) Rydb.

\section{SPECIES BIOLOGY}

Taxonomy - Alkali Grass (78); Inland Saltgrass (639).

Also D. spicata (L.) Greene var. stricta (Gray) Beetle

\section{Origin and Range}

Native to North America. Occurs throughout the Canadian prairies, to eastern Washington, California, Texas and much of the American dry interior. Also in Mexico $(430,47)$.

\section{Growth Habit}

Low, extensively creeping, sod-forming grass (312, 78). Erect or decumbent (312). Extremely aggressive scaly rhizomes, sometimes with stolons $(426,47)$.

\section{Nitrogen Fixing - None}

Longevity - Warm season (639) perennial $(47,312)$

\section{Self Propagation}

Dioecious (426, 78, 312). Very poor seed production (426). Aggressive vegetative spreading by rhizomes and stolons $(47,78,426)$.

\section{Ecological Setting}

Commonly occurs in lowlands (264) and where sites are wet and drainage is poor. Also on so-called sub-irrigated lands which are subject to alternating dry and wet periods (426). Requires $20 \mathrm{~cm}$ of precipitation (639). Generally occurs on saline or alkaline sites; occasionally on dry slopes $(47,199$, 312).

\section{TOLERANCES}

\section{Soil Preferences}

Soils are usually saline or alkaline, often Solonetzic, and may include silty and loamy materials through to clays $(316,230,264)$. Sites are often intermittently wet and dry (426).

\section{Nutrient Requirements}

Saltgrass meadows typically have low fertility (264); requirements are therefore presumed to be modest.

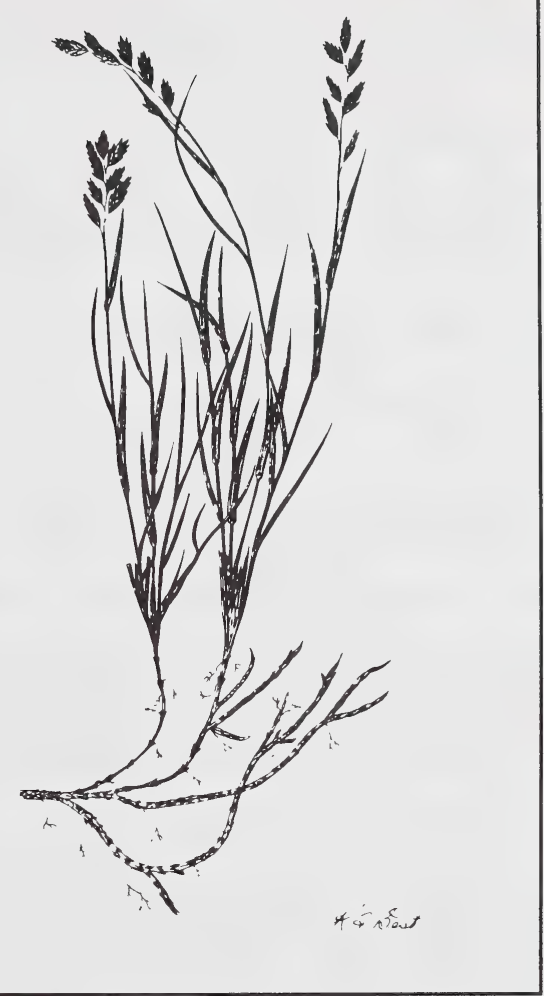

\section{Soil Reaction}

Well adapted to alkaline soil conditions $(47,264$, 426).

\section{Soil Salinity}

Considered to have very high tolerance to saline conditions, possibly above $16 \mathrm{mS} / \mathrm{cm}(361,469)$. It is reported by others to withstand $2 \%$ salt and electrical conductivity in the range of $24 \mathrm{mS} / \mathrm{cm}$ (468).

\section{Drought}

Saltgrass is distributed on very dry upper slopes and ridge tops at Estevan (230) and apparently withstands intermittent drought (426).

\section{Heavy Metals and Hydrocarbons}

No particular tolerances or sensitivities were noted from the literature consulted. 


\section{Shade}

No specific information, but based on normal habitat, saltgrass is presumed to be relatively shade intolerant.

\section{Grazing or Mowing}

The species is not grazed extensively, nor is it often mowed, but its rhizomatous habit suggests it would withstand such pressure well.

\section{Susceptibility to Disease and Insect Damage}

No information is available from the literature consulted.

\section{RECLAMATION CONSIDERATIONS}

\section{Soil Building and Erosion Control Capability}

Saltgrass is considered an outstanding species for wind or water erosion control (426) due to its extremely strong rhizomatous growth habit. In fact, it is difficult to eradicate except by spraying (264).

\section{Adaptation to Disturbance}

The species is persistent even where mechanical means are used for eradication (264). Though seed production is low, rhizomes can be expected to cause colonization of all suitable sites adjacent to established stands.

\section{Competitive Ability}

Saltgrass is expected to be an extremely strong competitor on suitable alkaline or saline sites.

\section{Commercial Value}

Major usefulness for stabilization of extremely saline or alkaline sites, and for maintenance of an erosion controlling ground cover (426).

\section{Palatability and Nutritive Value}

Though the species may be palatable (and grazed) in spring when it is green (426), or where palatable species are generally lacking, it is generally considered unpalatable $(132,264)$.

\section{Seed or Planting Stock Availability}

Commercial seed is not available due to poor natural seed production capability (426). Colorado State University Horticulture and Botany
Departments are putting some effort into breeding and improving seed (132). Small quantities of seed can now be obtained from dealers in Idaho. Approximately 520000 seeds/lb (639).

\section{Methods and Ease of Establishment}

Transplanting or sprigging would probably be effective establishment methods, based on knowledge of natural habits. Seeding may also be effective, but since seed is not generally available, a seeding program may prove costly. Summer seeding at a rate of $10 \mathrm{lbs}$ PLS/ac has been recommended (639). Planting alone may encourage grazing, and would facilitate management (426).

\section{Current Status for Reclamation}

The species is found naturally, particularly in lowland saline or alkaline sites $(264,230)$. It is also a volunteer on saline mined land refuse, particularly in the Estevan area of Saskatchewan (316). It is considered an encouraging species for special purposes at high altitudes (132) and in mined land reclamation (426).

The species appears to have excellent adaptation to certain troublesome site situations (salinity, alkalinity, and intermittent wet and dry periods), but is hampered in its usefulness by poor seed availability. 
Elymus innovatus

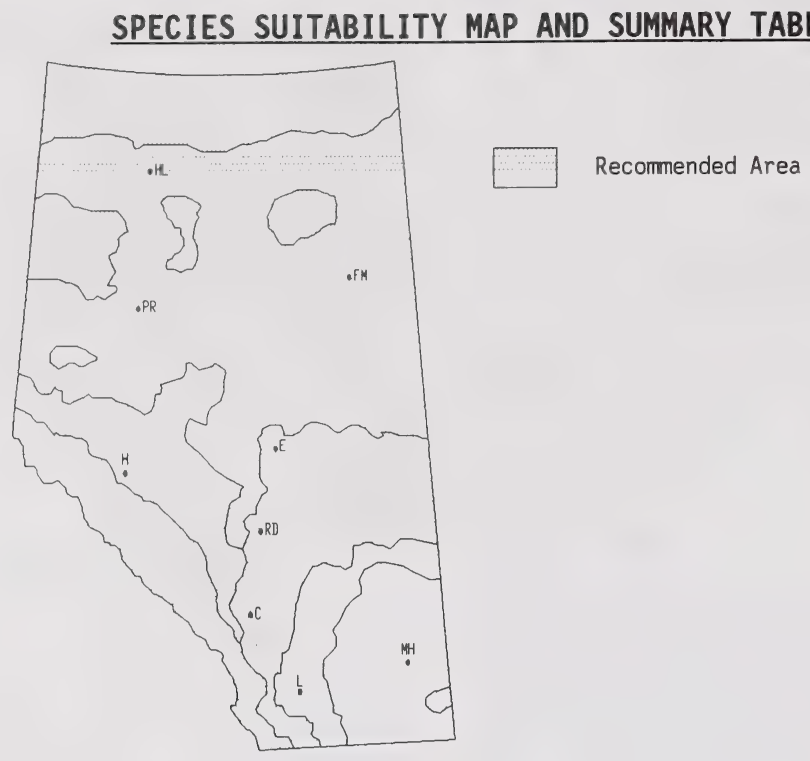

Commercially Available: Yes No.

\begin{tabular}{|c|c|c|c|c|c|}
\hline \multirow{2}{*}{$\begin{array}{l}\text { RECLAMATION SUITABILITY } \\
\text { CRITERIA }\end{array}$} & \multicolumn{5}{|c|}{ SUITABILITY,RATING } \\
\hline & Very High & High & Medium & Low & None \\
\hline Drought Tolerance & & & & $x$ & \\
\hline Salt Tolerance & & & & $\mathrm{x}$ & \\
\hline pH Acid & & & & $x$ & \\
\hline Tolerance Base & & & & $\mathrm{x}$ & \\
\hline Winter Hardiness & & $x$ & $x$ & & \\
\hline Erosion Control & & $x$ & $x$ & & \\
\hline Persistence & & & $x$ & & \\
\hline Palatability & & $x$ & & $x$ & \\
\hline Browse Tolerance & & & $x$ & & \\
\hline Moisture Preference & Dry to & oist. & & & \\
\hline Soil Preference & Coarse & 0 fine & tured, we & raine & \\
\hline
\end{tabular}




\section{Elymus innovatus Beal}

\section{SPECIES BIOLOGY}

Taxonomy - Hairy Wild Rye

\section{Origin and Range}

Native. Grows from Alaska to the Red River in Manitoba, and southward into Montana, North and South Dakota, Idaho and Washington. In Alberta, it occurs within the Parkland and northward, in the Cypress Hills, and throughout the lower ranges of the Rocky Mountains (506). Hybridizes with Agropyron dasystachyam, $\underline{\text { A. smithii and }}$ A. trachycaulum (312).

\section{Growth Habit}

Tall, erect sod-forming grass, with slender scaly rhizomes (365). Usually $100 \mathrm{~cm}$ or more in height. Noted for its deep and spreading root system (507).

Nitrogen Fixing - None

Longevity - Perennial grass (405).

\section{Self Propagation}

Seeds and creeping rhizomes. Noted for abundant seed production (453). Noted for poor seed set (D. Walker, pers.comm.).

\section{Ecological Setting}

Very common in open woodlands, especially in pine forests of western Alberta (312), up to the midsubalpine (209), to at least $1400 \mathrm{~m}$ (214). Rare in the south but more abundant in the north (47). Noted as an indicator species of Pinus/Picea glauca/Arctostaphylos uva-ursi association (edaphic climax) on well drained sand dunes in Alberta $(253,258)$. Also found growing on glacial outwash in Alaska (209).

\section{TOLERANCES}

\section{Soil Preferences}

Associated with sandy soil (214). It develops dense stands under open poplar and pine stands where the soil is sandy or gravelly (453). Provides ground cover on coarse textured soils in the Peace River parkland region and on coarse to fine textured soils in the boreal mixed wood region (435).

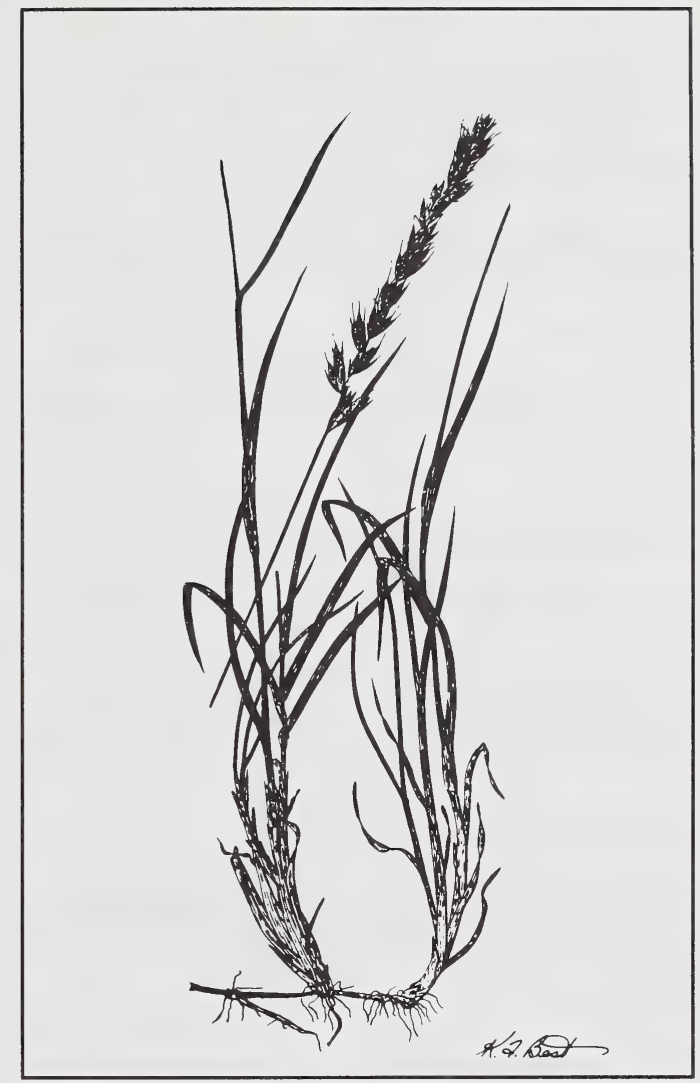

Nutrient Requirements

Responds to nitrogen fertilization, although it grows well on low nutrient soils.

\section{Soil Reaction}

No tolerances noted in the literature, but expected to be tolerant of mildly acidic to mildly alkaline soils.

\section{Soil Salinity}

Presumed to be tolerant of mildly saline soils.

\section{Drought}

Does best where the probability of drought is low.

\section{Heavy Metals and Hydrocarbons}

Hairy wild rye provided good growth in initial growth chamber tests on lean oil sand, heavy oil sand, and soil mixes with variable oil content $(404,209)$. Other tolerances not known. 


\section{Shade}

Associated with forest openings, and is presumably relatively shade tolerant.

\section{Grazing or Mowing}

Generally not eaten. Expected to be moderately tolerant of mowing.

\section{Susceptibility to Disease and Insect Damage}

Seed heads often develop rust infections, especially in wet years.

\section{RECLAMATION CONSIDERATIONS}

\section{Soil Building and Erosion Control Capability}

Hairy wild rye colonizes disturbed areas rapidly and, along with its deep and spreading root system, acts to reduce wind and water erosion (453). Regarded as a good sand binder (258).

\section{Adaptation to Disturbance}

Will readily invade disturbed sites in adapted area. Often a pioneer on such sites (453).

\section{Competitive Ability}

Noted for establishing quickly on all sites cleared of poplar (Populus spp.) and jackpine (Pinus banksiana) (506).

\section{Commercial Value}

Erosion control and soil stabilization.

\section{Palatability and Nutritive Value}

Not palatable and will not be eaten by cattle if other grasses are available $(47,506)$. The coarse leaves and stems are not succulent at any time, and the hairiness probably discourages consumption (506). However, hairy wild rye has been identified as one of the most valuable native forage plants (435), presumably where more palatable species are absent. It accumulates nitrates to poisonous levels if over-fertilized, and therefore must be used with caution (D. Walker, pers.comm.).

\section{Seed or Planting Stock Availability}

Not commercially available. Several chromosome races occur, some of which produce sterile progeny (D. Walker, pers.comm.).

\section{Methods and Ease of Establishment}

Spring seeding of $\underline{E}$. innovatus on reclaimed pipeline berms in north-eastern British Columbia resulted in $50 \%$ germination and survival (431). Transplanting sod clumps of hairy wild rye has proved successful for sand dune reclamation in Alberta, although the technique appears costly (258). The very hairy seeds of hairy wild rye could cause problems in a seed drill or broadcast seeder (455).

\section{Current Status for Reclamation}

Hairy wild rye is a native grass which is abundant in most forested areas of Alberta. Growth trials using local seed sources of hairy wild rye indicate good growth on coal mine spoil in the Rocky Mountain foothills of Alberta (271). It is being tested for pipeline revegetation in arctic and boreal regions of North America (298). It is currently under investigation at the University of Alberta for high elevation revegetation and wildlife range improvement uses (453).

It is an abundant seed producer, facilitating field collection and harvesting of seed. It is well adapted to sandy soils, has apparent tolerance to bitumen materials, and preliminary growth trials indicated potential suitability for oil sands revegetation (particularly where establishment of native species is desired). It also appears useful for revegetation in the mountains and foothills (453). Drawbacks include limited field experience defining applied uses and conditions for reclamation suitability, and limited wildlife forage value. It may be useful along highways where wildlife use is to be discouraged. 
Elymus junceus

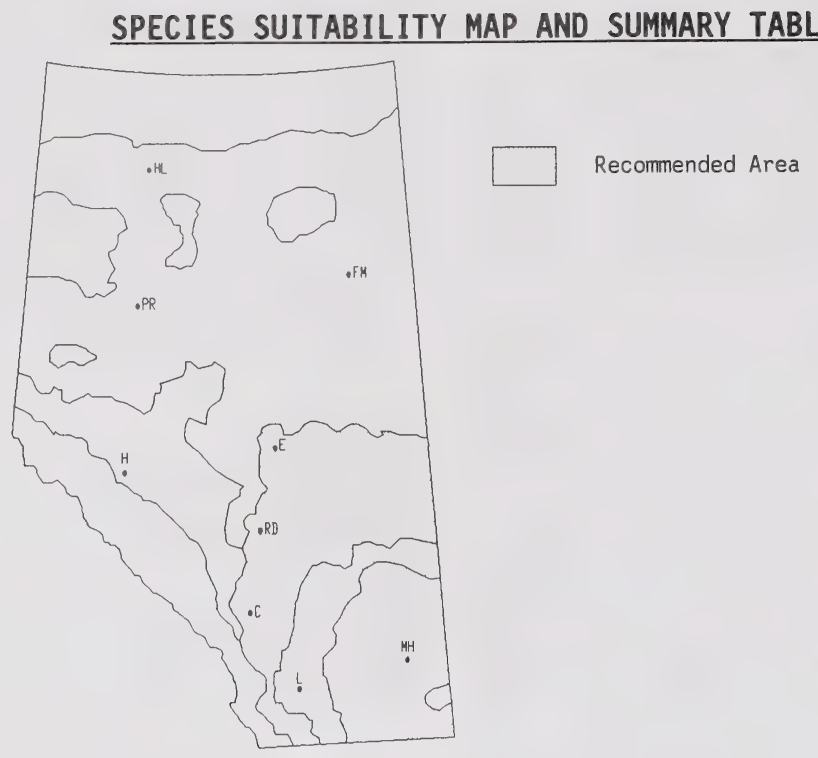

\begin{tabular}{|c|c|c|c|c|c|}
\hline \multirow{2}{*}{$\begin{array}{l}\text { RECLAMATION SUITABILITY } \\
\text { CRITERIA }\end{array}$} & \multicolumn{5}{|c|}{ SUITABILITY RAIING } \\
\hline & Very High & High & Medium & Low & None \\
\hline Drought Tolerance & & $x$ & $x$ & & \\
\hline Salt Tolerance & & $x$ & & & \\
\hline Acid & & & & $x$ & \\
\hline Tolerance Base & & & $x$ & & \\
\hline Winter Hardiness & & & $x$ & & \\
\hline Erosion Control & & & $x$ & & \\
\hline Persistence & & $x$ & & & \\
\hline Palatability & $x$ & $x$ & & & \\
\hline Browse Tolerance & & $x$ & & & \\
\hline Moisture Preference & Dry to & oist. & & & \\
\hline Soil Preference & Sandy & clayej & & & \\
\hline
\end{tabular}


Elymus junceus Fisch.

\section{SPECIES BIOLOGY}

Taxonomy - Russian Wild Rye

\section{Origin and Range}

Introduced. Originates from western Siberia (138). Used as a pasture crop throughout the prairie area of western Canada (138), and throughout much of the western United States.

\section{Growth Habit}

A tall, densely tufted, deep rooted bunchgrass. Mature plants stand 90 to $120 \mathrm{~cm}$ tall.

Nitrogen Fixing - None

\section{Longevity}

Long-lived, cool season (639) perennial (391) bunchgrass.

\section{Self Propagation}

Seed. No vegetative reproduction. A good natural reseeder (335).

\section{Ecological Setting}

Dryland pasture lands throughout the prairie area of Canada (138). Requires $30 \mathrm{~cm}$ of precipitation (639). May be suitable for use on disturbed lands in the subalpine regions of Alberta $(269,209,337)$; marginal success on lands at $2070 \mathrm{~m}$ (380). In Colorado, Russian wild ryegrass seeded on a high elevation nursery (2 $800 \mathrm{~m} \mathrm{ASL}$ ) maintained itself for 9 years, but had rapid decline in the tenth year (193). Generally restricted to cultivated or improved situations.

\section{TOLERANCES}

\section{Soil Preferences}

Suited for dryland pasture on loam soils (506). "Sawki" variety is noted for its adaptation to loam and clay soils on the prairies and semiarid interior of British Columbia (138). Growth trials on coal mine waste in the southern interior near Hat Creek of British Columbia demonstrated good growth on bentonitic clay materials, relative to other species tested (187). Adapted to both light and heavy soils (340).

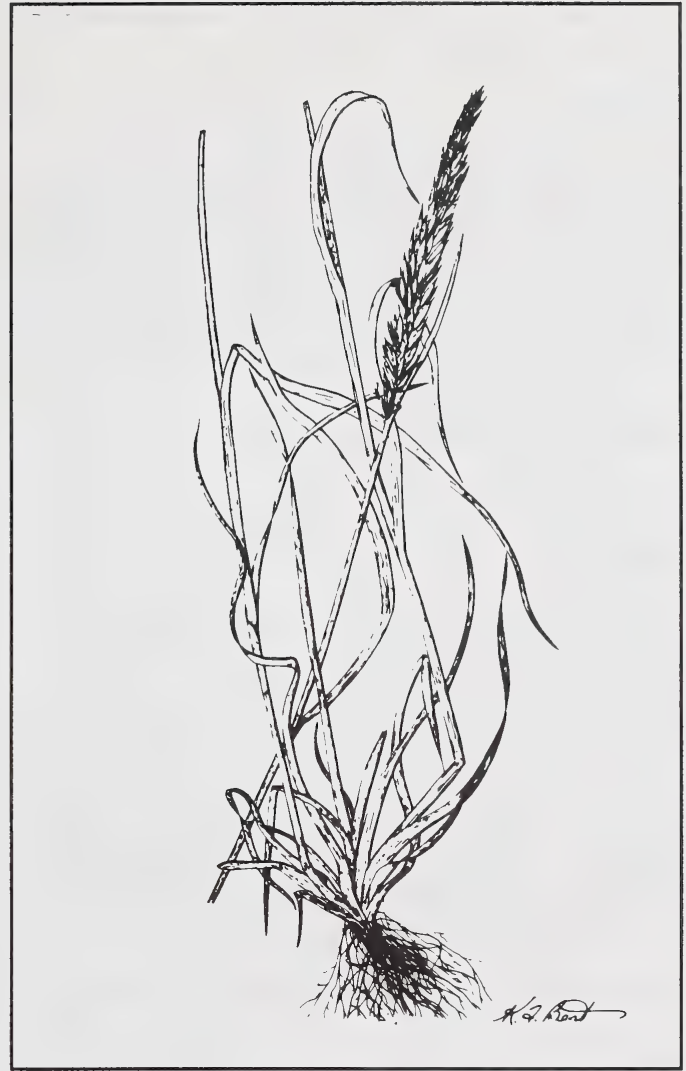

Nutrient Requirements

In general, annual applications of fertilizer at heavy rates will provide good yields, for many years, from a single seeding (252). It is adapted to both light and heavy soils, especially those with moderate to high available nitrogen (340).

\section{Soil Reaction}

It grows well on lime bearing soils, or at least those which are basic in reaction, rather than neutral or acid (138). Rated suitable for alkaline soils (338).

\section{Soil Salinity}

Has high tolerance ( 11 to $16 \mathrm{mS} / \mathrm{cm})$ to salt $(125$, $340,252)$. A greenhouse trial of emergence in various saline solutions showed no statistically significant effects of salts up to $16 \mathrm{mS} / \mathrm{cm}$, although emergence was considerably lower in the $16 \mathrm{mS} / \mathrm{cm}$ (691). "Sawki" noted particularly for its salt tolerance (138). On alkaline sites it is more productive than crested wheatgrass (340). Provided 
good growth on prairie coal mine waste with high salt content (180).

\section{Drought}

Noted for its drought tolerance (138), although small seedlings are sensitive to frost and drought (340). Emergence in soils at field capacity, "moderately dry" and "dry" was statistically similar, though better in the field capacity soils; root weight and shoot length were greater after 21 days in the field capacity soils (691).

\section{Heavy Metals and Hydrocarbons}

No information available.

\section{Shade}

Recommended for unshaded sites; it is not shadetolerant (340).

\section{Grazing or Mowing}

Noted essentially as a pasture grass (506). Recovers rapidly after grazing when moisture is adequate; resumes growth much better after cutting than crested wheatgrass (Agropyron cristatum) or bromegrass (Bromus inermis) (252).

\section{Susceptibility to Disease and Insect Damage}

"Mayak" and "Swift" noted for their resistance to leafspot diseases. "Cabree" was rated better than

"Sawki" in resistance to powdery mildew and spot blotch, and better than "Mayak" in resistance to leaf rust. "Piper" has moderate resistance to leaf blight and anthracnose (138).

\section{RECLAMATION CONSIDERATIONS}

\section{Soil Building and Erosion Control Capability}

Russian wild ryegrass showed the most successful growth in sand dune stabilization experiment in Alberta amongst species tested (258). Suitable for cultivation, though not a strong natural invader of other disturbed sites.

\section{Adaptation to Disturbance}

The sod formed by Russian wild ryegrass is extremely tough and withstands considerable abuse from trampling and driving (252). Suitable for cultivation, though not a strong natural invader of other disturbed sites.

\section{Competitive Ability}

Russian wild ryegrass does not invade adjacent areas as does crested wheatgrass (252).

\section{Commercial Value}

Essentially a pasture grass, and it should not be seeded for hay (252). Established pastures of Russian wild ryegrass have demonstrated greater beef production than native ranges in Alberta (390). Also, one of the best grasses for farmyards and lawns that cannot be watered (252). Potential erosion control value.

\section{Palatability and Nutritive Value}

Russian wild ryegrass pasture is grazed by livestock in all seasons, but is best from August to November when its protein and digestible carbohydrate contents are higher than those of other cultivated or native grasses. Cures into a very palatable hay (although difficult to cut), or cures on the stem (138). Spring seeded Russian wild ryegrass provides excellent spring and early summer pasture (391). Highly preferred by both deer and livestock.

\section{Seed or Planting Stock Availability}

Licensed varieties in Canada include "Mayak, "Sawki", "Cabree", "Swift", and "Piper" (138). Seed supplies can be purchased from most seed houses in western Canada (506). "Vinall" and "Bozoiski" are available in the US (639). Approximately 175000 seeds/lb (639).

\section{Methods and Ease of Establishment}

The species is characterized in general by poor seedling vigor and therefore is often difficult to establish. If established under dry conditions, it may take 2 or 3 years to develop an adequate stand (391). "Cabree" variety, however, is noted for outstanding seedling vigor (138). Establishment potential by transplanting rated as good (338). Fall seeding at a rate of 8 to $10 \mathrm{lbs}$ PLS/ac has been recommended (639).

\section{Current Status for Reclamation}

Experience with Russian wild ryegrass for reclamation of disturbed lands is available from a wide range of sites throughout Alberta, particularly coal mine waste, although much information is from experimental work. It is regarded as a promising species for revegetation of mined lands in the foothills to reestablish ungulate ranges $(144,209)$. 
Russian wild ryegrass is noted as a slow starter, but has become quite well established on reclaimed coal mine waste in the foothills and in adjacent subalpine areas $(354,269,267)$. However in the Crowsnest Pass, Russian wild ryegrass was recorded to be relatively unsuccessful at $1950 \mathrm{~m}$ ASL, apparently due to poor germination and overwintering losses (377). Follow-up studies on coal mine overburden waste there indicated relatively low ground cover provided by all grasses tested, although $\underline{E}$. junceus had relatively high biomass production (380). Particularly good establishment is noted where coal mine spoil is topdressed with salvaged soil materials (209). Initial revegetation trials on oil sand tailings in Alberta resulted in mediocre growth relative to other species tested (257). Presently being used in species mix evaluations for revegetation of overburden and disturbed soils in the oil sands area (249). Revegetation trials on coal mine waste in the southern interior of British Columbia resulted in excellent growth of Russian wild ryegrass, except on carbonaceous materials. Good growth was noted on bentonitic clay and gritstone soils, relative to other species (187). Russian wild ryegrass provided very good first year growth on disturbed mineral soils (pipeline development) in Alaska (459), but very poor growth at similar sites in the Northwest Territories (196). In general, this grass proved unsuccessful in establishing growth over one or two years on both organic and mineral soils in these studies (196).

Russian wild ryegrass provides several adaptations useful for revegetation including salt tolerance, alkalinity tolerance, ability to stabilize sand, forage value and commercial availability of seed. It is particularly useful where moisture is deficient. 
Festuca arundinacea

\section{SPECIES SUITABILITY MAP AND SUMMARY TABLE}

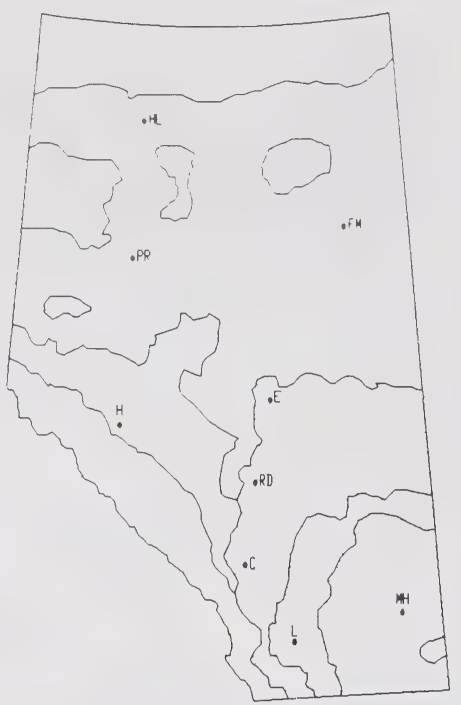

Recommended Area

Commercially Available: Yes $\underline{X}$ No

\begin{tabular}{|c|c|c|c|c|c|}
\hline \multirow{2}{*}{$\begin{array}{l}\text { RECLAMATION SUITABILITY } \\
\text { CRITERIA }\end{array}$} & \multicolumn{5}{|c|}{ SUITABILITY RATING. } \\
\hline & Very High & High & Medium & Low & None \\
\hline Drought Tolerance & & & $x$ & & \\
\hline Salt Tolerance & & $x$ & & & \\
\hline Acid & & 4.5 & & & \\
\hline Tolerance Base & & & $X$ & & \\
\hline Winter Hardiness & & & $x$ & & \\
\hline Erosion Control & & $x$ & & & \\
\hline Persistence & & $x$ & & & \\
\hline Palatability & & $x$ & $x$ & $x$ & \\
\hline Browse Tolerance & & $x$ & & & \\
\hline Moisture Preference & Moist. & & & & \\
\hline Soil Preference & Medium & 0 fine & tured, $\mathrm{p}$ & drair & \\
\hline
\end{tabular}


Festuca arundinacea (Schreb.)

\section{SPECIES BIOLOGY}

Taxonomy - Tall Fescue (138).

Also $\underline{F}$. elatior L. (214), E. elatior var. arundinacea (507).

\section{Origin and Range}

Introduced. Tall fescue was introduced into Canada from England in the early 1920's. It is a native of central Europe. It is widely cultivated and is well established especially in the northwestern States (507).

\section{Growth Habit}

Tall fescue is a tufted bunchgrass to $100 \mathrm{~cm}$ tall $(214,138)$. It produces an abundance of leafy growth $(130,391)$. Low-growing turf-type varieties have also been developed.

Nitrogen Fixing - None

\section{Longevity}

Long-lived, cool season (712) perennial (138). It may not be winter hardy in northern and western parts of Alberta (391).

\section{Self Propagation}

Spreads by seed (138) and rhizomes (400).

\section{Ecological Setting}

Tall fescue is adapted to humid and subhumid climates $(67,183)$. It has spread from fields to roadsides, yards, fallow fields, ditch banks and waste places. It is well adapted to the moist conditions of eastern Canada and the United States as well as to favorable sites in western North America $(433,138,507)$. Requires 40 to $50 \mathrm{~cm}$ of precipitation (639). Tall fescue showed decreasing plant cover over three growing seasons when seeded at $2100 \mathrm{~m} \mathrm{ASL}$ in southeastern B.C. (119).

\section{TOLERANCES}

\section{Soil Preferences}

"Kentucky 31 " is adapted to a wide range of soil types (138). Tall fescue prefers moist sites and dies out under only limited irrigation (375). Performance

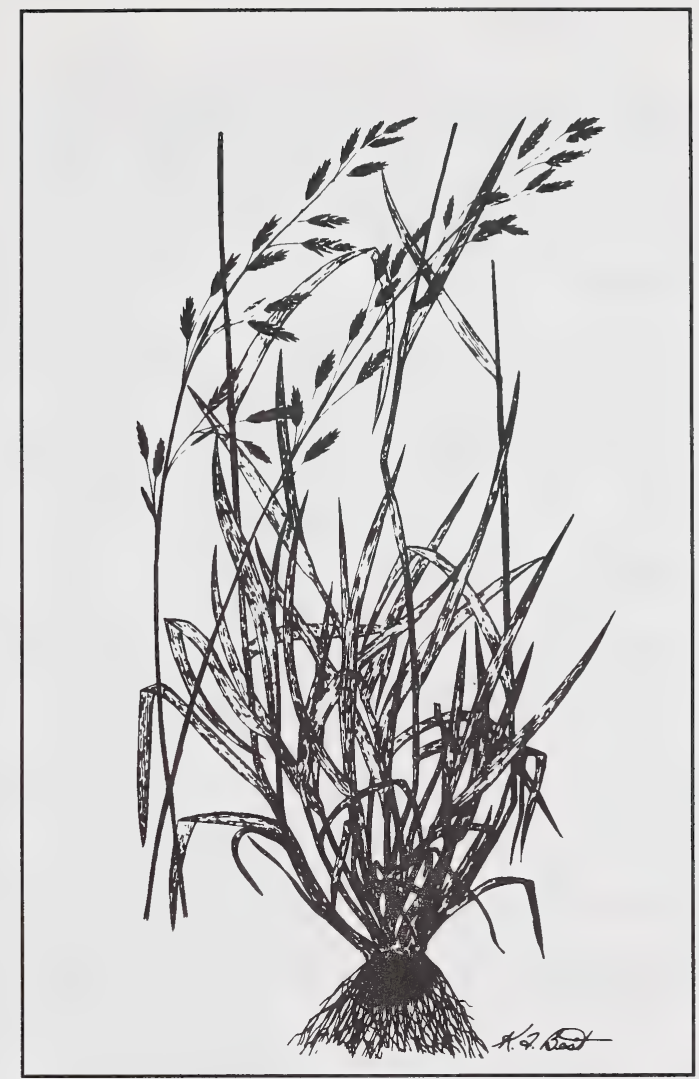

has been rated as poor on dry sites and fair on moist to wet sites (422). It does best on heavy soils (183), or moist medium to heavy textured soils (37).

\section{Nutrient Requirements}

Tall fescue grows best in moist, well fertilized soils. Adequate fertilization with $\mathrm{N}, \mathrm{P}, \mathrm{K}, \mathrm{Ca}$ and $\mathrm{Mg}$ is required for long-term maintenance and survival (37).

\section{Soil Reaction}

Tall fescue will grow on a wide range of soils from highly acidic to highly alkaline. Although the range of adaptation to $\mathrm{pH}$ has been given as 4.5 to 8.0 $(423,444,712)$, it probably has the widest soil reaction tolerance range of any commonly grown grass species (138). However, tall fescue had only satisfactory growth on mine spoil of $\mathrm{pH} 5.4$ and had poor growth or failed completely on more acid spoils. Tall fescue has been recommended for planting on alkaline and calcareous spoil $(\mathrm{pH}>7.3)$ and acidic spoil (pH 3.6 to 5.5) in Kentucky (346). 


\section{Soil Salinity}

Tall fescue has a fairly high tolerance of soil salinity. Upper tolerance limits of 8 to $12 \mathrm{mS} / \mathrm{cm}$ have been reported $(247,422)$. It has been recommended as a useful pasture grass on wet or seep lands because of its tolerance to saline soils (391).

\section{Drought}

"Alta" apparently remains green during dry summers in western Oregon. "Kentucky 31 " and "Arid" turftype varieties are tolerant of wide temperature extremes (138) and are among the more drought tolerant grasses in the eastern United States (37, 712).

\section{Heavy Metals and Hydrocarbons}

"Goens" is tolerant of boron, while "Alta" is only moderately tolerant of boron, at concentrations of $5 \mathrm{ppm}$ in spoil materials (344).

\section{Shade}

Presumably prefers open, sunny locations.

\section{Grazing or Mowing}

Turf-type tall fescues are tolerant of close mowing (138).

\section{Susceptibility to Disease and Insect Damage}

No information available.

\section{RECLAMATION CONSIDERATIONS}

\section{Soil Building and Erosion Control Capability}

Tall fescue is a deep-rooted grass (138), with extensive rhizomes (400). Tall fescue seeded on road backslopes in western Oregon was present only as scattered individuals after the first year (130). Tall fescue increased the amount of organic matter in a mine spoil; available soil moisture increased as well (227). "Kentucky 31 " tall fescue is regarded as excellent for erosion control (183). Tall fescue has a fair rate of spread (424). Tall fescue exhibited highest growth rates in spring and fall (375).

\section{Adaptation to Disturbance}

Tall fescue is often found in waste places and other disturbed areas in Alberta $(312,78)$.

\section{Competitive Ability}

Tall fescue is said to lack the ability to compete with other grasses on sites where it is poorly adapted (43). Otherwise, its sod-forming habit would indicate good competitive ability.

\section{Commercial Value}

Tall fescue is used principally for erosion control, hay and pasture (423). It also can be used to provide wildlife forage (422). Tall fescue produces excellent hay yields when grown with legumes and when properly fertilized and irrigated $(391,375)$. It also provides excellent waterway protection (391). It has been used extensively for mine reclamation, roadbanks, construction sites and roadside development (37).

\section{Palatability and Nutritive Value}

Under certain conditions, forage of tall fescue may be tough and unpalatable. However, it is as palatable as other grass species when properly managed and fertilized (138). Use of Festuca spp. has been reported to be medium for bighorn sheep and elk, high for mule deer and low for moose (144). When grown under irrigation, tall fescue is not as palatable to livestock as other grasses (391). The palatability of "Alta" has been rated as low (427). Palatability of tall fescue may be a problem in mixtures as other species may be preferred. It should be grazed closely for best animal acceptance and feeding value (183).

\section{Seed or Planting Stock Availability}

Varieties licensed for use in Canada include "Alta", "Kentucky 31", "Mustang" and "Arid". "Fawn" is available in the US (639). Approximately 565000 seeds/lb (639).

\section{Methods and Ease of Establishment}

Percent germination of seed stored in wooden sheds decreased from $93 \%$ in the year of collection to $4.5 \%$ after 19 years (211). Typical purity and germination are 96 and $86 \%$, respectively (376). In Kentucky, seeding of tall fescue was most successful in late winter or early spring (444). Ease of establishment has been rated as good (424). Seeding rates of 10 to $20 \mathrm{lbs}$ PLS/ac have been recommended for the eastern US (712); $8 \mathrm{lbs}$ PLS/ac in the spring for the western US (639). 


\section{Current Status for Reclamation}

Tall fescue did not prove winter hardy when planted at $2167 \mathrm{~m}$ in Alberta (377), however it had moderate performance on waste rock and overburden at six mines surveyed in the southern interior of B.C. (143). Tall fescue produced a groundcover of $88 \%$, after four growing seasons on uranium tailings near Elliot Lake, Ontario. This species did not yield as well as other species but its sod forming ability was a definite asset (318).

Tall fescue has proved successful for mine reclamation in the western United States, provided it is adequately fertilized (90). It has been used extensively for streambank stabilization (266). "Alta" tall fescue has been recommended for revegetation of critical sites in northwestern Colorado. It was recommended for moist sites at elevations greater than $2667 \mathrm{~m}$ ASL (427). Tall fescue establishes well but is not persistent in the subalpine in Colorado. It is more persistent under foot traffic than Phleum pratense and Agropyron trachycaulum (41). Transplants of tall fescue had poor first year survival on an alpine/subalpine site in Colorado (75). It is widely used in mine spoil reclamation in Kentucky where it was recommended for seeding on spoils with $\mathrm{pH}$ values greater than 4.5 (444).

Tall fescue is a long-lived bunchgrass that has a deep root system. It is adapted to a wide range of soil types but does best on heavy soils and requires moist conditions. It is adapted to a wide range of soil reaction classes from moderately acidic to moderately alkaline and is tolerant of soil salinity. Tall fescue can be as palatable as other grasses if proper management and fertilizer techniques are employed. 
Festuca ovina

SPECIES SUITABILITY MAP AND SUMMARY TABLE

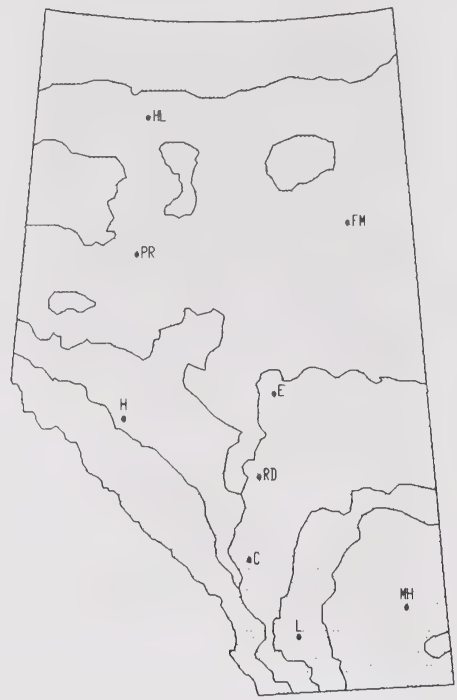

Recommended Area

Commercially Available: Yes $X$ No

\begin{tabular}{|c|c|c|c|c|c|}
\hline \multirow{2}{*}{$\begin{array}{l}\text { RECLAMATION SUITABILITY } \\
\text { CRITERIA }\end{array}$} & \multicolumn{5}{|c|}{ SUITABILITY RATING } \\
\hline & Very High & High & Medium & Low & None \\
\hline Drought Tolerance & & $x$ & $x$ & & \\
\hline Salt Tolerance & & & & $x$ & \\
\hline pH Acid & & & $x$ & & \\
\hline Tolerance Base & & & & $x$ & \\
\hline Winter Hardiness & $x$ & & & & \\
\hline Erosion Control & & $\mathrm{x}$ & & & \\
\hline Persistence & & $x$ & & & \\
\hline Palatability & & $x$ & $x$ & $x$ & \\
\hline Browse Tolerance & & $x$ & $x$ & & \\
\hline Moisture Preference & Dry to & oist. & & & \\
\hline Soil Preference & Sandy, & ravel1 & loamy, & Iraine & \\
\hline
\end{tabular}


Festuca ovina L.

\section{SPECIES BIOLOGY}

\section{Taxonomy}

Sheep Fescue (312); Hard Fescue (138).

Includes F. ovina var. saximontana (Rydb.) Gleason (312), $\mathbf{F}$. ovina var. duriuscula (L.) Koch, or F. longifolia Thuille.

\section{Origin and Range}

Regarded as a native by some authors (391). Some varieties introduced from Eurasia (312). Native from Alaska to Newfoundland, south to California, New Mexico and New York (507). This circumboreal species (214) is also found in South America (507). It is found as an escapee throughout the Canadian prairies $(78,312)$. Includes $F$. ovina var. duriuscula ( $F$. longifolia Thuill.) or hard fescue (138), which is also introduced (500).

\section{Growth Habit}

Sheep fescue is a densely tufted low-growing bunchgrass. It is slender and 15 to $60 \mathrm{~cm}$ high $(312,78)$. Hard fescue is a synthetic perennial turf variety. "Biljart" hard fescue is 15 to $70 \mathrm{~cm}$ tall (138). "Parar" hard fescue is a short, fine bunchgrass (232).

\section{Nitrogen Fixing}

Does not fix atmospheric nitrogen (331). Evidence of a rhizosheath has been observed in populations of sheep fescue on disturbed sites in Alberta. Such a rhizosheath may have the ability to fix atmospheric nitrogen and contribute to the success of this species in colonizing nutrient poor sites (P. Lulman, pers.comm.).

\section{Longevity}

Long-lived, cool season (639) perennial. Several plantings of "Durar" hard fescue in Colorado are over 20 years old (131). It has excellent winter hardiness (139).

\section{Self Propagation}

Sheep fescue reproduces from seed (312).

\section{Ecological Setting}

Sheep fescue is found from gravelly prairies to alpine slopes (507). Plants have been selected at

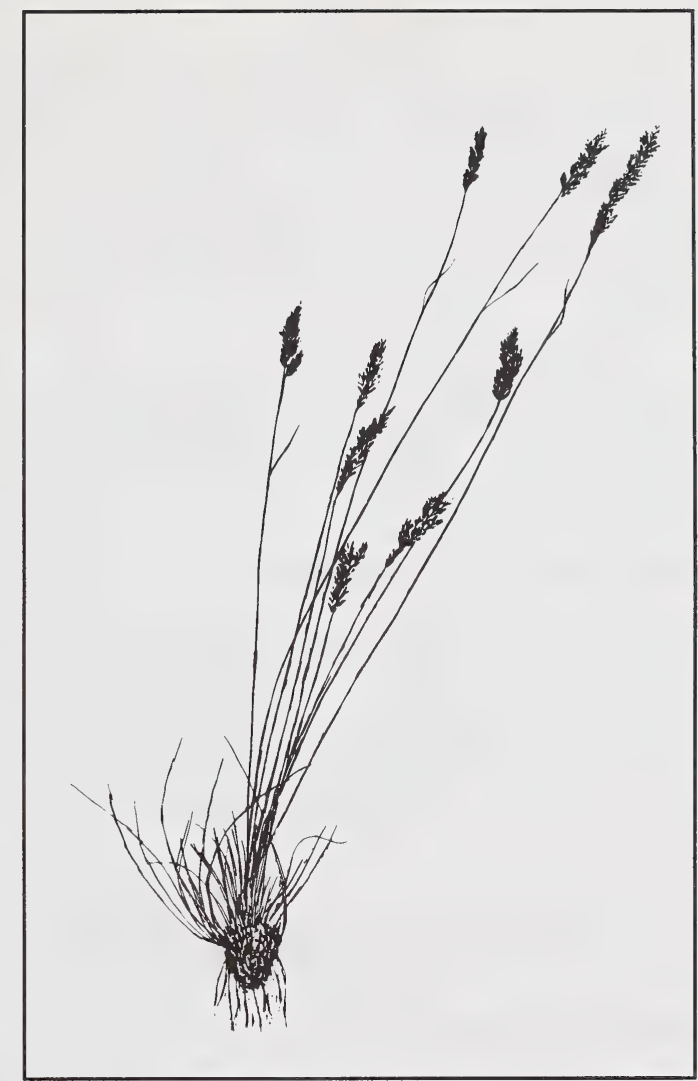

$3467 \mathrm{~m} \mathrm{ASL}$ in Montana (465). Sheep fescue is often found on rocky slopes above timberline (185). It has been reported at elevations between 1667 to $3267 \mathrm{~m}$ ASL on moist to dry sites in Carbon County, Wyoming (18). Requires 25 to $30 \mathrm{~cm}$ of precipitation (639).

\section{TOLERANCES}

\section{Soil Preferences}

Sheep fescue is better adapted than most grasses to sandy, gravelly soils. It is used as a turfgrass on sandy soils in the northern States of the US (183). "Durar" hard fescue is adapted to well drained soils (426). Sheep fescue is adapted to dry to moist habitats. Optimum slope is 9 to $30 \%$ and optimum soil depth is 30 to $60 \mathrm{~cm}$. Growth on sandy and loamy soil is good, while on clayey soil it is only fair (446).

\section{Nutrient Requirements}

Hard fescue has low fertility requirements (500). 


\section{Soil Reaction}

Sheep fescue is reported to grow on acid mine wastes in Britain (387).

\section{Soil Salinity}

"Durar" hard fescue has poor salt tolerance (424).

\section{Drought}

Hard fescue is adapted to fairly dry sites (41). Sheep fescue is drought tolerant but less so than hard fescue (183). Hard fescue is adapted to areas receiving approximately $36 \mathrm{~cm}$ or more mean annual precipitation (426).

\section{Heavy Metals and Hydrocarbons}

Herbage comprising principally of sheep fescue and sedges showed no toxicity symptoms when grown on soil with concentrations of $\mathrm{Pb}$ at $3680 \mathrm{ppm}, \mathrm{Zn}$ at $1330 \mathrm{ppm}$ and $\mathrm{Cu}$ at $48 \mathrm{ppm}$. However, concentrations of up to $74 \mathrm{ppm} \mathrm{Pb}, 230 \mathrm{ppm} \mathrm{Zn}$ and $31 \mathrm{ppm} \mathrm{Cu}$ were found in the herbage (11).

\section{Shade}

Hard fescue can tolerate shady areas (427). Sheep fescue is used for turf in shaded areas (391).

\section{Grazing or Mowing}

Hard fescue has good tolerance to grazing (339).

\section{Susceptibility to Disease and Insect Damage}

Hard fescue has good resistance to disease and insects (339).

\section{RECLAMATION CONSIDERATIONS}

\section{Soil Building and Erosion Control Capability}

"Durar" hard fescue has a moderate rate of spread (424). Sheep fescue produces excellent growth cover and root production is high (252). The species can generally be considered a good soil stabilizer.

\section{Adaptation to Disturbance}

The aggressiveness of hard fescue has been rated as weak. It is slow in becoming established (500). Its status as an "escapee" however, suggests that it may be a fair pioneer.

\section{Competitive Ability}

Hard fescue has very good compatibility with other plants (339), but its aggressiveness is poor (500).

\section{Commercial Value}

"Durar" hard fescue is used in Alaska for highway cutbank stabilization (298). It is also used for erosion control and soil improvement in the Pacific northwest (183), the intermountain region, the northern and central Rocky Mountains, and adapted sites in the northern Great Plains (426). Sheep fescue is used as turf grass on sandy soils and for erosion control in the northern US. It is also used for stabilization along canals and on road cuts and fills where moisture is adequate (183).

\section{Palatability and Nutritive Value}

Hard fescue has tougher leaves than sheep fescue (183), and is therefore sometimes rated as having low palatability (427). Palatability of spring growth is fairly good, however, decreasing to only fair by summer (339). While sheep fescue is apparently palatable and well grazed in spring, it is not widely used for pasture (183); this may be accounted for by its low stature and forage production (252). Utilization of all Fescue spp. is rated as high for mule deer, medium for bighorn sheep and elk, and low for moose (144). Forage value of sheep fescue has been rated as fair for mule deer, game birds and small mammals. Cover value for mule deer is poor, while it is fair for game birds and good for small mammals (446).

\section{Seed or Planting Stock Availability}

"Biljart" hard fescue is a variety licensed for use in Canada; other cultivars are not licensed (138). "Covar" is a newly released U.S. variety and "Scaldis" has been on the market in the U.S. for some time. Approximately 680000 seeds/lb (639).

\section{Methods and Ease of Establishment}

Ease of establishment of "Durar" hard fescue has been rated as good (424); seedling vigor has been rated as moderate to weak (41). Ease of transplanting of hard fescue is very good. Germination rate is very good and it is relatively easy to establish by planting (339). Fall/spring seeding at a rate of $10 \mathrm{lbs}$ PLS/ac has been recommended (639). 


\section{Current Status for Reclamation}

"Durar" hard fescue had excellent second year survival and was among the species which provided adequate third year cover on an alpine site in Alberta $(378,723)$. Hard fescue showed promise for reclamation use at Grande Cache, Alberta where it provided good cover without excessive top growth and persisted well $(268,269,271)$. It provided good cover for four years in the arctic tundra (Mackenzie River Delta) and then declined (644). Sheep fescue produced good first year ground cover (111) and has persisted well for 12 years (644) on a simulated pipeline right-of-way near Norman Wells, N.W.T. (latitude $66^{\circ} \mathrm{N}$ ). Good growth of sheep fescue on tailings sand has been reported in a growth chamber study (209). At Fort McMurray, sheep fescue produced very good fourth year cover on amended tailings sand (643).

Selection of sheep fescue is being carried out in Alaska for possible use in revegetation of dry sites (298). "Durar" hard fescue has also been recommended for revegetation use in Alaska (5) and for critical area planting in areas receiving at least $30 \mathrm{~cm}$ precipitation in the southern Rocky Mountains in Colorado (424). Hard fescue has been suggested as a species useful in certain situations in the subalpine in Colorado. This species did suffer considerable winterkill in the first two years when seeded at Climax (3 $767 \mathrm{~m} \mathrm{ASL}$ ) in Colorado (41). Subsequent reports however indicate that it was persistent at this site and was one of the best performing species on several subalpine sites in Colorado (236). "Durar" hard fescue has been recommended for revegetation of mountain sites above $1000 \mathrm{~m}$ ASL in California in situations which require a short, uniform and fine textured cover (232).

The advantage of sheep (and hard) fescue is its wide adaptability over a range of habitats from prairies to alpine slopes. It does well on dry to moist sandy or gravelly soils; its nutrient requirements are low and it has excellent winter hardiness. Sheep fescue is tolerant of acid soils and high levels of certain heavy metals. It has potential use for erosion control and revegetation across Alberta. 
Festuca rubra

\section{SPECIES SUITABILITY MAP AND SUMMARY TABLE}

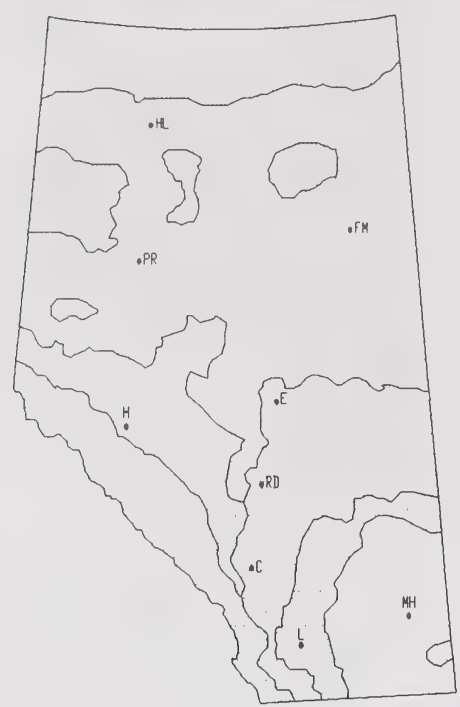

Recommended Area

Commercially Available: Yes $X$ No

\begin{tabular}{|c|c|c|c|c|c|}
\hline \multirow{2}{*}{$\begin{array}{l}\text { RECLAMATION SUITABILITY } \\
\text { CRITERIA }\end{array}$} & \multicolumn{5}{|c|}{ SUITABILITY RATING } \\
\hline & Very High & High & Medium & Low & None \\
\hline Drought Tolerance & & $\mathrm{x}$ & $\mathrm{X}$ & & \\
\hline Salt Tolerance & & $x$ & $x$ & & \\
\hline Acid. & & $4-5$ & & & \\
\hline Tolerance Base & & & $\mathrm{X}$ & & \\
\hline Winter Hardiness & $x$ & $\mathrm{x}$ & & & \\
\hline Erosion Control & & $x$ & & & \\
\hline Persistence & & $x$ & & & \\
\hline Palatability & $x$ & & & & \\
\hline Browse Tolerance & & $x$ & & & \\
\hline Moisture Preference & Moist. & & & & \\
\hline Soil Preference & Wide & tural & & & \\
\hline
\end{tabular}


Festuca rubra L.

\section{SPECIES BIOLOGY}

Taxonomy - Red Fescue

\section{Origin and Range}

Red fescue is a widely distributed grass of the northern temperate zone. About one hundred species of fescue occur in temperate and cool climate zones (633). Forms of this species are native to North America, North Africa, Eurasia and Iceland (507), Alaska to Newfoundland, south to southern California, New Mexico, Texas and South Carolina (507). An extremely variable species (214). Variety arenaria (Osbeck) Fries has been reported at Lake Athabasca, northern Alberta. The species is regarded both as a native species in Alberta and as an escapee from cultivation (312).

\section{Growth Habit}

Red fescue is a loosely tufted, sod-forming grass with matted rootstocks. Decumbent with short rhizomes $(312,507)$. Three distinct forms of red fescue are distinguishable by their creeping habits. Creeping red fescue (Festuca rubra var. rubra) spreads by strong underground stems. The chewings fescue type (Festuca rubra var. commutata) is tufted and does not spread. The foliage is finer and the seed culms are shorter than creeping red fescue. The third type is intermediate between chewings and creeping red fescue, and forms short rhizomes (138).

\section{Nitrogen Fixing}

Evidence of a rhizosheath has been observed in populations of red fescue on disturbed sites in Alberta. Such a rhizosheath may have the ability to fix atmospheric nitrogen and contribute to the success of this species in colonizing nutrient-poor sites (P. Lulman, pers.comm.).

\section{Longevity}

Cool season (639) perennial (312). Apparently its susceptibility to disease reduces its longevity (435). It is unaffected by frost (137).

\section{Self Propagation}

Seed. Some varieties spread by rhizomes (138).

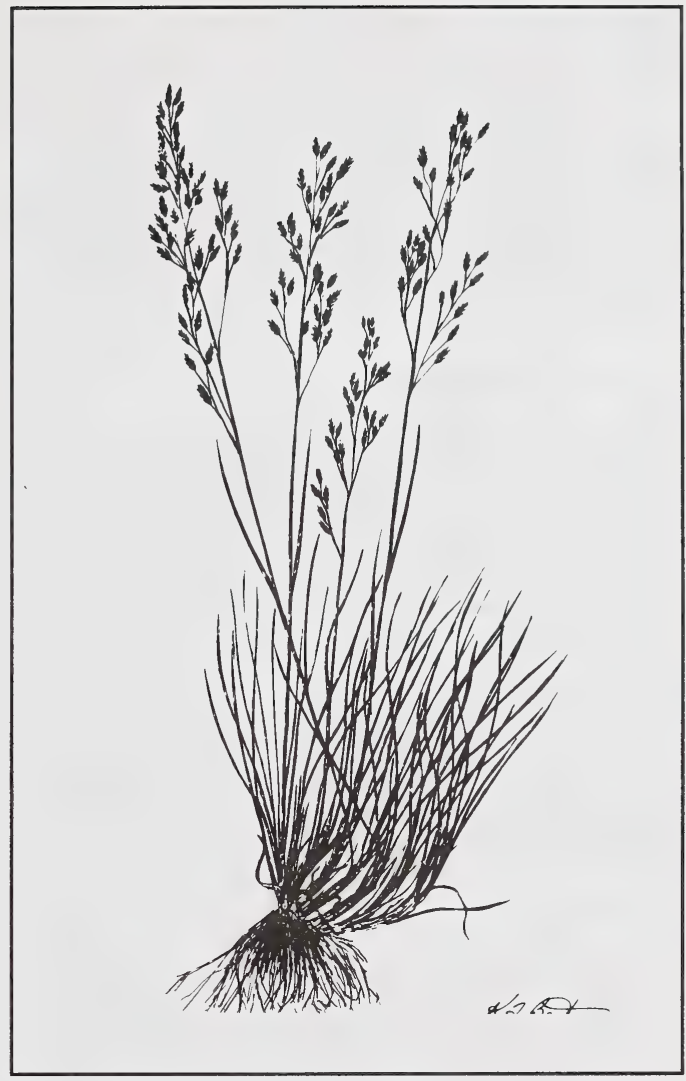

Seed is produced abundantly where there is ample moisture and nutrients (137).

\section{Ecological Setting}

Red fescue is found from coastal marshes and sand dunes to montane forests and meadows (507). It is found along shores and in lake meadows in Alberta (312). It is used extensively for forage and lawn turf throughout Canada (138). Red fescue thrives in cool, moist conditions and does best in areas where it receives ample moisture; $45 \mathrm{~cm}$ minimum (639). It starts to grow early in the spring, grows slowly in midsummer and then grows vigorously until freezeup. It is a dominant component of tidelands in Alaska (4). Red fescue is an important introduced ground cover species in boreal and mixed wood forests, the Peace River parkland, on some sites in the central parkland, and in the fescue grassland regions in Alberta (435). 


\section{TOLERANCES}

\section{Soil Preferences}

Red fescue is adapted to a wide range of soil types including Chernozemic and Luvisolic soil zones of the western provinces. It needs less moisture than timothy (Phleum pratense). It is not suitable on drier Chernozemic soils except under cultivation (137).

\section{Nutrient Requirements}

Red fescue grows well on both fertile and poor soils. It grows better on poor soils than Kentucky bluegrass (Poa pratensis) or timothy. Nitrogen fertilizers increase the productive period of the stand and increase the seed yield. Good response to additional phosphorus has also been recorded in central Alberta (137).

\section{Soil Reaction}

Red fescue is tolerant of soil $\mathrm{pH}$ in the range of 4.5 (37). It is also reported to grow on calcareous material (387).

\section{Soil Salinity}

"Arctared" red fescue was successfully established on tailings with electrical conductivities of 20 to $24 \mathrm{mS} / \mathrm{cm}$. This was attributed to favorable early season precipitation (163). Elsewhere, red fescue was not affected by soil salinity of $5 \mathrm{mS} / \mathrm{cm}$, but plants appeared to lack vigor at soil salinity levels of $9 \mathrm{mS} / \mathrm{cm}$ and $19 \mathrm{mS} / \mathrm{cm}$ (404).

\section{Drought}

Red fescue is less drought resistant than crested wheatgrass (Agropyron cristatum), and it requires irrigation when grown in drier areas of Alberta (137). It is a component of a seed mix developed for droughty soils in Wisconsin. This mix gave good ground cover on a silty sand subsoil (77).

\section{Heavy Metals and Hydrocarbons}

Growth of red fescue was stimulated by the application of residue of Kuwait crude oil. Possible reasons given were release of nutrients from the oil, from oil-killed vegetation, or an hormonal effect (26). Red fescue has been rated as having a medium tolerance to oil (282). Populations of red fescue are tolerant of heavy metals in calcareous lead/zinc wastes in Wales (386). "Boreal" performed well in a grass/legume mix on an ash lagoon west of Edmonton (696).

\section{Shade}

Red fescue is tolerant of shade (37). It does well as a bottom grass in pasture mixtures (137).

\section{Grazing or Mowing}

The dense turf of red fescue tends to bunchiness if not closely clipped. Regular mowing at a height of 4 to $5 \mathrm{~cm}$ will maintain a good turf which will control weeds. Cutting closer than about $4 \mathrm{~cm}$ will reduce stand vigor (137). Presumably also tolerates close grazing similarly.

\section{Susceptibility to Disease and Insect Damage}

Some varieties show susceptibility to red thread, powdery mildew, rust and leaf spot diseases; others such as "Olds" are not subject to disease in Alberta (138).

\section{RECLAMATION CONSIDERATIONS}

\section{Soil Building and Erosion Control Capability}

Red fescue is a deep rooting species (138). It has an extensive, fibrous root system and a creeping habit. It is regarded as a valuable species for soilbuilding (137). Produces a stable, crumb-structured soil (633). In four years red fescue developed a thick sod and a ground cover of $95 \%$ on pyritic uranium tailings near Elliot Lake, Ontario (318).

\section{Adaptation to Disturbance}

The dense turf of red fescue can withstand heavy trampling (137). Presumed to be a moderately good colonizer.

\section{Competitive Ability}

Red fescue effectively outcompeted alfalfa and the alfalfa was effectively eliminated by the third growing season (24). It is not as aggressive as the strongly creeping grasses such as bromegrass (Bromus inermis) (137).

\section{Commercial Value}

Red fescue is used in mixtures for dryland and irrigated pastures and for erosion control on irrigation ditches and permanent waterways in cultivated fields. It is also used for seeding along seismic lines, pipelines, and highway and railway rights-of-way. It is also used extensively for home lawns, playgrounds, cemeteries, parks and industrial areas over most of Canada (633). Red fescue is 
grown for seed in the Peace River area and the Olds-Innisfail region of Alberta. It is not a good hay crop as it is too short and is hard to cut (137). Red fescue is regarded as one of the best pasture grasses in the foothills and can provide grazing until the snow is deep (391).

\section{Palatability and Nutritive Value}

Red fescue is extremely palatable throughout the growing season. It maintains its green color and above average protein content into autumn (138). Red fescue provides succulent winter pasture without injury to stand. It also provides early spring grazing and, if not severely overgrazed during the summer, it will produce succulent fall pasture (137). Use of Festuca spp. has been rated as medium for bighorn sheep and elk, high for mule deer and low for moose. Seeds of red fescue are favored by meadow voles (111). Palatable to cattle and horses (633).

\section{Seed or Planting Stock Availability}

Varieties of red fescue which are licensed for use in Canada are: "Arctared", "Boreal", "Dawson", "Duraturf", "Duralawn", "Highlight", "Jamestown", "Koket", "Pennlawn" and "Reptans" (138). Approximately 615000 seeds/lb (639).

\section{Methods and Ease of Establishment}

Red fescue has aggressive seedling growth and fast sod development (49). Seedling vigor has been rated as fair to good (41). Fall/spring seeding at a rate of $10 \mathrm{lbs} \mathrm{PLS} / \mathrm{ac}$ has been recommended (639).

\section{Current Status for Reclamation}

Red fescue is widely used in mine reclamation (633). "Boreal" red fescue consistently performed well after five to six years of testing in subalpine and alpine sites along the eastern slopes region of Alberta $(378,705,722,732,740)$. The native variety and "Boreal" performed equally well after five years in the alpine at Tent Mountain. "Arctared" and "Erica" chewings fescue also had excellent second and third year survival at Tent Mountain $(378,723)$. "Arctared" red fescue maintained a cover of 90 to $95 \%$ in the arctic tundra (Mackenzie River Delta) after twelve years while "Boreal" died out after four years (644). "Boreal" was the dominant grass after four years along the Norman Wells to Zama pipeline (644). At Fort McMurray "Boreal" produced the best cover after five years of testing. It has persisted in a mix for 17 years on amended tailings sand and overburden with minimal fertilization (641).
"Boreal" was the best grass in mixed seedings after five years at Cold Lake (685) and Swan Hills (646). In the Peace River Coal Block, growth of red fescue was good above treeline and excellent below treeline. At seven metal mines in southern B.C., initial performance of red fescue was good on waste rock overburden, and excellent on tailings (143). Red fescue performed well on various disturbed sites above $1650 \mathrm{~m} \mathrm{ASL}$ in southeastern B.C. It was also successful on test plots established at 2 200 m ASL (494).

"Boreal", "Arctared" and "Olds" have been recommended for revegetation use in Alaska (5). Research is presently ongoing in Alaska to derive a red fescue superior to "Arctared" for winter hardiness and snowmold resistance for use in grazing, turf and revegetation (298). Red fescue has shown promise on upper subalpine sites in Colorado, particularly sites that have long periods of snow cover $(41,236)$. Red fescue is used for disturbed land revegetation in the eastern US (37). Red fescue has been recommended as a species suitable for use in sand dune stabilization

(482). It has shown promise as a grass that suppresses undesirable weedy growth on replanted forest clearcuts (633).

Red fescue is a variable species adapted to a wide range of soil conditions and climatic regimes. It has a low maintenance requirement. Although it is drought tolerant, it does best on cool, moist sites. It is quite tolerant of saline soils. This species is used extensively for erosion control and as a turf grass because of its low creeping growth habit and its aggressive sod-forming properties. Several varieties have excellent winter hardiness and show promise for revegetation of disturbed sites to the alpine in Alberta. 
Hierochloe alpina

\section{SPECIES SUITABILITY MAP AND SUMMARY TABLE}

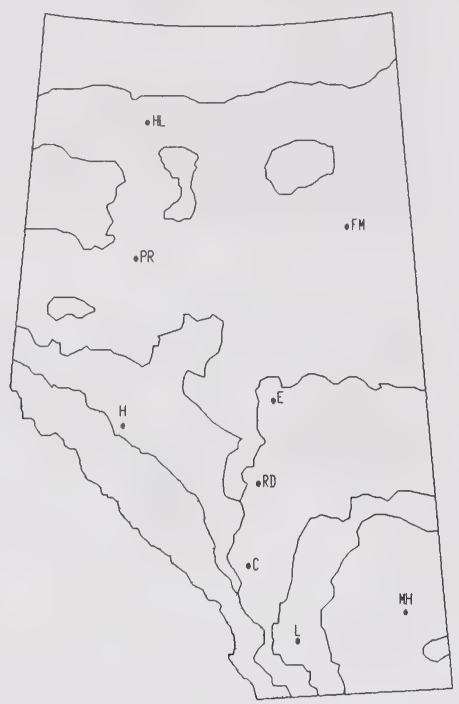

Recommended Area

Commercially Available: Yes No

\begin{tabular}{|c|c|c|c|c|c|}
\hline \multirow{2}{*}{$\begin{array}{l}\text { RECLAMATION SUITABILITY } \\
\text { CRITERIA }\end{array}$} & \multicolumn{5}{|c|}{ SUITABILITY RATING } \\
\hline & Very High & High & Medium & Low & None \\
\hline Drought Tolerance & & & $x$ & $x$ & \\
\hline Salt Tolerance & & & $x$ & & \\
\hline Acid & & & & $x$ & \\
\hline Tolerance Base & & & & $\mathrm{X}$ & \\
\hline Winter Hardiness & $x$ & & & & \\
\hline Erosion Control & & $x$ & & & \\
\hline Persistence & & & $x$ & & \\
\hline Palatability & & & & $\mathrm{x}$ & \\
\hline Browse Tolerance & & & $x$ & & \\
\hline Moisture Preference & Dry to & 1oist. & & & \\
\hline Soil Preference & Sandy & stony. & & & \\
\hline
\end{tabular}


Hierochloe alpina (Sw.) R. \& S.

\section{SPECIES BIOLOGY}

Taxonomy - Sweetgrass; Vanillagrass (199)

\section{Origin and Range}

Native, with circumboreal distribution; extending south from Alaska along the Rocky Mountains (66).

\section{Growth Habit}

Sod-forming grass 10 to $40 \mathrm{~cm}$ tall (241). The foliage is sparse, mainly basal, and not particularly dense (241).

\section{Nitrogen Fixing - None}

\section{Longevity}

Perennial (405). Tendency for sod binding to occur in older stands (66).

\section{Self Propagation}

Seeds. Seed sets described as generous (66). Nursery observations indicate seed is of good size and germinates freely (66). Spreads very rapidly by rhizomes (241).

\section{Ecological Setting}

Alpine meadows and heaths, and rocky slopes to at least $1800 \mathrm{~m}$ (214). Also noted as an early colonizer of dry, sandy, and stony burned areas in the Northwest Territories (209).

\section{TOLERANCES}

\section{Soil Preferences}

Growth on dry, sandy soils noted (209).

\section{Nutrient Requirements}

Found on low nutrient sites. Responds to nitrogen fertilization.

\section{Soil Reaction}

Observed to favor slightly acidic to neutral soils.

\section{Soil Salinity}

Will not tolerate excessively saline sites.

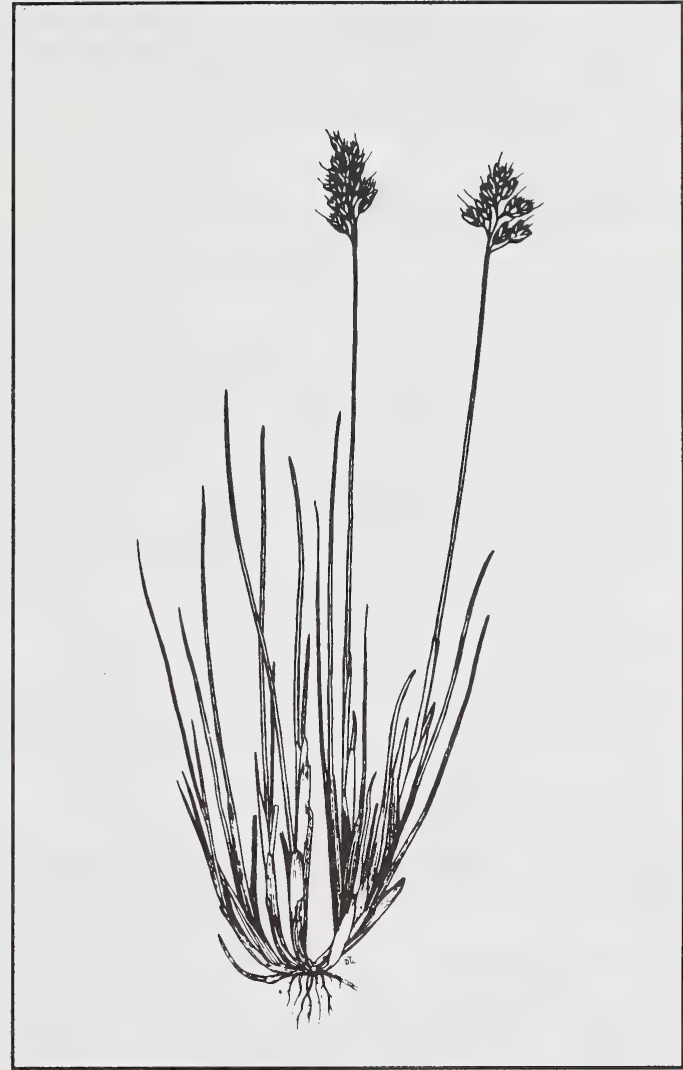

\section{Drought}

Will tolerate short periods of drought.

Heavy Metals and Hydrocarbons

No data on tolerances available.

\section{Shade}

As an alpine grass, $\underline{H}$. alpina is judged to be at least somewhat shade intolerant.

\section{Grazing and Mowing}

Hierochloe spp. are not very palatable to native ungulates and horses, and therefore have a moderate chance of surviving even in areas where grazing pressure is quite high (66).

\section{Susceptibility to Disease and Insect Damage}

The aroma and bitter taste of Hierochloe spp., attributable to the chemical coumarin, enhances the 
use of sweetgrasses for bedding material and basketry because it reduces pests in bedding and damage by insects (66). No information regarding disease was located from the literature.

\section{RECLAMATION CONSIDERATIONS}

\section{Soil Building and Erosion Control Capability}

A related species, $\underline{H}$. odorata (the prairie representative of Hierochloe), is regarded as an excellent grass to help control water erosion (9). This capability is attributed to shallow, but numerous, roots (9). Nursery growth of $\underline{H}$. alpina is characterized by "fairly tight" sod (66). Soil binding and erosion control capability are therefore thought to be good.

\section{Adaptation to Disturbance}

Will invade disturbed sites in adapted areas. Noted to invade burns in the Northwest Territories (209).

\section{Competitive Ability}

Heavy sod production promotes competitive advantage.

\section{Commercial Value}

A related species, $\underline{H}$. odorata, has been used for fine basketry, in ticking (bedding material) and in perfumery (66). Erosion control value as well.

\section{Palatability and Nutritive Value}

Field observation indicate that large areas of Hierochloe were pawed and churned up by moose and that the rhizomes were eaten (66). The species appears to be grazed less than most range grasses.

\section{Seed or Planting Stock Availability}

Not currently available commercially. Undergoing testing (66).

\section{Methods and Ease of Establishment}

Clones of $\underline{H}$. alpina gathered in the field have been successfully transplanted to nurseries; seed obtained from nursery stock has produced good stands on disturbed alpine land (66).

\section{Current Status for Reclamation}

This sweetgrass would seem to be suitable for introduction to cultivation (66). Seed of $\underline{H}$. alpina, produced on small nursery plots at the University of British Columbia, has given good stands on disturbed alpine lands in the B.C. interior low snowfall zone (66). The bitterness of Hierchloe spp. may make them useful for roadside seedings and in other areas where grass, but not grazing by ungulates, is desired (unpalatable erosion control grasses) (66). 
Hordeum jubatum

SPECIES SUITABILITY MAP AND SUMMARY TABLE

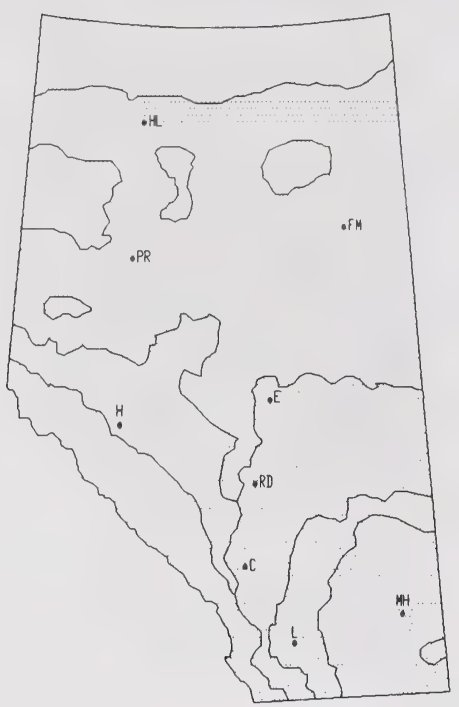

Recommended Area

Commercially Available: Yes

No

\begin{tabular}{|c|c|c|c|c|c|}
\hline \multirow{2}{*}{$\begin{array}{l}\text { RECLAMATION SUITABILITY } \\
\text { CRITERIA }\end{array}$} & \multicolumn{5}{|c|}{ SUITABILITY RATING } \\
\hline & Very High & High & Medium & Low & None \\
\hline Drought Tolerance & & & $x$ & & \\
\hline Salt Tolerance & $x$ & & & & \\
\hline Acid & & & & & $x$ \\
\hline Tolerance Base & & & $x$ & & \\
\hline Winter Hardiness & & $x$ & & & \\
\hline Erosion Control & & $x$ & & & \\
\hline Persistence & & $x$ & & & \\
\hline Palatability & & & $x$ & $x$ & \\
\hline Browse Tolerance & & & $x$ & & \\
\hline Moisture Preference & Dry to & vet. & & & \\
\hline Soil Preference & Loamy & clayes & & & \\
\hline
\end{tabular}


Hordeum jubatum L.

\section{SPECIES BIOLOGY}

\section{Taxonomy - Foxtail Barley}

\section{Origin and Range}

Native. Alaska east to Newfoundland. Northern United States and south in the mountains to Mexico $(214,9)$. Variety caespitosum (Schribn.) Hitchc. (bobtail barley) is common on saline flats and around sloughs on the prairies (312). Hybrids occur with $\underline{H}$. breviaristatum and Agropyron pauciflorum (214).

\section{Growth Habit}

Erect, tufted bunchgrass, 30 to $100 \mathrm{~cm}$ tall, erect or decumbent at base (312).

\section{Nitrogen Fixing - None}

\section{Longevity}

Perennial (312), annual or biennial (214).

\section{Self Propagation}

Foxtail barley is a prolific seed producer; the seeds are readily spread by wind (9).

\section{Ecological Setting}

Commonly found in low meadows, fields and in waste areas. It is the dominant species on moist and saline flats throughout the prairies $(312,78)$. In Alaska, it is found on river banks and sandy soil, and along roads as a weed (214). Commonly found on lowland communities with restricted soil drainage $(450,254)$.

\section{TOLERANCES}

\section{Soil Preferences}

Foxtail barley is adapted to a wide range of moisture regimes from dry to wet. The optimum soil depth has been reported as 30 to $60 \mathrm{~cm}$ and the optimum slope is 0 to $8 \%$. Growth on loamy and clayey soil is reported to be good, while growth on sandy soil is fair (447).

\section{Nutrient Requirements}

Nutrient requirements of foxtail barley are moderate.

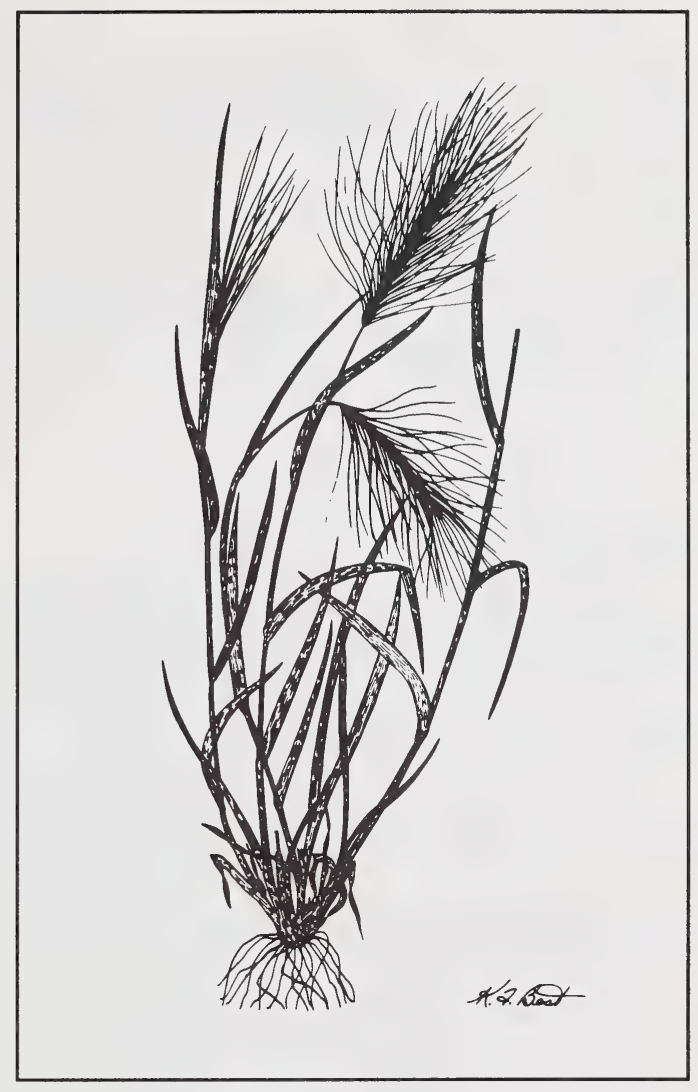

Seedlings established on acid mine tailings had better survival and growth when fertilized (246).

\section{Soil Reaction}

Prefers basic soils. Will not tolerate acidic soils (246). Commonly found on somewhat alkaline sites (4).

\section{Soil Salinity}

Foxtail barley is commonly found on soils that are slightly saline (4). It was successfully established on saline mine tailings with conductivities in the order of 20 to $24 \mathrm{mS} / \mathrm{cm}$ (163). Foxtail barley has been reported as a pioneer on saline mine spoils that are highly sodic in some areas (316). It is an important component of the prairie cordgrass community characteristic of strongly saline soils. The electrical conductivities in those locations range from 17 to $23 \mathrm{~ms} / \mathrm{cm}$ (469). 


\section{Drought}

Although this species is generally found on moist sites, it can withstand physiologically droughty conditions.

\section{Heavy Metals and Hydrocarbons}

Foxtail barley had limited growth on tailings high in $\mathrm{Cu}(1710 \mathrm{ppm})$ and $\mathrm{Zn}(178 \mathrm{ppm})$ and subject to high temperatures reported at $30^{\circ} \mathrm{C}(246)$.

\section{Shade}

Prefers bright sunny sites.

\section{Grazing or Mowing}

Invades overgrazed ranges due to the unpalatability of the seeds (78). Expected to be tolerant of mowing as it thrives on roadsides which are mown.

\section{Susceptibility to Disease and Insect Damage}

No specific pests or diseases were noted from the literature reviewed.

\section{RECLAMATION CONSIDERATIONS}

\section{Soil Building and Erosion Control Capability}

Extensive root systems and aggressive habit make this species good for erosion control and soil building.

\section{Adaptation to Disturbance}

Plants can become established on freshly seeded pastures and hayland, and cause the pasture or hay to become unpalatable (9). Foxtail barley is a pioneer on disturbed sites in the Yukon, especially where the soils are basic (246). It has been reported as a pioneer on disturbed sites near Norman Wells, N.W.T. $(45,110)$. Foxtail barley is also found as a pioneer on mine tailings in B.C. (384). Wild barley has been noted to vigorously invade fertilized pasture, or fertilized ground prepared for planting (455).

\section{Competitive Ability}

Very aggressive on adapted sites.

\section{Commercial Value}

Regarded as a weed species (312). Value for erosion control.

\section{Palatability and Nutritive Value}

Produces low quality hay because of the unpalatable seeds. The long awns often cause mouth, eye or skin irritation to grazing animals ( 78 , 9). Foxtail barley is apparently palatable before flowering (78). Forage value is reported to be good for mule deer and small mammals, and fair for game birds. Cover value is fair for game birds, and good for small mammals (447).

\section{Seed or Planting Stock Availability}

Not currently available commercially, but a prolific seed producer in native stands.

\section{Methods and Ease of Establishment}

Considered a weed, so seed production may be hindered by the Noxious Weed Act. Seeding is expected to provide the best results. The long awns may clog machinery. Establishment requirements are rated as low (447).

\section{Current Status for Reclamation}

Wild barley is found throughout Alberta on a wide range of moisture regimes. It is an aggressive pioneer on disturbed sites. This species is tolerant of saline and sodic soils and certain heavy metals. It has potential for revegetation of saline mine spoils where forage value is of secondary importance. Foxtail barley has been recommended as a species suitable for rehabilitation of wildlife habitat on disturbed lands in Montana and Wyoming (447). 
Koeleria macrantha

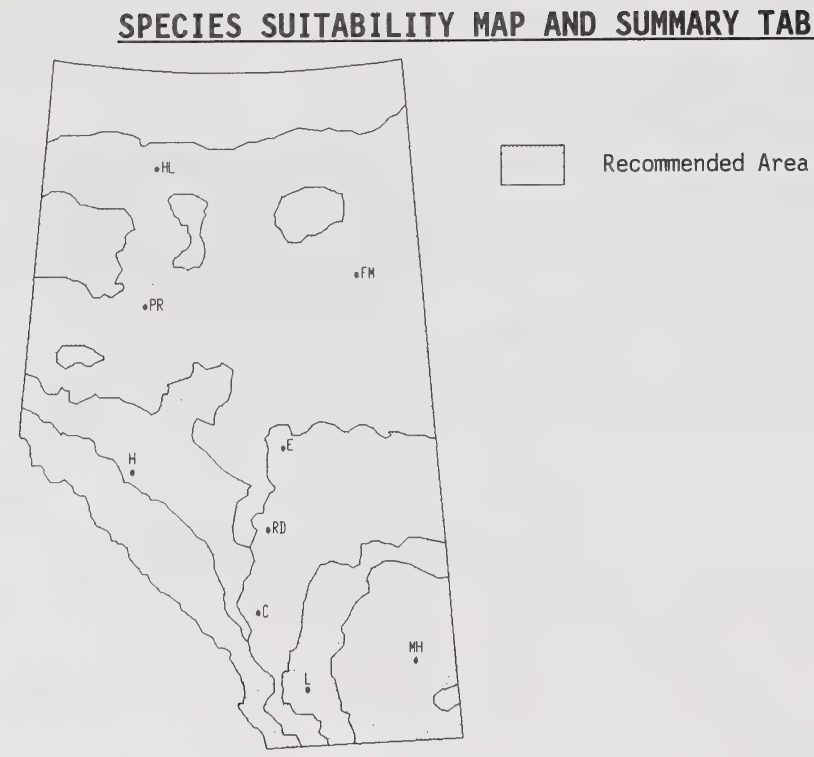

Commercially Available: Yes $X$ No

\begin{tabular}{|c|c|c|c|c|c|}
\hline \multirow{2}{*}{$\begin{array}{l}\text { RECLAMATION SUITABILITY } \\
\text { CRITERIA }\end{array}$} & \multicolumn{5}{|c|}{ SUITABILITY RATING } \\
\hline & Very High & High & Medium & Low & None \\
\hline Drought Tolerance & & $x$ & $x$ & & \\
\hline Salt Tolerance & & & & $x$ & \\
\hline Acid... & & & & $x$ & \\
\hline Tolerance Base & & & $x$ & & \\
\hline Winter Hardiness & & $x$ & & & \\
\hline Erosion Control & & & $x$ & & \\
\hline Persistence & & $x$ & & & \\
\hline Palatability & & $x$ & & & \\
\hline Browse Tolerance & & & $x$ & & \\
\hline Moisture Preference & Dry tc & oist & & & \\
\hline Soil Preference & Wide & & & & \\
\hline
\end{tabular}


Koeleria macrantha (L.) J.A. Schultes $f$.

\section{SPECIES BIOLOGY}

Taxonomy - June Grass

K. cristata (L.) Pers., ‥ nitida Nutt

\section{Origin and Range}

Native. A common species of the prairie throughout Canada and the northern US states. South in the mountains to California. June grass is circumboreal in distribution $(312,78,214)$.

\section{Growth Habit}

A low tufted bunch grass with a spike-like head 3 to $15 \mathrm{~cm}$ long (78). Culms are usually 20 to $50 \mathrm{~cm}$ tall (312).

\section{Nitrogen Fixing - None}

Longevity - A long-lived perennial.

\section{Self Propagation}

June grass flowers early in the summer (78), when it is 2 or 3 years old (467). It propagates itself by seed.

\section{Ecological Setting}

It is an important component of the Festuca Association of the aspen parkland and the Agropyron-Stipa Association found in south-eastern Alberta, the Peace River prairie and is found on dry open slopes of the foothills and mountains (455). A very common species of the Canadian prairie particularly in southern areas. Found mainly in dry areas, it has a more slender form in the foothills (78). It is a characteristic species of the grassy subalpine openings found on west- to southeastfacing slopes in Alberta (144). It is a common component of Agropyron-Poa communities of southern B.C. rangelands (114).

\section{TOLERANCES}

\section{Soil Preferences}

June grass is a characteristic species of the excessively drained high prairie and the sandhills tallgrass prairie $(469,170)$. June grass is found on Chernozems, and often also on some Brunisols and Regosols, especially in steep terrain.

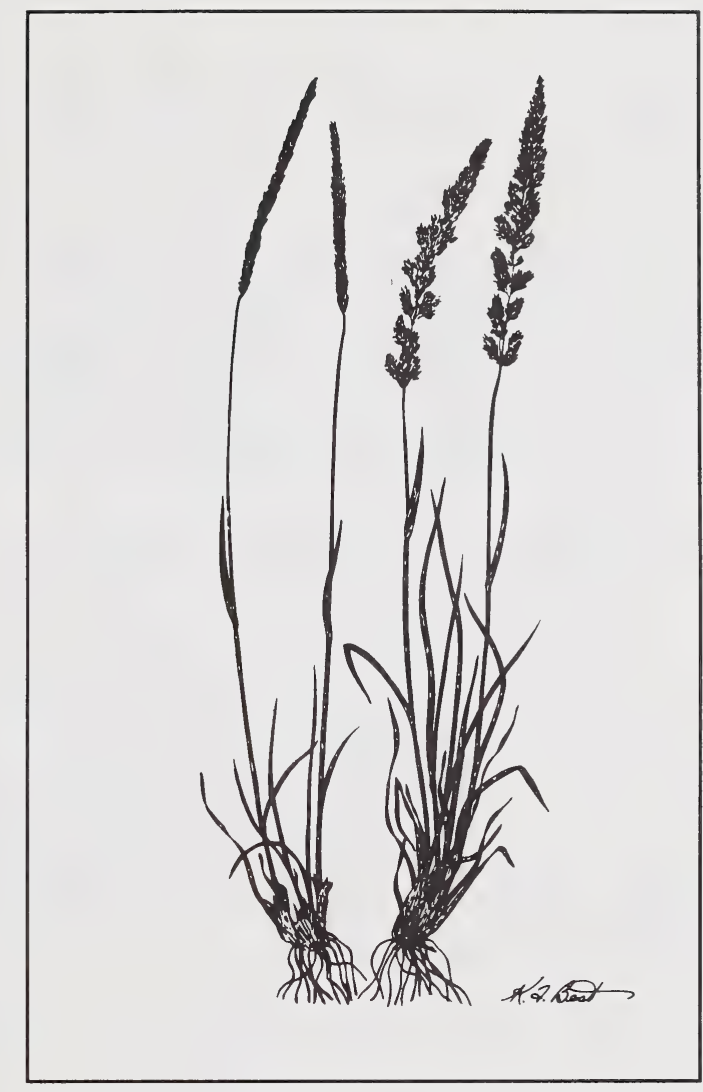

\section{Nutrient Requirements}

Responds to fertilizer applications, particularly $\mathrm{N}$, but will grow on low fertility sites as well.

\section{Soil Reaction}

Does best on near neutral soils. May also perform satisfactorily in proximity to alkaline areas (427).

\section{Soil Salinity}

Saline tolerance is not known, but is thought to be no more than slight.

\section{Drought}

Moderately drought tolerant (427).

\section{Heavy Metals and Hydrocarbons}

No specific tolerances noted. 
Shade

Grows best on open sites but will tolerate some shade.

\section{Grazing or Mowing}

June grass increased in cover on sites protected from grazing, especially those sites that had advanced from poor to fair condition. It decreased, however, on sites which reached excellent condition. It is one of the first species to respond to early range protection measures (287). This good recovery rate suggests moderate tolerance to grazing.

\section{Susceptibility to Disease and Insect Damage}

No specific pests noted.

\section{RECLAMATION CONSIDERATIONS}

\section{Soil Building and Erosion Control Capability}

The fibrous roots are good for soil building and erosion control.

\section{Adaptation to Disturbance}

Has been observed invading disturbed sites.

\section{Competitive Ability}

Moderately aggressive in pioneering stands.

\section{Commercial Value}

June grass is a valuable forage crop in the prairies (78) and mountains. It also has erosion control value.

\section{Palatability and Nutritive Value}

It is highly palatable on Colorado rangelands (427). The species is fairly highly palatable for livestock on southern B.C. rangelands (160). June grass has twice as much crude protein in its leaves as in its culms in the cured state (114). High utilization by bighorn sheep, medium utilization by elk and low utilization by mule deer and moose has been reported (144).

\section{Seed or Planting Stock Availability}

No licensed cultivars are currently available, however native seed is occasionally available.

\section{Methods and Ease of Establishment}

June grass seed gives good germination after the seeds are moistened with a $0.2 \%$ solution of $\mathrm{KNO} 3$ at $20^{\circ} \mathrm{C}$ for 16 hours, or warmed at $30^{\circ} \mathrm{C}$ for 8 hours. Light is required for germination (455).

\section{Current Status for Reclamation}

June grass has been suggested as a species with potential use for reclamation on coarse textured soils (435). It had been evaluated for reclamation in the foothills near Luscar, Alberta (144). Containerized seedlings, raised from a mixed seed collection from the eastern slopes, had high survival after three years on various alpine and subalpine sites along the Eastern Slopes $(366,723)$. At Fort McMurray, june grass exhibited high cover and vigor after five years on amended tailings sand soil (705). June grass has been recommended for revegetation of critical sites in northwestern Colorado.

June grass is a widely distributed species found in both the prairies and mountains. It is drought tolerant. Research has indicated that this species has potential for revegetation of disturbed alpine ranges. 
Lolium Perenne

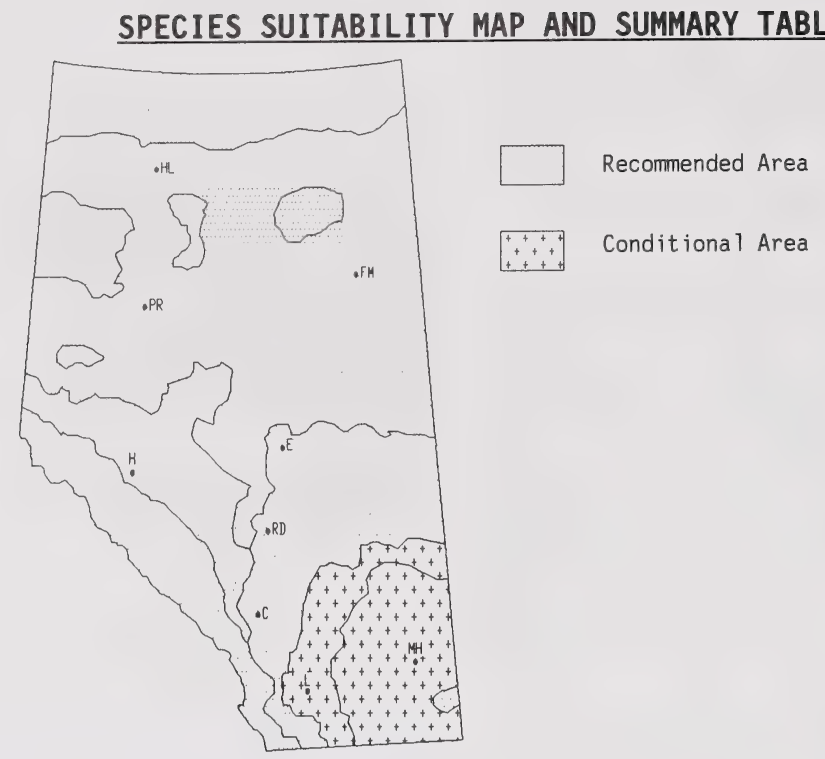

Commercially Available: Yes $\mathrm{X}$ No

\begin{tabular}{|c|c|c|c|c|c|}
\hline \multirow{2}{*}{$\begin{array}{l}\text { RECLAMATION SUITABILITY } \\
\text { CRITERIA }\end{array}$} & \multicolumn{5}{|c|}{ SUITABILITY RATING } \\
\hline & Very High & $\mathrm{High}$ & Medium & Low & None \\
\hline Drought Tolerance & & & & $x$ & \\
\hline Salt Tolerance & & & $x$ & & \\
\hline Acid & & 4.5 & & & \\
\hline Tolerance Base & & & & $x$ & \\
\hline Winter Hardiness & & $x$ & & & \\
\hline Erosion Control & & & $x$ & & \\
\hline Persistence & & & & $x$ & \\
\hline Palatability & & $x$ & & & \\
\hline Browse Tolerance & & $\mathrm{X}$ & & & \\
\hline Moisture Preference & Moist & o wet & & & \\
\hline Soil Preference & Wide $t$ & xtural & ge, moder & to $\mathrm{p}$ & raine \\
\hline
\end{tabular}


Lolium perenne L.

\section{SPECIES BIOLOGY}

Taxonomy - Ryegrass

\section{Origin and Range}

Introduced from Europe; widely cultivated. Newfoundland to Alaska and south to Virginia and California, occasionally further south (199). It is a common pasture grass in western Europe, New Zealand and northeastern United States (47) and Oregon (138).

\section{Growth Habit}

Erect, tufted grass with culms 20 to $80 \mathrm{~cm}$ tall (199, 47) with a fairly shallow root system (138). It is a cool season grass (712) that tends to die out in hot weather.

\section{Nitrogen Fixing - None}

\section{Longevity}

Perennial ryegrass is a rapidly developing (179), short-lived perennial (199), or a winter annual. It generally persists for 3 to 4 years (108). Will not last more than about 3 years on the prairies (D. Walker, pers.comm.). It is completely winter hardy throughout the prairie provinces. "Manhattan" perennial ryegrass is hardier than other strains of the species (209). "Norlea" perennial ryegrass is rated as having excellent winter hardiness for this species (252).

\section{Self Propagation}

Propagates by seed or by tillers.

\section{Ecological Setting}

Perennial ryegrass is often used in lawn-seed mixtures. It is also found as an escapee in waste places and along streambanks (199). To produce high yields, perennial ryegras requires a fertile soil, a mild climate and about 75 to $125 \mathrm{~cm}$ of rainfall annually. The effective environmental zone has been reported to be 40 to more than $152 \mathrm{~cm}$ precipitation (500); $30 \mathrm{~cm}$ minimum (639). Perennial ryegrass apparently does best in cool, moist regions with mild winters. It is well adapted to the Pacific northwest (183). It apparently will not persist in areas with climatic extremes of cold, heat or drought.

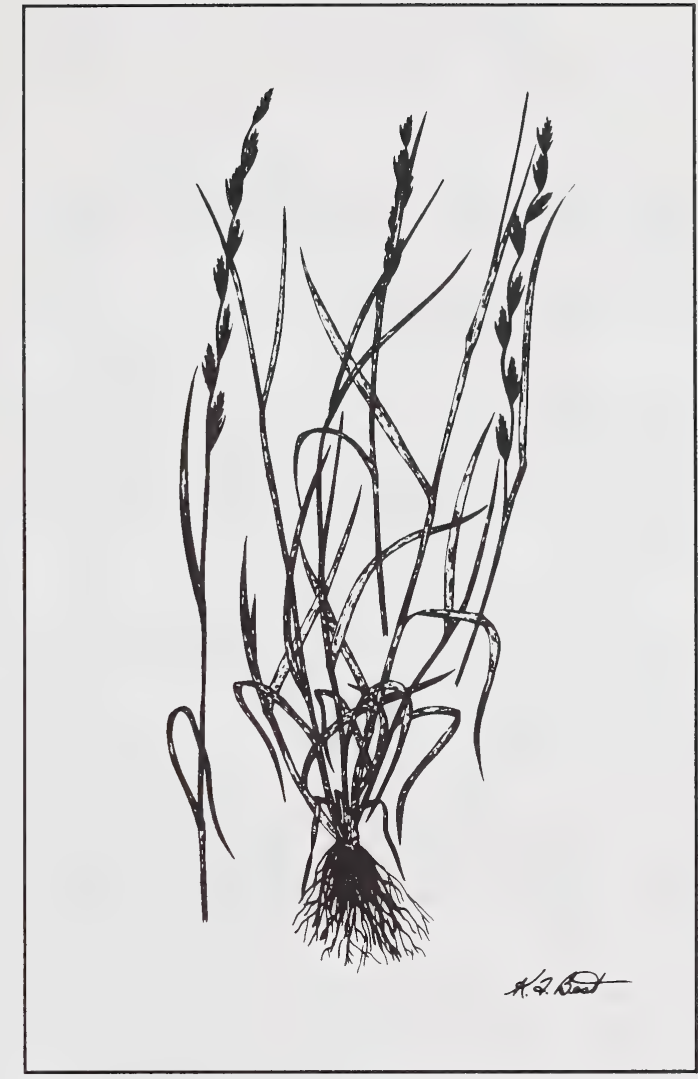

\section{TOLERANCES}

\section{Soil Preferences}

Perennial ryegrass is adapted to a wide range of soil conditions and soil drainage regimes. It is best suited to soils that are not excessively drained or very poorly drained, provided mean annual precipitation is greater than $45 \mathrm{~cm}$ (179). It grows well on heavy soils (183). It will withstand fairly wet soils if there is good surface drainage (500).

Nutrient Requirements - medium to high (500).

\section{Soil Reaction}

A lower limit of $\mathrm{pH} 4.5$ has been suggested for the eastern US (712).

\section{Soil Salinity}

Perennial ryegrass survived on tailings material with an electrical conductivity of 9 to $15 \mathrm{~ms} / \mathrm{cm}$ (326). 
Perennial ryegrass has moderate salt tolerance (424). Survived on shale with an EC of about $10 \mathrm{mS} / \mathrm{cm}$ (344).

\section{Drought}

Lolium perenne is not particularly drought tolerant (500).

\section{Heavy Metals and Hydrocarbons}

"Wimmera" annual rye grass (L. rigidum $x$ L. multiflorum) has a tolerance of boron in concentration of $5 \mathrm{ppm}$ on shale. Perennial ryegrass had good growth on limed acid tailings with a high gypsum content (20 to $25 \% \mathrm{Fe}$ ) (326).

\section{Shade}

It is expected that perennial ryegrass would tolerate at least partial shade.

\section{Grazing or Mowing}

"Pennfine" perennial ryegrass is more easily mowed than "Norlea" or "Manhattan" and there is little foliage shedding following mowing with a reel mower (138). Perennial ryegrass tolerates heavy grazing (104).

\section{Susceptibility to Disease and Insect Damage}

"Pennfine" perennial ryegrass was developed for snow mold tolerance, among other selection criteria. "Norlea" perennial ryegrass is susceptible to leaf rust (138)

\section{RECLAMATION CONSIDERATIONS}

\section{Soil Building and Erosion Control Capability}

Perennial ryegrass has a fibrous root system (106). "Manhattan" produces abundant tillers under favorable conditions with moderate spreading ability. Decumbent stems may root at the nodes. "Manhattan" produces a moderately dense turf (138). The rate of spread is considered fair (424). It has medium sod-forming characteristics (500). The species can be considered at least a moderately good soil stabilizer.

\section{Adaptation to Disturbance}

Perennial ryegrass has been reported as a pioneer on alkaline $(\mathrm{pH} 9.0)$ asbestos tailings which were also high in $\mathrm{Ni}$ and $\mathrm{Cr}$. Most volunteers were observed on pockets of soil or overburden incorporated into the tailings (310).

\section{Competitive Ability}

"Pennfine" perennial ryegrass is not as competitive in mixtures as "Manhattan", but it is more competitive than "Norlea" (138). When seeded with long-lived grasses and legumes, the perennial ryegrass content should be kept below $5 \%$ (D. Walker, pers.comm.). More than this will reduce the amount of longer-lived plants through competition (197).

\section{Commercial Value}

Perennial ryegrass is used in short-term pasture and hay land, and in lawn-grass mixtures (47). It is generally too short for hay production. In pastures it is often sown with white and red clover. In eastern Canada and throughout southern B.C., it is an important pasture species. It is also used for erosion control (138). Common ryegrass (Lolium spp.) is used to provide a quick ground cover for temporary stabilization of earth structures such as dams, for erosion control on cropland subject to overflow, for winter cover cropping and with clovers as a green manure (179).

\section{Palatability and Nutritive Value}

Perennial ryegrass is nutritious and palatable (183).

\section{Seed or Planting Stock Availability}

Varieties licensed for use in Canada include "Manhattan", "Norlea" and "Pennfine" (138). Certified seed of "Norlea" perennial ryegrass is available in quantity in Canada. Seed of "Manhattan" and "Pennfine" perennial ryegrass is also available from Canadian seed distributors (138). Seed sources include hybrids of Lolium perenne and L. multiflorum (Italian ryegrass, an annual) which behave as short-lived perennials. Approximately 227000 seeds/lb (639).

\section{Methods and Ease of Establishment}

The typical purity/germination is $98 / 90 \%$ (132). Germination rates of perennial ryegrass on acid (pH 3.3) mine spoil were reduced by soaking the seeds in various concentrations of ammonium nitrate and triple superphosphate fertilizers. This experiment was designed to simulate hydroseeding conditions. Germination was best on unfertilized loamy sand of pH 5.8 (273). Perennial ryegrass is commonly used in lawn-seed mixtures because it 
germinates rapidly and forms a green turf quickly. It is slightly slower than common ryegrass (Lolium spp. including L. multiflorum) in becoming established, but when fully developed it equals it in production, and is more persistent (179). Perennial ryegrass has been rated as having excellent ease of establishment (424). It is a vigorous and rapidly establishing grass (256). Fall seeding at a rate of 25 to $35 \mathrm{lbs}$ PLS/ac has been recommended (639).

\section{Current Status for Reclamation}

Preliminary results indicate good growth in the subalpine at Grande Cache, Alberta (268). Perennial ryegrass has been used for revegetation of land disturbed by coal mining in southeastern B.C. (119). It has shown promise at sites above $1650 \mathrm{~m}$ in southeastern B.C. but tended to decline at the lower elevations (494). A preliminary survey of five mine sites in southern B.C. indicated that perennial ryegrass has poor performance on waste rock and overburden and was absent on tailings. Most of these sites did not have maintenance fertilization (143). It failed as a companion crop on subalpine test sites at Adanac and Cadomin (705). Perennial ryegrass has also been reported to be suitable for use in the Mackenzie and Yukon River Valleys as a quick nurse crop (398).

In the U.S. perennial ryegrass has been recommended as a species suitable for including in seed mixes designed for quick cover (temporary) to control erosion (346). Perennial ryegrass seeded on road backslopes in western Oregon gave excellent cover for the first year but declined gradually thereafter (130). It has been recommended as a good shortlived filler for use in the subalpine in Colorado (193). It has also been used as part of a seed mix to form a dense ground cover in northern Minnesota and Pennsylvania (123).

Perennial ryegrass is a readily established and vigourous sod-forming grass. It is a cool season grass that tends to die out in hot, dry weather. Winter hardy varieties are available and some may persist for up to three years in favorable conditions. Perennial ryegrass can tolerate soil salinity. It is best suited to moist soils but can withstand wet soils if surface drainage is adequate. This grass has potential use as a companion crop and can provide a quick vegetative cover to prevent surface erosion on moist sites. 
Muhlenbergia asperifolia

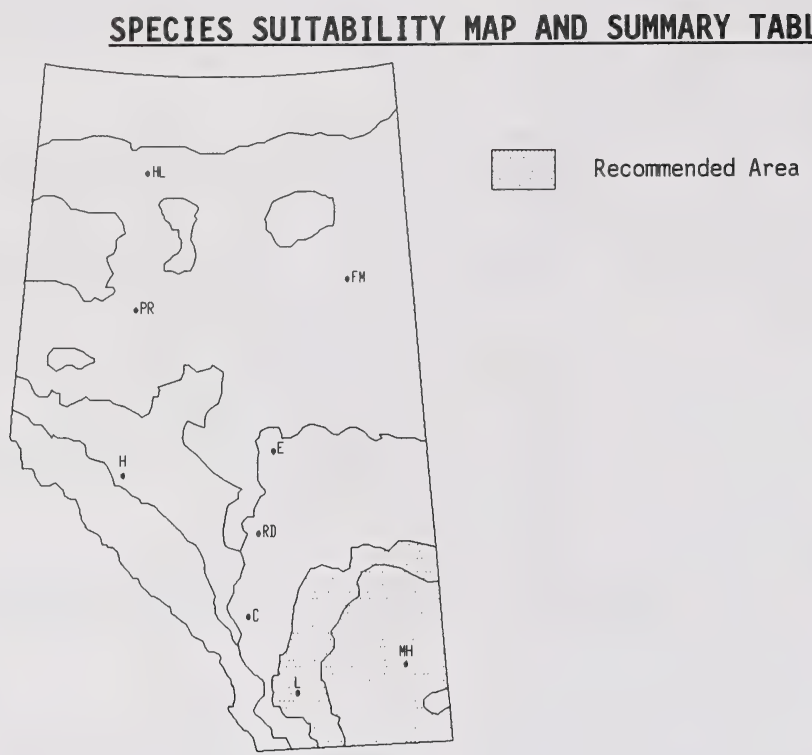

\begin{tabular}{|c|c|c|c|c|c|}
\hline \multirow{2}{*}{$\begin{array}{l}\text { RECLAMATION SUITABILITY } \\
\text { CRITERIA }\end{array}$} & \multicolumn{5}{|c|}{ SUITABILITY RATING } \\
\hline & Very High & High & Medium & Low & None \\
\hline Drought Tolerance & & & & $x$ & \\
\hline Salt Tolerance & & $x$ & & & \\
\hline pH Acid & & & & & \\
\hline Tolerance Base & & $x$ & & & \\
\hline Winter Hardiness & & & $x$ & & \\
\hline Erosion Control & & $x$ & & & \\
\hline Persistence & & $x$ & & & \\
\hline Palatability & & & $x$ & $x$ & \\
\hline Browse Tolerance & & $x$ & & & \\
\hline Moisture Preference & Moist & dry. & & & \\
\hline Soil Preference & Sandy. & & & & \\
\hline
\end{tabular}


Muhlenbergia asperifolia (Nees \& Mey.) Parodi

\section{SPECIES BIOLOGY}

Taxonomy - Scratch Grass

\section{Origin and Range}

Native (405). Found from British Columbia to California and Mexico, east to Idaho and Montana and to Texas and the Mississippi valley (348). Not common on the Canadian prairies (9).

\section{Growth Habit}

Erect and wiry grass of small to medium size. Mostly rhizomatous (312) root system. Grows in dense stands (9). Culms branching at the base and spreading. Slender, and 10 to $40 \mathrm{~cm}$ tall (312).

Nitrogen Fixing - None

Longevity - Perennial (withering) grass (405).

\section{Self Propagation}

Propagation is both by seeds, and by vegetative spreading from rhizomatous rootstocks (312).

\section{Ecological Setting}

Scratch grass is found on the moist prairie, and in meadows of southeastern Alberta $(312,506)$. In North Dakota, scratch grass occurs on moderately saline surface and strongly saline subsurface soils, in association with foxtail (Hordeum jubatum), slender wheatgrass (Agropyron trachycaulum) and other grasses of the prairie cordgrass (Spartina pectinata) community (469).

\section{TOLERANCES}

\section{Soil Preferences}

Grows in sandy soil (312) which is usually moist to dry (199).

\section{Nutrient Requirements}

Responds to nitrogen fertilization but will grow on sites with moderately low nutrient status.

\section{Soil Reaction}

Often associated with alkaline soils (199), and is therefore considered moderately tolerant of high $\mathrm{pH}$.

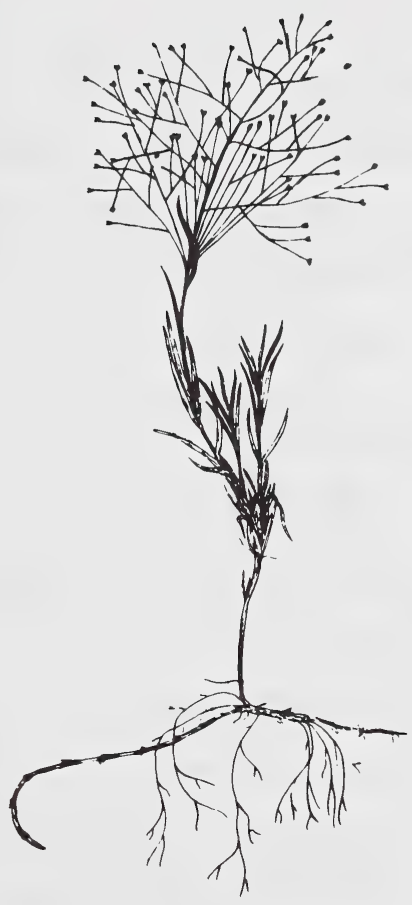

\section{Soil Salinity}

Frequently associated with saline soils (312).

\section{Drought}

Generally found on moist sites with good drainage.

\section{Heavy Metals and Hydrocarbons}

No specific tolerances noted.

\section{Shade}

Presumably shade intolerant, based on range and ecological setting.

\section{Grazing or Mowing}

Muhly grasses are considered to be "increaser" range plants, increasing in number as more desirable plants are grazed out. Tolerance to mowing is not known. 


\section{Susceptibility to Disease and Insect Damage}

No specific pests noted.

\section{RECLAMATION CONSIDERATIONS}

\section{Soil Building and Erosion Control Capability}

Extensive root and rhizome systems make this species good for soil building and erosion control, particularly on saline sites.

\section{Adaptation to Disturbance}

Rated as an "increaser" on rangeland. Invades disturbed saline sites.

\section{Competitive Ability}

A relatively aggressive, rhizomatous species.

\section{Commercial Value}

Major value is for erosion control.

\section{Palatability and Nutritive Value}

In general, muhly grasses are rated as poor to moderately good forage plants (9). Overall, palatability is inferior to many range grasses.

\section{Seed or Planting Stock Availability}

Not known to be available commercially.

\section{Methods and Ease of Establishment}

Seeding is thought to be the best establishment method although no reports on establishment were reviewed.

\section{Current Status for Reclamation}

No apparent use has been made of scratch grass for revegetation of disturbed lands to date. Distribution favors potential use in southeastern and east central Alberta. Tolerance for saline soils may be useful for revegetation of soils affected by brine spills or sodic soils. Adaptability to sandy and saline soils warrants revegetation research on tailings sand slopes in the Alberta oil sands area, although climatic conditions may present constraints to growth. 
Oryzopsis hymenoides

SPECIES SUITABILITY MAP AND SUMMARY TABLE

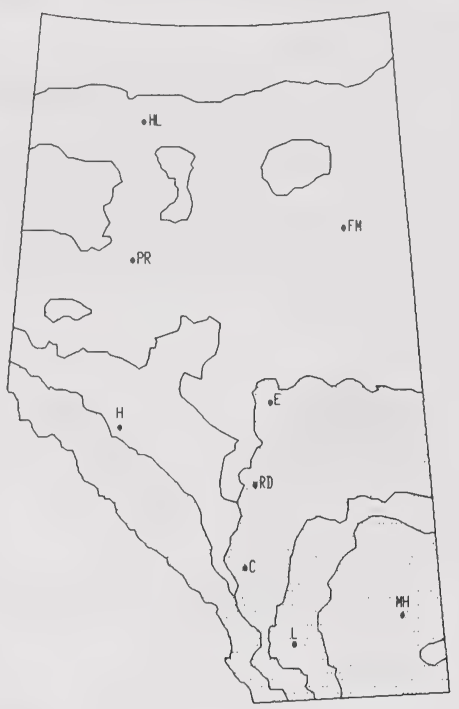

Recommended Area

Commercially Available: Yes X No.

\begin{tabular}{|c|c|c|c|c|c|}
\hline \multirow{2}{*}{$\begin{array}{l}\text { RECLAMATION SUITABILITY } \\
\text { CRITERIA }\end{array}$} & \multicolumn{5}{|c|}{ SUITABILITY RATING } \\
\hline & Very High & High & Medium & Low & None \\
\hline Drought Tolerance & $x$ & $x$ & & & \\
\hline Salt Tolerance & & & $x$ & & \\
\hline Acid & & & & $x$ & \\
\hline Tolerance Base & & & $\mathrm{X}$ & & \\
\hline Winter Hardiness & & $x$ & & & \\
\hline Erosion Control & & $x$ & $x$ & & \\
\hline Persistence & & & $x$ & & \\
\hline Palatability & & $x$ & $x$ & & \\
\hline Browse Tolerance & & $x$ & & & \\
\hline Moisture Preference & Dry. & & & & \\
\hline Soil Preference & Rocky & to sandy, & olerates wid & e range & e well drained \\
\hline
\end{tabular}


Oryzopsis hymenoides (R. and S.) Ricker

\section{SPECIES BIOLOGY}

Taxonomy - Indian Rice Grass

\section{Origin and Range}

Native, widely distributed throughout the western United States (322), from North Dakota to Washington, and south to California and Texas (183).

\section{Growth Habit}

Indian rice grass is a tufted, stout grass 30 to $70 \mathrm{~cm}$ tall $(78,312)$. It is a bunchgrass with each leaf growing from the base of the plant (322). Variously described as warm season (322) and cold/cool season grass $(183,639)$. There is a considerable ecotypic variation within the species (426).

Nitrogen Fixing - None

\section{Longevity}

Long-lived perennial (322). Persistence is good (339).

\section{Self Propagation}

Seed production is excellent, and natural spreading ability is moderate (339).

\section{Ecological Setting}

Indian rice grass is commonly found on rocky slopes, dry banks and in sandhills in the southwestern prairies (78). It is also a high elevation species in Alberta (378). In the western United States it is found at elevations between 600 to $3000 \mathrm{~m}$. It is most common in the low semi-arid rangeland to the higher elevation juniper-pinyon zones. Indian rice grass is found on ridgetops on south or west-facing dry slopes at higher elevations (322). Requires $22 \mathrm{~cm}$ of precipitation (639).

\section{TOLERANCES}

\section{Soil Preferences}

Indian rice grass is found on a range of soils from shallow to deep; it is adapted to dry sandy soils $(322,183)$. It is not adapted to poorly drained soils (322).

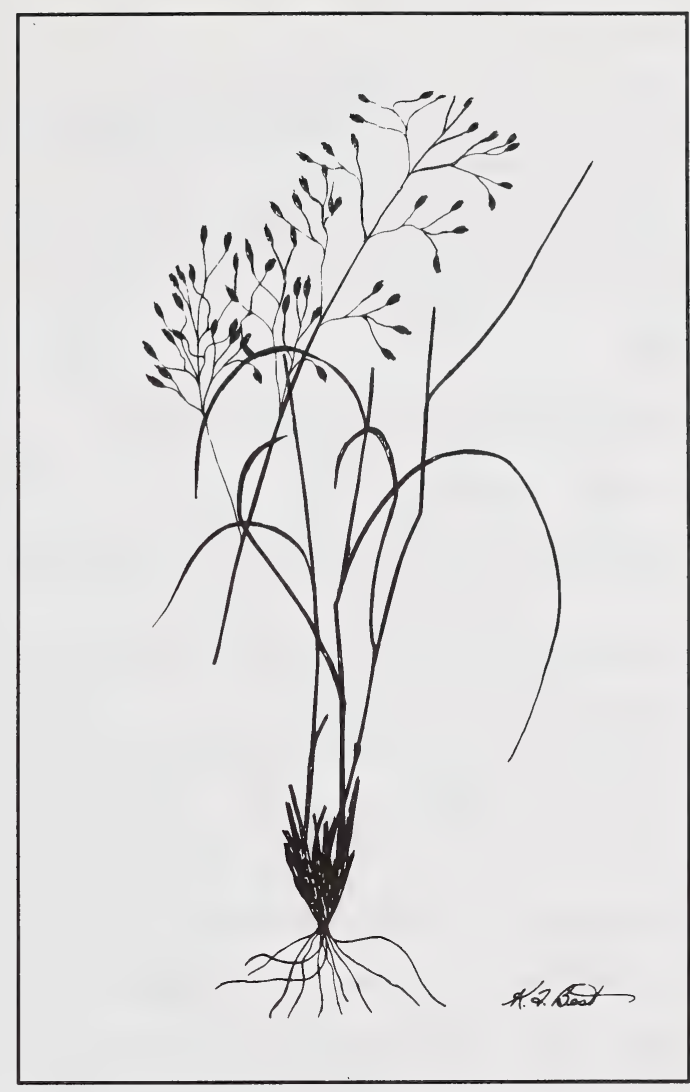

\section{Nutrient Requirements}

Relatively low nutrient requirements. Appears to respond to modest additions of nitrogen. Annual fertilization rates of $90 \mathrm{~kg} / \mathrm{ha}-\mathrm{N}$ have been recommended as a starting point where no soil test information is available (322).

\section{Soil Reaction}

Evidence indicates a probable preference for at least mildly alkaline sites.

\section{Soil Salinity}

Indian rice grass is at least somewhat tolerant of soil salinity (285) and it has been used for range improvement in the salt-desert regions of Colorado (428). Indian rice grass seeded on sodic mine spoils near Edmonton did not survive. However, mortality may have been due to flooding (304). 


\section{Drought}

Indian rice grass is adapted to dry sandy soils. It is one of the most drought tolerant native grasses in the United States (322).

\section{Heavy Metals and Hydrocarbons}

No specific tolerances noted.

\section{Shade}

Observed to be moderately shade tolerant.

\section{Grazing or Mowing}

Indications are that the species has excellent tolerance to grazing (339).

\section{Susceptibility to Disease and Insect Damage}

"Paloma" indian rice grass tested in Arizona, Colorado and New Mexico did not exhibit any problems with insects or disease (322). Good resistance reported (339).

\section{RECLAMATION CONSIDERATIONS}

\section{Soil Building and Erosion Control Capability}

Fibrous root systems and the ability to survive on extreme sites make this grass a good soil builder. Also noted to have moderate soil stabilizing abilities (339).

\section{Adaptation to Disturbance}

Indian rice grass often invades disturbed areas, particularly on sandy sites $(455,322)$.

\section{Competitive Ability}

Good on adapted sites. Compatibility is rated as excellent (420).

\section{Commercial Value}

Indian rice grass is mostly used for rangeland restoration (428).

\section{Palatability and Nutritive Value}

Indian rice grass is nutritious (183) and palatable to all types of livestock (322). The seeds are eaten by birds (including mourning doves and pheasants) and small rodents (322). It is an important range forage grass in the semi-arid areas of the United
States where it is frequently used as a source of winter feed (322). It is reported to be browsed by Rocky Mountain mule deer (245). It has been noted as desirable forage for sheep and deer (425). The forage covers very well (322). Palatability is good in spring, but drops to only fair by late summer (339).

\section{Seed or Planting Stock Availability}

Native seed is only available in limited quantities (322) and is very expensive (132). There are many varieties including "Nezpar" and "Paloma" (430). Approximately 141000 seeds/lb (639).

\section{Methods and Ease of Establishment}

Seedheads comprise an open panicle and seeds are readily shed $(322,331)$. Seed stored for longer than a year after harvest has a much higher rate of germination than freshly collected seed (332). Seed dormancy can be broken by first soaking in concentrated sulphuric acid for 30 minutes, then storing at $5^{\circ} \mathrm{C}$ for 4 weeks. Germinate the seeds at $15^{\circ} \mathrm{C}$ in the dark. The seeds can be wetted with a $100 \mathrm{ppm}$ solution of gibberellic acid to promote germination (455). Indian rice grass has excellent seedling vigour and is readily established (426). Best results are obtained by sowing seed in the fall through to mid-winter at 20 to $45 \mathrm{~mm}$ depth. Fall seeding at a rate of 6 to $8 \mathrm{lbs}$ PLS/ac has been recommended (639). Deeper placement of seed is recommended on light textured soils. It has been established at other times of the year under certain favorable conditions. Seedlings are susceptible to damping off in wet soil (322).

\section{Current Status for Reclamation}

Indian rice grass has been used successfully for stabilizing roadcuts and disturbed areas in Utah. It is particularly suited for use in the juniper-pinyon and big sagebrush vegetation zones (336). "Nezpar" indian rice grass is used for range improvement in the intermountain area of the west. "Paloma" indian rice grass is used for range seeding and soil stabilization in Arizona, Colorado and New Mexico (322). Indian rice grass is suited for planting in very dry areas (232). It has been used for revegetation of mine spoils in Arizona (173).

This species is very variable and is found on a range of soil types. It is adapted to dry sandy or rocky soils and is very tolerant of drought. It is relatively resistant to disease and is easily established. The species is used widely in the western U.S. for erosion control and range rehabilitation in dry areas. 
Phalaris arundinacea

\section{SPECIES SUITABILITY MAP AND SUMMARY TABLE}

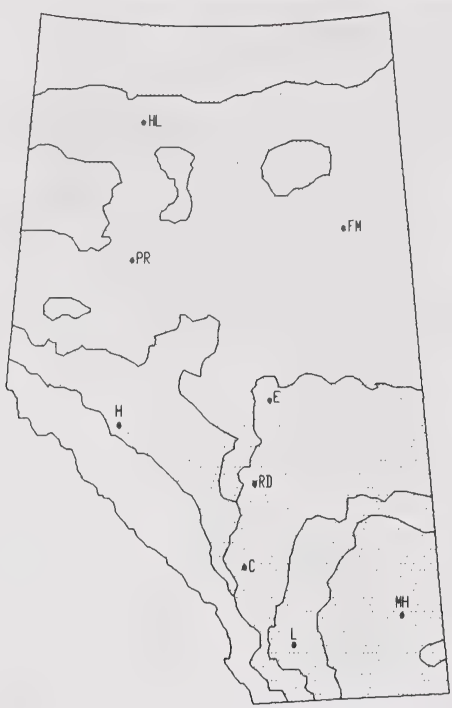

Recommended Area

Commercially Available: Yes $X$ No

\begin{tabular}{|c|c|c|c|c|c|}
\hline \multirow{2}{*}{$\begin{array}{l}\text { RECLAMATION SUITABILITY } \\
\text { CRITERIA }\end{array}$} & \multicolumn{5}{|c|}{ SUITABILITY RATING } \\
\hline & Very High & High & Medium & Low & None \\
\hline Drought Tolerance & & & $x$ & $\mathrm{X}$ & \\
\hline Salt Tolerance & & $x$ & $x$ & $x$ & \\
\hline $\mathrm{pH}$ Acid & & 5.0 & $x$ & & \\
\hline Tolerance Base & & & $x$ & & \\
\hline Winter Hardiness & & & $x$ & & \\
\hline Erosion Control & & $x$ & & & \\
\hline Persistence & $x$ & & & & \\
\hline Palatability & & & $x$ & $x$ & \\
\hline Browse Tolerance & & $x$ & & & \\
\hline Moisture Preference & Moist & wet, $h$ & $y$ toler & flo & \\
\hline Soil Preference & Medium & fine $t$ & ured, moc & $1 y$ to & drain \\
\hline
\end{tabular}


Phalaris arundinacea $\mathrm{L}$.

\section{SPECIES BIOLOGY}

Taxonomy - Reed Canary Grass; Reed Canarygrass

\section{Origin and Range}

Native. Found throughout the prairies on favorable sites (78). Reed canary grass is circumboreal in distribution (480). It occurs throughout the northern prairie states, Alaska, British Columbia east to Newfoundland (214).

\section{Growth Habit}

It is a tall, coarse, cool season grass (258), 0.6 to $1.5 \mathrm{~m}$ tall (312). Reported heights for "Castor" are $103 \mathrm{~cm}$, for "Frontier" $89 \mathrm{~cm}$ and for "Suba" $89 \mathrm{~cm}$ (362). Heights of up to $2.0 \mathrm{~m}$ have been reported (5). Reed canary grass grows in dense clumps but will spread by coarse, creeping root stocks to form a close sod when properly managed (171).

Nitrogen Fixing - None

\section{Longevity}

Reed canary grass is a long-lived, cool season (639) perennial $(480,171,5)$. "Frontier" has been reported to be moderately winter hardy in Alaska (5). "Castor", "Frontier" and "Suba" have been noted as having excellent hardiness (139).

\section{Self Propagation}

Reed canary grass is a sod-forming grass that spreads by rhizomes or creeping rootstocks $(480$, 331). It has moderate seed production (5).

\section{Ecological Setting}

Reed canary grass is commonly found in wet places but not usually in permanent standing water (480). It is well adapted to the northern United States and Canada where there is adequate moisture and the climate is cool (171). Requires $40 \mathrm{~cm}$ of precipitation (639). It has been reported between 1 200 and 3000 m ASL elevation in Carbon County, Wyoming (18). It performed well on several montane and subalpine sites ( 3200 and $3100 \mathrm{~m}$ ASL) in southeastern Idaho, northeastern Utah and western Wyoming (209). It does well on upland soil that has adequate moisture for spring and early summer growth (171). It is found growing wild along river banks and sloughs and on land with high water tables (171).

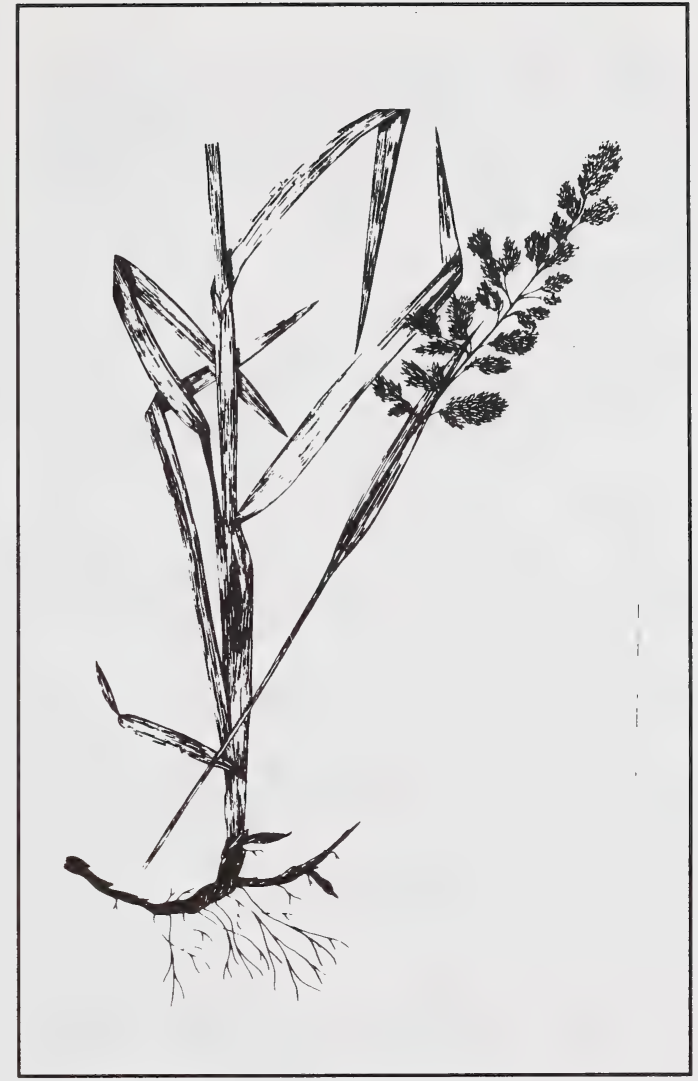

\section{TOLERANCES}

\section{Soil Preferences}

"Frontier" reed canary grass is reported to be adapted to a wide range of soil groups and textures, and is adapted to moist to wet soils $(477,190)$. It is highly tolerant of wetness and flooding (5). "Frontier" reed canary grass did poorly on organic soil but better on mineral soil in the N.W.T. (195). Reed canary grass can tolerate flooding for long periods (up to seven weeks) (171). Growth is good on loam soil and clay soil but fair on sandy soil (447). It can be grown on upland soils where adequate precipitation or irrigation is available (426). It grows well on sandy loam muck and peat and also on heavy clay soils (171). The optimum slope for reed canary grass is reported to be 0 to $8 \%$ and the optimum soil depth as $>63 \mathrm{~cm}$.

\section{Nutrient Requirements}

Fertilizer (nutrient) requirements have been variously reported as moderate (100) and low to medium $(190,466)$. 


\section{Soil Reaction}

"Frontier" reed canary grass has very good acid tolerance (5). It has been recommended as part of a seed mix for vegetation of spoils with $\mathrm{pH}$ of at least 5.0 in Pennsylvania (123). Also considered moderately alkaline tolerant (426).

\section{Soil Salinity}

Reed canary grass is moderately saline tolerant (426). It can grow in soils with an electrical conductivity of 5 to $10 \mathrm{mS} / \mathrm{cm}$ (468). It should not be grown on strongly saline soils (171), however.

\section{Drought}

"Frontier" reed canary grass has good drought resistance (5). It can at least endure short summer drought (500).

\section{Heavy Metals and Hydrocarbons}

Reed canary grass is reported to have a good tolerance to oil $(5,113)$. Other tolerances are not known.

Shade - Favors open sunny sites.

\section{Grazing or Mowing}

Reed canary grass has a rapid recovery rate after cutting (5). Cut and uncut plots of reed canary grass showed no difference in groundcover (318). Continuous close grazing results in a mass of roots in the top layers of soil (171).

\section{Susceptibility to Disease and Insect Damage}

No specific pests noted.

\section{RECLAMATION CONSIDERATIONS}

\section{Soil Building and Erosion Control Capability}

Reed canary grass is a sod-forming grass (5) with a medium rate of growth (179). When planted on uranium tailings near Elliot Lake, Ontario it produced complete groundcover rapidly. This provided an effective means of protection against wind erosion. It was, however, rated as a poor sodforming grass at this site (318). In general, reed canary grass provides low and moderate, longlasting cover, but total cover is high due to litter production $(5,485)$.

\section{Adaptation to Disturbance}

Reed canary grass was found to spread aggressively onto bare areas of uranium tailings at Elliot Lake, Ontario.

\section{Competitive Ability}

It has been rated as a poor companion crop since it will rapidly outcompete other species unless cut (318).

\section{Commercial Value}

Reed canary grass is used for mine reclamation on moist or wet sites, or on areas receiving additional moisture. It is used for forage and for erosion control on wet areas (426). It has potential use as a green manure crop because of its good growth rate and herbage yield (318). "loreed" was developed for usage by the Soil Conservation Service in lowa as a rapid-developing, vigouroussodding, productive perennial.

\section{Palatability and Nutritive Value}

Palatability has been rated as low although it has high potential forage yield (5). A new variety "Venture" has improved palatability through reduction in undesirable alkaloids, as has "Palaton". Herbage yields of "Venture", "Frontier", "Castor" and "Suba" have been rated as good to very good (141). Forage value has been rated as good for game birds but only fair for mule deer and small mammals (147). Feeding value and palatability deteriorate rapidly after heading. Crude protein in pasture ranged from $20 \%$ to $27 \%$ (171). Cut at the proper time (as the heads appear) reed canary grass makes a nutritious and palatable hay (191). Seeds are favored by meadow voles but not by red-backed voles or chestnut-cheeked voles (111). It provides good cover value for mule deer, game birds and small mammals.

\section{Seed or Planting Stock Availability}

There are several licensed cultivars available from seed dealers in Canada. These include "Castor", "Frontier", "Vantage" and "Venture" (139, 500). Approximately 533000 seeds/lb (639).

\section{Methods and Ease of Establishment}

Plants produce seed in the second year. Seeds mature from the top of the head downward and the seed starts to shatter about two weeks after 
flowering (171). Seed of this species does not store well; germination rate declines after about 16 to 18 months in storage. It is recommended that only newly tested seed should be used (426). The species is often difficult to establish from seed (41) though it has been characterized as a quick sprouter. Sow 1.2 to $2.5 \mathrm{~cm}$ deep (171). Fall/spring seeding at a rate of 5 to $10 \mathrm{lbs}$ PLS/ac has been recommended (639). Seedling vigour is regarded as weak (323). Transplanting may have some potential (41). Typical purity/germination is $95 / 90 \%$ (132). Stands of reed canary grass may be regerminated by shallow ploughing, allowing it to reestablish by volunteering (171).

\section{Current Status for Reclamation}

"Frontier" reed canary grass has persisted for 12 years on a moist test site in the Upper Mackenzie region of the boreal forest (latitude $66^{\circ} \mathrm{N}$ ) (644). "Vantage" performed well along the Norman Wells to Zama pipeline where, after 4 years, it was restricted to moist to wet areas (644). "Frontier" reed canary grass planted in the arctic tundra, at Inuvik and Tuktoyaktuk, provided excellent first year cover but winter-killed and died out the first winter (195). It has been recommended for pit and quarry rehabilitation in northern and southern Ontario (190). It was able to sustain good growth on saline mine tailings on a climatically severe site in the Yellowknife area (163). Reed canary grass did best on moist sites in the subalpine at several locations in northcentral and central Colorado (236).

Reed canary grass is tolerant of drought, can tolerate flooding and waterlogged soils and is moderately tolerant of saline soils. It spreads aggressively onto bare disturbed areas and is sometimes responsible for choking drainage ditches. 
Phleum alpinum

\section{SPECIES SUITABILITY MAP AND SUMMARY TABLE}

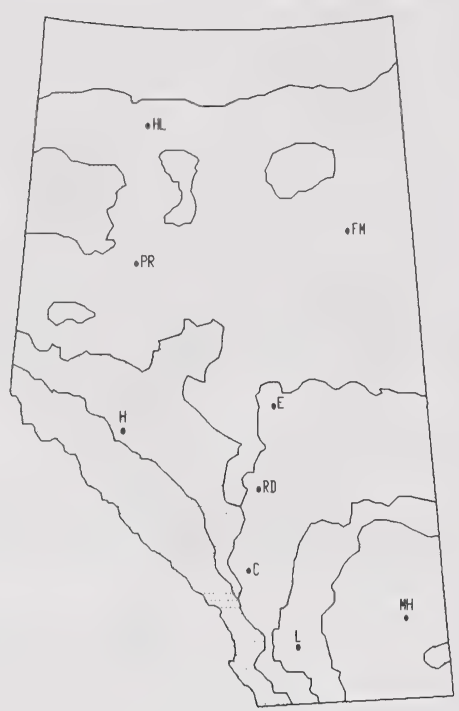

Recommended Area

Commercially Available: Yes $\mathrm{X} N$

\begin{tabular}{|c|c|c|c|c|c|}
\hline \multirow{2}{*}{$\begin{array}{l}\text { RECLAMATION SUITABILITY } \\
\text { CRITERIA }\end{array}$} & \multicolumn{5}{|c|}{ SUITABILITY, RATING } \\
\hline & Very High & High & Medium & Low & Non \\
\hline Drought Tolerance & & $x$ & & & \\
\hline Salt Tolerance & & & $x$ & & \\
\hline pH Acid & & & $x$ & & \\
\hline Tolerance Base & & & $x$ & & \\
\hline Winter Hardiness & $x$ & & & & \\
\hline Erosion Control & & & $x$ & $x$ & \\
\hline Persistence & & & $x$ & & \\
\hline Palatability & & $x$ & & & \\
\hline Browse Tolerance & & $x$ & $x$ & & \\
\hline Moisture Preference & Moist. & & & & \\
\hline Soil Preference & $\begin{array}{l}\text { Sandy } \\
\text { imperf }\end{array}$ & $\begin{array}{l}\text { oam to } \\
\text { ctly } d r\end{array}$ & $\begin{array}{l}\text { y clay } 10 \\
\text { d. }\end{array}$ & modera & \\
\hline
\end{tabular}




\section{Phleum alpinum L.}

\section{SPECIES BIOLOGY}

Taxonomy - Alpine Timothy

\section{Origin and Range}

Native grass, circumpolar distribution; in North America from Alaska to Newfoundland and along the Rocky Mountains and most mountain subalpine areas of the western United States to South America $(214,199)$; in Alberta, common in the Cypress Hills (312).

\section{Growth Habit}

A shallow rooted grass with short creeping rootstalks (506) and with culms solitary or in small tufts 20 to $50 \mathrm{~cm}$ tall (312). It has fairly dense basal leafage (506).

\section{Nitrogen Fixing - None}

Longevity - Perennial bunch grass (405).

\section{Self Propagation}

Self propagation is primarily by seed.

\section{Ecological Setting}

Mountain slopes and alpine meadows, to about $1700 \mathrm{~m}$ (214); also forest borders and open slopes (312) of the foothills and parkland. Also occurs on streambanks, bogs and wet places in the mountains (199). In Alberta, it is found in association with the following grasses in alpine areas: Poa alpina, Poa arctica, Trisetum spicatum, Festuca saximontana, Festuca brachyphylla, and Festuca baffinesis (455). Noted growing at up to $3270 \mathrm{~m}$ in Wyoming (18).

\section{TOLERANCES}

\section{Soil Preferences}

Will tolerate poorly developed alpine soils, but generally found on Brunisolic soils with textures ranging from sandy loam to silty clay loam. Prefers moderately well drained to imperfectly drained sites. Also observed to favor moist locations (D. Walker, pers.comm.).

\section{Nutrient Requirements}

Presumably it has minimal nitrogen requirements

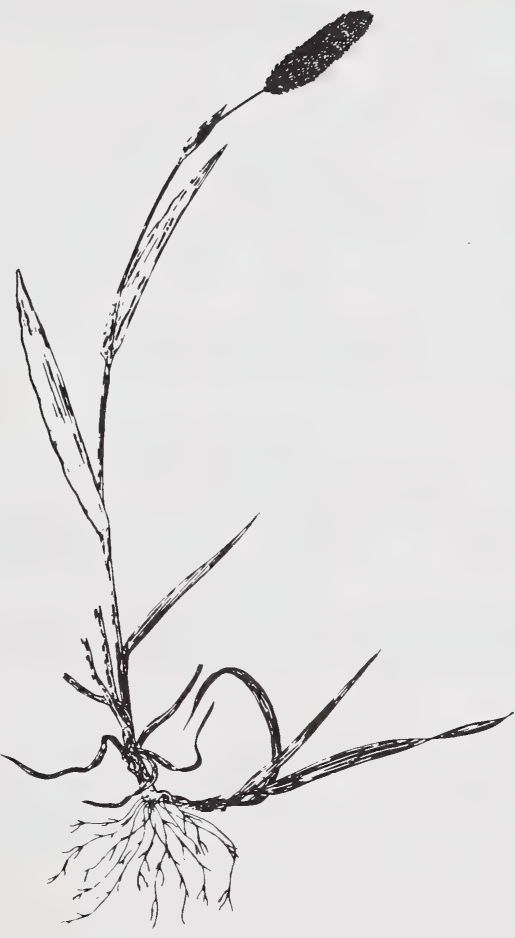

since it grows on alpine soils deficient in nitrogen (209).

\section{Soil Reaction}

Has been used successfully on acidic mine spoils (185). Grown successfully on acidic mine spoil in alpine areas of Montana when supplied with lime and other amendments (75). Also found on soils developed from basic parent materials.

\section{Soil Salinity}

Will not tolerate excessive salinity.

\section{Drought}

Presumably drought tolerant because of its growth on open alpine slopes with a dry south exposure.

\section{Heavy Metals and Hydrocarbons}

No specific tolerances noted in the literature reviewed. 


\section{Shade}

Presumably relatively shade intolerant because of its association with alpine habitats. Will withstand minor shading.

\section{Grazing or Mowing}

High root:shoot ratio allows sufficient reserves to regenerate after grazing on native ranges.

\section{Susceptibility to Disease and Insect Damage}

No specific susceptibilities noted from the literature reviewed.

\section{RECLAMATION CONSIDERATIONS}

\section{Soil Building and Erosion Control Capability}

Grows in solitary tufts (435) and may not be effective by itself for extensive erosion control, although fibrous roots can promote sod formation.

\section{Adaptation to Disturbance}

Colonizes bare soils (185). In Montana, alpine timothy is noted as an active colonizer on disturbances in alpine habitats (76).

\section{Competitive Ability}

Moderately aggressive on favored locations. Compatibility with other alpine species is good.

\section{Commercial Value}

It is entirely an alpine pasture grass, not only because it grows in places inaccessible to harvesting equipment, but because its low growth habit makes it difficult to mow and gather (506). On alpine ranges in Wyoming and Colorado, alpine timothy is second only to hairgrass (Deschampsia caespitosa) in importance according to its range, abundance, amount of herbage produced, and use by domestic sheep (60).

\section{Palatability and Nutritive Value}

Readily eaten by all classes of livestock (506) and by grazing ungulates.

\section{Seed or Planting Stock Availability}

Development of seed stocks is currently underway although no seed is presently available through commercial seed dealers.

\section{Methods and Ease of Establishment}

In Montana, alpine timothy has been grown successfully in the greenhouse (76). First year survival of transplants on reclaimed acid alpine mine spoils was better than the average of all species tested. Results with seeding alpine timothy here were also favorable (75). Survival rate of transplanted seedlings in Alberta ranged from $96 \%$ to $100 \%$, in two different samples (453). In alpine habitats, recommended for seeding in September and October (323).

\section{Current Status for Reclamation}

Current use for reclamation is not widespread, ( 455 , $453,379)$. Recommended for revegetation of alpine ranges and wildlife habitats in Alberta (435). However, performed poorly after six years in mix trials in the subalpine east slopes region of the Rocky Mountains on topsoil and overburden (705). Local collections also performed poorly at Banff ( 1 $390 \mathrm{~m}$ ) (732). Alpine timothy did reasonably well at Fort McMurray in five years of testing on amended tailings sand (705). Phleum alpinum gave the best results in establishment and winter survival in revegetation trials on disturbed land in the western Canadian arctic and did equally well on peat and mineral soils (209). Alpine timothy has been used with some success for revegetation of high-elevation mine wastes in the United States $(75,76)$. First year results of revegetation on mine spoil in Montana at $2950 \mathrm{~m} \mathrm{ASL}$ indicated that density of a native species mix (seed collected locally), including P. alpinum, was significantly higher than for an introduced species mix under all treatments (74). Similar tests on lime, fertilizer and manure amended acid mine spoil at $3000 \mathrm{~m} \mathrm{ASL}$ in the subalpinealpine transition zone area in Montana indicated that alpine timothy was among the must successful species. However, without these amendments, poor growth resulted (75).

Alpine timothy is a high elevation grass with wildlife and rangeland value. Other characteristics useful for reclamation include good colonization ability and establishment (in field trials) by seed or transplantation of seedlings. 
Phleum pratense

SPECIES SUITABILITY MAP AND SUMMARY TABLE

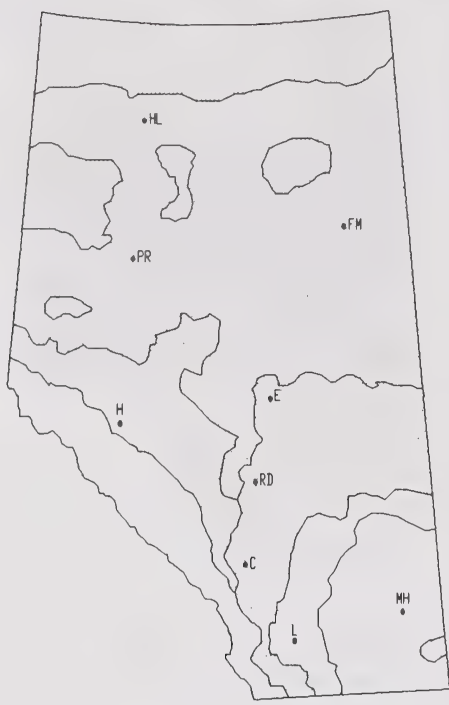

Recommended Area

Commercially Available: Yes $\underline{X}$ No

\begin{tabular}{|c|c|c|c|c|c|}
\hline \multirow{2}{*}{$\begin{array}{l}\text { RECLAMATION SUITABILITY } \\
\text { CRITERIA }\end{array}$} & \multicolumn{5}{|c|}{ SUITABILITY RAIING. } \\
\hline & Very High & High & Medium & Low & None \\
\hline Drought Tolerance & & & & $x$ & \\
\hline Salt Tolerance & & & & $x$ & \\
\hline pH Acid & 3.5 & & & & \\
\hline Tolerance Base & & & & $x$ & \\
\hline Winter Hardiness & & & $x$ & & \\
\hline Erosion Control & & & $x$ & & \\
\hline Persistence & & $x$ & $x$ & & \\
\hline Palatability & & $x$ & & & \\
\hline Browse Tolerance & & & $x$ & & \\
\hline Moisture Preference & Moist. & & & & \\
\hline Soil Preference & Loam & clay & ed, o & i1 & \\
\hline
\end{tabular}


Phleum pratense L.

\section{SPECIES BIOLOGY}

Taxonomy - Timothy

\section{Origin and Range}

Introduced grass. Native to Europe (312). Found throughout North America. Partly naturalized in many inhabited areas (214).

\section{Growth Habit}

Erect bunchgrass 40 to $90 \mathrm{~cm}$ tall, with shallow, fibrous roots extending to more than $1.2 \mathrm{~m}$ (138, 385).

\section{Nitrogen Fixing - None}

\section{Longevity}

Short-lived, cool season (639) perennial grass (391, 47). Long-lived in cool, humid and subhumid regions (67). Winter hardy (183). Poor reseeding at higher elevations causes stands to die out after 5 or 6 years (41).

\section{Self Propagation}

By seed. Its natural reseeding ability is considered moderate, and it displays no apparent ability to reproduce vegetatively (338). Viable seed is not produced at higher elevations (41), though viable seed is produced at $2100 \mathrm{~m}$ in southeastern B.C.

\section{Ecological Setting}

Commonly seeded for hay and pasture in the foothills and parklands (47). Found in the lower subalpine. Usually it does not produce viable seeds at higher altitudes $(41,185)$, although it usually is incorporated into high altitude seeding mixes (41, $131,106)$. Seeded at elevations to $4000 \mathrm{~m} \mathrm{ASL}$ in Colorado (73, 462), $2730 \mathrm{~m}$ ASL in Wyoming (18), and $1070 \mathrm{~m}$ ASL in Alberta (380). Requires $40 \mathrm{~cm}$ (639) to $45 \mathrm{~cm}$ (138) of precipitation.

\section{TOLERANCES}

\section{Soil Preferences}

Generally recommended for growth on loamy textured material (423). Timothy was included as part of a seed mix for moist, moderately well to well drained soils (83). "Engmo" timothy was recommended for seeding of disturbed soils in

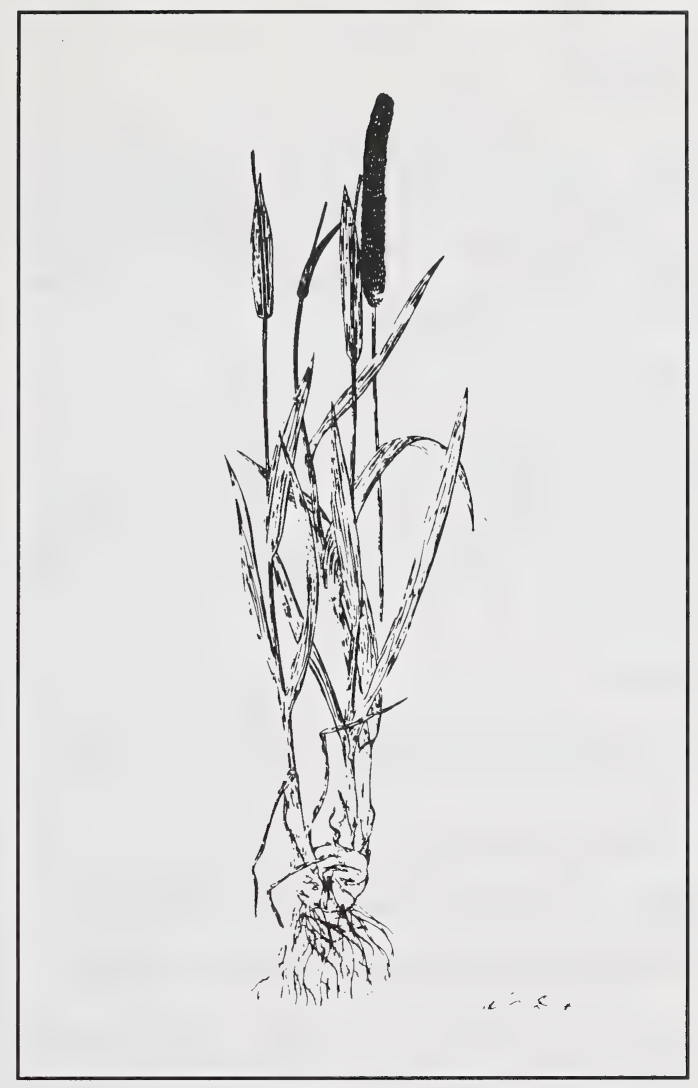

permafrost areas (79). Tolerance of organic soils has been indicated (436). The optimum slope for growth is 0 to $8 \%$. Optimum soil depth is more than $60 \mathrm{~cm}$. Fair growth has been achieved on sandy soils, good growth on loamy and clayey soils (447).

\section{Nutrient Requirements}

Regarded as a species with high nutrient requirements (466).

\section{Soil Reaction}

Timothy is regarded as acid tolerant (436). It has been identified as a successful species on acid (pH 3.5 to 5.3) mine wastes (overburden) treated with lime (209). It has been recommended for growth on mine spoil with a pH range of 5.6 to 7.3 (423). The lower pH limit for growth has been estimated at $4.5(346,123)$.

\section{Soil Salinity}

Considered to have a low tolerance to salt, in the 
range of 0 to $4 \mathrm{mS} / \mathrm{cm}$ (247).

\section{Drought}

Does not tolerate drought or high temperatures (183). Timothy requires considerable moisture to maintain itself. When annual precipitation is less than $45 \mathrm{~cm}$, other grasses will produce more and better hay (138). Poor recovery under limited moisture conditions (183).

\section{Heavy Metals and Hydrocarbons}

Timothy has medium tolerance to oil (282). Growth tests on pyritic uranium tailings indicated that timothy produced well, but is susceptible to black discoloration, which causes it to become dormant (318). No other susceptibilities or tolerances have been noted.

\section{Shade}

Categorized as shade tolerant, and well suited to seeding under trees (340).

\section{Grazing or Mowing}

Not resistant to close, continuous grazing (183).

\section{Susceptibility to Disease and Insect Damage}

No susceptibilities were noted in the literature reviewed.

\section{RECLAMATION CONSIDERATIONS}

\section{Soil Building and Erosion Control Capability}

In the Alberta foothills, "Climax" produced the greatest cover on raw coal mine overburden and on overburden topdressed with mineral soil. It was rated as the most promising species for rapid erosion control (10). Elsewhere, it has been rated medium for soil stability (338).

\section{Adaptation to Disturbance}

Observed to be a pioneer on Alberta mine spoils.

\section{Competitive Ability}

Timothy will spread from cultivated fields into adjacent rangelands (368). Good adaptation to disturbance (338).

\section{Commercial Value}

Used for hay, pasture, and silage throughout Canada. Some erosion control capability.

\section{Palatability and Nutritive Value}

Palatable and nutritious (183), and considered valuable hay grass. Used particularly for spring and fall pasture by livestock (395). Foliage used as forage by some grazing ungulates (245), and seed used by birds (346).

\section{Seed or Planting Stock Availability}

A large number of varieties are available (139) for different ecological settings. Commercial varieties (and certified seed) are available in Canada including: "Astra", "Bounty", "Champ", "Clair", "Climax", "Drummond", "Itasca", "Milton", "Toro", "Basho", "Pronto", "Richmond", and "Timfor" (138). Seed supplies are adequate, but are considered relatively high priced (132). Approximately 1300000 seeds/lb (639).

\section{Methods and Ease of Establishment}

Establishment by seed has been rated very good, and by transplanting it has been rated good (338). Fall/spring seeding at a rate of $1 \mathrm{lb}$ PLS/ac has been recommended (639). Its ability to establish fall stands quickly makes timothy valuable in mixtures with slower growing species (340). Timothy is judged to be a species which establishes well, but is not persistent in subalpine revegetation. Seedling vigour is good in the subalpine. Because timothy does not produce viable seed at higher elevations, stands begin to die out after 5 or 6 years (41). In general, it provides rapid emergence, early spring growth and late fall growth (436). Successful growth of timothy has been established with hydroseeding techniques on road embankments at high altitudes (162).

\section{Current Status for Reclamation}

Revegetation of disturbed lands in Alberta includes successful revegetation of coal mine wastes in the Rocky Mountain foothills in Alberta $(272,197,378)$ and in central Alberta (304). To date, use of timothy for high altitude reclamation has been characterized by mixed success, with good establishment indicated near Grande Cache (272) and unsuccessful growth relative to other grasses in the Crowsnest Pass area at elevations $1950 \mathrm{~m}$ ASL 
(377), both involving revegetation of coal mine waste. Timothy performed well above and below treeline (at $1500 \mathrm{~m} \mathrm{ASL}$ ) in revegetation of coalfield disturbances in northeastern British Columbia (including alpine tundra and alpine forest habitats) (143). Similarly, timothy was successfully incorporated into species mixes for coal mine reclamation on lands in the montane and subalpine zones (1 $650 \mathrm{~m}$ to $2200 \mathrm{~m} \mathrm{ASL}$ ) in the Rockies of southern British Columbia (494), and as high as $2950 \mathrm{~m}$ ASL in Montana (74). "Engmo" provided relatively good first and second year cover in tests in the arctic tundra and then declined rapidly due to winterkill (644). Timothy provided good growth on waste rock, overburden, and tailings at metal mines in the southern interior of British Columbia (143). On growth tests on pipeline berms in the Northwest Territories, "Climax" showed moderate growth at selected sites relative to other grasses; in other areas, it produced most of the combined first year grass growth (459). On the Norman Wells to Zama Pipeline "Climax" had relatively good cover and vigour in mixed seedings for the first two years and then declined rapidly (644). At Fort McMurray "Climax" did well for 2 to 3 years in a grass-legume mix on amended tailings sand soil and overburden, and then declined rapidly (643). In the Swan Hills, "Climax" remained co-dominant with "Boreal" creeping red fescue in a grass-legume mixture ten years after seeding (646).

Timothy is a common component of hay crops and revegetation species mixtures. Attractive features for revegetation include livestock forage value, commercial availability of seed, and rapid establishment. Suited wherever reclamation objectives indicate an agricultural land use (hay and pasture crop), as well as for interim erosion control seeding. 
Poa alpina

\section{SPECIES SUITABILITY MAP AND SUMMARY TABLE}

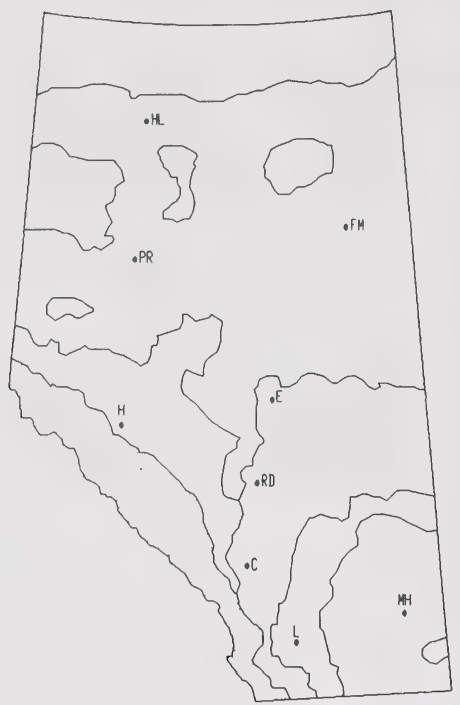

Recommended Area

Commercially Available: Yes $X$ No

\begin{tabular}{|c|c|c|c|c|c|}
\hline \multirow{2}{*}{$\begin{array}{l}\text { RECLAMATION SUITABILITY } \\
\text { CRITERIA }\end{array}$} & \multicolumn{5}{|c|}{ SUITABILITY RATING } \\
\hline & Very High & High & Medium & Low & None \\
\hline Drought Tolerance & & & $x$ & & \\
\hline Salt Tolerance & & & & $x$ & \\
\hline $\mathrm{pH}$ Acid & & $x$ & & & \\
\hline Tolerance Base & & & & & \\
\hline Winter Hardiness & $x$ & & & & \\
\hline Erosion Control & & & $x$ & & \\
\hline Persistence & & $x$ & & & \\
\hline Palatability & & $x$ & & & \\
\hline Browse Tolerance & & $x$ & & & \\
\hline Moisture Preference & Dry to & moist. & & & \\
\hline Soil Preference & Gravel & to loam & tured, w & drained. & \\
\hline
\end{tabular}




\section{Poa alpina $L$.}

\section{SPECIES BIOLOGY}

Taxonomy - Alpine Bluegrass

\section{Origin and Range}

Native. Circumpolar distribution; important over arctic and alpine regions of North America. Extending south to Quebec, northern Michigan, and the alpine summits of Colorado, Utah, Washington, Oregon, and Mexico $(214,199)$.

\section{Growth Habit}

Erect, densely tufted bunchgrass, 10 to $30 \mathrm{~cm}$ tall (312).

\section{Nitrogen Fixing}

None; but has been shown to be associated with $\mathrm{N}_{2}$-fixing bacteria (601).

Longevity - Cool season (639) perennial (199).

Self Propagation - Seed.

\section{Ecological Setting}

Common in the mountains (312) on dry slopes, meadows, rocks (214), also moist alpine slopes (50). Associated with many alpine plant communities including tufted hairgrass (Deschampsia caespitosa) in Colorado and Wyoming (60) and as part of Carex nigricans-Poa alpina-Erigeron peregrinus communities of alpine alluvial sites in British Columbia (355). Recorded at $3600 \mathrm{~m}$ ASL elevation in Wyoming (18). In the eastern Canadian arctic, Poa alpina is found in association with Poa rigens and Polygonum viviparum in sheltered valleys on well drained fine sandy limestone (177). Requires $50 \mathrm{~cm}$ of precipitation (639).

\section{TOLERANCES}

\section{Soil Preferences}

Will grow on bare soils, acidic mine spoils (185), and talus slopes (209). Also noted growing on (alpine) alluvial sites with loamy soil over fast draining gravel (355).

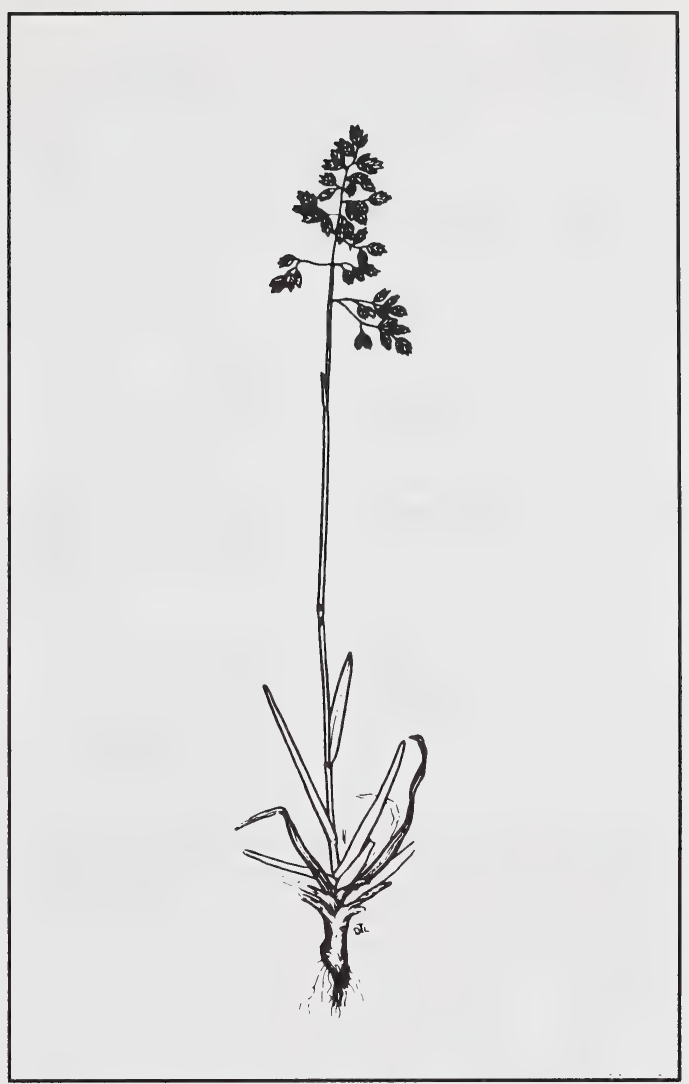

\section{Nutrient Requirements}

In general, application of inorganic fertilizers to native soils favors short-lived grasses and annual weeds, at the expense of long-lived perennials (455). This is thought to be applicable to alpine bluegrass.

\section{Soil Reaction}

Noted growing on acidic mine spoils in Montana $(185,76)$.

\section{Soil Salinity}

Will tolerate mildly saline soils.

\section{Drought}

Presumably drought tolerant. 
Heavy Metals and Hydrocarbons

No specific tolerances noted in the literature.

\section{Shade}

Presumably shade intolerant.

\section{Grazing or Mowing}

Apparently resistant to grazing (355).

\section{Susceptibility to Disease and Insect Damage}

No specific insect pests noted in literature reviewed. Found to be susceptible to snow mold although some strains appear resistant (J. Weijer, pers.comm.).

\section{RECLAMATION CONSIDERATIONS}

\section{Soil Building and Erosion Control Capability}

Its ability to colonize disturbances and its high root:shoot ratio make this species a good candidate for soil building, although the bunched habit of alpine bluegrass prevents it from being very effective at surface runoff control.

\section{Adaptation to Disturbance}

Alpine bluegrass is described as an active colonizer on virtually all disturbances in alpine environments (76). Considered to be relatively less susceptible to trampling by recreationists and horses than most other alpine vegetation; noted thriving on trampled soil (355).

\section{Competitive Ability}

Competitive ability depends on the genotype (D. Walker, pers.comm.). Observed to be not as aggressive as other alpine and subalpine grasses.

\section{Commercial Value}

Alpine grassland ranges with $P$ oa alpina are grazed by domestic sheep in Colorado and Wyoming (60).

\section{Palatability and Nutritive Value}

Rated high for palatability (427), alpine bluegrass is among those grass species preferred by domestic sheep on alpine rangelands in Montana (60); also used by grazing wildlife.

\section{Seed or Planting Stock Availability}

A limited supply of native seed stock is usually available. Approximately 1000000 seeds/lb (639). "Gruening" alpine bluegrass was released from Alaska for production in 1987 (738).

\section{Methods and Ease of Establishment}

In Alberta, Poa alpina seeds have been collected in the field and germinated in growth chambers. Nursery plants grown in containers derived from these seed collection efforts have been transplanted to disturbed subalpine sites, many on coal mine waste with excellent survival of the transplanted seedlings; the average number of seedheads was significantly higher on disturbed plots $(455,453$, 379). In Montana, Poa alpina was also successfully grown under greenhouse conditions (79). Seedlings transplanted to alpine mine spoils survived and were actively growing one year later (74). Alpine bluegrass recommended for seeding in Colorado at elevations above $2400 \mathrm{~m}$ ASL (427). Fall/spring seeding at a rate of $1 \mathrm{lb}$ PLS/ac has been recommended (639).

\section{Current Status for Reclamation}

The results of preliminary seeding and transplant studies involving establishment of Poa alpina on disturbed lands in alpine and subalpine areas of Alberta and Montana $(76,75,455,453,379)$ indicate the suitability of alpine bluegrass for reclamation of high elevation disturbances. Test seedings in alpine and subalpine sites in the eastern slopes region of Alberta and in the Upper Mackenzie region of the boreal forest (latitude $63^{\circ} \mathrm{N}$ ) had high survival and vigour after three years $(723,644)$. However, in mix trials in the eastern slopes alpine bluegrass did poorly after six years (705). At Fort McMurray alpine bluegrass did relatively well after five years on amended tailings sand (705). As a native species and a component of high elevation wildlife ranges, Poa alpina fulfills several criteria for species selection in revegetation planning.

First-year results of growth trials on alpine mine disturbance in Montana indicated that a native species grass mix, including alpine bluegrass, produced greater cover than an introduced species mix under all experimental treatments (74). The Alberta Environmental Centre is currently selecting a number of lines of Poa alpina for potential commercial production and fitness for reclamation (655). 
SPECIES SUITABILITY MAP AND SUMMARY TABLE

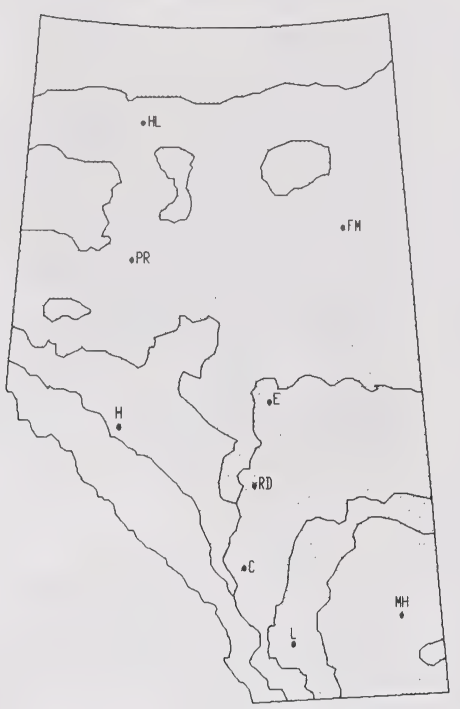

Recommended Area

Commercially Available: Yes $X$ No

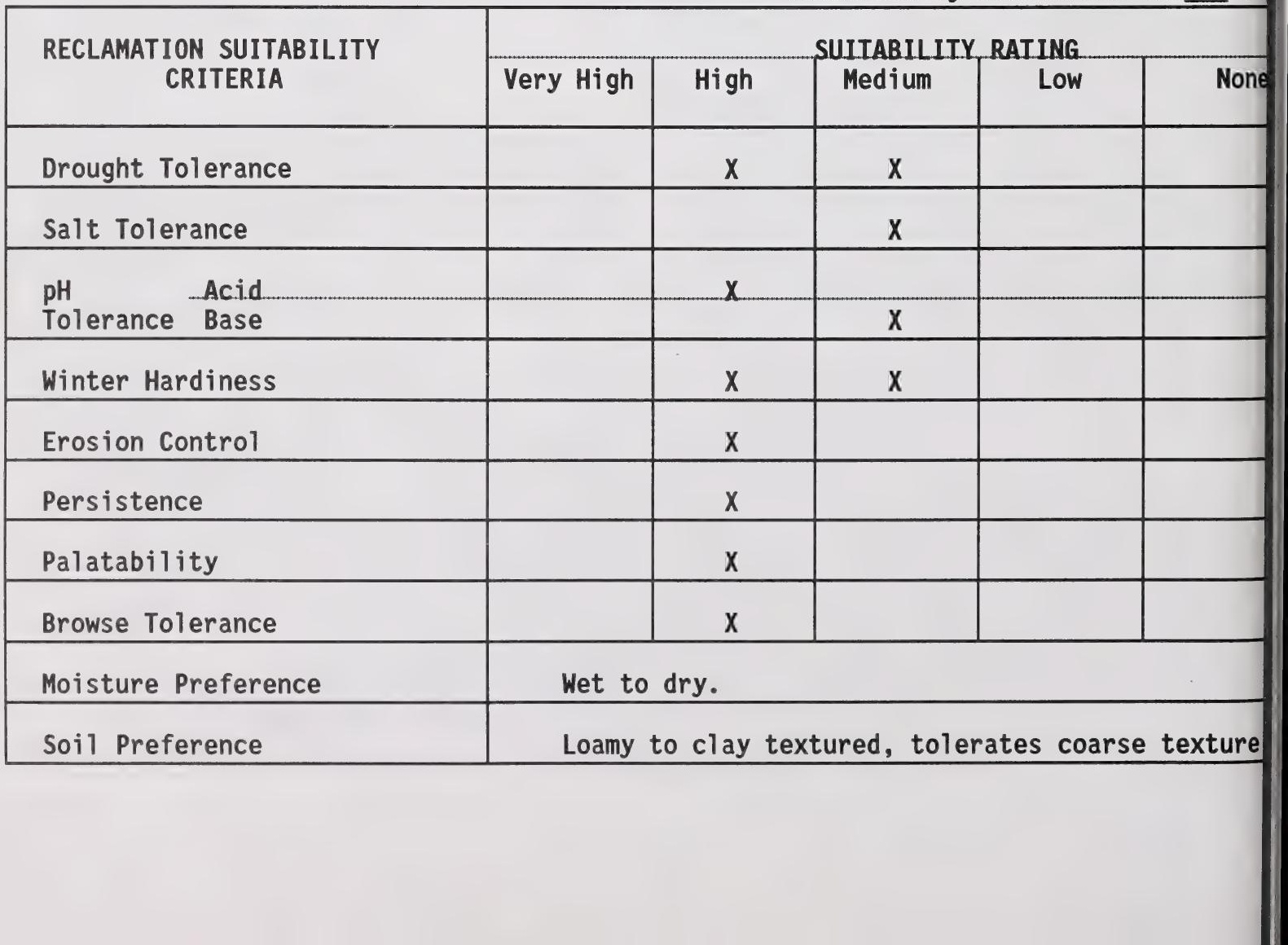


Poa compressa L.

\section{SPECIES BIOLOGY}

Taxonomy - Canada Bluegrass

\section{Origin and Range}

Variously described as a native (138) or introduced $(214,312)$ grass, found from Alaska to Newfoundland, south through much of United States (507).

\section{Growth Habit}

Medium tall, erect sod-forming grass with a dense creeping root system, long rhizomes and numerous fibrous roots extending deep into the soil. About 20 to $70 \mathrm{~cm}$ tall $(138,312)$. High root:shoot ratio. Low growth habit (436).

\section{Nitrogen Fixing - None}

\section{Longevity}

Long-lived, cool season (639) perennial.

\section{Self Propagation}

Seeds. Also spreads vegetatively by rhizomes, rated very good in this respect (338).

\section{Ecological Setting}

Widely used for pastures and as a substitute for P. pratensis in lawns (507). Commonly found on waste ground, roadsides, meadows, and open woods $(312,507)$. Found occurring in a wide range of wet to dry prairie stands in southern Michigan (413). Found growing as high as $2460 \mathrm{~m}$ ASL on moist sites in Wyoming (18). Transplants successfully growing on mine spoils at $3000 \mathrm{~m}$ ASL (75) in Colorado. Requires $45 \mathrm{~cm}$ of precipitation (639).

\section{TOLERANCES}

\section{Soil Preferences}

t grows on a variety of soils of low fertility or poor drainage (138). It occurs specifically on low fertility prairie and forest soils in the Pacific northwest and great basin states (179). Optimum slope for growth is 0 to $8 \%$; optimum soil depth 30 to $60 \mathrm{~cm}$. Good growth on loamy and clayey soils, and fair growth on sandy soil, in Colorado (446). In the Mackenzie

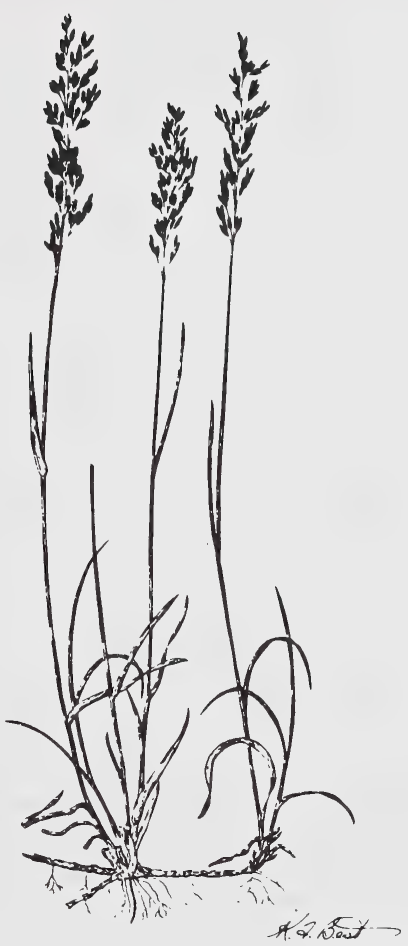

River Delta area, vigour of Canada bluegrass was rated good in terms of overwintering ability on both mineral and organic soils. It provided good cover in seeded areas after the second year of growth (486). Canada bluegrass showed good survival and growth on disturbed tundra and gravel bars in Alaska (284). Significantly higher survival on mineral soil than on organic soil in the Northwest Territories (111).

\section{Nutrient Requirements}

Has tolerance for low nutrient situations (436).

\section{Soil Reaction}

Spreads well on acidic mine spoils (185). Seedlings showed good establishment (first year growth) on acid spoils in Montana (75).

\section{Soil Salinity}

Shows moderate tolerance to soil salinity. 


\section{Drought}

Considered to be drought tolerant $(498,476)$.

Heavy Metals and Hydrocarbons

No references noted.

\section{Shade}

Moderately tolerant of at least partial shade.

\section{Grazing or Mowing}

Noted for its resistance to grazing (138).

\section{Susceptibility to Disease and Insect Damage}

No specific pests or diseases noted in literature reviewed.

\section{RECLAMATION CONSIDERATIONS}

\section{Soil Building and Erosion Control Capability}

Used for cover and erosion control on roadsides, roadcuts and fills, borrow pits, dam sites, and recreational areas (179). Its ability to persist and produce on poor quality soils makes it useful for regrassing eroded areas (506). Able to stabilize sandy loam soil (476).

\section{Adaptation to Disturbance}

Noted for its resistance to trampling (138). In general, good adaptation to disturbance (338). Able to cope with blowing sand (132). Persistent; reinvades improved pasture situations (179).

\section{Competitive Ability}

Subject to competition from other species: Canada bluegrass grew well in single species tests at $2100 \mathrm{~m} \mathrm{ASL}$, but was virtually absent in grasslegume mixes (497).

\section{Commercial Value}

Pasture grass for livestock (138), erosion control (179). However, it is difficult to eradicate and rapidly reinvades improved pasture seedings unless heavy management is practiced (179).

\section{Palatability and Nutritive Value}

Used as a pasture grass. Under some conditions, it is fairly productive for hay (138). Observations indicate that Canada bluegrass has some natural curing properties as livestock, particularly horses, maintain their condition when pasturing on it during the autumn and early winter (506). Generally quite palatable from early spring until late fall (138).

\section{Seed or Planting Stock Availability}

Seed of "Ruebens" and common Canada bluegrass is commercially available. Approximately 2500000 seeds/lb (639).

\section{Methods and Ease of Establishment}

Establishment by seed rated as good; establishment by transplanting rated as very good (338). In Colorado, it has low seedling vigour when seeded on disturbed subalpine sites, but is persistent once established, spreading by rhizomes (41). Fall/ spring seeding at a rate of 1 to $2 \mathrm{lbs}$ PLS/ac has been recommended (639). Field studies in Montana indicate good survival of Canada bluegrass transplants on acid spoils in the subalpine and alpine area (75).

\section{Current Status for Reclamation}

Canada bluegrass seeded on a coal exploration site in Alberta (at $1950 \mathrm{~m}$ ASL elevation) showed good to very good first year growth, but had heavy wintering losses (377). Marginal first year success was noted on coal mine waste at $1070 \mathrm{~m} \mathrm{ASL}$ in the Crowsnest area (380). Performance after six years had not improved (705). In tests near Banff (1 $390 \mathrm{~m}$ ) Canada bluegrass had good vigour after four years (732). On disturbed peat and mineral soils in the western Canadian arctic and Mackenzie Delta, "Canon" Canada bluegrass showed good establishment and winter survival for five years before declining (644). In the Northeast coal block of British Columbia, growth on exploration disturbances was rated as moderate above treeline (1 $370 \mathrm{~m} \mathrm{ASL}$ ) and excellent below treeline (70). Canada bluegrass had the poorest emergence of all species studied on coal mine wastes at Hat Creek, British Columbia (439). In the oil sands, "Ruebens" maintained high vigour and relatively good growth after five years testing on amended tailings sand (705).

Canada bluegrass is generally recommended for revegetation of poor soils in dry climates throughout North America. In Canada, it is frequently included in grass-legume mixtures at mine waste reclamation projects, though with mixed success. Its spreading (rhizomatous) habit, apparent tenacity, and erosion control ability are favored for revegetation. It is useful where reclamation objectives specify 
agricultural land use, particularly livestock pasture.

Many sources indicate slow establishment and relatively poor first year growth on agricultural and disturbed soils. It generally provides good cover and long term growth after the first year, however. 


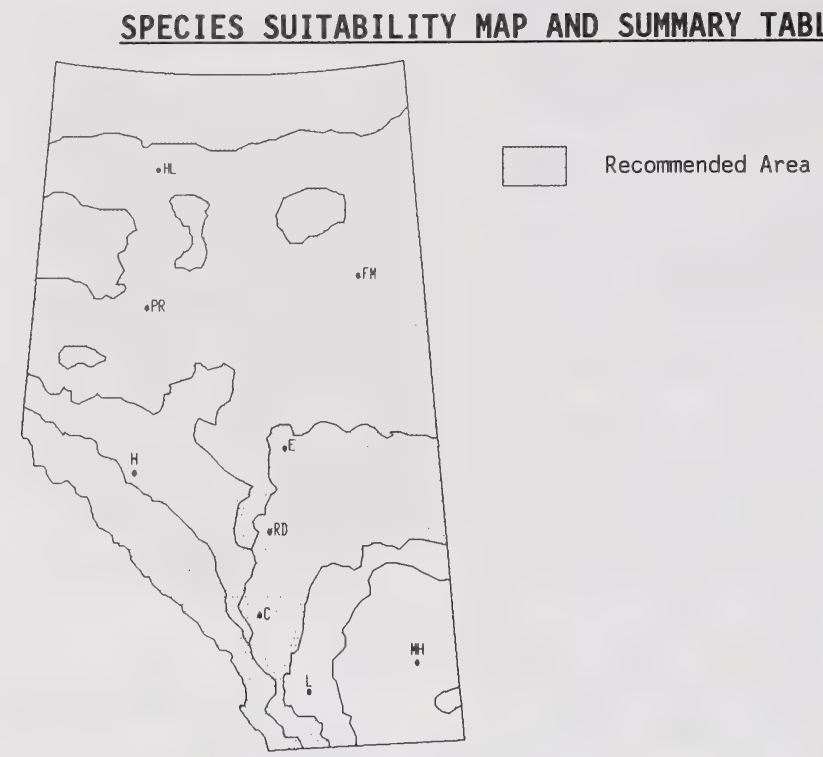

Commercially Available: Yes $X$ No

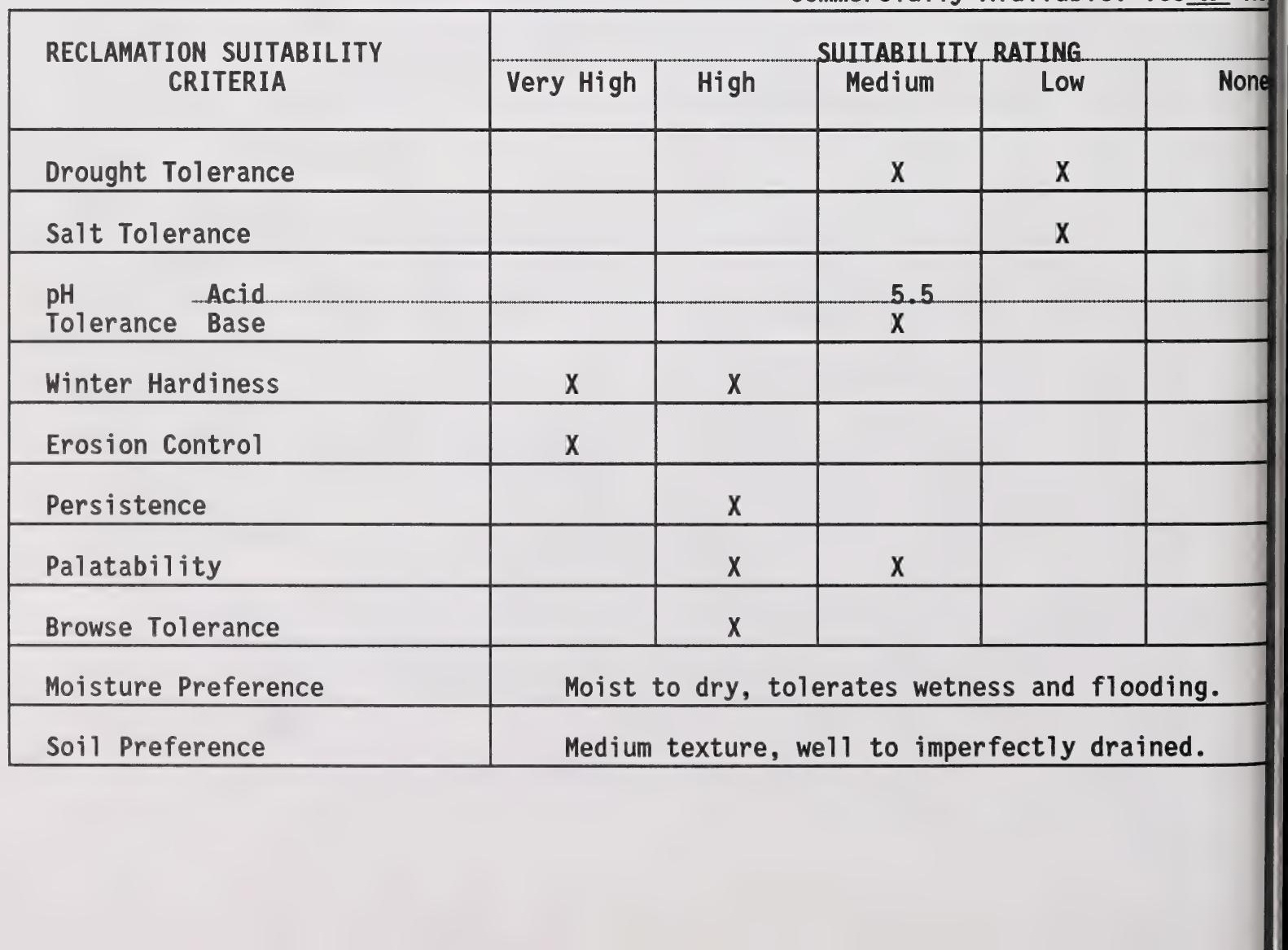


Poa pratensis L.

\section{SPECIES BIOLOGY}

Taxonomy - Kentucky Bluegrass

Includes $\underline{P}$. alpigena (Fr.) Lindm., $\underline{P}$. agassizensis Bovin \& D. Love

\section{Origin and Range}

Introduced from Eurasia. Widespread in most of temperate Canada and all but the southeastern U.S. (507). It occurs on the prairie grassland of central and northern Alberta (312). It has invaded rangelands to such a degree that it is often considered to be a native (506). There are a large number of varieties (70) licensed for use in Canada (138).

\section{Growth Habit}

A sod-forming grass with culms 30 to $80 \mathrm{~cm}$ tall (312). It is rhizomatous and produces dense sod under favorable conditions (391). It has a shallow root system subject to drying out in dry weather (340).

\section{Nitrogen Fixing - None}

\section{Longevity}

Long-lived, cool season (639) perennial (391). Kentucky bluegrass seeded at $3120 \mathrm{~m}$ ASL in southwestern Montana persisted or increased over a ten year period (193). It is persistent in most areas of the United States including Alaska (37). Several varieties have excellent winter hardiness $(5$, 138).

\section{Self Propagation}

Seeds. The formation of seed without fertilization (apomixis) is a common characteristic of Kentucky bluegrass varieties, consequently pollinated seeds are rare (138). Kentucky bluegrass produces abundant seed (138). Also spreads by rhizomes (391).

\section{Ecological Setting}

Roadsides and waste areas to dry or moist prairies and woodland (507), meadows and lawn (312). An mportant range grass for cattle throughout the aspen parkland in Alberta (506). Kentucky pluegrass is adapted to a cool, humid climate and grows on moist sites in meadows, pastures, fields, and open woods (138). Requires $45 \mathrm{~cm}$ of

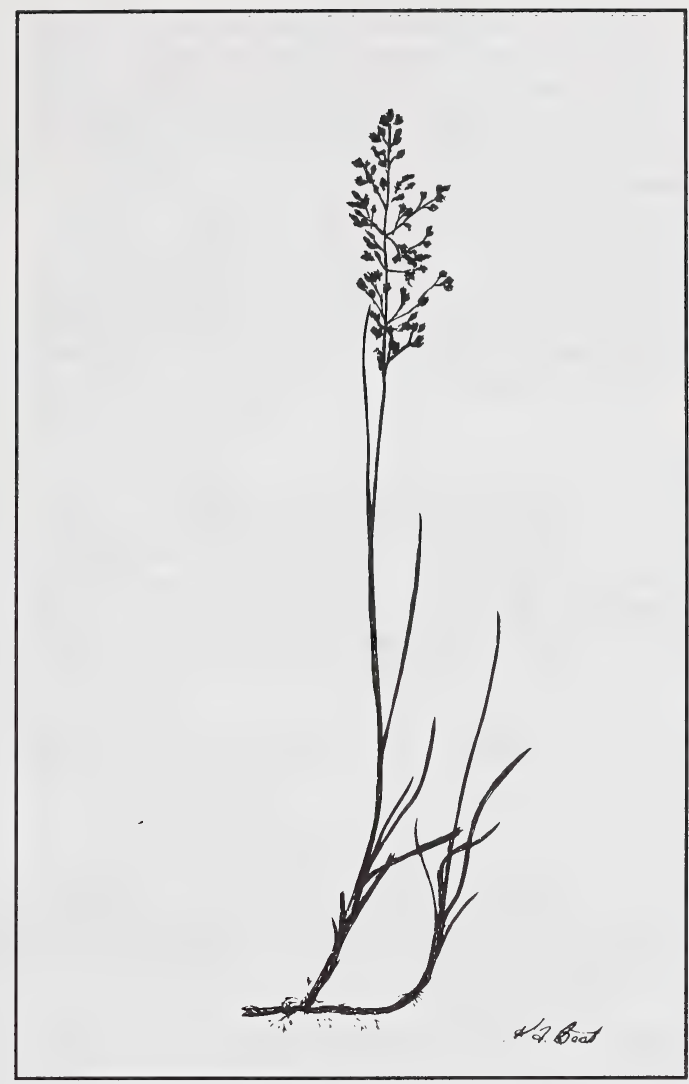

precipitation (639). It requires more moisture than is available over most of the prairies and thus has never been popular for pasture purposes where rainfall is less than $50 \mathrm{~cm}$ annually (506). Areas best suited are moderately moist with precipitation greater than $38 \mathrm{~cm}$, moderately cold to cold and at elevations greater than $2167 \mathrm{~m}$ ASL (427). Kentucky bluegrass requires cool, moist conditions for optimum growth; it therefore grows best on northern exposures or at higher elevations (37). Kentucky bluegrass is an important component of the sandhills tallgrass prairies in North Dakota (469).

\section{TOLERANCES}

\section{Soil Preferences}

Kentucky bluegrass grows best in soils of medium texture (138). It is adapted to a range of soil moisture regimes from well drained through to imperfectly or poorly drained. It is adapted to a wide range of soil groups and soil textures. Kentucky bluegrass has good tolerance to wetness and flooding (5). Kentucky bluegrass performed 
better on mineral soil than organic soil when seeded on a disturbed site near Norman Wells, N.W.T. (110). Growth on sandy soil is fair whereas growth on loamy and clayey soil is rated as good (447).

\section{Nutrient Requirements}

It grows best in soils of high fertility (138), and fertilizer requirement has been rated as high (5). Kentucky bluegrass has rather exacting nutrient requirements and it responds favorably to high nitrogen fertilization (37).

\section{Soil Reaction}

It has been noted as having only fair tolerance to soil acidity (5); soil pH must be at least 5.5 for good growth (712). Kentucky bluegrass does well on soils of limestone origin (37).

\section{Soil Salinity}

Kentucky bluegrass has poor tolerance to soil salinity (424).

\section{Drought}

It is not drought resistant (138). Yields can be increased with irrigation (391). It may go dormant during dry weather (37).

\section{Heavy Metals and Hydrocarbons}

Kentucky bluegrass was the best agronomic grass on metal tailings ( $\mathrm{Pb}, \mathrm{Ag}, \mathrm{Zn})$ in the Yukon after three years (611). At the site of a diesel spill near Whitehorse, Kentucky bluegrass was surviving where there was not direct contact with the diesel, but where diesel was present in the soil (216).

\section{Shade}

Kentucky bluegrass will grow in slightly shaded situations, if moisture and nutrients are available, but it grows better in open sunlight (37).

\section{Grazing or Mowing}

Kentucky bluegrass has a rapid recovery rate after cutting (5).

\section{Susceptibility to Disease and Insect Damage}

Various varieties are subject to stripe rust, leaf rust, stem rust, powdery mildew, leaf spot, Helminthosporium, red thread, and stripe smut (138).

\section{RECLAMATION CONSIDERATIONS}

\section{Soil Building and Erosion Control Capability}

An excellent grass for controlling erosion and promoting soil stability $(340,338)$. Kentucky bluegrass produces a dense rhizomatous sod under favorable conditions (37). It has high ground cover production (436) and a good rate of spread (424, 338).

\section{Adaptation to Disturbance}

Tolerant of trampling. Its short foliage and tough sod features make it useful for seeding camp, picnic areas, and other turf areas (340). Kentucky bluegrass is common throughout the moist prairies, where it has escaped from lawns and pasture (78); it is an early colonizer of old fields in adapted areas (145). Spring burning tends to reduce vigour and cover (145).

\section{Competitive Ability}

Kentucky bluegrass is slow to establish when seeded in a mixture, but grows well with white clover (Trifolium repens), or other legumes (391). Compatibility has been rated as good $(436,5)$. Kentucky bluegrass seeded on tailings sand slopes in northern Alberta was dominant at low fertilizer rates but at higher rates it was unable to compete with larger smooth brome grass and the wheatgrasses (359).

\section{Commercial Value}

An important pasture grass (391). Also important for hay crops (138). It is used extensively in mixtures for the production of general turf and highly developed lawns throughout Canada (138).

\section{Palatability and Nutritive Value}

Kentucky bluegrass is palatable and very nutritious for cattle (19) during the spring; however, unless it is kept grazed, it soon becomes stemmy and unpalatable (506). It is relatively unproductive in mid-summer when it goes dormant during dry weather (391). Forage value for mule deer has been rated as fair, while for small mammals forage value has been rated as good (447). Poa spp. received medium use by moose and bighorn sheep, and high use by mule deer and elk (144).

\section{Seed or Planting Stock Availability}

Seed of Kentucky bluegrass is available 
commercially. Over twenty licensed cultivars are available: "Amazon", "Baron", "C-1", "Delta", "Fylking", "Kenon" (no certified seed available), "Merion", "Nugget", "Park", "Prato", "Primo", "Sydsport", "Troy", "Ram 1", "Regent", "Windsor", "Banff", "Birka", "Bono", "Cheri", "Dormi", "Majestic", "Touchdown", "Victa" (138). Approximately 2177000 seeds/lb (639).

\section{Methods and Ease of Establishment}

In mixtures, this plant is slower to become established than most grasses and legumes, not appearing until two or three years after a mixture is seeded (391). Seedling vigour has been rated as fair (5). Establishment by seed and by transplanting has been rated as very good (338). Plants are persistent once established (41). Fall/spring seeding at a rate of 2 to $3 \mathrm{lbs}$ PLS/ac has been recommended (639).

\section{Current Status for Reclamation}

Kentucky bluegrass has been used extensively for reclamation in Canada (316). "Troy" and "Nugget" did equally well providing acceptable cover in the first three years in the subalpine on overburden and topsoil in the Eastern Slopes region of Alberta (723). "Nugget" produced better cover on topsoil than on raw overburden (364). At Banff "Nugget" provided adequate short-term (2 to 3 year) cover at $1390 \mathrm{~m}$ before declining (732). In tests in the Mackenzie River Delta (latitude $70^{\circ} \mathrm{N}$ ) "Nugget" has persisted strongly for twelve years without follow-up fertilizer (643). "Regent" had excellent survival and vigour in the upper Mackenzie region of the Boreal Forest (latitude $63^{\circ} \mathrm{N}$ ) after three years. Common Kentucky bluegrass performed poorly in a mix on the Norman Wells to Zama pipeline (644). It also performed poorly in a grass-legume mix at Cold Lake (685). At Fort McMurray, "Nugget" had moderately high plant vigour and cover after five years on amended tailings sand (705). Kentucky bluegrass has been recommended for coal mine reclamation on sites above $1650 \mathrm{~m} \mathrm{ASL}$ in southeastern B.C. This species also proved successful in test plots established at $2200 \mathrm{~m} \mathrm{ASL}$ in the same area (494). An initial assessment of Kentucky bluegrass seeded on dry mine wastes at 3 mines in southeastern B.C. showed it to have moderate performance on waste rock and poor performance on tailings and overburden (143). Kentucky bluegrass has been recommended as a suitable grass for planting on critical areas in Alaska (5), for tundra sites in the Mackenzie and Yukon Valley and for boreal forest sites (37).
It is used extensively throughout the northeastern United States to obtain a fast cover on disturbed land areas (37). It is used in highway roadbank seedings in Alaska and is under experimentation there (298). It has been recommended as suitable for planting in critical sites in northwestern Colorado. Kentucky bluegrass was one of the best grasses tested at several subalpine sites in northcentral and central Colorado. It persisted for at least three years and spread out from the seeded zones (236). Kentucky bluegrass is used for soil stabilization after road construction (176) in Colorado and Wisconsin.

Kentucky bluegrass is a long-lived, sod-forming grass providing excellent soil erosion control, posture and turf over a wide geographic range, preferring medium to heavier textured soils and moist sites. Being slow to establish it should be seeded with a mix on sites requiring immediate protection. 
Puccinellia distans

\section{SPECIES SUITABILITY MAP AND SUMMARY TABLE}

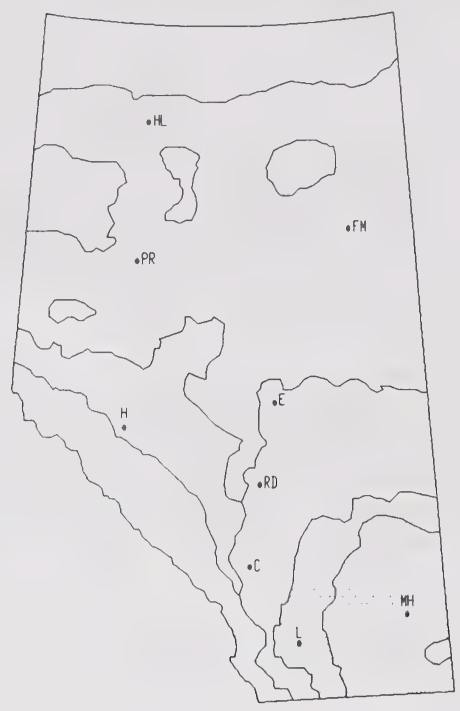

Recommended Area

Commercially Available: Yes $X$ No

\begin{tabular}{|c|c|c|c|c|c|}
\hline \multirow{2}{*}{$\begin{array}{l}\text { RECLAMATION SUITABILITY } \\
\text { CRITERIA }\end{array}$} & \multicolumn{5}{|c|}{ SUITABILITY RATING. } \\
\hline & Very High & High & Medium & Low & None \\
\hline Drought Tolerance & & & $x$ & & \\
\hline Salt Tolerance & $x$ & $x$ & & & \\
\hline pH Acid... & & & & $x$ & \\
\hline Tolerance Base & & $x$ & & & \\
\hline Winter Hardiness & & & $x$ & & \\
\hline Erosion Control & & $x$ & & & \\
\hline Persistence & & & $x$ & & \\
\hline Palatability & & & $x$ & & \\
\hline Browse Tolerance & & & & $x$ & \\
\hline Moisture Preference & Moist & wet, & rates $d r$ & dry & e soi \\
\hline Soil Preference & Loamy & clay & ure. & & \\
\hline
\end{tabular}


Puccinellia distans (L.) Parl.

\section{SPECIES BIOLOGY}

\section{Taxonomy}

Slender Salt-Meadow Grass (78); Alkaligrass (639).

\section{Origin and Range}

Introduced from Eurasia. Apparently not very common in Alberta, found occasionally in the southeastern portion of the Canadian prairies. Alaska, British Columbia to Quebec, south to Maryland, Michigan, Wisconsin, and North Dakota; Washington, south to New Mexico and California. Regarded as an introduced weed (214). P. distans intergrades with $\underline{P}$. nuttalliana (Schult.) Hitchc. (P. airoides (Nutt.) Wats. and Coult.) which is called Nuttall alkali grass or Nuttall's salt-meadow grass and is a native of western North America $(312,78$, 199).

\section{Growth Habit}

A short, tufted bunchgrass. Erect or decumbent, generally 20 to $50 \mathrm{~cm}$ tall $(312,199,78)$.

Nitrogen Fixing - None

Longevity - Cool season (639) perennial (435).

Self Propagation - By seed.

\section{Ecological Setting}

Slender salt-meadow grass is found in moist, slightly alkaline flats in the southeastern portion of the Canadian prairies (78). In Alaska, it is found along roads, in yards and waste areas. Nuttall alkali grass is common throughout the prairies in moist saline depressions. Also found in dry to wet alkaline soils. It is often found growing with Distichlis stricta (47). Requires $38 \mathrm{~cm}$ of precipitation (639).

\section{TOLERANCES}

\section{Soil Preferences}

Slender salt-meadow grass prefers moist to wet soils. Optimum slope is $9 \%$ to $30 \%$ and optimum soil depth is greater than $60 \mathrm{~cm}$. Growth on sandy soil is fair, and growth on loamy and clayey soil is good (446). Although it is usually located on moist soils, some ecotypes do colonize and persist well in drier situations (435).

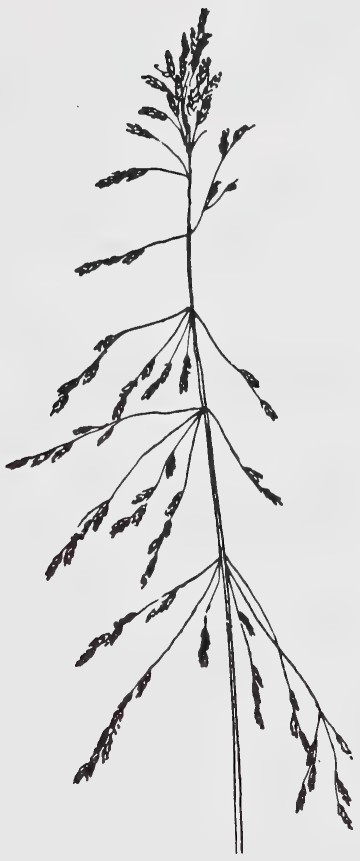

\section{Nutrient Requirements}

Requires low to moderate soil nutrient levels.

\section{Soil Reaction}

Slender salt-meadow grass is tolerant of alkaline soils (446).

\section{Soil Salinity}

Slender salt-meadow grass is salt tolerant (446). Nuttall alkali grass has very high salt tolerance (361).

\section{Drought}

Adapted to physiologically dry conditions, although it is found on moist sites.

\section{Heavy Metals and Hydrocarbons}

No specific tolerances noted. 
Shade

Does not persist if shaded.

Grazing or Mowing

Puccinellia spp. are often severely damaged when grazed (199).

\section{Susceptibility to Disease and Insect Damage}

No disease or insect pests noted in the literature reviewed.

\section{RECLAMATION CONSIDERATIONS}

\section{Soil Building and Erosion Control Capability}

The ability of both alkali grasses to grow on saline soils may contribute to stabilization and soil building in these sites.

\section{Adaptation to Disturbance}

Invades disturbed saline depressions.

\section{Competitive Ability}

Not particularly aggressive.

\section{Commercial Value}

May be used for forage although not as productive as many other species.

\section{Palatability and Nutritive Value}

Puccinellia spp. are generally fairly palatable, but seldom abundant enough to be heavily used except in muddy areas (199). Nuttall alkali grass makes a palatable hay but stands are too sparse to obtain heavy yields. Conflicting evidence indicates that it is common but it is not readily grazed (78). It apparently produces considerable forage in the regions where it is common and a form called "Zawadke" alkali-grass is cultivated in Montana. The forage value of slender salt-meadow grass has been rated as poor for mule deer and game birds, and fair for small mammals. Cover value is poor for mule deer, and fair for gamebirds and small mammals (440).

\section{Seed or Planting Stock Availability}

Nuttall alkali grass is sometimes cultivated under the name of "Zawadke" alkali grass $(312,78)$. "Fults" available in the US (639). Approximately
1200000 seeds/lb (639).

\section{Methods and Ease of Establishment}

By seed. Fall/spring seeding at a rate of 2 to $3 \mathrm{lbs}$ PLS $/ 1000 \mathrm{ft}^{2}$ (639). No other specific methods of establishment were noted in the literature reviewed.

\section{Current Status for Reclamation}

Slender salt-meadow grass has been recommended for long term rehabilitation of disturbed land in northwestern Colorado (446). Some research into the use of $\underline{P}$. nuttalliana and $\underline{P}$. distans for reclamation is being done at Colorado State University (132). They both have potential for reclamation of alkaline or saline soils in Alberta (435). Nuttall alkali grass, invading disturbed sites at Pinchi Lake mine in British Columbia, has been noted to increase after fertilizer application. The occurrence of this species on harsh tailings has prompted seed collections for further testing (394). Showed excellent survival and vigour after three years in the Upper Mackenzie region of the boreal forest (latitude $63^{\circ} \mathrm{N}$ ) (644). 
$\underline{\text { Stipa viridula }}$

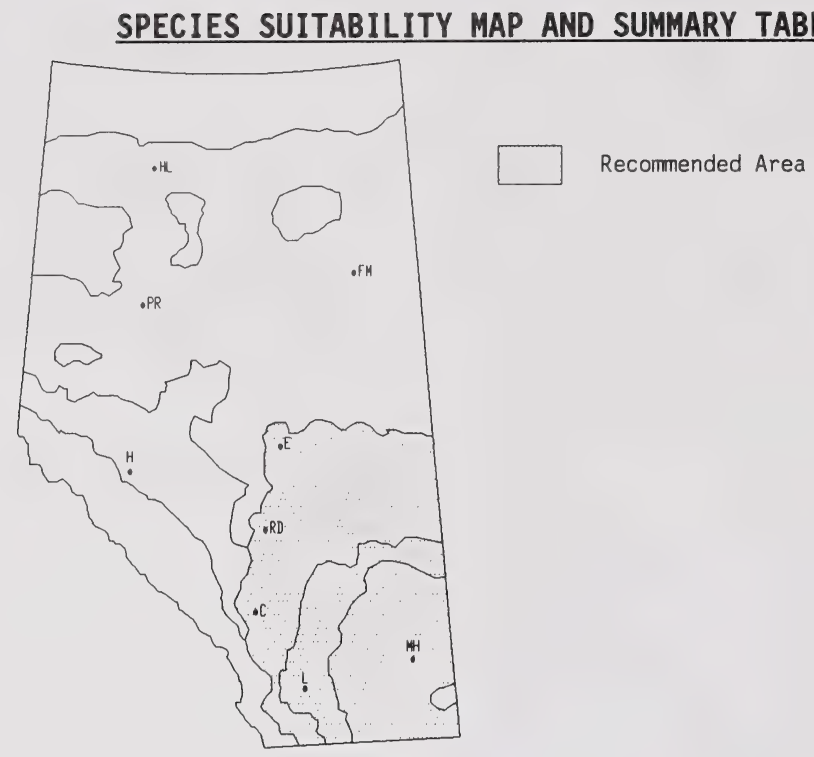

Commercially Available: Yes No

\begin{tabular}{|c|c|c|c|c|c|}
\hline \multirow{2}{*}{$\begin{array}{l}\text { RECLAMATION SUITABILITY } \\
\text { CRITERIA }\end{array}$} & \multicolumn{5}{|c|}{ SUITABILITY RATING } \\
\hline & Very High & High & Medium & Low & None \\
\hline Drought Tolerance & & & $x$ & & \\
\hline Salt Tolerance & & & & $x$ & \\
\hline Acid & & & & & \\
\hline Tolerance Base & & & $x$ & & \\
\hline Winter Hardiness & & & $x$ & & \\
\hline Erosion Control & & & $x$ & & \\
\hline Persistence & & & $x$ & & \\
\hline Palatability & & $x$ & $x$ & & \\
\hline Browse Tolerance & & & $x$ & $x$ & \\
\hline Moisture Preference & Dry to & oist. & & & \\
\hline Soil Preference & Loamy & clay & Ired, wid & ge. & \\
\hline
\end{tabular}


Stipa viridula Trin.

\section{SPECIES BIOLOGY}

Taxonomy - Green Needle Grass

\section{Origin and Range}

Native. Found throughout the southern portion of the Canadian prairies and southern B.C. (78). In the U.S. it is found from Wisconsin to Montana and south to New Mexico (183).

\section{Growth Habit}

A tall, tufted bunchgrass usually 40 to $80 \mathrm{~cm}$ tall (312). It has a fibrous root system, and is fairly deep rooted (392).

\section{Nitrogen Fixing - None}

\section{Longevity}

Cool season (639) perennial (365). Green needle grass generally flowers when plants are three years old. It requires a certain dry period to flower (467).

\section{Self Propagation}

Seed. Shoots originate from tillers (467).

\section{Ecological Setting}

Green needle grass is common in the dry prairie grassland (312). Apparently common in moister places and heavier soil throughout the southern part of the Canadian prairies (78). It is most common in areas receiving $38 \mathrm{~cm}$ or more mean annual precipitation, but it occurs in areas receiving as little as $25 \mathrm{~cm}$ (426). Subalpine needle grass (Stipa columbiana) is a component of the submontane prairie (454). Needle and thread (Stipa comata) is an important component of the mixed prairie (435). It is characteristic of the excessively drained high prairie of eastern North Dakota $(465,170)$.

\section{TOLERANCES}

\section{Soil Preferences}

Green needle grass is found on dry to moist, deep fertile soils throughout the prairies (47). It is adapted to a wide range of soil textures but it is more abundant on clay textured soils (426). Planting on loamy or clayey soils was recommended for critical areas in Colorado (424). Growth on sandy soil is reported to be fair, while on

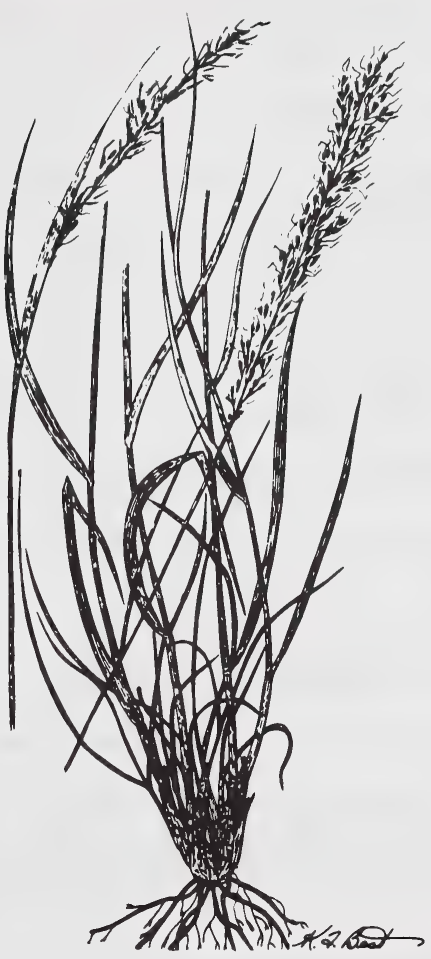

loamy and clayey soil, growth is good (446).

\section{Nutrient Requirements}

Additions of $\mathrm{N}$ fertilizer increased the number of vegetative tillers, but did not affect the number of floral tillers (467).

\section{Soil Reaction}

No specific tolerances noted in the literature reviewed, although it is expected to be tolerant of moderately alkaline sites.

\section{Soil Salinity}

Green needle grass has poor salt tolerance (424).

\section{Drought}

Moderately drought tolerant.

Heavy Metals and Hydrocarbons

No specific tolerances noted in the literature. 


\section{Shade}

Presumably relatively intolerant of shade. Prefers open sunny locations.

\section{Grazing or Mowing}

Needle and thread was found to increase on grazed rangelands in the interior of B.C. $(114,287)$, but to decrease under increased grazing pressure in the Stipa-Bouteloua prairie of Alberta $(389,390,122$, 392). Deeper rooted needle and thread tended to be replaced by shallow rooted little club moss (Selaginella) and blue grama (Bouteloua) on heavily grazed Stipa-Bouteloua prairie soils (392).

\section{Susceptibility to Disease and Insect Damage}

No specific diseases or insect pests noted for this species.

\section{RECLAMATION CONSIDERATIONS}

\section{Soil Building and Erosion Control Capability}

Green needlegrass is a bunchgrass with fibrous roots (47), and is fairly deep rooted (392); therefore, it could be expected to provide moderate erosion protection. It has a fair rate of spread (424).

\section{Adaptation to Disturbance}

Invades disturbed sites in areas of adaptation.

\section{Competitive Ability}

Moderately aggressive although compatible with other grasses.

\section{Commercial Value}

Used extensively as a range forage plant for livestock and wildlife in the southern Canadian prairies and northern prairie states.

\section{Palatability and Nutritive Value}

Stipa spp. are one of the most valuable forage grasses on western ranges, both for hay and pasture. In some species (especially $\underline{\mathrm{S}}$. spartea and $\underline{\mathrm{S}}$. comata) the seed lemmas are needle-like and injurious to the mouth parts and skin of grazing animals, particularly sheep. They are therefore grazed mainly when young. They are palatable much of the year however $(309,199)$. Needle and thread is considered relatively poor summer and winter forage compared to bluebunch wheatgrass
(Agropyron spicatum) (114). When comparing western wheatgrass (Agropyron smithii), green needle grass (Stipa viridula), blue grama (Bouteloua gracilis) and little bluestem (Andropogon scoparius), western wheatgrass and green needle grass had the highest hemicellulose values throughout the growing season; therefore they were the most digestible. However, they were the most lignified at the end of the growing season. Crude protein content decreased with salinity (231). Forage value of green needle grass is reported to be fair for mule deer and game birds, and good for small mammals (446).

\section{Seed or Planting Stock Availability}

Seed is apparently available for released cultivars in the U.S. (426). Two cultivars are "Green Stipagrass", which is superior to common needle grass in forage, seed yields, seedling vigour and regrowth, and "Lodorm" which is relatively expensive (D. Walker, pers.comm.) (426). These are not licensed in Canada. Approximately 181000 seeds/lb (639).

\section{Methods and Ease of Establishment}

Green needle grass has a typical purity/germination of $97 / 24 \%$ (132). Seed of green needle grass is very dormant. Only about $4 \%$ of its seed germinates without pretreatment (455). Ease of establishment of green needle grass has been rated as good (424). Fall seeding at a rate of 8 to $10 \mathrm{lbs}$ PLS/ac has been recommended (639).

\section{Current Status for Reclamation}

Subalpine needle grass (Stipa columbiana) collected from a subalpine site in Alberta (Pigeon Mountain) had good survival after three years on several alpine and subalpine sites in Alberta (723). Survival tended to be higher on undisturbed sites $(84 \%)$ when compared to disturbed sites $(64 \%)$. This was attributed to better soil moisture conditions on the undisturbed site (184). Subalpine needle grass produced better cover on overburden topdressed with mineral soil than on raw overburden after one year at a subalpine site (Cadomin) in Alberta. The cover after the first year was very low, however (364). Needle and thread has also been suggested for possible use on high $\mathrm{pH}$, high lime and coarse textured soils in the mixed prairie region of Alberta (435).

Green needle grass is used extensively in single seedling mixtures in the northern great plains and for mine revegetation in that same area (426). A survey of 17 mines in the southern great plains coal province (which includes parts of Montana, North 
Dakota, South Dakota, Nebraska and Wyoming) indicated that $71 \%$ of the mines used green needle grass in their seeding mixtures (31). Subalpine needle grass (Stipa columbiana) seeded at two sites in Utah and Wyoming at $3000 \mathrm{~m}$ and $2900 \mathrm{~m} \mathrm{ASL}$, respectively, produced poor stands after 18 years (213). "Lodorm" green needle grass has proved useful for mine reclamation in the western United States (90). 
$\underline{\text { Trisetum spicatum }}$

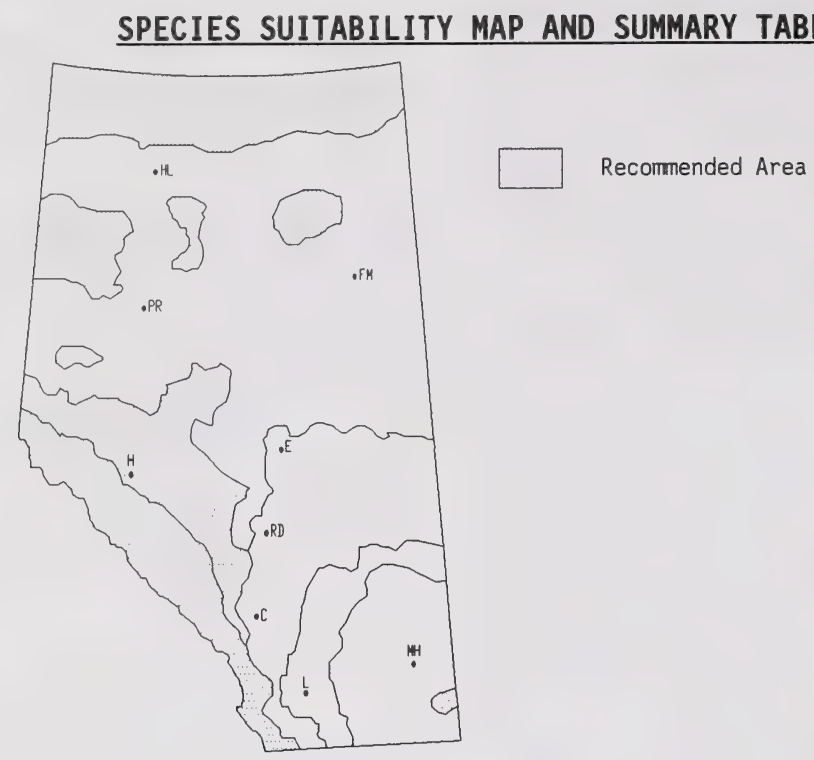

Commercially Available: Yes

\begin{tabular}{|c|c|c|c|c|c|}
\hline \multirow{2}{*}{$\begin{array}{l}\text { RECLAMATION SUITABILITY } \\
\text { CRITERIA }\end{array}$} & \multicolumn{5}{|c|}{ SUITABILITY RATING } \\
\hline & Very High & High & Medium & Low & None \\
\hline Drought Tolerance & $x$ & $x$ & $x$ & & \\
\hline Salt Tolerance & & & & $x$ & \\
\hline Acid & & & $x$ & & \\
\hline Tolerance Base & & & $\mathrm{X}$ & & \\
\hline Winter Hardiness & $x$ & & & & \\
\hline Erosion Control & & & $x$ & & \\
\hline Persistence & & $x$ & & & \\
\hline Palatability & & $\mathrm{x}$ & & & \\
\hline Browse Tolerance & $x$ & $x$ & & & \\
\hline Moisture Preference & Dry. & & & & \\
\hline Soil Preference & Rocky & se & ured. & & \\
\hline
\end{tabular}




\section{Trisetum spicatum (L.) Richt.}

\section{SPECIES BIOLOGY}

Taxonomy - Spike Trisetum

\section{Origin and Range}

Native. A northern species found from Alaska east to Hudson Bay and Newfoundland. South to the mountains from British Columbia to northern California. Also northern Eurasia (214). A wide ranging species in Alberta (312).

\section{Growth Habit}

An erect, fairly tall and tufted bunchgrass (309). Usually 10 to $50 \mathrm{~cm}$ tall (312).

\section{Nitrogen Fixing}

None; but has been associated with $\mathrm{N}_{2}$-fixing bacteria (601).

Longevity - Long-lived perennial.

\section{Self Propagation}

Mainly by seed but viviparous plants may occur (214).

\section{Ecological Setting}

Common species of the northern tundra and in dry places in the mountains (18); snow beds to at least $2000 \mathrm{~m}$ ASL in Alaska (214). In Alberta, wideranging, particularly in meadows, on slopes and or on ridges (312). It has been found in the Cypress Hills, though it is not a common species of the prairie region (78). Seed has been collected at Mount Rae $(2500 \mathrm{~m})$ and Mountain Park Pass $(2230 \mathrm{~m})$ in Alberta (453). This alpine grass is adapted to an environment where there may be only two months of summer and a frost free period as short as seven days. It is able to grow, flower and set seed at temperatures below freezing (455).

\section{TOLERANCES}

\section{Soil Preferences}

Spike trisetum is found on dry mountain soils (214), dry rock outcrops and rockslides $(209,427)$.

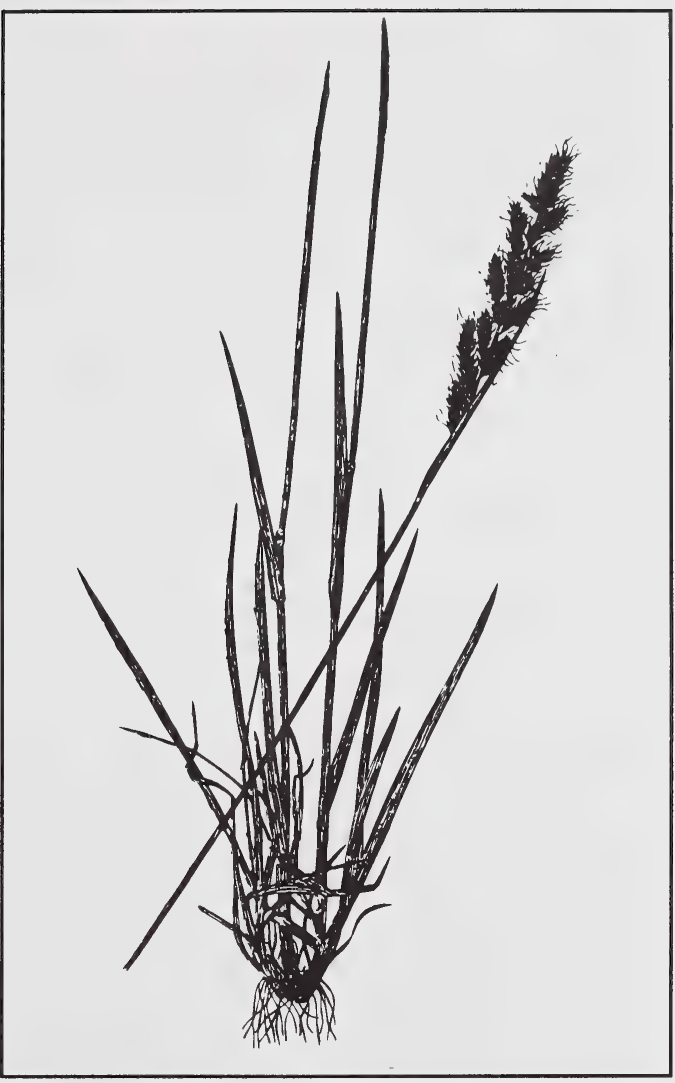

\section{Nutrient Requirements}

Spike trisetum has been recommended for revegetation of shallow, infertile soils at elevations above $2665 \mathrm{~m} \mathrm{ASL}$ in northwestern Colorado (427). Nutrient requirements are probably modest.

\section{Soil Reaction}

Spike trisetum has been observed as a pioneer on calcareous, talus slopes in British Columbia (209). It has been recommended for revegetation of mountain soils derived from granitic, basaltic, sandstone or shale materials (427). It can be assumed therefore that tolerances encompass at least mildly alkaline to mildly acidic soil conditions.

Soil Salinity - Low tolerance of saline soils. 


\section{Drought}

Moderately to extremely drought tolerant. There may be considerable ecotypic variation.

Heavy Metals and Hydrocarbons

No specific tolerances noted.

Shade - Will grow in partial shade.

Grazing or Mowing - Can withstand severe grazing.

Susceptibility to Disease and Insect Damage

No specific pests noted.

\section{RECLAMATION CONSIDERATIONS}

\section{Soil Building and Erosion Control Capability}

Spike trisetum has a high root:shoot ratio and is thought to be useful for soil building and erosion control.

\section{Adaptation to Disturbance}

Spike trisetum was observed as a pioneer on road cuts and fills in the alpine zone of Rocky mountain National Park in Colorado. It was most prominent on slopes where late-lying snow occurred (177). It also invaded test plots established on Harmer Knob $(2200 \mathrm{~m})$ in southeastern B.C. (491). Trisetum sp. has been rated as a pioneer on glacial outwash in the Canadian Rocky Mountains. Spike trisetum has been observed as a pioneer of both north and south-facing talus slopes of the Liard Plateau, B.C. (209). It has also been observed as a pioneer on mine tailings in B.C. (384). Trisetum spicatum subsp. spicatum was a pioneer on dry areas disturbed by animal diggings on the top of pingos near Prudhoe Bay, Alaska (45).

\section{Competitive Ability}

Moderately aggressive on favored locations.

\section{Commercial Value}

Wildlife forage and erosion control.

\section{Palatability and Nutritive Value}

Spike trisetum is an important forage plant in the alpine and subalpine (8). It has high palatability (427). It has been reported to be grazed by Rocky Mountain mule deer (245).

\section{Seed or Planting Stock Availability}

Commercial seed is under development, but is not currently available.

\section{Methods and Ease of Establishment}

There is ecotypic variation in germination response amongst populations with regard to temperature and light. Germination has been found to be related to the typical temperature at elevations where the population is naturally found. Seed from populations of lower latitudes reach maximum germination more gradually and at higher temperatures than seed from higher latitudes (92). Seedlings transplanted to subalpine sites in Alberta (Sunshine and Coal Valley) had good first year survival (79\%) (453). In general, satisfactory germination can be obtained at $20^{\circ} \mathrm{C}$ (455).

\section{Current Status for Reclamation}

The species is not widely used and success to date in high elevation revegetation has been mixed. Spike trisetum had the highest survival in subalpine and alpine sites at Tent Mountain and Adanac (723) but failed in mixture trials at Cadomin and Adanac (705). At Fort McMurray the species did moderately well after five years on amended tailings sand (705).

Spike trisetum has been recommended for planting on critical sites in northwestern Colorado, at elevations above $2665 \mathrm{~m}$. These areas are cold and moist, with precipitation above $50 \mathrm{~cm}$. Soils are mostly shallow (427). It has proved a successful species for revegetation of disturbed alpine sites in Montana (71). Spike trisetum showed promise in early seeding trials for revegetation of disturbed areas at 3000 to $3665 \mathrm{~m} \mathrm{ASL}$ in Rocky Mountain National Park, Colorado (209).

There is very little information on the autecology of this species. Spike trisetum is found on dry mountain sites so is presumably winter hardy and drought tolerant. Nutrient requirements appear to be low. This species has been successfully established by transplants on disturbed alpine areas in Alberta and the northwestern United States. It shows promise for revegetation of these areas but further research is needed into ecotypic variation. 
SPECIES INFORMATION - FORBS

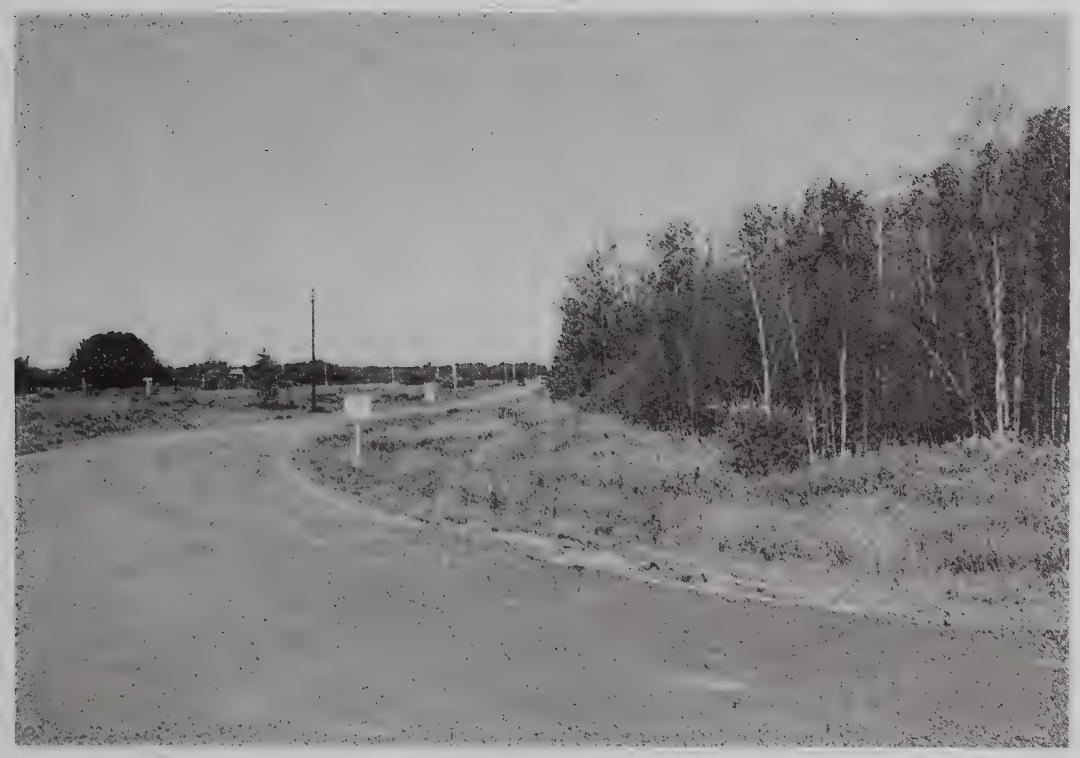


3 Combined performance chart - forbs

ies

aus cicer

um spp.

arum spp.

us ochroleucus

corniculatus

$s$ argenteus

go spp.

us alba

ychis viciifolia

pis spp.

$\mathrm{m}$ hybridum

$\mathrm{m}$ pratense

$m$ repens

mericana

\section{Reclamation Suitability Criteria}

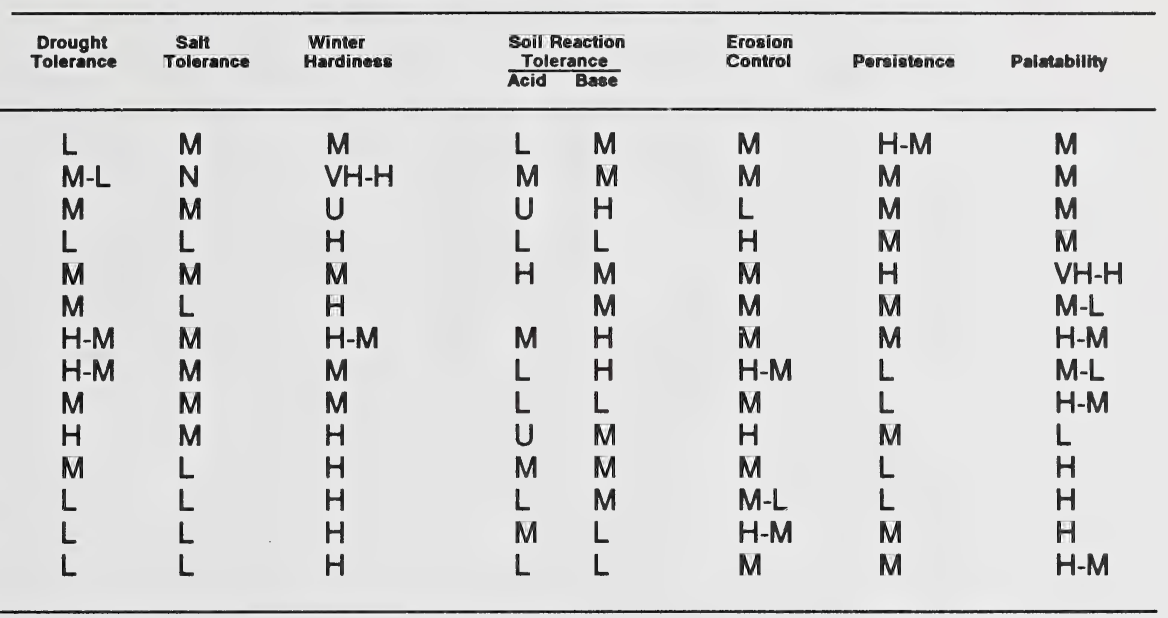

gh

edium

(n)

known 
Astragalus cicer

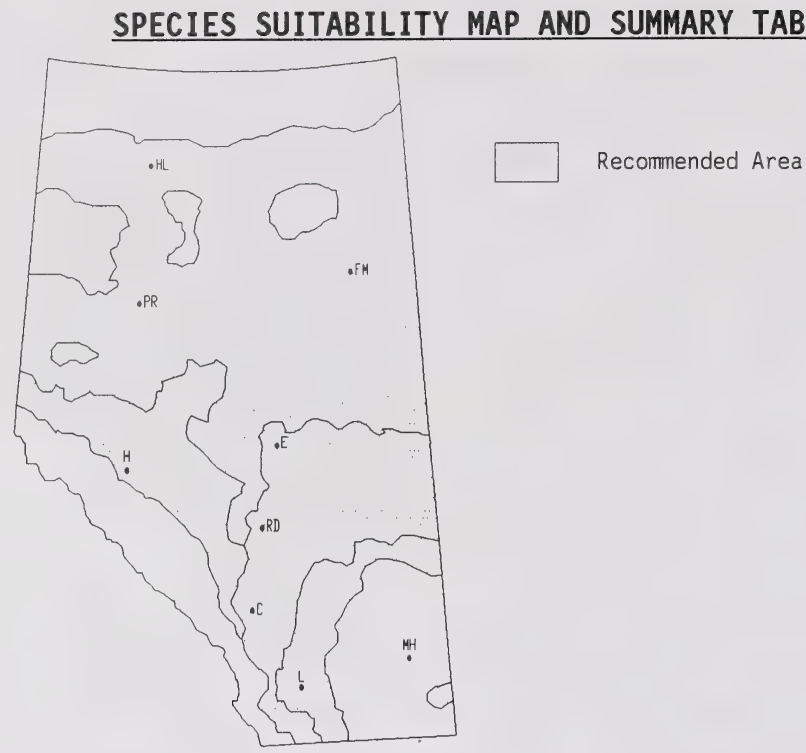

Commercially Available: Yes $\mathrm{X}$ No

\begin{tabular}{|c|c|c|c|c|c|}
\hline \multirow{2}{*}{$\begin{array}{l}\text { RECLAMATION SUITABILITY } \\
\text { CRITERIA }\end{array}$} & \multicolumn{5}{|c|}{ SUITABILITY RATING. } \\
\hline & Very High & High & Medium & Low & None \\
\hline Drought Tolerance & & & & $\mathrm{X}$ & \\
\hline Salt Tolerance & & & $x$ & & \\
\hline Acid. & & & & $x$ & \\
\hline Tolerance Base & & & 8.1 & & \\
\hline Winter Hardiness & & & $x$ & & \\
\hline Erosion Control & & & $x$ & & \\
\hline Persistence & & $x$ & $x$ & & \\
\hline Palatability & & & $\mathrm{X}$ & $x$ & \\
\hline Browse Tolerance & & & $x$ & & \\
\hline Moisture Preference & Dry tc & moist. & & & \\
\hline Soil Preference & Mediun & to coar & exture, & drain & \\
\hline
\end{tabular}


Astragalus cicer $\mathrm{L}$.

\section{SPECIES BIOLOGY}

Taxonomy - Cicer Milk Vetch

\section{Origin and Range}

European $(430,139)$. Introduced.

\section{Growth Habit}

Medium growth habit (41) relative to alfalfa (Medicago spp.). Height is 20 to $25 \mathrm{~cm}$ (139). Sodforming legume with leafy, semiprostrate stems (179). Strongly rhizomatous (138). Yellow flowers 10-15 mm long (690).

\section{Nitrogen Fixing}

Fixes atmospheric nitrogen (41).

\section{Longevity}

Moderately long-lived, cool season (713) perennial herb $(175,417)$.

\section{Self Propagation}

Predominantly by seeds, but also rhizomatous, thus a thin, initial stand can spread and increase (262). Low germination rate, seedling vigour and emergence rate in Alberta (138), though apparently better elsewhere (339).

\section{Ecological Setting}

Similar to alfalfa. In Alberta, it is adapted to a wide range of conditions, but prefers cool, moist sites $(179,391)$. Apparently not adapted to the upper subalpine (41), although successful growth (relative to other grasses and legumes seeded) has been noted at elevations up to $3420 \mathrm{~m}$ ASL in Colorado $(236,44)$. Requires 30 to $45 \mathrm{~cm}$ of precipitation and is cold hardy (639); 30 to $101 \mathrm{~cm}(713)$. In the intermountain region of Utah, Nevada, Idaho, and Wyoming, $\underline{A}$. cicer proved to be valuable only on lowland rangelands with over $30 \mathrm{~cm}$ precipitation (340); in the Pacific northwest and great basin states, the species is regarded as useful where mean annual precipitation exceeds $35 \mathrm{~cm}$ (179).

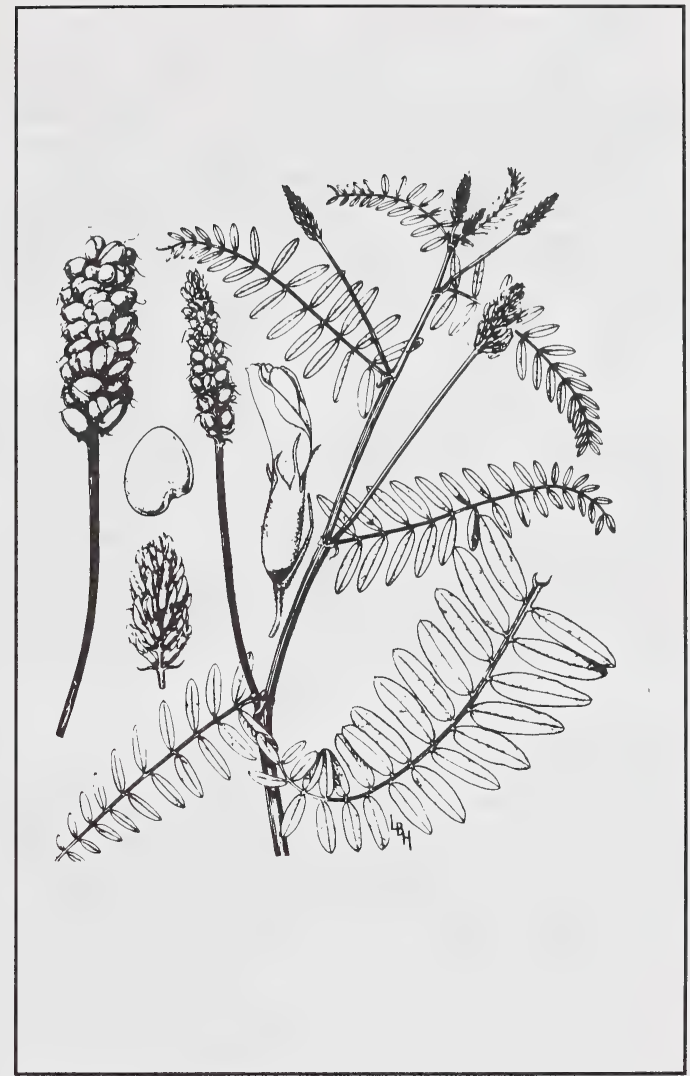

\section{TOLERANCES}

\section{Soil Preferences}

Cicer milk vetch is adapted to Chernozemic,Luvisolic and Podzolic soils with coarse textures (391). It is especially well adapted to soils derived from limestone. Cicer milk vetch is used in place of alfalfa in grass-legume mixtures where alfalfa is restricted in growth by shallow soils (179). Established successfully on clay loam soil with moderate to good moisture content, on a northeastern British Columbia pipeline right-of-way (431). Also established on coarse textured subalpine soils, primarily glacial till $(236,44)$. Achieves its best creeping form on coarse or medium textured soils (138). Good on medium to clayey textures (639). 


\section{Nutrient Requirements}

Cicer milk vetch and alfalfa established best on tailings sand slopes (oil sands) at the lowest fertilization rates, and success decreased with increased fertilizer application (359). A very low cover rate was achieved under fertilizer applications on high elevation coal mine spoil in Alberta (380). This and other legumes perform best with little or no fertilizer.

\section{Soil Reaction}

More tolerant of alkaline (pH 8.1) or acid soils than alfalfa (391). Prefers slightly alkaline conditions to somewhat acid $(338,179)$. Cicer milk vetch is more persistent and higher in production than alfalfa on subirrigated or irrigated, slightly acid to moderately alkaline alluvial soils, including Regosols, where a high water table exists (179). Poor on acid soils; lower limit is 5.0 (713).

\section{Soil Salinity}

Salinity tolerance less than sainfoin (Onobrychis viciaefolia) on amended tailings sands and overburden in northern Alberta (404). Salinity tolerance can therefore not be ranked better than modest; fair (713).

\section{Drought}

Likely not particularly drought resistant.

\section{Heavy Metals and Hydrocarbons}

Growth chamber tests on oil sands with varying oil contents indicate that germination and plant growth was inferior to both alfalfa and sainfoin (404).

\section{Shade}

Cicer milk vetch is slightly shade tolerant, and grows well on most mountain rangelands (often forested) of the intermountain states (340).

\section{Grazing or Mowing}

A. cicer recovers rapidly after it is cut or grazed on western U.S. ranges (179) but appears to be slower to recover in Canada (138). However, milk vetch plants should not be grazed until firmly established; this usually requires two years, during which time hay crops can be taken (179). Because it propagates vegetatively, as well as by seed, it is not readily killed by rodents $(340)$. Tolerance to grazing is said to be moderate (339).

\section{Susceptibility to Disease and Insect Damage}

Noted to be "remarkably free" of diseases and insects in the Pacific Northwest and Great Basin states $(179,138)$. Prone to damage by pocket gophers (41).

\section{RECLAMATION CONSIDERATIONS}

\section{Soil Building and Erosion Control Capability}

Used for erosion control (175), and apparently a good soil stabilizer (339) due to its rhizomatous habits.

\section{Adaptation to Disturbance}

Well adapted to establishment on disturbed sites (339).

\section{Competitive Ability}

In Alberta, it is slow to establish and will not compete with rapidly growing plants (391). Alternate-row seeding is recommended for good stands of both grass and the legume when planted together (179). Once established, compatibility is good (339).

\section{Commercial Value}

Livestock hay or pasture, wildlife forage, erosion control, and aesthetic use $(175,179)$. Cultivars characterized by very low herbage yield (139), although in the Pacific Northwest and Great Basin states, production averages are higher (179).

\section{Palatability and Nutritive Value}

Low palatability in certain subalpine situations (41), though overall palatability is said to be good (339). Reported not to cause bloat (447, Granite 89), but evidence is conflicting (138). In Alberta, Astragalus spp. in general, provide food for ungulates with high utilization by bighorn sheep, and low utilization by elk, mule deer and moose. Tests with laboratory animals and livestock indicate that cicer milk vetch has no toxic alkaloids (179), and does not accumulate selenium (138).

\section{Seed or Planting Stock Availability}

Two cultivars, tested by Agriculture Canada, are "Oxley" (Canada) and "Wyoming Cicer" (Netherlands) (139). "Oxley" is licensed in Canada (138) and seed is readily available from commercial 
sources. "Lutana" and "Monarch" (639), and "Cicar" (713) are available in the US. Approximately 145000 seeds/lb (639).

\section{Methods and Ease of Establishment}

Seed should be scarified prior to planting $(175,417)$ to improve germination and establishment (138); slow to establish (175). Noted for weak seedling vigour $(41,417)$, although the prospects for improving seedling vigour are promising (417). Hardiness rated as moderate. Should be seeded in Canada as a supplement to a grass mixture, with no more than $25 \%$ legume content. Successful establishment of cicer milk vetch at high elevations (3 $350 \mathrm{~m} \mathrm{ASL}$ ) in Colorado required a very high seeding rate, although initial establishment was greater than other legumes seeded (236). Protect from grazing in the early stages (179). Spring/Fall seeding at a rate of 20 to $25 \mathrm{lbs}$ PLS/ac has been recommended (639); 10 to $15 \mathrm{lbs}$ PLS/ac for eastern US (713).

\section{Current Status for Reclamation}

A relatively new species to reclamation (175). Much of the experience to date as a plant for revegetation of disturbed lands is experimental. Cicer milk vetch was part of a grass-legume mix used for spring planting on a pipeline river crossing area. First year growth assessments indicated strong establishment comparable to alfalfa (431). Cicer milk vetch produced better grass-legume growth relationships than "Rambler" alfalfa in tests on coarse textured soils in an arid climate (Smoliak 1983). At Fort McMurray it failed in a mix on amended tailings sand (643). Species adaptability trials on high elevation coal mine spoil dumps and exploration disturbances showed rather poor establishment and subsequent growth $(380,371$, 723). Strip mine revegetation studies near Grande Cache indicate that cicer milk vetch is poorly suited to that area compared to alfalfa, white clover, alsike clover and birdsfoot trefoil $(270,269)$. It performed rather poorly, relative to other legumes, in revegetation trials on coal surface mined lands in Montana (117). When seeded on waste rock, overburden and tailings at two metal mines in the southern interior of British Columbia, no growth occurred (143). Establishment of $\underline{A}$. cicer on ski slopes in Colorado was rated as "good" to "excellent", at elevations from $2850 \mathrm{~m}$ to $3420 \mathrm{~m}$ ASL (236). After ten growing seasons, cicer milk vetch is noted as the only introduced legume that shows promise in plantings at the Climax mine in Colorado (44). Cicer milk vetch appears suitable for high elevation revegetation, although results in Alberta show uncertain success to date. Local conditions may warrant plot studies to determine establishment, fertilization requirements and growth.

Cicer milk vetch has several desirable characteristics such as its ability to spread by rhizomes, nitrogen fixation ability, and apparent absence of bloat causing substances. It is best adapted to cool, moist sites with medium to coarse textured soils and responds well to irrigation. Adaption to alpine sites requires further testing. 
Epilobium spp.

\section{SPECIES SUITABILITY MAP AND SUMMARY TABLE}

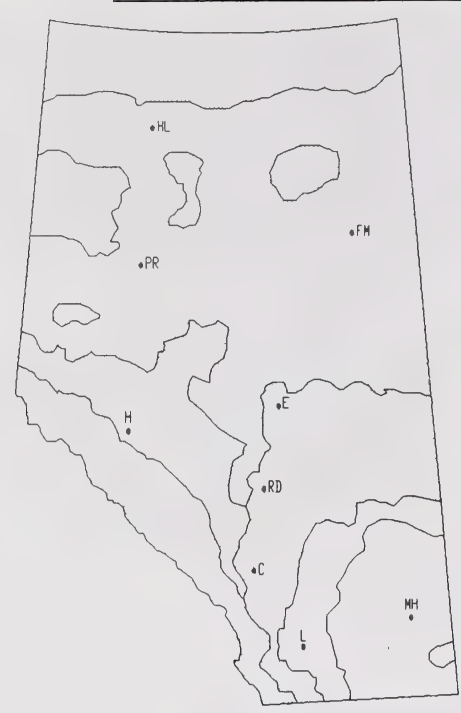

Recommended Area

Commercially Available: Yes $\mathrm{X}$ No

\begin{tabular}{|c|c|c|c|c|c|}
\hline \multirow{2}{*}{$\begin{array}{l}\text { RECLAMATION SUITABILITY } \\
\text { CRITERIA }\end{array}$} & \multicolumn{5}{|c|}{ SUITABILITY RATING } \\
\hline & Very High & High & Medium & Low & None \\
\hline Drought Tolerance & & & $x$ & $x$ & \\
\hline Salt Tolerance & & & & & $x$ \\
\hline Acid.... & & & $x$ & & \\
\hline Tolerance Base & & & 8.1 & & \\
\hline Winter Hardiness & $x$ & $x$ & & & \\
\hline Erosion Control & & & $x$ & & \\
\hline Persistence & & & $x$ & & \\
\hline Palatability & & & $x$ & & \\
\hline Browse Tolerance & & & & $x$ & \\
\hline Moisture Preference & Moist. & & & & \\
\hline Soil Preference & Clay 1 & am to $\mathrm{s}$ & & & \\
\hline
\end{tabular}




\section{Epilobium spp.}

\section{SPECIES BIOLOGY}

\section{Taxonomy}

Fireweed; Great Willow-herb; River Beauty (E. latifolium) (214).

Includes E. angustifolium ssp. angustifolium and ssp. circumvagum Mosquin, and Epilobium latifolium ssp. latifolium.

\section{Origin and Range}

Native plants, with circumpolar distribution (214).

\section{Growth Habit}

Varies from erect stems (E. angustifolium) to $2 \mathrm{~m}$ high, with thick creeping roots and woody rootstocks, to stems (few to several) which are decumbent (E. latifolium) and 10 to $60 \mathrm{~cm}$ long (Moss 1983). Flowers pink, purple or white, rarely yellow (690).

\section{Nitrogen Fixing - None}

Longevity - Perennial herbs (405).

\section{Self Propagation}

By seed $(194,257)$ (germination capacity of $57 \%$ ), and by rhizomes.

\section{Ecological Setting}

For $\underline{E}$. angustifolium, open woods, meadows, river bars, aspen thickets, forest clearings, road sides, burned-over forest areas. Optimum slope for revegetation is $9 \%$ to $30 \%$ (447). Up to $2900 \mathrm{~m}$ ASL elevation (18). For E. latifolium, wet places, especially along mountain streams (690) and scree slopes (214) of subalpine and alpine regions. Part of pioneer stage of plant succession on river alluvium in Alaska (52).

\section{TOLERANCES}

\section{Soil Preferences}

For revegetation purposes, good growth of E. angustifolium is noted on sandy, loamy, and clayey soil, although it requires moist habitat (447). Optimum soil depth is 33 to $60 \mathrm{~cm}(447)$.

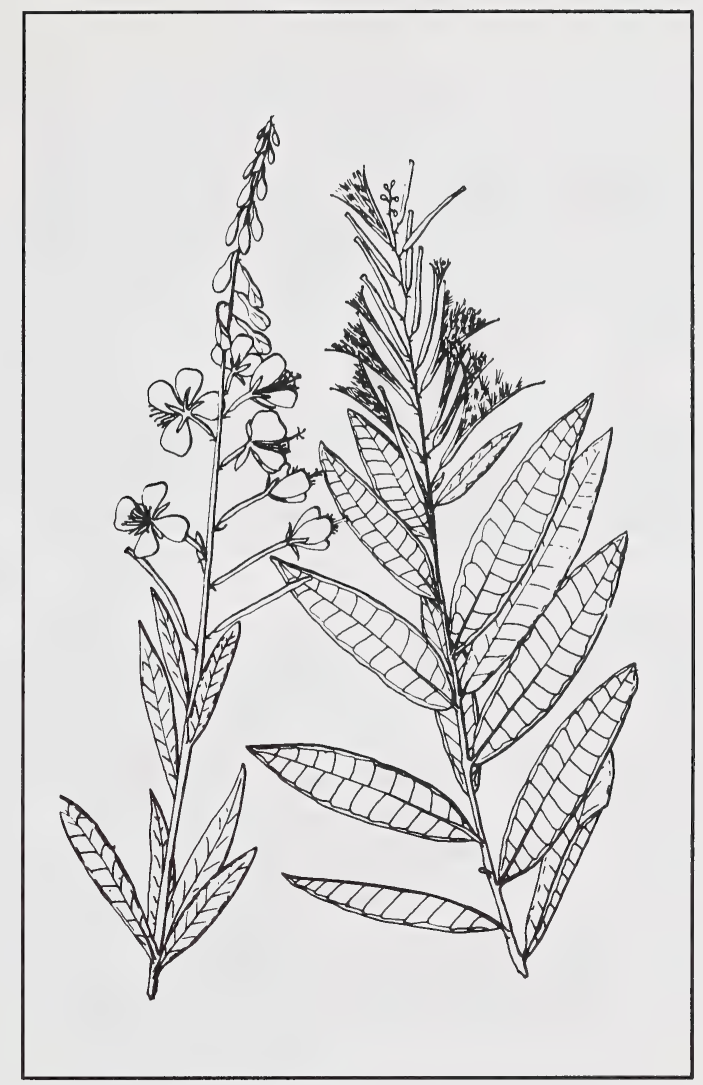

Nutrient Requirements

E. angustifolium considered to be a nitrophilous plant associated with increases in soil nutrients following fire (460). This "post fire nutrient flush" is equivalent to a fertilizer application of $13 \mathrm{~kg} / \mathrm{ha}$ in the first season after fire in a forest-tundra site in the Mackenzie River delta (458).

\section{Soil Reaction}

No specific tolerance noted in the literature reviewed, but both species are found on soils with a wide $\mathrm{pH}$ range.

\section{Soil Salinity}

Generally not found on saline soils.

\section{Drought}

E. angustifolium cannot germinate under droughty conditions (314). Otherwise this species is known 
to tolerate rather dry conditions.

\section{Heavy Metals and Hydrocarbons}

Tolerance of $\underline{E}$. angustifolium to diesel oil spill indicated (Whitehorse area), where only aboveground portions of the plants have been affected. Where oil penetrated the soil, effects on root systems resulted in death (216).

\section{Shade}

As a volunteer plant associated with early successional stages, especially following fire, fireweed is presumably at least somewhat shade intolerant. Natural populations do occur in open, moist forest however.

\section{Grazing or Mowing}

Under intense grazing fireweed is seriously depleted (4)

\section{Susceptibility to Disease and Insect Damage}

No particular susceptibilities noted.

\section{RECLAMATION CONSIDERATIONS}

\section{Soil Building and Erosion Control Capability}

Extensive underground rhizomes presumably act to hold soil. Potential of E. angustifolium for erosion control in northwest Colorado is rated as medium (293).

\section{Adaptation to Disturbance}

E. angustifolium is noted as a plant that increases following fire (460). It is able to invade exposed peat and mineral soil in the Mackenzie Delta area $(194,459)$. Fireweed is the most prevalent plant of volunteer growth on fresh and stored peat in the oil sands area (153). Disturbed sites invaded by fireweed in northern environments include roadsides (E. angustifolium) and stream sides (E. latifolium) (459). E. anqustifolium is present on reclaimed coal strip mines in southeastern British Columbia (393). Both species are noted to colonize disturbed sites associated with tailings ponds at selected metal mine sites in British Columbia (384). One of the most common species on landfills in Finland (630).

\section{Competitive Ability}

A common pioneer after fire on disturbed sites (E. angustifolium) (185), and bare till associated with recessional moraines of Alaskan glaciers (E. latifolium) (104). Noted for invading areas previously disturbed and seeded with erosion control species (494). The need to compete under these conditions is infrequent, but the species tends to diminish as succession proceeds and secondary species appear.

\section{Commercial Value}

Flower is considered to be of ornamental value; otherwise, the species is noted as a weed (405). Fireweed (E. angustifolium) is also used as a honey plant (bee pasture). Territorial flower of the Yukon.

\section{Palatability and Nutritive Value}

Good forage value for mule deer (447), with moderate use in spring and summer (245). Also grazed by moose. Small mammals such as chipmunks and pika utilize seeds. Chemical composition analyses of selected alpine tundra plants in Alberta indicated that crude protein, calcium, phosphorus, and ash contents of E. angustifolium generally averaged higher than those of selected grasses. Average cellulose content and digestibility coefficients were lower than in the grasses (225).

\section{Seed or Planting Stock Availability}

E. angustifolium (marketed as Fireweed) and E. latifolium (marketed as Dwarf Fireweed) are both commercially available from seed suppliers, but only in relatively small quantities. They are inexpensive relative to other native forbs, though expensive compared to grasses and legumes. Plants flower in summer/fall (639). 8500000 seeds/lb (639).

Approximately

\section{Methods and Ease of Establishment}

Trial plots on disturbed soil conditions in the N.W.T. indicate that cereal nurse crops do not enhance the rate of cover of $\underline{E}$. angustifolium; this actually resulted in a decrease in cover (195). Indoor germination time of seed is 10 to 15 days at 16 to $20^{\circ} \mathrm{C}$; outdoor germination time is 15 to 30 days (293). The exceedingly small seeds cause handling problems ( $P$. Ziemkiewicz, pers.comm.). A seeding rate of $0.25 \mathrm{lbs}$ PLS/ac is recommended (639).

\section{Current Status for Reclamation}

E. angustifolium was under study (144) for application in revegetation of mined-land in Alberta. Revegetation trials on oil sand tailings indicated that E. angustifolium did not establish when seeded with 
other grass and herb mixtures, and on various surface treatments. However, where surface soil and organic matter was mixed into tailings sands, E. angustifolium was among the species established (257). Experimentation with several native species on winter roads in the Northwest Territories indicated that $\underline{E}$. anqustifolium was the most successful species of the native mix used (195). Fireweed has been introduced on rock waste at a Quebec iron mine; no additional information is available (316). In eastern ponderosa forests of Montana and Wyoming, this fireweed is considered to have high revegetation potential and low establishment requirements for strip mine reclamation (447).

General observations of fireweed naturally colonizing disturbed sites associated with mining, and road and pipeline development indicate its potential for revegetation of reclaimed lands, particularly in the early stages of reclamation (384, 393). 
Hedysarum spp.

\section{SPECIES SUITABILITY MAP AND SUMMARY TABLE}

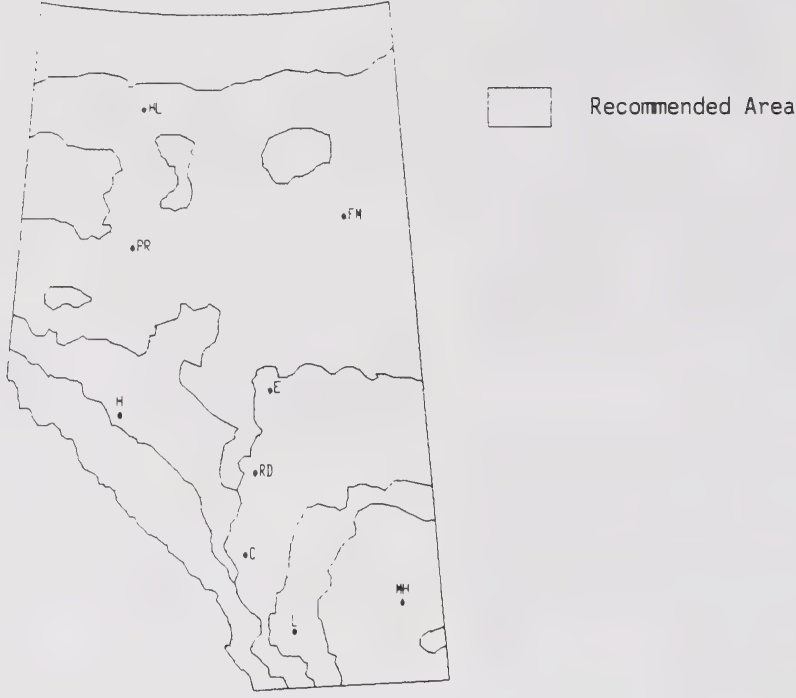

Commercially Available: Yes No

\begin{tabular}{|c|c|c|c|c|c|}
\hline \multirow{2}{*}{$\begin{array}{l}\text { RECLAMATION SUITABILITY } \\
\text { CRITERIA }\end{array}$} & \multicolumn{5}{|c|}{ SUITABILITY, RATING } \\
\hline & Very High & High & Medium & Low & None \\
\hline Drought Tolerance & & & $x$ & & \\
\hline Salt Tolerance & & & $x$ & & \\
\hline Acid. & & & & & \\
\hline Tolerance Base & & $x$ & & & \\
\hline Winter Hardiness & & & $x$ & & \\
\hline Erosion Control & & & & $x$ & \\
\hline Persistence & & & $x$ & & \\
\hline Palatability & & & $x$ & & \\
\hline Browse Tolerance & & & & $x$ & \\
\hline Moisture Preference & Dry to & noist. & & & \\
\hline Soil Preference & Silt 1 & am to $\mathrm{s}$ & loam. & & \\
\hline
\end{tabular}


Hedysarum spp.

\section{SPECIES BIOLOGY}

\section{Taxonomy}

Alpine Hedysarum (Hedysarum alpinum); Northern Hedysarum, Mackenzie Hedysarum, Northern Sweetvetch (ㅂ. . boreale); Sulphur Hedysarum; Yellow Hedysarum (브. sulphurescens) $(506,78)$.

Hedysarum alpinum L. var. americanum (Michx.), H. boreale Nutt. var. boreale and var. mackenzii (Rich.) C.L. Hutchc.; also $\underline{H}$. mackenzii Rich.; H. sulphurescens Rydb.

\section{Origin and Range}

Native. Circumpolar distribution (214). Range throughout western North America. In Alberta, primarily along the Rocky Mountains and adjacent boreal and aspen parkland forests (690).

\section{Growth Habit}

Forbs with erect or ascending (several to numerous) stems, 10 to $70 \mathrm{~cm}$ high (690). Noted for bunch growth habit and late fall growth (436); however, also noted for good spring growth and limited forage production in fall (665). Flowers pink, purple, yellow or whitish (690).

\section{Nitrogen Fixing}

Hedysarum supports nitrogen fixing bacteria enabling it to grow in relatively infertile soil materials. It will grow adequately without rhizobia (J. Weijer, pers.comm.).

\section{Longevity}

Perennial forbs (405). Alpine hedysarum and Mackenzie hedysarum have demonstrated good winter hardiness (239).

\section{Self Propagation}

Seeds from simple dry dehiscent fruit (214).

\section{Ecological Setting}

Generally abundant through the foothills, the Cypress Hills, the prairies, and in open woods of the Rocky Mountains (690). $\underline{H}$. boreale appears on rocky slopes, dry hillsides, and river bars to about $1200 \mathrm{~m}$ ASL (214). Distribution of these three species extends from alpine tundra $(\underline{H}$. boreale) to boreal and sub-boreal spruce forest $(214,459)$. $\underline{\text { H. }}$.

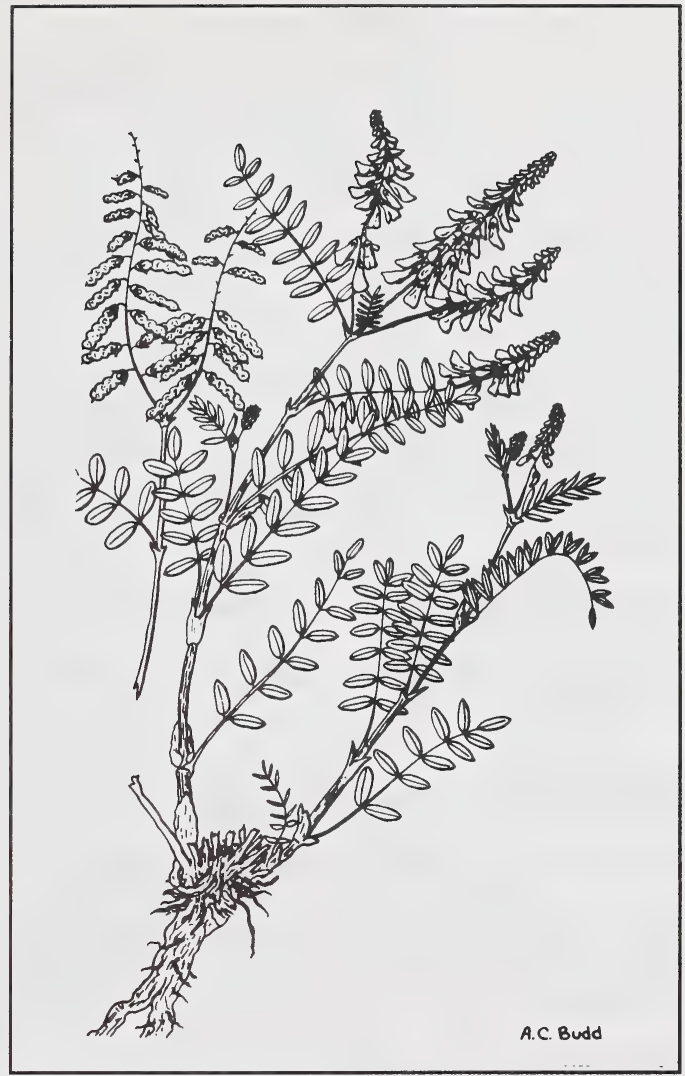

alpinum noted as part of the tall shrub-herb community associated with floodplains and lake shores in Mackenzie Delta (97).

\section{TOLERANCES}

\section{Soil Preferences}

Moist to dry sandy loam to silt loam soils. Will grow on poorly developed colluvial materials as well.

\section{Nutrient Requirements}

Expected to do well on sites low in nutrients.

\section{Soil Reaction}

Noted for alkalinity tolerance (436).

\section{Soil Salinity}

Moderately tolerant of saline soils.

Drought - Moderately drought tolerant. 
Heavy Metals and Hydrocarbons

No specific tolerances noted from the literature reviewed

\section{Shade}

Will grow in partial shade.

\section{Grazing or Mowing}

Most native legumes regrow poorly after cutting compared to cultivated legumes (239). Hedysarum spp. are characterized as "decreaser" range plants, i.e., relatively sensitive to grazing pressure. Overuse of these species usually indicates an overgrazed range.

\section{Susceptibility to Disease and Insect Damage}

$\underline{H}$. boreale regarded as resistant to northern diseases (436).

\section{RECLAMATION CONSIDERATIONS}

\section{Soil Building and Erosion Control Capability}

These plants have woody taproots (505). Nitrogen fixing capability of Hedysarum increases soil nitrogen levels.

\section{Adaptation to Disturbance}

In general, native legumes are pioneer species which can invade and grow in barren areas; nitrogen fixation permits growth in relatively infertile soil materials (239).

\section{Competitive Ability}

$\underline{H}$. boreale rated for "good biocompetitive ability" (436), but observed to have very slow first year growth (D. Walker, pers.comm.).

\section{Commercial Value}

Regarded as desirable plants to native ranges (for cattle). Flowers have ornamental value (214). Also important for wildlife range, and for nitrogen contributions.

\section{Palatability and Nutritive Value}

Reports on the nutritive value of Hedysarum spp. vary considerably. $\underline{H}$. boreale reported to be poisonous (214) and not toxic (665). Crude protein in 11 western US $\underline{\mathrm{H}}$. boreale ecotypes varied from
$12.9 \%$ to $16.6 \%$ at first harvest and $5.4 \%$ to $10.3 \%$ for the second harvest near Logan, Utah (alfalfa control values were $17.6 \%$ and $10.7 \%$ respectively) (665). Roots and stems of $\underline{\mathrm{H}}$. alpinum are edible; the plant is eaten by bears and mice (214). Hedysarum spp. are noted as range plants useful for sheep, cattle, and grazing ungulates (elk, bighorn sheep).

\section{Seed or Planting Stock Availability}

No source of commercial seed has been located. Flowers in spring with approximately 33000 seeds/lb (639). Seed weight varied between $0.137 \mathrm{~g} / 25$ seeds to $0.243 \mathrm{~g} / 25$ seeds for 11 western US ecotypes (665).

\section{Methods and Ease of Establishment}

Seed collection is relatively easy when plants are abundant because of pod formation and large seeds. Hedysarum produces plants in fair abundance. Germination of seeds may be enhanced through scarification of seed coat or immersion in concentrated sulphuric acid (239). Greenhouse tests of $\underline{H}$. alpinum seeds collected in the field indicated that Hedysarum has a germination rate of about $50 \%$ which is about $10 \%$ better than Oxytropis spp. (268). A seeding rate of $15 \mathrm{lbs}$ PLS/ac has been recommended (639).

\section{Current Status for Reclamation}

The status of Hedysarum spp. for revegetation of disturbed lands is still one of experimentation. Attractive features include winter hardiness, wildlife range value, nitrogen fixing ability, status as native species, and aesthetic considerations. Revegetation research at Grande Cache included seed collection and seeding of $\underline{H}$. alpinum, although little or no growth occurred (268). Revegetation along pipeline rights-of-way in northeastern B.C. indicated that survival and germination of $\underline{H}$. alpinum seed stock (ecotype derived from native seed collections) varied from $3 \%$ on unstable and steep slopes with sandy soil to $10 \%$ on slopes with clay loam soils and more stable conditions (431). Revegetation tests of various native legumes in Alaska indicate that Hedysarum may be adapted to commercial utilization (239). The group warrants further investigation. Ecotypic variability within western US H. boreale indicates a good chance of finding adaptable plants and breeding these for specific uses (665). 
Lathyrus ochroleucus

\section{SPECIES SUITABILITY MAP AND SUMMARY TABLE}

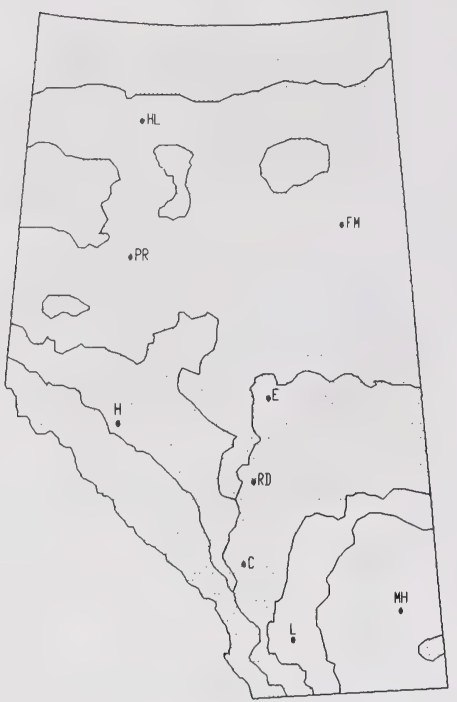

Recommended Area

Commercially Available: Yes No $X$

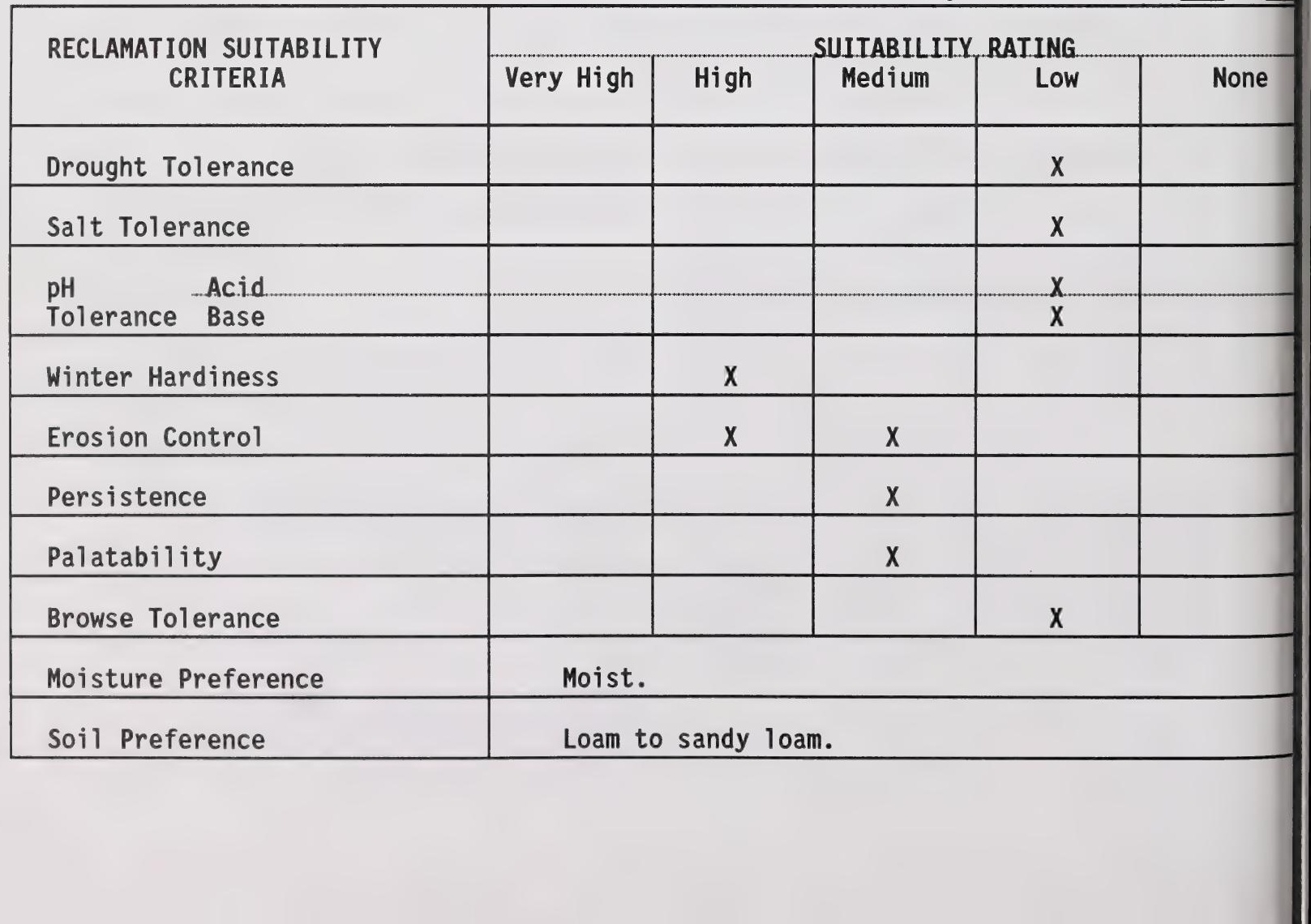




\section{Lathyrus ochroleucus Hook.}

\section{SPECIES BIOLOGY}

Taxonomy - Vetchling, Pea Vine

\section{Origin and Range}

Native. Ranging from Mackenzie District, Northwest Territories to Quebec, south to northeastern Washington, Idaho, Montana and the north central states to central Pennsylvania. General in the eastern half of British Columbia. In Alberta and most of southern Canada in forested areas (214, 199, 690).

\section{Growth Habit}

Herb with horizontal rootstocks and slender climbing stems (long and twining), up to about $1 \mathrm{~m}$ tall; leaves alternate, pinnate, usually tendril-bearing at the tip; flowers in axillary racemes (312). Yellowish white flowers (690).

\section{Nitrogen Fixing}

Fixes atmospheric nitrogen.

\section{Longevity}

Perennial (withering) herb $(312,405)$.

\section{Self Propagation}

Simple dry dehiscent fruit (405), with several seeds contained in a linear pod (317).

\section{Ecological Setting}

Open woods and northern meadows (690) from boreal white and black spruce forests (405) to montane lodgepole pine - Douglas fir forests and the aspen parkland.

\section{TOLERANCES}

\section{Soil Preferences}

Prefers loam to sandy loam soils. Generally found on Podzols, Brunisols and Luvisols. Distribution indicates that the species favors moist soil conditions.

\section{Nutrient Requirements}

Can withstand low nitrogen soils. Requires fair

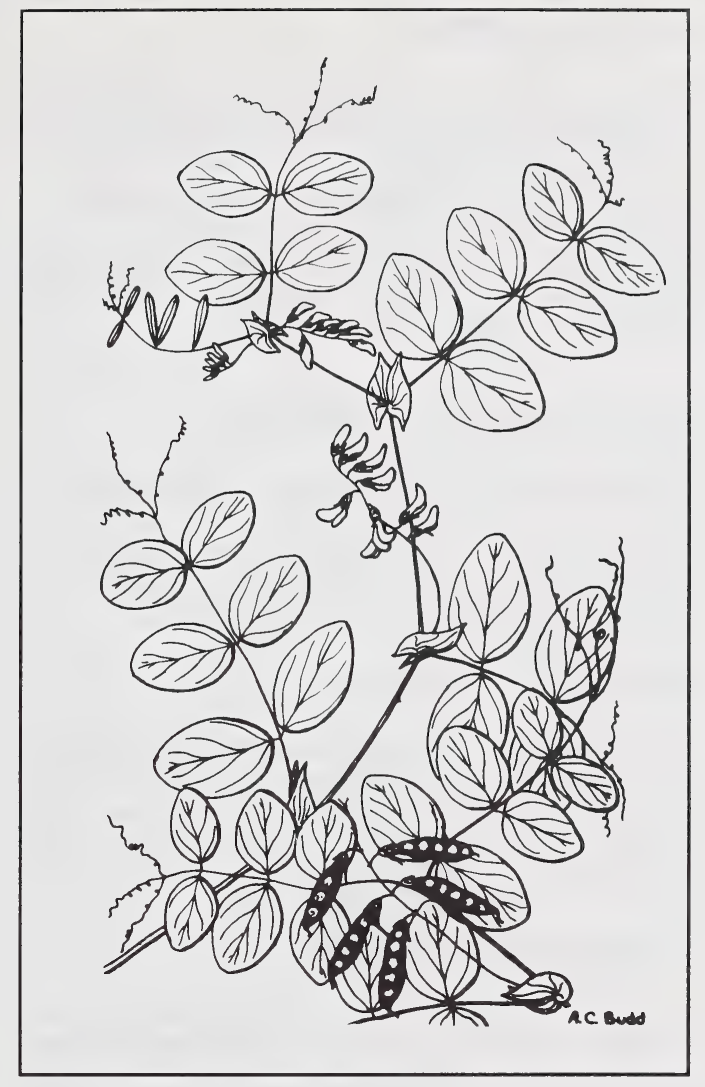

levels of other nutrients.

\section{Soil Reaction}

Appears to be generally restricted to near neutral $\mathrm{pH}$ ranges.

\section{Soil Salinity}

Can be expected to tolerate mild soil salinity.

\section{Drought}

Moderately intolerant of droughty conditions.

\section{Heavy Metals and Hydrocarbons}

No specific tolerances noted.

\section{Shade}

Presumably moderately shade tolerant, because of its association with open woods. 


\section{Grazing or Mowing}

Lathyrus spp. are regarded as "decreaser" species, sensitive to continued overuse on cattle ranges.

\section{Susceptibility to Disease and Insect Damage}

Resistance to disease and insects of related Lathyrus spp. on Utah ranges is rated from "medium" to "very good" (339).

\section{RECLAMATION CONSIDERATIONS}

\section{Soil Building and Erosion Control Capability}

Soil stabilizing ability associated with growth of related Lathyrus spp. on Utah ranges, varies from medium to very good (339).

\section{Adaptation of Disturbance}

As a "decreaser" plant on Alberta ranges, Lathyrus spp. appear not to withstand physical disruption particularly well. The species is, however, often noted colonizing moist roadsides and other disturbances.

\section{Competitive Ability}

Overuse of this species is associated with conditions favorable for establishment of other species more tolerant to grazing or more unpalatable for grazers. In general, Lathyrus spp. are rated medium to poor for initial establishment on Utah ranges (339), and noted for "good" persistence. Though not highly competitive, the species are not easily eliminated from established forests and meadows unless heavily grazed.

\section{Commercial Value}

This species is a native nitrogen fixing legume, suitable for reclamation, including moderate wildlife use.

\section{Palatability and Nutritive Value}

Utilized to a moderate extent by wildlife. Presumed to provide moderately good nutrition.

\section{Seed or Planting Stock Availability}

Native seed production and handling of Lathyrus spp. in Utah is very good. Ease of planting of related species varies from medium to very good (339).

\section{Methods and Ease of Establishment}

Lack of success in establishing $L$. ochroleucus on pipeline rights-of-way in northeastern British Columbia may indicate a lengthy dormancy period prior to germination of seeds (431). Ease of transplanting of related Lathyrus spp. on Utah ranges is generally regarded as good (339).

\section{Current Status for Reclamation}

Information reviewed indicates that the usefulness of Lathyrus ochroleucus for reclamation remains to be established. Because of some characteristics, including nitrogen fixing ability and adaptability to a wide range of ecological patterns, the plant warrants further study, better defining revegetation suitability. Related species demonstrate usefulness in reestablishment of native range. 
Lotus corniculatus

\section{SPECIES SUITABILITY MAP AND SUMMARY TABLE}

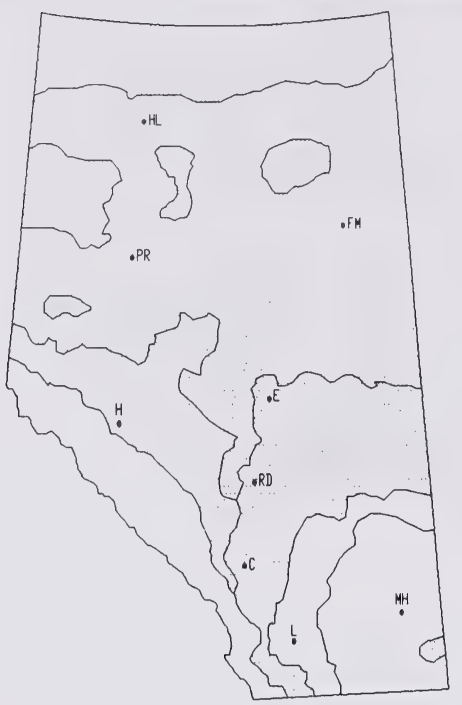

Recomnended Area

Commercially Available: Yes $X$ No

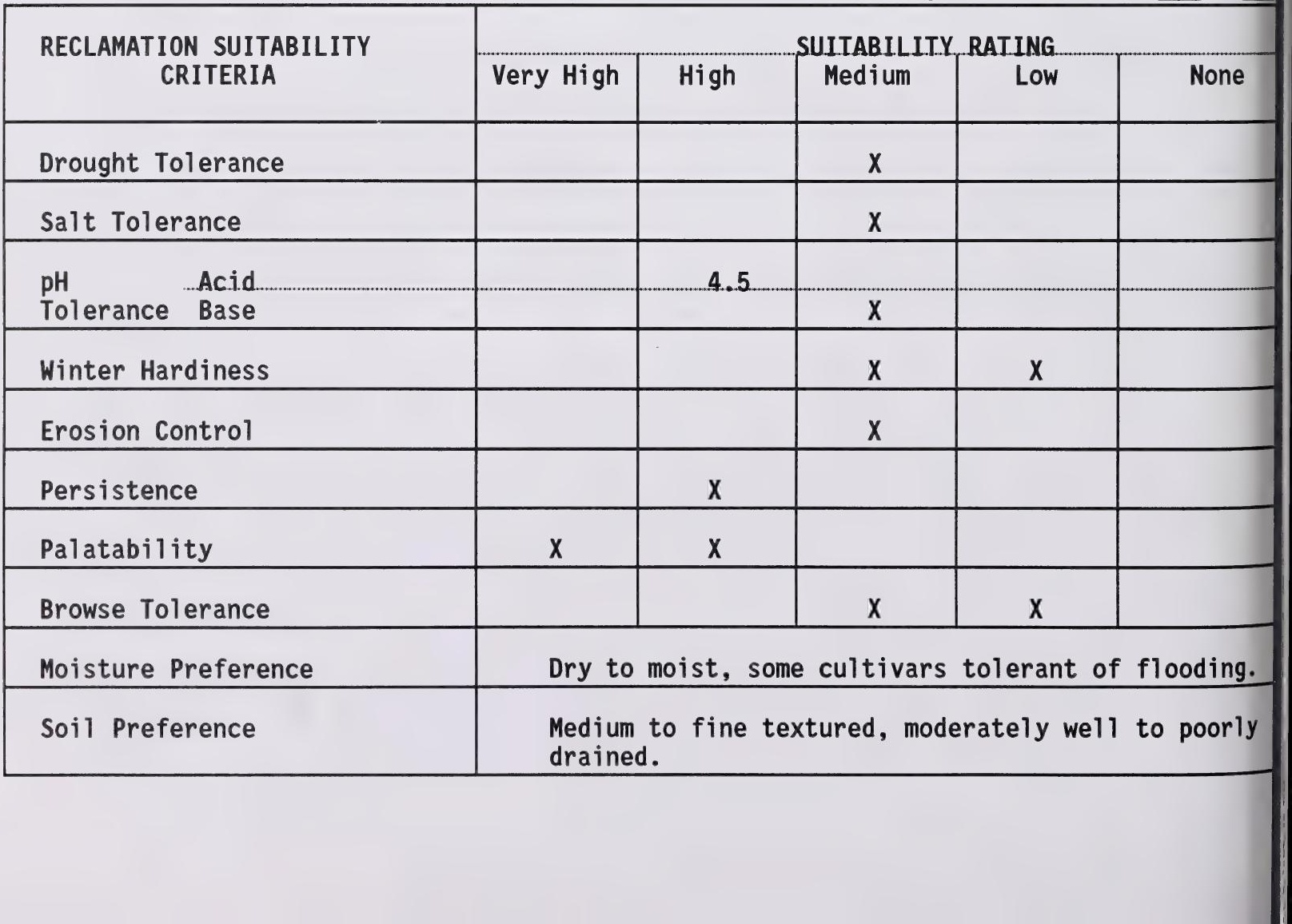


Lotus corniculatus $\mathrm{L}$.

\section{SPECIES BIOLOGY}

Taxonomy - Birdsfoot Trefoil.

\section{Origin and Range}

Native to Europe, from the Mediterranean to Scandinavia. It was probably introduced to North America accidentally around the turn of the present century (138).

\section{Growth Habit}

The distinct foliage and delicate yellow flowers make this an aesthetically pleasing plant (41). Plants are similar to alfalfa (Medicago spp.) in growth habit, and reach heights of about 30 to $75 \mathrm{~cm}$. Stems are slender and branched (138). It spreads by underground rhizomes (446). It has a well developed taproot system with numerous lateral branches (37). Flowers yellow, often red-tinged (690).

\section{Nitrogen Fixing}

Birdsfoot trefoil fixes atmospheric nitrogen. Nodulated plants have been observed on soils with $\mathrm{pH}$ as low as 4.5 (444). Stand establishment may, however, be limited by poor nodulation on some spoils with pH below 5.0 (40).

\section{Longevity}

Relatively long-lived cool season (713) perennial (138). Birdsfoot trefoil was found to give an excellent initial stand but thinned out rapidly after the second or third growing season (228). Some cultivars are susceptible to winterkilling; "Carroll" is more winter hardy than other licensed cultivars (138), although "Cree" is best (D. Walker, pers.comm.).

\section{Self Propagation}

Propagation is predominantly by seed. The cultivar "Leo" requires long day length to produce seed. It becomes dormant early in the fall (6).

\section{Ecological Setting}

Birdsfoot trefoil may persist for a few years in the upper subalpine (Colorado) (41). However, it was reported to do poorly at $2570 \mathrm{~m} \mathrm{ASL} \mathrm{(417),} \mathrm{and} \mathrm{at}$ $3350 \mathrm{~m}$ ASL (44) in Colorado. Does best with 45 to $114 \mathrm{~cm}$ precipitation (713).

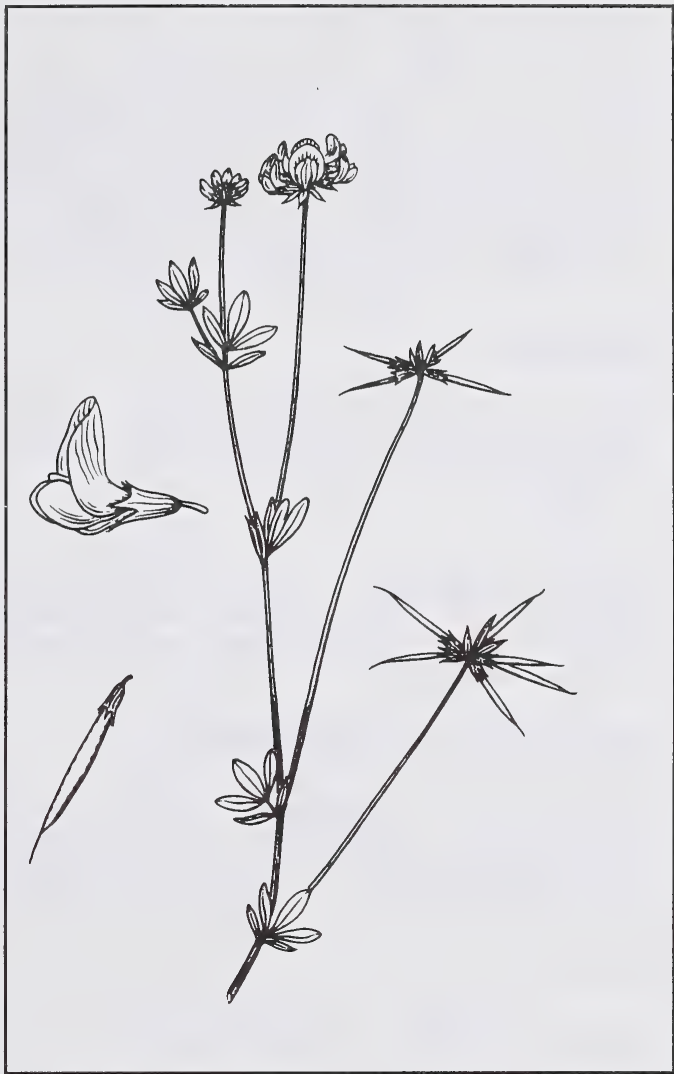

TOLERANCES

\section{Soil Preferences}

Birdsfoot trefoil prefers moist sites and may require irrigation in drier reclamation areas (426). It will grow on poorly drained through to droughty soils 937). "Empire" and "Leo" are varieties tolerant of wet land and flooding. "Carroll" is also tolerant of imperfectly drained soils (6). "Maitland" is less tolerant of saturated soils (138).

\section{Nutrient Requirements}

Birdsfoot trefoil has low nutrient requirements (466). Legumes are usually sensitive to low plant-available potassium and phosphorus, conditions which are sometimes present on coarse textured spoils.

\section{Soil Reaction}

In field trials, birdsfoot trefoil grew on spoils with $\mathrm{pH}$ values as low as 4.5 (278). In general, grasses will survive on soils in the $\mathrm{pH}$ range 4.5 to 5.5 but this 
is too acidic for most legumes (44). Birdsfoot trefoil has been established on coal spoils of $\mathrm{pH} 5.0$ to 5.5 (228). It has been recommended for revegetating spoil with $\mathrm{pH}$ values of at least 4.5 (713) to 5.0 (123). Some genotypes can apparently withstand considerable acidity. In a laboratory test, liming acid spoils with dolomite inhibited the establishment of birdsfoot trefoil compared to spoils limed with hydrated lime or agricultural lime (411).

\section{Soil Salinity}

Birdsfoot trefoil had satisfactory growth on tailings with an electrical conductivity of $8 \mathrm{mS} / \mathrm{cm}$ (163).

\section{Drought}

Legumes in general do poorly on coarse textured droughty soils (44). Birdsfoot trefoil, however, appears to grow satisfactorily on moderately droughty soils (37).

\section{Heavy Metals and Hydrocarbons}

Birdsfoot trefoil exhibited no toxicity symptoms when grown on three spoils containing $50 \mathrm{ppm}$ water-soluble manganese (40). No other tolerances have been noted.

\section{Shade}

Generally intolerant of excessive shade.

\section{Grazing or Mowing}

Its low growth form allows grazing or mowing with minimal reduction in plant vigour. Some cultivars are sensitive to overgrazing or cutting, and are slow to recover. Most recover quickly (138). Persistent.

\section{Susceptibility to Disease and Insect Damage}

May be attacked by Sclerotinia trifoliorum Erikss. and Rhizoctonia spp. which are not serious pests in Canada (138).

\section{RECLAMATION CONSIDERATIONS}

\section{Soil Building and Erosion Control Capability}

Birdsfoot trefoil has a well developed taproot system with numerous lateral branches. It will root to a depth of $1 \mathrm{~m}$ or more in good soil conditions (37).

\section{Adaptation to Disturbance}

Does well on disturbed sites, including agricultural lands.

\section{Competitive Ability}

Fairly aggressive initially, but dies back as stands become established.

\section{Commercial Value}

Birdsfoot trefoil is used for forage and in stabilization plantings (426). It is a perennial forage legume used for pasture, hay, and silage in the northwest and north-central US. (37).

\section{Palatability and Nutritive Value}

Birdsfoot trefoil is a highly palatable (427), non-bloat causing species $(41,138)$. Herbage yield of several cultivars including "Diana", "Lot", "Maitland", "Mansfield" and "Tara" have been rated as very good to excellent (139). Birdsfoot trefoil may contain hydrocyanic acid (221).

\section{Seed or Planting Stock Availability}

Seed readily available from most dealers. Licensed varieties grown in Canada include "Empire", "Viking", "Leo", "Maitland", "Mirabel", "Carroll" and "Cree" (6, 138). "Dawn", "Fergus", "Cascade", "Granger", "Tana", "Douglas", "Mansfield" and "Norcen" available in the US $(639,713)$. Approximately 418000 seeds/lb (639).

\section{Methods and Ease of Establishment}

Typical purity/germination is $96 / 90 \%$ (132). Birdsfoot trefoil generally has weak seedling establishment and vigour, but has excellent persistence, although growth is slow (6). A seeding rate of 10 to $15 \mathrm{lbs}$ PLS/ac has been recommended for the Eastern US (713).

\section{Current Status for Reclamation}

Birdsfoot trefoil is a fairly widely used pasture species, though it is also utilized for silage, hay and erosion control in Alberta. It has been successfully established on unfertilized coal mine reject material near Grande Cache, Alberta. Plants were vigourous and nodules were present (271). Birdsfoot trefoil was, however, the poorest of eleven legumes tested at Norman Wells, N.W.T. (195). It also failed in the subalpine in first year testing at Tent Mountain (723). "Empire" birdsfoot trefoil was persistent after four growing seasons on limed, acid uranium mine tailings at Elliot Lake, Ontario. Yield and nodule formation was poor, however (318). It also produced well on an ash lagoon after three years 
(696). It showed promise for revegetation in Montana and on subalpine sites in southeastern Idaho, northeastern Utah and western Wyoming and at $1900 \mathrm{~m}$ (subalpine) in north central Washington (209). Birdsfoot trefoil was poor in vigour and ground cover density after four growing seasons compared to alfalfa on mine tailings in northwestern Colorado (1 850 to $2450 \mathrm{~m}$ ) (39). Birdsfoot trefoil has been recommended for revegetation of disturbed sites in northwestern Colorado that were cold and moist, received more than $50 \mathrm{~cm}$ of precipitation per year and were above $2670 \mathrm{~m} \mathrm{ASL}$ elevation. Soils were mostly shallow and low in fertility (427). It is used successfully in Britain for mine reclamation (123). The cultivar "Leo" is regarded as suitable for use in Alberta and the Peace River region where a non-bloating legume is required. This cultivar has good seedling vigour and responds to high fertility (6).

Birdsfoot trefoil is an attractive legume with a low spreading growth habit which provides little competition to planted trees. Some varieties are moderately drought tolerant while others can withstand poorly drained soils. It fixes atmospheric nitrogen and its ability to grow well on acid spoils has led to its widespread use for revegetation on acid coal mine spoils in Europe and the northwestern United States. 
Lupinus argenteus

\section{SPECIES SUITABILITY MAP AND SUMMARY TABLE}

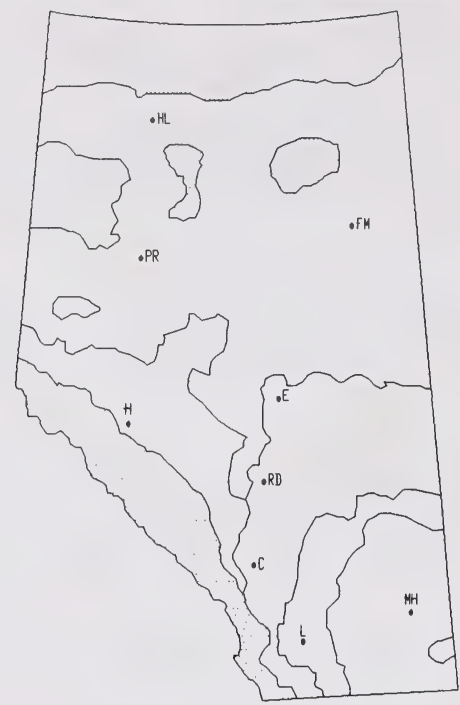

Recommended Area

Commercially Available: Yes No $x$

\begin{tabular}{|c|c|c|c|c|c|}
\hline \multirow{2}{*}{$\begin{array}{l}\text { RECLAMATION SUITABILITY } \\
\text { CRITERIA }\end{array}$} & \multicolumn{5}{|c|}{ SUITABILITY RATING } \\
\hline & Very High & High & Medium & Low & None \\
\hline Drought Tolerance & & & $x$ & & \\
\hline Salt Tolerance & & & & $x$ & \\
\hline Acid. & & & & & \\
\hline Tolerance Base & & & $X$ & & \\
\hline Winter Hardiness & & $\mathrm{x}$ & & & \\
\hline Erosion Control & & & $x$ & & \\
\hline Persistence & & & $x$ & & \\
\hline Palatability & & & $\mathrm{X}$ & $x$ & \\
\hline Browse Tolerance & & & $x$ & $x$ & \\
\hline Moisture Preference & Moist & 0 dry. & & & \\
\hline Soil Preference & Clay 1 & am to $s$ & loam. & & \\
\hline
\end{tabular}


Lupinus argenteus Pursh

\section{SPECIES BIOLOGY}

Taxonomy - Perennial Lupine; Silvery Lupine

A taxonomically difficult genus (Moss 1983). Hybridizations between $\underline{L}$. argenteus and L. caudatus complexes can explain many taxonomic variations (657).

\section{Origin and Range}

Native. Common in the Alberta foothills, Cypress Hills and submontane prairie in southwestern Alberta (78). Southern British Columbia to Saskatchewan south to northeastern California; Arizona, New Mexico and South Dakota (690).

\section{Growth Habit}

A shrubby many-branched herb, 50 to $100 \mathrm{~cm}$ tall $(78,690)$. It is a highly variable species with growth habit varying from stemmy to bush (236). Flowers light violet, occasionally whitish (690).

\section{Nitrogen Fixing}

Estimated seasonal fixation rate of $0.14 \mathrm{mg} \mathrm{N}_{2} / \mathrm{gm}$ of nodules for silvery lupine growing in lodgepole pine forests in southeastern Wyoming. Maximum $\mathrm{N}$ fixing rate was estimated at $0.1 \mathrm{~g} \mathrm{~m}^{-2} \mathrm{yr}^{-1}$ in these dry, infertile stands. Silvery lupine is capable of fixing nitrogen on high altitude disturbed sites. It fixes nitrogen at rates 5 to 15 times greater than other legumes growing at high altitudes in Utah and Montana. The large size of nodules suggested that they may function over more than one growing season. Nodule mass varies from 0.05 to $2.0 \mathrm{~g}$ dry wt. per plant (666).

\section{Longevity}

Hardy, perennial herb $(312,293)$. Dies back in fall.

\section{Self Propagation}

By seed (690), spreads slowly to form colonies.

\section{Ecological Setting}

Silvery lupine is a common species of the prairie and the submontane prairie of southwestern Alberta (78). Grasslands and roadsides, prairie slopes and ridges (690). Silvery lupine is found on a wide range of habitats from forest understorey, road banks and sagebrush communities to sand dunes (236). One of the most widespread lupines in high

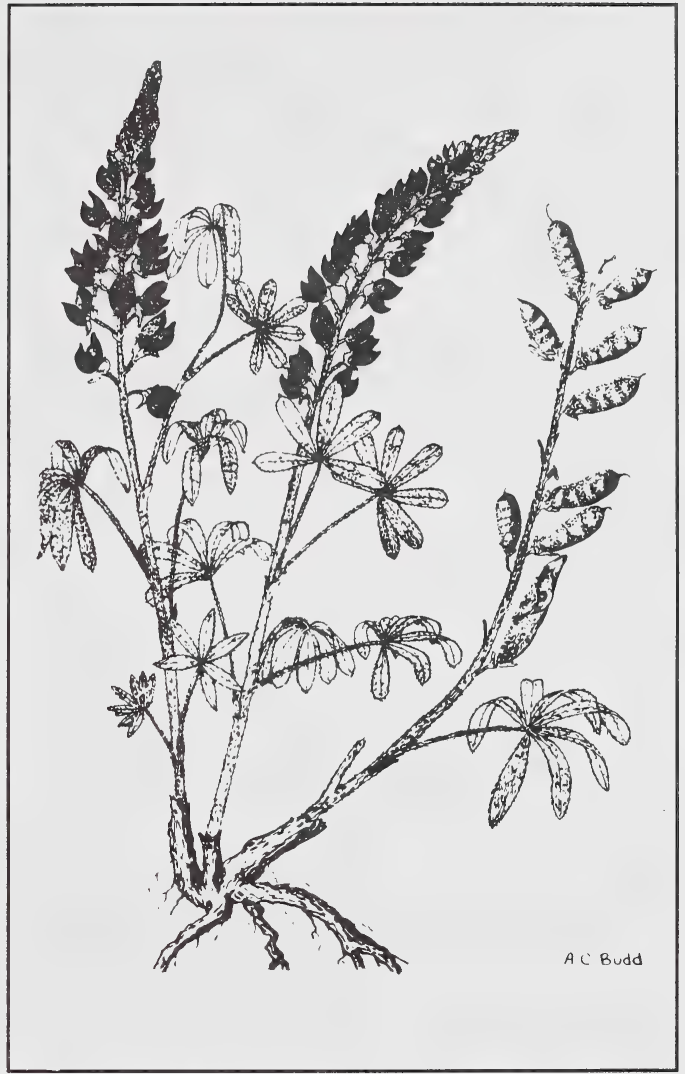

altitude areas in western North America (666). It has been reported at $1450 \mathrm{~m}$ ASL in northeastern British Columbia (70). It is often found on alpine sites in association with Dryas octopetala or Dryas integrifolia (209).

\section{TOLERANCES}

\section{Soil Preferences}

Silvery lupine has been reported on a variety of soil textures from gravelly clay loam to clay loam and on shallow soils (70). Growth is reported to be good on sandy and loam soil and fair on clayey soil. Optimum soil depth reported as 0.3 to $0.7 \mathrm{~m}$ and the optimum slope is $9 \%$ to $30 \%$ (446). Silvery lupine is reported to do best on moist to dry habitats (446). Prefers mesic habitats in southern Alberta. Has been described as strict calcifuge found only on non-carbonate soils (682).

\section{Nutrient Requirements}

Lupines in general do well on low nutrient sites 
(436). Requires high levels of available phosphate and to a lesser extent high available iron (682). Reported to grow well on high altitude sites, one with high levels of phosphate, potassium and magnesium and the other with high levels of magnesium and calcium (666). Actively mycorrhizal.

\section{Soil Reaction}

Found on moderately acid soils (636). Reported on two sites with soil $\mathrm{pH}$ values measured at between 4.5 and 5.0, and 5.5 to 7.0 (666). Found only on non-carbonate soils (682).

\section{Soil Salinity}

Not particularly tolerant of saline soils.

Drought - Relatively drought tolerant (436).

\section{Heavy Metals and Hydrocarbons}

Grew well on a site with excessively high levels of iron and copper (666).

\section{Shade}

Does best on open sites. Most commonly found in sun (677).

\section{Grazing or Mowing}

Not usually subjected to heavy grazing as it is relatively unpalatable.

\section{Susceptibility to Disease and Insect Damage}

Lupines found in northern areas are resistant to northern diseases (436). The related species L. sericeus is susceptible to stem rot (383). Susceptible to fungus disease Erysiphe polygoni DC ex Merat. Silvery lupine is alkalloid containing, therefore it is less likely to be damaged by herbivory (677).

\section{RECLAMATION CONSIDERATIONS}

\section{Soil Building and Erosion Control Capability}

Has long slender taproot with numerous lateral roots which could aid in erosion control. Potential for significant nitrogen input via $\mathrm{N}$-fixation, particularly in some lodgepole pine stands where lupine density may exceed 10000 stems/ha (632).

\section{Adaption to Disturbance}

Active colonizer of high altitude, disturbed sites (666). Lupinus spp. volunteered along the margins of disturbed mine site in the subalpine near Grande Cache, Alberta. It also became established from seed introduced in the soil topdressed on the disturbed area $(271,679)$. Silvery lupine has been reported as a pioneer on disturbed drill pad sites in the northeast coal block, British Columbia (70).

\section{Competitive Ability}

Not particularly aggressive.

\section{Commercial Value}

Erosion control, wildlife cover (187).

\section{Palatability and Nutritive Value}

Silvery lupine is reported to have low palatability (427). Has been found to contain an alkaloid (anagyrine) in concentrations sufficient to cause crooked calf disease in in-calf cows (624). Alkaloid found mostly in seeds and pods, has caused sheep losses (226). Silvery lupine found to exhibit considerable variability in alkaloid content. It may be possible to develop low alkaloid strains (623). Silvery lupine is reported to be a source of browse for Rocky Mountain mule deer (245). It has been reported to provide good cover for small mammals and game birds and poor cover for mule deer. Forage value has been rated as good for mule deer, small mammals and game birds (446).

\section{Seed or Planting Stock Availability}

No source of native seed has been identified. Several other related species are available in the US, including $\underline{L}$. alpestris (mountain lupine) and $\underline{L}$. caudatus (tailcup lupine) (639).

\section{Methods and Ease of Establishment}

The pods of silvery lupine are about $2 \mathrm{~cm}$ long and contain 4 to 6 seeds. These can be collected while they are green and then air dried to open the pods. When dried, lupine seeds can be stored for long periods of time. However, they develop a hard seedcoat with storage. Approximately 70 seeds $/ g$. Fresh seed can be sown, or stored seeds can be treated with boiling water and soaked 12 to 24 hours before sowing. Germination times are 10 to 20 days indoors $\left(18\right.$ to $24^{\circ} \mathrm{C}$ ) and 15 to 30 days outdoors $(293,39,419)$. Late fall seeding of 
legumes has been recommended in high altitude regions since in some cases they will germinate early enough the following spring to produce enough growth for over-wintering root reserves (236). Early fall seeding in some cases results in limited growth. Innoculation of Lupinus sp. with the microflora of the rhizosphere (Azotobacter) produced greater crop yields than fertilizing with NPK on coal spoil banks (209).

\section{Current Status for Reclamation}

Silvery lupine is a variable species found in many habitats to the subalpine in Alberta. It has been recommended as a species suitable for revegetation of critical sites in northwestern Colorado. The suggested zones for planting this species are moist and cold, and at elevations above $2700 \mathrm{~m}$ ASL where soils are shallow and there are many slides and rock outcrops (427). Transplants of silvery lupine were successful on a disturbed minesite in the alpine of southern Montana (76). Silvery lupine has been rated as poor for revegetation of processed oil shale in Colorado (396). Various populations of silvery lupine are being evaluated for revegetation potential (236).

Silvery lupine is a particularly promising species for revegetation of disturbed areas at high altitudes. Major assets are its ability to grow well on eroded or rocky soils, its colonizing characteristics and its ability to fix atmospheric nitrogen. Although it may be poisonous to livestock, it is browsed by game to some extent and there is potential to develop low alkaloid strains. Further research is needed into seed production and requirements for establishment. 
Medicago spu.

\section{SPECIES SUITABILITY MAP AND SUMMARY TABLE}

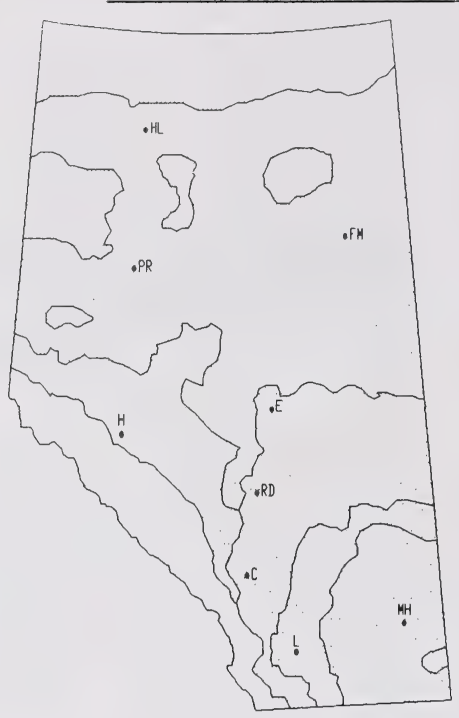

\section{Recommended Area}

Commercially Available: Yes $\mathrm{X}$ No

\begin{tabular}{|c|c|c|c|c|c|}
\hline \multirow{2}{*}{$\begin{array}{l}\text { RECLAMATION SUITABILITY } \\
\text { CRITERIA }\end{array}$} & \multicolumn{5}{|c|}{ SUITABILITY RATING. } \\
\hline & Very High & High & Medium & Low & None \\
\hline Drought Tolerance & & $x$ & $x$ & & \\
\hline Salt Tolerance & & & $x$ & & \\
\hline Acid... & & & 5.5 & & \\
\hline Tolerance Base & & $x$ & $x$ & & \\
\hline Winter Hardiness & & $x$ & $x$ & & \\
\hline Erosion Control & & & $x$ & & \\
\hline Persistence & & & $\mathrm{x}$ & $\mathrm{X}$ & \\
\hline Palatability & & $x$ & $x$ & & \\
\hline Browse Tolerance & & & $\mathrm{x}$ & & \\
\hline Moisture Preference & \multicolumn{5}{|c|}{ Moist to dry. } \\
\hline Soil Preference & \multicolumn{5}{|c|}{$\begin{array}{l}\text { Deep loam - tolerates wide textural range, well } \\
\text { drained. }\end{array}$} \\
\hline
\end{tabular}


Medicago spp.

\section{SPECIES BIOLOGY}

\section{Taxonomy}

Yellow Lucerne; Sickly Medick; Black Medick; Alfalfa; Lucerne.

$\underline{M}$. falcata $L ., \underline{M}$. sativa $L$. and $\underline{M}$. lupulina $L$.

\section{Origin and Range}

All species have been introduced to North America. Originated in Asia Minor (138). Widespread throughout North America and Europe. Recently, other varieties which originate from crosses of $\underline{\mathrm{M}}$. sativa and $\underline{\mathrm{M}}$. falcata have been developed. These varieties are often grouped under the species name $\underline{M}$. media Pers. Some examples are the cultivars "Ladak", "Beaver", and "Rambler" (191). These varieties provide adaptability for a wide range of climatic regions in Canada.

\section{Growth Habit}

Herbs with slender stems which are elongated and erect (M. falcata and $\underline{M}$. sativa) (up to $1 \mathrm{~m}$ long) or prostrate and wide-spreading ( $\underline{M}$. lupulina) (20 to $80 \mathrm{~cm}$ long) (312). Much branched. Deep rooted (405). Root systems of various varieties include tap root, branch root, rhizomatous root, and creeping root (191). Heights of cultivars tested in Canada range from 48 to $77 \mathrm{~cm}$ (139). Flowers yellow or bluish purple, occasionally whitish (690).

Nitrogen Fixing - Fixes atmospheric nitrogen.

\section{Longevity}

Annual (M. lupulina), or perennial (M. falcata; M. sativa) herbs (312). M. sativa is a cool season species (713). Subject to winterkill, primarily due to unfavorable weather conditions (191).

\section{Self Propagation}

Seeds. Creeping rooted plants also develop horizontal rootstalks from which shoots and independent plants arise (191).

\section{Ecological Setting}

Common in fields, waste places, and along roadsides (312). It is adapted to a wider range of climate and soil than any other legume (79). Can be grown in all areas of Alberta (39). In Wyoming, $\underline{M}$. sativa found at elevations between

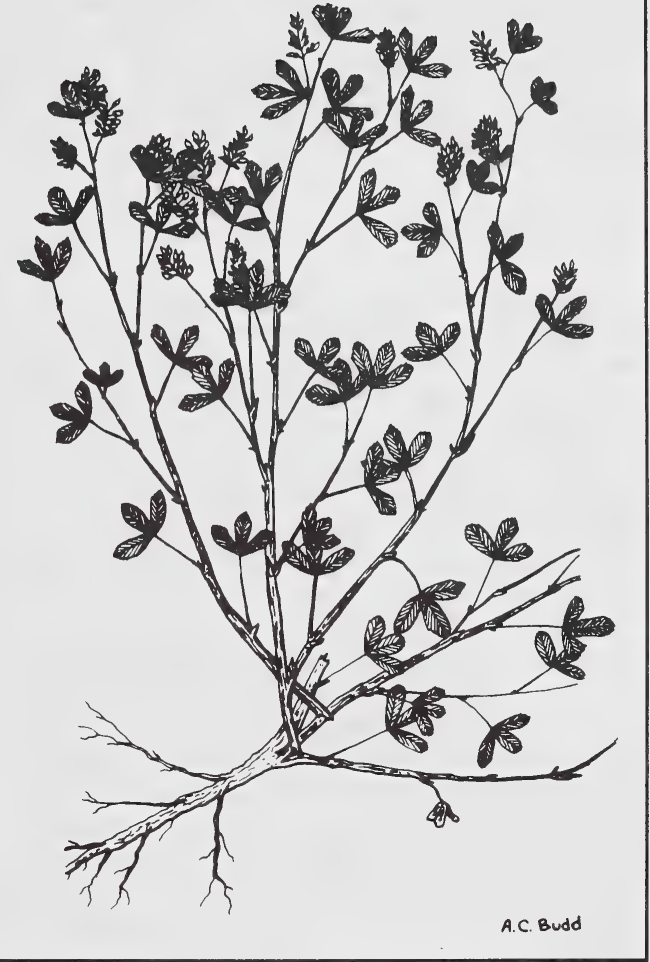

$1260 \mathrm{~m}$ and $2640 \mathrm{~m} \mathrm{ASL} \mathrm{(19).} \mathrm{M.} \mathrm{sativa} \mathrm{is}$ considered poorly adapted to the upper subalpine (41), although $\underline{M}$. sativa showed good to excellent growth at high elevation sites in Colorado between $3000 \mathrm{~m}$ and $3300 \mathrm{~m}$ ASL (rated as difficult to establish here) (44). Alfalfa had the best persistence of legumes tested on various mountain meadows in Colorado (359). In southeastern British Columbia, alfalfa grew satisfactorily on disturbed subalpine sites to $2190 \mathrm{~m} \mathrm{ASL}$ (162). Fair performance and adaptation on north and east facing slopes, and poor growth on south and west facing slopes in Montana (422). Alfalfa requires a mean annual precipitation of $40 \mathrm{~cm}(179) ; 38$ to $50 \mathrm{~cm}$ (713). In Arizona, Colorado, and Montana it grows well with less than $35 \mathrm{~cm}$ mean annual precipitation, in the absence of irrigation (175).

\section{TOLERANCES}

\section{Soil Preferences}

Alfalfa requires deep, well drained soils (179). In Alberta, alfalfa is best adapted to deep loam soils with porous subsoils; good drainage is essential 
(391). It has great value as a soil improving crop (391), particularly due to nitrogen fixing ability. M. falcata is suited to sandy or gravelly soil. In northwest Colorado, $\underline{M}$. sativa is rated as providing fair growth on sandy and clayey soil (446). $\underline{M}$. falcata outperformed $\underline{M}$. sativa on clay loam soils (with moderate to good moisture content) at a pipeline revegetation project in northeast British Columbia (431).

\section{Nutrient Requirements}

As a nitrogen fixing plant, alfalfa needs little or no additional nitrogen from fertilization. However, legumes such as alfalfa require relatively large amounts of phosphorus, potassium, and sulphur and will respond to the addition of fertilizer when these nutrients are not adequately supplied by the soil (391). Comparative growth tests on coal mine waste near Grande Cache, Alberta indicate that growth was superior in plots not fertilized since initial fertilization, but they appear more vigourous in those plots where maintenance applications of fertilizer have been made (269). Similar results were noted after 14 years in mixed seedings on amended tailings sand (645). Use of leonardite (low energy coal), as a soil amendment, improved growth of alfalfa on mine spoil and soil mixtures in greenhouse tests; results suggested that greater availability of native $\mathrm{Zn}$ and $\mathrm{Mn}$ in the presence of leonardite resulted in improved growth (367).

\section{Soil Reaction}

Alfalfa is particularly well adapted to soils with a high lime content or soils that are nearly neutral (191). It is relatively tolerant of alkaline soils, but sensitive to acidic conditions (391). It is suited to a $\mathrm{pH}$ range of 5.5 to 7.0 (362); minimum of 6.0 (713). In Kentucky, alfalfa was recommended for seed mixtures on alkaline and calcareous coal spoil $(\mathrm{pH}$ above 7.3 ); also for moderately acid to alkaline spoil (pH 6.2 to 7.3 ) (423).

\section{Soil Salinity}

Alfalfa has medium tolerance to salt ( 4 to $8 \mathrm{mS} / \mathrm{cm}$ ) relative to other plants (247), with poor tolerance at the germination stage, but good tolerance at the established stage (468). Alfalfa is indicated to have lower salinity tolerance than sainfoin on artificially salinized tailings sand and overburden (404). In Montana, it is indicated to show fair performance and adaptation to saline-alkali sites, comparable to sweetclover (Melilotus spp.) and cicer milk vetch (Astragalus cicer).

\section{Drought}

Selected varieties are noted for drought resistance ("Rambler") (191). In Alberta, it is considered highly drought resistant, but becomes dormant during drought periods and resumes growth only when moisture conditions become favorable (391).

\section{Heavy Metals and Hydrocarbons}

Alfalfa has a relatively low tolerance to oil $(282,113)$. Alfalfa tested at Wabamun, Alberta indicated that plants grown on various surface cappings over ash showed boron levels within the normal agricultural range (305). Biomass production on ash was best of any legume after three years (696). Alfalfa (M. sativa) was successfully grown on asbestos tailings, with high $\mathrm{pH}$ and relatively high concentration of $\mathrm{Ni}$ and $\mathrm{Cr}$ (310). Alfalfa and other seeded species provided satisfactory growth on gypsum waste, containing minor amounts of fluoride (163). Alfalfa produced high yields after four years of growth on uranium tailings in Ontario (better than other legumes), although rapid decline in health and vigour apparently occurs after this period. The tailings were characterized by high concentrations of heavy metals, low $\mathrm{pH}$, very little $\mathrm{N}$ or $\mathrm{P}$, low CEC (318). Comparative growth chamber tests of alfalfa, cicer milk vetch, and sainfoin on oil sands materials high in bitumen indicated that all legumes were successfully grown although covers provided were not considered adequate (404).

\section{Shade}

Associated with shade free areas (340).

\section{Grazing or Mowing}

Flemish types developed in Europe recover more rapidly after cutting and yield more at second and third cuttings than Standard types developed in North America, although Flemish types are more susceptible to diseases. Alfalfa withstands continuous grazing quite well, but it thins out rapidly when closely grazed (191). Because hay strains of alfalfa have a single taproot, rodents such as pocket gophers can reduce stands; kangaroo rats and mice also cause damage (340). Alfalfa is more subject to overgrazing than grasses, and is thus rendered more susceptible to drought and winter injury. Crown-spreading or creeping alfalfas (eg. "Nomad", "Rhizoma", "Sevelra") are more persistent and, once established, are not injured as readily by rodents (340). 
Susceptibility to Disease and Insect Damage

Intensive breeding work has increased its resistance to plant diseases and insects (179). Selected varieties are resistant to bacterial wilt ("Range") (191). So-called Flemish types, originating in Europe, are less resistant to diseases than Standard types, developed in North America (191). Susceptible to bacterial wilt, winter crown rot or snow mold, crown bud rot, leaf spot, and yellow leaf blotch. These problems can be avoided or overcome with prescribed management practices or selection for resistant varieties. Insects causing damage include lygus bug, Plagiognathus sp., and the pea aphid, Acyrthosiphon pisum. These are controlled with chemicals (191).

\section{RECLAMATION CONSIDERATIONS}

\section{Soil Building and Erosion Control Capability}

M. sativa included as a plant suitable for soil stabilization on disturbed lands in northwestern Colorado (446). Contributes nitrogen.

\section{Adaptation to Disturbance}

Rated as relatively good (338).

\section{Competitive Ability}

In grass-legume mixtures applied to coal mine wastes (Hat Creek, British Columbia), fall rye probably inhibited development of alfalfa and other species by better taking available moisture and nutrients (187). Similar observations are indicated at Grande Cache where application of nitrogen, in particular, results in vigourous growth of grass, supplanting alfalfa if the latter does not comprise at least $20 \%$ of the seed mixture (269). Seeding of tailings sand slopes resulted in good growth of alfalfa and other legumes at low rates of fertilization; as application rates increased, grasses became dominant (359).

\section{Commercial Value}

Feed for livestock and wildlife pasture, hay, and erosion control (175). Also used for production of processed alfalfa livestock feed (391).

\section{Palatability and Nutritive Value}

Wildlife forage for pronghorn antelope and mule deer (Wyoming) (381). Alfalfa forage is noted for its high protein content (191). Palatable, but causes bloat if the stand is not mature, or if grasses do not comprise at least $50 \%$ (175). When mixed with native hays, it increases their digestibility and apparent palatability; high protein and mineral contents make it an excellent supplementary feed (405). M. sativa, in particular, is noted for moderate use by mule deer in spring, and heavy use in summer and fall, where available (245). Potential problems for livestock include photosensitization, toxic concentrations of nitrate, and bloat (226).

\section{Seed or Planting Stock Availability}

Seed for many varieties has been selected for specific performance or disease resistance. Selected varieties suitable for Alberta include "Ladak", "Beaver", "Drylander", "Kane", "Rambler", and "Roamer" (391). Many licensed varieties are available. Alfalfa (M. sativa) seeds retain viability for at least 14 years storage. "Peace" is a new winter hardy forage variety and "Anik" is a new reclamation variety. Approximately 210000 seeds/lb for M. sativa (639).

\section{Methods and Ease of Establishment}

Can be drill or broadcast seeded (427). In northwestern Colorado, at elevations above $2400 \mathrm{~m}$, no more than one-fourth of the mix should be alfalfa, with three-fourths grass (427). Experimentation near Grande Cache, Alberta has determined that alfalfa should comprise at least $20 \%$ of a grass-legume mixture in order for the alfalfa to respond to competition from the grasses (269). Liming and other management practices enable alfalfa to persist on acid soils (191). Seed should be no deeper than $2.5 \mathrm{~cm}$. Seeding is not recommended in dry areas where surface soil seldom remains moist enough for germination. The best time to seed is in early spring (338). Fall/ spring seeding at a rate of 8 to $15 \mathrm{lbs}$ PLS/ac has been recommended (639); 15 to $20 \mathrm{lbs}$ PLS/ac for the Eastern US (712). Establishment potential by transplanting rated as relatively good (338).

\section{Current Status for Reclamation}

In Alberta, revegetation trials have demonstrated successful alfalfa growth on coal mine overburden waste in mountain and foothill settings $(371,364)$, prairie strip mine spoil materials (279), coal bottom ash and fly ash materials (271), and ash lagoon material at a coal power generation site $(305,696)$. Growth success is generally expressed in terms of establishment and cover development relative to other legumes tested $(45,143,86,187)$, and referenced to site-specific surface treatments. Review indicates mixed success on high-elevation sites in Alberta, probably due to varieties selected, 
growth media, and local conditions for plant growth (723). The new variety "Anik" is noted for its extreme winter hardiness and low biomass, and may be useful at high-elevation sites. "Rambler" and "Drylander" performed adequately on a variety of overburden and waste rock materials at $1675 \mathrm{~m}$ ASL near Cadomin (380) but were ultimately considered a failure (723). In Colorado, however, successful seedings and growth of alfalfa were noted on strip mine spoils at $1980 \mathrm{~m}$ to $2280 \mathrm{~m}$ ASL (43). "Rangelander" and "Anik" showed excellent survival and vigour after three years, in tests in the Upper Mackenzie region of the boreal forest (latitude $63^{\circ} \mathrm{N}$ ). While seed production was good, viability was likely poor due to the short growing season (644). "Rambler" alfalfa has persisted well in mixes on overburden and amended tailings sand for 10 to 14 years without maintenance fertilization (644). "Rambler" dominated a grass legume mixture after two seasons on coarsetextured soil in an arid climate (717). In British Columbia, alfalfa grew favorably on disturbed sites in subalpine areas from 1150 to $2100 \mathrm{~m}(494,498)$, but did not set seed. Other cases of successful alfalfa growth for reclamation include volcanic waste rock in the southern interior of British Columbia (143), gypsum waste with extremely acid reaction (163), pipeline berm materials $(436,195)$, coal mine wastes in British Columbia (187), coal spoil in Kentucky (423), and rehabilitation of wildlife habitat on disturbed lands in northwestern Colorado (446, 447).

Key features of alfalfa advantageous for reclamation use include adaptability to a wide range of ecological settings, with many commercially licensed varieties available for local conditions and land uses throughout Alberta. Variety in rooting types, combining other favored characteristics (superior forage yield and quality, nitrogen fixing capability), aids species selection planning. Limitations include sensitivity to acid soils and high elevations. Alfalfa generally complements grass species selection and satisfies criteria for a number of reclamation objectives and land uses (eg., agricultural production, wildlife habitat, etc.). 
Melilotus alba

\section{SPECIES SUITABILITY MAP AND SUMMARY TABLE}

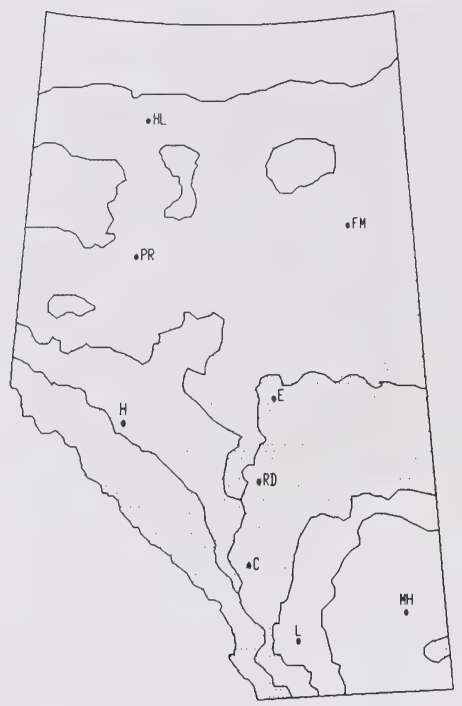

Recommended Area

Commercially Available: Yes $\underline{X}$ No

\begin{tabular}{|c|c|c|c|c|c|}
\hline \multirow{2}{*}{$\begin{array}{l}\text { RECLAMATION SUITABILITY } \\
\text { CRITERIA }\end{array}$} & \multicolumn{5}{|c|}{ SUITABILITY RATING } \\
\hline & Very High & High & Medium & Low & None \\
\hline Drought Tolerance & & $x$ & $x$ & & \\
\hline Salt Tolerance & & & $x$ & & \\
\hline pH Acid... & & & & $x$ & \\
\hline Tolerance Base & & 9.2 & & 8.0 & \\
\hline Winter Hardiness & & & $x$ & & \\
\hline Erosion Control & & $x$ & $x$ & & \\
\hline Persistence & & & & $x$ & \\
\hline Palatability & & & $x$ & $\mathrm{x}$ & \\
\hline Browse Tolerance & & & $x$ & & \\
\hline Moisture Preference & Dry to & noist. & & & \\
\hline Soil Preference & Wide $r$ & nge, clay & o sandy. & & \\
\hline
\end{tabular}


Melilotus alba Desr., $\underline{\text { M. }}$ officinales (L.) Lam.

\section{SPECIES BIOLOGY}

\section{Taxonomy}

Sweet Clover (Melilotus spp.) (138); White Sweet Clover (M. alba); Yellow Sweet Clover (M. officinales)

\section{Origin and Range}

Introduced from Europe and Asia (78). Circompolar. Throughout North America and also introduced into South America, South Africa, New Zealand and Australia (214).

\section{Growth Habit}

An erect plant; $\underline{M}$. officinales 0.2 to $2 \mathrm{~m}$ high and $\underline{M}$. alba 0.6 to $2.5 \mathrm{~m}$ high (78). Flowers of $\underline{M}$. alba are white, those of $\underline{M}$. officinales are yellow; also $\underline{M}$. officinales has shorter and finer stems, more spreading growth, and finer leaves than $\underline{M}$. alba (138). Taprooted. Sweet clover has a fast rate of growth (190). A dwarf form of sweet clover is apparently found on high peaks in British Columbia (185). White flowers (690).

\section{Nitrogen Fixing}

Sweet clover fixes atmospheric nitrogen (331).

\section{Longevity}

White sweet clover and yellow sweet clover are cool season (713) biennials (269).

\section{Self Propagation}

Seed; reseeds on some sites (500).

\section{Ecological Setting}

Introduced as a forage plant but common along roadsides and in waste areas throughout the prairies (78). The effective environmental zone for sweet clover (moisture equivalent) has been variously reported to be approximately 38 to $85 \mathrm{~cm} /$ year (500); 35 to $101 \mathrm{~cm} \mathrm{(713);} 25$ to $30 \mathrm{~cm}$ minimum (639). In southeastern B.C., sweet clover grew well at $1800 \mathrm{~m}$ to $2230 \mathrm{~m} \mathrm{ASL}$ but growth above $2430 \mathrm{~m}$ was poor (162). Sweet clover has proved to be a winter hardy species in Alaska (5).

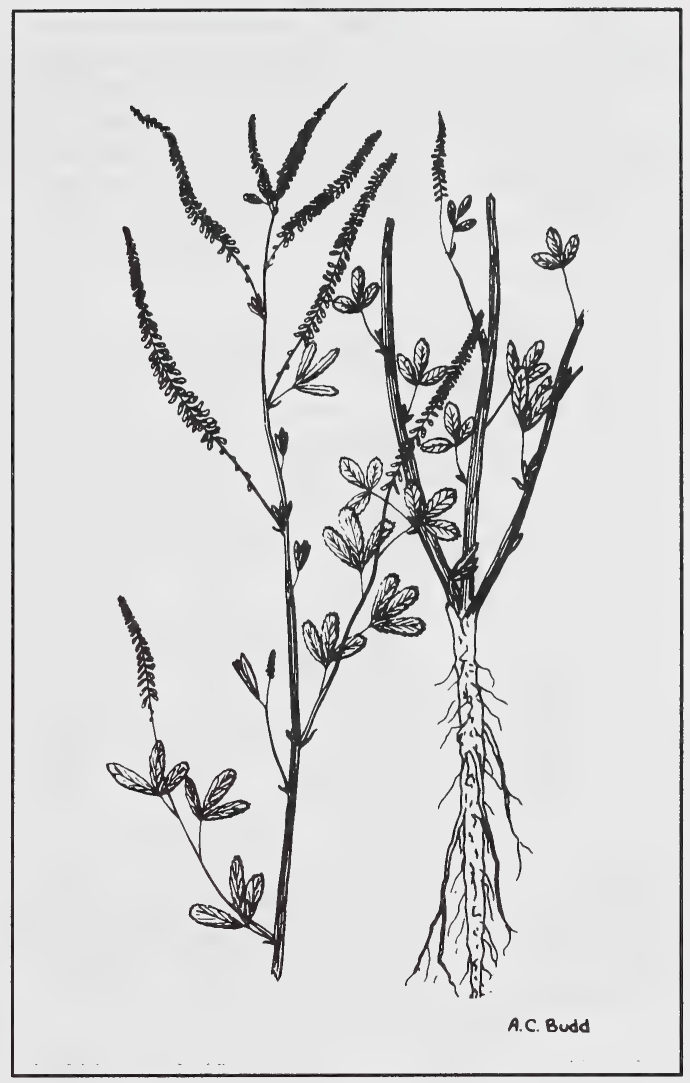

\section{TOLERANCES}

\section{Soil Preferences}

Melilotus spp. are adapted to a wide range of soil textures. Sweet clover is suited to moist (180), or dry to moist soil conditions (190). Optimum soil depth for sweet clover is more than $62 \mathrm{~cm}$ and optimum slope is 0 to $8 \%$ (447). They have a poor tolerance of wetness and flooding (5). Growth is reported to be good on soils that have textures ranging from sandy to clayey (447). Sweet clover has been recommended for revegetation use in Kentucky on steep (>70\% slope) and stony mine spoils (423).

\section{Nutrient Requirements}

Sweet clover has very low to medium nutrient requirements $(190,446,500)$. Since legumes fix atmospheric nitrogen, they need less fertilizer than 
grasses (278). In growth chamber studies on alkaline, sodic spoil material, yield of yellow sweet clover increased with the addition of NPK fertilizer. This was essentially due to $\mathrm{P}$ and inclusion of $\mathrm{N}$ with $\mathrm{P}$ usually depressed the yield. A sulphuric acid amendment increased the $\mathrm{P}$ concentration of the plants (368).

\section{Soil Reaction}

Melilotus spp. have poor acid tolerances (5). The $\mathrm{pH}$ tolerance range of sweet clover is 6.0 to $8.0 ; 5.5$ minimum (713). It has been recommended for revegetation of alkaline and calcareous $(\mathrm{pH}>7.3)$ mine spoils in Kentucky (423). White sweet clover was used successfully to revegetate alkaline $(\mathrm{pH}$ 9.2) asbestos mine tailings in Quebec (309).

\section{Soil Salinity}

Sweet clovers (Melilotus spp.) are salt tolerant species (163). Tolerates moderate salinity (3 to $5 \mathrm{mS} / \mathrm{cm}$ ) (500). Yellow sweet clover has been successfully established on sodic mine spoils near Estevan, Saskatchewan (447).

\section{Drought}

Melilotus spp. have good drought resistance (5).

\section{Heavy Metals and Hydrocarbons}

Sweetclovers (M. officinales and $\underline{M}$. alba) accumulate molybdenum. This uptake is favored by alkaline soil conditions. Copper to molybdenum ratios of less than 5 to 1 have been reported for sweet clover growing on mine spoils in the northern great plains. These ratios could cause molybdenosis in cattle and sheep (142). White sweet clover was one of the best legumes on an ash lagoon near Lake Wabamum after three years (696).

\section{Shade}

Does not tolerate shading.

\section{Grazing or Mowing}

The minimum stubble height required by Melilotus spp. has been reported as $10 \mathrm{~cm}(5)$. Presumed to tolerate grazing satisfactorily.

\section{Susceptibility to Disease and Insect Damage}

No specific susceptibilities noted.

\section{RECLAMATION CONSIDERATIONS}

\section{Soil Building and Erosion Control Capability}

Sweet clover has an erect habit and a tap-root (423). The root system is deep and abundant. Sweetclover has the ability to convert insoluble phosphorus into forms more readily available to other plants (500). Can be used to build up organic matter content of soils (138). Yellow sweet clover has been found useful for stabilizing roadcuts, and other disturbed areas in Utah (336).

\section{Adaptation to Disturbance}

Sweet clover is a pioneer on Alberta $(331,358)$ and British Columbia mine spoils (384). When planted, the sweet clover generally does well for 3 to 4 years and then is replaced by foxtail barley and weedy species. Site productivity declined to very level on Alberta mine spoils with the decline in sweet clover (85). White sweet clover has been reported as a pioneer on serpentine asbestos mine wastes ( $\mathrm{pH}$ 9.2) in Quebec (310). It is often found as a roadside weed $(34,78)$.

\section{Competitive Ability}

Sweet clover has been rated as moderately aggressive in the first year of planting, and can be very competitive in the second year of growth (500). Sweet clover seeded on mine spoils at Aleece Lake, B.C. had the poorest germination of legumes seeded and appeared to suffer from competition with seeded grasses. It performed best on the edge of plots where competition was less (187). However, sweet clover seeded with rye and spring vetch had strong growth (166). Yellow sweet clover established on sodic mine spoils in Saskatchewan spread to other plots seeded with grasses, and after four years became a dominant species in those plots (180).

\section{Commercial Value}

Hay, pasture (423). Some varieties outyield alfalfa (138). Bee pasture (138). Nitrogen fixation (331).

\section{Palatability and Nutritive Value}

Sweet clover has a well-balanced nutrient content during its early growth, but loses much of its protein as plants mature. In its early growth stage it provides palatable pasture for all classes of livestock, and when cut early and cured it makes a desirable hay (138). However, spoiled or improperly 
cured hay or silage may be poisonous to cattle; sheep and rabbits have proved susceptible in experiments (226). There is some controversy regarding dicoumarin problems from sweet clover. This substance may cause internal and external bleeding in cattle. Some workers claim that dicoumarin may arise only when cattle are fed wetbale or silage sweet clover, while others maintain that it can cause problems in cattle feeding on range sweet clover (72). "Cumino" and "Polara" are low coumarin varieties licensed in Canada, with little danger of causing hemorrhage or sweet clover disease in Canada (138). Forage of "Norgold", a recently developed variety, contains only traces of coumarin with no risk of this disease. Tough fibres also develop in over-mature hay. These may cause "hair balls" or obstruction of intestines (226). It provides good forage for mule deer, game birds and small mammals. It provides good cover for game birds and small mammals and fair cover for mule deer (296). Light to moderate use by mule deer has been reported (245). Yellow sweet clover and alfalfa were reported to compose $40 \%$ of the July diet of pronghorn antelope in Wyoming (381).

\section{Seed or Planting Stock Availability}

Seed available from most seed dealers. Approximately 260000 seeds/lb (639).

\section{Methods and Ease of Establishment}

Spring hydroseeding was found to be more successful than fall hydroseeding in trials at Luscar, Alberta (1 $800 \mathrm{~m} \mathrm{ASL}$ ) (144). Yellow sweet clover has low establishment requirements (446). Typical purity/germination is $99 / 85 \%$ (268). Sweet clover has also been successfully hydroseeded on road embankments in B.C. (162). Spring/fall seeding at a rate of 10 to $15 \mathrm{lbs}$ PLS/ac has been recommended $(639,713)$.

\section{Current Status for Reclamation}

Sweet clover has been used in hydroseeding trials on mined land in the subalpine near Luscar, Alberta (144). Germination of sweet clover was low when hydroseeded on sand dunes near Lesser Slave Lake, northern Alberta. Growth of surviving plants was poor on the dune crest but satisfactory in all other topographic positions. White sweet clover has been suggested as a species with potential use for revegetation in the Rocky Mountains (426). Regarded by some as a green manure crop only in revegetation (500). Mixed sweet clover ( $\underline{M}$. alba and $\underline{M}$. officinales) has been eliminated from seed mixes used for revegetation of oil sands tailings in northern Alberta because of poor performance
(152), although yellow sweet clover has been suggested as a suitable legume for revegetation of oil sands tailings on moist to dry sites (12). Sweet clover provided the initial cover on unseeded overburden and amended tailings sand persisting strongly for 4 to 5 years before grasses become dominant. Sweet clover has persisted as a minor component in mixed seedings for 15 years on amended tailings sand with low-maintenance fertilization (641). White sweet clover has been used successfully for revegetation of land disturbed during mining operations in the interior dry belt of B.C. (332). Sweet clover has also been successfully hydroseeded on road embankments in B.C. (162). It is often planted in association with trees and shrubs (466). White sweet clover is used for reclamation in both Europe and the USA. $(316,2$, 331). Yellow sweet clover is widely used for rehabilitation of dry, sodic or alkaline sites in Alberta, Saskatchewan and B.C. It is particularly important for mine reclamation near Estevan, Saskatchewan. It has been found suitable for reclamation use in the mid-grass prairie of central and eastern North and South Dakota. Annual precipitation in this area is about 40 to $50 \mathrm{~cm}$ and mainly cool season native grasses are used (327). It tends to out-compete seeded grasses and other legumes because of its shrub-like growth formation. Significant growth only every second year (biennial) is a disadvantage for reclamation ( $P$. King, pers.comm.). 
Onobrychis viciaefolia

\section{SPECIES SUITABILITY MAP AND SUMMARY TABLE}

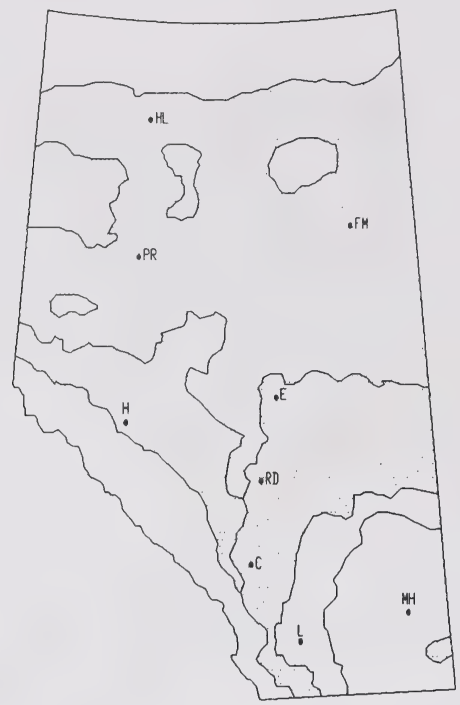

Recommended Area

Commercially Available: Yes $X$ No

\begin{tabular}{|c|c|c|c|c|c|}
\hline \multirow{2}{*}{$\begin{array}{l}\text { RECLAMATION SUITABILITY } \\
\text { CRITERIA }\end{array}$} & \multicolumn{5}{|c|}{ SUITABILITY, RATING } \\
\hline & Very High & High & Medium & Low & None \\
\hline Drought Tolerance & & & $x$ & & \\
\hline Salt Tolerance & & & $x$ & & \\
\hline pH Acid. & & & & $x$ & \\
\hline Tolerance Base & & & & $x$ & \\
\hline Winter Hardiness & & & $x$ & & \\
\hline Erosion Control & & & $x$ & & \\
\hline Persistence & & & & $x$ & \\
\hline Palatability & & $x$ & $x$ & & \\
\hline Browse Tolerance & & & $x$ & & \\
\hline Moisture Preference & Moist. & & & & \\
\hline Soil Preference & Loamy & sandy & 1 draine & & \\
\hline
\end{tabular}


Onobrychis viciaefolia Scop.

\section{SPECIES BIOLOGY}

\section{Taxonomy - Sainfoin}

\section{Origin and Range}

Introduced to North America. Originated in Europe. It has established in British Columbia, western Washington, Montana, and probably elsewhere (199).

\section{Growth Habit}

Tall leafy legume (199), with erect stems to $60 \mathrm{~cm}$ or less, and deep roots (426). Height of various cultivars ranges from 48 to $85 \mathrm{~cm}$ (139). Flowers pink to purplish (690).

Nitrogen Fixing - Fixes atmospheric nitrogen.

\section{Longevity}

Short-lived (175) perennial herb (405). Relatively tolerant of frost (179).

Self Propagation - Seed.

\section{Ecological Setting}

Common sainfoin is a forage plant introduced to agricultural areas, but has spread to roadsides and waste places (426). Common sainfoin grew "satisfactorily" on high-altitude sites (1 $650 \mathrm{~m}$ to $2010 \mathrm{~m} \mathrm{ASL}$ ) in the Fording River valley of British Columbia (162). Requires a minimum of 38 to $46 \mathrm{~cm}$ of precipitation (639); performs best in areas with $40 \mathrm{~cm}$ or more mean annual precipitation (426).

\section{TOLERANCES}

\section{Soil Preferences}

Common sainfoin is adapted to well drained soils of sandy to loamy texture (456). Good growth has been recorded on coarse textured materials (gritstone, colluvium and glacial gravels) as well as on difficult finer textured surfaces (bentonitic clay and baked clay) in a hot, arid B.C. setting (439).

\section{Nutrient Requirements}

Revegetation trials in the northeast coal block of British Columbia determined that little difference in growth could be seen between two levels of

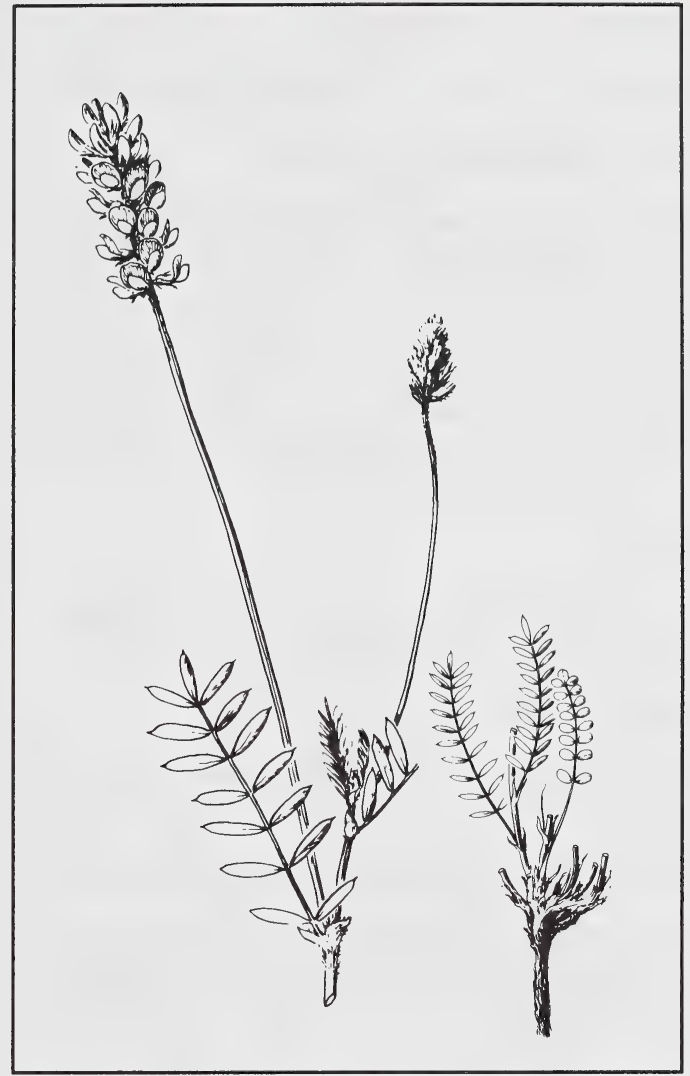

fertilization, although comparisons may be meaningless since growth was poor in both cases (70). As with most legumes, it can be inferred that nutrient requirements are fairly low, and competition with grasses would be most successful at low fertilization rate.

\section{Soil Reaction}

Growth chamber studies, testing plant growth on tailings sand and overburden materials, indicate that common sainfoin could be grown successfully in the $\mathrm{pH}$ range normally encountered at oil sands sites (slightly acid to slightly alkaline); under some conditions (low pH) it outperformed alfalfa in development of root nodules (404).

\section{Soil Salinity}

Growth chamber experiments in the Alberta oil sands tested the growth of various plant species on a tailings sand mix artificially salinized. Common sainfoin had the highest salinity tolerance of the legumes tested (cicer milk vetch and alfalfa) (404). 


\section{Drought}

Generally considered to be drought resistant (179).

Heavy Metals and Hydrocarbons

Common sainfoin was tentatively judged to warrant further study in field trials on lean oil sands $(7.8 \%$ oil content) in the Alberta oil sands, although alfalfa had a substantially better root yield. None of the legumes tested provided adequate growth on a heavy oil sand mix (oil content of $14.4 \%$ ) (404). Appears not to do well on coaly waste materials and fly ash (439). No other tolerances were noted from the literature reviewed.

\section{Shade}

Presumed to be relatively shade intolerant because of its use of agricultural settings.

\section{Grazing or Mowing}

Status as a forage plant indicates at least moderate grazing tolerance.

\section{Susceptibility to Disease and Insect Damage}

Considered to be "remarkably free" from insect pests and most plant diseases, although crown rot may occur (179).

\section{RECLAMATION CONSIDERATIONS}

\section{Soil Building and Erosion Control Capability}

Sainfoin is characterized as a deep-rooted legume (426) which may be useful for erosion control; however, its short life is not conducive to long-term erosion control (175).

\section{Adaptation to Disturbance}

Selected to grow in agricultural settings so presumably adapted to disturbance. Often considered a weed (405).

\section{Competitive Ability}

Grows well as a companion crop with grasses.

\section{Commercial Value}

Used for hay and pasture (426). Flowers are attractive to bees (179). The species may therefore be important for honey making. May also have erosion control value. A nitrogen fixer with soil nitrogen improvement ability.

\section{Palatability and Nutritive Value}

Widely used in Europe for hay and pasture, and locally important in portions of the western great plains and northern intermountain region in the United States (426). Considered equal to alfalfa in feed quality (179). It does not cause bloat (426). Observations of legume growth on revegetated mine spoil in Colorado indicate intensive grazing of common sainfoin by wildlife (449).

\section{Seed or Planting Stock Availability}

Seed is commercially available. "Eski" and "Remont" are two cultivars available in quantity; "Remont" was selected for its superior regrowth characteristics (426). Thirteen other cultivars have been tested for yield in Canada (139). Seed supply is apparently limited (175). "Melrose" and "Nova" are licensed in Canada. "Nova" is noted for winter hardiness. Approximately 30000 seeds/lb (639).

\section{Methods and Ease of Establishment}

Establishment is usually by seed. Typical purity/germination is $97 / 80 \%$ (417). Successfully seeded on coal surface-mined lands in Montana by a rangeland drill seeding a grass-legume mixture. Good establishment during second growing season following an apparent slow start during initial season (117). Spring seeding at a rate of 35 to $45 \mathrm{lbs}$ PLS/ac has been recommended (639).

\section{Current Status for Reclamation}

Common sainfoin is a fairly widely used hay and pasture species, both in Canada and the northern US. Its moisture requirements are moderate, and therefore it is less successful in dry prairie situations than in the mountains or moist parkland. Performance is generally acceptable on waste overburden in the forested regions, however persistence is poor.

Although the species is not regarded as particularly successful at high elevations, common sainfoin showed satisfactory growth on high elevations in southeastern B.C. (2 $010 \mathrm{~m} \mathrm{ASL}$ ) (162). Common sainfoin is currently used in grass-legume mixtures at oil sands sites (152) and has been tested in growth studies (404). In the Smoky River area, first year evaluations of growth ranged from "poor" to "good"; no plants survived the following winter, presumably due to the harsh overwintering conditions of the alpine (1 $950 \mathrm{~m} \mathrm{ASL}$ ) tundra. Sainfoin performed well in mixed seeding and in 
pure stands on overburden waste in the lower subalpine region near Hinton (647) and Canmore, respectively. The cultivar "Krasnodar" was used (377). First-year results on coal mine wastes in the Hat Creek Valley of British Columbia indicate that common sainfoin ("Melrose") showed good emergence on all materials except carbonaceous soils (shale and coal waste) and fly ash. It clearly outperformed all other legume species tested (Drylander alfalfa, sweet clover, red clover). Additions of topsoil seemed beneficial (439). Revegetation trials in the northeast coal block of B.C. (elevations 1065 to $1720 \mathrm{~m}$ ) indicated poor growth of sainfoin below treeline; however all species grew poorly above treeline (70). Comparative evaluation of several legumes for persistence and forage production on mountain meadows in Colorado indicated poor performance of sainfoin relative to other legumes (417). 
Oxytropis spp.

\section{SPECIES SUITABILITY MAP AND SUMMARY TABLE}

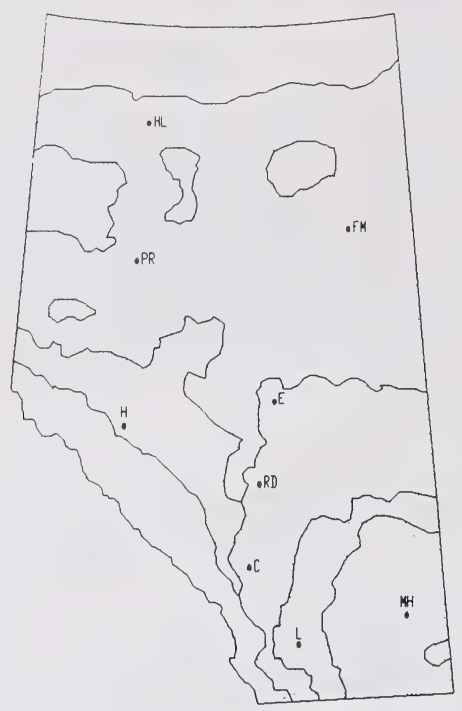

Recommended Area

Commercially Available: Yes No $\underline{X}$

\begin{tabular}{|c|c|c|c|c|c|}
\hline \multirow{2}{*}{$\begin{array}{l}\text { RECLAMATION SUITABILITY } \\
\text { CRITERIA }\end{array}$} & \multicolumn{5}{|c|}{ SUITABILITY RAIING } \\
\hline & Very High & High & Medium & Low & None \\
\hline Drought Tolerance & & $x$ & & & \\
\hline Salt Tolerance & & & $\mathrm{x}$ & & \\
\hline Acid. & & & & & \\
\hline Tolerance Base & & & 8.4 & & \\
\hline Winter Hardiness & & $x$ & & & \\
\hline Erosion Control & & $x$ & & & \\
\hline Persistence & & & $\mathrm{X}$ & & \\
\hline Palatability & & & & $x$ & \\
\hline Browse Tolerance & & & $x$ & & \\
\hline Moisture Preference & Dry to & loist. & & & \\
\hline Soil Preference & Clay 1 & m to & loam. & & \\
\hline
\end{tabular}




\section{Oxytropis spp.}

\section{SPECIES BIOLOGY}

\section{Taxonomy}

Loco-weed (‥ monticola); Alpine Loco-weed (‥ cusickiii).

O. monticola A. Gray ssp. monticola, also

O. campestris (L.) DC. var. gracilis (A.Nels.) Barneby; and $\underline{0}$. cusickii Greenm., also O. campestris (L.) DC. var. cusickii (Greenm.) Barneby.

\section{Origin and Range}

Native. Alaska, south in the mountains to Colorado, and Wyoming. Scattered representation around Hudson Bay, Labrador and Nova Scotia. Also northwestern Europe (214).

\section{Growth Habit}

Plants of this genus are usually without stems (78). Erect leaves 110 to $310 \mathrm{~cm}$ tall (690). Oxytropis spp. generally have a bunch growth habit (436). Root:shoot ratio is high (436). Flowers blue, purple, whitish or yellowish (690).

Nitrogen Fixing - Fixes atmospheric nitrogen.

\section{Longevity}

Perennial herb (788). The species is regarded as being winter hardy (240).

Self Propagation - By seed.

\section{Ecological Setting}

Oxytropis monticola is common in open woodlands and throughout the prairies where it is not excessively dry. $\underline{0}$. cusickii occurs at high altitudes in the Rocky Mountains $(78,690)$.

\section{TOLERANCES}

\section{Soil Preferences}

Oxytropis campestris prefers sandy loam to loam clay soils. It will not tolerate water saturated soils such as heavy clays.

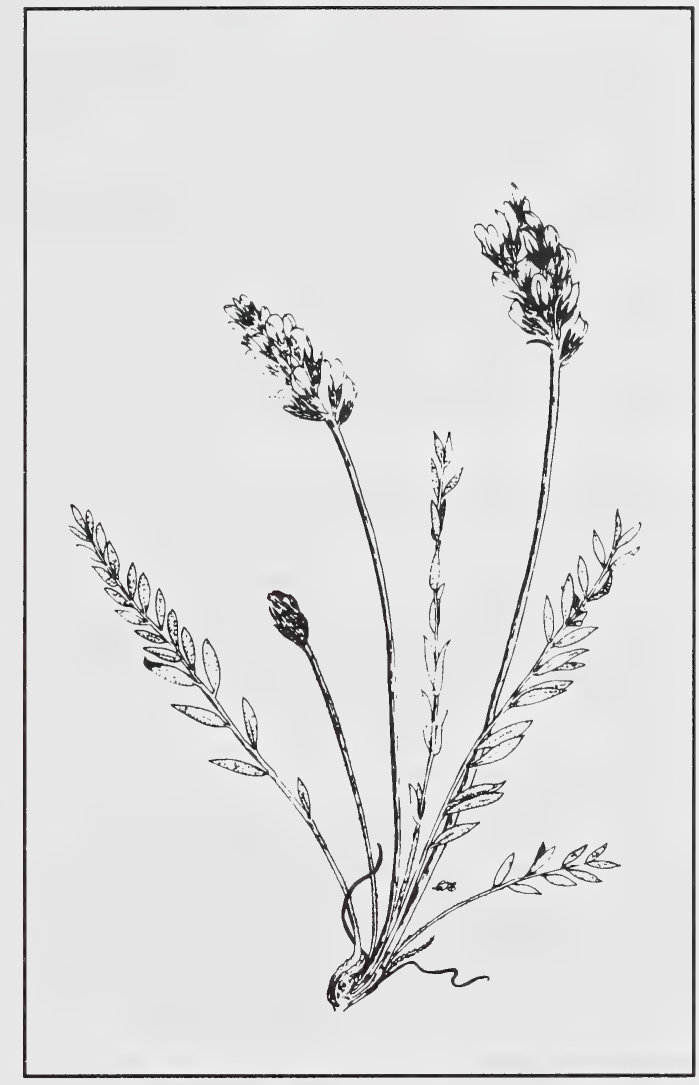

\section{Nutrient Requirements}

Loco weeds in general are tolerant of low nutrient conditions (436).

\section{Soil Reaction}

Oxytropis cusickii has been reported as a pioneer on alkaline ( $\mathrm{pH} 8.0$ to 8.4 ) glacial outwash in Alaska (332).

\section{Soil Salinity}

Tolerant of moderately saline soils.

\section{Drought}

Loco weeds in general are drought tolerant (436).

\section{Heavy Metals and Hydrocarbons}

No specific tolerances noted. 


\section{Shade}

Will not tolerate excessive shade.

\section{Grazing or Mowing}

Moderately tolerant of grazing since it is generally avoided by livestock and wildlife.

\section{Susceptibility to Disease and Insect Damage}

Locoweed species found naturally in northern areas are resistant to northern diseases (436).

\section{RECLAMATION CONSIDERATIONS}

\section{Soil Building and Erosion Control Capability}

The nitrogen fixing ability and high root:shoot ratio make this species an excellent soil builder with a high erosion control capability.

\section{Adaptation to Disturbance}

Oxytropis cusickii has been reported as a pioneer on gravel outwash on the Muldrow Glacier, Alaska (332). Oxytropis monticola has been reported as a pioneer on coal mine spoil near Cadomin, Alberta. This site is located at $1675 \mathrm{~m} \mathrm{ASL}$ and has severe climatic limitations (wind and drought) (357).

\section{Competitive Ability}

Good competitive ability on preferred sites.

\section{Commercial Value}

No commercial value, except soil building and nitrogen fixation.

\section{Palatability and Nutritive Value}

Some Oxytropis spp. are poisonous to livestock as they contain alkaloids which cause "loco" disease (312).

\section{Seed or Planting Stock Availability}

Seed is easily collected from native stands, although germination rate is low (268).

\section{Methods and Ease of Establishment}

Late yellow loco-weed often has a lengthy dormancy period before germination (431). Germination of Oxytropis spp. has been reported as about $10 \%$ (268).

\section{Current Status for Reclamation}

Late yellow loco-weed is currently being evaluated for growth on tailings sand from Yellowknife (332). Very little use is otherwise apparently made of it. Late yellow loco-weed is a drought tolerant species and tolerant of saline soils. Its ability to fix atmospheric nitrogen and its high root to shoot ratio are attributes which suggest this species has potential for reclamation purposes in Alberta. 
Trifolium hybridum

\section{SPECIES SUITABILITY MAP AND SUMMARY TABLE}

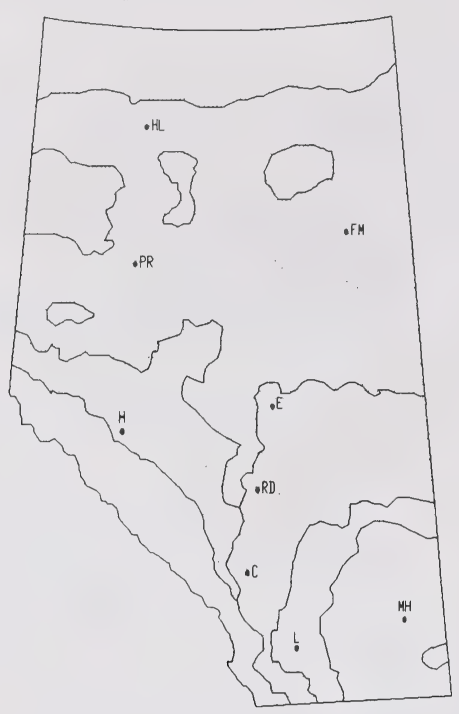

Recommended Area

Commercially Available: Yes $X$ No

\begin{tabular}{|c|c|c|c|c|c|}
\hline \multirow{2}{*}{$\begin{array}{l}\text { RECLAMATION SUITABILITY } \\
\text { CRITERIA }\end{array}$} & \multicolumn{5}{|c|}{ SUITABILITY RATING } \\
\hline & Very High & High & Medium & Low & None \\
\hline Drought Tolerance & & & $x$ & & \\
\hline Salt Tolerance & & & & $x$ & \\
\hline Acid & & & $x$ & & \\
\hline Tolerance Base & & & $x$ & & \\
\hline Winter Hardiness & & $x$ & & & \\
\hline Erosion Control & & & $x$ & & \\
\hline Persistence & & & & $x$ & \\
\hline Palatability & & $\mathrm{x}$ & & & \\
\hline Browse Tolerance & & $x$ & $x$ & & \\
\hline Moisture Preference & Moist, & tolerat & easonal $f$ & ng. & \\
\hline Soil Preference & Clay $t$ & sandy & & & \\
\hline
\end{tabular}




\section{Trifolium hybridum L.}

\section{SPECIES BIOLOGY}

\section{Taxonomy - Alsike Clover}

\section{Origin and Range}

Origin is obscure (138). Introduced from Europe (331). Cultivated in Alaska, throughout Canada and the United States. Scattered circumboreal distribution (214).

\section{Growth Habit}

Alsike clover is an erect to decumbent plant, 20 to $80 \mathrm{~cm}$ high $(312,78)$. Stems are usually much branched (690). Flowers commonly pinkish (690).

\section{Nitrogen Fixing - Fixes atmospheric nitrogen}

\section{Longevity}

Alsike clover is a short-lived perennial species (690). "Aurora" and "Dawn" varieties are noted for winter hardiness (138). Generally dies in two years (713)

Self Propagation - Primarily by seed.

\section{Ecological Setting}

Escaped from cultivation. Alsike clover is common in waste places, along roads, and in wooded areas of the prairies (78). It is well adapted to cool climates (256). Alsike clover did not persist more than two years at several high altitudes (>2 $100 \mathrm{~m}$ ) sites in Colorado (417). Alsike Clover has been recommended for use in the aspen and subalpine zones of the intermountain region of Utah and Nevada. In areas with annual precipitation less than $34 \mathrm{~cm}$, planting should be restricted to moist lowlands (424). The effective environmental zone (moisture equivalent) has been variously reported to be 45 to $135 \mathrm{~cm} /$ year (500) and 38 to $101 \mathrm{~cm}(713)$; minimum of $89 \mathrm{~cm}(639)$.

\section{TOLERANCES}

\section{Soil Preferences}

Alsike clover is adapted to soils with moisture regimes ranging from well and moderately well drained to poorly drained soils that are usually waterlogged (5) and seasonally flooded $(12,256)$. Best growth can be expected on moist soils. The

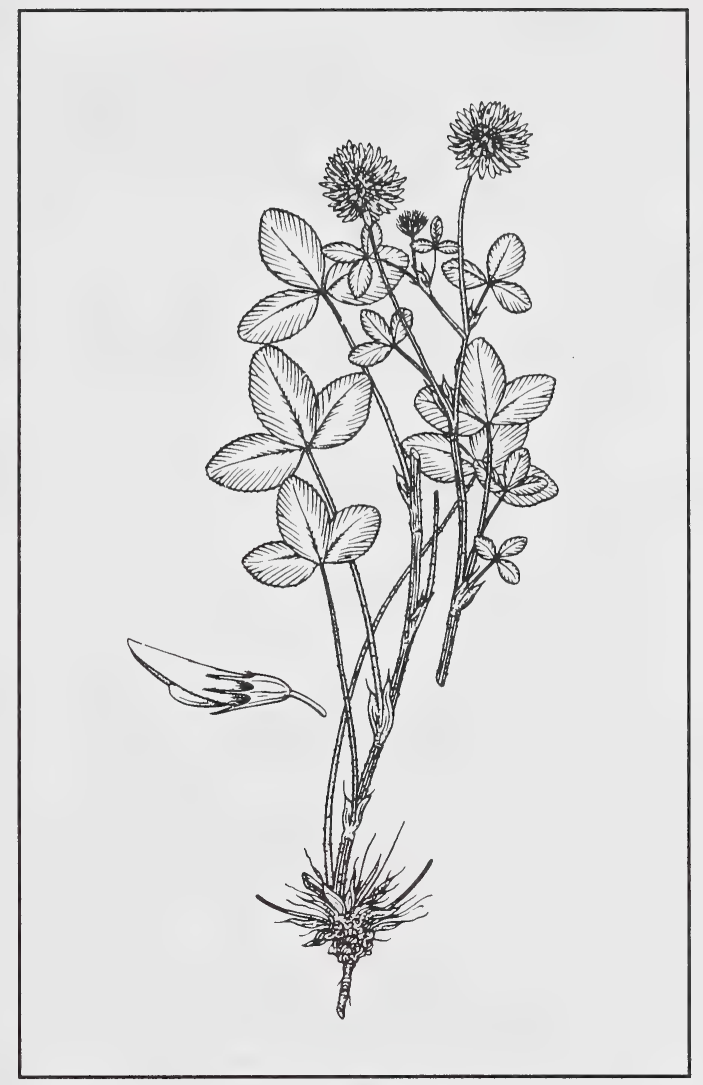

optimum slope is 0 to $8 \%$ and the optimum soil depth is more than $62 \mathrm{~cm}$. Growth on sandy soil is fair, and on loam soil and clayey soil growth is good (447).

\section{Nutrient Requirements}

Alsike clover requires moderate amounts of phosphate and potassium for satisfactory growth (500).

\section{Soil Reaction}

Alsike clover can tolerate acid and alkaline conditions (256). It is not as sensitive to low soil pH as alfalfa (Medicago spp.) and sweetclover (Melilotus spp.), or as tolerant of low pH as sericea lespedeza (Lespedeza cuneata) and birdsfoot trefoil (Lotus corniculatus) (27). Alsike clover has good acid tolerance (5). It does well on soils that are too acid for red clover (Trifolium pratense) and it can tolerate more alkalinity than most other clovers (138). Lower limit is 5.0 (713). 


\section{Soil Salinity}

Alsike clover is not generally tolerant of salinity (500). Salt tolerance has been rated as moderate (424). The limit of soil salinity tolerance has been reported to be 2 to $4 \mathrm{mS} / \mathrm{cm}$ (468).

\section{Drought}

"Aurora" alsike clover is drought tolerant (12). Overall, alsike clover has fair drought tolerance (5).

\section{Heavy Metals and Hydrocarbons}

Alsike clover has a high tolerance of oil (282). No other tolerances were noted.

Shade - Prefers bright, open locations.

\section{Grazing or Mowing}

It is presumed that the species has moderate to good tolerance to grazing and mowing.

\section{Susceptibility to Disease and Insect Damage}

No specific disease or insect pest information was located.

\section{RECLAMATION CONSIDERATIONS}

\section{Soil Building and Erosion Control Capability}

This species is not rhizomatous (41). The tap root may be up to $1 \mathrm{~m}$ deep (500). Its value for soil building lies in its contribution of fixed nitrogen and in its fibrous lateral roots.

\section{Adaptation to Disturbance}

Alsike clover is planted, and has satisfactory survival and growth, under a wide variety of disturbed soil situations including roadsides, cultivated fields, and on denuded industrial sites. It has a good rate of spread (424).

\section{Competitive Ability}

Alsike clover is only weakly aggressive (500).

\section{Commercial Value}

Alsike clover is grown on wet soils, mixed with grasses, for hay (138). Primary use is as a nitrogen supplier, for hay and pasture, and for site rehabilitation.

\section{Palatability and Nutritive Value}

Yield potential for alsike clover has been rated as moderate (5). It is considered a palatable species (41). Alsike clover may cause photosensitive irritation in livestock (226), and bloat (639). Forage value has been rated as good for mule deer, game birds, and small mammals. The cover value is poor for mule deer and game birds, and good for small mammals (447).

\section{Seed or Planting Stock Availability}

Licensed varieties for use in Canada include "Aurora", "Dawn" and "Tetra" (138). Approximately 680000 seeds/lb (639).

\section{Methods and Ease of Establishment}

Purity/germination is typically $99 / 85 \%$ (132). Alsike clover has good seedling vigour (41). Ease of establishment has been rated as good (424). The species is usually seeded in combination with grasses to provide a source of fixed soil nitrogen. A seeding rate of 5 to $10 \mathrm{lbs} \mathrm{PLS} / \mathrm{ac}$ has been recommended for the Eastern US $(713) ; 6$ to 8 Ibs PLS/ac in the spring for the west (639).

\section{Current Status for Reclamation}

"Aurora" alsike clover gave satisfactory first year results when seeded on raw overburden at Cadomin (subalpine), Alberta (364) but failed to persist (705). Alsike clover was reported to grow above treeline in northeastern B.C., but only in sheltered moist pockets (70). "Aurora" performed well in mixtures on disturbed soils near Cold Lake and in the oil sands on amended tailings sand and on overburden, generally peaking after three or four seasons and then declining rapidly $(641,685,704)$. Alsike clover is one of several grasses and legumes which were successfully established on organic and nutrient enriched coarse asbestos tailings $(\mathrm{pH}$ 9.2) in Quebec (309). Alsike clover has been recommended for revegetation of disturbed sites below $3330 \mathrm{~m}$ ASL in Colorado (462). "Dawn" alsike clover is recommended for areas with excessive acidity, alkalinity, spring flooding or a high water table (209). "Aurora" alsike clover has been used for revegetation in Alaska (298).

Alsike clover is a short lived, non-spreading legume. It can tolerate both moderately acid and alkaline soils. It is well adapted to cool climates and wet soils and will withstand flooding for long periods. It has potential use as a companion crop for revegetation of disturbed areas where its nitrogen fixing ability is an asset. 
Trifolium pratense

\section{SPECIES SUITABILITY MAP AND SUMMARY TABLE}

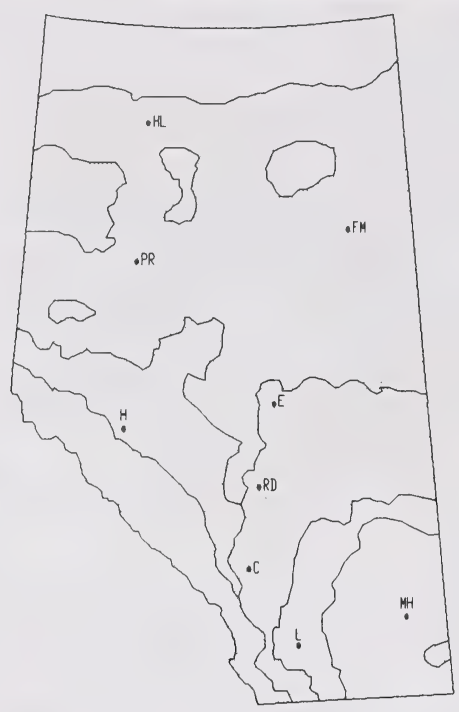

Recommended Area

Commercially Available: Yes $\mathrm{X}$ No

\begin{tabular}{|c|c|c|c|c|c|}
\hline \multirow{2}{*}{$\begin{array}{l}\text { RECLAMATION SUITABILITY } \\
\text { CRITERIA }\end{array}$} & \multicolumn{5}{|c|}{ SUITABILITY RAIING. } \\
\hline & Very High & High & Medium & Low & None \\
\hline \multicolumn{6}{|l|}{ Drought Tolerance } \\
\hline \multicolumn{6}{|l|}{ Salt Tolerance } \\
\hline \multicolumn{6}{|l|}{ pH Acid } \\
\hline Tolerance Base & & & $x$ & & \\
\hline \multicolumn{6}{|l|}{ Winter Hardiness } \\
\hline \multicolumn{6}{|l|}{ Erosion Control } \\
\hline \multicolumn{6}{|l|}{ Persistence } \\
\hline \multicolumn{6}{|l|}{ Palatability } \\
\hline \multicolumn{6}{|l|}{ Browse Tolerance } \\
\hline Moisture Preference & \multicolumn{5}{|c|}{ Moist, tolerates flooding. } \\
\hline Soil Preference & \multicolumn{5}{|c|}{$\begin{array}{l}\text { Silty clay to sandy loam, well to moderately well } \\
\text { drained. }\end{array}$} \\
\hline
\end{tabular}




\section{Trifolium pratense $\mathrm{L}$.}

\section{SPECIES BIOLOGY}

\section{Taxonomy - Red Clover}

\section{Origin and Range}

Introduced from Europe (78). It is a native over most of Europe and parts of Asia (138). Cultivated in Alaska, British Columbia east to Newfoundland, south to California in the west and Florida in the east (214). Circumboreal distribution (214).

\section{Growth Habit}

An erect or spreading, widely branched herb. Red clover is usually 40 to $80 \mathrm{~cm}$ tall (312). There are two types in Canada: early flowering or double-cut and late flowering or single-cut. The early flowering type produces two hay crops per year (138). Not rhizomatous (41). Flowers red, pink or nearly white (690).

\section{Nitrogen Fixing}

Red clover fixes atmospheric nitrogen. Good nodulation and nitrogen fixation have been obtained on acid soils (down to $\mathrm{pH} 3.5$ ) by applying the appropriate Rhizobia and a small amount of molybdenum with the seed at the time of planting (38).

\section{Longevity}

Biennial or short-lived, cool season (713) perennial species (78). Under favourable conditions it may survive for three growing seasons (426). The early flowering type is a biennial or short-lived perennial whereas the late flowering type is usually always perennial (138). 'Alaskaland' red clover has excellent winter hardiness (240). "Altaswede" red clover is winter hardy (12). Red clover persisted from 2 to 5 years at several high altitude (over $2100 \mathrm{~m} \mathrm{ASL}$ ) sites in Colorado (417).

\section{Self Propagation}

Propagation is primarily by seed.

\section{Ecological Setting}

Red clover is the most widely grown of all true clovers. It is best adapted to cool or warm summer temperatures where there is adequate moisture throughout the growing season (138). This species has escaped from cultivation (312). It is rarely

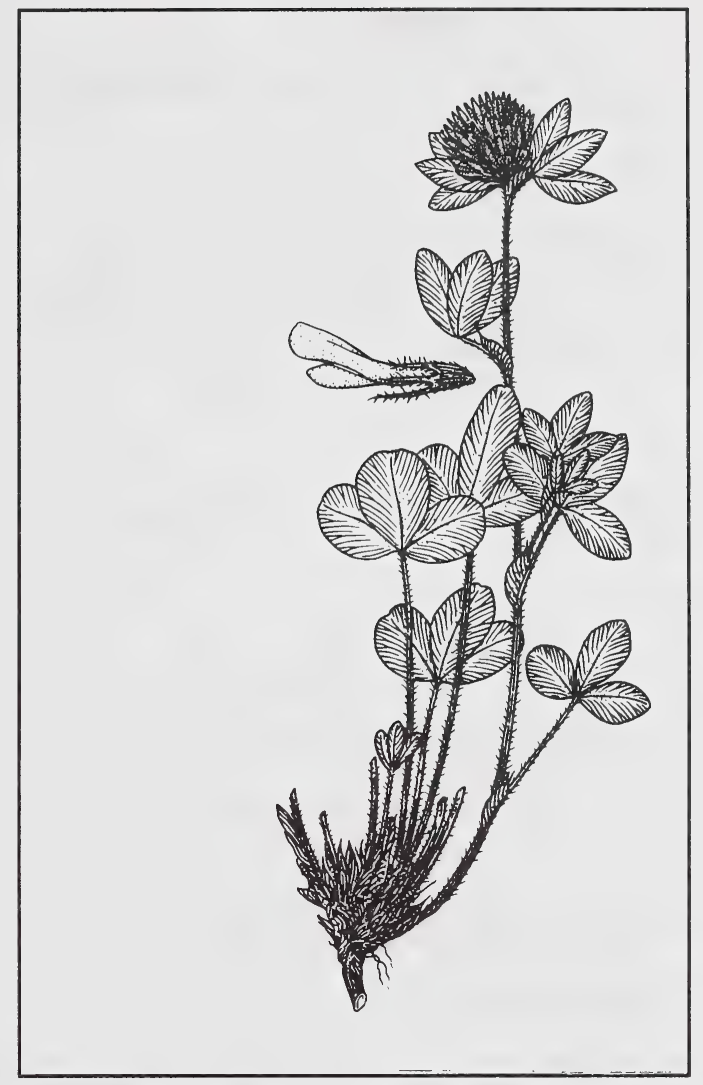

found in the western part of the Canadian prairies but is fairly common in waste areas in the east and north (78). It is mainly used in the eastern United States but can be used on irrigated areas in the western United States except the arid southwest (426). In areas with less than $30 \mathrm{~cm}$ precipitation planting should be restricted to moist lowlands (424). Precipitation range is 50 to $127 \mathrm{~cm}$ (713); $89 \mathrm{~cm}$ minimum (639).

\section{TOLERANCES}

\section{Soil Preferences}

Red clover is adapted to soils with medium textures from sandy loam to silty clay loam (5). It has fair tolerance to wetness and flooding (5). For good growth, red clover requires ample moisture and good drainage. It grows well on Luvisolic and Chernozemic soils (391). The optimum slope is 0 to $8 \%$ and the optimum soil depth is more than $62 \mathrm{~cm}$. Growth is also good on sandy soil, loamy soil and clayey soil (447). 


\section{Nutrient Requirements}

Presumed to have no more than modest nutrient requirements.

\section{Soil Reaction}

Red clover is not as sensitive to low soil $\mathrm{pH}$ as alfalfa (Medicago spp.) and sweet clover (Melilotus spp.), or as tolerant of low pH as birdsfoot trefoil (Lotus corniculatus) (27). It has poor to fair acid tolerance (5). Lower limit is 5.0 (713).

Soil Salinity

Red clover has low tolerance to soil salinity ( 0 to $4 \mathrm{mS} / \mathrm{cm})$ (163).

\section{Drought}

Red clover has fair drought tolerance (5).

Heavy Metals and Hydrocarbons

No tolerances noted from the literature.

\section{Shade}

Prefers open situations and good light.

\section{Grazing or Mowing}

Presumably relatively tolerant to mowing and grazing.

\section{Susceptibility to Disease and Insect Damage}

"Altaswede" is susceptible to powdery mildew and northern anthracnose. "Dolland" is moderately resistant to northern anthracnose, leafhoppers and wilt. "Norlac" is resistant to northern anthracnose (138).

\section{RECLAMATION CONSIDERATIONS}

\section{Soil Building and Erosion Control Capability}

This species is not rhizomatous (41). Red clover has a tap root system with many side branches. It is not as deep rooted as alfalfa (138). Erosion control ability is presumed to be slight; however, the species is valuable for its nitrogen fixing abilities.

\section{Adaptation to Disturbance}

Red clover has a good rate of spread (424). It has been reported as a volunteer on reclamation test plots near Wabamun, Alberta (305). Red clover had good performance on sites disturbed by mining above $1650 \mathrm{~m} \mathrm{ASL}$ in southeastern B.C. (494). It commonly occurs on disturbed roadsides, and is adapted to planting under cultivation.

\section{Competitive Ability}

Double cut red clover seeded in a mixture on reclamation test plots at Aleece Lake, B.C. showed growth on plot edges where competition was presumably less (187)

\section{Commercial Value}

Red clover is an important forage crop (426). Because of its rapid growth in the first year it should be seeded with grasses to reduce the hazard of bloat (391). It has been recommended for revegetation of critical sites in Canada. It is commonly used on roadsides for forage and hay, and to provide ground cover.

\section{Palatability and Nutritive Value}

Red clover has high protein content and is an excellent forage species (256). Forage yield for livestock has been rated as moderate (5). It is highly palatable (427). It may cause photosensitization in livestock. The grazing of a second cut has occasionally caused slobbering and loss of appetite in cattle and sheep (226). Forage value has been rated as good for mule deer, game birds and small mammals. Cover value is poor for mule deer, fair for game birds and good for small mammals (447).

\section{Seed or Planting Stock Availability}

Licensed varieties for use in Canada include "Altaswede", "Dollard", "Hungaropoli", "Lakeland", "Lasalle", "Manhardy", "Norlac", "Pacific", "Florei" and "Ottawa" (138). "Altaswede", a late flowering perennial type, is very winter hardy but not particularly drought tolerant and in Alberta is best suited to sites north and west of Edmonton where the average annual precipitation is greater than $42 \mathrm{~cm}$ (138). "Norlac" is also adapted to Alberta conditions. "Arlington", "Mammoth", "Midland", "Lakeland", "Kenland", "Pennscott", "Kenstar", and "Chesapeake" are available in the US (713). Approximately 275000 seeds/lb (639).

\section{Methods and Ease of Establishment}

High quality seed should have a purity of $98 \%$ and a germination rate of $90 \%$ (138). Red clover is readily established because of its high seedling 
vigour (342). Because it will not normally persist more than 3 years, reseeding is required to maintain production (342). A seeding rate of 10 to $12 \mathrm{lbs}$ PLS/ac has been recommended for the Eastern US (713); 8 to $10 \mathrm{lbs}$ PLS/ac in spring/fall for the west (639).

\section{Current Status for Reclamation}

Red clover is a widely used forage species throughout much of North America. It is commonly used for roadside revegetation, and is a common component of reclamation seed mixtures. "Altaswede" dominated grass - legume seedings for three years on the reclaimed Judy Creek test coal mine in northwest Alberta (646). Red clover planted at exploration sites above treeline in northeastern B.C. fared well but only in sheltered, moist pockets (70). Red clover has only fair drought tolerance, is not as sensitive to low soil $\mathrm{pH}$ as alfalfa or sweet clover, and can persist in the subalpine for severa! years. Red clover has been recommended for revegetation of disturbed sites in northeastern Colorado (427). Commonly used for "corridor reclamation" of seismic lines and pipeline rights-ofway in Alberta (P. Sims, pers.comm.). 
Trifolium repens

\section{SPECIES SUITABILITY MAP AND SUMMARY TABLE}

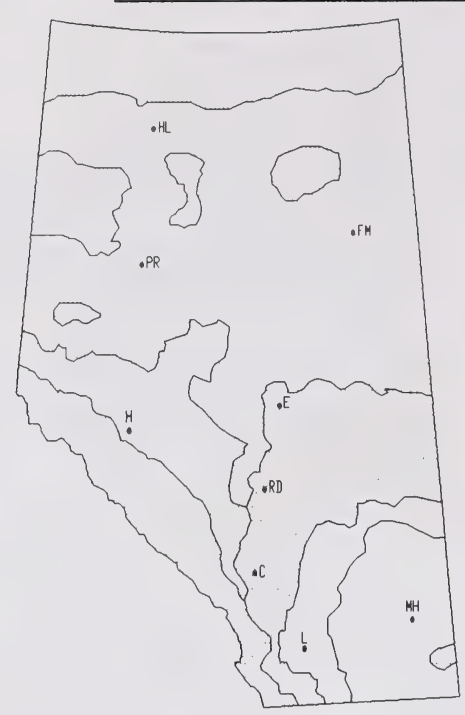

Recommended Area

Commercially Available: Yes $X$ No

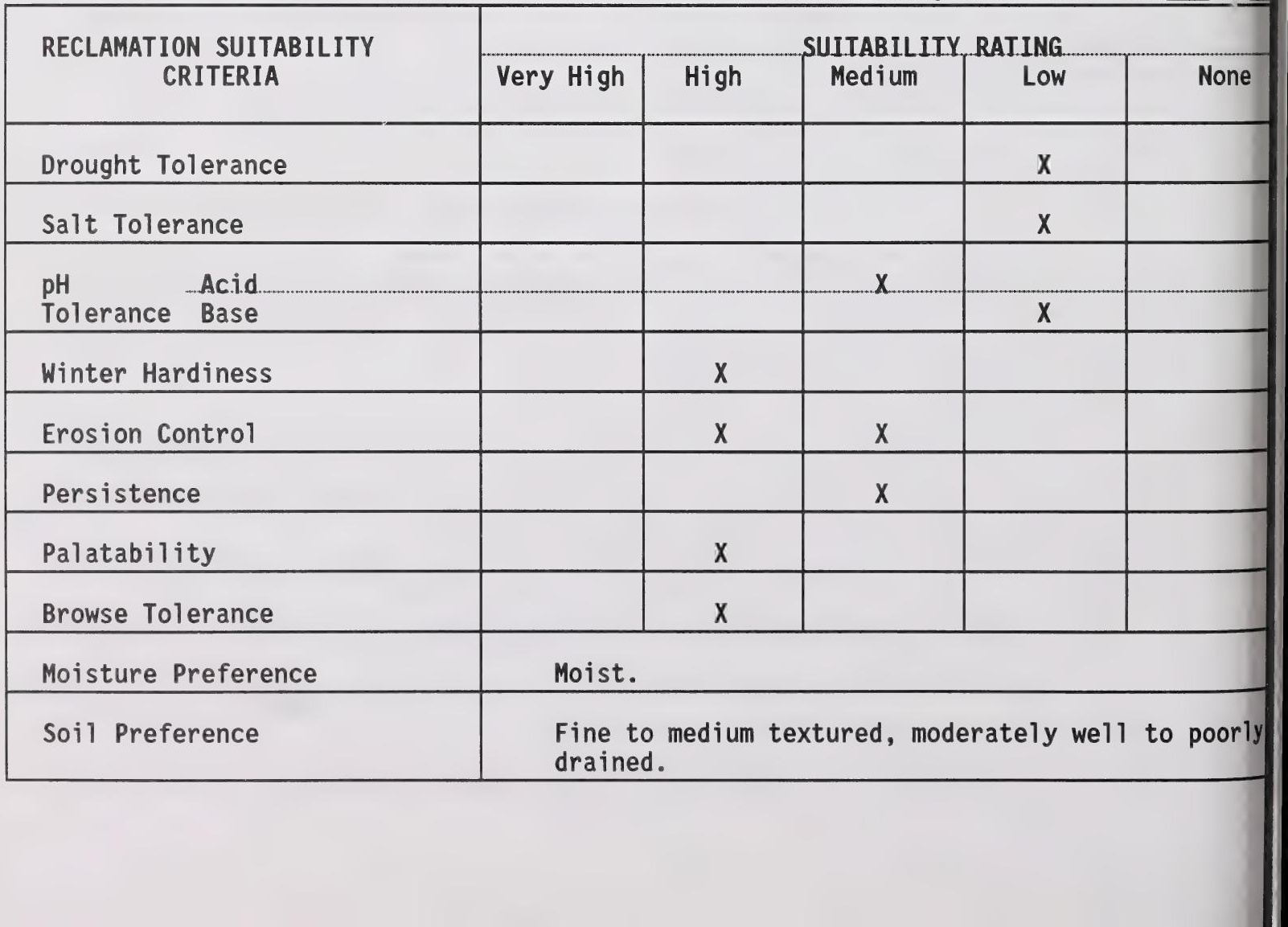




\section{Trifolium repens $\mathrm{L}$.}

\section{SPECIES BIOLOGY}

Taxonomy - White Clover; Dutch Clover.

\section{Origin and Range}

Introduced from Europe. Originated in the eastern Mediterranean countries or in Asia Minor (138). Cultivated in Alaska, and throughout Canada and in the United States (214). Circumboreal distribution (214).

\section{Growth Habit}

A low creeping species which often roots at the nodes (690). It has stoloniferous stems (138). White or pinkish flowers (690).

\section{Nitrogen Fixing}

White clover fixes atmospheric nitrogen (331) if properly innoculated prior to seeding (500).

\section{Longevity}

Long-lived, cool season (713) perennial (78). With good management it may persist for 5 years or more (391). White clover has excellent winter hardiness (240). "Pilgrim" and "Merit" white clover have been developed for winter hardiness (179).

\section{Self Propagation}

Propagates by seed, as well as spreading by stoloniferous stems (138).

\section{Ecological Setting}

It is best adapted to a wide range of altitudes (500). White clover grows best in humid sections of the temperate zone during the cool, moist seasons (138). Commonly used for lawns, this species has escaped from cultivation and is found along roads, in meadows and in wooded areas (78). It is adapted to humid climates (256). Precipitation range is 45 to $114 \mathrm{~cm}$ (713); minimum $89 \mathrm{~cm}$ (639).

\section{TOLERANCES}

\section{Soil Preferences}

White clover does best on moist sites $(41,447)$. It is best adapted to moderately fine to medium textured soils (426) ranging from sandy loam to silty clay loam $(5,256)$. Soil moisture regime ranges

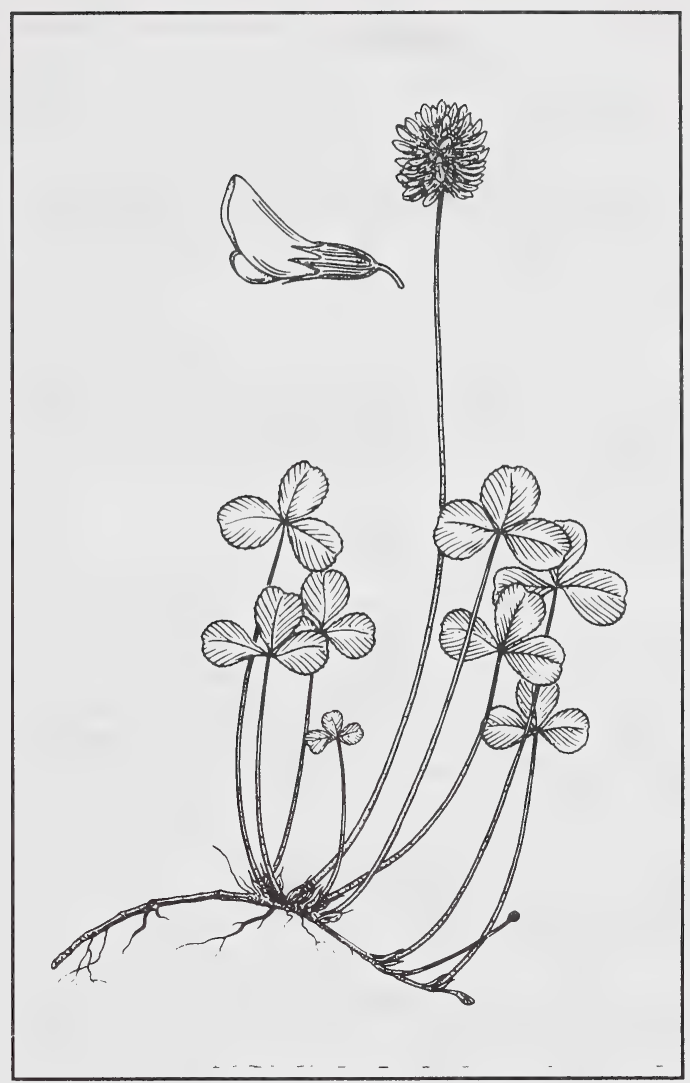

from well or moderately well drained to poorly drained soils that are waterlogged, although there is some doubt regarding the ability of this species to withstand flooding (5). The optimum slope is 0 to $8 \%$ and it prefers deep soils. Periods of prolonged high temperatures with either high or low rainfall are unfavourable for growth (138).

\section{Nutrient Requirements}

White clover can be readily established in areas of low fertility (342) although it has been rated as having moderate fertility requirements (500). "Ladino" white clover requires high applications of phosphate fertilizer to obtain high forage production (179). Phosphorus and calcium levels are critical (713).

\section{Soil Reaction}

White clover is not as sensitive to low soil pH as alfalfa (Medicago spp.) and sweet clover (Melilotus spp.), or as tolerant of low pH as birdsfoot trefoil (Lotus corniculatus) (27). It has poor acidity tolerance (5); lower limit is 5.5 (713). "Ladino" white 
clover is tolerant of slightly acidic to slightly alkaline soils (179).

\section{Soil Salinity}

White clover is not tolerant of saline soil (500). Tolerance limits have been reported at less than $4 \mathrm{mS} / \mathrm{cm}$ (247).

\section{Drought}

White clover has fair drought tolerance (5), although when white clover was seeded as part of a mix designed for drought-prone soils it did not perform well (77).

\section{Heavy Metals and Hydrocarbons}

In sand-culture experiments, additions of $320 \mathrm{ppm} \mathrm{Cu}, 3000 \mathrm{ppm} \mathrm{Pb}$ or $4000 \mathrm{ppm} \mathrm{Zn}$ resulted in an 80 to $90 \%$ reduction in dry weight of white clover (221). White clover has medium tolerance to oil (282). It was difficult to establish and had poor growth on ash at Lake Wabamun (696).

Shade - Prefers open situations.

\section{Grazing or Mowing}

White clover can withstand close grazing and recovers rapidly (391).

\section{Susceptibility to Disease and Insect Damage}

No susceptibilities noted from the literature.

\section{RECLAMATION CONSIDERATIONS}

\section{Soil Building and Erosion Control Capability}

White clover is a low, spreading legume that forms roots at the stem nodes. It has a shallow root system (138). "Ladino" white clover has a short tap root (less than $40 \mathrm{~cm}$ long). Roots and upright stems form at the stolon nodes, but these roots are short. This growth habit makes white clover well suited to shallow soils. The effective root zone of mature "Ladino" white clover plants is not more than $50 \mathrm{~cm}$ (179).

\section{Adaptation to Disturbance}

White clover is a pioneer on Alberta mine spoils (331).

\section{Competitive Ability}

It is a moderately aggressive species (500).

\section{Commercial Value}

Different cultivars are used for forage, turf (sod), and erosion control (426). White clover-grass mixtures are used for hay and silage.

\section{Palatability and Nutritive Value}

White clover is highly nutritious and palatable to cattle (256). Yield potential is low (5). It is one of the more nutritious and palatable legumes (138). Forage value has been rated as good for mule deer, game birds and small mammals (447). Causes bloat (639).

\section{Seed or Planting Stock Availability}

Certified licensed seed of "Ladino", "Merit" and "Pilgrim" varieties is available through the seed trade $(138,713)$. Approximately 850000 seeds/lb (639).

\section{Methods and Ease of Establishment}

White clover seed can apparently be stored for long periods. Seed stored for 25 years in unheated sheds had a germination rate of $73 \%$, compared to $88 \%$ in the year of collection (211). Typical purity/germination is $99 / 85 \%$ (132). White clover can be established more easily on poorly prepared seedbeds than other legumes (342). Seedling vigour has been rated as fair to poor (41). A seeding rate of 1 to $5 \mathrm{lbs}$ PLS/ac has been recommended for the Eastern US (713); spring/fall seeding at a rate of 2 to $6 \mathrm{lbs}$ PLS/ac for the west (639).

\section{Current Status for Reclamation}

White clover is widely used for pasture, hay and silage. It is a common component of reclamation mixes throughout the moister parts of western Canada. Commonly used for "corridor reclamation" of seismic lines and pipeline rights-of-way in Alberta (P. Sims, pers.comm.). It has been used to successfully revegetate acid ( $\mathrm{pH} 4.0$ to 5.0) coal mine wastes in New Brunswick (2). White clover had good performance when seeded on disturbed sites above $1650 \mathrm{~m} \mathrm{ASL}$ in southeastern B.C. (494). It was a failure in mix trials in subalpine Alberta (705) and winterkilled the first winter in tests in the Upper Mackenzie region of the boreal forest (latitude $63^{\circ} \mathrm{N}$ ) (644). White clover gave poor 
results when seeded in the alpine in Colorado (164). It was difficult to establish (like most legumes) but performed well on moist sites at $3530 \mathrm{~m}$ ASL in Colorado $(236,73,462)$.

White clover is a long-lived perennial clover that spreads by rhizomatous stems; it also fixes nitrogen. In general, it has only fair drought tolerance and is best suited to moist sites. The varieties "Pilgrim" and "Merit" have excellent winter hardiness and should be suited for revegetation planting in Alberta to the lower subalpine. 
Vicia americana

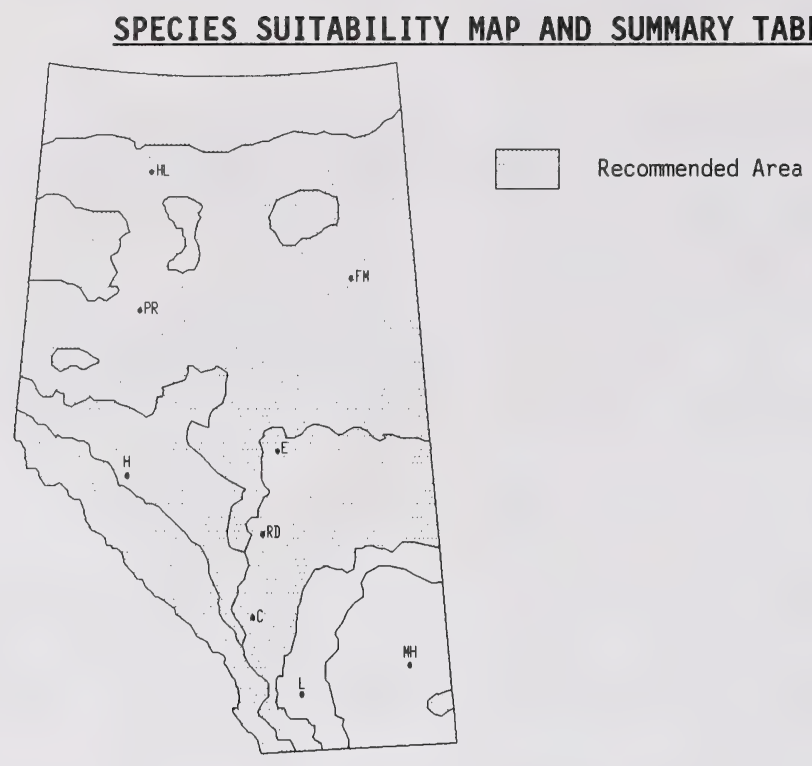

Commercially Available: Yes $X$ No

\begin{tabular}{|c|c|c|c|c|c|}
\hline \multirow{2}{*}{$\begin{array}{l}\text { RECLAMATION SUITABILITY } \\
\text { CRITERIA }\end{array}$} & \multicolumn{5}{|c|}{ SUITABILITY RAIING } \\
\hline & Very High & High & Medium & Low & None \\
\hline Drought Tolerance & & & & $x$ & \\
\hline Salt Tolerance & & & & $x$ & \\
\hline Acid. & & & & $x$ & \\
\hline Tolerance Base & & & & $x$ & \\
\hline Winter Hardiness & & $x$ & & & \\
\hline Erosion Control & & & $x$ & & \\
\hline Persistence & & & $x$ & & \\
\hline Palatability & & $x$ & $\mathrm{x}$ & & \\
\hline Browse Tolerance & & & & $\mathrm{X}$ & \\
\hline Moisture Preference & Moist. & & & & \\
\hline Soil Preference & Clay 1 & am to $s$ & & & \\
\hline
\end{tabular}


Vicia americana Muhl.

\section{SPECIES BIOLOGY}

\section{Taxonomy - Wild Vetch}

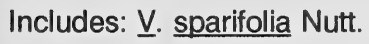

\section{Origin and Range}

Native. Yukon east across Canada to Hudson Bay; Ontario south to Pennsylvania. South in the mountains to California (214). Wild vetch is highly variable.

\section{Growth Habit}

A perennial herb with stems 30 to $100 \mathrm{~cm}$ long. Trailing or climbing plant $(78,690)$. Flowers reddish purple, drying bluish (690).

\section{Nitrogen Fixing}

Expected to fix nitrogen as it is a legume.

Longevity - A perennial.

Self Propagation - By seed.

\section{Ecological Setting}

Wild vetch is found in open woods and thickets throughout Alberta. Also found at the edges of bluffs and in shady areas of the prairies $(78,690)$. It ranges from plains to open woods, and meadows of the subalpine (185). Found at between 925 and $2675 \mathrm{~m} \mathrm{ASL}$ in moist situations in Wyoming (18). In the southwestern portion of its range, it is common in pine forests at elevations of 1600 to $3300 \mathrm{~m}$ ASL (426).

\section{TOLERANCES}

\section{Soil Preferences}

Wild vetch generally occurs in favourable moisture situations $(12,426)$. Growth has been reported as fair on sandy and clayey soils, and good on loam soil (146).

\section{Nutrient Requirements}

Wild vetch is generally found on favourable fertility sites (12).

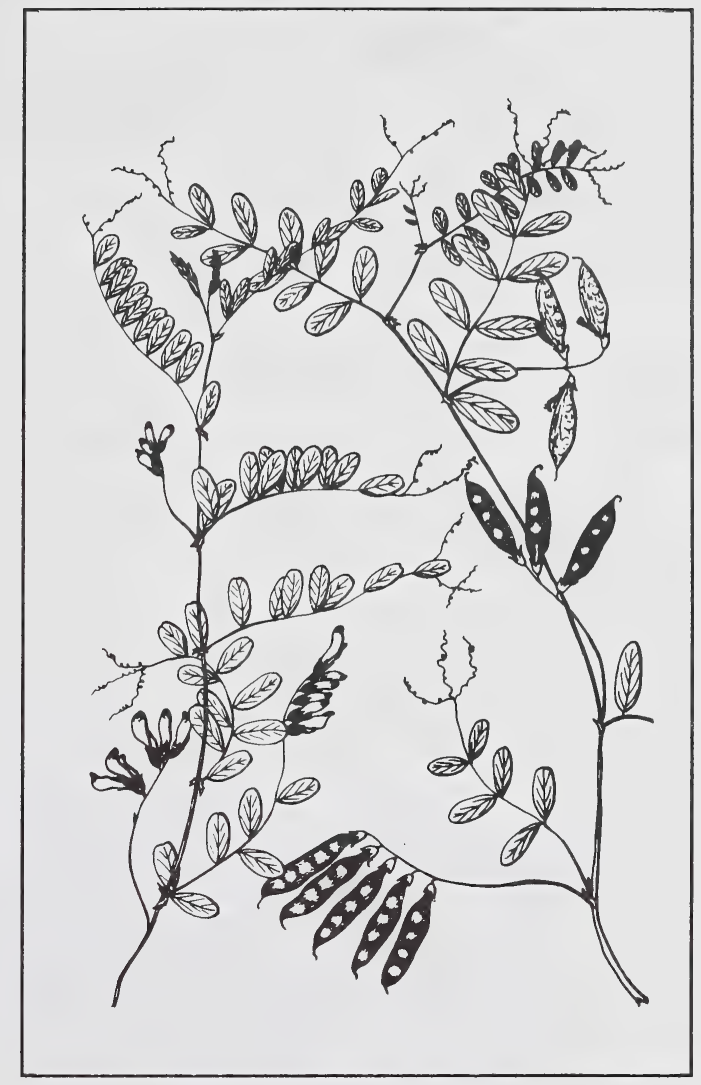

\section{Soil Reaction}

Prefers neutral soils, but will tolerate mildly acidic to mildly alkaline soils as well.

\section{Soil Salinity}

Found on mildly saline soils.

\section{Drought}

Favours moist sites. Will not tolerate excessive drought.

\section{Heavy Metals and Hydrocarbons}

No specific tolerances noted.

\section{Shade}

Found on fully shaded sites. 


\section{Grazing or Mowing}

Wild vetch is found on ranges in good condition but decreases under grazing (426). This may be due to preferential grazing rather than low tolerance.

Susceptibility to Disease and Insect Damage

No specific pests noted.

\section{RECLAMATION CONSIDERATIONS}

\section{Soil Building and Erosion Control Capability}

The creeping growth form and nitrogen fixing ability make this species a good soil builder.

\section{Adaptation to Disturbance}

Will invade disturbed sites in adapted area. Found on roadsides.

\section{Competitive Ability}

Very aggressive growth form, often choking out other species.

\section{Commercial Value}

No known commercial value, besides nitrogen fixation abilities.

\section{Palatability and Nutritive Value}

Wild vetch has been described as an excellent forage plant that is palatable to both livestock and wildlife (426). Wild vetch is reported to be lightly browsed by mule deer (245). It has been noted as providing good forage value for mule deer, game birds and small mammals (229).

\section{Seed or Planting Stock Availability}

Commercial availability not known.

\section{Methods and Ease of Establishment}

Seeds are easily collected. Establishment only by seed. Planting in northwestern Colorado is only recommended on soils deeper than $65 \mathrm{~cm}$ (446).

\section{Current Status for Reclamation}

Wild vetch has been used successfully for revegetation of alpine tundra disturbances in British Columbia (185) and in hydroseeding trials on mined land at Luscar, Alberta $(144,209)$. A hydroseeding trial of wild vetch on oil sand tailings in northern Alberta was unsuccessful (257). It has been recommended for revegetation in northwestern Colorado. 


\section{SPECIES INFORMATION - SHRUBS AND TREES}

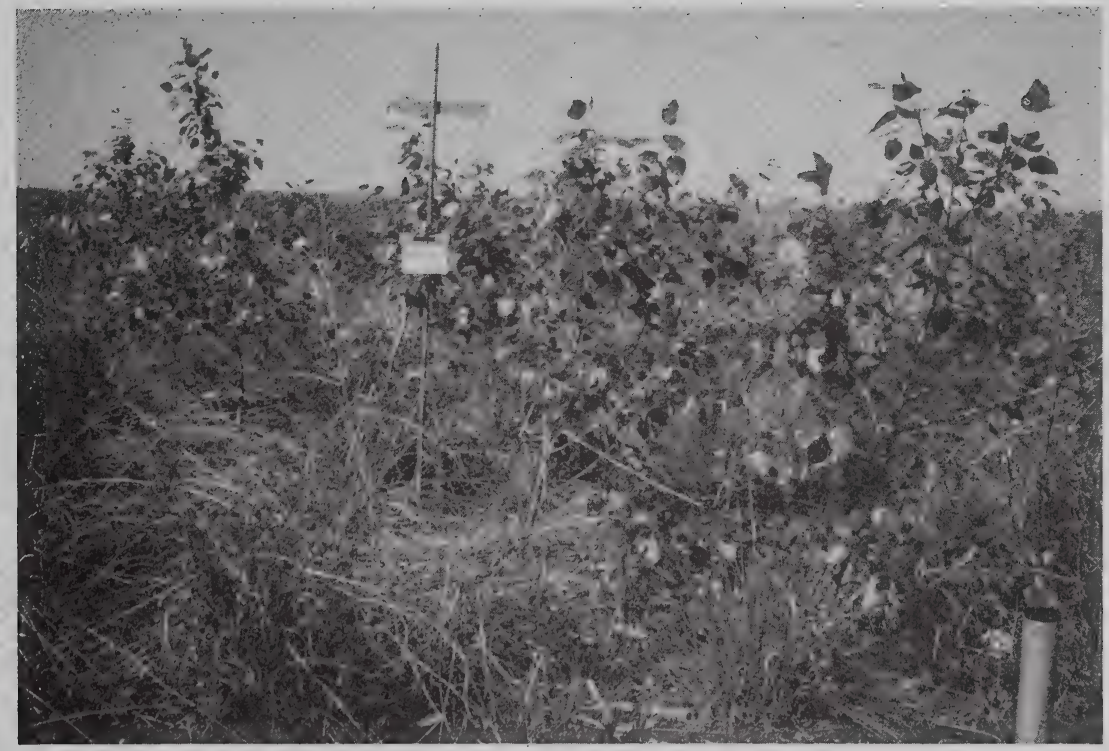


254 
Abies lasiocarpa

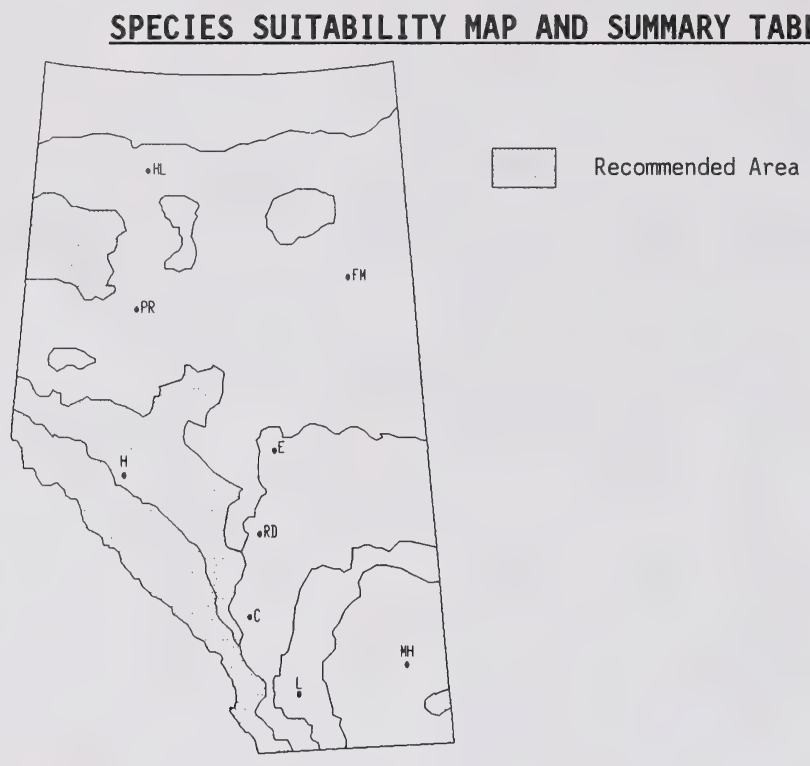

Commercially Available: Yes $\mathrm{X}$ No

\begin{tabular}{|c|c|c|c|c|c|}
\hline \multirow{2}{*}{$\begin{array}{l}\text { RECLAMATION SUITABILITY } \\
\text { CRITERIA }\end{array}$} & \multicolumn{5}{|c|}{ SUITABILITY RATING. } \\
\hline & Very High & High & Medium & Low & None \\
\hline Drought Tolerance & & & & $x$ & \\
\hline Salt Tolerance & & & & $x$ & \\
\hline Acid... & & $x$ & & & \\
\hline Tolerance Base & & & & & \\
\hline Winter Hardiness & & $x$ & & & \\
\hline Erosion Control & & & $x$ & & \\
\hline Persistence & & $x$ & & & \\
\hline Palatability & & & $x$ & & \\
\hline Browse Tolerance & & & $x$ & & \\
\hline Moisture Preference & Moist & to dry. & & & \\
\hline Soil Preference & Wide $v$ & ariety - & my soils, & olerates 1 & de range. \\
\hline
\end{tabular}


Abies lasiocarpa (Hook.) Nutt.

\section{SPECIES BIOLOGY}

Taxonomy - Alpine Fir

\section{Origin and Range}

Native. Southeast Alaska, central Yukon Territory, south through British Columbia and southwestern Alberta and in the mountains to New Mexico, Arizona and Oregon (443). In Alberta, alpine fir extends eastward from the mountains to Pigeon Lake and Whitecourt in central Alberta. It probably intergrades with $\mathrm{A}$. balsamea in the region of Lesser Slave Lake and the Athabasca River $(690,205)$.

\section{Growth Habit}

Usually a small or medium sized tree (443). Alpine fir may be up to $30 \mathrm{~m}$ high and $70 \mathrm{~cm}$ in diameter $(443,205)$. At timberline it is reduced to a prostrate shrub that may be very thick as a result of rooting of the lowermost branches $(690,501)$.

Nitrogen Fixing - None

Longevity - Long-lived perennial.

\section{Self Propagation}

Seed, layering, stolons $(5,437)$. Natural reseeding capability is better developed than vegetative reproductive means (338).

\section{Ecological Setting}

Alpine fir is characteristic of subalpine forests and northwestern areas of the boreal forest at elevations ranging from 600 to $2300 \mathrm{~m}$ ASL (205). It is generally found above Engelmann spruce (Picea engelmannii) and is usually associated with cool, moist north and west facing slopes (501). Common native associates are: Picea engelmannii, Pinus contorta var. latifolia, Populus tremuloides, and Larix lyallii (391).

\section{TOLERANCES}

\section{Soil Preferences}

Alpine fir grows best on well drained loamy soils (205). It is adapted to moderately well drained to well drained soils, and occurs on a wide variety of soil textures $(5,205)$.

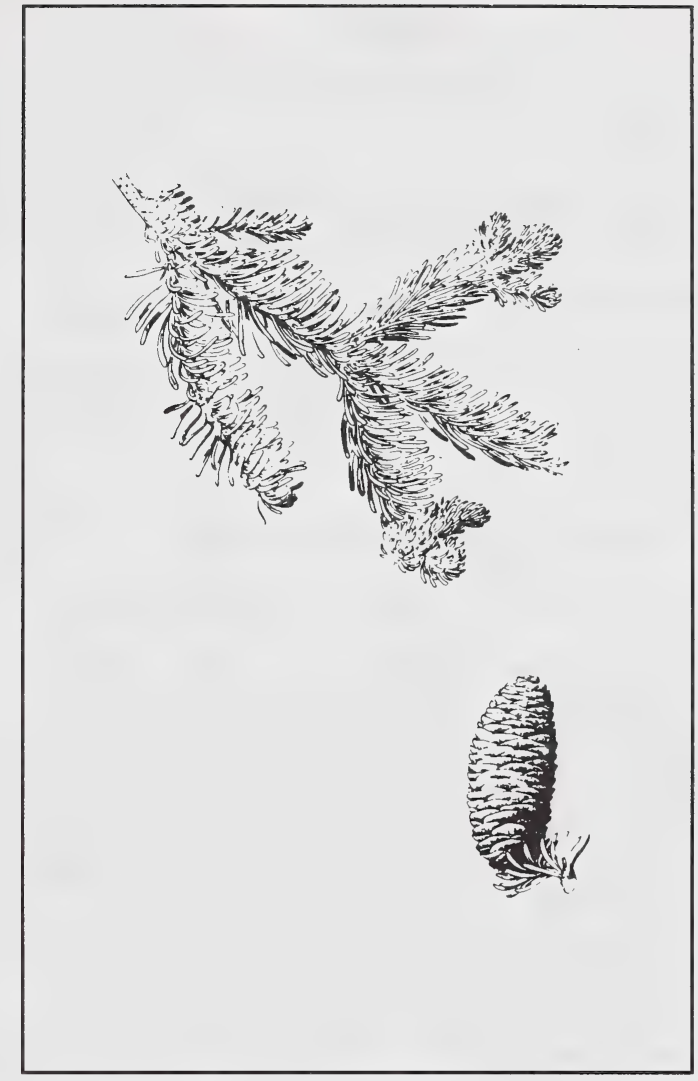

Nutrient Requirements

The ability of alpine fir to grow on infertile soils suggests low nutrient requirements.

\section{Soil Reaction}

Alpine fir is reported to have a high acid tolerance (5).

\section{Soil Salinity}

No specific information is available, but a fairly low tolerance of saline conditions would be expected.

\section{Drought}

Alpine fir grows best on moist sites where risk of drought is low.

\section{Heavy Metals and Hydrocarbons}

No information available in the literature reviewed. 
Shade

Alpine fir is very shade tolerant $(443,5)$.

\section{Browsing}

Though browsing is not extensive, the species appears to withstand it satisfactorily.

\section{Susceptibility to Disease and Insect Damage}

Alpine fir is susceptible to needle rust, needle cast, snow blight, snow mold, needle blight, Armillaria root rot, and white pocket rot $(29,198)$.

\section{RECLAMATION CONSIDERATIONS}

\section{Soil Building and Erosion Control Capability}

Alpine fir has a shallow root system which is widespreading. The tree is not windfirm (205). The species is rated "good" for its ability to stabilize soil (338). At treeline the lower branches may root by layering, resulting in a thick hedge-like shrub, the centre of which is quite often the dead parent tree (501). It has a slow height growth rate and a slow cover rate (5).

\section{Adaptation to Disturbance}

The species has a medium adaptation to disturbance (338).

\section{Competitive Ability}

At least moderate on suitable sites.

\section{Commercial Value}

Used for general construction lumber and pulp (205). Alpine fir is also used for watershed protection, and as an ornamental (419).

\section{Palatability and Nutritive Value}

Alpine fir is selectively browsed by elk, moose, deer and snowshoe hare, especially the new growth.

\section{Seed or Planting Stock Availability}

Very small quantities of native seed are available at high cost (349).

\section{Methods and Ease of Establishment}

Seed. Interval between seed crops is usually 2 to 3 years (119). Seed germination can be improved by storing cones which are collected early, in cool, moist conditions for several weeks. Seed can be stored for long periods in sealed containers at or near $0^{\circ} \mathrm{C}$ with a seed moisture content of 9 to $12 \%$ (419). Seed has embryo dormancy. Cold stratify at 2 to $9^{\circ} \mathrm{C}$ for 6 to 8 weeks. Fall sowing is possible. Seed viability varies between 25 and $40 \%$ (119). Fir seedlings have slow initial growth and are usually outplanted as 2 to 3 year old seedlings, or as 3 to 4 year old transplants (419). Firs may also be established from cuttings (322).

\section{Current Status for Reclamation}

Alpine fir is recommended for revegetation in southeastern Alaska. The maximum spacing for planting seedlings and transplants has been suggested to be $3 \mathrm{~m}$ by $3 \mathrm{~m}$ (5). Alpine fir has been successfully transplanted using tree digging and planting machines (283). 
Acer negunda

SPECIES SUITABILITY MAP AND SUMMARY TABLE

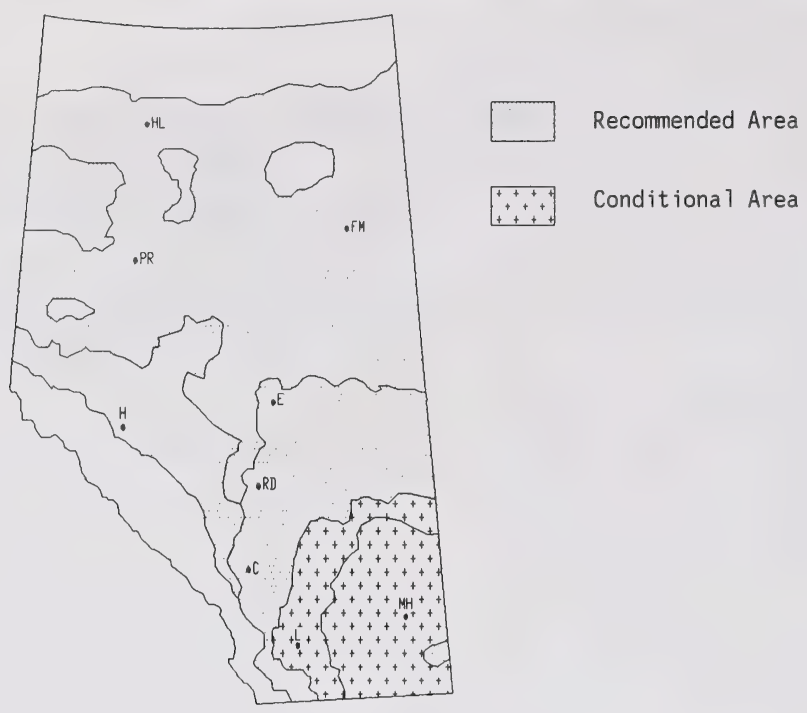

Commercially Available: Yes $\mathrm{X}$ No

\begin{tabular}{|c|c|c|c|c|c|}
\hline \multirow{2}{*}{$\begin{array}{l}\text { RECLAMATION SUITABILITY } \\
\text { CRITERIA }\end{array}$} & \multicolumn{5}{|c|}{ SUITABILITY RATING } \\
\hline & Very High & High & Medium & Low & None \\
\hline Drought Tolerance & & & & $x$ & \\
\hline Salt Tolerance & & & & $x$ & $x$ \\
\hline Acid & & & & $x$ & \\
\hline Tolerance Base & & & & & \\
\hline Winter Hardiness & & & $x$ & & \\
\hline Erosion Control & & & $x$ & & \\
\hline Persistence & & $x$ & & & \\
\hline Palatability & & & & $\mathrm{x}$ & \\
\hline Browse Tolerance & & & $x$ & & \\
\hline Moisture Preference & Moist. & & & & \\
\hline Soil Preference & Loamy & o clay, & 1 to impe & $1 y \mathrm{dr}$ & \\
\hline
\end{tabular}


Acer negundo L.

\section{SPECIES BIOLOGY}

Taxonomy - Manitoba Maple, Box Elder

\section{Origin and Range}

Native. Throughout the southern prairie provinces and most of the United States (419). It has been widely planted and has established itself beyond its natural range (205).

\section{Growth Habit}

Manitoba maple is a small to medium sized tree, $13 \mathrm{~m}$ to $16 \mathrm{~m}$ in height and $0.3 \mathrm{~m}$ to $0.6 \mathrm{~m}$ in diameter. It may occasionally reach heights of $34 \mathrm{~m}$ (205). Manitoba maple may be shrub-like if precipitation is inadequate for good growth (159).

Nitrogen Fixing - None

Longevity - Long-lived perennial.

\section{Self Propagation}

Manitoba maple is a dioecious species, and reproduction is by seed $(205,419)$.

\section{Ecological Setting}

Manitoba maple is usually found along banks of streams and wooded valleys in central and southern Alberta. Widely planted as an ornamental and for shelterbelts throughout the prairies (205). Manitoba maple is characteristic of hardwood draws in North Dakota. These are usually moist sites in the break areas of major rivers (265). Considered to be very cold tolerant (608).

\section{TOLERANCES}

\section{Soil Preferences}

Soil preferences are observed to be fairly broad, ranging from well to imperfectly drained sites, and clayey and loamy soils.

\section{Nutrient Requirements}

Sites where Manitoba maple is naturally found

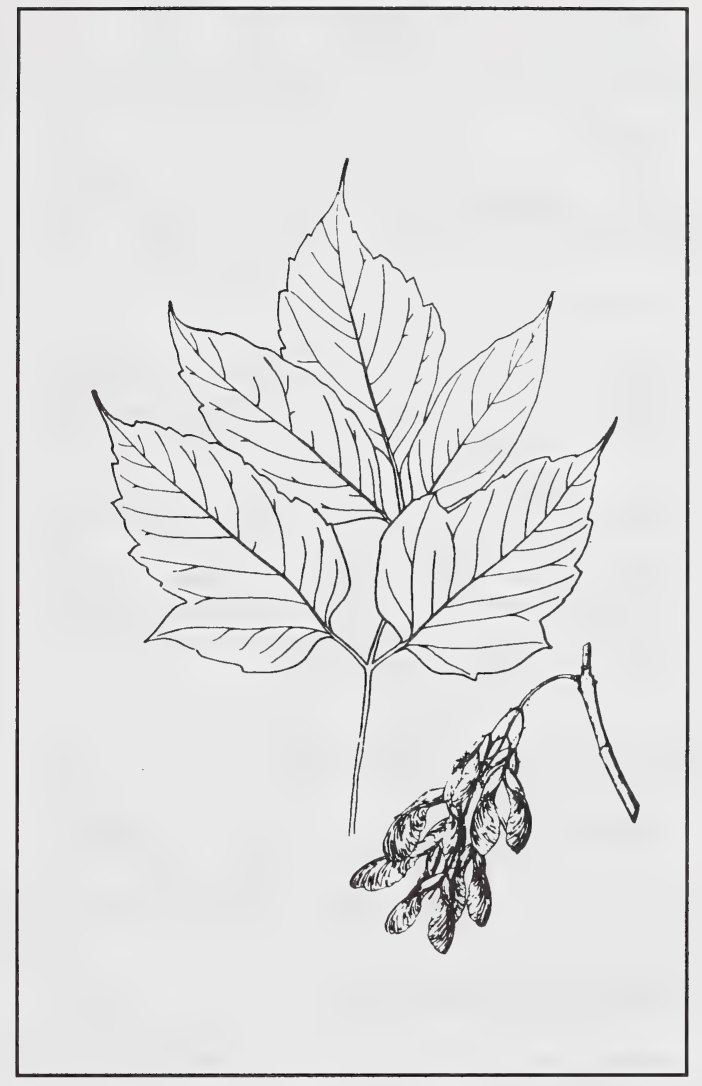

suggest moderate nutrient requirements.

\section{Soil Reaction}

Survival of Manitoba maple planted on acid (pH below 4.5) mine spoils, low in phosphorus was very low (21\%) in trials in eastern Kentucky (335). Probably favours slightly acid conditions.

\section{Soil Salinity}

Manitoba maple is rather intolerant of saline soils (229).

\section{Drought}

Manitoba maple is not very drought tolerant. Trees planted in trials at Saskatchewan Landing, Saskatchewan, suffered top-dieback during drought years. 
Heavy Metals and Hydrocarbons

No information located in the literature reviewed.

\section{Shade}

Manitoba maple appears to be relatively shade intolerant.

\section{Browsing}

Infrequently browsed, therefore tolerances to browsing are not known. The species resprouts well after cutting however.

Susceptibility to Disease and Insect Damage

Manitoba maple is susceptible to large leaf spot, powdery mildew, leaf spot, tar spot, white ring spot, and white spongy rot (198). The seedlings are susceptible to "damping-off" (419).

\section{RECLAMATION CONSIDERATIONS}

\section{Soil Building and Erosion Control Capability}

The species is considered a good soil stabilizer (338).

\section{Adaptation to Disturbance}

Manitoba maple is a seral species on floodplains in North Dakota (265). Its adaptation to disturbance is considered "medium" (338).

\section{Competitive Ability}

Presumed to be moderate.

\section{Commercial Value}

The wood of Manitoba maple is used for boxes and rough construction lumber. Manitoba maple is also widely planted as an ornamental and in shelter belts $(205,222)$.

\section{Palatability and Nutritive Value}

Manitoba maple appears to be avoided by wildlife, suggesting low palatability.

\section{Seed or Planting Stock Availability}

Seed and containerized seedlings are fairly readily available.

\section{Methods and Ease of Establishment}

Seed requires warm stratification for 180 days, followed by cold stratification for 180 days. Manitoba maple has a hard pericarp which should be mechanically ruptured before stratification. Treatment of the seed with either boric acid or hydrogen peroxide has aided germination. Best results are obtained when seeds are sown in mulched beds in the fall. Shade will aid in seedling establishment (419). Rocky mountain maple can be established with difficulty from seed, by transplanting and stem cuttings. The recommended spacing is approximately $2.5 \mathrm{~m}$ by $2.5 \mathrm{~m}$ (174). On heavy soils, the spacing requirement was calculated to be $6 \mathrm{~m}$ by $6 \mathrm{~m}$, and on light soils $9 \mathrm{~m}$ by $9 \mathrm{~m}$ (222). Manitoba maple is one of several trees and shrubs recommended for the construction of "hedges" from unrooted cuttings. These cuttings are planted in wedge-shaped trenches across steep slopes and the resulting hedge stabilizes the slope (325).

\section{Current Status for Reclamation}

Manitoba maple is recommended for plantations in southern Alberta and Saskatchewan on sites with sufficient moisture. Survival in tests on alpine and subalpine sites in Alberta was very poor $(671,707)$. At Fort McMurray survival on amended tailings sand was high after seven years, however the plantings suffered heavy annual dieback (706). Manitoba maple is used in reclamation in Germany (331). 
Alnus crispa

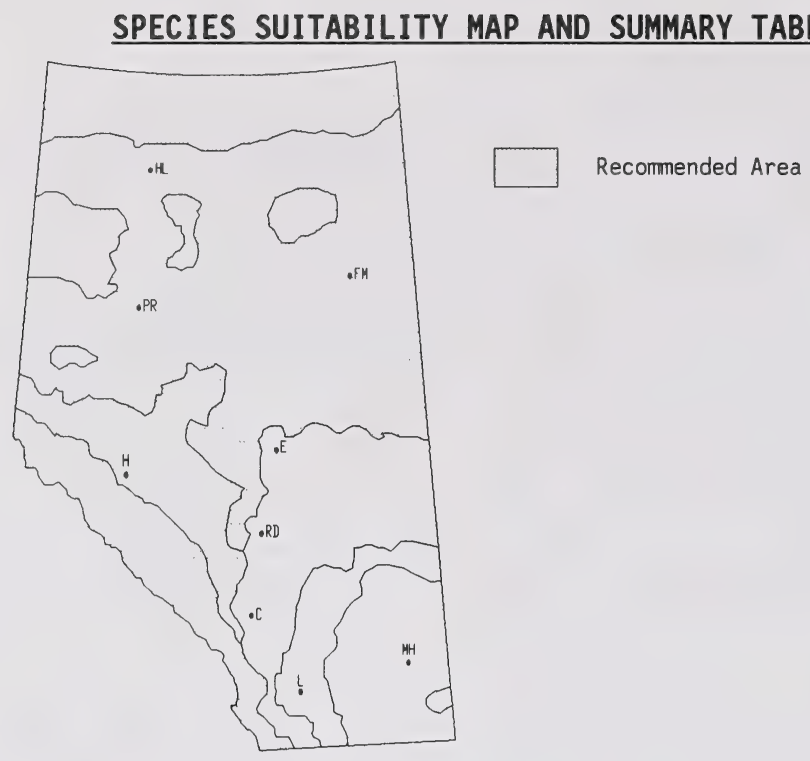

Commercially Available: Yes $\mathrm{X}$ No

\begin{tabular}{|c|c|c|c|c|c|}
\hline \multirow{2}{*}{$\begin{array}{l}\text { RECLAMATION SUITABILITY } \\
\text { CRITERIA }\end{array}$} & \multicolumn{5}{|c|}{ SUITABILITY RATING } \\
\hline & Very High & High & Medium & Low & None \\
\hline Drought Tolerance & & & & $x$ & \\
\hline Salt Tolerance & & & & $x$ & \\
\hline pH Acid & & & 5.5 & & \\
\hline Tolerance Base & & & 8.0 & & \\
\hline Winter Hardiness & $x$ & & & & \\
\hline Erosion Control & & & $x$ & & \\
\hline Persistence & & $x$ & & & \\
\hline Palatability & & & $\mathrm{x}$ & & \\
\hline Browse Tolerance & & & $\mathrm{X}$ & & \\
\hline Moisture Preference & $\begin{array}{l}\text { Moist } \\
\text { water. }\end{array}$ & wet, & rates se & & flowi \\
\hline Soil Preference & Sandy & am to & y clay 1 & & \\
\hline
\end{tabular}


Alnus crispa (Ait.) Pursh.

\section{SPECIES BIOLOGY}

Taxonomy - Green Alder

Subspecies: ssp. crispa and ssp. sinuata (Regel) Hult.

\section{Origin and Range}

Native. Alaska and the Yukon Territory to Labrador, Newfoundland and Greenland, south to New York, North Carolina (in mountains), Michigan and Oregon. Also across northern Asia. This species intergrades with sitka alder (Alnus sitchensis) towards the southern coast of Alaska (443). Some authors regard sitka alder as a subspecies of A. crispa (443).

\section{Growth Habit}

Shrub 1 to $5 \mathrm{~m}$ high. Deciduous. Often forms dense thickets (312).

\section{Nitrogen Fixing}

Fixes atmospheric nitrogen. Associated with the $\mathrm{N}_{2}$ fixing actinomycete Frankia and the basidiomycete Alpova diplophloeus (622).

Longevity - Long-lived perennial.

Self Propagation - Seed.

\section{Ecological Setting}

Common in central and northern Alberta. Throughout the latitudinal range of the eastern slopes. Sandhills, open woods, borders of bogs, and along stream channels. Disturbed sites and floodplains. Extends above snowline along creek beds or scree slopes subject to avalanches (501). Common native associates (mixed-wood): Pinus banksiana, Picea glauca, Populus tremuloides, Vaccinium myrtilloides, Viburnum edule, Rosa acicularis $(443,312)$.

\section{TOLERANCES}

\section{Soil Preferences}

Adapted to a range of soil moisture conditions from well drained through to poorly drained. Found on

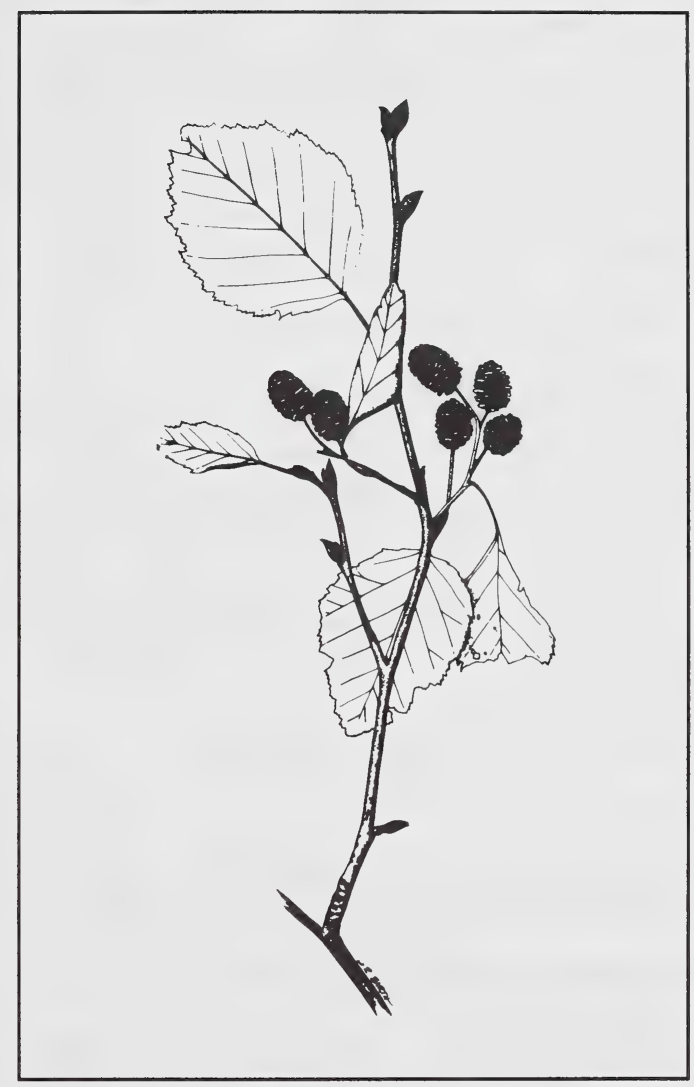

a range of soil textures from sandy loam to silty clay loam (5). Alnus crispa ssp. crispa reported to be capable of growing in up to $20 \mathrm{~cm}$ of flowing water during the peak spring run-off in the Mackenzie River delta area (97).

\section{Nutrient Requirements}

Observed on nutrient deficient sites in Alberta (306).

\section{Soil Reaction}

High acid tolerance (5). The growth of alder planted on a sandy soil ( $\mathrm{pH} 5.5)$ was reduced by the addition of lime (154). However green alder is often a pioneer on alkaline glacial outwash (pH 8.0) (105). The closely related $\underline{A}$. viridis is a continental alpine species that occurs naturally on soils from acid rocks and has been described as an acidophile. However, good growth has been reported for $\underline{A}$. viridis in soil where their roots overlie chalk (405). 
Soil Salinity

Salinity tolerance not known, but presumed to be minimal.

Drought

Alder is generally not very drought tolerant (495).

Heavy Metals and Hydrocarbons

Green alder showed good recovery 2 to 3 years after summer and winter crude oil spills near Norman Wells, N.W.T. On the mature forest taiga sites, green alder was reported to be vigorous and root nodules were common (216). Unaffected by a winter methanol spill near Inuvik, N.W.T. (487). Green alder is sensitive to high soil copper concentrations. Nodule production was completely inhibited at copper concentrations above 100 ppm (154).

Shade - Low shade tolerance $(5,172)$.

\section{Browsing}

Resprouts rapidly after cutting (5). Could be expected to withstand moderate browsing well.

\section{Susceptibility to Disease and Insect Damage}

Susceptible to powdery mildew, leaf blister, white rot (198). Susceptible to insects such as alder fly beetle, poplar and willow borer, striped alder sawfly, and western tent caterpillar (P. King, pers.comm.).

\section{RECLAMATION CONSIDERATIONS}

\section{Soil Building and Erosion Control Capability}

Rapid cover rate (5). In general, alders have shallow root systems (365). Successfully used for slope stabilization near Norman Wells, N.W.T. (110). The fertility and physical properties of soil are improved by all species of alder (176).

\section{Adaptation to Disturbance}

Will resprout from stumps if killed by fire or cut (5). One of the early plants to reinvade burned dry tundra (sandy soil) near Inuvik, N.W.T. (458). Reported to be a pioneer on seismic lines in the Mackenzie Delta, N.W.T. (194) and in Alberta (P. Sims, pers.comm.). Observed on eroding slopes in Alberta (277).

\section{Competitive Ability}

Judging by its growth in natural stands, green alder is thought to be relatively aggressive.

\section{Commercial Value}

Twigs and buds are winter food for white-tailed ptarmigan (443); potential use as nursery crop for timber production (172).

\section{Palatability and Nutritive Value}

Component of winter diet of moose on the Kenai Peninsula, Alaska (255). Some use by mule deer (245).

\section{Seed or Planting Stock Availability}

Native seed is available at moderate cost (349).

\section{Methods and Ease of Establishment}

Seed embryo dormancy encountered in some seed lots (419). Seed can be stratified at 1 to $5^{\circ} \mathrm{C}$ for 60 days (419). Spring sow non-dormant seed; fall sow dormant seed (21). Propagation by $0.3 \mathrm{~m}$ hardwood cuttings is also possible (21). Greenhouse trials indicate germination rates of 17 to $18 \%$ for seed collected near Fort McMurray, Alberta (149). Green alder may be germinated without stratification, however, stratification accelerates germination (495). Use of seed or seedlings and transplants (maximum spacing of $1.5 \mathrm{~m}$ by $1.5 \mathrm{~m}$ ) is recommended for propagation of green alder in Alaska (5).

\section{Current Status for Reclamation}

Survival on amended tailings sand at Fort McMurray is generally poor, $50 \%$ or less after 5 years is typical; however, growth of survivors is rated as good $(641,705)$. Eighth year survival on a subalpine site in Alberta (Tent Mountain) was high $(78 \%)$, suggesting that green alder has potential for reclamation on protected subalpine sites; however, growth and development may be limited by browsing. Green alder is noted for its ability to colonize tailings at the Discovery Mine, N.W.T. (49). A fall planting of hardwood cuttings on an unstable, water-saturated, gravelly slope near Norman Wells, N.W.T. had excellent first year survival $(100 \%)$. Spring planting of $1 \mathrm{~m}$ cuttings gave very good survival as well (78 to $100 \%)(110)$. Recommended for revegetation planting in interior Alaska (5). 


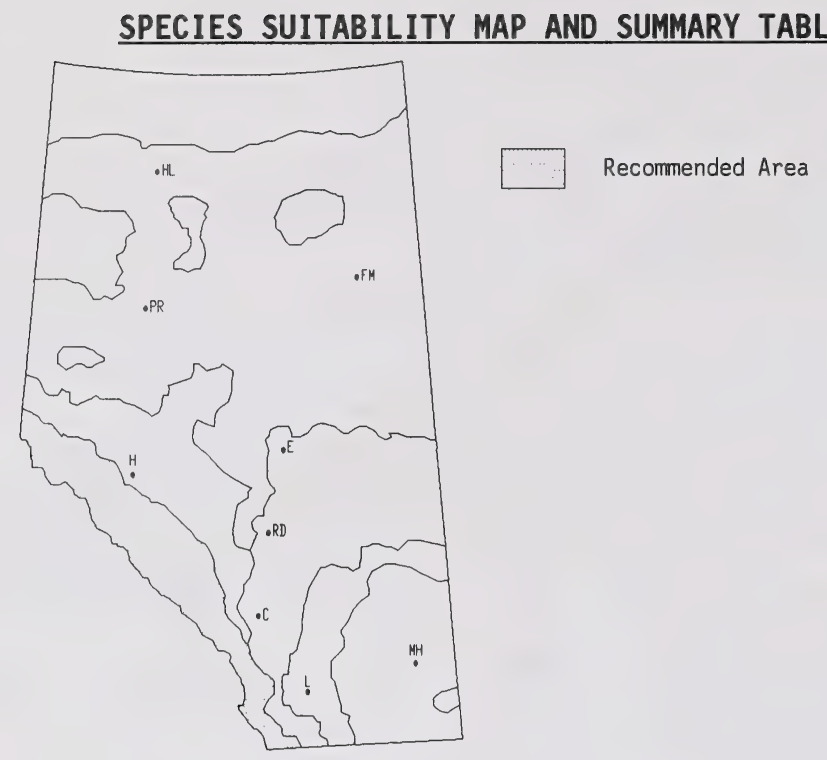

Commercially Available: Yes $\mathrm{X}$ No

\begin{tabular}{|c|c|c|c|c|c|}
\hline \multirow{2}{*}{$\begin{array}{l}\text { RECLAMATION SUITABILITY } \\
\text { CRITERIA }\end{array}$} & \multicolumn{5}{|c|}{ SUITABILITY RATING. } \\
\hline & Very High & High & Medium & Low & None \\
\hline Drought Tolerance & & & & $x$ & \\
\hline Salt Tolerance & & & & $x$ & \\
\hline $\mathrm{pH} \quad$ Acid. & & & $x$ & & \\
\hline Tolerance Base & & & & & \\
\hline Winter Hardiness & $x$ & & & & \\
\hline Erosion Control & & $\mathrm{X}$ & & & \\
\hline Persistence & & $x$ & & & \\
\hline Palatability & & & & $\mathrm{x}$ & $x$ \\
\hline Browse Tolerance & & $\mathrm{X}$ & & & \\
\hline Moisture Preference & Moist & wet. & & & \\
\hline Soil Preference & Wide $r$ & ge of & ures, well & ained & rlogged \\
\hline
\end{tabular}


Alnus sinuata (Reg.) Rydb.

\section{SPECIES BIOLOGY}

\section{Taxonomy}

Sitka Alder (205); Mountain Alder; Wavyleaf Alder (419).

Also A. sitchensis (Reg.) Sarg., A. fruticosa Rupr. var. sinuata (Reg.) Hult. (443).

\section{Origin and Range}

Native. Yukon and Alaska southeast to southwestern Alberta, western Montana and northern California. Also in northeastern Asia (443). Intergrades with American green alder (Alnus crispa (Ait.) Pursh) in Alaska (443). Regarded as geographic variation of Alnus crispa (Ait.) Pursh, by some authors. Under that classification, Sitka alder is a subspecies with the name Alnus crispa (Ait.) Pursh ssp. sinuata (Reg.) Hulten (205). In southeastern B.C. occurs only above $1000 \mathrm{~m}$ (120).

\section{Growth Habit}

Deciduous shrub 1.5 to $4.5 \mathrm{~m}$ high; on favourable sites it may reach tree size of up to $9 \mathrm{~m}$ with a diameter of $20 \mathrm{~cm}(443,205)$. Often forms dense thickets (312).

\section{Nitrogen Fixing}

Fixes atmospheric nitrogen (120) on the recessional moraines of the Herbett and Mendenhall Glaciers in southeastern Alaska. Nitrogen accumulated at a rate of $4.0 \mathrm{~g} / \mathrm{m}^{2} / \mathrm{yr}$ in the leaf litter and mineral soil over 10 to 60 years. The decline in the rate of nitrogen accumulation at 60 to 70 years paralleled a similar decline in the dominance of alder in the forest stand (104). The positive effects of sitka alder nitrogen content on avalanche debris have been noted after 5 years.

Longevity - Long-lived perennial.

\section{Self Propagation}

Seed. Resprouts from stumps after fire (5).

\section{Ecological Setting}

Found in cool and moist situations at both high and low elevations (205). Forms thickets along streams, and in clearings from sea level to the alpine in

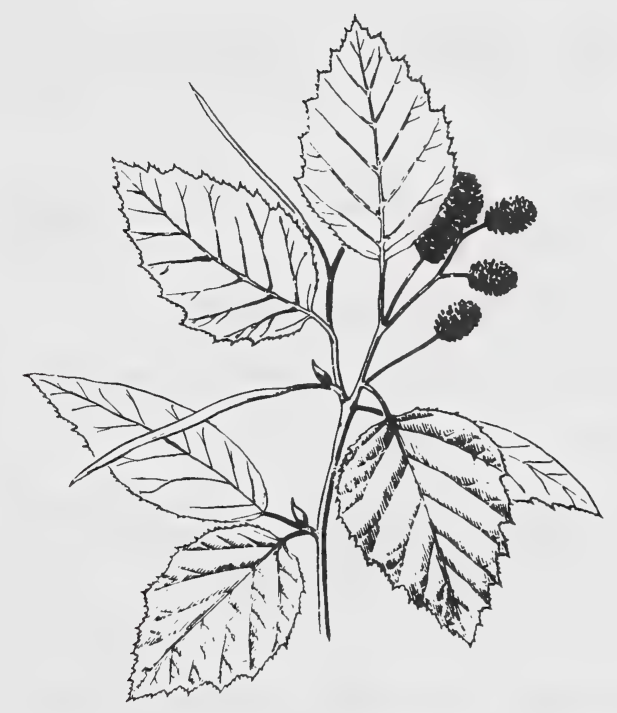

Alaska (443). Pioneer species which follows disturbances such as landslides, snowslides, logging or glacial retreat (443). It is common in moist woods and on open slopes in southwestern Alberta, often forming thickets on mountain slopes (312).

\section{TOLERANCES}

\section{Soil Preferences}

Adapted to soils that are well, moderately well, or poorly drained and waterlogged (5). Found on a wide range of soil textures (5). Reported to require a mineral soil seedbed and to develop rapidly on moist sites (443).

\section{Nutrient Requirements}

Apparently grows on soils too sterile for other trees (443). 
Soil Reaction

Moderate acid tolerance (5).

Soil Salinity

Specific tolerance levels not found in literature reviewed. Suspected to be relatively intolerant.

\section{Drought}

Appears from its site preferences to be susceptible to drought.

Heavy Metals and Hydrocarbons

Suspected to be relatively tolerant to oil spills.

\section{Shade}

Low shade tolerance (5). Reported to thrive in direct light but disappears from stands once overtopped by sitka spruce (443).

\section{Browsing}

Expected to recover fairly quickly by resprouting.

\section{Susceptibility to Disease and Insect Damage}

No specific susceptibilities noted.

\section{RECLAMATION CONSIDERATIONS}

\section{Soil Building and Erosion Control Capability}

Has rapid cover rate $(5,205,312)$. It is a spreading shrub (205) that often forms extensive, dense thickets. Regarded as a nurse tree, building soil by adding nitrogen and organic matter. Has abundant leaf fall and its habit is effective in trapping the leaf litter of other plant species. The decomposition of this litter greatly increased soil acidity at Glacier Bay, Alaska; the $\mathrm{pH}$ of the uppermost soil horizons under alder was reduced from 8.0 to 5.0 within 35 to 60 years (105). In Alaska, the rate of accumulation of above-surface organic residues under alder is reported at 5 to $6 \mathrm{~kg} / \mathrm{m}^{2}, 6$ to $7 \mathrm{~cm}$ deep, within 40 to 50 years (105). Calcium carbonate under alder declined from $5 \%$ to zero in the first 35 to 50 years (105).

\section{Adaptation to Disturbance}

Alnus crispa subsp. sinuata reported to invade the recessional moraines of glaciers in southeastern Alaska (104). Invaded moist mine tailing slopes at
$1340 \mathrm{~m} \mathrm{ASL}$ in southeastern B.C. (96). Pioneer on coal mine spoil at Cadomin, Alberta (1 $675 \mathrm{~m} \mathrm{ASL}$ ) where severe climatic limitations were evident (wind, drought) (257).

\section{Competitive Ability}

Because it is intolerant of shade and smaller than red alder, sitka alder is readily overtopped and outcompeted by red alder on logged areas in Alaska (443).

\section{Commercial Value}

Erosion control (120), and soil building.

\section{Palatability and Nutritive Value}

Some use by mule deer in winter and summer (245). Generally avoided by moose and elk.

\section{Seed or Planting Stock Availability}

Native seed is available commercially.

\section{Methods and Ease of Establishment}

Yearly seedcrops (419). Seeding is the recommended method of establishment (5). Seed of closely related Alnus crispa usually does not require stratification; occasional dormant lots can be stratified at 1 to $5^{\circ} \mathrm{C}$ for 30 to 60 days (419). Fall sow dormant seed or stratify. Spring sow nondormant seed (21). Seed should not be allowed to dry below $10 \%$ moisture content (419). Alnus spp. may also be propagated from $0.3 \mathrm{~m}$ hardwood cuttings $(21,120)$.

\section{Current Status for Reclamation}

Sitka alder has been recommended for revegetation in southeastern Alaska on well drained through to wet sites (5). This species is restricted to cool moist situations in the foothills and mountains of southwestern Alberta. It is a pioneer on recently disturbed or nutrient poor soils and spreads rapidly, forming dense thickets. Sitka alder has potential use for erosion control and reclamation, particularly on poor soils where its ability to fix atmospheric nitrogen is a valuable asset. Further research is needed into the best methods of establishment and early management. 
Alnus tenuifolia

\section{SPECIES SUITABILITY MAP AND SUMMARY TABLE}

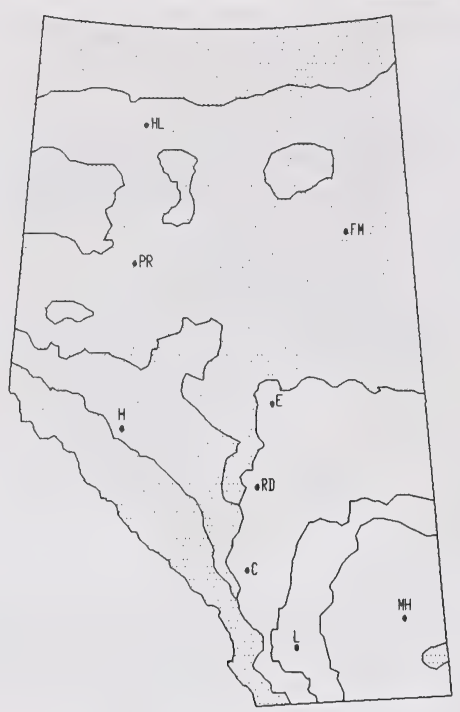

Recommended Area

Commercially Available: Yes $\mathrm{X}$ No

\begin{tabular}{|c|c|c|c|c|c|}
\hline \multirow{2}{*}{$\begin{array}{l}\text { RECLAMATION SUITABILITY } \\
\text { CRITERIA }\end{array}$} & \multicolumn{5}{|c|}{ SUITABILITY RAIING } \\
\hline & Very High & High & Medium & Low & None \\
\hline Drought Tolerance & & & $x$ & & \\
\hline Salt Tolerance & & & & & $x$ \\
\hline $\mathrm{pH} \quad$ Acid... & 3.5 & $x$ & & & \\
\hline Tolerance Base & & & & $x$ & \\
\hline Winter Hardiness & & $x$ & & & \\
\hline Erosion Control & & $x$ & & & \\
\hline Persistence & & $x$ & & & \\
\hline Palatability & & $x$ & $x$ & & \\
\hline Browse Tolerance & & & $\mathrm{x}$ & & \\
\hline Moisture Preference & Moist & wet, & rates $\mathrm{fl}$ & & \\
\hline Soil Preference & Wide $r$ & ge of & ures, we & poor & ned. \\
\hline
\end{tabular}


Alnus tenuifolia Nutt.

\section{SPECIES BIOLOGY}

Taxonomy - River Alder; Mountain Alder (608).

Also Alnus incana (L.) Moench ssp. tenuifolia (Nutt.) Breitung, A. rugosa (Du Roi.) Spreng.

\section{Origin and Range}

River alder is often treated as a variety or subspecies of the Eurasian species $\underline{A}$. incana (L.) Moench (European speckled alder). It is also closely related to speckled alder (A. rugosa (Du Roi.) Spreng) which replaces it from Saskatchewan eastward. It occurs from Alaska and the Yukon Territory, southeast through British Columbia and Alberta to southwestern Saskatchewan. It also is found south in the mountains to New Mexico and California $(443,205)$.

\section{Growth Habit}

A large shrub or small tree, 2 to $8 \mathrm{~m}$ high (443); up to $9 \mathrm{~m}(608)$. On the best sites may reach up to $15 \mathrm{~m}$ high with a diameter of $27 \mathrm{~cm}$ (205). Commonly forms large clumps. Fast growing (608).

\section{Nitrogen Fixing}

Fixes atmospheric nitrogen $(331,120)$. Nitrogen was reported to accumulate at an average rate of $156.4 \mathrm{~kg} / \mathrm{ha} / \mathrm{yr}$ in 20 year old alder (Alnus incana (L.) Moench. ssp. tenuifolia (Nutt.) Breitung) stands near Fairbanks, Alaska (90).

Longevity - Long-lived perennial.

Self Propagation - Seed (5).

\section{Ecological Setting}

Borders of streams and lakes (312); preference for wet sites (608). Closely related speckled alder reported to grow best in relatively wet situations, in gullies and swamps that have some drainage (205). Found in western part of Canadian prairies. More common as species of mountain to subalpine zones (331). In northern Alberta, characteristically found along wet but freely drained depressions and river bottom lands (399). Common native associates: Populus balsamifera, Cornus stolonifera, Viburnum edule, Salix bebbiana.

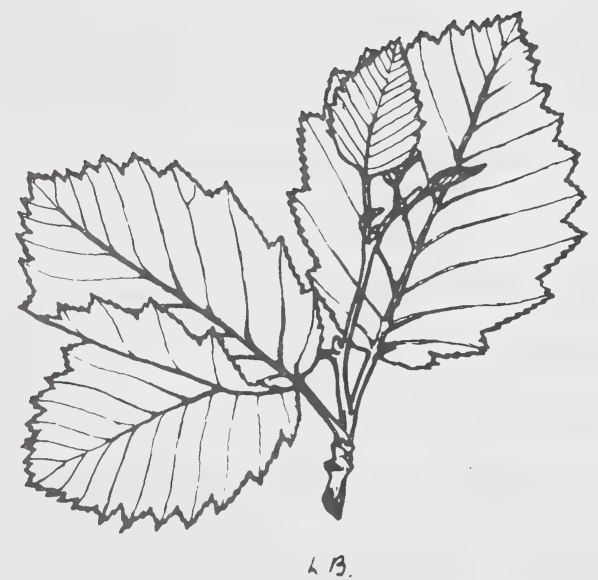

\section{TOLERANCES}

\section{Soil Preferences}

Usually found on alluvial and other moist soils (64). Adapted to a range in soil moisture conditions from well drained to poorly drained (5). Found on a wide range of soil textures (5). Can withstand flooding during the growing season (5).

\section{Nutrient Requirements}

Occasional pioneer on gravel bars which are low in nutrients (422). More vigorous growth is associated with nutrient rich sites in central Alberta.

\section{Soil Reactions}

Moderate acid tolerance (5). Rates of survival of the related Alnus incana (L.) Moench. were not related to soil acidity (pH 3.4 to 7.7$)$ for five year old plants 
on Ohio spoil banks (262). Speckled alder has been noted on spoil banks of pH 3.5 (291).

\section{Soil Salinity}

Not generally found on saline soils.

\section{Drought}

Reported as occasional pioneer on drought prone gravel bars in interior Alaska. These sites were also susceptible to rapid freezing and thawing (442).

Heavy Metals and Hydrocarbons

No specific tolerance noted.

Shade - Low shade tolerance $(5,356)$.

\section{Browsing}

If plant cut, will resprout from the stem (5).

\section{Susceptibility to Disease and Insect Damage}

Susceptible to powdery mildew, leaf spot, leaf blister, and catkin blister (198).

\section{RECLAMATION CONSIDERATIONS}

\section{Soil Building and Erosion Control Capability}

Has rapid height growth and rapid cover rate (5). Successfully used for slope stabilization near Norman Wells, N.W.T. (110). The fertility and physical properties of soil are improved by all species of alder (88).

\section{Adaptation to Disturbance}

Reported to be a pioneer on Alberta mine spoils (331). Alnus incana and $\underline{A}$. tenuifolia sometimes present as pioneers on exposed gravel and silt bars of the Chena River, interior Alaska (442).

\section{Competitive Ability}

Alnus incana was reported to have a low rate of survival on Ohio spoil banks due to excessive competition from black locust (Robinia pseudoacacia) and crown-vetch (Coronilla varia) on extremely acid sites (262).

\section{Commercial Value}

Large trees have been cut for poles, and the wood has also been used to smoke salmon (443); erosion control $(110,120)$.

\section{Palatability and Nutritive Value}

Moderate use by mule deer in winter and summer (245); high frequency of browse use ( 31 to $100 \%$ ), and moderate intensity of browse use by mule deer and elk in southeastern B.C. (393).

\section{Seed or Planting Stock Availability}

Native seed is available commercially.

\section{Methods and Ease of Establishment}

Seed has been recommended as the best method for establishment (5). A low percentage (less than $5 \%$ ) of good seed has been reported for some collections, usually in sparse seed crops (419). Germination capacity of fresh seed was reported to be good for stratified and non-stratified seed (419). Air dried seed can be stored in sealed containers at 1 to $3^{\circ} \mathrm{C}(419)$. Seeds should not be allowed to dry below $10 \%$ moisture content (419). Seedlings and transplants should be planted at a maximum spacing of $1.5 \mathrm{~m}$ by $1.5 \mathrm{~m}$ (5). Also, suited for propagation from $0.3 \mathrm{~m}$ hardwood cuttings (21, 120).

\section{Current Status for Reclamation}

A fall planting of hardwood cuttings (Alnus incana) on an unstable, water-saturated, gravelly slope near Norman Wells, N.W.T., had very good first year survival. Spring planting of $1 \mathrm{~m}$ cuttings gave similar results (110). Very low survival was found in test plantings on amended tailings sand at Fort McMurray (706). Initial mortality was high ( $80 \%)$ but subsequent mortality was low ( $14 \%$ survival at 8 years) in tests at Tent Mountain (subalpine) in Alberta. Growth of survivors was limited by harsh conditions resulting in heavy dieback and by heavy browsing (707). River alder has been recommended for revegetation in Alaska on well drained to wet sites (5).

Among its attributes, river alder is moderately tolerant of soil acidity and drought. It is fast growing and has the ability to fix atmospheric 
nitrogen. The closely related species European speckled alder (Alnus incana) is used extensively for mine reclamation in Europe. Mountain alder is considered to be an excellent choice for riparian restoration (608). River alder has potential for reclamation use throughout Alberta but further research is needed into the best method of establishment. 


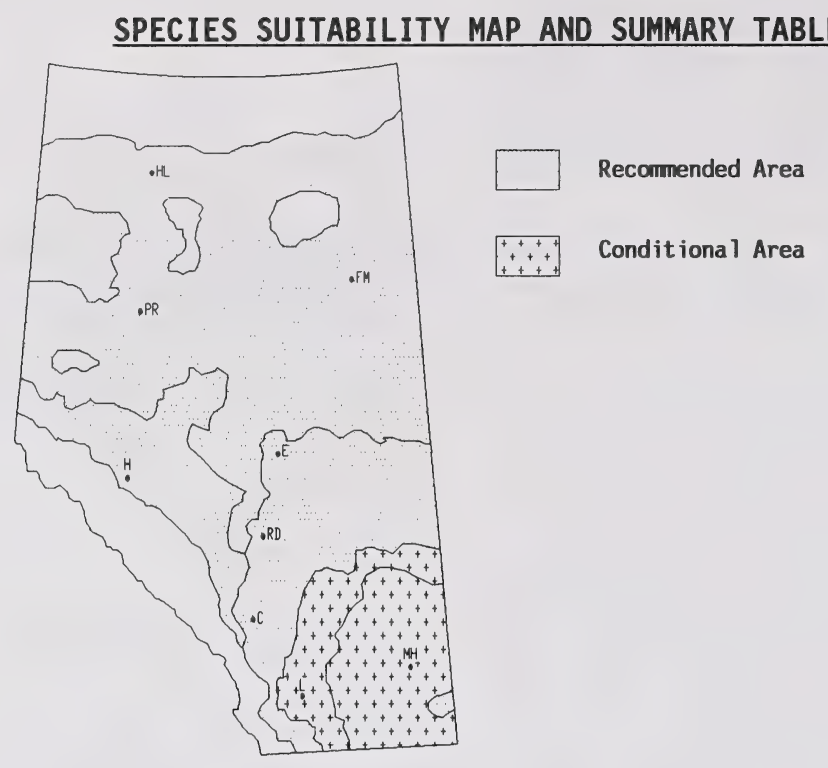

Commercially Available: Yes $X$ No

\begin{tabular}{|c|c|c|c|c|c|}
\hline \multirow{2}{*}{$\begin{array}{l}\text { RECLAMATION SUITABILITY } \\
\text { CRITERIA }\end{array}$} & \multicolumn{5}{|c|}{ SUITABILITY RATING } \\
\hline & Very High & High & Medium & Low & None \\
\hline Drought Tolerance & & $x$ & & & \\
\hline \multicolumn{6}{|l|}{ Salt Tolerance } \\
\hline Acid & & & $x$ & & \\
\hline Tolerance Base & & & $x$ & & \\
\hline Winter Hardiness & & & $x$ & & \\
\hline Erosion Control & & & $x$ & & \\
\hline Persistence & & $\mathrm{x}$ & & & \\
\hline Palatability & & $x$ & $x$ & & \\
\hline Browse Tolerance & & & $x$ & & \\
\hline Moisture Preference & \multicolumn{5}{|c|}{ Moist to dry. } \\
\hline Soil Preference & \multicolumn{5}{|c|}{ Coarser texture, tolerates wide range. } \\
\hline
\end{tabular}


Amelanchier alnifolia Nutt.

\section{SPECIES BIOLOGY}

Taxonomy - Saskatoon; Serviceberry

Hybrids between the main species of serviceberry (Amelanchier Medic) have been reported (205).

\section{Origin and Range}

Native. Southern Yukon and Northwest Territories to Newfoundland with only scattered representation in central Ontario. Distributed south to Oregon and Utah, east to northwestern lowa $(419,205,186)$.

\section{Growth Habit}

A shrub or small tree 1 to $6 \mathrm{~m}$ in height; manystemmed, deciduous $(78,312)$. Low and spreading shrub in the subalpine (501).

\section{Nitrogen Fixing - None}

Longevity - Long-lived perennial. Individual stems live up to 70 years, root crowns probably much longer $(621,719)$.

\section{Self Propagation}

Natural cross pollination estimated at $20 \%(600)$. By seed. Spreads by stolons to form colonies (690). Produces suckers after burning (604). May form single-clove thickets occupying up to 0.4 ha. Seed dispersal is accidental via birds and mammals (621).

\section{Ecological Setting}

Saskatoon is adapted to a wide range of habitats extending from near sea level to the subalpine (200). It is adapted to a wide range of climatic conditions (186), including low temperature extremes $(638,668,689)$. Throughout the northern prairie states, it is very common on bluffs and coulees. Usually found on mid to lower slopes when growing in coulees. Throughout the boreal forest, it is largely confined to south-facing bluffs, clearings, open woodlands and road margins. Common native associates: Rosa acicularis, Vaccinium myrtilloides, Linnaea borealis, Alnus crispa, Populus tremuloides $(78,690)$.

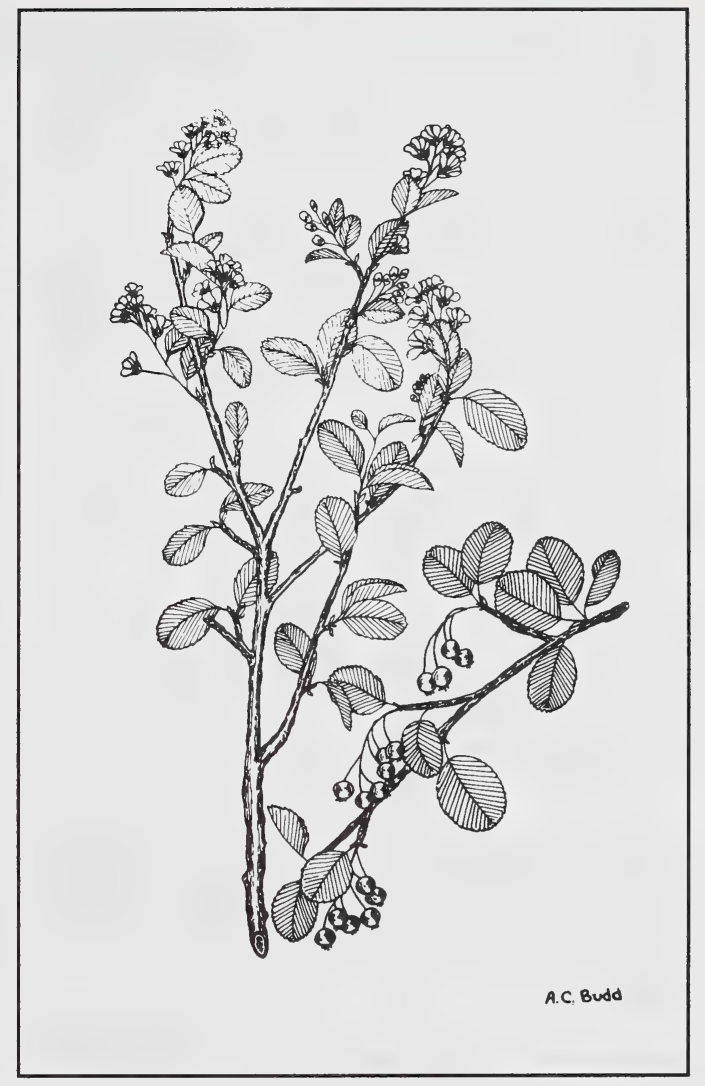

TOLERANCES

\section{Soil Preferences}

Found on all types of soil except poorly drained and heavy clay soils lacking in humus (186), prefers coarser textured soils. It is found on well drained drier sites in the northern part of range; it prefers moister situations in southern part of range (426, 443). Best growth on well drained, light textured soil with high organic matter $(>3 \%)$ content. Addition of peat moss or green manuring may be beneficial (G. Grainger pers. comm.).

\section{Nutrient Requirements}

Good survival noted for seedlings planted on road cutbanks and fills in eastern Washington, but seedlings had poor vigour. Fertilizers were 
suggested to improve effectiveness of growth (415). There is no evidence that fertilizing is beneficial on agricultural soils with normal fertility (G. Grainger pers. comm.)

\section{Soil Reaction}

Saskatoon is found on moderately acidic to moderately alkaline soils (338). Adapted to a wide range of soil reaction (689). Best growth on soils with $\mathrm{pH}$ range 6.0 to 7.0 (G. Grainger pers. comm.), and can tolerate $\mathrm{pH} 5.5$ to 7.5 (621).

\section{Soil Salinity}

No specific tolerances known, but it is not found in saline conditions (621).

\section{Drought}

Seedlings have good drought tolerance (303). This is one of the more drought tolerant native shrubs.

\section{Heavy Metals and Hydrocarbons}

Considered to have moderate heavy metal tolerance as indicated from observations of its growth near smelters (eg. Trail, B.C.). However, it survived poorly on Cu-Mo tailings (667).

\section{Shade}

Appears to be fairly shade tolerant although it prefers open sites. However, the higher humidity resulting from shading, typically when crowded by aspens causes increased disease, progressive weakening and eventually death (621).

\section{Browsing}

Can withstand moderate browsing when bush is mature. Hedging occurs on heavily browsed plants.

\section{Susceptibility to Disease and Insect Damage}

Saskatoon is susceptible to defoliation by the forest tent caterpillar, northern tent caterpillar and the tortrix. Gall damage to foliage is common. Oyster shell scale (Lepidosaphus ulni) weakens or kills branches. Sawfly (Hoplocampa sp.) can infest the fruit. Tortricid moth larva (Argynotaenia quadrifusciana), gall midge and circulionids can damage flowers and fruit (719). Saskatoon is especially susceptible to the fungus Morilinia amelanchieris which causes mummy fruit; and mildew. Seedlings are susceptible to "damping off" (Pythium rhizoctonia) and leaf spot (Entomosporium maculatum). Gymnosporangia spp. (rusts) cause shoot dieback and fruit malformation (alternate hosts: Family Cupressaceae). Rust infection can be prevented by removing all common junipers growing near the saskatoons $(186,620,208)$.

\section{RECLAMATION CONSIDERATIONS}

\section{Soil Building and Erosion Control Capability}

Saskatoon has thick, woody, widely branched roots with numerous fibrous roots. Seedlings grow slowly for first 2 or more years until root system is established. Provides good medium term soil stablility once properly established (621). Is rated "good" for soil stability (338). It spreads by stolons to form dense thickets (312).

\section{Adaptation to Disturbance}

Saskatoon has been rated as having good adaptation to disturbance (338). In Alberta, it was found to be rare on disturbance sites in the northern and central east slopes of the Rocky Mountains. It was more common on disturbances in the south (365). Saskatoon requires removal of humus to become established by seed and this occurs with fires and mechanical disturbance (620). Increased plant density from sucker regeneration resulted under regime of annual spring burning in east central Alberta (604). Present in both early and later successional stages after fire. Can resprout but requires some time to regrow to pre-fire form (661).

\section{Competitive Ability}

Tolerant of competition from other species on sites disturbed by fire (661).

\section{Commercial Value}

Ornamental; sweet fruit used locally for preserves, pies, leathers and wines; wildlife forage and cover $(443,419,186)$. A saskatoon fruit crop industry has been started with orchards, packing plant and commercial winery (619).

\section{Palatability and Nutritive Value}

In general shrubs receive highest utilization by deer; seedlings are much less utilized (472). Moderate use by mule deer (245). Heavy use reported by elk, moose (392) and range cattle (681, 699). Saskatoon buds provide winter food for sharp-tailed grouse (683). Provides shelter for mule deer (439). Rated as having moderate to good palatability $(427,337)$. Moderate palatability to mule deer (726). Highly palatable to snowshoe hare 
(698). Vegetative parts of saskatoon (except fruit) contain pruasin, a glucoside that releases hydrogen cyanide upon hydrolysis. Toxicity of saskatoon browse to cattle and mule deer is attributed to $\mathrm{HCN}$ rapidly released by rumen microbial enzymes (680). Large intakes can be fatal to domestic or wild animals. Most hazardous period is spring when browse contains high levels of prunasin in both leaves and twigs $(613,681)$. Amelanchier alnifolia var. cusickii was found to have much higher concentrations than A. alnifolia var. alnifolia (613). With advancing maturity over the growing season, there is an increase in fibre and lignin and decrease in crude protein. Calcium, phosphorus, magnesium and potassium changes over the growing season (735). Calcium and protein contents of serviceberry sufficient to meet maintenance requirement of sheep and cattle during the growing season (629). Fruit is eaten by many birds and mammals (621).

\section{Seed or Planting Stock Availability}

Some native seed is being collected, propagated and sold (349) but stocks are generally scarce. Seed available from Northplan Seed Producers, available at local nurseries. Approximately 45000 seeds/lb (639).

Over 12 named cultivars have been released for fruit production; plus one ornamental (J. Davidson pers. comm.). Cultivars developed include: "Regent", "Northline", "Parkhill", "Porters", "Pembina", "Smoky", "Thiessen", "Forestburg" and "Honeywood" (684, 686). Can be grafted onto Craetaegus arnoldina Sang. and Sorbus aucuparia L. stocks (693).

\section{Methods and Ease of Establishment}

Germination largely genetically controlled but some influence from environmental factors. Viability of seed lots from the wild varies greatly $3-67 \%(600)$. Seeds have embryo dormancy (617) and seed coat impermeability. Fruit should be collected when ripe (July or August). Seed crops can be periodic i.e. every 3 to 5 years. Screen, macerate with water, float off and dry. Alternatively clean with Dybvig seed cleaner and then dry prior to storage (Howe pers. comm). Store seed as cold as possible, in sealed onctianers to prevent dessiccation (186). Cold stratify at $5^{\circ} \mathrm{C}$ for 120 days. Alternatively, stratify for 60 days at $20^{\circ} \mathrm{C}$ and 120 days at $5^{\circ} \mathrm{C}$ or dip in concentrated sulfuric acid for 15 minutes followed by 120 days cold stratification (Howe pers. comm). Good germination reported with 24 hour soak in water followed by cold stratification $\left(2-3^{\circ} \mathrm{C}\right)$ for 90 days (667) or 12 weeks (621). Sow seeds 1 to $2 \mathrm{~cm}$ deep. Sow fresh seed in August. Alternatively sow in spring with stratified seed. Light shade or mulch is beneficial (Howe pers. comm). Seedlings need half shade for one year (419). Seedlings

require bare mineral soil to become established, and will not survive in humus or in full shade (620).

Variable results obtained with vegetative propagation $(607,631,634,649,656)$. Root sprouts, root cuttings and divisions of the root crown considered reliable (186). Root cuttings collected from parent plants, cut into $5 \mathrm{~cm}$ pieces, stored at $4^{\circ} \mathrm{C}$ for 2 months and then placed in plastic bags filled with peat moss and stored in the dark at $21^{\circ} \mathrm{C}$. When shoots are evident (2 to 4 weeks) roots are covered with soil. Resultant softwood etiolated cuttings are removed after 1 to 2 weeks and rooted in a moist bed (Howe pers. comm). Good rooting success (99\%) reported when softwood cuttings taken from etiolated stock material (694). Shoots can be grown in liquid media from excised plant tips (650). Good success with tissue culture production but varied with cultivar and source of explant (actively growing $1 / 2$ year old plants best) $(701,702)$.

Fall planting is recommended provided the plants are allowed to go dormant and harden off naturally (621). Best establishment from bare root stock planted in spring compared to direct seeding in fall or transplanting potted seedlings in spring (628).

\section{Current Status for Reclamation}

Saskatoon was used for erosion control on easily eroded coarse textured soil in northeastern B.C. (431). Survival rates at oil sands reclamation sites have been good $(645,641,706)$. However, growth rate on amended tailings sand was relatively poor $(641,706)$. It responds negatively to heavy groundcover (667). Saskatoon planted on waste rock in south central B.C. had good survival after 1 year. Poor survival when planted in tailings (667). Saskatoon wildlings transplanted to sand dunes in northern Alberta had excellent survival rates (258). Good survival of bare root stock in eastern Washington (419).

Saskatoon has good drought tolerance once established and is found on a wide range of soil textures. Establishment is enhanced by partial shade and reduced dessiccation, but thereafter good health requires full sun. It generally has a good growth rate and has potential for erosion control. It is a wide ranging species and there is the possibility that ecotypes exist. Further research is needed into the ecology and the genetic variability of this species and into improving methods of establishment. 
Arctostaphylos rubra

\section{SPECIES SUITABILITY MAP AND SUMMARY TABLE}

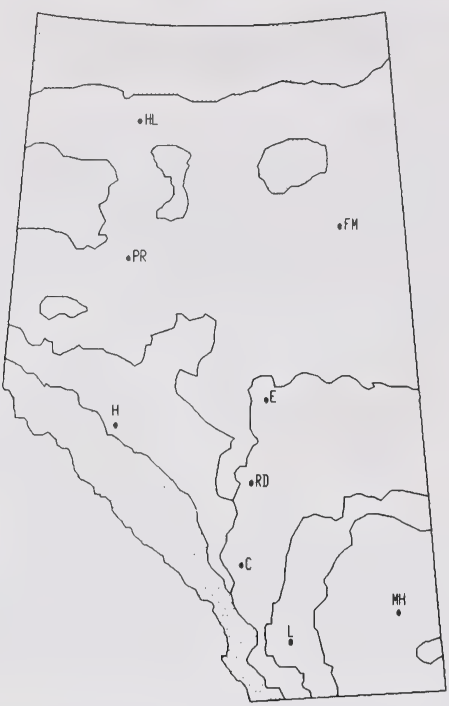

Recommended Area

Commercially Available: Yes No $x$

\begin{tabular}{|c|c|c|c|c|c|}
\hline \multirow{2}{*}{$\begin{array}{l}\text { RECLAMATION SUITABILITY } \\
\text { CRITERIA }\end{array}$} & \multicolumn{5}{|c|}{ SUITABILITY RATING } \\
\hline & Very High & High & Medium & Low & None \\
\hline Drought Tolerance & & & $x$ & & \\
\hline \multicolumn{6}{|l|}{ Salt Tolerance } \\
\hline pH Acid & & $x$ & & & \\
\hline Tolerance Base & & & $x$ & & \\
\hline Winter Hardiness & $x$ & & & & \\
\hline Erosion Control & & & & $x$ & \\
\hline Persistence & & $x$ & & & \\
\hline Palatability & & & $x$ & & \\
\hline Browse Tolerance & & & $x$ & & \\
\hline Moisture Preference & \multicolumn{5}{|c|}{ Moist to wet. } \\
\hline Soil Preference & Sandy & 10 & ay & $11 \mathrm{t}$ & \\
\hline
\end{tabular}


Arctostaphylos rubra (Rehder \& Wils.) Fern.

\section{SPECIES BIOLOGY}

Taxonomy - Alpine Bearberry

Also Arctous rubra (Rehd. and Wilson) Nakai

\section{Origin and Range}

Native. Alaska to Baffin Island, south to St. Lawrence Bay, James Bay, and southern British Columbia. Also native to eastern Asia (443).

\section{Growth Habit}

It forms a prostrate evergreen shrub up to $0.3 \mathrm{~m}$ in height (690).

\section{Nitrogen Fixing - None}

Longevity - Long-lived perennial.

\section{Self Propagation}

Red fruit bearberry propagates itself both by seeds and stolons (5).

\section{Ecological Setting}

In Alberta, it is commonly found in the Rocky Mountains, in moist subalpine forests. In northern Alberta, it occurs in lightly forested tamarack and open black spruce (generally well-drained) bog sites. In northern Canada, it is a common species of the tundra. It is often a pioneer on gravel floodplains $(501,690,443)$. Common native associates: Salix bebbiana, Betula gladulosa, and Ledum groenlandicum.

\section{TOLERANCES}

\section{Soil Preferences}

Adapted to a range of soil moisture conditions, from well drained through to poorly drained soils. Soil texture preferences range from sandy loam through to silty clay loam (5).

\section{Nutrient Requirements}

Low nutrient requirements assumed due to its growth on gravelly or boggy, low nutrient sites.

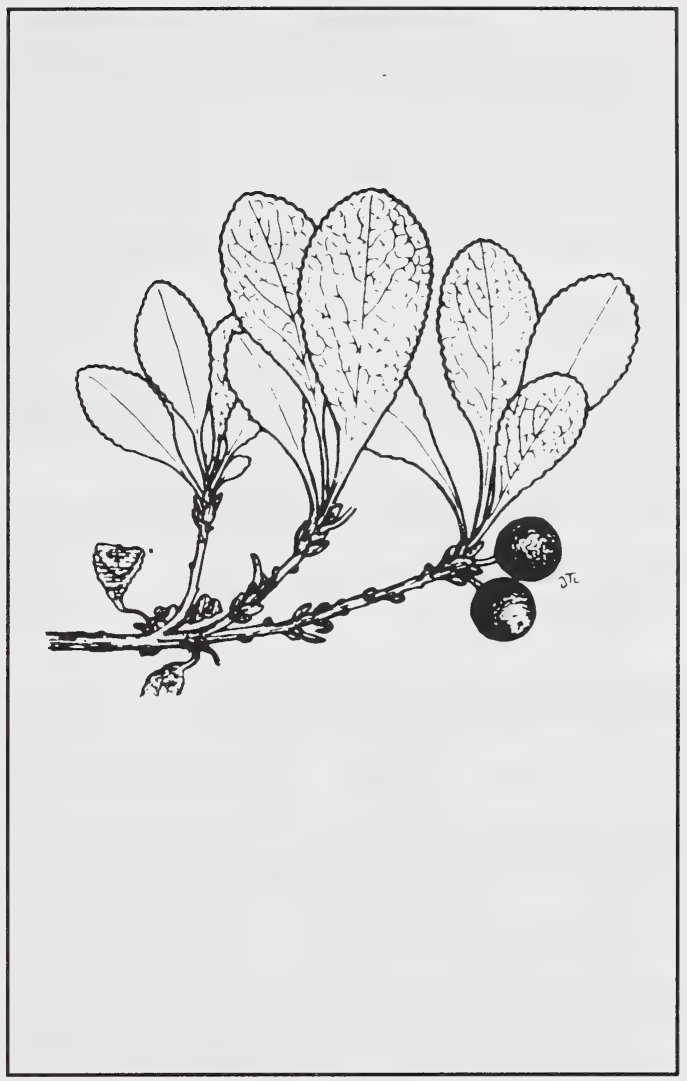

Soil Reaction

Alpine bearberry has a high acid tolerance (5).

However, it is reported to always occur on soils derived from basic rocks in the Rocky Mountains (501).

\section{Soil Salinity}

No specific tolerances noted.

\section{Drought}

Observed to be less drought tolerant than common bearberry.

\section{Heavy Metals and Hydrocarbons}

At a crude oil spill site near Norman Wells, N.W.T., Arctostaphylos rubra was reported to have recovered within 2 to 3 years of the spill. On winter 
spill sites, Arctostaphylos rubra was markedly stimulated and it is suggested that this is probably due to reduced competition by other species killed by the spill (216).

\section{Shade}

Alpine bearberry has low shade tolerance (5).

\section{Browsing}

Tolerance to grazing is not known, but probably depends largely on the degree of physical disruption of plants by browsers/grazers.

\section{Susceptibility to Disease and Insect Damage}

No particular susceptibilities noted in the literature reviewed.

\section{RECLAMATION CONSIDERATIONS}

\section{Soil Building and Erosion Control Capability}

Alpine bearberry has a slow cover rate (5). It spreads by stolons to form trailing mats (5).

\section{Adaptation to Disturbance}

Alpine bearberry reinvades burned areas (458). It was reported to regenerate on a seismic line initially $98 \%$ bare and formed a carpet of plant material in the Mackenzie Delta region (194).

\section{Competitive Ability}

Observed to be relatively aggressive on favourable sites.

\section{Commercial Value}

No commercial value known. Fruits eaten by wildlife.

\section{Palatability and Nutritive Value}

Although the fruit is apparently watery and insipid, it is eaten by bears and many kinds of birds (501).

\section{Seed or Planting Stock Availability}

No source of commercial stock known.

\section{Methods and Ease of Establishment}

The seeds of Arctostaphylos have hard seedcoats and display embryo dormancy. The seedcoat can be scarified by soaking in sulphuric acid for 3 to 6 hours, stratifying at $25^{\circ} \mathrm{C}$ for 60 to 120 days, followed by moist chilling at 2 to $5^{\circ} \mathrm{C}$ for 60 to 90 days. Avoid excessive acid immersion. This can be monitored by breaking the endocarp and examining the embryo for acid damage $(21,419)$. Good germination of Arctostaphylos has been obtained by soaking the seeds in sulphuric acid for 2 to 5 hours, then sowing in early summer. Seeds germinate the following spring (419). Evergreen cuttings have been suggested as the best method of establishment. These can be collected in the fall (119).

\section{Current Status for Reclamation}

Alpine bearberry has been recommended for revegetation on well drained to wet sites in Alaska (5). It is found in moist situations in northern Alberta and in the Rocky Mountains to the subalpine. Alpine bearberry has shown some promise for revegetation of disturbed areas and is a pioneer on nutrient poor gravel floodplains. Propagation of this species by seed is a lengthy and difficult process and further research is needed into better methods of propagation. 
Arctostaphylos uva-ursi

SPECIES SUITABILITY MAP AND SUMMARY TABLE

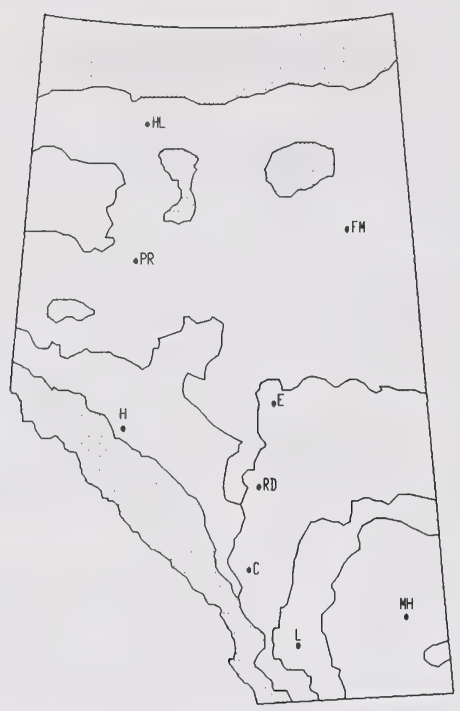

Recommended Area

Commercially Available: Yes $X$ No

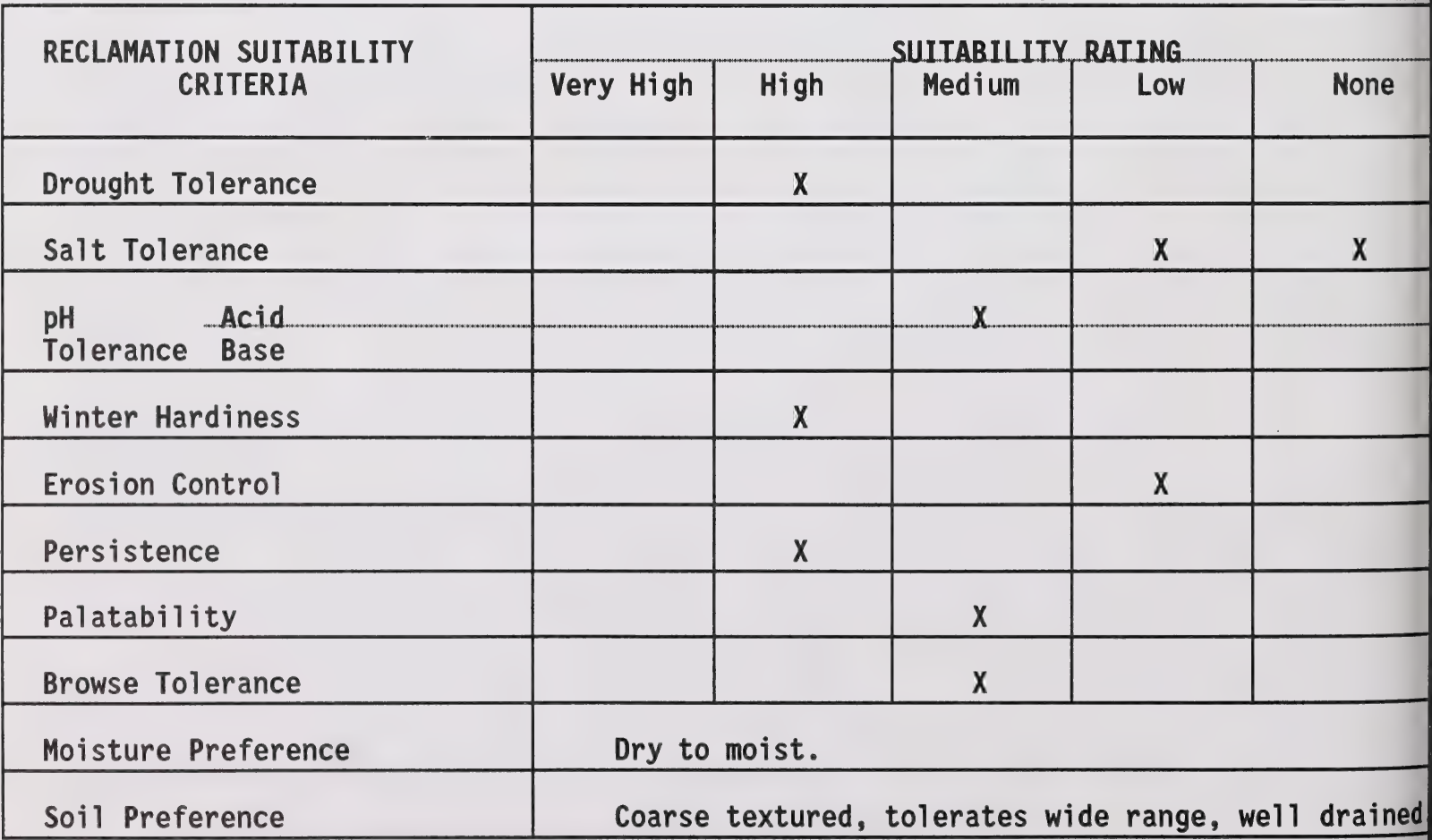


Arctostaphylos uva-ursi (L.) Spreng.

\section{SPECIES BIOLOGY}

Taxonomy - Kinnikinnick; Common Bearberry.

Also ssp. adenotricha (Fern and Maclr.) Calder and Taylor, ssp. stipitata Packer and Denford and, ssp. longipilosa Packer and Denford ssp. arctostaphylos.

\section{Origin and Range}

Native. Alaska to Newfoundland, south through the mountains to Georgia and California. Also native to northern Europe and Asia (419).

\section{Growth Habit}

A prostrate trailing shrub. Often forms trailing mats several metres across; evergreen $(78,443)$.

\section{Nitrogen Fixing}

Some disagreement exists in the literature as to nitrogen fixing ability of Arctostaphylos uva-ursi. Often reported to possess nitrogen fixing nodules. However, a recent paper indicates that these structures contained no endophytes and do not fix nitrogen. The structures were most likely latent buds (384).

Longevity - Long-lived perennial.

\section{Self Propagation}

Propagates itself both by seeds, by stolons and by rooting along the branches.

\section{Ecological Setting}

Common on dry sites in the boreal forest and throughout the prairies. Often found on eroded slopes or rock bluffs. Commonly found in open stands of jack pine or lodgepole pine on dry upland sites. Common native associates: Pinus banksiana, Vaccinium myrtilloides, Oryzopsis pungens, Vaccinium vitis-idaea, Juniperus communis, Pinus contorta var. latifolia $(690,78,443)$.

\section{TOLERANCES}

\section{Soil Preferences}

Bearberry is found on a wide range of soil textures. It is commonly found on coarse textured soils that are well to excessively drained (5). Prefers gravelly

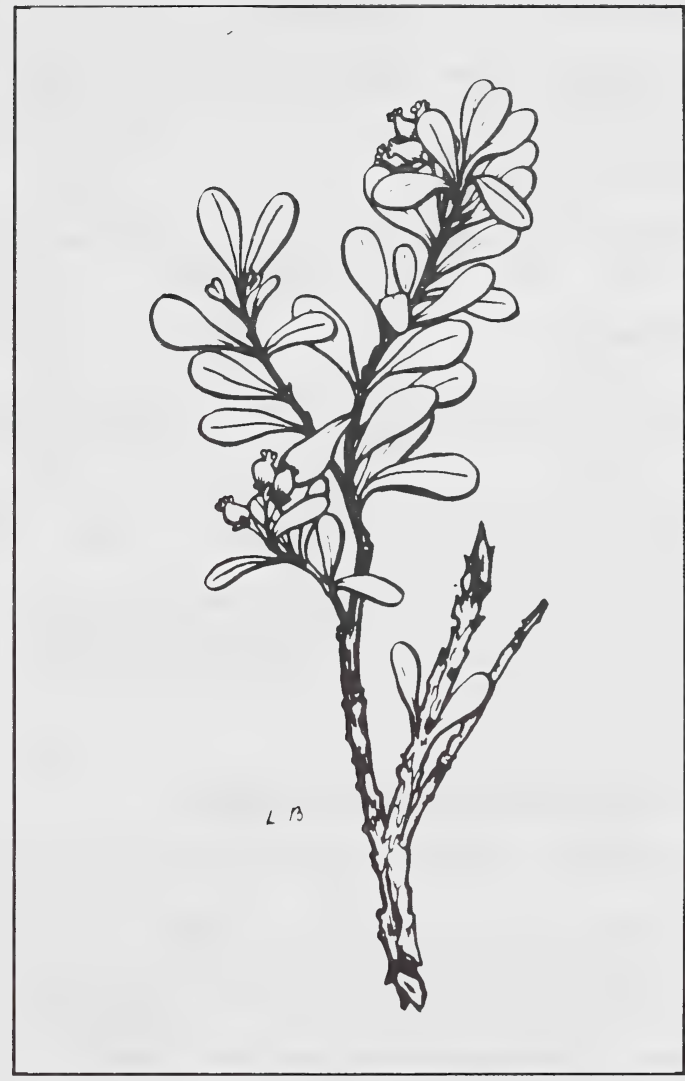

or sandy loams (608).

\section{Nutrient Requirements}

Bearberry is commonly found on nutrient poor, coarse-textured soils and on gravel terraces (501) suggesting low nutrient requirements.

\section{Soil Reaction}

Bearberry characterized as having "moderate" acid tolerance relative to other woody plants (5).

\section{Soil Salinity}

No tolerance noted, but thought to be relatively intolerant based on known site preferences.

\section{Drought}

Can withstand excessively dry conditions (325). In a study in North Dakota most normal growth (66\%) occurred during June when moisture and temperature conditions were optimum (416). 
Heavy Metals and Hydrocarbons

Reported to be killed by diesel spills near Whitehorse (322).

\section{Shade}

Alternately described as having low shade tolerance (325), or preferring partial shade (608).

\section{Browsing}

Not known, but bearberry sustains use by elk and deer on winter ranges in Alberta and British Columbia.

\section{Susceptibility to Disease and Insect Damage}

Bearberry is host to yellow witches broom (parasite) which affects white, black and Engelmann spruce in Alberta. This disease is considered economically unimportant (198).

\section{RECLAMATION CONSIDERATIONS}

\section{Soil Building and Erosion Control Capability}

Bearberry has a moderate cover rate (325). It is often found on erosion susceptible, coarse textured soils and erosion slopes. It often forms trailing mats several metres in diameter (443). Low leaf fall is a factor reducing soil building capability. Observed to be only a fair erosion controller.

\section{Adaptation to Disturbance}

Bearberry possesses latent buds on horizontal stems which give plants the ability to resprout following disturbance or damage. Found to produce shoots under stressed conditions in the field (416). Bearberry is common in dry, open disturbed sites especially on coarse textured soils and road cutbanks throughout the eastern slopes of the Rocky Mountains in Alberta. It often invades disturbed sites by spreading from adjacent vegetation (365).

\section{Competitive Ability}

Aggressive on open sites but dies back in shady locations.

\section{Commercial Value}

Occasionally used as an ornamental, in which case, wildling stock is transplanted.

\section{Palatability and Nutritive Value}

Moderate use reported for mule deer throughout winter, spring and autumn (245).

Berries eaten by bears in the autumn, by many birds including ptarmigan, and small mammals (443). Berries provide winter food for grouse and wild turkey (608). Berries are important food for bears in early spring.

\section{Seed or Planting Stock Availability}

Seed is available commercially (349) but on a limited basis, and at high cost. Planting stock is available (e.g. 608).

\section{Methods and Ease of Establishment}

Seed should be collected in the fall. Seedcrops form every one to five years. Seed displays seedcoat and embryo dormancy. Soak seeds 2 to 5 hours in concentrated sulphuric acid; either sow outdoors in early summer for germination the following spring, or warm stratify at $25^{\circ} \mathrm{C}$ for 60 to 120 days, followed by moist chilling for 60 to 90 days at 2 to $5^{\circ} \mathrm{C}(21,419)$. Another technique is to snip off pointed ends of seeds and stratify as above (germination times in this case will be longer). Time of germination reported as 15 to 30 days (indoors) and 20 to 40 days (outdoors) $(119,293)$. Germination capacity found to be in the order of 30 to $50 \%$. Seedling susceptible to "damping off" (293). Evergreen cuttings taken in autumn regarded as the best establishment methods; seed treatment is time consuming (119). Problems still encountered with vegetative propagation: little success noted at Syncrude Canada Ltd. oil sands sites in Alberta (P. King, pers.comm.). The percentage of rooted cuttings and root volumes of cuttings were significantly increased when inoculum of ectomycorrhizal fungi was added to the rooting medium. There was also a specific interaction between a given bearberry cultivar and a particular fungus (260).

\section{Current Status for Reclamation}

Bearberry has been used for erosion control in northeastern B.C. on badly eroded, coarse textured soils (28). It has been recommended for revegetation under dry and well drained soil moisture conditions in Alaska. The suggested method of propagation was by seed or stem cuttings planted at a maximum spacing of $1 \mathrm{~m}$ by $1 \mathrm{~m}(5)$, although problems are still encountered with vegetative propagation at oil sands sites in Alberta (P. King, pers.comm.). 
Bearberry is commonly found on dry coarse textured soils in open coniferous forest and is often a pioneer on disturbed sites. It spreads by stolons to form trailing mats which may be useful for erosion control. Methods of propagation of this species are still difficult and time consuming, and further research is needed in this area. 
Betula papyrifera

\section{SPECIES SUITABILITY MAP AND SUMMARY TABLE}

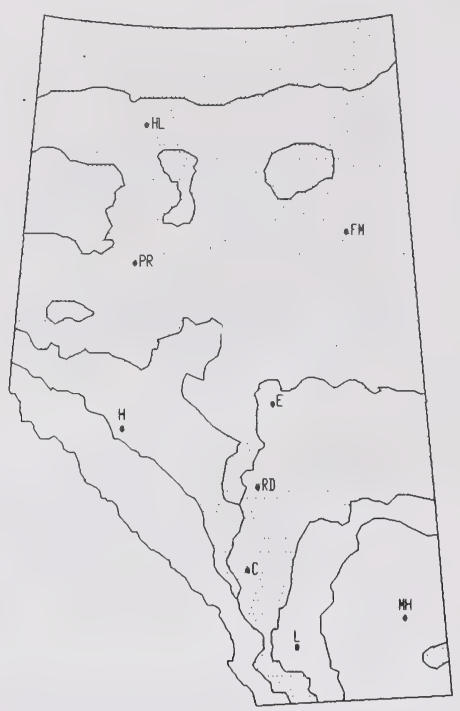

Recommended Area

Commercially Available: Yes $\underline{X}$ No

\begin{tabular}{|c|c|c|c|c|c|}
\hline \multirow{2}{*}{$\begin{array}{l}\text { RECLAMATION SUITABILITY } \\
\text { CRITERIA }\end{array}$} & \multicolumn{5}{|c|}{ SUITABILITY RATING } \\
\hline & Very High & High & Medium & Low & None \\
\hline Drought Tolerance & & $x$ & & & \\
\hline Salt Tolerance & & & & $x$ & \\
\hline Acid... & & 3.2 & & & \\
\hline Tolerance Base & & & & & \\
\hline Winter Hardiness & & $x$ & & & \\
\hline Erosion Control & & & $\mathrm{X}$ & & \\
\hline Persistence & & $x$ & & & \\
\hline Palatability & & & $x$ & & \\
\hline Browse Tolerance & & & $x$ & & \\
\hline Moisture Preference & Moist & o wet, & rates $f 10$ & & \\
\hline Soil Preference & Silty & oam to & y, well t & erfec & ained. \\
\hline
\end{tabular}


Betula papyrifera Marsh.

\section{SPECIES BIOLOGY}

Taxonomy - Paperbirch; White Birch

A variable species including var. papyrifera, var. commutata (Regal) Fern. and var. subcordata (Rydb.) Sarg.

\section{Origin and Range}

Native. Paper birch is widely distributed in northern North America, from Alaska east to Labrador and Newfoundland, south to the northeastern states, Pennsylvania and lowa and in the western states to Montana and northeastern Oregon $(443,419)$.

\section{Growth Habit}

Small to medium-sized tree usually 6 to $20 \mathrm{~m}$ high and 10 to $30 \mathrm{~cm}$ in diameter. It may grow up to $24 \mathrm{~m}$ in height and $60 \mathrm{~cm}$ in diameter $(389,391)$. It is deciduous (443).

\section{Nitrogen Fixing - None}

Longevity - Long-lived perennial.

\section{Self Propagation}

Paper birch usually establishes itself from seed. After being killed by fire, paper birch will often resprout from the base of the trunk $(5,205)$; also propagates from suckers (466).

\section{Ecological Setting}

Paper birch is widespread in central and northern Alberta on burned or cut-over areas where it often forms pure stands. As the forest matures it becomes restricted to openings. It is frequently found on thin rocky soils, or otherwise poor sites, to the subalpine. It also occurs in dry bogs $(443,205)$. It may be found along streams and riverbanks over the northern and eastern fringes of the prairies (205). Common native associates (upland mixed wood): Picea glauca, Populus tremuloides, Pinus banksiana and Amelanchier alnifolia.

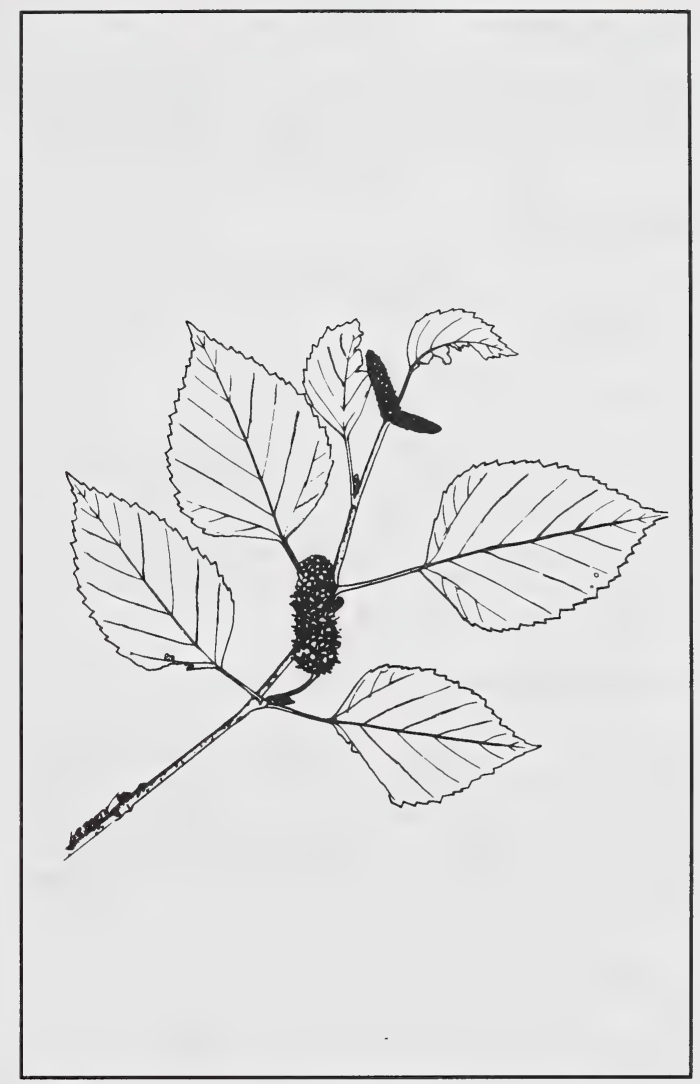

\section{TOLERANCES}

\section{Soil Preferences}

Paper birch is adapted to a wide range of soils from well drained soils through to poorly drained ones that are usually waterlogged. It is also found on a wide range of soil textures (5). It does best on well drained sandy or silty loam soils (205).

\section{Nutrient Requirements}

Birches have been reported to have low requirements for $P$ and $C a$, but require moderate amounts of $S$ and $N$ (372). 


\section{Soil Reaction}

Paper birch has moderate acid tolerance (5), and it has also been observed growing on semi-barren soils which are very acid (pH 3.2 to 4.4$)(28)$.

\section{Soil Salinity}

No specific tolerances noted in the literature consulted.

\section{Drought}

Birches in general have deep, penetrating roots and high root:shoot ratios. This suggests that birch has a relatively high tolerance to drought. Furthermore, birches are often colonizers on coal spoil piles which are subject to high temperatures and droughty conditions $(372,28)$.

\section{Heavy Metals and Hydrocarbons}

Paper birch has been observed growing on acid soils with elevated levels of $\mathrm{Ni}, \mathrm{Cu}$ and $\mathrm{Al}$ near Sudbury, Ontario (28). It is sensitive to oil spills. No sign of seedling establishment was observed three years after an oil spill killed stands of paper birch (216).

\section{Shade}

Appears to be relatively shade intolerant.

\section{Browsing}

Observed to resprout from root crowns when closely browsed, therefore at least somewhat tolerant to browsing.

\section{Susceptibility to Disease and Insect Damage}

Paper birch is susceptible to leaf spot, powdery mildew, "tinder cork", white spongy rot, pitted sap rot and brown cubicle rot, among others (198). Also observed to be susceptible to "birch dieback" and birch leaf miner ( $P$. King, pers. comm.). Extensive rodent damage has been observed for paper birch planted on oil sands tailings in northern Alberta (345).

\section{RECLAMATION CONSIDERATIONS}

\section{Soil Building and Erosion Control Capability}

Paper birch has a moderate to fast growth rate and a slow cover rate $(5,428)$. It spreads by suckering from the parent plant (466). The roots of young birch seedlings generally penetrate deep in the soil (372) and can be expected to provide good stabilization.

\section{Adaptation to Disturbance}

Paper birch has very thin flammable bark and is easily killed by fire (205). Trees outside the burn area can supply seed for reestablishment because seed is disseminated by wind over great distances (460). Trees killed by fire may resprout from the base of the trunk (205). Paper birch has been reported to be a pioneer on rocky eroded hillsides with a few shallow soil pockets near Sudbury, Ontario (28), particularly after these soils received amendments of lime and phosphate to raise $\mathrm{pH}$ and fertility (479).

\section{Competitive Ability}

Paper birch is an aggressive pioneer.

\section{Commercial Value}

Paper birch has moderately heavy, hard, strong and even-grained wood. It is used primarily for pulpwood, veneers, plywood and furniture (443, 205). Paper birch is planted as an ornamental (448, 443 ) and is used for reclamation of mine spoils in the United States (33).

\section{Palatability and Nutritive Value}

Apparently moderately palatable as it is browsed at least occasionally. Often regarded as an important winter browse species for moose.

\section{Seed or Planting Stock Availability}

Native seeds are available (349) but supplies are short and seed is costly. Seedlings are also available.

\section{Methods and Ease of Establishment}

Birch seed is collected while the strobiles are still green and firm. They should be laid out to dry and the seed removed from the opened strobiles by shaking or flailing. Seeds can be separated from debris by screening ( $1 / 8$ inch). Seed viability varies from year to year. Seed viability is usually 15 to $20 \%(119,419)$. Viable seeds can be estimated by viewing seeds under transmitted light. They can be stored at room temperature for up to 2 years with a moisture content of 1 to $5 \%$. Storage at -25 to $3^{\circ} \mathrm{C}$ ( 1 to $3 \%$ moisture content) may succeed for up to 10 years ( $P$. King, pers.comm.). Seed stratification may not be necessary if seeds are germinated 
under light. Otherwise these may be stratified at $5^{\circ} \mathrm{C}$ for 60 to 70 days. Fall sow or spring sow stratified seed. Broadcast seed, and cover lightly. Seedlings require shade for 2 to 3 months in the first summer. Container seedlings are more easily produced than bare root stock (5). Also, layering, cuttings, budding and grafting are practical methods of establishment (21). Birches in general require high temperatures and plenty of light for germination and early development (372).

\section{Current Status for Reclamation}

In the subalpine zone of southeastern B.C., the low organic matter content and pH (range 6.5 to 8.5 ) of coal mine spoils causes poor survival of planted native tree species. Paper birch is an exception, however, and produces satisfactory results (292). Cuttings of paper birch planted on an unstable, water-saturated, gravelly side-slope and on an abandoned winter road near Norman Wells, N.W.T. failed to survive. Paper birch is regarded as unsuitable for slope stabilization in this location (110). On tests in the eastern slopes region of Alberta (subalpine) paper birch suffered heavy dieback and survival declined steadily (707). On amended tailings sand at Fort McMurray survival was high but growth after six years was mediocre and dieback was high (706, Suncor 1983). Paper birch is used for reclamation purposes in the eastern United States (33) and elsewhere in Canada (466), as well. 
Ceanothus velutinus

SPECIES SUITABILITY MAP AND SUMMARY TABLE

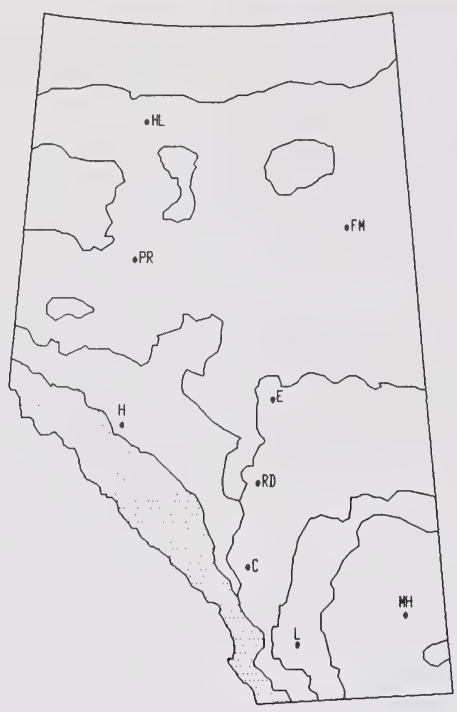

Recommended Area

Commercially Available: Yes $\mathrm{X}$ No

\begin{tabular}{|c|c|c|c|c|c|}
\hline \multirow{2}{*}{$\begin{array}{l}\text { RECLAMATION SUITABILITY } \\
\text { CRITERIA }\end{array}$} & \multicolumn{5}{|c|}{ SUITABILITY RATING } \\
\hline & Very High & High & Medium & Low & None \\
\hline Drought Tolerance & & & $x$ & & \\
\hline \multicolumn{6}{|l|}{ Salt Tolerance } \\
\hline Acid & & & $x$ & & \\
\hline Tolerance Base & & & & & \\
\hline Winter Hardiness & & $\mathrm{x}$ & & & \\
\hline Erosion Control & & $x$ & & & \\
\hline Persistence & & $x$ & & & \\
\hline Palatability & & $x$ & $\mathrm{x}$ & $x$ & \\
\hline Browse Tolerance & & & $x$ & & \\
\hline Moisture Preference & \multicolumn{5}{|l|}{ Dry. } \\
\hline Soil Preference & \multicolumn{5}{|c|}{ Moderately acidic substrate to neutral. } \\
\hline
\end{tabular}


Ceanothus velutinus Dougl. ex Hook.

\section{SPECIES BIOLOGY}

Taxonomy - Snow Brush; Deer Brush.

\section{Origin and Range}

Native. Snow brush is found in the coast ranges from British Columbia south to California and east to southwest Alberta, Montana, South Dakota and Colorado (419).

\section{Growth Habit}

A medium evergreen shrub 1 to $30 \mathrm{~m}$ high, snow brush is usually found growing in dense patches (690). It forms a spreading, dense round-topped bush. The thickets may be up to $10 \mathrm{~m}$ wide and are often dense and impenetrable (480).

\section{Nitrogen Fixing}

Snow brush fixes atmospheric nitrogen, which assists in its success (and that of neighbouring plants) on infertile soils $(120,480,159,107)$. In nitrogen-free media, Ceanothus plants were found to fix $760 \mathrm{mg} \mathrm{N}$ per plarit in a 48 week period. About $60 \mathrm{~kg} \mathrm{~N}$ per annum was fixed under field conditions (33).

\section{Longevity}

Long-lived perennial (243). Snow brush is apparently susceptible to winter die-back on exposed sites (415).

\section{Self Propagation}

Snow brush spreads by seed and will spread by root sprouts after logging or fire (480).

\section{Ecological Setting}

Ceanothus spp. are largely confined to the Pacific coast region of North America. In Alberta, Ceanothus velutinus is mainly found on mountain slopes in the southwestern corner of the province. It can be found from sea level to high mountains. It is an understory shrub characteristic of Ponderosa pine (Pinus ponderosa) and Douglas-fir (Pseudotsuga mensiesii) forests $(690,419,480)$.

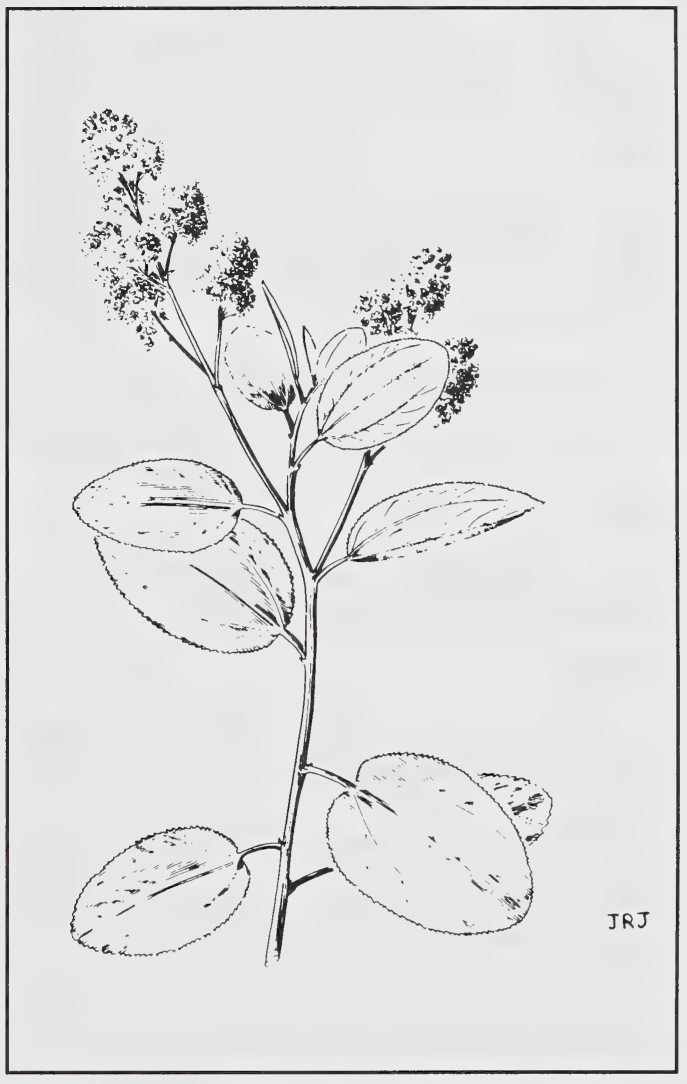

\section{TOLERANCES}

\section{Soil Preferences}

Snow brush is adapted to moderately acid to neutral soil. It is often the most vigorous shrub on granite (acidic) substrate (480). It is generally found on dry sites (120).

\section{Nutrient Requirements}

Found on sites with poor nutrient status, so low requirements suspected.

\section{Soil Reaction}

Does best on neutral to moderately acidic soils. No specific $\mathrm{pH}$ ranges noted. 


\section{Soil Salinity}

No specific tolerance noted.

\section{Drought}

Tolerant of dry conditions, but resistance to actual drought not known. Species has the ability to fold leaves to reduce transpirational loss when leaves exposed to heat.

\section{Heavy Metals and Hydrocarbons}

No specific tolerances noted in literature reviewed.

\section{Shade}

Likely moderately shade tolerant, due to its frequent occurrence under open forest types.

\section{Browsing}

Will resprout from root crowns, and apparently survives at least some browsing.

\section{Susceptibility to Disease and Insect Damage}

Aphids are a problem with this species (P. Ziemkiewicz, pers.comm.).

\section{RECLAMATION CONSIDERATIONS}

\section{Soil Building and Erosion Control Capability}

Snow brush is a thicket forming shrub that spreads by root suckers (480). It is therefore presumed to bind soil and reduce erosion potential. Snow brush is rated as excellent for soil stabilizing (338).

\section{Adaptation to Disturbance}

Snow brush is often observed as a pioneer after fire (419). In a burned area in Oregon, snow brush germinated over much of the area one year after the fire, particularly in the ponderosa pine-sedge and ponderosa pine-mixed fir sites (15). It has been reported growing on mine spoil in British Columbia (120). It is rated as having good adaptation to disturbance (338). In California, maintenance of Ceanothus spp. is dependent on fire.

\section{Competitive Ability}

Observed to be moderately aggressive on open sites.

\section{Commercial Value}

Snow brush is an important winter forage for big game. It is also important for nitrogen fixation, erosion control, conservation and as an ornamental $(480,107,608)$.

\section{Palatability}

The genus has been rated as having low value for wildlife (397), but $\underline{\mathrm{C}}$. velutinus is browsed by elk, deer, and mountain goat and often comprises an important component of high-elevation ungulate winter ranges. Valuable browse for big game and birds (608). Ceanothus has also been recommended as an understory plant for providing shelter for elk (437). Low growing ecotypes are more palatable than others (480). Moderate to heavy use by mule deer has been reported (245). Contains the poison, Saponen ( $P$. Ziemkiewicz, pers.comm.).

\section{Seed or Planting Stock Availability}

Some native seed is known to be available from American dealers, but ecotype suitability is not known. Seedlings may also be available (e.g. 608).

\section{Methods and Ease of Establishment}

Seed should generally only be collected from healthy plants. Weak or diseased plants do not produce sound seed pods. These clusters should not be cut as the seed pods will not ripen properly. The pods split when ripe and eject seeds. The interval between seed crops is 1 to 3 years. Seed is apparently long-lived and can be stored at 2 to $5^{\circ} \mathrm{C}$. It has seedcoat embryo dormancy. Soak in water at $90^{\circ} \mathrm{C}$ until the water is cool (or boil for 3 minutes), then cold stratify at $5^{\circ} \mathrm{C}$ for 60 to 90 days. Heat apparently renders the seed permeable to water. Seeds should be sown 0.3 to $0.6 \mathrm{~cm}$ deep in an acid planting medium ( $\mathrm{pH} 6.5$ ). Other methods of establishment include evergreen cuttings (in the fall) and root cuttings $(119,135$, 120). Snow brush is also readily established from transplanted wildlings, containerized wildlings and bare root nursery stock (480). The species is ranked as having good establishment by transplanting, but only fair establishment by seeding (338). P. King (pers.comm.) reported best results with semi-hardwood root cuttings ( $72 \%$ rooting) treated with Hormodin (semi-hardwood formulation).

\section{Current Status for Reclamation}

Snow brush is a dense shrub with lateral growth 
habit. It has been variously described as slow growing and as an aggressive invader of disturbed sites. It fixes atmospheric nitrogen and is a valuable ungulate browse species. It is adapted to dry and acid soils and easily propagated from seed or root suckers. Snow brush has been used for erosion control on roadways and other disturbed sites (480). Survival of one year old bare root seedlings planted on road cut and fill sites in the Wenatchee National Forest (77 to $1478 \mathrm{~m} \mathrm{ASL}$ ), eastern Washington, was variable after two years. Slopes ranged from $40 \%$ to greater than $70 \%$ and soil nutrient levels were very low. Snow brush had higher survival on road fill sites (25\% to $74 \%$ ) than on road cut sites (4\% to $42 \%$ ), probably due to less soil movement on the fill slopes. It is slow growing and susceptible to burial from moving soil. Snow brush has been suggested as a species suitable for revegetation in the Rocky Mountains of Alberta (331). 


\section{SPECIES SUITABILITY MAP AND SUMMARY TABLE}

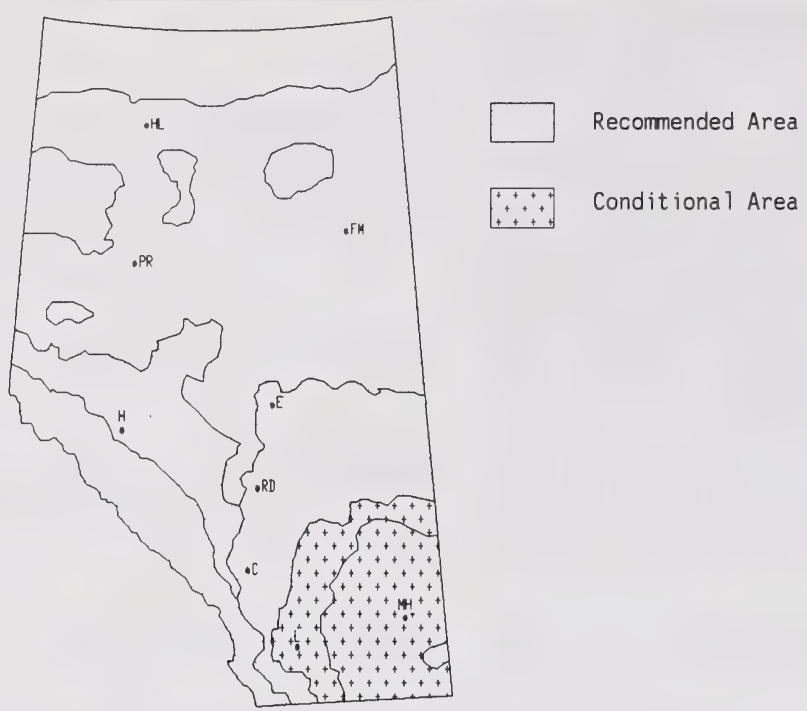

Commercially Available: Yes $X$ No

\begin{tabular}{|c|c|c|c|c|c|}
\hline \multirow{2}{*}{$\begin{array}{l}\text { RECLAMATION SUITABILITY } \\
\text { CRITERIA }\end{array}$} & \multicolumn{5}{|c|}{ SUITABILITY RATING } \\
\hline & Very High & High & Medium & Low & None \\
\hline Drought Tolerance & & & & $x$ & \\
\hline Salt Tolerance & & & & & $x$ \\
\hline pH Acid & & & $x$ & & \\
\hline Tolerance Base & & & $x$ & & \\
\hline Winter Hardiness & & $x$ & & & \\
\hline Erosion Control & & & $\mathrm{x}$ & $x$ & \\
\hline Persistence & & $x$ & & & \\
\hline Palatability & & $x$ & $\mathrm{x}$ & & \\
\hline Browse Tolerance & & $x$ & & & \\
\hline Moisture Preference & Moist & wet, & rates $\mathrm{fl}$ & & \\
\hline Soil Preference & Medium & to coar & extured, & ates & range. \\
\hline
\end{tabular}


Cornus stolonifera Michx.

\section{SPECIES BIOLOGY}

\section{Taxonomy}

Red Osier; Dogwood; Kinnikinnick

\section{Origin and Range}

Native. Newfoundland to Alaska, south to California, New Mexico and Nebraska, in northern United States from Wisconsin to New York (419).

\section{Growth Habit}

Deciduous, thicket forming shrub. Red osier averages $1 \mathrm{~m}$ to $2 \mathrm{~m}$ high. It can grow up to $5 \mathrm{~m}$ high and is many-stemmed. The lower branches may root at the tip $(443,312)$.

Nitrogen Fixing - None

Longevity - Long-lived perennial.

\section{Self Propagation}

Methods include root sprouts, stolons, layering (5, 377). Plants flower when about 4 years old. Seeds are spread by birds (377).

\section{Ecological Setting}

Red osier is found throughout the boreal forest region and is common in woodlands and coulees throughout the prairies. It is common in moist soil in clearings or open woodland, and on river banks and river flood plains. It is found over a wide range of elevations ( 1370 to $3050 \mathrm{~m}$ in the central Rocky Mountains). The common native associates are (Mixed-wood Forest): Linnaea borealis, Vaccinium vitis-idaea, Ribes triste, Rosa acicularis, Alnus crispa, Viburnum edule $(690,377,399)$.

\section{TOLERANCES}

\section{Soil Preferences}

Red osier is found on a range of soil moisture conditions from well drained to poorly drained soils. It can withstand flooding during the growing season (5). It is also found in drier situations along forest margins and it often invades grasslands (377). Red osier does best on free draining soils with adequate available moisture. It is also found on a range of soil textures (5).

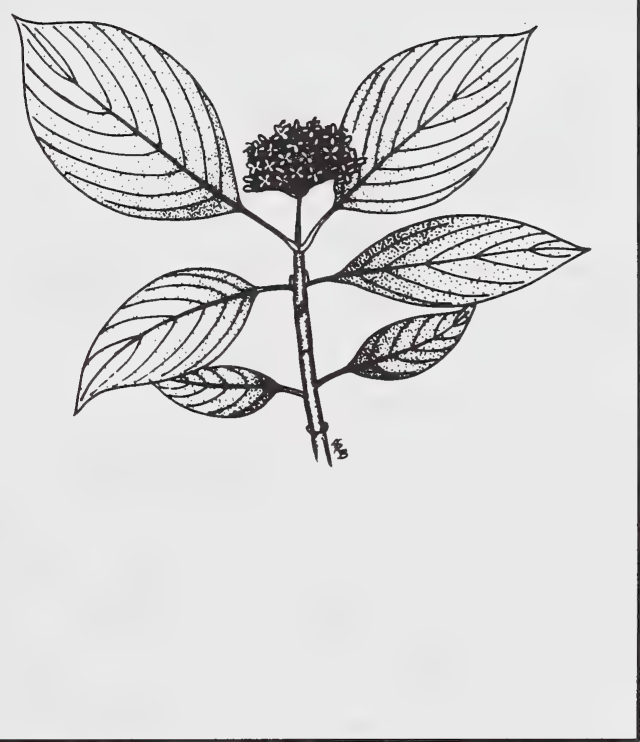

Nutrient Requirements

Appears to favour nutrient rich sites.

\section{Soil Reaction}

Red osier has medium acid tolerance (5). It is found on soils with various $\mathrm{pH}$ values, from moderately acidic to moderately alkaline $(338,377)$.

\section{Soil Salinity}

No specific tolerances noted.

Drought - Low drought tolerance (5).

\section{Heavy Metals and Hydrocarbons}

Red osier has a high tolerance to oil (282).

\section{Shade}

Red osier is slightly shade tolerant - prefers open sites, but will grow under light shade (356). May 
survive in relatively dense forests as a remnant.

\section{Browsing}

Often extensively browsed with little loss of vigour.

Susceptibility to Disease and Insect Damage

Some galls and leaf spots have been observed. No specific susceptibilities noted. Oyster shell scale can kill plants (P. Sims, pers.comm.).

\section{RECLAMATION CONSIDERATIONS}

\section{Soil Building and Erosion Control Capability}

Red osier has a medium cover rate and will spread by root sprouts after it has been established (5). It therefore is able to provide some protection to soil surfaces.

\section{Adaptation to Disturbance}

It is known to invade disturbed alluvial sites.

Competitive Ability

Aggressive on preferred sites.

\section{Commercial Value}

Red osier is important in providing food and cover for wildlife and many birds, including ruffed grouse (377); it is also sometimes favoured as an ornamental (443).

\section{Palatability and Nutritive Value}

Moderate to heavy use of red osier by mule deer has been reported (245). It is a preferred browse species of moose during fall and winter, especially young twigs (443). Also browsed by elk (377). Red osier is useful in providing a heavy shrub layer suitable for shelter for mule deer (71).

\section{Seed or Planting Stock Availability}

Native seed is available from U.S. dealers. Ecotypic suitability is not known. A large range in seed weight has been reported: about 300400 seeds $/ \mathrm{kg}$ is typical; $44 \mathrm{~kg}$ of seed per $1200 \mathrm{~kg}$ fruit can be expected; approximately 380600 seeds/kg (639).

\section{Methods and Ease of Establishment}

Seed can be collected in July or August (as soon as ripe). One to two years can be expected between good seed crops. Seed can be stored at $-18^{\circ} \mathrm{C}$ for 1 or 2 years before planting out. Seed has an embryo dormancy and requires stratification at 2 to $5^{\circ} \mathrm{C}$ for 60 to 90 days $(119,434)$. Stratification at $5^{\circ} \mathrm{C}$ also produces good (98\%) germination (102). Seed is best sown in the fall at depths of 0.6 to $1.25 \mathrm{~cm}(119,208)$. Hardwood cuttings should be planted in autumn; softwood cuttings in summer (174). It is easily propagated from stem cuttings (443) and root cuttings (174).

\section{Current Status for Reclamation}

Well adapted to growth on amended tailings sand at Fort McMurray. Survival is high and dieback light $(645,706)$. Red osier was unable to compete with grass cover $(149,667)$. Red osier has been recommended for revegetation on well drained to wet sites in Alaska. The maximum spacing suggested was approximately $1.3 \mathrm{~m}$ by $1.3 \mathrm{~m}(5)$. Though it has been widely used for soil stabilization (42), some authors have recommended that it not be used for controlling slope erosion (110). 
Dryas drummondi i

\section{SPECIES SUITABILITY MAP AND SUMMARY TABLE}

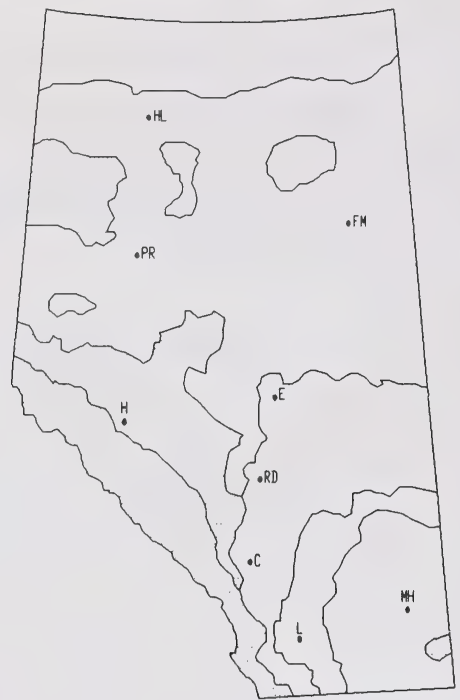

Recommended Area

Commercially Available: Yes No $x$

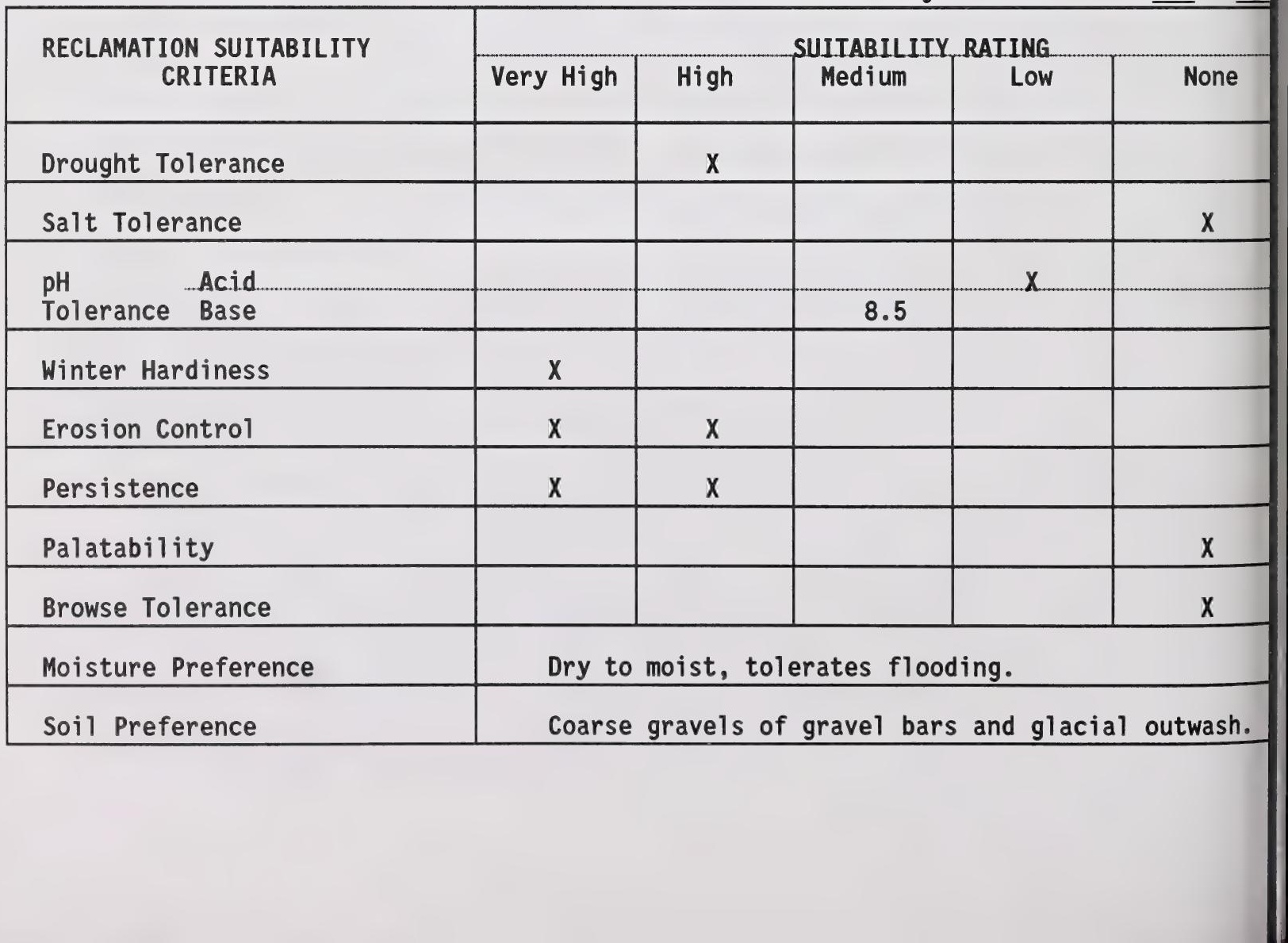


Dryas drummondii Richards.

\section{SPECIES BIOLOGY}

Taxonomy - Yellow Dryad; Mountain Avens.

\section{Origin and Range}

Native to North America (214), with circumpolar distribution. Range extends from Alaska to Mexico generally along the Rocky Mountains and adjacent foothills. Associated with rocky slopes, gravel bars, and glacial outwash $(160,312,405)$.

\section{Growth Habit}

Forms extensive continuous mats (160) with flower stalks up to $25 \mathrm{~cm}$ high (690). Stem from long, woody caudex (214), leaves all basal (214), with extensive root system (160).

\section{Nitrogen Fixing}

Mountain avens is associated with nitrogen fixing endophytic fungi on root nodules (similar to that observed in Alnus); nitrogen content of the upper $5 \mathrm{~cm}$ of soil increased by almost $200 \%$ during 28 years of Dryas cover in Alaska $(160,105)$, thus aiding survival and stimulating growth of woody plants. Root nodules are usually found $15 \mathrm{~cm}$ or more beneath the surface (251).

\section{Longevity}

A perennial evergreen shrub (405). Initial colonization of barren ground by mountain avens may take 10 years; plants usually disappear within 20 to 30 years because of shading by other plants. Holds position as first dominant plant species on deglaciated terrain for 20 to 40 years, as noted in Alaska (251).

\section{Self Propagation}

Monoclinous (i.e. with bisexual flowers on all plants) (405). Wind-dispersed fruits enhance its colonizing ability (251). Good self-seeding.

\section{Ecological Setting}

Subalpine and boreal type forests, particularly dry sites on river gravel bars, to at least $1100 \mathrm{~m} \mathrm{ASL}$ (214). Preferred water table depth is noted at $60 \mathrm{~cm}$ and favoured moisture reqime is considered

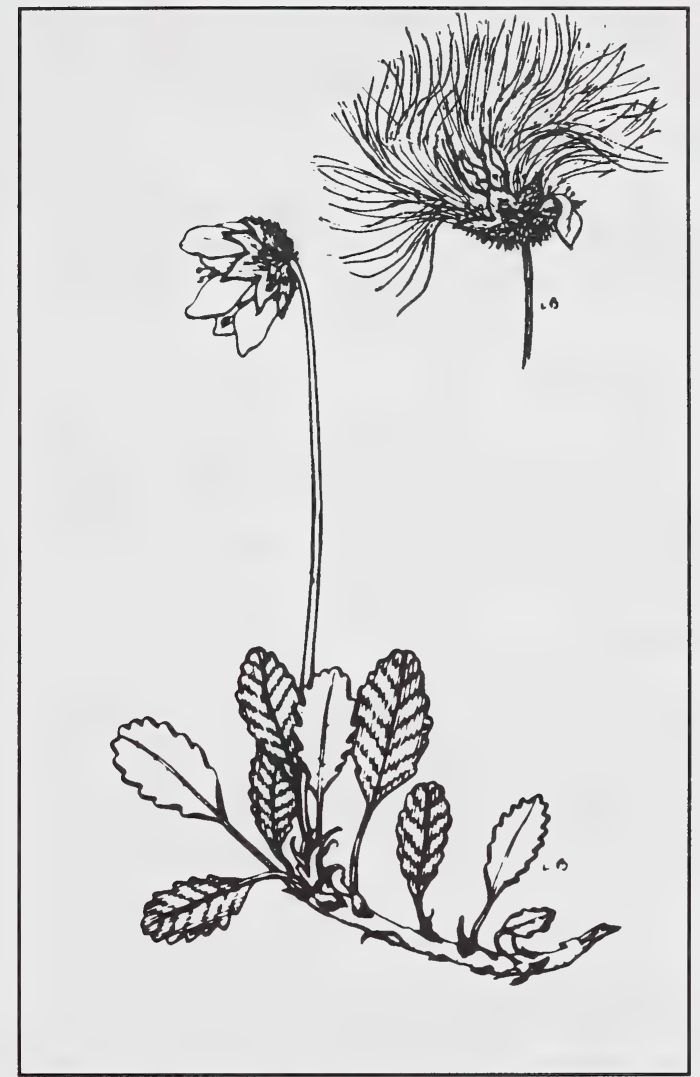

on newly deglaciated terrain and noted to speed up rate of succession to a fully developed forest by as much as 20 to 30 years (251).

\section{TOLERANCES}

\section{Soil Preferences}

Associated with coarse gravelly soils of river bars. The species is adapted to the dry conditions of the tops of gravel bars where most fine sand and silt have been removed by flood waters $(160)$. Sites are characterized by low availability of nutrients and low moisture-holding capacity of soil. On newly deglaciated terrain, mountain avens is conspicuous on raw sands, gravels, and silt loams of till and outwash, and occurs on surfaces more than 10 years and less than 60 years old (251).

\section{Nutrient Reauirements}


with low nitrogen content (251). Capable of growing vigorously at low nitrogen levels characteristic of glacial debris (22).

\section{Soil Reaction}

Noted to be growing best on soils with $\mathrm{pH}$ in the range of 7.8 to 8.5 , in Alaska. Dryas growth has been associated with slight increases in soil acidity after about 20 years (251).

\section{Soil Salinity}

Appears to be restricted to calcareous substrata and to grow best on soils with a calcium carbonate content of about $5 \%$ (of the fine earth fraction) in Alaska (251), and calcareous gravels bars in the mountains (185).

\section{Drought}

Mountain avens are well adapted to dry conditions. Adaptations include low spreading growth form, extensive root systems, leathery leaves, and accumulation of litter throughout annual leaf fall, which increases the moisture holding capacity of the soil (160).

\section{Heavy Metals and Hydrocarbons}

A related species, $\underline{D}$. integrifolia, shows tolerance to crude oil contact and spills at high-arctic tundra sites (216). No other tolerances have been noted.

\section{Shade}

Dryas is extremely shade intolerant, and usually disappears within 20 to 30 years because of shading by other plants (140).

\section{Browsing}

Not applicable, since use by wildlife is virtually nonexistent.

\section{Susceptibility to Disease and Insect Damage}

No specific susceptibilities noted.

\section{RECLAMATION CONSIDERATIONS}

\section{Soil Building and Erosion Control Capability}

Annual leaf fall causes an accumulation of litter which increases the moisture holding capacity of the soil (160). The extensive root system contributes to erosion control capability. Noted for rapid stabilization of soil surfaces against erosion on newly glaciated terrain in Alaska (251).

\section{Adaptation to Disturbance}

Mountain avens is an efficient colonizer of coarse textured, gravelly soils of river bars subject to flooding and related disturbance. Dryas species also occupy alpine areas disturbed by frost heaving (160).

\section{Competitive Ability}

Very aggressive pioneer on preferred sites. Dryas usually disappears within 20 to 30 years after initial colonization because of shading by other plants. Dryas creates conditions suitable for a Populus community (251).

\section{Commercial Value}

Ornamental value associated with growth form and flowers (405).

\section{Palatability and Nutritive Value}

Generally not eaten by wildlife. Should be considered unpalatable.

\section{Seed or Planting Stock Availability}

Seed is easily collected from pure native stands.

\section{Methods and Ease of Establishment}

Mainly by seed which is easily collected and germinates well (J. Weijer, pers.comm.).

\section{Current Status for Reclamation}

Yellow mountain avens is a common native invader of river bars and glacial outwashes. The species has not apparently been incorporated into full scale revegetation operations. Noted as growing on bedrock spoil material at an abandoned coal strip mine, near Cadomin, an area subject to high winds, soil moisture deficiency, and abrasive effects of air borne weathered spoil particles (357). Encouraging attributes include extensive root system and spreading habit, primary successional status, adaptation to dry sites, adaptation to high elevations and its nitrogen fixing ability. 
Dryas octopetala

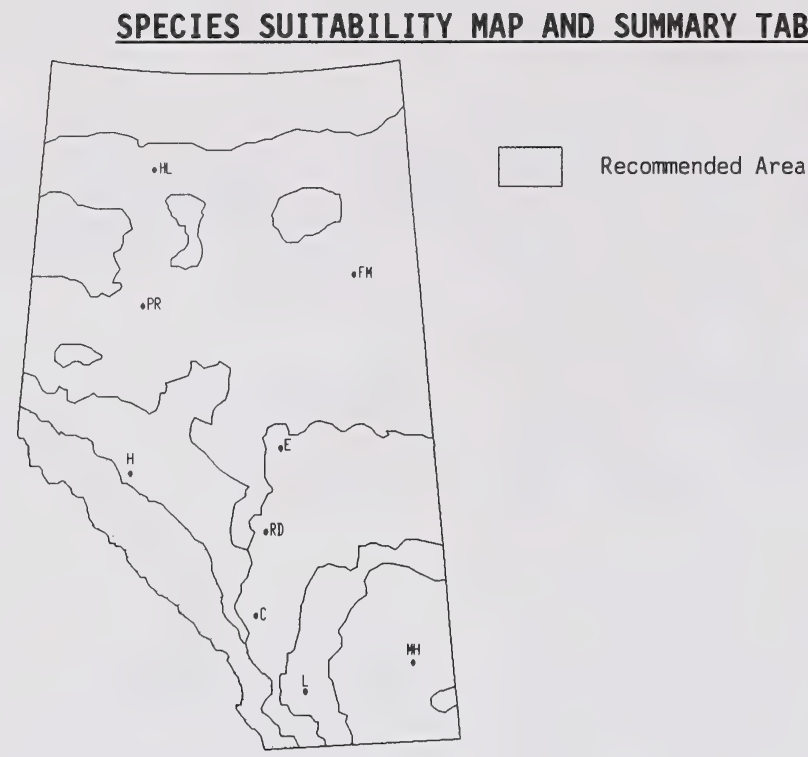

Commercially Available: Yes No $x$

\begin{tabular}{|c|c|c|c|c|c|}
\hline \multirow{2}{*}{$\begin{array}{l}\text { RECLAMATION SUITABILITY } \\
\text { CRITERIA }\end{array}$} & \multicolumn{5}{|c|}{ SUITABILITY RATING } \\
\hline & Very High & High & Medium & Low & None \\
\hline Drought Tolerance & & $x$ & & & \\
\hline Salt Tolerance & & & & $x$ & \\
\hline Acid & & & & $x$ & \\
\hline Tolerance Base & & & $\mathrm{X}$ & $\mathrm{X}$ & \\
\hline Winter Hardiness & $x$ & & & & \\
\hline Erosion Control & & $\mathrm{X}$ & & & \\
\hline Persistence & & & $x$ & & \\
\hline Palatability & & & & & $x$ \\
\hline \multicolumn{6}{|l|}{ Browse Tolerance } \\
\hline Moisture Preference & \multicolumn{5}{|c|}{ Dry to moist. } \\
\hline Soil Preference & \multicolumn{5}{|c|}{$\begin{array}{l}\text { Rocky infertile moderately drained, tolerates frost } \\
\text { boils and soil creep. }\end{array}$} \\
\hline
\end{tabular}


Dryas octopetala L. ssp. hookeriana (Juz.) Hult.

\section{SPECIES BIOLOGY}

Taxonomy - White Dryad.

\section{Origin and Range}

Native to western North America, with circumpolar distribution. Range extends along the Rocky Mountains from Alaska to Mexico (214).

\section{Growth Habit}

Dwarf evergreen shrub forming small dense mats (690).

\section{Nitrogen Fixing}

Described as nodulated plants capable of fixing atmospheric nitrogen (25).

Longevity - Perennial (405).

\section{Self Propagation}

Observed to propagate by seed and matted habit.

\section{Ecological Setting}

Generally on rocky areas; high mountains, mostly above timberline (312); alpine heaths to at least $2000 \mathrm{~m} \mathrm{ASL}$ (214). Noted to develop on well drained bare surfaces such as deglaciated terrain, although less frequently than $\underline{D}$. drummondii, in Alaska (25).

\section{TOLERANCES}

\section{Soil Preferences}

Observed on rocky infertile soils in exposed sites. Often associated with frost boils and soil creep areas. Does best on moderately well drained sites.

\section{Nutrient Requirements}

Thought to have low nutrient requirements due to its ability to colonize nutrient poor sites.

\section{Soil Reaction}

Appears to favour soils derived from basic materials; neutral to slightly basic $\mathrm{pH}$ is expected to be best.

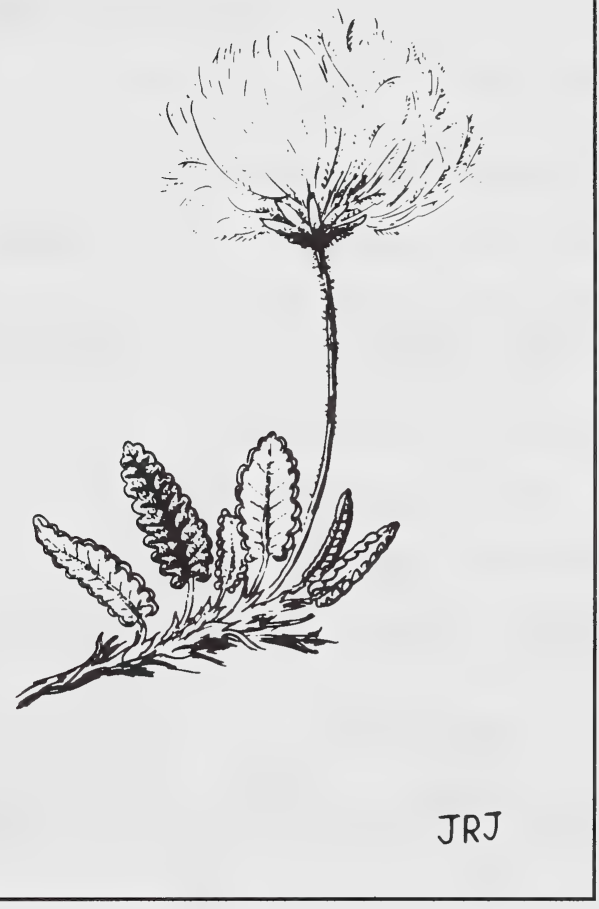

\section{Soil Salinity}

Not thought to be particularly tolerant of saline conditions.

\section{Drought}

Found thriving on sites with high moisture stress. Adaptations to dry sites include leathery leaves, pubescence and low growth.

\section{Heavy Metals and Hydrocarbons}

A related species, ‥ integrifolia, shows tolerance and good ability to survive crude oil contact and spills at high-arctic tundra sites (216). No other tolerances noted.

\section{Shade}

Generally out competed on shady sites. 


\section{Browsing}

Not generally eaten, therefore tolerance is not known.

\section{Susceptibility to Disease and Insect Damage}

No particular susceptibilities noted.

\section{RECLAMATION CONSIDERATIONS}

\section{Soil Building and Erosion Control Capability}

The ability of white dryad to fix nitrogen and colonize naturally unstable sites indicates a high capability for erosion control.

\section{Adaptation to Disturbance}

Invades suitable disturbed sites.

\section{Competitive Ability}

Highly competitive on suitable sites due to spreading habit.

\section{Commercial Value}

Some ornamental value (405), otherwise the species value is limited to its erosion control characteristics.

\section{Palatability and Nutritive Value}

Not generally eaten by wildife although the seed may occasionally be eaten by birds.

\section{Seed or Planting Stock Availability}

Seed is easily collected, but not known to be available commercially.

\section{Methods and Ease of Establishment}

Reported to have very high (99\%) germination (J. Weijer, pers.comm.). Vegetative propagation is also thought to be worth investigating.

\section{Current Status for Reclamation}

White dryad is reported to show good potential for revegetation of calcareous coal mine spoils in alpine areas of Montana (209). Factors cited as favourable include natural association with calcareous rocky sites, nitrogen fixing ability, and pioneering ability. 


\section{SPECIES SUITABILITY MAP AND SUMMARY TABLE}

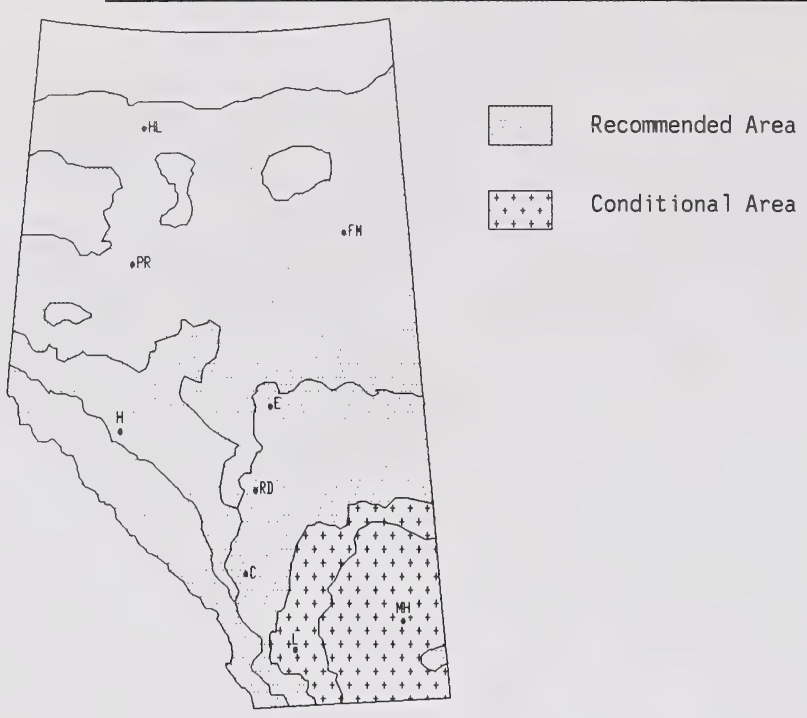

Commercially Available: Yes $\underline{X}$ No

\begin{tabular}{|c|c|c|c|c|c|}
\hline \multirow{2}{*}{$\begin{array}{l}\text { RECLAMATION SUITABILITY } \\
\text { CRITERIA }\end{array}$} & \multicolumn{5}{|c|}{ SUITABILITY RATING } \\
\hline & Very High & High & Medium & Low & None \\
\hline Drought Tolerance & & & $x$ & $x$ & \\
\hline Salt Tolerance & & & $x$ & & \\
\hline Acid & & & $x$ & & \\
\hline Tolerance Base & & & $x$ & & \\
\hline Winter Hardiness & & $x$ & & & \\
\hline Erosion Control & & $x$ & $x$ & & \\
\hline Persistence & & $x$ & & & \\
\hline Palatability & & & & $x$ & \\
\hline Browse Tolerance & & & $x$ & & \\
\hline Moisture Preference & Dry to & loist. & & & \\
\hline Soil Preference & & & I Idili lo & 10 & \\
\hline
\end{tabular}


Elaeagnus commutata Bernh. ex. Rydb.

\section{SPECIES BIOLOGY}

Taxonomy - Silver-berry; Wolf Willow.

\section{Origin and Range}

Native. Alaska and the Yukon Territory east to Great Slave Lake, James Bay and the Gaspe Peninsula; south to Minnesota, South Dakota, Colorado and Utah.

\section{Growth Habit}

Deciduous thicket-forming shrub; from 1 to $4 \mathrm{~m}$ high (312).

\section{Nitrogen Fixing}

Silver-berry fixes nitrogen under most conditions (329). It is associated with the $\mathrm{N}_{2}$-fixing actinomycete Frankia and vesicular-arbuscular mycorrhizae (728). Poplar growing adjacent to silver-berry stands show higher tree production, higher percentage $\mathrm{N}$ in leaves and litter, and a greater quantity of $\mathrm{N}$ in above-ground parts than in poplar growing some distance away (470).

Longevity - Long-lived perennial.

Self Propagation - Seeds, root sprouts (5).

\section{Ecological Setting}

Common on valley slopes throughout the Canadian prairies where adequate moisture is available; often on the edge of aspen groves (312). On rocky south-facing slopes and river sandbars in the interior of Alaska; occurs over a wide range of elevations $(119,214)$. Common native associates (Alberta): Poa pratensis, Juncus balticus, Rosa acicularis, Populus tremuloides.

\section{TOLERANCES}

\section{Soil Preferences}

Silver-berry prefers well drained soils (5); it is largely confined to medium textured soils (silt loam to sandy loam) $(690,5,332)$.

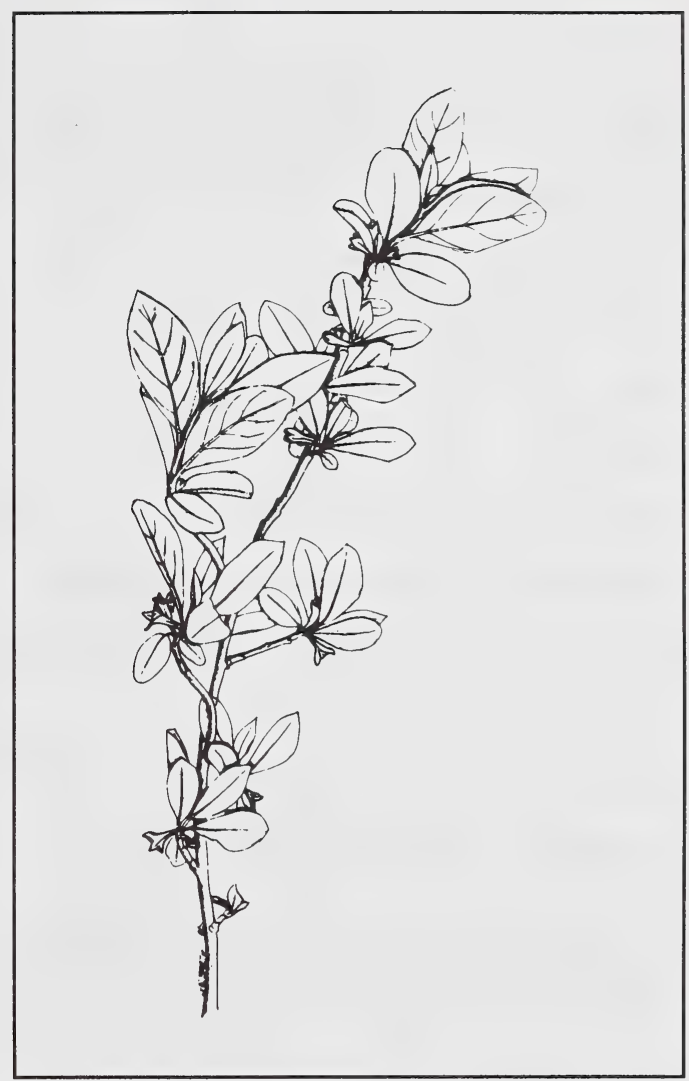

\section{Nutrient Requirements}

The species is often observed on poor sites such as erosion slopes in Alberta $(306,332)$. Twenty week old seedlings grown in the greenhouse were larger when fertilized; however, they had considerably fewer nodules (690). This may have some effect on the quality of the stock for outplanting.

\section{Soil Reaction}

The species displays moderate acid tolerance (5).

\section{Soil Salinity}

Silver-berry is often found on moderately saline sites. 


\section{Drought}

Moderate; can tolerate soils with low water-holding capacity (5). However, low survival of this species on amended tailings sands was attributed to low drought tolerance (A. Fedkenheuer, pers.comm.).

Heavy Metals and Hydrocarbons

No specific tolerances have been noted.

Shade - Low shade tolerance (5).

\section{Browsing}

Moderate grazing tolerance (430).

\section{Susceptibility to Disease and Insect Damage}

Susceptible to leaf spot, leaf rust, dieback and root rot (Peniophora cremea) (198).

\section{RECLAMATION CONSIDERATIONS}

\section{Soil Building and Erosion Control Capability}

Although it has a slow cover rate (5) it is adapted to soils with high erosion susceptibility; it has been used for erosion control (120). Spreads rapidly on amended tailings sand (643).

\section{Adaptation to Disturbance}

Spreads rapidly in overgrazed pastures throughout the aspen parkland (312).

\section{Competitive Ability}

Thought to be able to maintain its cover, but not highly aggressive.

\section{Commercial Value}

Windbreaks, ornamental (443), and erosion control (120).

\section{Palatability and Nutritive Value}

Some use by mule deer (245) and bighorn sheep (144); reported to have low palatability (427). Increased nitrogen content of forage plants under silver-berry, particularly Kentucky bluegrass (Poa pratensis), makes forage more desirable for grazing livestock (470).

\section{Seed or Planting Stock Availability}

Very small quantities of seed are available commercially. Approximately 20 to $65 \mathrm{~kg}$ of seed can be expected from $100 \mathrm{~kg}$ of fruit, depending on the seed collection date.

\section{Methods and Ease of Establishment}

Seed crops are produced every 1 to 2 years. Seed should be collected between August and October. Approximately one man-day is required to collect $1 \mathrm{~kg}$ of seed (119). Seed has an embryo dormancy, therefore fall sowing or stratification at $5^{\circ} \mathrm{C}$ for 60 days is recommended. Sow seeds 1.0 to $2.0 \mathrm{~cm}$ below surface, at 180 to 270 seeds $/ \mathrm{m}^{2}$ in mulched beds (486). Hydroseeding has been successful (144); container seedlings (207) and bare root stock (434) can be produced successfully. Hardwood cuttings taken in fall and planted in spring $(120,119)$ and root cuttings (5) can also be successful.

\section{Current Status for Reclamation}

Well adapted to amended tailings sand at Fort McMurray. Survival remained high after seven years, growth and vigour were good and reproduction by rhizomes was vigorous $(643,706$, 149). Inoculated silver-berry outplanted onto tailings sand had considerably lower survival than uninoculated plants; however, the inoculated survivors were considerably larger and had more nodules (728). In northeastern British Columbia, seedlings are reported to have a $60 \%$ first year survival rate when transplanted to a sandy soil on a steep, unstable slope (431). 


\section{SPECIES SUITABILITY MAP AND SUMMARY TABLE}

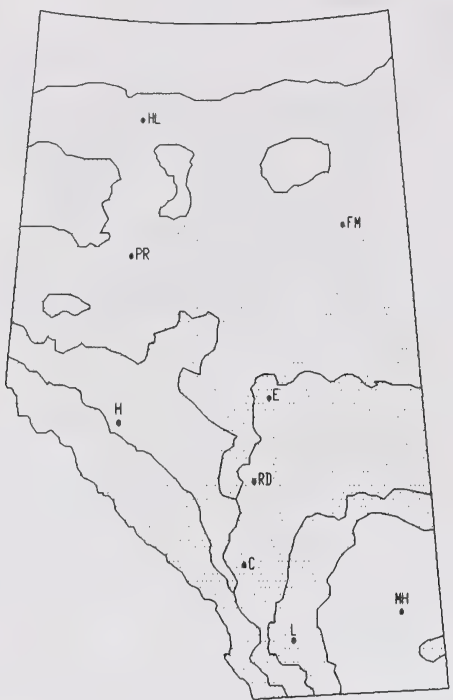

Recommended Area

Commercially Available: Yes $X$ No

\begin{tabular}{|l|c|c|c|c|c|}
\hline \multirow{2}{*}{$\begin{array}{l}\text { RECLAMATION SUITABILITY } \\
\text { CRITERIA }\end{array}$} & Very High & High & Medium & Low & None \\
\hline Drought Tolerance & & & $X$ & & \\
\hline Salt Tolerance & & & & $X$ & \\
\hline $\begin{array}{l}\text { pH Acid } \\
\text { Tolerance Base }\end{array}$ & & $X$ & & & \\
\hline $\begin{array}{l}\text { Winter Hardiness } \\
\text { Erosion Control }\end{array}$ & & & & & \\
\hline $\begin{array}{l}\text { Persistence } \\
\text { Palatability }\end{array}$ & & & & $X$ & \\
\hline Browse Tolerance & & & $X$ & & \\
\hline $\begin{array}{l}\text { Moisture Preference } \\
\text { Soil Preference }\end{array}$ & Sry to moist. & & \\
\hline
\end{tabular}


Juniperus communis $L$.

\section{SPECIES BIOLOGY}

Taxonomy - Ground Juniper; Common Juniper.

Also $\rfloor$. communis var. saxatilis Pall and var. depressa Pursh. Syme, ‥ sibirica Burgsa.

\section{Origin and Range}

Native. Greenland, Newfoundland to Alaska south to Arizona, New Mexico, Georgia and South Carolina. Also in Europe and Asia. Most widespread tree species in the north temperature zone (443).

\section{Growth Habit}

A (usually) prostrate shrub. May grow up to $1.0 \mathrm{~m}$. Evergreen (443) forms clumps up to $3 \mathrm{~m}$ in diameter (443). Reaches tree size in Europe (443).

Nitrogen Fixing - None

Longevity - Long-lived perennial.

\section{Self Propagation}

Propagates itself by seed (5).

\section{Ecological Setting}

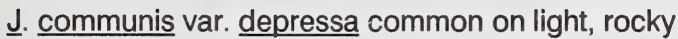
soil throughout most of the prairies (78). Common juniper is a common species of woods and open slopes throughout most of Alberta (690). It extends from the lower foothills and montane zones into the upper subalpine. It is commonly found on dry open slopes with southerly exposures. Common juniper is characteristically associated with buffaloberry and common bearberry in dry, open lodgepole pine forests (365).

\section{TOLERANCES}

\section{Soil Preferences}

Adapted to generally dry sites, from soils with no moisture limitations to excessively drained soils with severe limitations due to low water holding capacity. Found on a range of soil textures from silt loam through to sand. Most common on coarse textured soils (5).

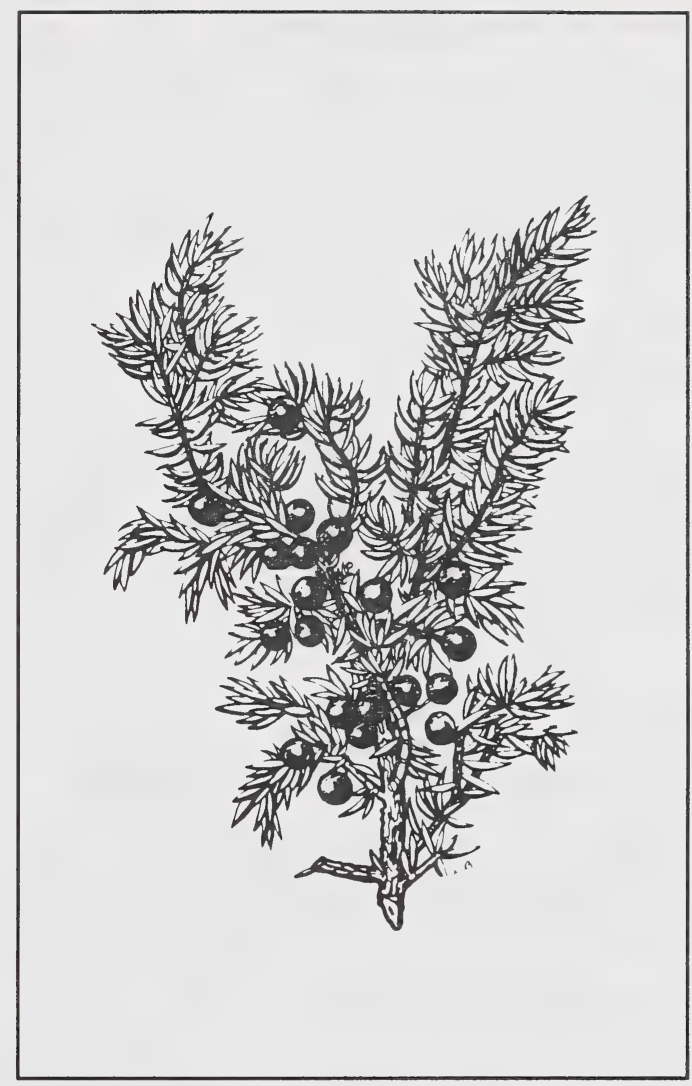

\section{Nutrient Requirements}

Expected to have low nutrient requirements due to its ability to grow on poor sites.

\section{Soil Reaction}

Ground juniper has high acid tolerance (5).

\section{Soil Salinity}

No salinity tolerance information noted, although not generally found on saline soils.

\section{Drought}

Appears to be relatively tolerant of low soil moisture conditions; drought tolerant (608). 


\section{Heavy Metals and Hydrocarbons}

No specific tolerances noted.

\section{Shade}

Variously low shade tolerance (5) and shade tolerant (608).

\section{Browsing}

Will generally regrow from root crowns.

\section{Susceptibility to Disease and Insect Damage}

Juniper seedlings are resistant to "damping off" disease and root rot (419). They are susceptible to cedar blight caused by Phomopsis juniperovora and cedar apple rust (198).

\section{RECLAMATION CONSIDERATIONS}

\section{Soil Building and Erosion Control Capability}

Reported to have a slow cover rate (5). The species provides some erosion protection once shrubs are sizeable, but stabilizing ability generally is slight.

\section{Adaptation to Disturbance}

Reportedly does not regenerate vegetatively after being cut or killed by fire (5). Ground juniper is found on disturbed sites throughout the latitudinal range of the eastern slopes of Alberta where a seed source is nearby. However, it is not an aggressive pioneer (365).

\section{Competitive Ability}

Observed to be fairly aggressive on favourable sites.

\section{Commercial Value}

The fruits of some junipers are used for flavouring in the manufacture of gin. Used occasionally as an ornamental.

\section{Palatability and Nutritive Value}

Not generally eaten by wildlife, although fruits may be used to a extent, especially by birds.

\section{Seed or Planting Stock Availability}

Thought to be available in seedling or small shrub form from commercial distributors (e.g. 608). Approximately $35 \mathrm{~kg}$ of seed/100 kg fruit (119).

\section{Methods and Ease of Establishment}

Irregular intervals can be expected between seed crops. Cones mature in 2 to 3 years, and are persistent on the plant. Collect seeds between August and October. Seeds may be stored either as dried fruits or as cleaned seeds (419). Seeds can be cleaned with Dybvig seed cleaner. Seeds can be stored for fairly long periods in sealed containers at $-1^{\circ} \mathrm{C}$ to $4^{\circ} \mathrm{C}(419)$. Unstratified seed may be sown in the fall and mulched in the seedbed until germination during the second spring after planting. Juniper seedlings are reported to be susceptible to frost heaving (419). Warm stratify for 45 to 90 days followed by cold stratification $\left(5^{\circ} \mathrm{C}\right)$ for $90+$ days; seeds may be sown in fall for germination the following spring (119). Propagation from seed has been reported to be difficult ( $P$. King, pers.comm.). Evergreen cuttings should be taken in autumn (119). Common juniper has been recommended for revegetation in southeastern Alaska. The suggested method is seed or seedlings planted at a maximum spacing of $2 \mathrm{~m}$ by $2 \mathrm{~m}$ on dry or well drained sites (5). It is generally planted as 2-1 stock (419).

\section{Current Status for Reclamation}

Ground juniper is found throughout Alberta on coarse textured soil susceptible to drought and is tolerant of acid soils. It is considered unpalatable. Although it is found on disturbed sites it is a slow pioneer. Germination from seed may also be difficult. It may be of some use for reclamation on dry, coarse textured soils where erosion control is not an important consideration. 
Juniperus horizontal is

\section{SPECIES SUITABILITY MAP AND SUMMARY TABLE}

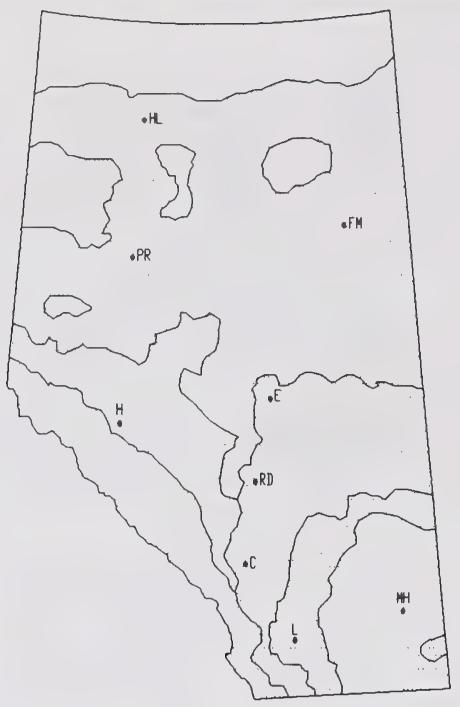

Recommended Area

Commercially Available: Yes $X$ No

\begin{tabular}{|c|c|c|c|c|c|}
\hline \multirow{2}{*}{$\begin{array}{l}\text { RECLAMATION SUITABILITY } \\
\text { CRITERIA }\end{array}$} & \multicolumn{5}{|c|}{ SUITABILITY RATING } \\
\hline & Very High & High & Medium & Low & None \\
\hline Drought Tolerance & $x$ & $x$ & & & \\
\hline Salt Tolerance & & & & $x$ & \\
\hline Acid & & $x$ & & & \\
\hline Tolerance Base & & $x$ & & & \\
\hline Winter Hardiness & & $x$ & & & \\
\hline Erosion Control & & & $x$ & & \\
\hline Persistence & & $x$ & & & \\
\hline Palatability & & $\mathrm{x}$ & $\mathrm{x}$ & & \\
\hline Browse Tolerance & & $X$ & & & \\
\hline Moisture Preference & Dry. & & & & \\
\hline Soil Preference & Silt 1 & am to si & rapidly & erate & drained \\
\hline
\end{tabular}


Juniperus horizontalis Moench

\section{SPECIES BIOLOGY}

Taxonomy - Creeping Juniper

Also Sabina horizontalis (Moench) Rydb.

\section{Origin and Range}

Native. Alaska east across Canada to Great Slave Lake, Hudson Bay, Labrador, Newfoundland, south to New York, Michigan, lowa, and Colorado. At Banff and in the Crows Nest Pass, semi-erect individuals have been described. These may be hybrids between Juniperus scopulorum and $\underline{J}$. horizontalis (690).

\section{Growth Habit}

A normally prostrate shrub. May be up to $1 \mathrm{~m}$ high in some places. Often forms large mats with long horizontal stems, often rooting $(443,312,78)$. Evergreen (443).

Nitrogen Fixing - None

Longevity - Long-lived perennial.

\section{Self Propagation}

By seed and layering.

\section{Ecological Setting}

Very common throughout Alberta on dry banks; sandy and rocky hill sides $(78,312)$. Ascends to about 2000 m ASL in Banff National Park (501).

\section{TOLERANCES}

\section{Soil Preferences}

Found on a wide range of soils, but most often on sands (426). Adapted to drier soils from moderately well drained soils to excessively drained soils. These soils may have severe limitations for plant growth due to very low water holding capacity or steep slopes (5). Soils may also be very thin (5). Creeping juniper is adapted to soils with textures ranging from silt loam to sand (5).

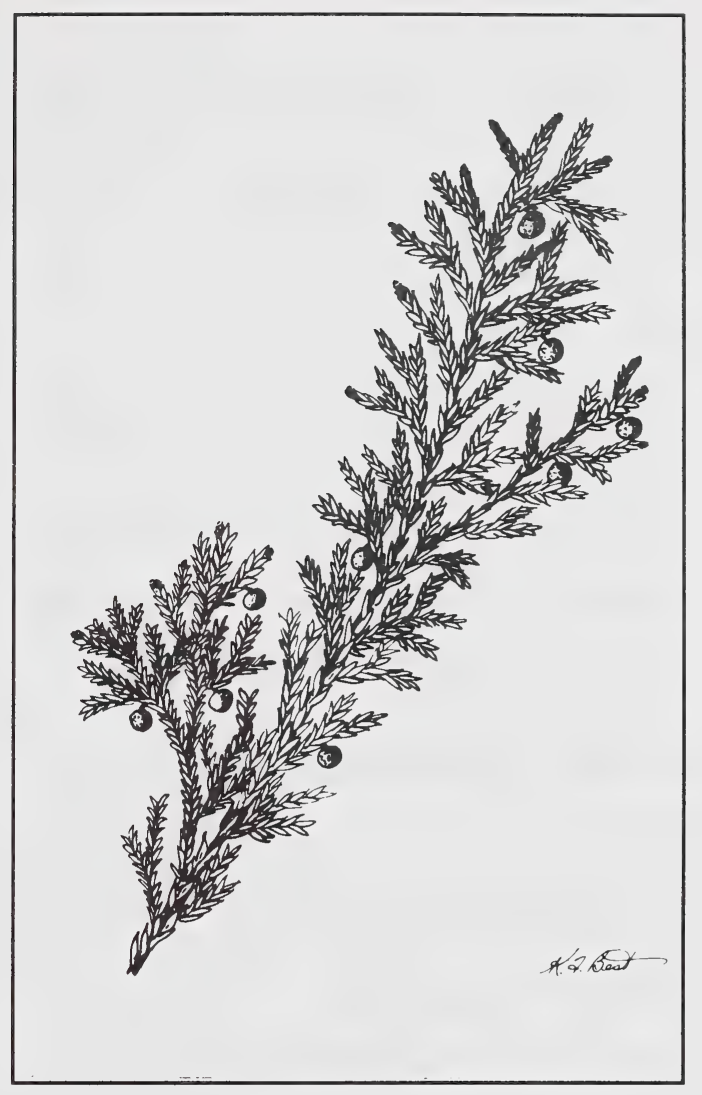

\section{Nutrient Requirements}

Expected to be low due to good growth on poor sites.

\section{Soil Reaction}

Apparently always found on calcareous soil (501), but also reported to have a high tolerance to acidic conditions (5).

\section{Soil Salinity}

No specific tolerances noted in the literature, but suspected to be slightly more tolerant of saline soils than other junipers. 


\section{Drought}

Can withstand drought conditions that are intolerable to grasses (140); very drought tolerant (608).

\section{Heavy Metals and Hydrocarbons}

No indications of specific tolerances.

Shade

Creeping juniper has a low shade tolerance (5).

\section{Browsing}

Tends to maintain its cover on overgrazed ranges.

Susceptibility to Disease and Insect Damage

No specific susceptibilities noted.

\section{RECLAMATION CONSIDERATIONS}

\section{Soil Building and Erosion Control Capability}

Creeping juniper has a moderate cover rate (5), and may assist soil stabilization efforts.

\section{Adaptation to Disturbance}

Tends to slowly invade dry disturbed sites.

\section{Competitive Ability}

Not very aggressive. Tends to be out competed on all but the driest slopes.

\section{Commercial Value}

Soil stabilization (426), ornamental.

\section{Palatability and Nutritive Value}

Moderate to heavy use by mule deer has been reported (245).

\section{Seed or Planting Stock Availability}

Many horticultural cultivars are available as small shrubs $(198,426,443)$.

\section{Methods and Ease of Establishment}

Creeping juniper can be established from seed, seedlings and transplants and possibly layering
$(332,5)$. Seedlings and transplants should be spaced a maximum of $1.5 \mathrm{~m}$ by $1.5 \mathrm{~m}$ (5).

\section{Current Status for Reclamation}

Creeping juniper has been recommended for revegetation in southeastern Alaska (5). It is ideal for planting on steep banks or rocky slopes (140). This species is found on coarse textured soils throughout Alberta. It is highly tolerant of acid soils and apparently of alkaline soil. Creeping juniper has a high tolerance to drought and it has been used for soil stabilization (426). It may prove useful for reclamation and erosion control but further research is needed into methods of establishment. 


\section{SPECIES SUITABILITY MAP AND SUMMARY TABLE}

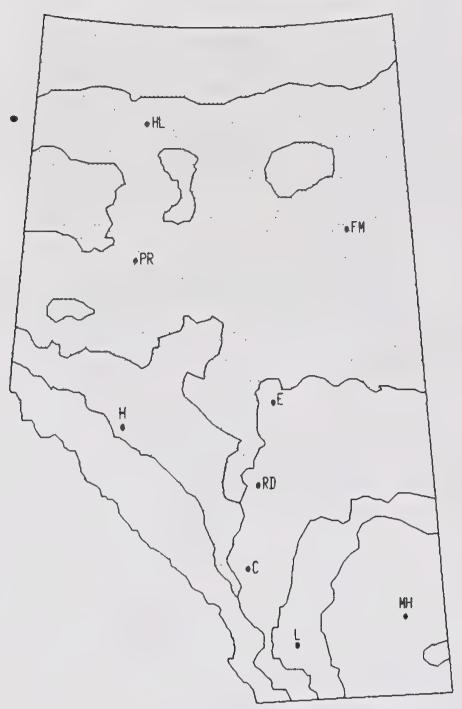

Recommended Area

Commercially Available: Yes No $X$

\begin{tabular}{|c|c|c|c|c|c|}
\hline \multirow{2}{*}{$\begin{array}{l}\text { RECLAMATION SUITABILITY } \\
\text { CRITERIA }\end{array}$} & \multicolumn{5}{|c|}{ SUITABILITY RATING } \\
\hline & Very High & High & Medium & Low & None \\
\hline Drought Tolerance & & & & $x$ & \\
\hline Salt Tolerance & & & & $\mathrm{x}$ & \\
\hline pH Acid & & & .5 .5 & & \\
\hline Tolerance Base & & & & 7.6 & \\
\hline Winter Hardiness & & $x$ & & & \\
\hline Erosion Control & & & $x$ & $x$ & \\
\hline Persistence & & $x$ & & & \\
\hline Palatability & & & & & $x$ \\
\hline Browse Tolerance & & & & & $x$ \\
\hline Moisture Preference & Moist & wet. & & & \\
\hline Soil Preference & Light & ils to & nic (peat & 11 to & draine \\
\hline
\end{tabular}


Larix laricina (Du Roi) K. Koch

\section{SPECIES BIOLOGY}

Taxonomy - Tamarack.

\section{Origin and Range}

Native. Alaska east across Canada along the northern treeline to Hudson Bay, Labrador and Newfoundland. Northeastern British Columbia southeast to New Jersey, Illinois and Minnesota. It also occurs locally to Maryland and West Virginia 9443, 419).

\section{Growth Habit}

Tamarack is a small to medium-sized deciduous tree 9 to $18 \mathrm{~m}$ high, with a straight trunk, 10 to $25 \mathrm{~cm}$ in diameter. In the far north it is often stunted, with a reduced crown $(443,205)$.

Nitrogen Fixing - None

Self Propagation - Tamarack spreads by seed (5).

\section{Ecological Setting}

Tamarack is generally found in cold, wet, poorly drained sites. It is generally restricted to Sphagnum bogs and swamps, or open muskegs. It is associated with black spruce (Picea mariana), alders (Alnus spp.) and willows (Salix spp.). In northern areas it may also be found on better drained sites where it has a growth rate comparable to black spruce. Common native associates: Populus tremuloides (on well drained sites), Betula papyrifera, and Abies balsamea $(443,205,312)$; also occurs with Pinus banksiana (D. Walker, pers.comm.).

\section{TOLERANCES}

\section{Soil Preferences}

Tamarack is adapted to a range of soil moisture conditions from well drained through to poorly drained peat materials. It is also found on a wide range of soil textures (5). It produces the best growth on moist, light well-drained soils $(205,419)$.

\section{Nutrient Requirements}

Expected to have moderate to low nutrient requirements, based upon sites normally occupied.

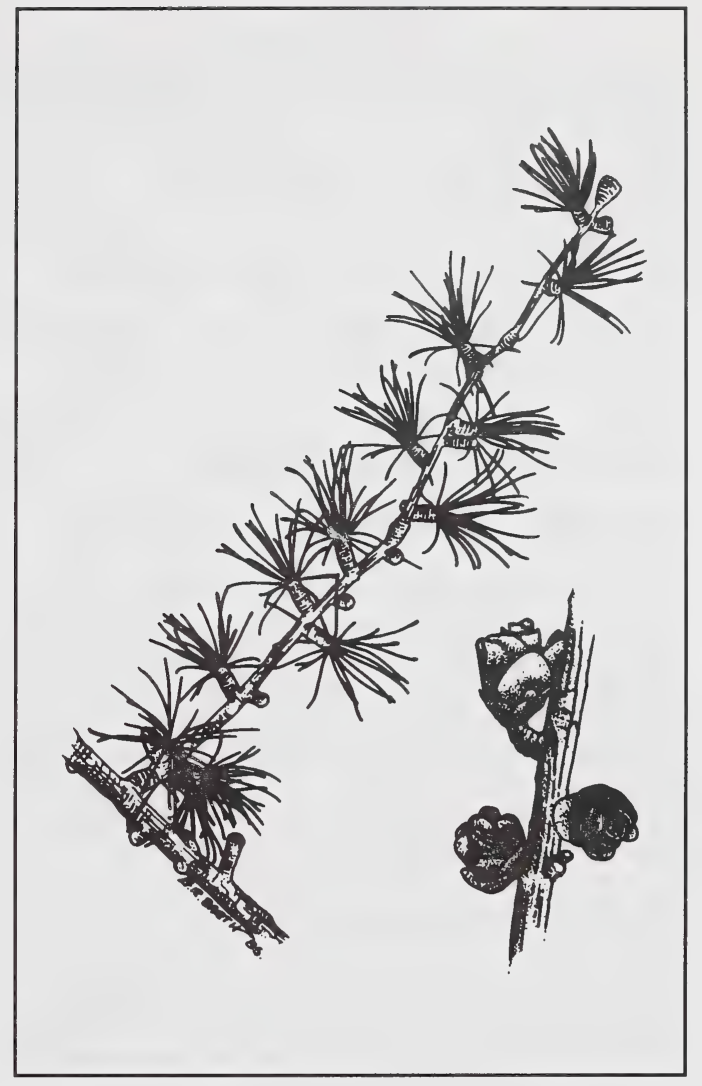

Soil Reaction

Tamarack prefers neutral soils ( $\mathrm{pH} 5.5$ to 7.6) (P. Sims, pers.comm.), but has been reported to have high acid tolerance (5).

\section{Soil Salinity}

Not generally found on saline soils.

\section{Drought}

Generally not tolerant of drought.

\section{Heavy Metals and Hydrocarbons}

Tamarack was killed by a summer oil spill and no tree seedling establishment was observed 3 years after the spill. The effect of a winter spill was less severe. Tamarack was largely defoliated by a summer diesel oil spill but survival was quite high (216). No other susceptibilities or tolerances were noted from the literature reviewed. 


\section{Shade}

Tamarack has very low shade tolerance; it requires well lighted situations and is rarely found in pure stands $(5,205)$.

Browsing - Cutting kills tamarack.

\section{Susceptibility to Disease and Insect Damage}

Tamarack is susceptible to needle cast, needle rust, "Amillaria root rot" and white pocket rot (198).

\section{RECLAMATION CONSIDERATIONS}

\section{Soil Building and Erosion Control Capability}

Tamarack has a relatively slow growth rate and slow cover rate (5). The root system is shallow, but widespreading so it is moderately windfirm (205). Tamarack was found to have a faster growth rate and provided a greater amount of litter than black spruce ( $P$. mariana) when planted on coal mine spoil piles. This factor was considered important since additional organic matter improved the spoil water holding capacity (15).

\section{Adaptation to Disturbance}

Tends to re-establish rapidly on burned bogs and muskeg where nutrient supply is enhanced and also where shade from competing species is temporarily removed ( $T$. Laidlaw, pers.comm.).

\section{Competitive Ability}

Good competitive ability on suitable sites. Grows best on upland sites but not common there, presumably partly because of low (seedling) competitive ability due to very low shade tolerance. It is recommended that tamarack plantings are not mixed with fast growing trees at normal planting densities, for the same reason ( $T$. Laidlaw, pers.comm.).

\section{Commercial Value}

Tamarack produces durable, strong wood. It is used for railway ties, poles, boat building and pulpwood $(443,205)$. Tamarack has been used for reforestation (419).

\section{Palatability and Nutritive Value}

Not generally eaten by wildlife, although seed may be eaten by birds and small mammals. Sharp-tailed grouse have been observed eating tamarack buds.

\section{Seed or Planting Stock Availability}

Potential sources of native seed or stock are not known.

\section{Methods and Ease of Establishment}

Tamarack can readily grow from seed. Cones are brown when ripe and can be collected in the fall as soon as they are ripe. Cones may be opened by heating at $49^{\circ} \mathrm{C}$ for 8 hours. In general, Larix seed may be stored for three or more years in sealed containers at -18 to $10^{\circ} \mathrm{C}$. Seed germination requirements are variable, depending on seed source. Some seed lots may require cold stratification at $5^{\circ} \mathrm{C}$ for 30 to 60 days. Unstratified seed can be sown in the fall, or stratified seed sown in spring. Sow seed $0.6 \mathrm{~cm}$ deep $(419,119)$.

\section{Current Status for Reclamation}

Tamarack exhibited variable success on amended tailings sand at Fort McMurray. Survival varied from 0 to $60 \%$ (A. Fedkenheuer, pers.comm.). Siberian larch has potential on protected subalpine sites in Alberta. Survival after 8 years ranged from 50 to $85 \%$ and growth was the best of all species tested at two high elevation sites in Alberta (708). Tamarack is recommended for revegetation in southern Alaska on well-drained sites (5). Survival of spring-planted tamarack at the end of summer was very low in a trial on an abandoned winter road near Norman Wells, N.W.T. (110). Tamarack is a widely distributed species and ecotypes probably exist. Two year old seedlings from different seed sources in Minnesota had significant differences in height growth, and bud set occurred earliest in those seedlings from northern sources (419). 


\section{SPECIES SUITABILITY MAP AND SUMMARY TABLE}

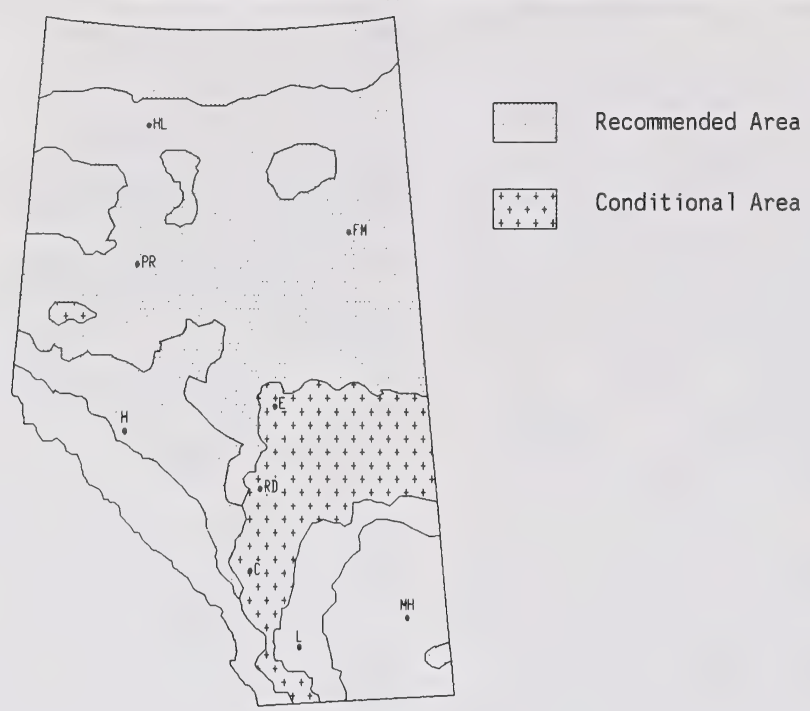

Commercially Available: Yes $\mathrm{X}$ No

\begin{tabular}{|c|c|c|c|c|c|}
\hline \multirow{2}{*}{$\begin{array}{l}\text { RECLAMATION SUITABILITY } \\
\text { CRITERIA }\end{array}$} & \multicolumn{5}{|c|}{ SUITABILITY RATING. } \\
\hline & Very High & High & Medium & Low & None \\
\hline Drought Tolerance & & & $x$ & & \\
\hline Salt Tolerance & & & & & $x$ \\
\hline Acid & & 4.5 & & & \\
\hline Tolerance Base & & & & & \\
\hline Winter Hardiness & & $x$ & & & \\
\hline Erosion Control & & & & $x$ & \\
\hline Persistence & & $x$ & & & \\
\hline Palatability & & $x$ & & & \\
\hline Browse Tolerance & & & & $x$ & \\
\hline Moisture Preference & Moist, & tolerate & looding. & & \\
\hline Soil Preference & Silty, & tolerate & ide rang & textu & \\
\hline
\end{tabular}




\section{Picea glauca (Moench) Voss}

\section{SPECIES BIOLOGY}

Taxonomy - White spruce

Varieties: var. albertiana (S. Brown) Sarg. and var. porsildii (Raup); P. canadensis (Mill.) B.S.P.

\section{Origin and Range}

Native. Alaska east across Canada to Hudson Bay, Labrador, and Newfoundland, south to New York, Minnesota, Montana, and British Columbia. Also locally in South Dakota and western Montana (443, 419). The most common form in Alberta is western white spruce (Picea glauca var. albertiana (S. Brown) Sarg.). Another variety, Porsild spruce (P. glauca var. porsildii), is found occasionally from Banff northwards. This variety is characterized by smooth bark covered with resin blisters. White spruce also intergrades with Engelmann spruce (P. engelmannii) at middle altitudes in the Rocky Mountains (205, 312), and Sitka spruce (P. sitchensis) where ranges overlap, such as north coastal B.C.

\section{Growth Habit}

A medium to large sized tree 12 to $21 \mathrm{~m}$ high and 15 to $46 \mathrm{~cm}$ in trunk diameter. It may grow up to $40 \mathrm{~m}$ high in favourable sites with diameters of up to $120 \mathrm{~cm}(443,205,690)$. At the timberline it becomes a prostrate shrub (krummholz) (443). Slow growing (659).

\section{Nitrogen Fixing}

None. White spruce is ectomycorrhizal (622).

Longevity - Long-lived perennial.

Self Propagation - Seed (5).

\section{Ecological Setting}

White spruce is a widespread tree characteristic of the boreal forest region. It is found in a variety of habitats, but most commonly on well drained moist sites to the subalpine. It is rarely found in pure stands but is found in a mixture with other species. Common native associates (mixed-wood): Populus tremuloides, Abies balsamea, Betula papyrifera (205).

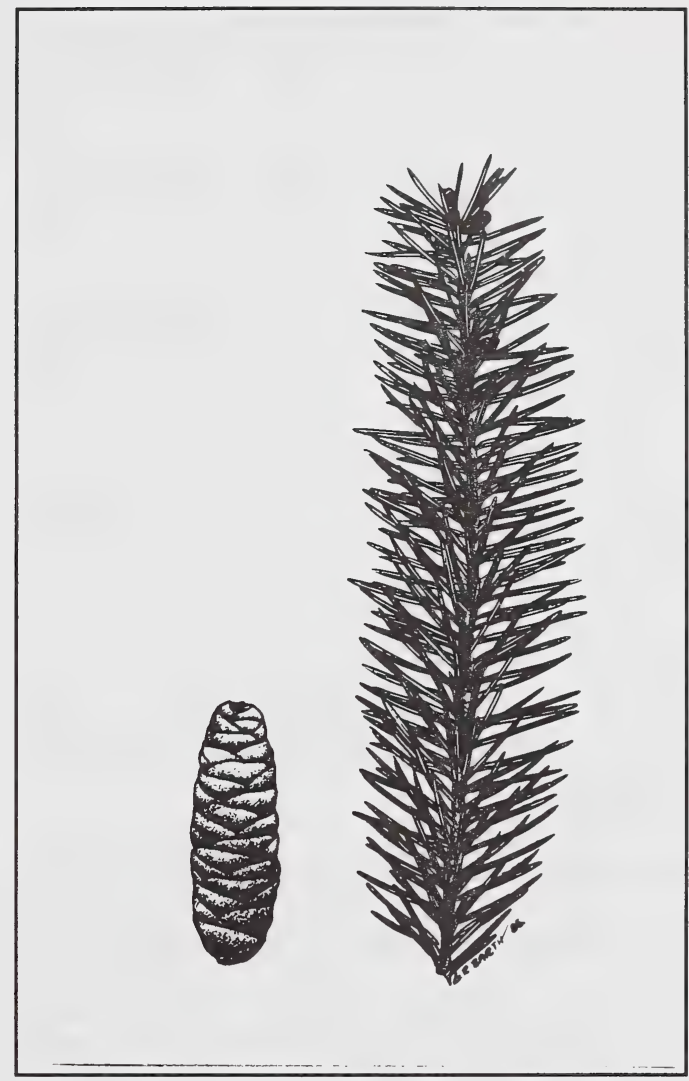

\section{TOLERANCES}

\section{Soil Preferences}

White spruce is adapted to well drained, somewhat dry soils through to soils that are poorly drained (5). It has best growth on well drained silty soils that have adequate available moisture (205). It occurs on a wide range of soil textures. White spruce can withstand flooding during the growing season (5).

\section{Nutrient Requirements}

Moderate (low to medium) (688) to "exacting" (659).

\section{Soil Reaction}

White spruce has high acid tolerance (5). The lower $\mathrm{pH}$ limit for white spruce has been reported to be 4.5 to 5.0 (346). However, seedlings grown in peat with $\mathrm{pH}$ adjusted (lime additives) from 3.9 upward 
to 5.0 had half the total weight and root weight of seedlings grown in peat of $\mathrm{pH} 3.9$ (295).

\section{Soil Salinity}

White spruce is intolerant of saline conditions (229).

\section{Drought}

White spruce has proved to be moderately drought tolerant when planted on tailings sand in northern Alberta (A. Fedkenheuer, pers.comm.).

\section{Heavy Metals and Hydrocarbons}

White spruce has a moderate tolerance to oil (282). No other tolerances were noted from the literature reviewed.

\section{Shade}

White spruce has high shade tolerance, and can tolerate completely shaded conditions $(5,205,346)$.

\section{Browsing}

Will regrow after minor amounts of pruning.

\section{Susceptibility to Disease and Insect Damage}

White spruce showed an adverse response after being planted on sites three days after glyphosphate spray application. There was no visible response when spruce was planted six days after the spray application (to control competing grasses) (99). White spruce is susceptible to needle rust, bad rust, snow blight, "Amillaria root rot" and brown cubicle rot (198). It is also susceptible to spruce sawfly and spruce gall aphid (P. King, pers. comm.).

\section{RECLAMATION CONSIDERATIONS}

\section{Soil Building and Erosion Control Capability}

White spruce has a shallow root system with many wide spreading lateral roots. It is only moderately resistant to windthrow (205). It has relatively slow initial height growth and slow cover rate (5).

\section{Adaptation to Disturbance}

Although primarily a climax species of the boreal forest region, it is commonly found on disturbed sites, especially where mineral soil has been exposed and there is a seed source nearby (365).

\section{Competitive Ability}

White spruce was found to compete successfully with perennial grasses and forbs after fertilization (99).

\section{Commercial Value}

White spruce is an important source of lumber and pulpwood in Canada (205).

\section{Palatability and Nutritive Value}

White spruce can be used on reclaimed sites to provide shelter for elk and mule deer (439). White spruce seed is a preferred red squirrel food. May be severely browsed by snowshoe hare.

\section{Seed or Planting Stock Availability}

Native seed and seedling stock is available commercially.

\section{Methods and Ease of Establishment}

Cones should be air dried for several weeks or in a kiln at temperatures of 38 to $49^{\circ} \mathrm{C}$. White spruce seeds are damaged at higher temperatures. Seeds can be stored for long periods (75 years) at 1 to $3^{\circ} \mathrm{C}$ at moisture contents of 4 to $8 \%$. White spruce seeds of some provenances can be germinated satisfactorily without any stratification. Seeds are fall sown at a depth of $0.6 \mathrm{~cm}$. Most often stratified seed is sown in containers or spring sown in the field. Seedlings are usually outplanted as $2-0$ stock (419).

\section{Current Status for Reclamation}

White spruce is regarded by the Alberta Forest Service as the best reclamation conifer species on coal overburden in the eastern slopes (377). It is well adapted to the foothills to the lower subalpine with good potential for protected sites in the subalpine (707). Eighth year survival at Tent Mountain (2 $100 \mathrm{~m}$ ) was $76 \%$. Susceptible to stem dieback on windy, high elevations sites (707). In the Crowsnest Pass area, bare root stock had higher survival than containerized stock (377). Other tests at Tent Mountain showed very good survival ( $P$. King, pers.comm.). White spruce is well adapted to reclamation of amended tailings sand near Fort McMurray $(645,706)$. Performance in several tests after 4 to 7 years on amended tailings and overburden indicated moderately good to excellent survival, good growth, no dieback and a positive response to heavy ground cover 
(J. Sherstabetoff, pers.comm., 641, 706). Survival and growth of white spruce at Elliot Lake, Ontario was found to be greater on vegetated coarse uranium tailings than on bare coarse tailings. The initial $\mathrm{pH}$ of the coarse tailings was 1.9 but this increased to between 3.5 to 4.0 as a result of leaching (317). 
Pinus banksiana

SPECIES SUITABILITY MAP AND SUMMARY TABLE

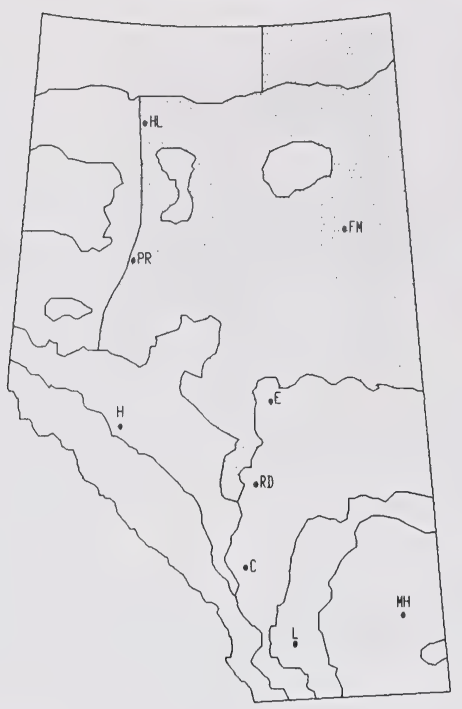

Recommended Area

Commercially Available: Yes $\mathrm{X}$ No

\begin{tabular}{|c|c|c|c|c|c|}
\hline \multirow{2}{*}{$\begin{array}{c}\text { RECLAMATION SUITABILITY } \\
\text { CRITERIA }\end{array}$} & \multicolumn{5}{|c|}{ SUITABILITY RATING } \\
\hline & Very High & High & Medium & Low & None \\
\hline Drought Tolerance & & & $x$ & & \\
\hline Salt Tolerance & & & & & $\mathrm{x}$ \\
\hline Acid. & 3.5 & & & & \\
\hline Tolerance Base & & & $x$ & & \\
\hline Winter Hardiness & & $x$ & & & \\
\hline Erosion Control & & & $x$ & & \\
\hline Persistence & & $x$ & & & \\
\hline Palatability & & & $x$ & & \\
\hline Browse Tolerance & & & $x$ & & \\
\hline Moisture Preference & Dry tc & loist. & & & \\
\hline Soil Preference & Clay & m, sand & d gravel & dra & \\
\hline
\end{tabular}


Pinus banksiana Lamb.

\section{SPECIES BIOLOGY}

Taxonomy - Jack Pine.

\section{Origin and Range}

Native. Jack pine is the most widely distributed pine species in Canada (615). It ranges from northeastern British Columbia and the Mackenzie River Valley in the Northwest Territories, southeasterly into the Great Lakes region and the New England States, running east into Nova Scotia and New Brunswick. In central and northern Alberta, hybridization occurs between jack pine and lodgepole pine (Pinus contorta Dougl.) where their ranges overlap.

\section{Growth Habit}

Jack pine has a conical, open crown and a slender, straight trunk with little or no taper. Heights range from 5 to $10 \mathrm{~m}$ on open or poor sites to $20 \mathrm{~m}$ on good sites. The root system is wide-spreading, moderately deep and without a tap root, except on deep porous soils (660). Medium growth rate (659).

\section{Nitrogen Fixing}

None. Jack pine is ectomycorrhizal (622).

Longevity - Long-lived perennial.

\section{Self Propagation}

Jack pine has been rated as good for natural reproduction by reseeding on mineral soil prepared mechanically (scarification and slash redistribution) or by fire.

\section{Ecological Setting}

Characteristically jack pine is a tree of the boreal forest region (660). Most jack pine stands occur in areas characterized by warm to cool summers, very cold winters, low annual rainfall and level to rolling topography $(615,637)$. It grows in extensive, even aged pure stands or in a mixture with other species such as black spruce, white spruce, balsam fir, trembling aspen, balsam poplar and white birch. Jack pine usually occurs in a pioneer stage of succession; it will invade where mineral soils have been bared and as a result many stands establish after fire. However, on very dry, sandy sites in the southwestern portion of its range it may regenerate itself in the absence of fire (615).

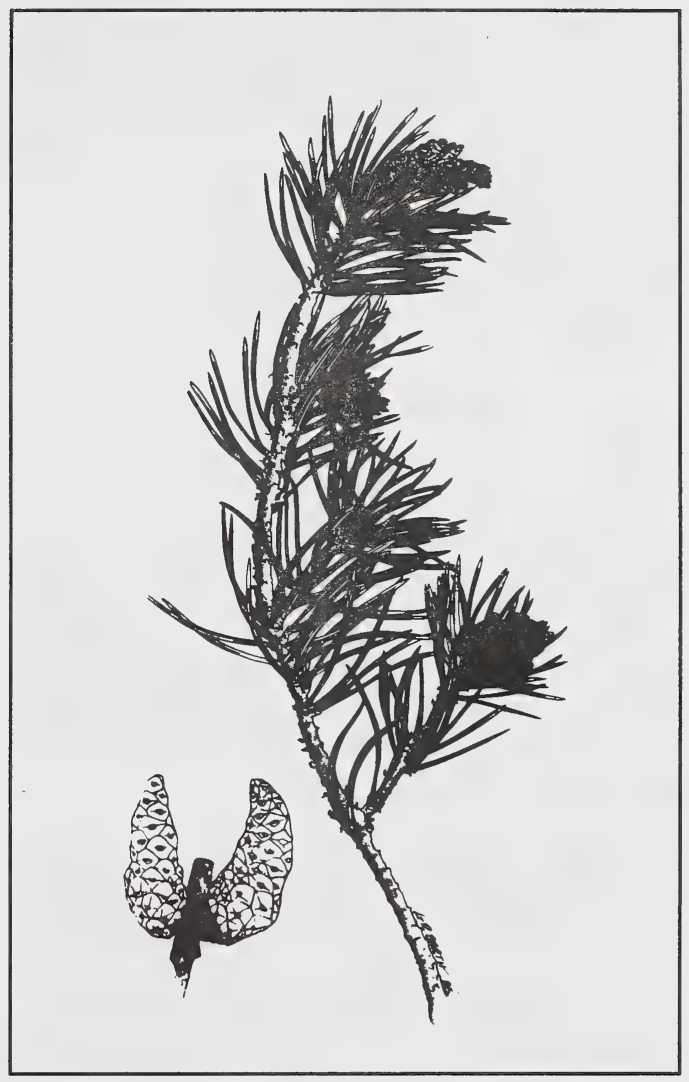

\section{TOLERANCES}

\section{Soil Preferences}

Jack pine is found on a wide range of soil textures ranging from gravelly or sandy through to clay loams. It also occurs on relatively thin rock outcrop soils $(615,637)$. The soil moisture conditions vary from dry to moist and only infrequently does it occupy soils that are poorly drained. Its best growth occurs on moist upland, well drained sandy soils. Jack pine is adversely affected by the formation or presence of iron pans (615).

\section{Nutrient Requirements}

Jack pine survives on nutrient poor sites and has low nutrient requirements (610).

\section{Soil Reaction}

Generally jack pine makes reasonably good growth on soils with a pH of 4.5 to 6.5 (637), but a recent study has reported that jack pine has a high acid 
tolerance and success on very acid soil (pH 3.5). Jack pine does not grow naturally where the surface soil is alkaline, however it will grow satisfactorily on calcareous soils ( $\mathrm{pH} 8.2$ ) if normal mycorrhizal association is present (637).

\section{Soil Salinity}

None reported in the literature reviewed.

\section{Drought}

Jack pine is adapted to xeric sites $(610,637)$.

\section{Shade}

Jack pine is intolerant of shade (615). However, seedlings can exist in light as low as $2.4 \%$ of full sunlight (637), but more light is required for establishment. Under stands, jack pine seedlings are most frequent and abundant in light intensities of 11 to $30 \%$ of full sunlight, but height growth is greatest in light intensities of $52 \%$ or more (653).

\section{Browsing}

Jack pine will sustain light to moderate browsing. Reduced growth, serious injury or death can result from moderate to heavy browsing pressure (637).

\section{Susceptibility to Disease and Insect Damage}

Susceptible to jack pine budworm (Choristoneura pinus), several sawflies (Empetria spp.), pine tussock moth (Dasychiia plagiata), northern pitch twig moth (Petrova albicapitana), white pine weevil (Pissodes strobi) and several caterpillars (Halisedota spp.) (637). Jack pine is also susceptible to a variety of rusts (198) such as spindle rust gall (Cronartium comandrae), globose rust gall (C. harkensii) and several needle rusts (Coleosporium spp.) (637). Dwarf mistletoe or witches broom (Areuthosium americanum) reduces vigour and is associated with considerable mortality (637).

\section{RECLAMATION CONSIDERATIONS}

\section{Soil Building and Erosion Control Capability}

Jack pine is fast growing with a shallow, wide spreading rooting system and is good for promoting soil stability.

\section{Adaptation to Disturbance}

Jack pine seedlings become quickly established on disturbed areas in its natural range.

\section{Competitive Ability}

Competition from other vegetation may adversely affect growth of seedlings, but once established jack pine seedlings and saplings can out-compete other vegetation.

\section{Commercial Value}

Jack pine is used for pulp and in general construction. Other uses include railroad ties, poles, pilings and mine timbers (660).

\section{Palatability and Nutritive Value}

Seedlings in particular may sustain heavy browsing pressure by snowshoe hare, porcupine and field mice. White-tailed deer, elk and moose will also browse jack pine during the winter months.

\section{Seed or Planting Stock Availability}

Native seeds and nursery stock are readily available. Seed yield averages $1 \mathrm{~kg}$ of seed per $100 \mathrm{~kg}$ of cones. There are approximately 288200 clean seeds per $\mathrm{kg}$ on average.

\section{Methods and Ease of Establishment}

Jack pine may be established directly from seed or from transplants (bare root or container). Cones should be dried immediately after collection to avoid mold development and excessive internal heating. The cones are serotinous and need at least $50^{\circ} \mathrm{C}$ to open. They should be dried in a kiln for 5 to 6 hours at $77^{\circ} \mathrm{C}$. Seeds can be stored for 10 years at $-18^{\circ} \mathrm{C}$ at a moisture content of 5 to $10 \%$. Jack pine seed may display embryo dormancy and can be cold stratified at $5^{\circ} \mathrm{C}$ for 0 to 7 days. The seeds can be sown in the spring or the fall to a depth of $0.6 \mathrm{~cm}$. Seedlings can be out planted as $1-0$ or 1.5 0 stock for easy to average sites, $1-1$ or 2-1 stock for difficult sites (615). Recommended plant spacing is $1.5 \mathrm{~m}$ by $1.8 \mathrm{~m}$. In one study overwintered seedlings contained in Japanese paper pots out-performed bare root seedlings in terms of survival and growth. Good seedling establishment during the first and second years following scarification (733). Areas should be scarified the 
same year and slash left over the area to ensure large amount of seed available. May and June are the two most favourable months for germination and seedling establishment (733).

\section{Current Status for Reclamation}

Jack pine is fast-growing, adapted to xeric, nutrient poor sites found commonly on coarse to medium textured well-drained soils. It has done well in tests on amended oil sands and has been recommended for reclamation of lands disturbed in oil sand mining $(610,645)$. After seven years testing on amended tailings sands near Fort McMurray, jack pine had the highest survival, vigour and growth (706). At another site jack pine survival levelled off at $70 \%$ at four years. Competition from ground cover appeared to reduce survival (641).

Jack pine survival rates on gravel pits after 15 years was $78 \%$ in Appalachia. Jack pine has performed quite well on mine spoil in a variety of conditions, however a drastic growth reduction was noted at 15 years. Survival rates on strip-mined soils after 2 years were: sand $59 \%$, sandy loam $84 \%$, stony clay $94 \%$. 


\section{SPECIES SUITABILITY MAP AND SUMMARY TABLE}

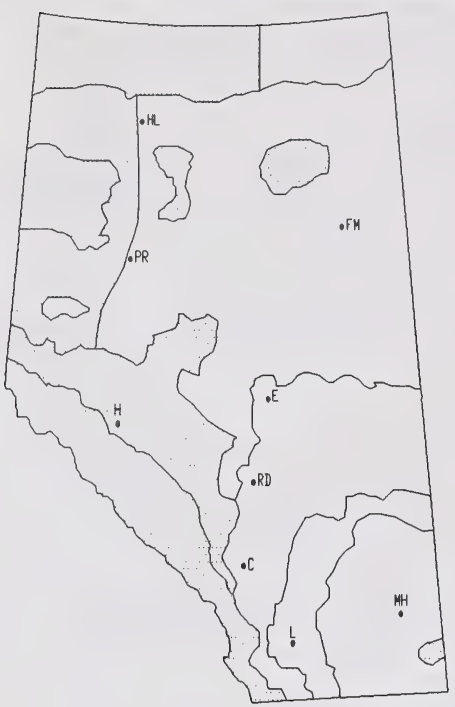

Recommended Area

Commercially Available: Yes $\mathrm{X}$ No

\begin{tabular}{|c|c|c|c|c|c|}
\hline \multirow{2}{*}{$\begin{array}{l}\text { RECLAMATION SUITABILITY } \\
\text { CRITERIA }\end{array}$} & \multicolumn{5}{|c|}{ SUITABILITY, RATING. } \\
\hline & Very High & High & Medium & Low & None \\
\hline Drought Tolerance & & $x$ & & & \\
\hline Salt Tolerance & & & & $x$ & \\
\hline pH Acid & & $x$ & & & \\
\hline Tolerance Base & & & $x$ & & \\
\hline Winter Hardiness & & $x$ & & & \\
\hline Erosion Control & & $x$ & $x$ & & \\
\hline Persistence & & $\mathrm{X}$ & & & \\
\hline Palatability & & & $x$ & $x$ & \\
\hline Browse Tolerance & & & $x$ & & \\
\hline Moisture Preference & Dry to & oist. & & & \\
\hline Soil Preference & $\begin{array}{l}\text { We11 } \\
\text { textur }\end{array}$ & $\begin{array}{l}\text { ined } \\
\text { (grave }\end{array}$ & $\begin{array}{l}\text { soilitity } \\
\text { to silty }\end{array}$ & $\begin{array}{l}\text { tes } \\
\text { loam }\end{array}$ & $\begin{array}{l}\text { e of } \\
\text { inage. }\end{array}$ \\
\hline
\end{tabular}


Pinus contorta Loudon

\section{SPECIES BIOLOGY}

Taxonomy - Lodgepole Pine

Variety: var. latifolia Engelm.

\section{Origin and Range}

Native. Lodgepole pine ranges from Alaska east to the southwestern Mackenzie region and south through western Alberta and British Columbia; also in the Rocky Mountains to Colorado and Utah (443).

\section{Growth Habit}

Lodgepole pine is the larger form, and has a narrow crown. It is usually between 15 and $33 \mathrm{~m}$ in height, and 20 to $60 \mathrm{~cm}$ in diameter $(443,205)$.

\section{Nitrogen Fixing}

None. Lodgepole pine is ectomycorrhizal (622).

Longevity - Long-lived perennial.

\section{Self Propagation}

Lodgepole pine has been rated as good for natural reproduction by reseeding $(5,358)$.

\section{Ecological Setting}

In Alberta, lodgepole pine is the most common tree species on the eastern slopes of the Rocky Mountains. It ranges from the lower foothills and montane zones into the upper subalpine. It also extends eastward to about Lesser Slave Lake in central Alberta. Lodgepole pine intergrades with jack pine (Pinus banksiana) where their ranges overlap in central and northern Alberta. It commonly forms pure stands after fire. It is found on a wide variety of sites from dry outwash gravels and sands to swampy areas $(443,205,312)$.

\section{TOLERANCES}

\section{Soil Preferences}

Lodgepole pine is found on a wide range of soil textures from very gravelly sands to silty clay loam (5). It is also found in a range of soil moisture

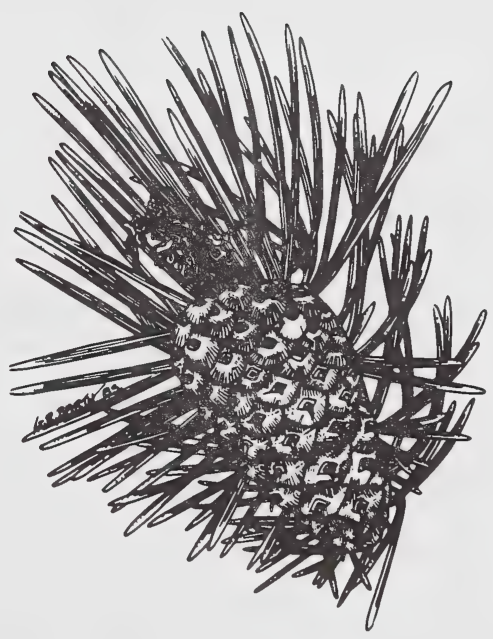

conditions from well drained soils with low water holding capacity to poorly drained soils (5). It achieves its best growth on well drained loamy soils (205).

\section{Nutrient Requirements}

Lodgepole pine invades very infertile sites. Plantings made on coarse, infertile soils in Colorado were reported to be successful (44).

Soil Reaction - High acid tolerance (5).

Soil Salinity - Generally not tolerant of saline soils.

\section{Drought}

One of the most drought tolerant of our native conifers. It is often successful on dry, or otherwise severe, sites due to its ability to survive where its less tolerant competitor trees succumb. 


\section{Heavy Metals and Hydrocarbons}

Moderately tolerant of oil spills. Other tolerances are not known.

\section{Shade}

Lodgepole pine is intolerant of shade and does not appear to reach light saturation even at light intensities of 12000 foot candles (356).

\section{Browsing}

Will regrow following moderate hedging.

\section{Susceptibility to Disease and Insect Damage}

Susceptible to pine bark beetle, in even aged mature stands, and lodgepole pine sawfly (Ips pini). Susceptible to a variety of rusts and dwarf mistletoe (P. King, pers.comm.). Generally few pests.

\section{RECLAMATION CONSIDERATIONS}

\section{Soil Building and Erosion Control Capability}

Lodgepole pine has a moderate height growth rate and a slow cover rate $(5,338)$. It has been rated as very good for promoting soil stability (338). The long slender form of this species makes it susceptible to wind throw.

\section{Adaptation to Disturbance}

Lodgepole pine seedlings become quickly established on disturbed areas within its natural range $(302,338,365)$.

\section{Competitive Ability}

Lodgepole pine had improved growth on plots scalped or sprayed for surface weed control compared to control plots (99). Results at Fort McMurray and Grande Cache, Alberta indicate that lodgepole pine can compete with grass if minimum moisture requirements are satisfied $(269,641)$.

\section{Commercial Value}

The wood of lodgepole pine is used for construction lumber and pulp. It is also used for railway ties, poles, mine timbers and locally for fuel $(443,205)$.

\section{Palatability and Nutritive Value}

Lodgepole pine has been reported to be lightly consumed relative to other plants during winter, summer and fall and moderately consumed in spring by mule deer (245). Important wildlife food for squirrels, chipmunks, grosbeak and Clark nutcracker (608). It is commonly known to support some forest furbearers; seedlings, in particular, may sustain heavy browsing pressure by snowshoe hare.

\section{Seed or Planting Stock Availability}

Native seed is available (349) and nursery stock is common. Approximately 202000 seeds $/ \mathrm{kg}$ (639). Seed yield averages 0.8 to $1.0 \mathrm{~kg}$ of seed per $100 \mathrm{~kg}$ of cones.

\section{Methods and Ease of Establishment}

Lodgepole pine may be established directly from seed or from transplants $(5,283,427,451)$. Cones should be dried immediately after collection to prevent mold and excessive internal heating. The cones are serotinous and can be opened by immersion in boiling water for 30 to 60 seconds and then air drying for 2 to 30 days (this technique may be effective for small lots, but is not used operationally by nurseries). Seed can be stored at 5 to $10 \%$ moisture content at -18 to $-15^{\circ} \mathrm{C}$ for long periods. Lodgepole pine seed displays embryo dormancy and can be cold stratified at $5^{\circ} \mathrm{C}$ for 30 to 50 days. Seeds can be sown in the fall, or spring sown after stratification. Sow seeds $0.3 \mathrm{~cm}$ below the soil surface. Seedlings can be outplanted as 2-0 stock $(119,419)$. Maximum plant spacing has been recommended as $3 \mathrm{~m}$ by $3 \mathrm{~m}$ (5). Lodgepole pine had a better survival rate in Hillson $\left(164 \mathrm{~cm}^{3}\right)$ and Tinus $\left(492 \mathrm{~cm}^{3}\right)$ containers compared to the smaller Ferdinands $\left(40 \mathrm{~cm}^{3}\right)$ and Fives $\left(80 \mathrm{~cm}^{3}\right)$. Some damage to seedlings has been noted where the tops were exposed during a low snowfall year (271).

\section{Current Status for Reclamation}

Lodgepole pine has potential for reclamation in the oil sands region near Fort McMurray (645). Survival on amended tailings sand ranged from 50 to $70 \%$ after 3 to 4 years and from 70 to $80 \%$ on clay to clayloam overburden (A. Fedkenheuer, pers.comm., 641). Growth averaged $12 \mathrm{~cm} /$ year over the first four years on amended tailings (641). Elsewhere in Alberta, lodgepole pine is a widely used forestry species, and undergoes systematic collection, propagation and planting by the Alberta Forest Service. It is also commonly used for reclamation of all types of disturbances throughout the Rocky Mountain east slopes where its range extends into the lower subalpine (707). Growth rate and survival after ten years was at least twice as great when lodgepole pine was planted on 30 or $70 \mathrm{~cm}$ of 
topsoil versus planting directly on overburden on the Judy Creek test mine in northwestern Alberta (642).

Lodgepole pine planted in tar paper plots had excellent survival (greater than $80 \%$ ) in the subalpine in Colorado $(451,16)$. Lodgepole pine has been recommended for planting on disturbed sites in the subalpine in northwestern Colorado. The soils in this area are shallow, often rocky and low in fertility (427). On high altitude sites or severely eroded sites in New Zealand, lodgepole pine showed fair to good growth. On exposed high altitude sites, the upright growing lodgepole pine was prone to bark abrasion from windborne ice and stones. Limited seeding of lodgepole pine was only successful where soil conditions were already fair to good (203). Lodgepole pine is also used in reclamation in the United Kingdom (331). 
Populus balsamifera

\section{SPECIES SUITABILITY MAP AND SUMMARY TABLE}

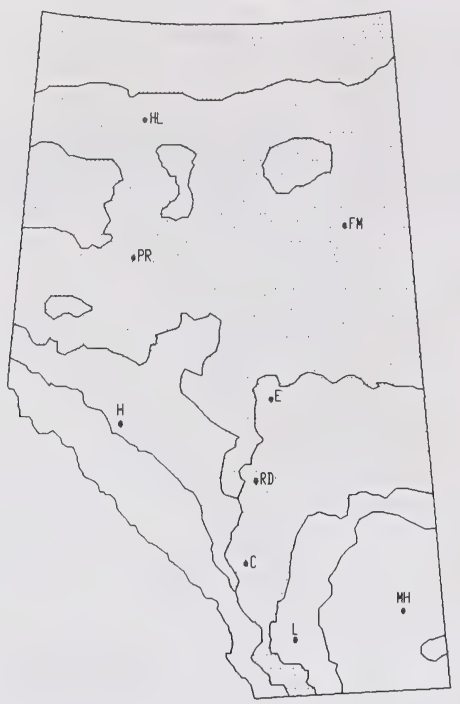

Recommended Area

Commercially Available: Yes $\mathrm{X}$ No

\begin{tabular}{|c|c|c|c|c|c|}
\hline \multirow{2}{*}{$\begin{array}{l}\text { RECLAMATION SUITABILITY } \\
\text { CRITERIA }\end{array}$} & \multicolumn{5}{|c|}{ SUITABILITY RATING } \\
\hline & Very High & High & Medium & Low & None \\
\hline Drought Tolerance & & & & $x$ & \\
\hline Salt Tolerance & & & $x$ & & \\
\hline Acid. & & & & $x$ & \\
\hline Tolerance Base & & & $x$ & & \\
\hline Winter Hardiness & & $x$ & & & \\
\hline Erosion Control & & & $x$ & & \\
\hline Persistence & & $x$ & & & \\
\hline Palatability & & $\mathrm{X}$ & $x$ & & \\
\hline Browse Tolerance & & $x$ & & & \\
\hline Moisture Preference & Moist & wet, & rates $\mathrm{fl}$ & & \\
\hline Soil Preference & Wide $r$ & ge fro & $1 t$, sand & avel. & \\
\hline
\end{tabular}


Populus balsamifera L.

\section{SPECIES BIOLOGY}

Taxonomy - Balsam Poplar

Subspecies: ssp. balsamifera and ssp. trichocarpa (T. and G. ex Hook.)

\section{Origin and Range}

Native. Alaska east across Canada to Labrador and Newfoundland, south in the eastern United States to West Virginia, Indiana and lowa and in the western mountains south to Colorado $(443,419)$. It hybridizes with black poplar ( $\boldsymbol{P}$. trichocarpa Torr and Gray) where their ranges overlap $(443,690)$.

\section{Growth Habit}

Balsam poplar is a medium-sized deciduous tree usually 9 to $25 \mathrm{~cm}$ in height and 30 to $70 \mathrm{~cm}$ in diameter. It may occasionally reach heights of over $30 \mathrm{~m}$ and diameters greater than $140 \mathrm{~cm}(443,205)$.

\section{Nitrogen Fixing - None}

Longevity - Long-lived perennial.

\section{Self Propagation}

Balsam poplar reproduces from seed. If the tree is cut or destroyed by fire, it will resprout from the stringers or roots. Branch segments also have the ability to take root (5).

\section{Ecological Setting}

Balsam poplar is common along river banks, river valleys, terraces, and gravelly flood plains. In Alberta, it is common throughout the forested region especially in openings and clearings on moist upland sites. It is found on wet sites throughout the prairies. In Alberta, its range extends into the subalpine. Common native associates (river bottom land): Alnus tenuifolia, Cornus stolonifera, Viburnum edule, Rosa acicularis and Rubus strigosus. On upland sites, balsam poplar is successional with the climax being white spruce or balsam fir $(443,205,78,399)$.

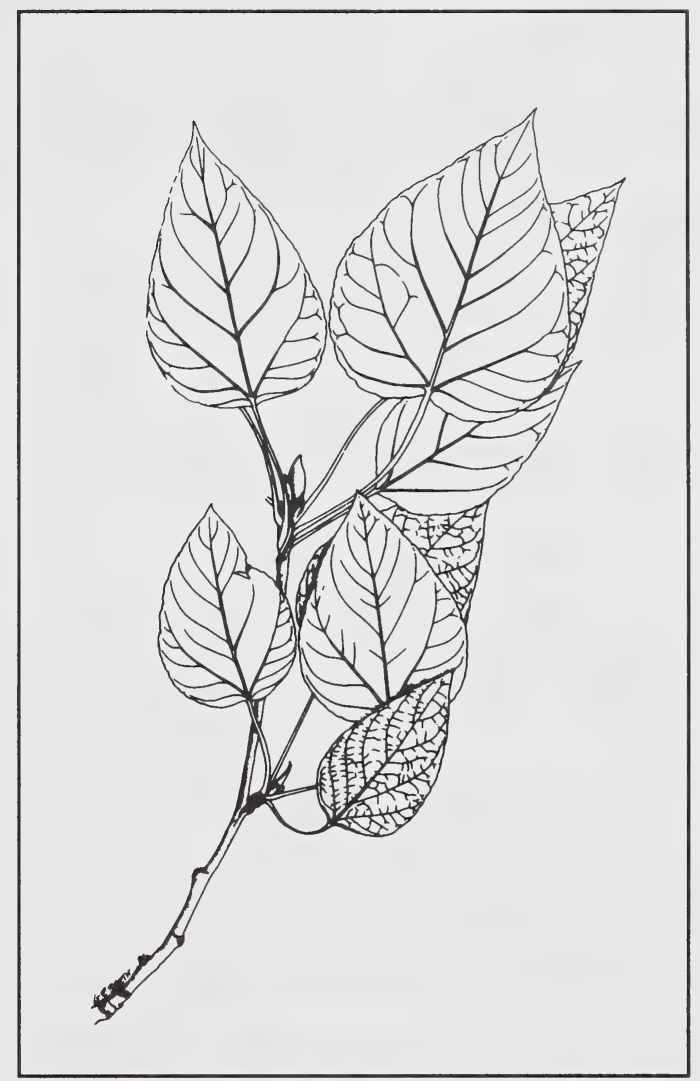

\section{TOLERANCES}

Soil Preferences

Balsam poplar is adapted to a range of soil moisture regimes from well drained through to poorly drained soils that may be waterlogged for short periods. It is also adapted to a range of soil textures (5). It does best on moist, low-lying ground (205).

\section{Nutrient Requirements}

Requires moderate amounts of nutrients; low to high (688). These are usually available on the moist, low sites it favours. 


\section{Soil Reaction}

Balsam poplar has a low acid tolerance (5). "Cottonwood" has been designated as suitable for planting on alkaline or saline soils (421).

\section{Soil Salinity}

Balsam poplar has poor growth and survival on saline spoil materials near Edmonton, Alberta (304).

\section{Drought}

Balsam poplar does best on sites where moisture stress is minimal.

\section{Heavy Metals and Hydrocarbons}

Balsam poplar was killed by a diesel spill near Whitehorse, N.W.T. (216). No other chemical sensitivities were noted from the literature.

\section{Shade}

Shade tolerance is rated from low (5) to medium (P. Sims, pers.comm.).

Browsing - Resprouts readily after cutting.

\section{Susceptibility to Disease and Insect Damage}

Balsam poplar is susceptible to leaf spot, leaf blight, leaf rust, powdery mildew, sooty bark canker, "Amillaria root rot", white spongy rot and brown mottled root rot (198). It is also susceptible to Cytospora canker which can cause serious damage to cuttings in nurseries and can kill shelterbelt trees in 2 to 3 years. Insects potentially damaging to balsam poplar include forest tent caterpillar, western tent caterpillar, poplar and willow borers, and oyster shell scales.

\section{RECLAMATION CONSIDERATIONS}

\section{Soil Building and Erosion Control Capability}

Balsam poplar has a relatively rapid height growth rate and a medium cover rate (5). It has a shallow root system (205), and a taproot in some situations (466).

\section{Adaptation to Disturbance}

Balsam poplar has been noted as a volunteer on mine overburden in British Columbia (316). It has also been noted as a pioneer on mine spoils in Alberta (357). It is apparently an aggressive pioneer on moist disturbances throughout the eastern slopes of the Rocky Mountains (365). Typical early colonizer of sand and gravel pits in Ontario (688).

\section{Competitive Ability}

Very aggressive in adapted areas. Cottonwood cuttings planted on a disturbed mine area in southeastern B.C. had good survival and growth even though the area had a good grass cover (P. King, pers.comm.).

\section{Commercial Value}

The wood is light, soft and not very strong. It is used for plywood, pulpwood and crates. A small amount is used for lumber. Balsam poplar is commonly used as a windbreak on the prairies (443, 205). It is also useful for providing cover and forage for game (180), especially in early successional phases (688).

\section{Palatability and Nutritive Value}

Extensively used by beaver. May occasionally be used by other wildlife. Susceptible to rodent damage (385). Young trees and new growth are often taken by browsers.

\section{Seed or Planting Stock Availability}

Seed is not commercially available; onsite collections of locally adapted ecotypes is the preferred method of acquiring seed.

\section{Methods and Ease of Establishment}

Balsam poplar produces abundant seed almost every year. Small catkin-bearing branches can be picked when a few of the catkins are beginning to open. These can be laid out to dry to allow the remaining catkins to open. Seed can be cleaned by tumbling the seed with cotton in an air stream in covered standard soil screens. The seed is tumbled in the uppermost screen (16 mesh) and is collected on the lower screens (32- and 150-mesh). Seed can be stored for relatively long periods at a moisture content of about $6 \%$, and at temperatures below $0^{\circ} \mathrm{C}$. Seeds require moist conditions for favourable development. They should not be covered or pressed into the soil. Seedling root development is initially very slow so care must be taken not to wash the seedlings out of the soil when watering the plants (419). Other methods of establishment are seedling transplants, root cuttings and stem cuttings. The recommended method is hardwood stem cuttings planted at a maximum spacing of $1.5 \mathrm{~m} \times 1.5 \mathrm{~m}(180,5)$. In a trial in northern Alberta, 
$59 \%$ of balsam poplar stem cuttings produced roots (149). Seed has been found to be as successful as stem cuttings as a method of propagation (A. Fedkenheuer, pers.comm.).

\section{Current Status for Reclamation}

"Northwest" poplar, a hybrid of balsam poplar, has been recommended for reclamation of oil sands materials (645). "Northwest" hybrid was the best poplar after six years (tallest, largest stem, highest vigour and lowest dieback) on amended tailings sand near Fort McMurray. Survival after four years on amended tailings sand was 60 to $70 \%$ under moderate to heavy ground cover. Growth of the container stock averaged $14 \mathrm{~cm} /$ year during this period (641). Tests in Alberta indicated that "Northwest" and balsam poplar are not suited for subalpine and lower subalpine regions. While initial survival of "Northwest" was acceptable (66\% at 2 years), long term (8 year) survival was very low $(1 \%)$ due to stem dieback and heavy browsing $(272,271,671,707)$. Hardwood cuttings planted as unrooted poles had poor survival (15\%) when planted on sand dunes near Lesser Slave Lake, northern Alberta (258). Balsam poplar has been used successfully for reforestation in the forested zone of Alberta up to 1230 to $1540 \mathrm{~m}$ ASL. In general, direct planted cuttings require more moisture and have slower growth in the initial years after planting than rooted cuttings (272). "Northwest" poplar planted as bare root stock had good survival and were vigorous on amended natural sands near Fort McMurray (A. Fedkenheuer, pers.comm.). 
Populus tremuioides

\section{SPECIES SUITABILITY MAP AND SUMMARY TABLE}

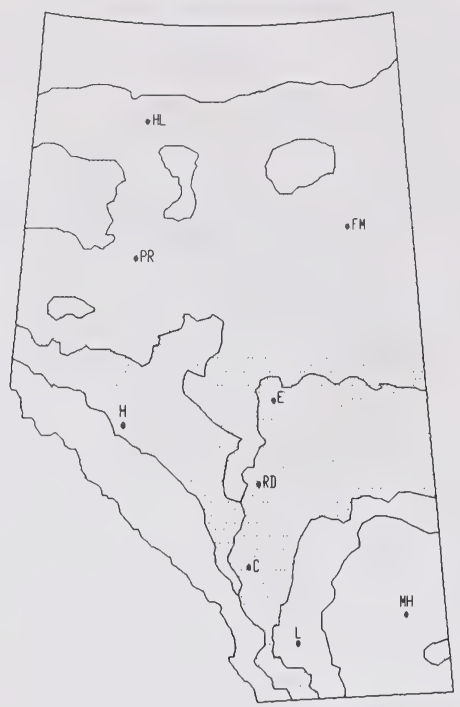

Recommended Area

Commercially Available: Yes $\mathrm{X}$ No

\begin{tabular}{|c|c|c|c|c|c|}
\hline \multirow{2}{*}{$\begin{array}{l}\text { RECLAMATION SUITABILITY } \\
\text { CRITERIA }\end{array}$} & \multicolumn{5}{|c|}{ SUITABILITY RATING } \\
\hline & Very High & High & Medium & Low & None \\
\hline Drought Tolerance & & & $x$ & & \\
\hline Salt Tolerance & & & & $x$ & \\
\hline $\mathrm{pH} \quad$ Acid. & & & & $x$ & \\
\hline Tolerance Base & & & $\mathrm{X}$ & & \\
\hline Winter Hardiness & & $x$ & & & \\
\hline Erosion Control & & $x$ & & & \\
\hline Persistence & $x$ & $x$ & & & \\
\hline Palatability & & $x$ & $x$ & & \\
\hline Browse Tolerance & & $x$ & $x$ & & \\
\hline Moisture Preference & Moist. & & & & \\
\hline Soil Preference & $\begin{array}{l}\text { Wide } r \\
\text { imperf }\end{array}$ & $\begin{array}{l}\text { ge of } \\
\text { tly } d r\end{array}$ & y, grave & soil & to \\
\hline
\end{tabular}


Populus tremuloides Michx.

\section{SPECIES BIOLOGY}

Taxonomy - Trembling Aspen.

\section{Origin and Range}

Native. Trembling aspen is the most widely distributed tree in North America. It ranges from Alaska east across Canada to Labrador and Newfoundland, south in the northeastern United States to New Jersey, Virginia, and Missouri and south in the western mountains to northern Mexico and southern California $(443,419)$. Hybridization occurs between many species of North American poplar where their ranges overlap and also between North American and European poplars (419).

\section{Growth Habit}

A slender, small to medium-sized deciduous tree, trembling aspen averages 13 to $20 \mathrm{~m}$ in height and 20 to $25 \mathrm{~cm}$ in diameter. It may attain heights of $30 \mathrm{~m}$ and diameters of $60 \mathrm{~cm}(443,205)$. The growth rate of $F 1$ hybrids between $P$. tremula and P. tremuloides is greater than either of the parents $(419,372)$.

\section{Nitrogen Fixing - None}

\section{Longevity}

A long-lived perennial. Growth of trembling aspen will continue until stands are aged 80 to 100 years, after which they begin to deteriorate (443).

\section{Self Propagation}

Trembling aspen reproduces occasionally by seed and root suckers $(30,275)$. Often clones of considerable size are produced as a result of sucker development (205). Suckering is not significant in undisturbed forest but is very vigorous when sites have been disturbed by burning or clear cutting. Sucker development is largely the result of increased soil temperature (275), but removal of apical dominance is also important.

\section{Ecological Setting}

Trembling aspen is an ubiquitous component of northern forested regions in Canada. It often occurs in pure stands as a result of fires where it acts as a "nurse tree" to various softwoods. These eventually replace trembling aspen in dominance

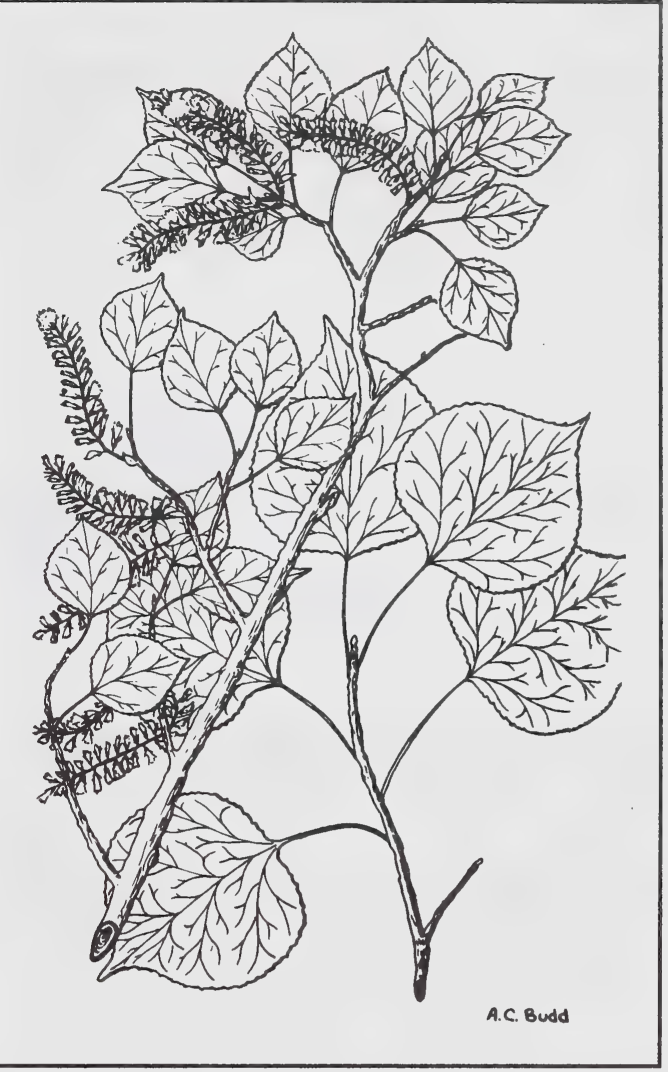

resulting in the mixed-wood and mature softwood stands characteristic of the boreal forest. Trembling aspen is also common throughout the prairie in bluffs and around sloughs. These bluffs interspersed with prairie give rise to the aspen parkland zone between northern forest and prairie (205), 64). It is found on dry, sandy slopes to the upper subalpine $(501,365)$. Common native associates: Populus balsamifera, Betula papyrifera, Picea glauca and Abies balsamea, with Pinus banksiana or $\underline{P}$. contorta on the drier sites.

\section{TOLERANCES}

\section{Soil Preferences}

Trembling aspen is found on a wide range of soils from well drained through to poorly drained soils. It is also found on a wide range of soil textures (5). It does best on well drained, moist, sandy or gravelly loam soils (205). 


\section{Nutrient Requirements}

Trembling aspen may grow in relatively poor soils. On open, dry, outwash plains they often grow as low plants in single groups and wherever the terrain (but not always the soil quality) becomes more favourable they reach tree size (372). Low to medium fertility requirements $(659,688)$.

\section{Soil Reaction}

Trembling aspen has been reported as having low acid tolerance (5). However, it has been observed as a successional species on flat barren sand areas near Sudbury, Ontario. The soils there are very acidic (pH 3.2 to 4.5 ) (28). The optimum $\mathrm{pH}$ range for hybrid aspen ( $P$. tremula $\times \underline{P}$. tremuloides) planted on tailings sand in the Netherlands has been reported to be between 4.0 and 5.1 (372).

\section{Soil Salinity}

Trembling aspen had poor survival on sodic mine spoils at Wabamun, Alberta (304).

\section{Drought}

Trembling aspen trees are moderately resistant to drought (248).

\section{Heavy Metals and Hydrocarbons}

Trembling aspen trees were killed by diesel oil spills presumably by the effects of the oil on the root systems (316). It has been observed as a pioneer species on acid barren sands with elevated levels of $\mathrm{Cu}, \mathrm{Ni}$ and $\mathrm{Al}(28)$.

\section{Shade}

The species is shade intolerant. High light intensities (about 3500 foot candles) are required for minimum photosynthesis $(356,248)$.

\section{Browsing}

Late-season heavy browsing has been suggested as a means of controlling the encroachment of aspen suckers onto prairie grasslands (24). It must therefore be concluded that heavy browsing will at least control rate of spread by killing new sucker growth.

\section{Susceptibility to Disease and Insect Damage}

Trembling aspen is susceptible to leaf spot, leaf rust, shoot blight, sooty bark canker and "Amillaria root rot" among others (198); insects such as the forest tent caterpillar and poplar borer are also damaging. The seedlings are susceptible to mildew and damping off (248).

\section{RECLAMATION CONSIDERATIONS}

\section{Soil Building and Erosion Control}

The root system is shallow and wide-spreading (205). Roots commonly produce root suckers, often a considerable distance from the parent tree and in this way invade grassland and disturbed sites. Suckers have been observed up to $32 \mathrm{~m}$ from the parent tree (40). It has been rated as very good in promoting soil stability (338) and is considered a "soil-improving species" (659).

\section{Adaptation to Disturbance}

Trembling aspen encroaches on "old fields", and has spread in the prairies since prairie fires have been suppressed $(64,469)$. It will invade prairies in the absence of heavy grazing (browsing) or mowing and where moisture is sufficient (40). Expands by root suckers into areas where seedling establishment would be difficult because of competition from grasses (40). Suckers may also be produced where surface soil temperatures are unfavourable for seedling development (275). Trembling aspen is a pioneer on mine spoils in Alberta (33) and British Columbia (384). Typical early colonizer of sand and gravel pits in Ontario (688).

\section{Competitive Ability}

Trembling aspen can spread by suckers through established grassland (248). However, production of aspen suckers was lower in a disced and seeded plot compared to a disced and unseeded plot. The aspen suckers competed less successfully with the seeded grasses than other woody plants such as snowberry (Symphoricarpos $\mathrm{sp}$.) and wild rose (Rosa sp.) (24).

\section{Commercial Value}

Trembling aspen is mainly used for pulpwood, chipboard ("aspenite"), veneer and plywood (205); also valuable for erosion control and game forage (120), and general cover in early successional stages (688).

\section{Palatability and Nutritive Value}

Trembling aspen is palatable to both deer and livestock $(40,245)$. Utilization of trembling aspen 
was rated as high by bighorn sheep, elk and moose, and medium by mule deer in the foothill ranges of Alberta (144).

\section{Seed or Planting Stock Availability}

Aspen seed is available, and seedlings and cuttings are fairly easy to collect or acquire. Many hybrids and cultivars are commercially available.

\section{Methods and Ease of Establishment}

Small catkin bearing twigs should be stripped from the tree when the catkins are on the point of dehiscence (or when the seeds are a light straw colour). These should then be spread out to dry which will result in the eruption of seed and "cotton" in a few days. Seeds need not be separated from the cotton which may provide a light mulch for the delicate seedlings. However, if seed is to be stored or used in container growing, the cotton should be removed as with balsam poplar ( $P$. King, pers.comm.). Seedlings require high light intensity for establishment. Seeds have no embryo dormancy and freshly collected seed usually has a high rate of germination (95 to $100 \%$ ). Seed can be stored for up to a year in a dessicator at $04^{\circ} \mathrm{C}$. Seeds should be sown on sterile substrate and kept moist and warm $\left(12^{\circ}\right.$ to $\left.20^{\circ} \mathrm{C}\right)(248,419)$. Unlike other poplars, trembling aspen can not be easily established from stem cuttings $(30,120,499)$. It can be successfully propagated from root cuttings or green cuttings taken from suckers $(275,499)$. The process to produce sucker cuttings is as follows: Root cuttings $(2.5 \mathrm{~cm}$ to $8 \mathrm{~cm}$ in diameter and $20 \mathrm{~cm}$ long) are treated with a fungicide, their ends are dipped in paraffin and then planted in moist vermiculite or coarse sand.

Suckers develop in 25 days to 6 weeks depending on temperature and humidity conditions. The bases of the sucker cuttings ( 3 to $10 \mathrm{~cm}$ long) are then treated with IBA (Indole-3-buteric acid) and planted directly in a moist rooting medium in containers. The suckers develop roots in 2 to 3 weeks after planting. Cuttings must be rooted in high humidity conditions. Root cuttings may be collected in fall or spring. There is clonal variation in suckering and rooting ability $(30,499,371)$. Misting of the seedbed with Captan and sulphur discourages damping off and mildew (248). Establishment of trembling aspen in the field directly from seed, has not been tried often. Sometimes established in Europe by laying catkin-bearing branches on the ground and covering them with a plastic sheet. It has been rated as good for establishment of transplants and seedlings. Plant spacings have been recommended as $1.6 \mathrm{~m}$ by $1.7 \mathrm{~m}(5,338$, 419).

\section{Current Status for Reclamation}

Survival of trembling aspen on amended tailings sand in northern Alberta was variable. Greatest survival was recorded on plots where grass and legume cover was least. This suggests that during early establishment, trembling aspen can not compete with grasses for moisture, particularly during dry years (149). Plantings on amended tailing sand had low survival after 7 years, however this may be attributable to poor planting stock (706). In operational plantings trembling aspen third year survival was $85 \%$ with a sparse ground cover but annual growth was relatively poor $(10 \mathrm{~cm}$ versus $35 \mathrm{~cm}$ for "Northwest" poplar") (645). Plantings in the alpine region of Alberta (Tent Mountain) had $52 \%$ survival after eight years. However, due to stem dieback and heavy browsing plant height averaged only $16 \mathrm{~cm}$ (708). This species is moderately resistant to drought, can grow in nutrient poor soils, and can easily be propagated by means of root cuttings. It has a wide geographical distribution and is found on a range of soil moisture regimes and soil textures. Trembling aspen is also fast growing and once established spreads vigorously by means of root suckers. It has great potential for reclamation purposes in Alberta but further research is needed into genetic variability of this species. There is the possibility that clones could be developed which are suitable for specific site conditions. 


\section{SPECIES SUITABILITY MAP AND SUMMARY TABLE}

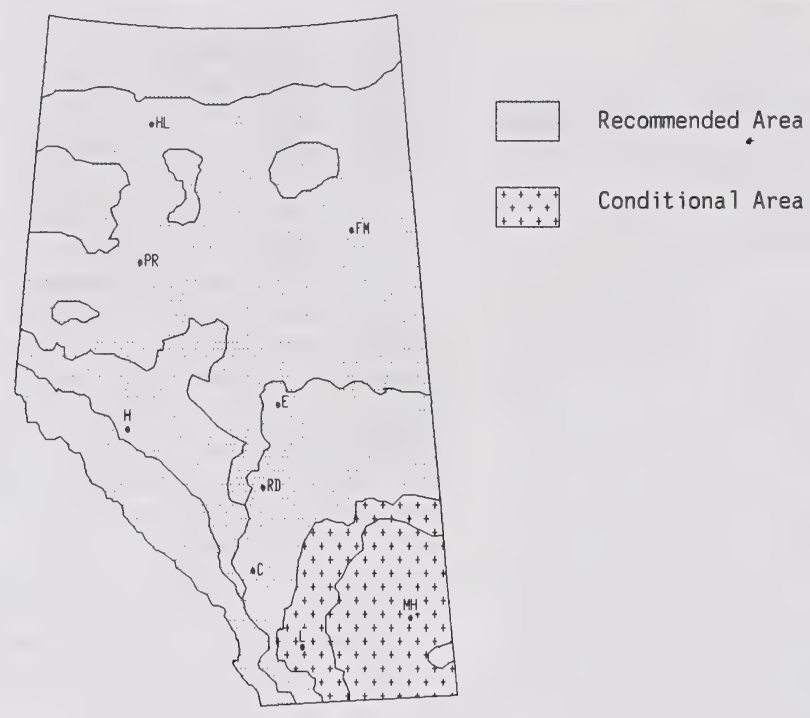

Commercially Available: Yes $X$ No

\begin{tabular}{|c|c|c|c|c|c|}
\hline \multirow{2}{*}{$\begin{array}{l}\text { RECLAMATION SUITABILITY } \\
\text { CRITERIA }\end{array}$} & \multicolumn{5}{|c|}{ SUITABILITY RATING } \\
\hline & Very High & $\mathrm{High}$ & Medium & Low & None \\
\hline Drought Tolerance & & & $x$ & & \\
\hline Salt Tolerance & & & & $x$ & \\
\hline pH Acid & & 4.5 & & & \\
\hline Tolerance Base & & & $x$ & & \\
\hline Winter Hardiness & & $x$ & & & \\
\hline Erosion Control & & & $x$ & & \\
\hline Persistence & & $x$ & & & \\
\hline Palatability & & & & $x$ & \\
\hline Browse Tolerance & & & $x$ & & \\
\hline Moisture Preference & Moist, & oleran & floodin & & \\
\hline Soil Preference & Sandy & loamy & ir on $\mathrm{cl}$ & & \\
\hline
\end{tabular}


Potentilla fruticosa L.

\section{SPECIES BIOLOGY}

Taxonomy - Shrubby Cinquefoil.

Also Pentaphylloides floribunda (Pursh) A. Love.

\section{Origin and Range}

Native. Alaska across Canada to Labrador, Newfoundland and Greenland. South to New Jersey, lowa, New Mexico and California. Also across Europe and Asia. Many cultivars available (443).

\section{Growth Habit}

Many-branched shrub 0.3 to $1 \mathrm{~m}$ high; deciduous (443).

\section{Nitrogen Fixing - None}

Longevity - Long-lived perennial.

\section{Self Propagation}

Propagates both by seed and by root sprouts (5). Rated as moderate for both natural reseeding and natural vegetative reproduction (338).

\section{Ecological Setting}

Found in a wide range of habitats, from prairie to alpine. In the Cypress Hills and foothills region of southern Alberta, it is found in low moist situations. Occurs in the boreal forests of northern Alberta where it is largely confined to swamps and borders of streams. In the mountains, it is found on dry rocky ledges and in open valley bottoms, and it is present in subalpine dwarf birch-willow communities $(78,690,429,428)$. Common native associates (muskeg): Salix bebbiana, Betula glandulosa, Ledum groenlandicum, Larix laricina, Picea glauca, Andromeda polifolia.

\section{TOLERANCES}

\section{Soil Preferences}

Shrubby cinquefoil is found on a wide range of soil conditions from well-drained through to poorly drained soils (5). Good growth reported on sandy and loamy soils with only fair growth on clayey soil (446). In Alaska, it has been rated as tolerant of wet conditions and flooding (5).

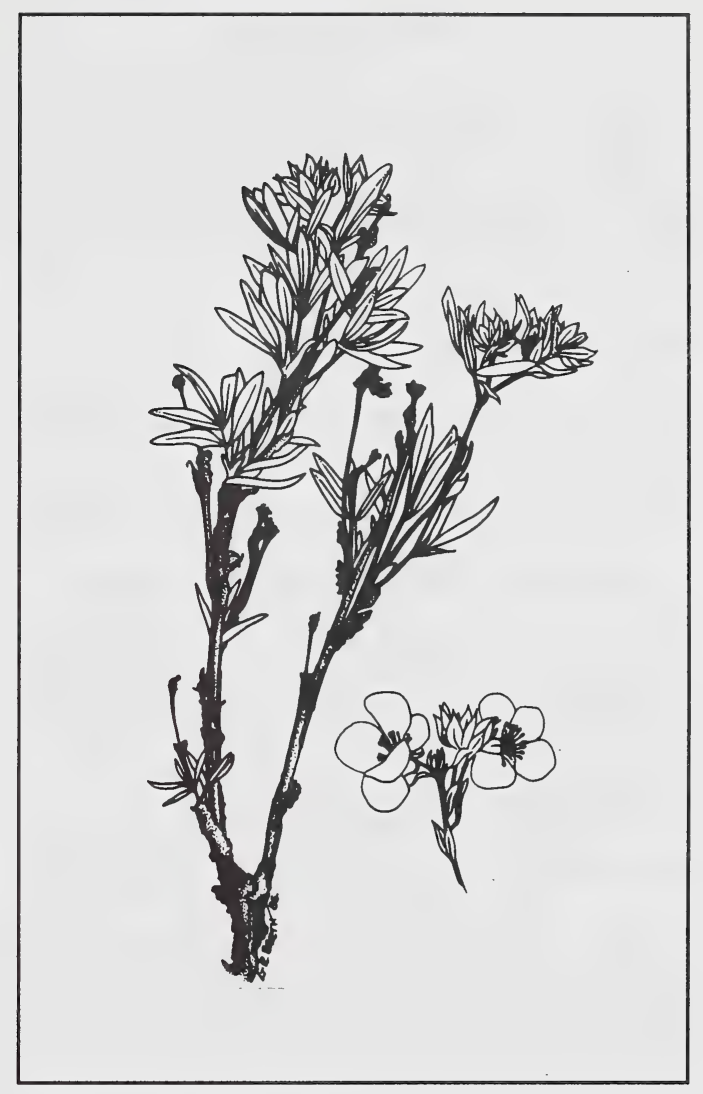

\section{Nutrient Requirements}

Shrubby cinquefoil is reported to grow well on low nutrient tailings sand amended with mineral fines and fertilizer in northern Alberta (149).

\section{Soil Reaction}

Shrubby cinquefoil has high acid tolerance; it can tolerate soils with $\mathrm{pH}$ below 4.5 (495). It is sometimes found occurring naturally in acid bogs (5). Also found on calcareous substrata $(332,136)$.

\section{Soil Salinity}

No specific tolerances noted from the literature, but is expected to be relatively intolerant of saline conditions.

\section{Drought}

Moderate (5) to good drought tolerance (A. Fedkenheuer, pers.comm.). 


\section{Heavy Metals and Hydrocarbons}

In a field study near Norman Wells, N.W.T. Potentilla fruticosa was killed by oil but reinvaded spill sites after 3 to 4 years. A simulated diesel oil spill largely defoliated the plants but they resprouted (216). Seedlings survived planting on a very acid $(\mathrm{pH} 3.2)$ coarse textured soil which was high in $\mathrm{Al}$ at a site near Dixonville, Alberta (434).

\section{Shade}

Slightly tolerant of shade; it prefers open sites but will grow under light shade (356).

Browsing - Can tolerate moderate browsing (430).

\section{Susceptibility to Disease and Insect Damage}

Susceptible to vole damage when planted on tailings sand with grasses, but less so than other woody shrubs (A. Fedkenheuer, pers.comm.).

\section{RECLAMATION CONSIDERATIONS}

\section{Soil Building and Erosion Control Capability}

It has a moderate cover rate with a fibrous root system (5). Optimum slope for establishment has been reported as 9 to $30 \%$ (446). Rated as moderate for erosion control (447) and soil stabilization.

\section{Adaptation to Disturbance}

Rare individuals reported to have invaded coal spoil piles at Cadomin, Alberta (1 $675 \mathrm{~m} \mathrm{ASL}$ ) where severe climatic limitations exist (wind and drought) (358). Reported as pioneer species on glacial outwash of the Muldrow Glacier (pH 8.0 to 8.4), Alaska (322). In southern Alberta, it is often found on open, grassy slopes where its presence is regarded as evidence of overgrazing. Invades disturbed areas when a seed source is nearby (365). Rated moderate in adaptation to disturbance (338). Potentilla tridentata, a related species, was found to invade tailings sand in northern Alberta (J. Sherstabetoff, pers.comm.).

\section{Competitive Ability}

Shrubby cinquefoil exhibited moderate vigour on plots subject to moderate grass competition and grasshopper infestation. Seedlings failed completely on plots subject to severe grass competition (102). The species invades and persists on overgrazed grasslands (due to its generally low palatability) and often must be controlled.

\section{Commercial Value}

Ornamental (378), erosion control (447).

\section{Palatability and Nutritive Value}

Low palatability; grazed by goats (domestic) but not sheep (domestic) (136); lightly browsed by mule deer (245) and bighorn sheep in the alpine tundra (225). Observed to be browsed by elk on winter ranges in Alberta.

\section{Seed or Planting Stock Availability}

Shrubs and seedlings are available at high cost from nurseries.

\section{Methods and Ease of Establishment}

Seed, seedlings and transplants (5), and hardwood cuttings (149). The seed is easily propagated in containers. Germination rate is reported to be 53 to $82 \%$ (121). Seeds ripen over a wide time span so that individual collections may be prone to low viability (J. Sherstabetoff, pers.comm.). Seed should be planted as soon as ripe. Seed is reported to be the best method of establishment (A. Fedkenheuer, pers.comm.). The maximum spacing for planting seedlings is recommended to be $1.2 \mathrm{~m}$ by $1.2 \mathrm{~m}$ (5). Wild plants transplant easily, as do bare root nursery stock $(480,337)$. Moist soil is needed for direct seeding. Seedlings are durable and persistent once established (480).

\section{Current Status for Reclamation}

Initial evaluation at the Upper Colorado Environmental Plant Centre rated Potentilla fruticosa as good for revegetation of disturbed lands in the subalpine, and good for roadside stabilization and beautification. It was rated very good for restoration of processed oil shale wastes, and fair for wildlife habitat improvement (266). It shows excellent survival as container seedlings on amended tailings sands in northern Alberta (121). It has been successfully used for revegetation of high altitude (3 $150 \mathrm{~m}$ to $4120 \mathrm{~m} \mathrm{ASL}$ ) lands disturbed by mining in Colorado (73). Recommended for revegetation in interior Alaska (5). Has been rated as providing fair cover for mule deer and good cover for game birds and small mammals (447). Survival on amended tailings sand was negatively affected by ground cover. Third year survival was $20 \%$ in dense versus $96 \%$ in sparse ground cover $(645,667)$. 


\section{SPECIES SUITABILITY MAP AND SUMMARY TABLE}

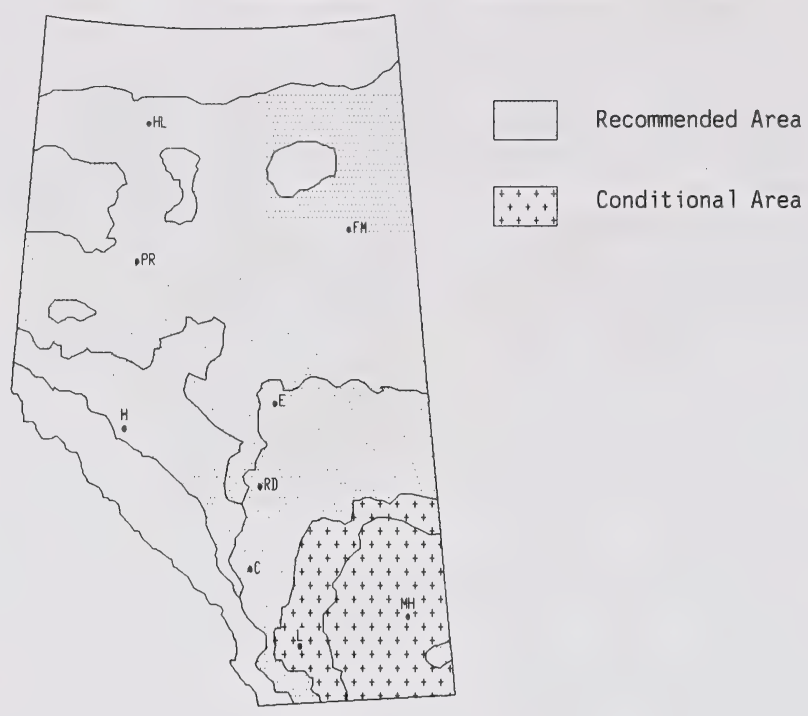

Commercially Available: Yes $\mathrm{X}$ No

\begin{tabular}{|c|c|c|c|c|c|}
\hline \multirow{2}{*}{$\begin{array}{l}\text { RECLAMATION SUITABILITY } \\
\text { CRITERIA }\end{array}$} & \multicolumn{5}{|c|}{ SUITABILITY, RATING } \\
\hline & Very High & High & Medium & Low & None \\
\hline Drought Tolerance & & . & $x$ & & \\
\hline Salt Tolerance & & & $x$ & & \\
\hline Acid & & & $x$ & & \\
\hline Tolerance Base & & & $\mathrm{X}$ & & \\
\hline Winter Hardiness & & & $x$ & & \\
\hline Erosion Control & & $x$ & & & \\
\hline Persistence & & $x$ & & & \\
\hline Palatability & & & $x$ & & \\
\hline Browse Tolerance & & & $x$ & & \\
\hline Moisture Preference & Moist. & & & & \\
\hline Soil Preference & Loamy, & $11 \mathrm{t}$ & rately & $a$ & \\
\hline
\end{tabular}


Prunus virginiana $L$.

\section{SPECIES BIOLOGY}

Taxonomy - Choke Cherry.

\section{Origin and Range}

Native. Newfoundland to British Columbia, south to southern California, New Mexico, Kansas, Illinois, Maryland and south to Georgia. Many cultivars available $(419,205,78)$.

\section{Growth Habit}

A shrub or small tree 0.6 to $6 \mathrm{~m}$ high. In favourable circumstances, it may reach a size of up to $10 \mathrm{~m}$ high, with a diameter of $15 \mathrm{~cm}(205,312)$.

Nitrogen Fixing - None

Longevity - Long-lived perennial.

\section{Self Propagation}

Primarily by seed, some suckering. Natural vegetative reproduction has been rated as very good and natural reseeding as moderate (338).

\section{Ecological Setting}

Common throughout the prairies in open situations along riverbanks, fence lines, and bordering wooded areas. It is found throughout the boreal forest in open situations. In northern parts of its range it is usually found on drier south-facing slopes. In the central Rocky Mountains, it is found in moist situations at elevations between 1500 and $2600 \mathrm{~m}$ (426). Common native associates: Rosa acicularis, Populus tremuloides, Alnus crispa (205, $312,78)$.

\section{TOLERANCES}

\section{Soil Preferences}

Prefers moist soil conditions with loamy soil textures. It is commonly found on rich moist soils (205). However, reported as accepting dry to mesic sites in Ontario (688). Reported to grow best in areas receiving at least $40 \mathrm{~cm}$ mean annual precipitation (426).

\section{Nutrient Requirements}

Moderate requirements; medium to high (688).

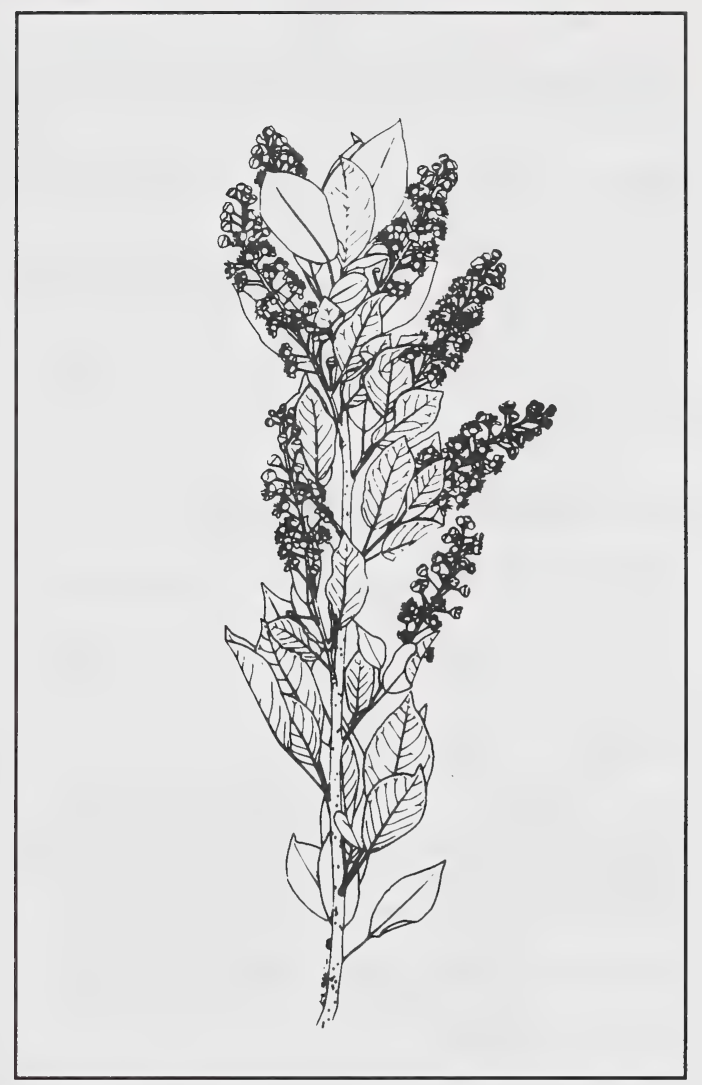

\section{Soil Reaction}

Choke cherry is adapted to soils that are moderately acidic to moderately alkaline (338).

\section{Soil Salinity}

Moderately tolerant of slightly saline soils.

\section{Drought}

Variously rated as: not tolerating excessive moisture stress (426); moderate to good with respect to drought tolerance (A. Fedkenheuer, pers.comm.); and, drought tolerant (608).

\section{Heavy Metals and Hydrocarbons}

No information available.

\section{Shade}

Choke cherry is relatively intolerant of shade (205). 


\section{Browsing}

Will resprout from root crowns. Tolerates moderate browsing.

\section{Susceptibility to Disease and Insect Damage}

Choke cherry saplings were found to be girdled by meadow voles and white-tailed deer mice on tailing sand dyke in northern Alberta (345) (J. Sherstabetoff, pers.comm.). Diseases include black knot and western $X$ disease ( $P$. King, pers.comm.).

\section{RECLAMATION CONSIDERATIONS}

\section{Soil Building and Erosion Control Capability}

Choke cherry has a good growth rate and has been rated as very good for soil stability (338).

\section{Adaptation to Disturbance}

Choke cherry has been rated as very good for adaptation to disturbance (338). It is found almost exclusively on disturbed sites in northern Alberta (A. Fedkenheuer, pers.comm.).

Competitive Ability - Not particularly aggressive.

\section{Commercial Value}

Ornamental, used as windbreak in prairies; wildlife food (419), especially winter browse (688). Berry picking; historically, used in preparation of pemmican (205).

\section{Palatability and Nutritive Value}

Foliage may contain hydrocyanic acid under drought stress or after frost (221). High frequency of browsing and moderate intensity of browsing by deer and elk reported in southeastern B.C. (393). Suggested to be moderately palatable to wild game and occasionally poisonous to sheep and cattle (205). Excellent for wildlife plantings $(608,639)$.

\section{Seed or Planting Stock Availability}

Many cultivars available from commercial nurseries. Predominantly ornamental shrub stock. Native seed is also available. Approximately 10560 seeds $/ \mathrm{kg}$ (639); approximately 40 to $55 \mathrm{~kg}$ seed per $100 \mathrm{~kg}$ fruit is produced.

\section{Methods and Ease of Establishment}

Fruit should be collected when fully ripe (red-purple to dark purple)(419). Seed has embryo dormancy. Cold stratify at $5^{\circ} \mathrm{C}$ for 120 to 160 days or sow in the fall. Sow seeds $1.0 \mathrm{~cm}$ deep (391). Seed should be subjected to weight separation as it can be heavily infested with worms (149). Direct seeding on tailings sand in northern Alberta was unsuccessful. However, field germination has been reported to be good at $2000 \mathrm{~m} \mathrm{ASL}$ in Colorado (397). Seeds can be stored at $-18^{\circ} \mathrm{C}(434)$. It is regarded as moderately difficult to germinate because of its hard seed coat. Warm storage of seed at high moisture contents even for only a few months will be harmful to seeds (419). Other methods of establishment for Prunus sp. are budding, grafting, suckers and root cuttings (21).

\section{Current Status for Reclamation}

Field tests have indicated that choke cherry has potential for reclamation in the oil sands. Third-year survival ranged 50 to $65 \%$ with moderate to heavy ground cover. Growth rate was comparable to other tall shrubs (645). Choke cherry underwent extensive testing in Saskatchewan before being recommended for shelterbelt plantings there (207). Commonly used in the northern and central great plains for windbreaks, soil stabilization and wildlife plantings (426). Choke cherry has been rated as good for establishment by transplants and moderate for establishment from seed (338). Black choke cherry has been used for revegetation of road sides and other disturbed or eroded areas in Utah (336). 
Rosa acicularis

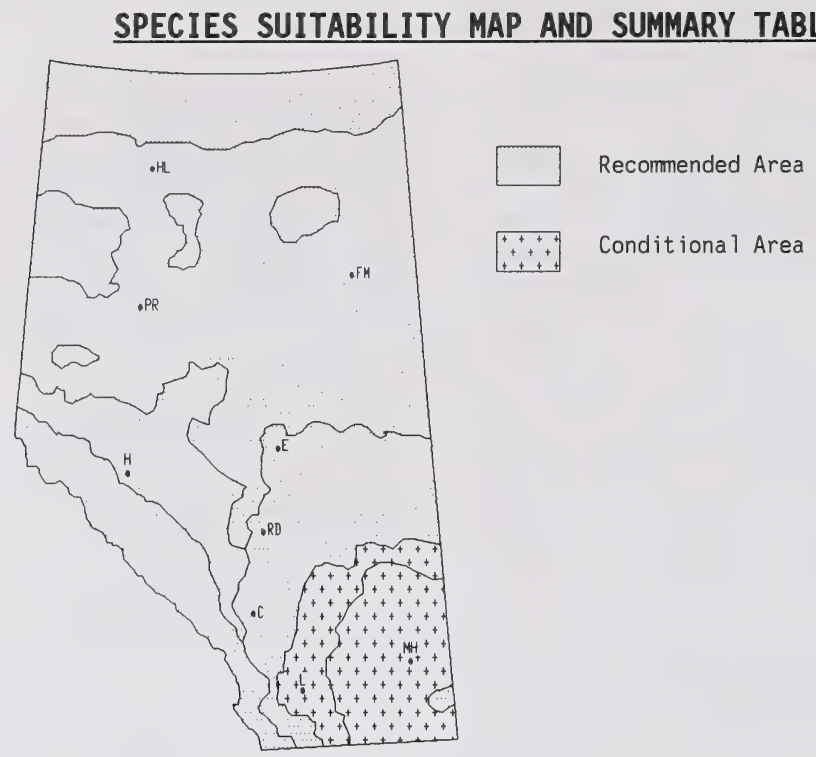

Commercially Available: Yes $\mathrm{X}$ No

\begin{tabular}{|c|c|c|c|c|c|}
\hline \multirow{2}{*}{$\begin{array}{l}\text { RECLAMATION SUITABILITY } \\
\text { CRITERIA }\end{array}$} & \multicolumn{5}{|c|}{ SUITABILITY, RATING } \\
\hline & Very High & High & Medium & Low & None \\
\hline Drought Tolerance & & & $\mathrm{x}$ & & \\
\hline Salt Tolerance & & & & $\mathrm{x}$ & \\
\hline Acid & & $x$ & & & \\
\hline Tolerance Base & & & & & \\
\hline Winter Hardiness & & $x$ & & & \\
\hline Erosion Control & & & $\mathrm{x}$ & & \\
\hline Persistence & & $X$ & & & \\
\hline Palatability & & $x$ & & & \\
\hline Browse Tolerance & & & $x$ & & \\
\hline Moisture Preference & Moist & wet, & rates fl & & \\
\hline Soil Preference & Wide & ge, we & o imperf & drair & \\
\hline
\end{tabular}


Rosa acicularis Lindl.

\section{SPECIES BIOLOGY}

Taxonomy - Prickly Rose.

Subspecies: ssp. sayi (Schiv.) also $\underline{R}$. bourgeauiana Crepin.

\section{Origin and Range}

Native. Alaska to Labrador, south to West Virginia, Minnesota, New Mexico, Idaho and British Columbia. It is also widespread across northern Eurasia (443). Hybridization with $\underline{R}$. woodsii common in Alberta (J. Packer, pers.comm.).

\section{Growth Habit}

A low bushy shrub 0.5 to $1.5 \mathrm{~m}$ in height. May grow to $2.5 \mathrm{~m}$ in the shade $(78,312)$.

\section{Nitrogen Fixing}

The species does not fix atmospheric nitrogen (331). No rhizosheath was observed on this species in a survey of vegetation on sandy, disturbed sites in Alberta (P. Lulman, pers.comm.).

Longevity - Long-lived perennial.

\section{Self Propagation}

Seeds take two years to germinate naturally. Seeds develop and mature the first growing season, warm stratify the next growing season (and the fruits decompose), cold stratify the following winter and germinate in the spring after snowmelt. Prickly rose also spreads by rhizomes to form clones. Root sprouts form when the plant is destroyed by fire or is cut $(5,121)$.

\section{Ecological Setting}

Prickly rose is found throughout the boreal forest region. It is especially common in the shaded undergrowth of mixed wood and deciduous forests. It occurs on old burns, in bogs and along roadsides. It is also found on river banks, in bluffs and in fields throughout the prairies where it is associated with Rosa woodsii and R. arkansas. Common native associates (mixed wood): Populus tremuloides, Picea glauca, Ribes triste, Viburnum edule, Rubus strigosus.

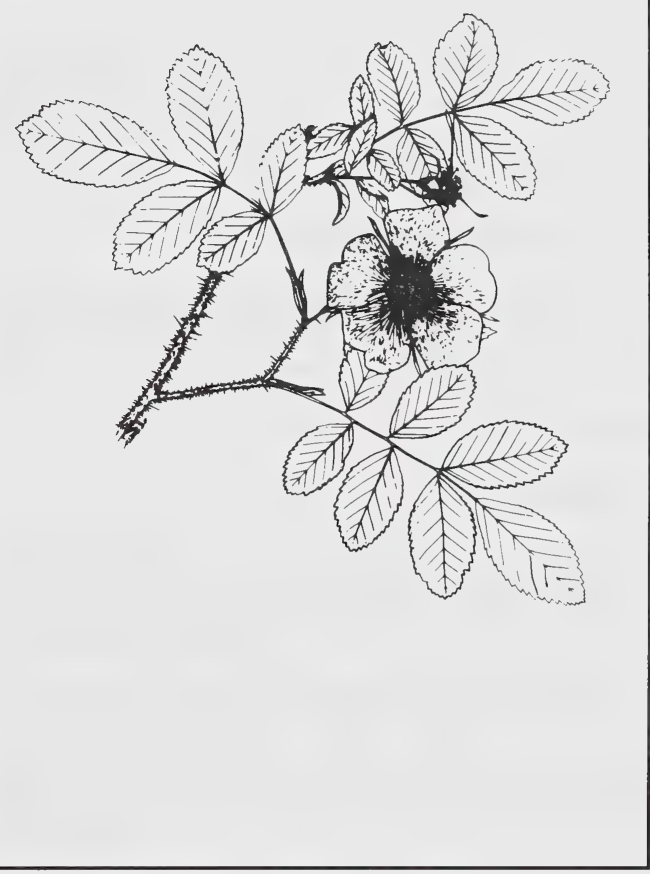

\section{TOLERANCES}

\section{Soil Preferences}

Prickly rose is adapted to a range of soil moisture regimes from well drained through to poorly drained soils. It can withstand flooding during the growing season, and is found on a wide range of soil textures (5).

\section{Nutrient Requirements}

Prickly rose has been reported as a pioneer on gravel and silt bars of the Cheena River, interior Alaska. The gravel is low in nutrients and susceptible to rapid freezing and thawing (442).

\section{Soil Reaction}

Prickly rose has high acid tolerance (5). 


\section{Soil Salinity}

Rosa spp. were found to be less common on disturbed sites where the soil was high in sodium (332).

\section{Drought}

Prickly rose has moderate drought resistance (5). It has been found to have good drought tolerance on amended tailings sand in northern Alberta (A. Fedkenheuer, pers.comm.).

\section{Heavy Metals and Hydrocarbons}

Prickly rose has been noted as moderately tolerant to crude oil (216). No other tolerances have been found in the literature examined.

Shade - It is moderately tolerant of shade (5).

\section{Browsing}

The stems are covered with straight bristles which may discourage excessive browsing (78). The plant will resprout from the roots if cut or killed by fire (5).

\section{Susceptibility to Disease and Insect Damage}

Prickly rose is susceptible to various leaf rusts, leaf spots, powdery mildew, stem canker and crown gall (198).

\section{RECLAMATION CONSIDERATIONS}

\section{Soil Building and Erosion Control Capability}

It has a rapid cover rate and spreads by rhizomes $(5,149)$.

\section{Adaptation to Disturbance}

Wild rose (Rosa acicularis/Rosa woodsii) are common on disturbance sites throughout the eastern slopes of the Rocky Mountains. They often invade disturbed bare areas, especially where mineral soils are exposed (365). Prickly rose has been reported as a pioneer on river gravel heaps (236) and burned areas (458). It invades disturbed sandy sites in northern Alberta (J. Sherstabetoff, pers.comm.).

\section{Competitive Ability}

Wild rose (Rosa acicularis/Rosa woodsii) had only $20 \%$ lower density in a plot disced and seeded with grass, compared to a disced and unseeded plot in a field experiment near Edmonton, Alberta. They were quite effective at competing with the seeded grasses (24).

\section{Commercial Value}

Rose hips are rich in vitamin C. They are used to make jellies, jams and ketchup (443); ornamental; wildlife food $(120,443)$. Provincial flower of Alberta.

\section{Palatability and Nutritive Value}

Prickly rose is browsed by mule deer (245). An ash content of $4.7 \%$ has been reported for samples collected in the Mackenzie Delta region, N.W.T. (403). Rose hips are eaten by grouse and other birds during fall and winter (443), and are noted to be high in vitamin $\mathrm{C}$.

\section{Seed or Planting Stock Availability}

Seedlings may be available for reclamation research purposes from the Provincial Tree Nurseries.

\section{Methods and Ease of Establishment}

Seed can be collected in the fall. Warm stratify at 20 to $27^{\circ} \mathrm{C}$ for 60 to 90 days, then cold stratify at 2 to $5^{\circ} \mathrm{C}$ for 90 to 120 days. Either warm stratify and sow in the fall, or fully stratify and sow in the spring. Sow seeds 0.6 to $1.8 \mathrm{~cm}$ deep (119). Root cuttings, and hardwood and softwood cuttings have apparently been used successfully (194). Upper stem (hardwood) cuttings gave poor results in northern Alberta, however. Best results are from bare stem cuttings about $15 \mathrm{~cm}$ long which include $8 \mathrm{~cm}$ of the top of the root (149).

\section{Current Status for Reclamation}

Prickly rose is a variable species (443) adapted to a wide range of moisture regimes and soil textures. Among its natural assets for reclamation are its tolerance of acidic conditions and its shade tolerance which may exceed common wild rose (Rosa woodsii). The large genetic variability of this species suggests that suitable ecotypes may be selected for use on specific undisturbed sites. Excellent survival has been obtained on amended tailings sands in northern Alberta, however vigour was low $(199,641,706)$. Rosa spp. are currently used for reclamation purposes in Denmark (331) and have been recommended for revegetation on moist to wet sites in Alaska (5). 

Rosa woodsii

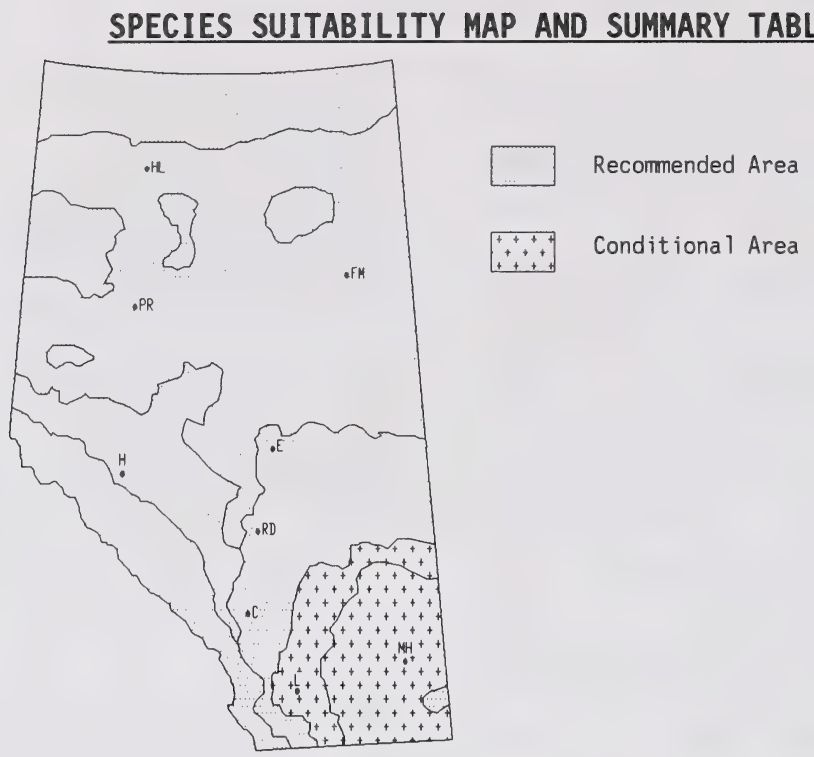

Commercially Available: Yes $X$ No

\begin{tabular}{|c|c|c|c|c|c|}
\hline \multirow{2}{*}{$\begin{array}{l}\text { RECLAMATION SUITABILITY } \\
\text { CRITERIA }\end{array}$} & \multicolumn{5}{|c|}{ SUITABILITY, RATING } \\
\hline & Very High & High & Medium & Low & None \\
\hline Drought Tolerance & & & $x$ & & \\
\hline Salt Tolerance & & & & $x$ & \\
\hline Acid. & & & $x$ & & \\
\hline Tolerance Base & & & $\mathrm{X}$ & & \\
\hline Winter Hardiness & & $x$ & & & \\
\hline Erosion Control & & $x$ & $x$ & & \\
\hline Persistence & & $\mathrm{x}$ & & & \\
\hline Palatability & & $\mathrm{X}$ & $\mathrm{X}$ & & \\
\hline Browse Tolerance & & $x$ & & & \\
\hline Moisture Preference & Moist. & & & & \\
\hline Soil Preference & Wide $r$ & ge. & & & \\
\hline
\end{tabular}


Rosa woodsii Lindl.

\section{SPECIES BIOLOGY}

Taxonomy - Common Wild Rose; Woods Rose.

Also ‥ fendleri Crepin., ‥ macounii Greene, R. ultramontana Heller.

\section{Origin and Range}

Native. British Columbia to Western Ontario and Minnesota, south to Missouri, Nebraska, Arizona, and northern Mexico (419). It is the most widespread and common rose in Alberta (690).

\section{Growth Habit}

A tall bushy shrub 0.3 to $2 \mathrm{~m}$ in height $(78,312)$. Its form is highly variable. Fast growing (608).

\section{Nitrogen Fixing - None}

Longevity - Long-lived perennial.

\section{Self Propagation}

Common wild rose spreads naturally by seeds and rhizomes (78).

\section{Ecological Setting}

Common wild rose is found on bluffs, dry grassy slopes and on sandhills throughout the prairies. It is also found on riverbanks and clearings in the boreal forest to the subalpine. It is commonly found growing with $\underline{R}$. acicularis in wooded areas and R. arkansas on the prairies $(78,312,501)$.

\section{TOLERANCES}

\section{Soil Preferences}

Common wild rose is adapted to a wide range of soil types and good growth has been reported on a wide range of soil textures. It can withstand dry conditions but prefers moist soil (446). Rosa spp. were more abundant on coarse and very coarse textured soils compared to other soil textures on disturbance sites in Alberta (332).

\section{Nutrient Requirements}

Rosa woodsii seedlings planted on road cutbanks and fills at various sites in eastern Washington had a high rate of survival after two years, but vigour was fair to poor. Many of the plants appeared

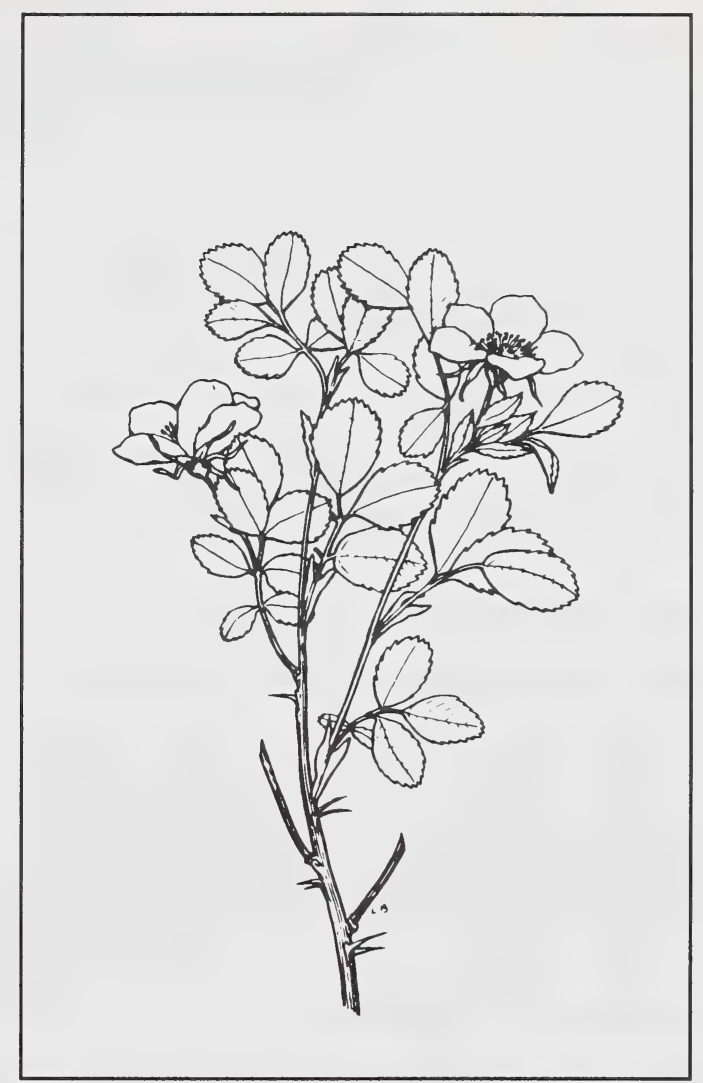

chlorotic, indicating higher nutrient requirements than other shrubs planted (415).

\section{Soil Reaction}

Common wild rose tolerates soils that are moderately alkaline to moderately acidic (338). It has been suggested as a useful species for revegetation on high $\mathrm{pH}$ and high lime soils (332).

\section{Soil Salinity}

Rosa spp. were found to decrease in abundance on disturbed sites where spoil materials were high in sodium (332).

\section{Drought}

Common wild rose has moderate drought tolerance.

\section{Heavy Metals and Hydrocarbons}

No specific tolerances noted. Expected to react as R. acicularis (c.f.). 


\section{Shade}

It prefers open sites, but will grow under light shade (356).

\section{Browsing}

Common wild rose has a fairly high tolerance to browsing as thorns discourage over-browsing. Thorniness is highly variable.

\section{Susceptibility to Disease and Insect Damage}

Common wild rose is susceptible to various leaf spots, as well as to leaf rusts, gray mold, powdery mildew, common gall and stem canker (249).

\section{RECLAMATION CONSIDERATIONS}

\section{Soil Building and Erosion Control Capability}

As for most roses, common wild rose is thicket forming, providing a dense soil cover. It has been rated as good for soil stabilization (470). Wood's rose (Rosa woodsii var. ultramontana) has been rated as very good for natural spread by vegetative means (rhizomes) (470). Growth rate is regarded as moderate (470).

\section{Adaptation to Disturbance}

Wild rose (Rosa acicularis/Rosa woodsii) is common on disturbance sites throughout the eastern slopes of the Rocky Mountains. It is especially prevalent along roadsides and southfacing cutbanks (365). Rosa spp. were found to invade nutrient deficient, coarse textured soils in the subalpine in Colorado (395). Common wild rose is rated as very good in its adaptation to disturbance (337). It is a common species on disturbed sandy sites in northern Alberta (J. Sherstabetoff, pers.comm.).

\section{Competitive Ability}

Wild rose (Rosa acicularis/Rosa woodsii) decreased in density by only $20 \%$ in a plot disced and seeded with grass compared to a disced and unseeded plot in a field experiment near Edmonton, Alberta. The roses were quite effective at competing with the seeded grasses compared to other forbs and woody plants (24).

\section{Commercial Value}

Rosa spp. are useful for erosion control and as wildlife forage (180). The hips of Wood's Rose
(Rosa woodsii var. ultramontana) are used for flavouring teas, jellies and puddings. They are rich in vitamin $C(480)$. Useful for ornamental and hedge plantings (608).

\section{Palatability and Nutritive Value}

Moderate use of common wild rose has been reported for mule deer and elk $(144,245)$. It has high palatability (38). It has been rated as providing good cover for mule deer and small mammals, and fair cover for game birds. It is a good food source for game birds and small mammals and a fair food source for mule deer (446), livestock and big game from spring through to fall (480). Important for winter food for wildlife (639) and game and nongame birds (608).

\section{Seed or Planting Stock Availability}

Native seed is available at moderate cost from American dealers. Approximately 45300 seeds/lb (639). There are approximately 23000 cleaned seeds per kilogram of fruit.

\section{Methods and Ease of Establishment}

Collect seeds in the fall. Seed has seedcoat dormancy and requires warm stratification followed by cold stratification. Either warm stratify and sow in the fall or cold stratify and sow in the spring (194). Seed viability ranged from 44 to $64 \%$ for seed collected in northern Alberta (J. Sherstabetoff, pers.comm.). Germination outdoors takes about 30 to 40 days (293). The species is also readily established by hardwood tips and bare root cuttings (hardwood and root), budding, suckers, layering and grafting $(21,480)$. Transplants are also successful (337). Best establishment on nutrient deficient sites can be obtained from hardwood cuttings or nursery stock $(338,302)$.

\section{Current Status for Reclamation}

A row seeding trial and a broadcast seeding trial were totally unsuccessful on a harsh site at Tent Mountain, Alberta after the first growing season.

Seed, however, was not pre-treated (380). Woods's rose (Rosa woodsii var. ultramontana) did poorly on amended tailings sand near Fort McMurray. While survival was high, vigour was low, and insect defoliation and dieback was high (706). Good results with hardwood cuttings have been obtained in Idaho where Rosa spp. are used for watershed plantings and erosion control. Wood's rose has been used by state and federal agencies for watershed plantings in Utah (302). It has also shown very good results in direct seeding and 
transplanting trials on clay soils in the subalpine in Utah. It was noted as a promising species for providing wildlife cover on high elevation ranges (337). Wood's rose has been recommended as a shrub species with low establishment requirements suitable for long term rehabilitation of juniper-pinyon woodland in northwestern Colorado. Here it is best suited to moist sites at an optimum slope of 9 to $30 \%$ (446). 
Rubus idaeus

\section{SPECIES SUITABILITY MAP AND SUMMARY TABLE}

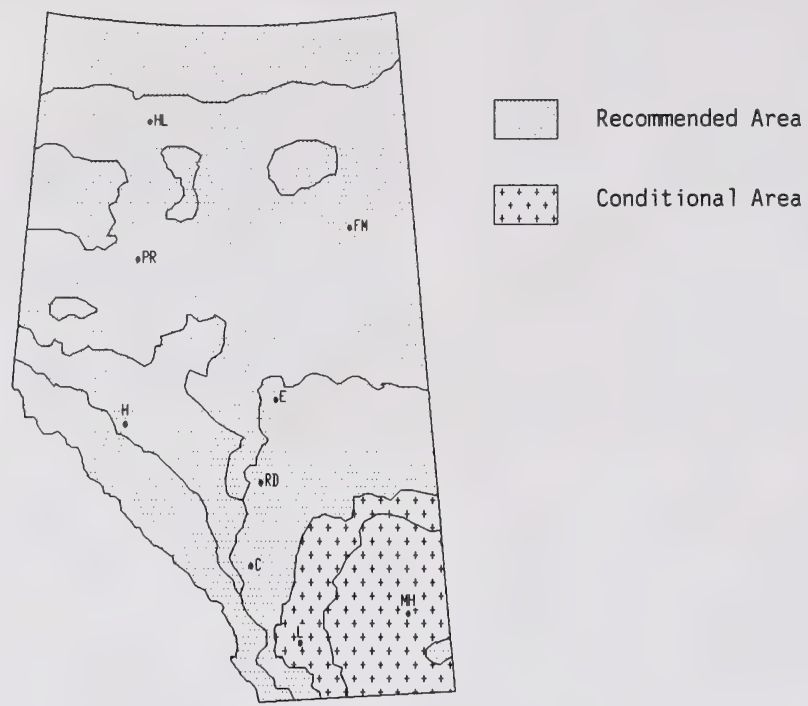

Commercially Available: Yes $X$ No

\begin{tabular}{|c|c|c|c|c|c|}
\hline \multirow{2}{*}{$\begin{array}{l}\text { RECLAMATION SUITABILITY } \\
\text { CRITERIA }\end{array}$} & \multicolumn{5}{|c|}{ SUITABILITY RATING } \\
\hline & Very High & High & Medium & Low & None \\
\hline Drought Tolerance & & $x$ & $x$ & & \\
\hline Salt Tolerance & & & $x$ & & \\
\hline & & & $x$ & & \\
\hline \multicolumn{6}{|l|}{ Tolerance Base } \\
\hline Winter Hardiness & & $x$ & & & \\
\hline Erosion Control & & & $x$ & & \\
\hline Persistence & & $x$ & & & \\
\hline Palatability & & & $x$ & $x$ & \\
\hline Browse Tolerance & & & $x$ & & \\
\hline Moisture Preference & Moist & 0 dry. & & & \\
\hline Soil Preference & $\begin{array}{l}\text { Silty } \\
\text { draine }\end{array}$ & 1ay loan & sandy $1 c$ & well $t$ & fectly \\
\hline
\end{tabular}


Rubus idaeus L.

\section{SPECIES BIOLOGY}

Taxonomy - Wild Red Raspberry.

Includes $\underline{\mathrm{R}}$. strigosus Michx. and $\underline{\mathrm{R}}$. melanolasius Focke.

\section{Origin and Range}

Native. A variable species with many geographic strains. Many commercial cultivars. Alaska to Newfoundland, south to North Carolina, lowa, Arizona, California and northern Mexico. Related varieties extend across northern Europe and northwestern Asia (443).

\section{Growth Habit}

Deciduous bushy shrub 0.6 to $2.0 \mathrm{~m}$ high. Stems covered with prickles $(78,690)$.

\section{Nitrogen Fixing - None}

\section{Longevity}

Long-lived perennial shrub with biennial stems (canes) (312). Several population samples of Rubus idaeus subsp. strigosus were collected in British Columbia and northern Alberta and significant differences in winter hardiness were noted among the samples (437).

\section{Self Propagation}

Wild red raspberry spreads by seed, root sprouts and stolons $(5,443)$.

\section{Ecological Setting}

Widespread throughout the boreal forest in clearings, at edges of woods, and on burnt areas. Found on bluffs and along riverbanks throughout the prairies. Also a roadside weed. It may be present on rocky screes or talus slopes above timberline (501). Common native associates (mixed-wood): Ribes triste, Rosa acicularis, Viburnum edule, Cornus stolonifera, Populus tremuloides, Picea glauca $(443,78,690,399)$.

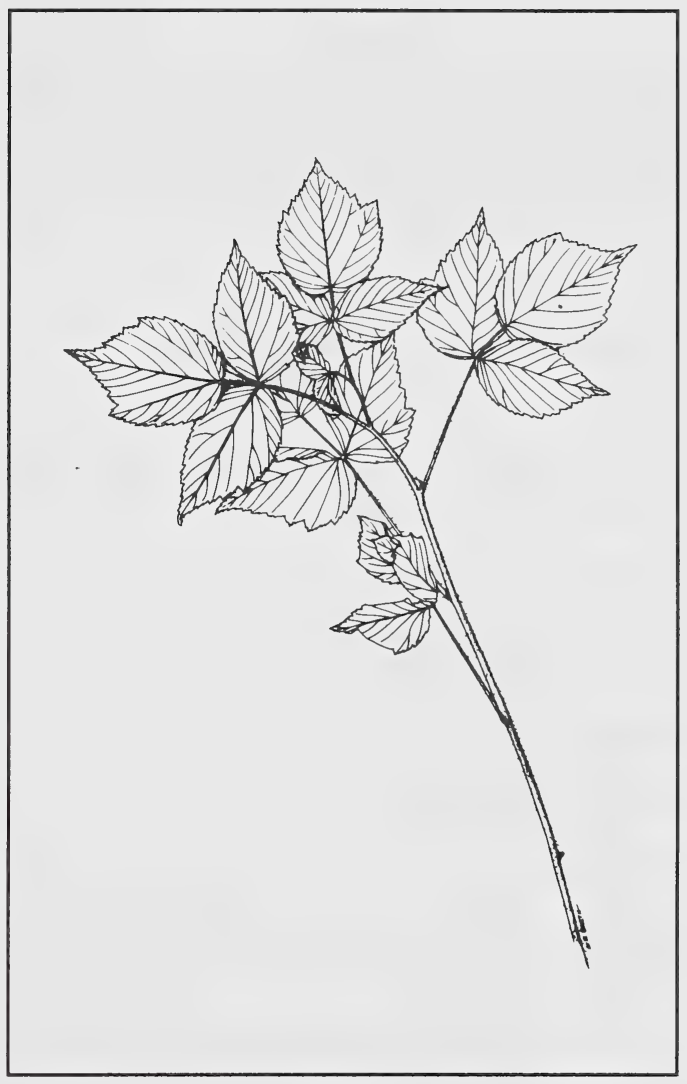

\section{TOLERANCES}

\section{Soil Preferences}

Found on soils that are poorly, imperfectly and well drained, and with textures ranging from sandy loam to silty clay loam (5). Best suited to moderately well drained soils, where moisture is available.

\section{Nutrient Requirements}

Rubus spp. grow well on barren and infertile soils (419); low to high fertility needs (688). 


\section{Soil Reaction}

Wild red raspberry has moderate acid tolerance (5). Rubus idaeus volunteered on previously barren, acid tailings sands that had been ameliorated with lime. This vegetation later deteriorated as the soil acidity increased again (from pH 4.8 to 3.9) (372).

Soil Salinity

Will probably tolerate moderate salinity.

\section{Drought}

Wild red raspberry is found on soils that have a tendency to be droughty (5).

\section{Heavy Metals and Hydrocarbons}

Has volunteered on lean tar sands in northern Alberta (J. Sherstabetoff, pers.comm.).

\section{Shade}

It has low shade tolerance (5).

\section{Browsing}

Will resprout from root crowns if cut late in the season.

\section{Susceptibility to Disease and Insect Damage}

Native Rubus spp. are generally well adapted to indigenous diseases and pests. Resistant.

\section{RECLAMATION CONSIDERATIONS}

\section{Soil Building and Erosion Control Capability}

Wild red raspberry forms thickets and has a rapid cover rate $(443,5)$.

\section{Adaptation to Disturbance}

Seedlings volunteered on a mixture of tailings sand and surface soil at an oil sands extraction plant in northern Alberta (257). Wild red raspberry is common on all disturbance sites in the eastern slopes of the Rocky Mountains in Alberta. It is apparently most vigourous on moist sites, or mineral soil and brush piles where it is often associated with fireweed (Epilobium angustifolium) (365). Common invader of disturbed sites including amended tailings sands and roadsides in northern Alberta (J. Sherstabetoff, pers.comm.).

\section{Competitive Ability}

Wild red raspberry was found to be unsuccessful at competing against grasses in an experiment near Edmonton, Alberta. Plant density decreased by $88 \%$ on seeded plots compared to unseeded plots (24).

\section{Commercial Value}

Cultivars are grown for the berries, which are eaten fresh or used in jams and jellies $(437,443)$.

\section{Palatability and Nutritive Value}

Fruit and young shoots eaten by wildlife. Thorns prevent excessive use.

\section{Seed or Planting Stock Availability}

Availability of native seed is not known. Cultivars are grown commercially for berry production from canes (stem cuttings).

\section{Methods and Ease of Establishment}

Seeds may be extracted by macerating the fruit in water, then floating-off or screening-out the pulp and empty seed. Seed can be stored at approximately $5^{\circ} \mathrm{C}$ for at least a year. The seed should be dried before storage. $\underline{R}$. idaeus will germinate after cold stratification for 120 days or longer. Rubus strigosus has a hard seed coat and germination may be improved with scarification with sulphuric acid for 20 to 60 minutes or with a $1 \%$ solution of sodium hyperchlorite (419). Seed viability ranged from 92 to $99 \%$ for six seed lots collected in northern Alberta (J. Sherstabetoff, pers.comm.). Other methods of establishment include stem cuttings, root cuttings, layering and suckers (21).

\section{Current Status for Reclamation}

Suitability of various ecotypes for reclamation purposes needs to be examined. Recommended for revegetation on well drained sites in the interior Alaska; maximum spacing suggested was $1 \mathrm{~m}$ by $1 \mathrm{~m}$ (5). Regarded as a pioneer for revegetating bare soils in the subalpine in Colorado (323). Wild red raspberry has been used successfully to stabilize roadcuts and disturbed areas in Utah (336).

Wild red raspberry is a variable species common on most disturbed sites in Alberta. It forms dense thickets and has been used successfully for erosion control. It is somewhat drought tolerant and can 
grow on infertile, bare mineral soil. This species has good potential for erosion control and revegetation on disturbed sites throughout Alberta. Research is needed into genetic variability of this species. It is easily established from stem cuttings, root cuttings and transplants. However, it cannot compete with grasses. 
Salix arctica

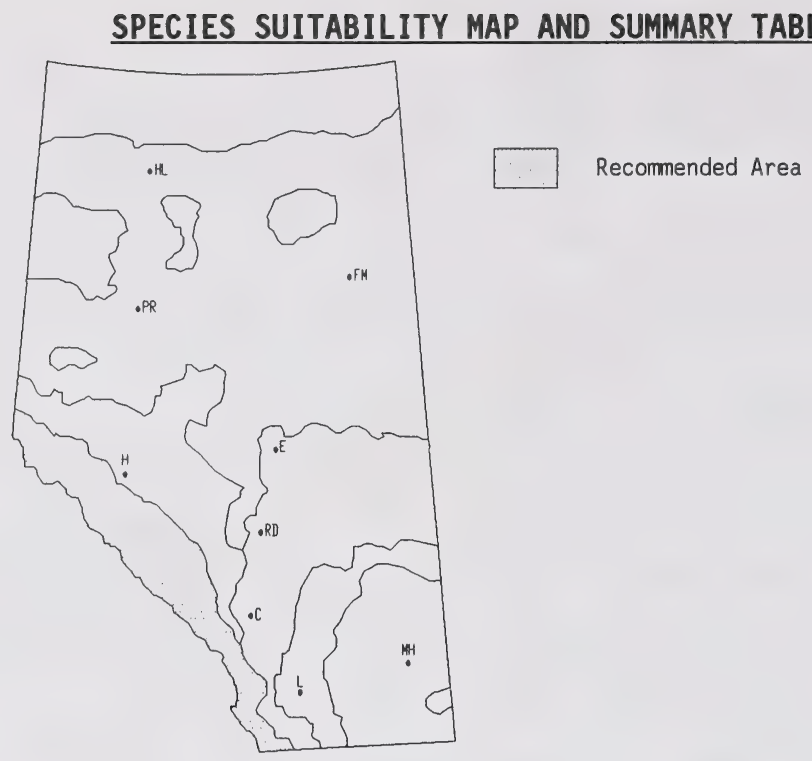

Commercially Available: Yes No $X$

\begin{tabular}{|c|c|c|c|c|c|}
\hline \multirow{2}{*}{$\begin{array}{l}\text { RECLAMATION SUITABILITY } \\
\text { CRITERIA }\end{array}$} & \multicolumn{5}{|c|}{ SUITABILITY RATING } \\
\hline & Very High & High & Medium & Low & None \\
\hline Drought Tolerance & & & $x$ & & \\
\hline Salt Tolerance & & & & $x$ & \\
\hline Acid & & & & & \\
\hline Tolerance Base & & & $x$ & & \\
\hline Winter Hardiness & $x$ & & & & \\
\hline Erosion Control & & & & $X$ & \\
\hline Persistence & & $x$ & & & \\
\hline Palatability & & & $x$ & & \\
\hline Browse Tolerance & & & $x$ & & \\
\hline Moisture Preference & Moist & dry. & & & \\
\hline Soil Preference & Loamy & and. & & & \\
\hline
\end{tabular}


Salix arctica Pallas

\section{SPECIES BIOLOGY}

Taxonomy - Arctic Willow.

Includes var. araioclada (Schneid.) Raup.

\section{Origin and Range}

Native. Alaska east across northern Canada, south in the mountains to Quebec and California. Also in northern Europe and Asia. Variable species, often sub-divided into several species (389).

\section{Growth Habit}

A depressed or low trailing shrub. Frequently forms dense mats 20 to $25 \mathrm{~cm}$ high $(443,312,12)$. Variable in growth habit (443).

Nitrogen Fixing - None

Longevity - Long-lived perennial.

Self Propagation - By seed and branch rooting.

\section{Ecological Setting}

Found throughout tundra and mountainous areas of Alaska. Arctic willow is found on both dry and wet sites; and in protected and unprotected situations. In southeastern Alaska it is sometimes found at sea level on glacial outwash and moraines (389). In Alberta, arctic willow is largely confined to the mountains; it is common at high elevations (312).

\section{TOLERANCES}

\section{Soil Preferences}

Observed on loamy to sandy loam soils. Generally on Regisols and alpine Brunisols. Appears to do best on very poor soils, although this may reflect poor competitive ability on sites which are favourable for grass and sedge growth.

\section{Nutrient Requirements}

Nutrient requirements expected to be low due to the type of site this species is usually found on.

\section{Soil Reaction}

Arctic willow often invades calcareous glacial moraines (332), and is therefore expected to somewhat favour pH's in excess of 7.0.

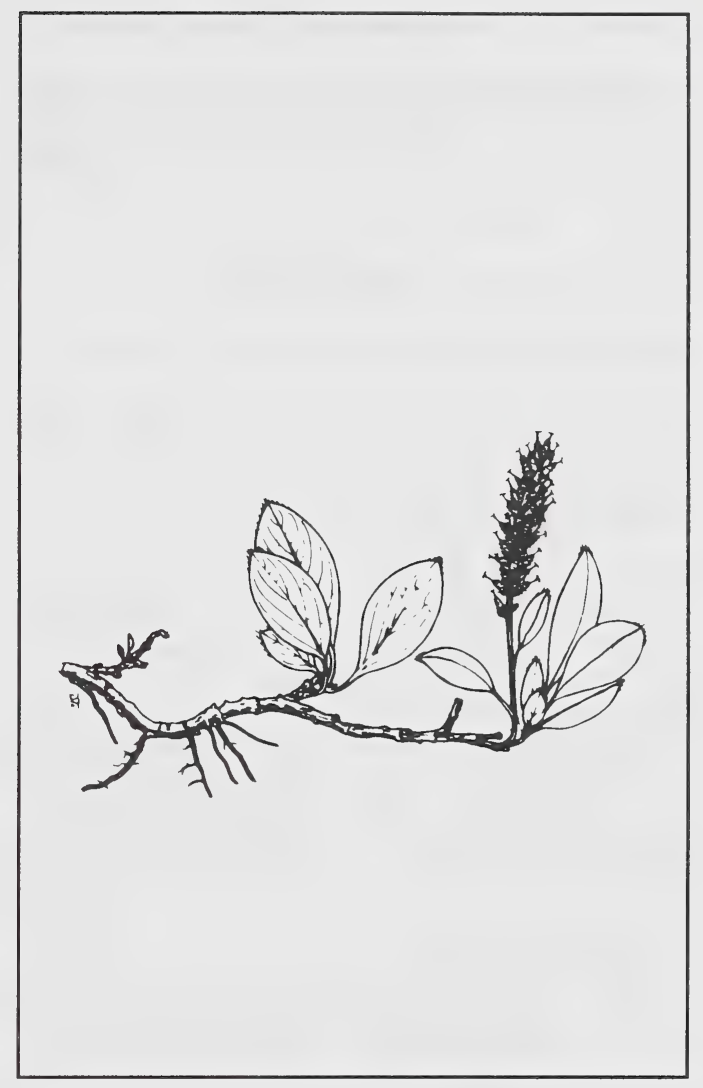

\section{Soil Salinity}

Would not be expected to tolerate saline soils.

\section{Drought}

Grows on sites which are subject to some moisture stress, or drought.

\section{Heavy Metals and Hydrocarbons}

Willows, in general, have been reported to have high tolerance for oil (282). No other tolerances have been noted.

Shade - Will not grow in shady situations.

\section{Browsing}

Regrows after browsing by bighorn sheep (225), and is known to be extensively browsed on the arctic tundra. This, plus the fact that these shrubs are notably slow growing, suggests moderate tolerance to browsing pressure. 


\section{Susceptibility to Disease and Insect Damage}

Various diseases have been reported to infect arctic willow. These include black rib, leaf spot, tar spot, shoot blight, twig blight, soft white rot, and pitted sap rot (198).

\section{RECLAMATION CONSIDERATIONS}

\section{Soil Building and Erosion Control Capability}

A slow growing species (22), that probably provides little protection from soil erosion.

\section{Adaptation to Disturbance}

Arctic willow invades disturbed dry sites in the Canadian high arctic, although it does not become established until much later than grasses (23). It was found to be an important colonizer of an abandoned airstrip on Ellesmere Island, N.W.T. where it comprised 30 to $40 \%$ of the ground cover compared to 5 to $10 \%$ in the undisturbed area (46). Arctic willow is a pioneer on glacial moraines at Glacier Bay, Alaska and near Clachnacudainn Snowfield, B.C. (332).

\section{Competitive Ability}

Thought to be a good competitor on harsh sites, but poorer than grasses in less severe locations.

\section{Commercial Value}

No commercial value, beyond forage value for wildlife, and aesthetic value on denuded sites.

\section{Palatability and Nutritive Value}

Arctic willow has been reported to contain 10 to $21 \%$ crude protein, 0.5 to $1.5 \%$ calcium, and 0.2 to $0.6 \%$ phosphorus. These values were considered adequate to provide nutritious forage for bighorn sheep (225). Also known to be an important food source for many arctic tundra wildlife species.

\section{Seed or Planting Stock Availability}

No commercial source of seed known.

\section{Methods and Ease of Establishment}

Seed. Sow seeds as soon as collected. Hardwood cuttings are also effective (21). Willows in general have been reported to be a readily obtainable woody plant material which roots rapidly and acts as a soil stabilizer. Tip cuttings (the upper 30 to $45 \mathrm{~cm}$ of willow shoots) can be collected in March or early April, tied in bundles with the base wrapped in wet paper towels and then stored at just above $0^{\circ} \mathrm{C}$ in plastic bags until planting time. These cuttings may then be planted to three-quarters their length at $45 \mathrm{~cm}$ intervals. The low growing types of willows (such as arctic willow) apparently provide good cover at relatively low cost (140).

\section{Current Status for Reclamation}

Arctic willow is found in alpine and subalpine environments in Alberta. It is usually confined to soils of low nutrient status. It is a slow growing pioneer that is palatable and is browsed by bighorn sheep. This species has potential use for revegetation of disturbed alpine areas in Alberta but research is needed into the best methods of propagation and early management. 


\section{SPECIES SUITABILITY MAP AND SUMMARY TABLE}

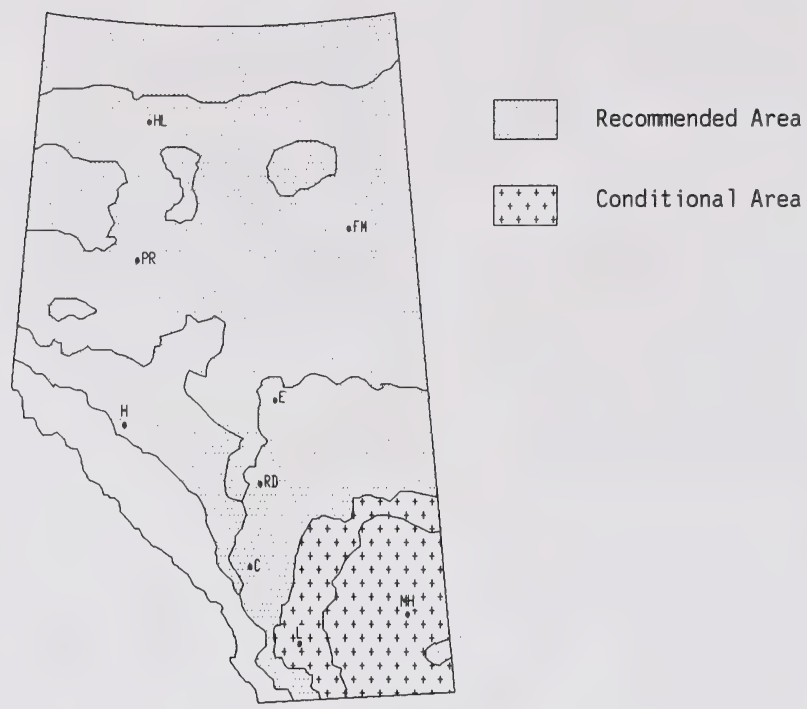

Commercially Available: Yes__ No X

\begin{tabular}{|c|c|c|c|c|c|}
\hline \multirow{2}{*}{$\begin{array}{l}\text { RECLAMATION SUITABILITY } \\
\text { CRITERIA }\end{array}$} & \multicolumn{5}{|c|}{ SUITABILITY RAIING. } \\
\hline & Very High & High & Medium & Low & None \\
\hline Drought Tolerance & & & & $x$ & \\
\hline Salt Tolerance & & & $x$ & & \\
\hline Acid & & & $x$ & & \\
\hline Tolerance Base & & & $x$ & & \\
\hline Winter Hardiness & & & $x$ & & \\
\hline Erosion Control & & & $x$ & & \\
\hline Persistence & & $x$ & & & \\
\hline Palatability & & $x$ & & & \\
\hline Browse Tolerance & & $x$ & & & \\
\hline Moisture Preference & Moist & wet, & rates $f 10$ & & \\
\hline Soil Preference & Sandy & ave & ell to im & ctly & \\
\hline
\end{tabular}


Salix bebbiana Sarg.

\section{SPECIES BIOLOGY}

Taxonomy - Beaked Willow (78) Bebb Willow (443).

Includes var. perrostrata (Rydb.) Schneid.

\section{Origin and Range}

Native. Alaska east to Hudson Bay, Labrador and Newfoundland, and south to New Jersey, Nebraska, New Mexico and central California $(443,419)$. Also in eastern Asia (443).

\section{Growth Habit}

A tall coarse shrub, or small tree up to $10 \mathrm{~m}$ in height $(443,64)$.

\section{Nitrogen Fixing - None}

Longevity - Long-lived perennial.

\section{Self Propagation}

Bebb willow establishes by seed, suckers, root shoots, and sprouting from branch segments (5, 347).

\section{Ecological Setting}

Bebb willow is very common throughout Alberta to the subalpine. It is common around sloughs in the prairies throughout the foothills and in upland forests of northern Alberta $(78,312,64)$. In Alaska it is found in thickets adjacent to streams, swamps and lakes. Forms large spreading shrubs in meadows. Throughout most forest types as scattered individuals (443). In northern Alberta often representative of tall shrub borders of rivers (399). Common native associates: Salix lasiandra, Alnus tenuifolia, Cornus stolonifera, Rubus pubescens.

\section{TOLERANCES}

\section{Soil Preferences}

Bebb willow is usually found on moist, sandy or gravelly soils (399). It is adapted to a range of soil moisture conditions from well drained to poorly drained soils, which are usually waterlogged. It is found on a wide range of soil textures (5). This willow will withstand flooding during the growing season (5).

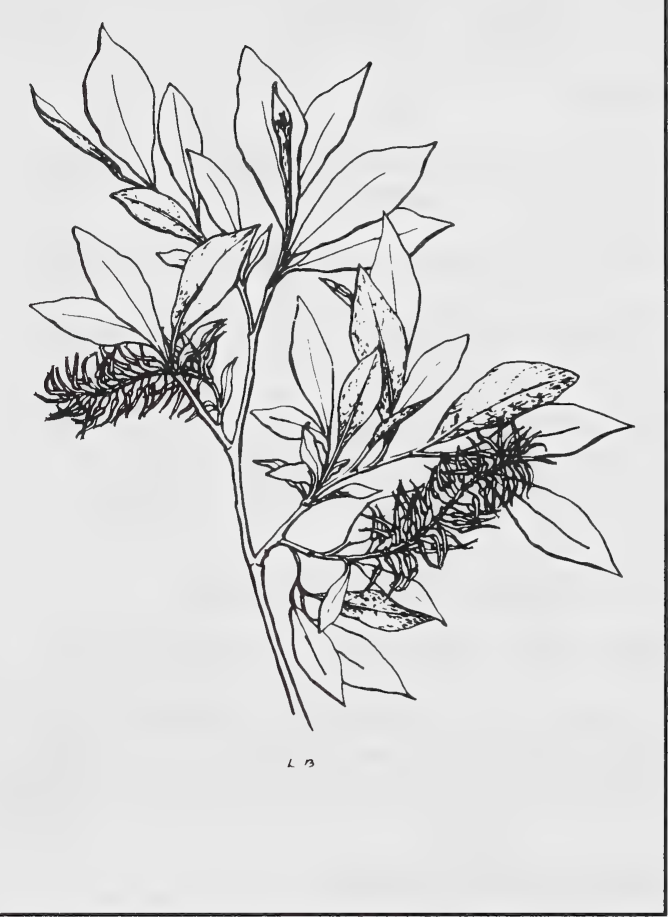

\section{Nutrient Requirements}

Expected to have low to moderate nutrient requirements.

\section{Soil Reaction}

Bebb willow will tolerate moderately alkaline soils but does poorly in extremely acidic or alkaline conditions (347). It is also tolerant of medium acid conditions (5). Bebb willow has been noted as a pioneer on flat, sandy barren areas near Sudbury, Ontario. These soils are very acid (pH 3.2 to 4.5).

\section{Soil Salinity}

Will probably tolerate moderately saline soils.

\section{Drought}

Does not tolerate drought well. Prefers sites with adequate moisture. 


\section{Heavy Metals and Hydrocarbons}

Willows are reported to have a high tolerance of oil (282). Bebb willow has been observed growing on barren acid soils with elevated levels of $\mathrm{Ni}, \mathrm{Cn}$ and Al, near Sudbury, Ontario (28).

\section{Shade}

Bebb willow has low shade tolerance $(5,356)$. It grows best in full sunlight (356).

Browsing - Regrows readily after browsing (347).

\section{Susceptibility to Disease and Insect Damage}

Willow sawfly may be a serious pest of willow cutting beds and rooted cuttings (102). Very heavy rodent damage on areas with heavy grass cover in northern Alberta (J. Sherstabetoff, pers.comm.).

\section{RECLAMATION CONSIDERATIONS}

\section{Soil Building and Erosion Control Capability}

Willows in general have shallow, dense root systems (205). Bebb willow has a moderate rate of height growth and a moderate cover rate (5). A relatively good soil stabilizer.

\section{Adaptation to Disturbance}

It is one of the most common species In willow stands succeeding fire on upland sites (443). Willows have been observed to invade mine spoil piles in southeastern B.C. (96) and Alberta (271, 357). Bebb willow has been observed invading barren acid soils near Sudbury, particularly after such soils received amendments of lime and phosphate $(28,479)$.

\section{Competitive Ability}

Moderately aggressive on suitable sites.

\section{Commercial Value}

Important source of "diamond willow" used for carving canes, lamp posts and furniture (443). Also important for wildlife browse (399) and for soil stabilization (205).

\section{Palatability and Nutritive Value}

Bebb willow is a major source of browse for moose and deer as well as rabbits and hares (347). Important browse for moose throughout interior Alaska (443). Willows are reported to be heavily utilized by bighorn sheep, elk, mule deer, and moose on foothills range in Alberta (144).

\section{Seed or Planting Stock Availability}

Willow seed is not available from commercial sources because, in general, it is viable for only a few days (419). "Wilson" bebb willow was released in 1985 in Alaska for screening, windbreaks and living fences, as well as for reclamation (738).

\section{Methods and Ease of Establishment}

Seed, seedlings, transplants, and stem cuttings (53). Salix bebbiana is a spring dispersing willow. Seed is green when preripe, and yellowish when ripe (419). In general, willow seed germinates in 12 to 24 hours (419). The maximum period of storage is from 4 to 6 weeks, but viability is markedly reduced after 10 days for seed stored at room temperature (419). However $\underline{\mathrm{S}}$. glauca and $\underline{\mathrm{S}}$. alaxensis were successfully stored for 14 to 16 months in polyethylene bags at $-10^{\circ} \mathrm{C}$ with no loss in seed viability (492). Seed must be sown Immediately after collection. Seedbeds must be moist for good seedling establishment (419). Recommended that plants be spaced at $1.5 \mathrm{~m}$ Intervals (5). Cuttings of Sallx bebblana did not root as readily as S. alaxensis. Rooting was more rapld In stems collected during the spring than in those collected in the fall (116). At the Indian Head Nursery in Saskatchewan, rooted willow cuttings are produced from $15 \mathrm{~cm}$ hardwood cuttings. These are harvested in early fall, stored over winter at $1^{\circ} \mathrm{C}$ and planted in the spring. The cuttings are planted out the following year as one year old (1-0) rooted cuttings (102). Rooting capacity of hardwood willow cuttings was greatest (95 to 97\%) for those cuttings immediately placed in cold storage after collection. If the hardwood shoots were exposed to indoor temperatures for even a short period after collection (6 days), rooting was significantly reduced (103).

\section{Current Status for Reclamation}

Salix bebbiana and $\underline{\mathrm{S}}$. interior hardwood stem cuttings (1-0) had a survival of from 30 to $70 \%$ on mine overburden in northern Alberta. Mortality was largely attributed to rodent damage. $\underline{S}$. bebbiana had poor overwintering ability on oil sands tailings (J. Sherstabetoff, pers.comm.). Fourth year survival of Bebb willow plantings on amended tailings sand averaged $63 \%$. Competition from ground cover 
negatively affected survival and growth. Growth averaged $15 \mathrm{~cm} /$ year, similar to "Northwest" poplar, silverberry and green alder (641). Bebb willow is recommended for revegetation planting in the southwest area of Alaska (5). 
$\underline{\text { Salix glauca }}$

\section{SPECIES SUITABILITY MAP AND SUMMARY TABLE}

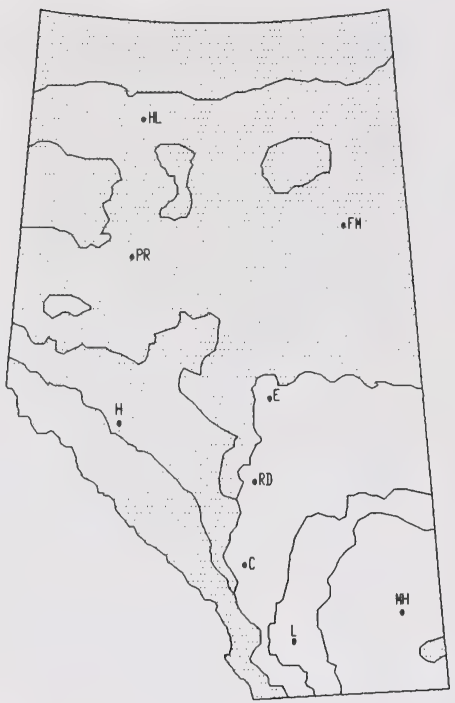

Recommended Area

Commercially Available: Yes No $X$

\begin{tabular}{|c|c|c|c|c|c|}
\hline \multirow{2}{*}{$\begin{array}{l}\text { RECLAMATION SUITABILITY } \\
\text { CRITERIA }\end{array}$} & \multicolumn{5}{|c|}{ SUITABILITY RATING } \\
\hline & Very High & High & Medium & Low & None \\
\hline Drought Tolerance & & & & $x$ & \\
\hline Salt Tolerance & & & & $x$ & \\
\hline $\mathrm{pH} \quad$ Acid & & & $x$ & & \\
\hline Tolerance Base & & & & & \\
\hline Winter Hardiness & & $x$ & & & \\
\hline Erosion Control & & & $x$ & & \\
\hline Persistence & & $x$ & & & \\
\hline Palatability & & $x$ & & & \\
\hline Browse Tolerance & & $x$ & & & \\
\hline Moisture Preference & Moist & wet, & rlogged. & & \\
\hline
\end{tabular}


Salix glauca L.

\section{SPECIES BIOLOGY}

Taxonomy - Grayleaf Willow (443).

Var. villosa (Hook.) Anderss.

\section{Origin and Range}

Native. Alaska east to Labrador and Newfoundland, south to southern British Columbia; in the Rocky Mountains to northern New Mexico. Also in northern Europe and Asia (443).

\section{Growth Habit}

An erect shrub 0.5 to $2 \mathrm{~m}$ tall (312). It may be repressed and spreading in exposed sites and in favourable sites can become a small tree to $6 \mathrm{~m}$ in height and $12.5 \mathrm{~cm}$ in diameter (443).

\section{Nitrogen Fixing - None}

Longevity - Long-lived perennial.

\section{Self Propagation}

Grayleaf willow spreads by seed. The stump will resprout if cut or destroyed by fire (323). In severe sites it may spread by means of rooting of long horizontal stems (369).

\section{Ecological Setting}

A widely variable species. It occurs over a wide range of habitats. In the arctic and western Alaska it grows on river cutbanks and floodplains and in protected sites on tundra (443). It occurs in most forest types in the boreal forest. In B.C. it is common in open or semi-open well drained sites east of the coastal mountains, and at or above timberline it forms extensive thickets (particularly in the north) (64). In northern and western Alberta, it is found in meadows, bogs, along streams and on Rocky Mountain slopes (690).

\section{TOLERANCES}

\section{Soil Preferences}

Grayleaf willow is found on a range of soil moisture conditions from well drained to poorly drained soils that are usually waterlogged (5). It is adapted to a wide range of soil texture conditions (144). In arctic Norway, it is found on shallow, waterlogged organic soils (369).

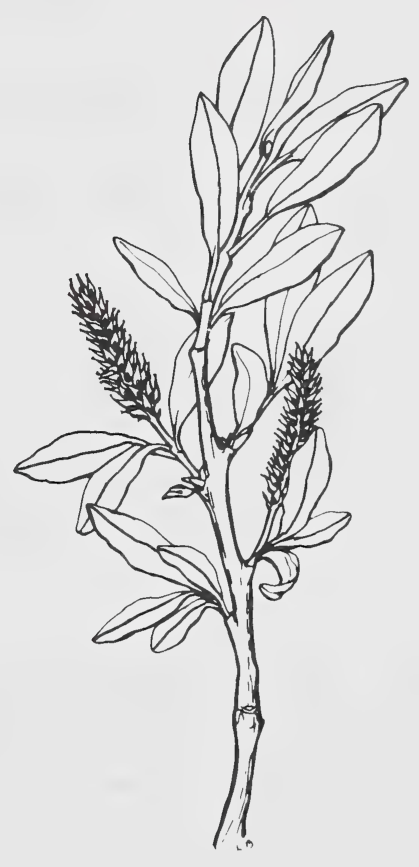

\section{Nutrient Requirements}

Moderate nutrient requirements.

\section{Soil Reaction}

Grayleaf willow has moderate tolerance to acid soil conditions (5).

\section{Soil Salinity}

Not generally found on saline sites.

\section{Drought}

Will not grow on sites where moisture stress is high.

\section{Heavy Metals and Hydrocarbons}

In a study of the heavy metal content of tundra plant species, willows were found to accumulate $\mathrm{Zn}, \mathrm{Cd}$, $\mathrm{U}, \mathrm{Pb}, \mathrm{Co}$ and $\mathrm{Cu}$ (332). Willows, in general, have been reported to have a high tolerance of oil (282). 


\section{Shade}

Grayleaf willow has low shade tolerance (5)

\section{Browsing}

Tolerant of very heavy browsing. Will resprout from root crown if cut.

\section{Susceptibility to Disease and Insect Damage}

No specific susceptibility noted.

\section{RECLAMATION CONSIDERATIONS}

\section{Soil Building and Erosion Control Capability}

Grayleaf willow has a moderate cover rate (5), and can be expected to provide moderate soil stabilizing abilities.

\section{Adaptation to Disturbance}

Grayleaf willow is a common pioneer after fire and occurs along roadsides and rivers. It also invades glacial outwash, mine tailings and abandoned fields in interior Alaska (443). Grayleaf willow was reported to invade disturbed sites on the Tuktoyaktuk Peninsula, N.W.T. and mud slumps in the Mackenzie River Delta (332).

\section{Competitive Ability}

$\underline{S}$ glauca is fairly aggressive on preferred sites such as burned-over areas in northwestern Alberta.

\section{Commercial Value}

An important wildlife browse species $(144,443)$. Soil stabilizer.

\section{Palatability and Nutritive Value}

Important browse source for moose (443). Willows generally are preferred food of bighorn sheep, elk and mule deer on foothills range in Alberta (144).

\section{Seed or Planting Stock Availability}

No source of commercial seed or planting stock is known; however, operators are relatively successful in propagating planting materials.

\section{Methods and Ease of Establishment}

Seed, seedling and transplant, stem cuttings and root cuttings (5) are all acceptable methods of establishment. Maximum spacing recommended is $3 \mathrm{~m}$ by $3 \mathrm{~m}$ (5). Hardwood cuttings generally fare better than softwood cuttings (332). Grayleaf willow cuttings did not root as readily under laboratory conditions as $\underline{\mathrm{S}}$. alaxensis or $\underline{\mathrm{S}}$. rovae-angliae (115). Grayleaf willow disperses seed in the autumn. Seed has been successfully stored in polyethylene bags at $-10^{\circ} \mathrm{C}$ for 14 to 16 months (492). Unlike most willows, grayleaf willow seed required stratification before germination can occur (493). Wide variations exist within the species, however. Some varieties may set seed in spring, while others ripen as late as October (495).

\section{Current Status for Reclamation}

Stem cuttings have been successfully used for revegetating unstable sand dunes in northern Alberta (258). Performance testing has indicated that while survival may be high, vigour tended to be low and dieback rate high $(645,706)$. Grayleaf willow did not survive in tests in the alpine region at Tent Mountain, Alberta (707). Recommended for revegetation of arctic and alpine areas in Alaska (5). Early (1931) plantings of grayleaf willow wildings on the Wasatch Plateau, Utah (subalpine) were reported as failures (337). In New Zealand, willow cultivars are widely used for erosion control, and a mechanical technique for deep planting of willow poles on deep unstable mountains scree slopes has been developed (203). 


\section{SPECIES SUITABILITY MAP AND SUMMARY TABLE}

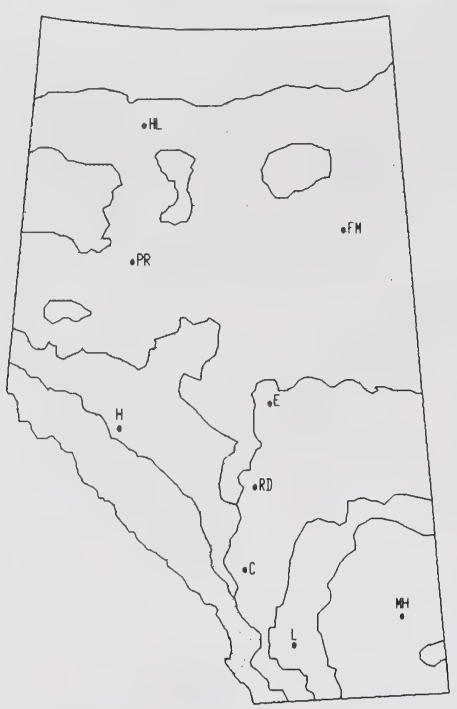

Recommended Area

Commercially Available: Yes No $X$

\begin{tabular}{|c|c|c|c|c|c|}
\hline \multirow{2}{*}{$\begin{array}{l}\text { RECLAMATION SUITABILITY } \\
\text { CRITERIA }\end{array}$} & \multicolumn{5}{|c|}{ SUITABILITY RATING } \\
\hline & Very High & High & Medium & Low & None \\
\hline Drought Tolerance & & & $x$ & $x$ & \\
\hline Salt Tolerance & & & $x$ & & \\
\hline pH Acid & & $x$ & & & \\
\hline Tolerance Base & & & & & \\
\hline Winter Hardiness & & $x$ & & & \\
\hline Erosion Control & & & $x$ & & \\
\hline Persistence & & $x$ & & & \\
\hline Palatability & & $x$ & & & \\
\hline Browse Tolerance & $\mathbf{x}$ & & & & \\
\hline Moisture Preference & Moist & wet, w & o poorly & ed wa & ed soils. \\
\hline Soil Preference & Wide & red & also & $0011 \mathrm{~s}$ & \\
\hline
\end{tabular}


Salix scouleriana Barr. ex Hook.

\section{SPECIES BIOLOGY}

\section{Taxonomy}

Scouler Willow (205); Mountain Willow (608).

Includes var. coetanea Ball.

\section{Origin and Range}

Native. Alaska east to Saskatchewan and south to New Mexico and California (443). It is the most common willow of southeastern and south central Alaska (428). Throughout B.C. but less common inland compared to other willows. The variety coetanea Ball occurs mainly east of the coastal mountains (64). Western and northern Alberta and Cypress Hills (690).

\section{Growth Habit}

In Alberta, a shrub or small tree 2 to $8 \mathrm{~m}$ high (690). In Alaska, it may reach heights of 15 to $18 \mathrm{~m}$ with a trunk diameter of 40 to $50 \mathrm{~cm}$ (443). Fast growing shrub or small tree (608).

Nitrogen Fixing - None

Longevity - Long-lived perennial.

\section{Self Propagation}

Seed; resprouts from cut trunk; branch segments (5). Rated moderate for natural vegetative reproduction (338).

\section{Ecological Setting}

Occurs over a wide range of habitats. In Alaska, Scouler willow is a common upland species where it has become widespread after fires. It is common in areas disturbed by logging and also along streams and roadsides (443). In Alberta, it is most common in the foothills and in northern Alberta on hillsides and along streams (312).

\section{TOLERANCES}

\section{Soil Preferences}

Scouler willow is adapted to a range of soil moisture conditions. It is found on well drained through to very poorly drained soils that are waterlogged (5). In Alaska, it is not very well adapted to excessively drained soils that are

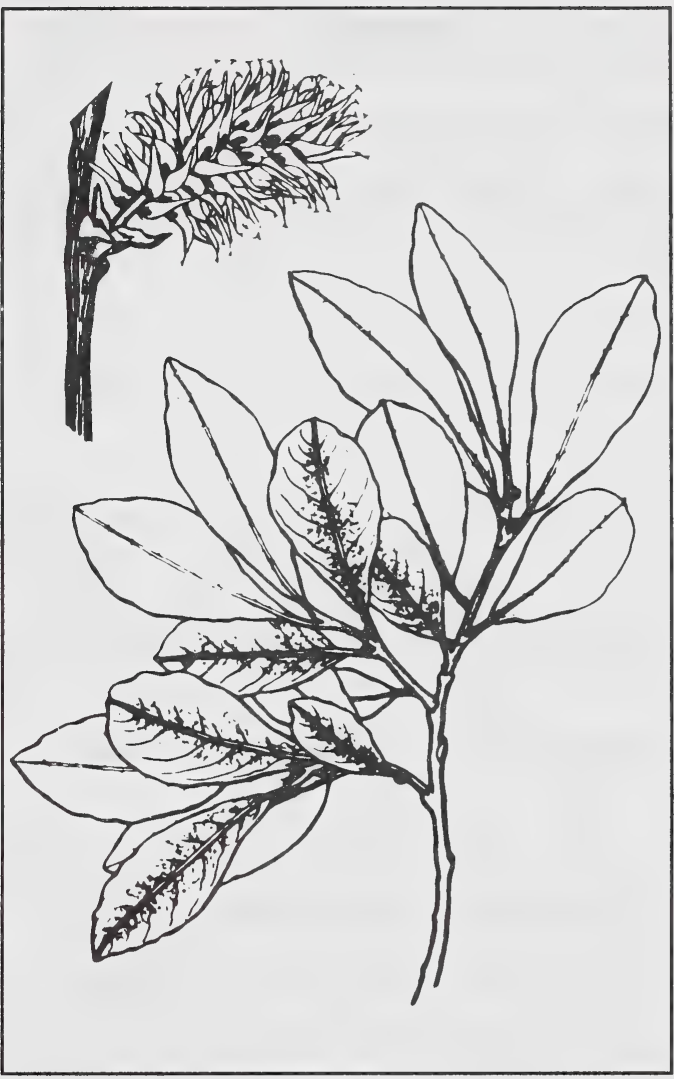

susceptible to drought. It has been reported, however, that Scouler willow is well adapted to dry mourtain slopes in Utah and Idaho (302). Scouler willow is found on a range of mineral soil textures and also occurs on peaty soils $(5,174,61)$.

\section{Nutrient Requirements}

Moderate nutrient requirements. Seems to do best on burned over sites where there is a flush of nutrients.

\section{Soil Reaction}

Scouler willow has a high tolerance of acid soil conditions (5).

\section{Soil Salinity}

Will not tolerate excessively saline soils.

\section{Drought}

Does not generally tolerate drought in northern latitudes (5), but is found on dry sites in the 
southern part of its range (302). Has invaded dry sites near Cadomin, Alberta (357).

\section{Heavy Metals and Hydrocarbons}

Willows, in general, have been reported to have a high tolerance of oil (282). No other tolerances are known.

\section{Shade}

Scouler willow has low tolerance of shade (5).

\section{Browsing}

Salix scouleriana produces the greatest amount of browse on branches which are browsed the previous winter. In one study area, an average unbrowsed branch produced $2.4 \mathrm{~g}$ of new growth, whereas a browsed branch produced $4.0 \mathrm{~g}$ of new growth in a given year (481).

\section{Susceptibility to Disease and Insect Damage}

No specific pests noted.

\section{RECLAMATION CONSIDERATIONS}

\section{Soil Building and Erosion Control Capability}

It has a relatively rapid height growth rate and a moderate cover rate (5). Scouler willow has been rated as good for ability to stabilize soil $(337,338)$. It has a moderate rate of spread by seed and vegetative means (337).

\section{Adaptation to Disturbance}

Scouler willow rapidly invades burned areas, often forming dense thickets (443). It also invades other disturbed sites such as logging areas and roadsides (443). It has been reported as a pioneer on coal mine spoil piles near Cadomin, Alberta. The Cadomin site, at $1675 \mathrm{~m} \mathrm{ASL}$, has severe climatic limitations (drought, wind) (357). Pioneer on gravel beds subject to moisture stress in Washington, U.S.A. (157).

\section{Competitive Ability}

Very aggressive on preferred sites often shading out other species, but will act as a "nurse" species for conifers which are shade tolerant (eg. white spruce).

\section{Commercial Value}

Source of "diamond willow" for carving, furniture, etc. (443); watershed protection (302); wildlife food and cover $(144,446)$.

\section{Palatability and Nutritive Value}

Scouler willow is an important source of browse for moose. In southcentral Alaska trees are commonly barked by moose (443). Salix spp. are preferred foods of bighorn sheep, elk, and mule deer on foothills range in Alberta (144). Provides good cover for mule deer, game birds and small mammals, good forage for mule deer and small mammals but only fair forage for game birds (446). Important winter browse for moose and deer (608).

\section{Seed or Planting Stock Availability}

No commercial source of seed or planting stock is known, but operators have generally good success at propagating for rehabilitation purposes.

\section{Methods and Ease of Establishment}

One of the earliest flowering willows. In Alaska, it flowers in May, seeds disperse in June and catkins are shed by July (443). In general, seed must be sown immediately after collection. Willow seed germinates in 12 to 24 hours. Seedbed must be moist for good seedling establishment (443). Hardwood cuttings are generally better than softwood cuttings $(322,380)$. Seedlings, transplants and stem cuttings planted at a maximum spacing of $1.5 \mathrm{~m}$ by $1.5 \mathrm{~m}$ have been recommended (5). Scouler willow can be readily planted as stem and root cuttings, or rooted in the greenhouse and then planted out $(302,303)$. It has been rated as good for establishment by transplants (337). Reported to have low establishment requirements.

\section{Current Status for Reclamation}

Scouler willow has been used by state and federal agencies for watershed plantings (streambank stabilization) in Utah (302). It is also considered useful for providing an environment in which other species can become established (302). Early (1931) plantings of Scouler willow wildlings on the Wasatch Plateau, Utah (subalpine) were reported as failures (377). Nonetheless it has been suggested as a suitable shrub for revegetation in the subalpine in Utah (337). Scouler willow has been recommended 
as a plant species suitable for revegetation of disturbed lands in the juniper-pinon woodland zone in northwestern Colorado. It is best suited to a wet habitat with an optimum slope of 0 to $8 \%$ (362). In New Zealand willow cultivars are widely used for erosion control, and a mechanical technique for deep plantings of willow (Salix spp.) poles (cuttings) on deep unstable mountain screes has been developed (203). 


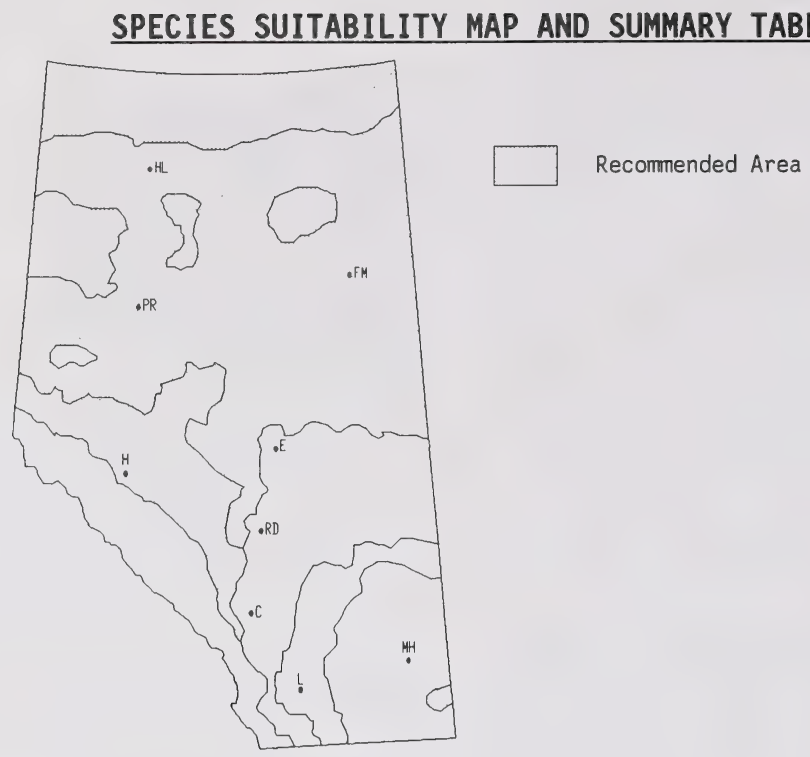

Commercially Available: Yes $X$ No

\begin{tabular}{|c|c|c|c|c|c|}
\hline \multirow{2}{*}{$\begin{array}{l}\text { RECLAMATION SUITABILITY } \\
\text { CRITERIA }\end{array}$} & \multicolumn{5}{|c|}{ SUITABILITY RATING } \\
\hline & Very High & High & Medium & Low & None \\
\hline Drought Tolerance & & & $x$ & & \\
\hline Salt Tolerance & & & $x$ & & \\
\hline pH Acid & & & $x$ & & \\
\hline Tolerance Base & & & $x$ & & \\
\hline Winter Hardiness & & $x$ & $x$ & & \\
\hline Erosion Control & & & $x$ & & \\
\hline Persistence & & $x$ & & & \\
\hline Palatability & & & & $x$ & \\
\hline Browse Tolerance & & $x$ & $x$ & & \\
\hline Moisture Preference & Moist & dry. & & & \\
\hline Soil Preference & $\begin{array}{l}\text { Silt } \\
\text { draine }\end{array}$ & to $s$ & loam, $r$ & $\bmod$ & well \\
\hline
\end{tabular}


Shepherdia canadensis (L.) Nutt.

\section{SPECIES BIOLOGY}

Taxonomy - Canadian Buffalo-berry.

\section{Origin and Range}

Native. Alaska and Yukon Territory to James Bay and Newfoundland, south in the mountains to Maine, New York, Michigan, New Mexico, and Oregon (443).

\section{Growth Habit}

Canadian buffalo-berry is a deciduous thornless shrub; 0.6 to $2.0 \mathrm{~m}$ tall $(443,690)$.

\section{Nitrogen Fixing}

Fixes nitrogen; in solution culture nodulation occurred at $\mathrm{pH} 6$ and 7 but not at pH 5 (164); nodulated plants have been observed in the subalpine (Colorado) (44). Associated with the $\mathrm{N}_{2}$ fixing actinomycete Frankia and vesicular-arbuscular mycorrhizae (728). Shoot weights of 12 week old inoculated buffalo-berry seedlings were 9 times greater than uninoculated seedlings and root weights were 4 times greater (Visser and Danielson 88).

Longevity - Long-lived perennial.

\section{Self Propagation}

Seed and suckers (J. Sherstabetoff, pers.comm.), although suckers are very short and propagation by this means is questionable (D. Walker, pers.comm.).

\section{Ecological Setting}

Throughout forested region of Alberta. Also found in the Cypress Hills and along the South Saskatchewan River banks. Open forests or dry uplands, aspen forests or old burns; river banks and gravel bars $(443,78)$; occurs over a wide range in elevation up to $2300 \mathrm{~m}$ to $3500 \mathrm{~m} \mathrm{ASL}$ in the Rocky Mountains in Colorado (356). Occurs to, or slightly above, timberline (501). Common native associates (mixed wood): Populus tremuloides, Rosa acicularis, Viburnum edule, Picea glauca; also common in dry, open lodgepole pine forests (365).

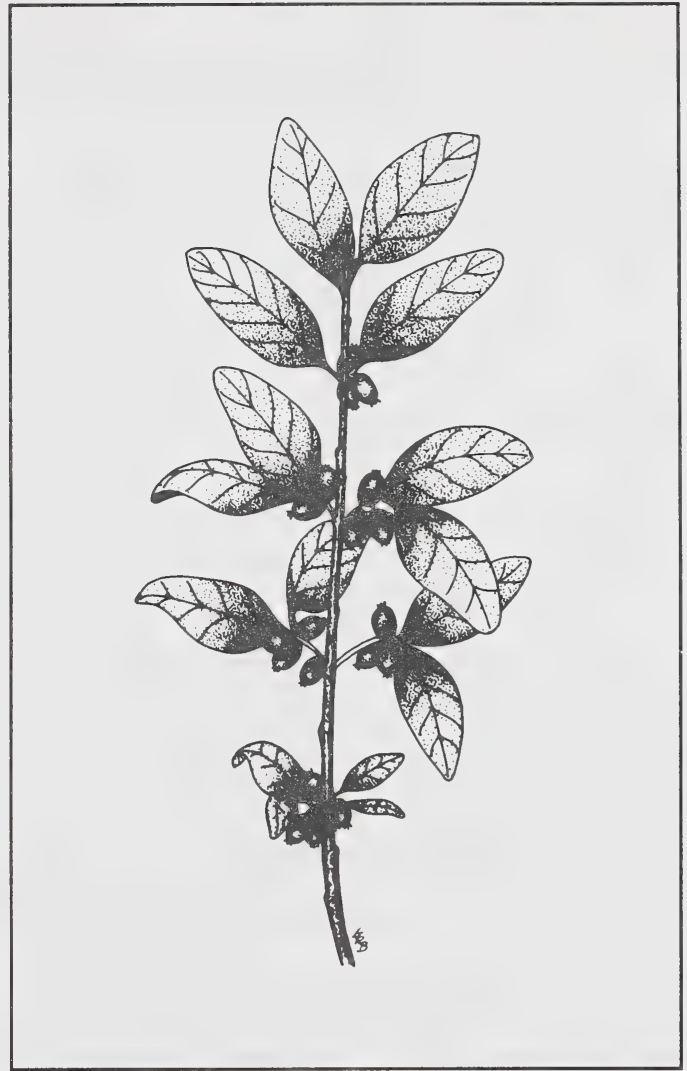

\section{TOLERANCES}

\section{Soil Preferences}

Found on coarse textured (silt loam to sandy loam) and well to moderately well drained soils (5). It is apparently well suited to planting on dry, rocky banks where few other shrubs can survive (419).

\section{Nutrient Requirements}

Buffalo-berry is capable of growing at low nitrogen levels characteristic of glacial outwash (332). It has been observed growing on poor sites such as erosion slopes in Alberta (306). Twenty week old seedlings were larger when fertilized in the greenhouse, but had considerably fewer nodules (728) which may have an effect on planting stock quality. 


\section{Soil Reaction}

Buffalo-berry can tolerate moderately alkaline ( $\mathrm{pH} 8.0$ to 8.4 ) to moderately acidic soils (332).

Drought - Moderate drought tolerance $(5,419)$.

\section{Heavy Metals and Hydrocarbons}

No specific tolerances noted.

\section{Shade}

Moderately tolerant. Grows in partial shade (356)

\section{Browsing}

Generally not browsed, but will regrow successfully from heavy pruning.

\section{Susceptibility to Disease and Insect Damage}

Buffalo-berry is susceptible to leaf spot, leaf rust and powdery mildew, among others (198).

\section{RECLAMATION CONSIDERATIONS}

\section{Soil Building and Erosion Control Capability}

The species often forms dense thickets (443). The related thorny buffalo-berry ( $\underline{\mathrm{S}}$. argentea (Pursh.) Nutt.) has been used for revegetation of roadcuts and other disturbed or eroded areas in Utah (336).

\section{Adaptation to Disturbance}

Buffalo-berry is common on disturbed sites throughout the eastern slopes of the Rocky Mountains in Alberta (365). It is often a pioneer on glacial outwash (332).

\section{Competitive Ability}

Moderately aggressive due to suckering ability.

\section{Commercial Value}

The berries are eaten by grouse and bears; it is also important as a ornamental (443) and is used for erosion control. It is a nitrogen fixer (120).

\section{Palatability and Nutritive Value}

Buffalo-berry has low palatability (427) but is reported to be lightly browsed by deer and elk (393). Berries provide forage for bears.

\section{Seed or Planting Stock Availability}

Limited commercial supplies of seed exist, but costs are high, and adapted ecotypes may not be available (349). Seed yield averages $26 \mathrm{~kg}$ per $100 \mathrm{~kg}$ of fruit and 90400 seeds comprise a kilogram.

\section{Methods and Ease of Establishment}

Seed should be collected from June to August. Chemical harvesting of seed produced good results (434). Seedcoat dormancy occurs and can be treated with $\mathrm{H}_{2} \mathrm{SO}_{4}$ for 10 to 30 minutes. Germination ranges from 14 to $19 \%$ (150). Germination rates of 40 to $75 \%$ have been reported for 6 seed collections in northern Alberta (J. Sherstabetoff, pers.comm.). Cold stratification for 60 days followed by seeding in the greenhouse has been moderately successful (D. Klym, pers.comm); or sow in the fall at $0.6 \mathrm{~cm}$ depth at a rate of 350 seeds $/ \mathrm{m}^{2}$ (119). Most easily propagated from seed (149). Can also be done with suckers (21) or root cuttings (120). Buffalo-berry is well suited to transplanting in containers; root cuttings of various types provide low success (0 to $1 \%$ ) (268, 150).

\section{Current Status for Reclamation}

Excellent fourth year survival (85\%) was found on amended tailings sands near Fort McMurray. Top growth averaged $5 \mathrm{~cm}$ per year in the first four years (641). Inoculated seedlings outplanted on amended tailings sand had much lower survival in the first year; however, the survivors were much larger than their uninoculated counterparts, even after two years (728). Seeding was moderately successful on amended tailings sand in northern Alberta (A. Fedkenheuer, pers.comm.). Buffaloberry has been recommended for planting on mine spoils on dry sites in British Columbia. Seed and root cuttings were the methods of establishment (120). Second year survival of bareroot stock in the subalpine (Coleman, Alberta) averaged 52\% (708). Buffalo-berry is often found on disturbance sites throughout Alberta to the subalpine. Recommended for revegetation on moist to dry sites in Alaska. Seed, seedlings, and transplants were suggested means of establishment (5). It is cold-hardy and tolerant of drought. Its abilities to form thickets and fix atmospheric nitrogen make this species a prime candidate for erosion control on dry sites in the western and northern parts of the province. Further research is needed into methods of establishment, since germination rates are low and results from cuttings have been variable. 


\section{SPECIES SUITABILITY MAP AND SUMMARY TABLE}

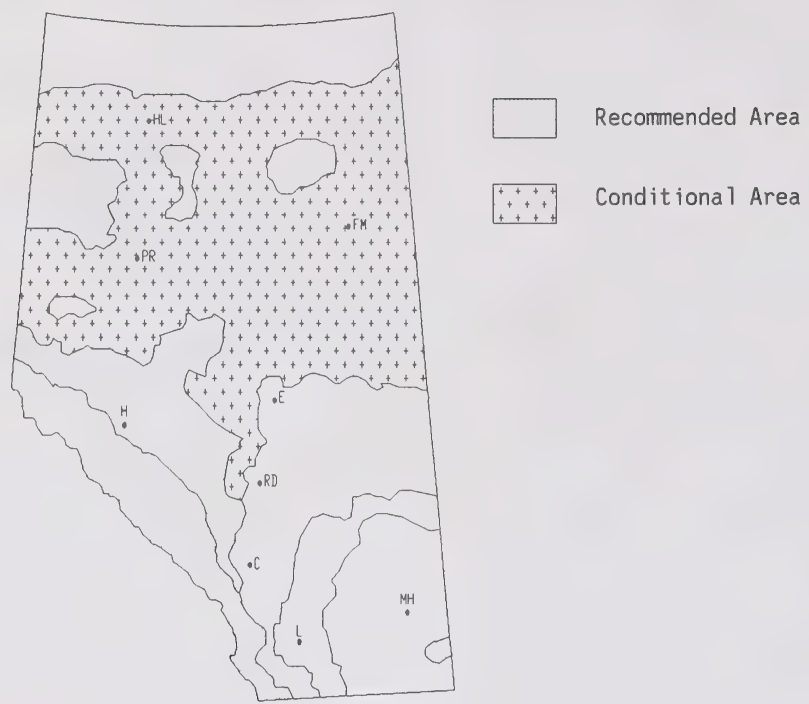

Commercially Available: Yes No $X$

\begin{tabular}{|c|c|c|c|c|c|}
\hline \multirow{2}{*}{$\begin{array}{l}\text { RECLAMATION SUITABILITY } \\
\text { CRITERIA }\end{array}$} & \multicolumn{5}{|c|}{ SUITABILITY RATING } \\
\hline & Very High & High & Medium & Low & None \\
\hline Drought Tolerance & & & & $x$ & \\
\hline Salt Tolerance & & & $x$ & & \\
\hline Acid. & & & & $x$ & \\
\hline Tolerance Base & & & & $x$ & \\
\hline Winter Hardiness & & $x$ & & & \\
\hline Erosion Control & & & $x$ & & \\
\hline Persistence & & $x$ & & & \\
\hline Palatability & & & & $x$ & \\
\hline Browse Tolerance & & & $x$ & & \\
\hline Moisture Preference & Moist. & & & & \\
\hline Soil Preference & Loamy & ils, w & to moder & well & \\
\hline
\end{tabular}


Spiraea betulifolia Pallas

\section{SPECIES BIOLOGY}

Taxonomy - White Meadowsweet; White Spirea.

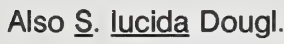

\section{Origin and Range}

Native. Common species of the Rocky Mountains and also eastward in the foothills and montane zone in Alberta. Common in the Cypress Hills $(78,312)$. British Columbia east to Saskatchewan, South Dakota and south to Wyoming and northern Oregon.

\section{Growth Habit}

White meadowsweet is a low deciduous shrub 0.3 to $1.0 \mathrm{~m}$ high. The stems and branches are erect, often dying down annually to the base. It has creeping rootstocks $(78,690)$.

Nitrogen Fixing - None

Longevity - Long-lived perennial.

\section{Self Propagation}

Seed and spreads vigorously by rhizomes (395).

\section{Ecological Setting}

White meadowsweet is common in open aspen groves and lodgepole pine forests of the eastern slopes of the Rocky Mountains in Alberta. It is also found on open slopes (690). It grows in a wide range of habitats from sea-level to the subalpine but it does best on recently disturbed sites in moist forests at moderate elevations (419).

\section{TOLERANCES}

\section{Soil Preferences}

Observed to prefer moist loamy soils which are well to moderately well drained.

\section{Nutrient Requirements}

Grows on sites with low nutrient status.

\section{Soil Reaction}

Will grow on soils which are mildly acidic to mildly alkaline.

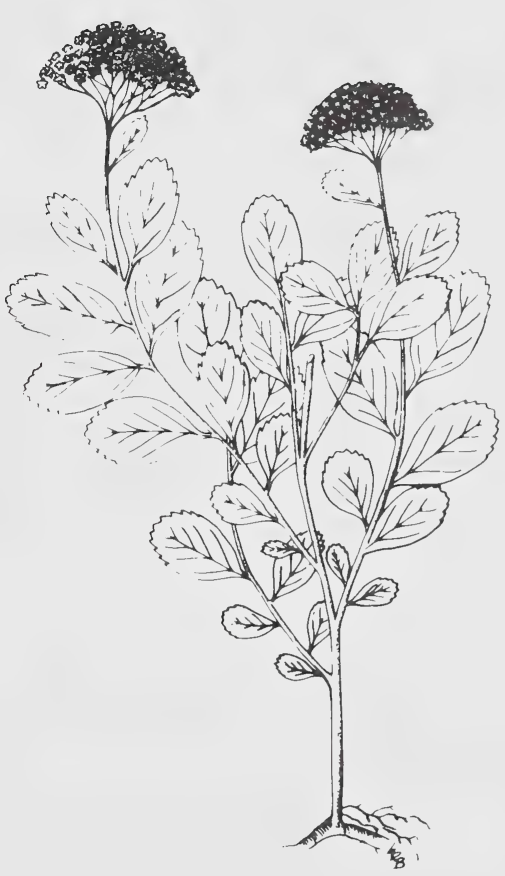

Soil Salinity - Found on moderately saline sites.

\section{Drought}

Found on sites subject to some moisture stress.

\section{Heavy Metals and Hydrocarbons}

No specific tolerances noted, but observed to grow on fuel soaked soils.

Shade

A common inhabitant of the forest understory, where other species are shaded out. Does best on open to semi-shady sites.

\section{Browsing}

Will resprout after cutting or browsing.

\section{Susceptibility to Disease and Insect Damage}

No specific pests noted. 


\section{RECLAMATION CONSIDERATIONS}

\section{Soil Building and Erosion Control Capability}

The extensive rhizome system and the ability to colonize disturbed sites suggest that this species is good for soil building and erosion control.

\section{Adaptation to Disturbance}

White meadowsweet has been observed as a pioneer on drill pads in the southeast coal block in British Columbia (70). It is found on disturbed sites throughout the eastern slopes of the Rocky Mountains in Alberta particularly in the southern parts of the province wherever a seed source is nearby (365). White meadowsweet has been observed as a pioneer on disturbed mine sites in British Columbia particularly in those sites close to lodgepole pine of the Interior Douglas Fir Zone (384).

\section{Competitive Ability}

Observed to be aggressive on favoured sites.

\section{Commercial Value}

Watershed protection (302); ornamental $(419,608)$.

\section{Palatability and Nutritive Value}

White meadowsweet was reported to be lightly browsed in an area frequented by deer and elk in southeastern B.C. (393).

\section{Seed or Planting Stock Availability}

No commercial source of seed is known. Available from some growers as container stock (608).

\section{Methods and Ease of Establishment}

The fruit is light brown when ripe. White meadowsweet seeds do not have a seedcoat or an embryo dormancy, and seed therefore does not require stratification. Seed germinates at low temperatures $\left(0\right.$ to $\left.2^{\circ} \mathrm{C}\right)$. It should be sown in late fall or early spring to take best advantage of favourable moisture conditions at spring melt. Seed collected in British Columbia was reported to have a germination capacity of $68 \%$. Root cuttings are also a successful method of establishment (119, 419).

\section{Current Status for Reclamation}

Spiraea spp. are used for reclamation in Denmark.
White meadowsweet has been planted in Idaho for watershed protection (302). It has been rated as potentially useful for watershed rehabilitation particularly, because of its strongly rhizomatous nature (419). 


\section{SPECIES SUITABILITY MAP AND SUMMARY TABLE}

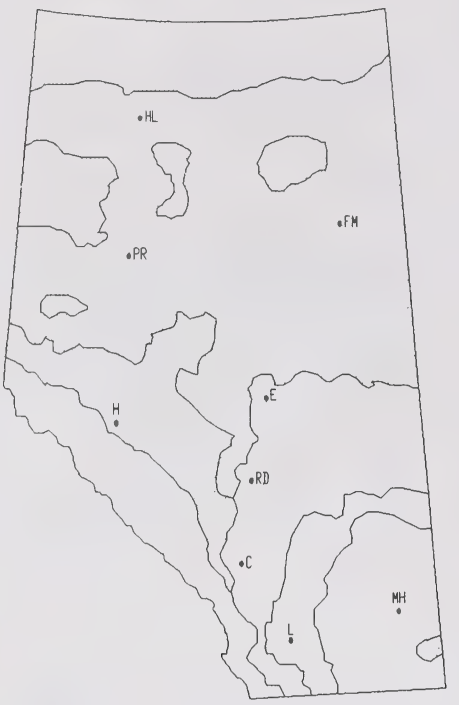

Recommended Area

Commercially Available: Yes $X$ No

\begin{tabular}{|c|c|c|c|c|c|}
\hline \multirow{2}{*}{$\begin{array}{l}\text { RECLAMATION SUITABILITY } \\
\text { CRITERIA }\end{array}$} & \multicolumn{5}{|c|}{ SUITABILITY RATING. } \\
\hline & Very High & High & Medium & Low & None \\
\hline Drought Tolerance & & & $x$ & & \\
\hline Salt Tolerance & & & $x$ & & \\
\hline Acid & & & & $x$ & \\
\hline Tolerance Base & & & $\mathrm{X}$ & & \\
\hline Winter Hardiness & & $x$ & & & \\
\hline Erosion Control & & & $x$ & & \\
\hline Persistence & & $x$ & & & \\
\hline Palatability & & $x$ & $x$ & & \\
\hline Browse Tolerance & & & $x$ & & \\
\hline Moisture Preference & Moist. & & & & \\
\hline Soil Preference & Medium & ture & cky. & & \\
\hline
\end{tabular}


Symphoricarpos albus (L.) Blake

\section{SPECIES BIOLOGY}

Taxonomy - Snowberry; Common Snowberry.

\section{Origin and Range}

Native. Southeast Alaska, Queen Charlotte Islands, and British Columbia across Canada to Quebec, south to Virginia, Michigan, Nebraska, Colorado and California (443).

\section{Growth Habit}

Snowberry is an erect, deciduous shrub from $0.5 \mathrm{~m}$ to $1 \mathrm{~m}$ in height, often dwarf with many slender branches $(78,690)$.

Nitrogen Fixing - None

Longevity - Long-lived perennial.

Self Propagation - Seed, spreads by suckers.

\section{Ecological Setting}

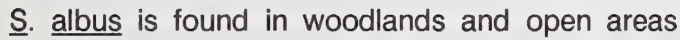
throughout the prairies, in the Cypress Hills, and in the foothills and mountain zone of the eastern slopes. It is often associated with upland aspenwhite spruce forests in the north and in southern areas with open mountain aspen groves and lodgepole pine forests $(78,690,365,399)$.

\section{TOLERANCES}

\section{Soil Preferences}

Snowberry is found on coarse textured and rocky soils (78). In northwestern Colorado, snowberry (Symphoricarpos sp.) occurs on moister areas and at elevations above $2200 \mathrm{~m} \mathrm{ASL}$, but is absent on dry, south and west-facing slopes (307).

\section{Nutrient Requirements}

Will tolerate low nutrient sites.

\section{Soil Reaction}

Will tolerate mildly acidic to moderately alkaline soils.

\section{Soil Salinity}

Grows on mildly saline sites. Not as tolerant as

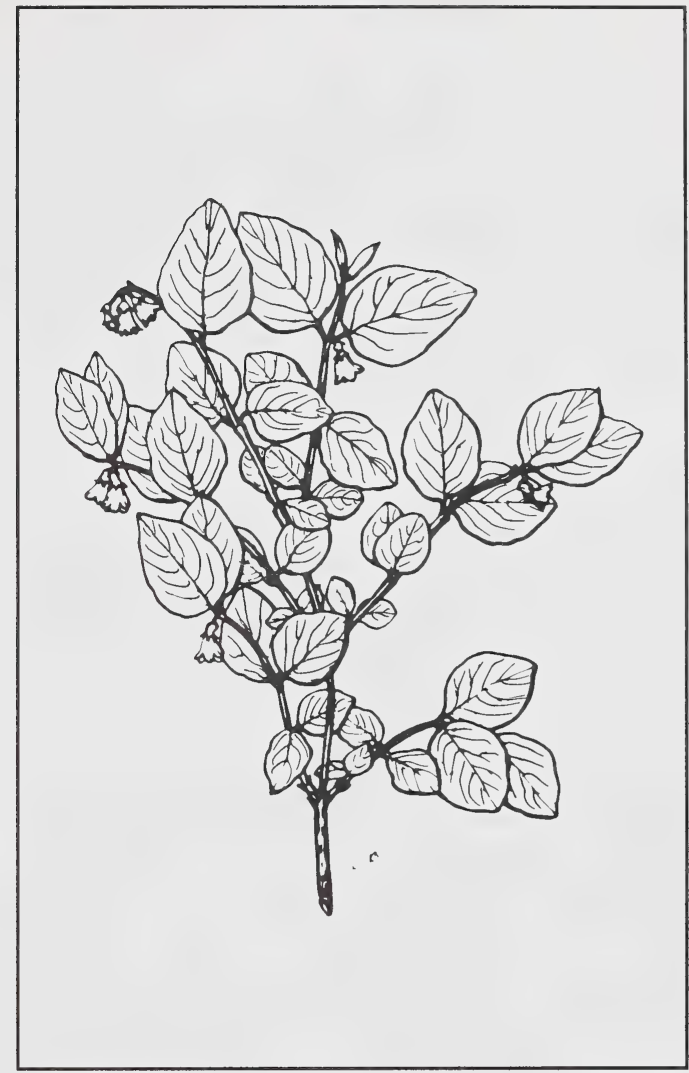

S. occidentalis.

Drought - Moderately drought tolerant.

\section{Heavy Metals and Hydrocarbons}

No specific tolerances noted, but commonly found on oil spill sites.

\section{Shade}

Prefers open sites but will grow in partial shade.

Browsing - Will resprout after cutting or grazing.

Susceptibility to Disease and Insect Damage

No specific pests noted.

\section{RECLAMATION CONSIDERATIONS}

\section{Soil Building and Erosion Control Capability}

Snowberry is a thicket forming shrub $(419,120)$, 
and, as such, affords some soil protection.

\section{Adaptation to Disturbance}

Snowberry was a principal native shrub to invade a burned, forested area in Oregon. After 2 years, it comprised $15 \%$ of the ground cover (15). Snowberry was found on disturbed sites throughout the eastern slopes of the Rocky Mountains, wherever a seed source was nearby; it was more prevalent on disturbed sites in the south than in the north, and was rarely found on disturbed sites in the subalpine (365).

\section{Competitive Ability}

On burned areas in Oregon, development of snowberry was much greater on an unseeded area compared to an area seeded with various grass species. Snowberry establishment was suppressed by competition from the grasses (15).

\section{Commercial Value}

Snowberry has been used to provide cover and forage for wildlife and as an ornamental (419); erosion control (120).

\section{Palatability and Nutritive Value}

Snowberry is an important browse species for deer and elk (15). Moderate use has been reported for Rocky Mountain mule deer (245). Fruit is used by birds in the winter.

\section{Seed or Planting Stock Availability}

Native seed is available from commercial American sources, but costs are high. The number of seeds per $\mathrm{kg}$ of fruit averages about 119000 ; approximately 167000 seeds/kg (639).

\section{Methods and Ease of Establishment}

Propagation from seed is difficult (120). Ripe fruit can be collected in the fall by knocking or stripping the fruit clusters onto canvas. The fruit is white when ripe. Seed can be extracted by macerating the fruit with water and screening off the pulp and the empty seeds. Dried seeds can be stored for several years at either room temperature or $5^{\circ} \mathrm{C}$. Seeds have a hard seedcoat and embryo dormancy. Warm stratification at $20^{\circ} \mathrm{C}$ for 4 to 6 months has been used to overcome seedcoat dormancy. Sulphuric acid scarification produced variable results. Cold stratify at $5^{\circ} \mathrm{C}$ for 3 to 4 months. Sow seeds $0.6 \mathrm{~cm}$ deep at a rate of 350 seeds per $m^{2}$. Seeds can be sown in the spring for germination the following spring. Other methods of establishment are division, hardwood and softwood cuttings and suckers $(419,21,119)$.

\section{Current Status for Reclamation}

First year survival of snowberry on amended tailings sand in northern Alberta has been reported to be very good $(75 \%)$ (378). Snowberry is often found on dry, disturbed sites to the upper montane in Alberta. It is a thicket-forming shrub with potential for use in erosion control. It has been recommended for erosion control throughout British Columbia (120). Snowberry has been used for reclamation of coal mine spoil in British Columbia (497). It is difficult to establish from seed and can not compete with grasses. It is a valuable source of wildlife browse. 


\section{SPECIES SUITABILITY MAP AND SUMMARY TABLE}

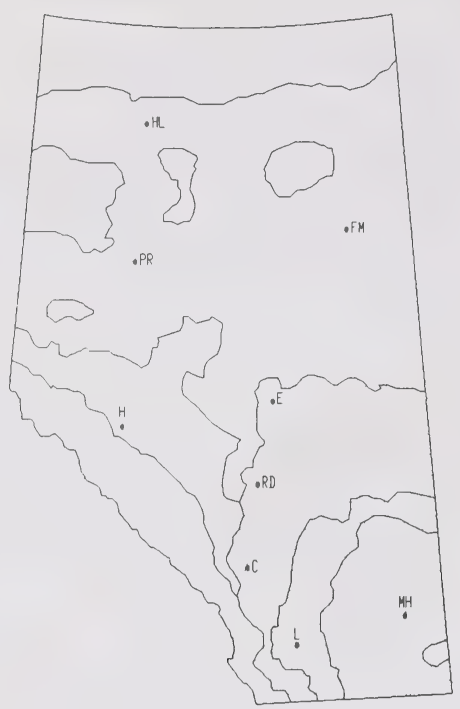

Recommended Area

Commercially Available: Yes No $x$

\begin{tabular}{|c|c|c|c|c|c|}
\hline \multirow{2}{*}{$\begin{array}{l}\text { RECLAMATION SUITABILITY } \\
\text { CRITERIA }\end{array}$} & \multicolumn{5}{|c|}{ SUITABILITY RAIING. } \\
\hline & Very High & High & Medium & Low & None \\
\hline Drought Tolerance & & & $x$ & & \\
\hline Salt Tolerance & & & $x$ & & \\
\hline pH Acid... & & & & $x$ & \\
\hline Tolerance Base & & & $x$ & & \\
\hline Winter Hardiness & & $x$ & & & \\
\hline Erosion Control & & & $x$ & & \\
\hline Persistence & & $x$ & & & \\
\hline Palatability & & $x$ & $x$ & & \\
\hline Browse Tolerance & & & $x$ & & \\
\hline Moisture Preference & Dry tc & loist. & & & \\
\hline Soil Preference & $\begin{array}{l}\text { Silt } \\
\text { impert }\end{array}$ & $\begin{array}{l}y \text { loam } \\
\text { tly dr }\end{array}$ & sandy 1 & mode & ell to \\
\hline
\end{tabular}


Symphoricarpos occidentalis Hook.

\section{SPECIES BIOLOGY}

\section{Taxonomy}

Buckbrush; Badger Brush; Wolfberry; Western Snowberry (608).

\section{Origin and Range}

Native. British Columbia east to Michigan, south to Illinois and New Mexico (419).

\section{Growth Habit}

Buckbrush is a spreading, robust shrub up to $1 \mathrm{~m}$ in height; deciduous $(78,690)$; colonies may grow from $1 \mathrm{~m}$ to $200 \mathrm{~m}$ in diameter (602).

Nitrogen Fixing - None

Longevity - Long-lived perennial.

\section{Self Propagation}

Reseeds itself and spreads by suckers (690).

\section{Ecological Setting}

Buckbrush is very common throughout the prairies where stands are often dense. It is common in ravines, coulees and throughout aspen groves ( 78 , 690).

\section{TOLERANCES}

\section{Soil Preferences}

Found on a range of soils from silty clay loams to sandy loams with moderate to poor drainage.

\section{Nutrient Requirements}

Grows on low nutrient sites.

\section{Soil Reaction}

Will tolerate mildly acidic to moderately alkaline sites.

\section{Soil Salinity}

Buckbrush is moderately tolerant of saline soil. It is

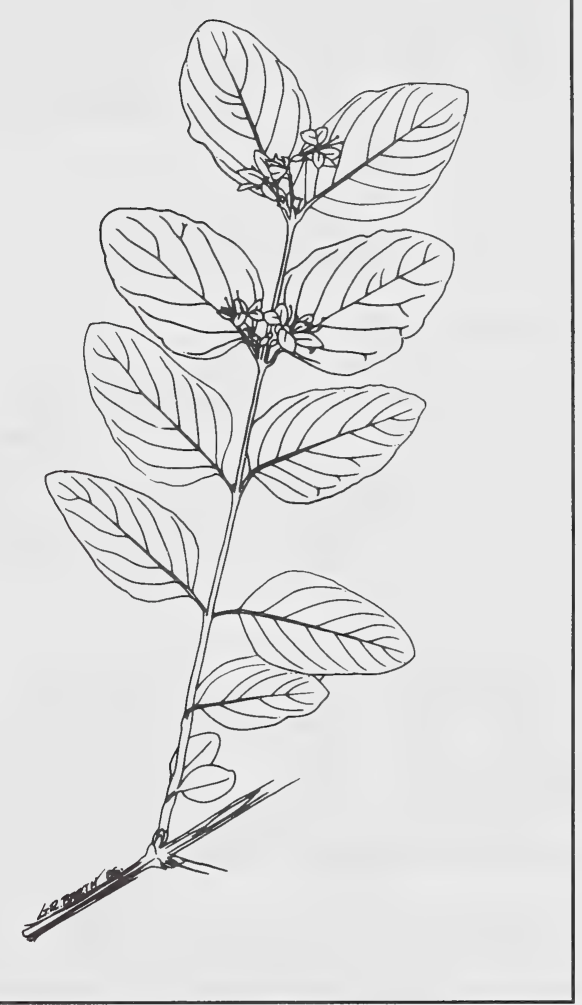

found as a component of pioneering communities on saline mine spoils material near Estevan, Saskatchewan (230).

Drought - Moderately drought tolerant.

\section{Heavy Metals and Hydrocarbons}

No specific references noted, but thought to be moderately tolerant of hydrocarbons.

\section{Shade}

Will grow in partial shade but prefers open sites.

Browsing - Will resprout after cutting.

Susceptibility to Disease and Insect Damage

Buckbrush is susceptible to herbicide damage (197). 


\section{RECLAMATION CONSIDERATIONS}

\section{Soil Building and Erosion Control Capability}

Buckbrush is a thicket-forming shrub (419), and can be expected to offer some protection against erosion.

\section{Adaptation to Disturbance}

Invader of disturbed sites in areas of adaptation.

\section{Competitive Ability}

Buckbrush is strongly competitive with grasses; in a field experiment near Edmonton it increased as rapidly in plots seeded with grass as in unseeded plots (24). Considered to be a "problem" species on rangeland in Alberta; a mow and spray, or burn and spray control program is recommended (602).

\section{Commercial Value}

Buckbrush has been used for erosion control and wildlife habitat plantings (419). The domestic goat (Capra capra) selects against buckbrush (D. Wooley, pers.comm.)

Palatability and Nutritive Value

Buckbrush is not a preferred browse species for cattle (197), though sheep and goats will use it to a greater extent (602). It is reported to be moderately to heavily consumed by Rocky Mountain mule deer (245).

\section{Seed or Planting Stock Availability}

Container stock is available from some growers (608). The number of seeds per $\mathrm{kg}$ of fruit averages 160000.

\section{Methods and Ease of Establishment}

Ripe fruit can be collected in the fall by knocking or stripping the fruit clusters onto canvas. The fruit is white when ripe. Seed can be extracted by macerating the fruit in water and screening off the pulp and empty seeds. Dried seeds can be stored for several years at room temperature or at $5^{\circ} \mathrm{C}$. Seeds have a hard seedcoat and embryo dormancy. Warm stratification at $30^{\circ} \mathrm{C}$ for 3 to 4 months has been used for fall sowing of buckbrush. For spring sowing, the warm stratification should be followed by cold stratification at $5^{\circ} \mathrm{C}$ for 6 months. Sow seeds $0.6 \mathrm{~cm}$ deep at $350 / \mathrm{m}^{2}$. Other methods of establishment are division, hardwood and softwood cuttings and suckers $(24,169,419)$.

\section{Current Status for Reclamation}

Buckbrush is a robust shrub that often spreads by suckers forming dense thickets on the open prairie. It has been used for erosion control. It is moderately tolerant of drought and saline soil conditions and can compete with seeded grasses. It may be one of the better shrubs for planting on sodic clays; it is a common invader on old sodic mine spoils in the Tofield-Canmore-Round Hill area (T. Laidlaw, pers.comm.). 
1. Aase, J.K., and J.R. Wight. 1973. Prairie sandreed (Calamovilfa longifolia): water infiltration and use. J. Range Manage. 26 (3): 212-214.

2. Abbot, D., and G.B. Bacon. 1976. Reclamation of coal mine wastes in New Brunswick. IN: Proceedings of the First Annual Meeting, Canadian Land Reclamation Association. University of Guelph. Guelph, Ont. (Abstr.).

3. Addison, P.A., and K.L. Bell. 1976. Plant growth in relation to surface disturbances, King Christian Island. IN: L.C. Bliss, ed. Indian and Northern Affairs, ALUR 75-76-73.

4. Agricultural Potential Committee of the Alaska Rural Development Council. 1974. Alaska's agricultural potential. Cooperative Extension Service, University of Alaska. Fairbanks, Al.

5. Alaska Rural Development Council. 1977. A revegetative guide for Alaska. Rural Development Council Publication No. 1, P. 238. Cooperative Extension Service, University of Alaska. Fairbanks, Al.

6. Alberta Agriculture. 1977. Agri-fax. Birdsfoot trefoil: Licensed varieties grown in Canada, 1977. Agdex 122/33-1. Edmonton, $\mathrm{AB}$.

7. Alberta Agriculture. 1977. Agri-fax. Alfalfa: Licensed varieties grown in Canada, 1977. Agdex 121/33-2. Edmonton, AB.

8. Alberta Agriculture. 1977. Agri-fax. Bromegrass: Licensed varieties grown in Canada, $1977 . \quad$ Agdex 127/33-1. Edmonton, $A B$.

9. Alberta Agriculture. n.d. Foxtail barley (Hordeum jubatum L.). Edmonton, AB.

10. Alberta Forest Service. 1979. Reclamation research program, reclamation section. Alberta Energy and Natural Resources. Edmonton, $\mathrm{AB}$.

11. Alloway, B.J., and B.E. Davies. 1971. Heavy metal content of plants growing on soils contaminated by lead mining. J. Agric. Sci. 76(2): 321-323.
12. Alsands Project Group. 1978. Environmental impact assessment presented to Alberta Environment in support of an oil sands mining project. Calgary, AB.

13. Andersen, D.C., and K.B. Armitage. 1976. Caloric content of Rocky Mountain subalpine and alpine plants. J. Range Manage. 29(4): 344-345.

14. Anderson, Clifton. n.d. Science rescues threatened native fine-leaved fescue. Impact. University of Idaho College of Agriculture.

15. Anderson, E.W., and L.E. Brooks. 1975. Reducing erosion hazard on a burned forest in Oregon by seeding. J. Range Manage. 28(5): 394-398.

16. Anonymous. 1974. Comprehensive plans for land reclamation and stabilization at the Climax Mine. Climax, Colo.

17. Anonymous. 1977. Russian wild ryegrass: a pasture grass for dry areas. United Grain Growers. Winnipeg, Man.

18. Anonymous. 1978. Plant Inventory Network: A. Plant inventory example (sample of computer printout).

19. Anonymous. 1978. Plant inventory network: B. Range improvement example. (Sample of computer printout.)

20. Antonovics, J., A.D. Bradshaw, and R.G. Turner. 1971. Heavy metal tolerance in plants. Advances in Ecological Research, 7: 2-85.

21. Babb, M.F. 1959. Propagation of woody plants by seed. Pages 6-8 IN: E.B. Peterson and N.M. Peterson, eds. Revegetation information applicable to mining sites in northern Canada. Indian and Northern Affairs, Environmental Studies No. 3. (Annotation)

22. Babb, T.A. 1972. High arctic disturbance studies. Pages 230-281 IN: L.C. Bliss and R.W. Wein, eds. Botanical studies of natural and man-modified habitats in the eastern Mackenzie delta region and the arctic islands. Indian and Northern Affairs, ALUR 71-72-14. 
23. Babb, T.A., and L.C. Bliss. 1974. Effects of physical disturbance on arctic vegetation in the Queen Elizabeth Islands. Pages 1011 IN: E.B. Peterson and N.M. Peterson, eds. Revegetation information applicable to mining sites in northern Canada. Indian and Northern Affairs, Environmental Studies No. 3. (Annotation)

24. Bailey, A.W. 1972. Forage and woody sprout establishment on cleared, unbroken land in central Alberta. J. Range Manage. 25(2): 119-122.

25. Bailey, L.H. 1949. Manual of cultivated plants. The MacMillan Co., New York.

26. Baker, J.M. 1970. The effects of oils on plants. Environ. Pollut. 1: 27-44.

27. Balasko, J.A. 1971. Plant and spoil characteristics affecting surface mine revegetation. Pages 19-20 IN: D.M. Bondurant, ed. Proceedings of the Revegetation and Economic Use of Surfacemined Land and Mine Refuse Symposium. West Virginia University. Morgantown, Va.

28. Balsillie, D., W.D. Mcllveen, and K. Winterhalder. 1978. Problems of revegetation of stressed ecosystems. Presented at 71st Annual Meeting of the Air Pollution Control Association. Houston, Tex.

29. Baranyay, J.A., R.J. Bourchier, and G.P. Thomas. 1962. Supplement to lectures on forest pathology. Environment Canada, Forestry Service, Information Report A-X17.

30. Barry, W.J., and R.M. Sachs. 1968. Vegetative propagation of quaking aspen. Calif. Agri. 22: 14-16.

31. Barth, R.C. 1977. Reclamation practices in the northern great plains coal province. Mining Congress Journal, May 1977: 60-64.

32. Bayne, D.A. 1975. Revegetation of tailings areas at vacated mines near Carcross, Yukon Territory. Pages 13-14 IN: E.B. Peterson and N.M. Peterson, eds. Revegetation information applicable to mining sites in northern Canada. Indian and Northern Affairs, Environmental Studies No. 3. (Annotation)
33. Becking, J.H. 1970. Plant-endophyte symbiosis in non-leguminous plants. Plant and Soil, 32: 611-654.

34. Bell, M.A.M., and D.V. Meidinger. 1976. Native species in reclamation of disturbed lands. Department of Biology, University of Victoria. Victoria, B.C.

35. Bell, K.L. 1975. Aspects of seed production and germination in some high arctic plants. Pages 62-72 IN: L.C. Bliss, ed. Plant and surface responses to environmental conditions in the western high arctic. Indian and Northern Affairs, ALUR 74-75-73.

36. Bell, K.L., and L.C. Bliss. 1973. Alpine disturbance studies: Olympic National Park, U.S.A. Pages 20-21 IN: E.B. Peterson and N.M. Peterson, eds. Revegetation information applicable to mining sites in northern Canada. Indian and Northern Affairs, Environmental Studies No. 3. (Annotation)

37. Bennet, O.L., E.L. Mathias, W.H. Armiger, and J.N. Jones, Jr. 1978. Plant materials and their requirements for growth in humid regions. Pages 285-305 IN: F.W. Schaller and P. Sutton, eds. Reclamation of drastically disturbed lands. American Society of Agronomy, Crop Science Society of America, Soil Science Society of America. Madison, Wis.

38. Bennet, O.L. 1971. Grasses and legumes for revegetation of strip-mined areas. Pages 23-25 IN: M.K. Wali, ed. Practices and problems of land reclamation in western North America. University of North Dakota Press. Grand Forks, N.D.

39. Berg, W.A. 1975. Revegetation of land disturbances by surface mining in Colorado. Pages 79-89 IN: M.K. Wali, ed. Practices and problems of land reclamation in western North America. University of North Dakota Press. Grand Forks, N.D.

40. Berg, W.A., and W.G. Vogel. 1968. Manganese toxicity of legumes seeded in Kentucky strip-mine spoils. U.S. Forest Service, Research Paper NE-119. 
41. Berg, W.A. 1974. Grasses and legumes for revegetation of disturbed subalpine areas. Pages 31-35 IN: W.A. Berg, J.A. Brown, and R.L. Cuany, eds. Proceedings of a Workshop on Revegetation of Highaltitude Disturbed Lands. Colorado State University. Information Series No. 10.

42. Berg, W.A. 1976. Species selection and plant soil relationships. Pages 102-103 IN: K.C. Vories, ed. Reclamation of western surface mined lands: Workshop proceedings.

43. Berg, W.A. and E.M. Barrau. 1973. Composition and production of seedings on strip-mine spoils in northwestern Colorado. Pages 215-224 IN: Research and Applied Technology Symposium on Mined-land Reclamation.

44. Berg, W.A. and E.M. Barrau. 1978. Management approaches to nitrogen deficiency in revegetation of subalpine disturbances. Pages 174-181 IN: S.T. Kenny, ed. Proceedings: High Altitude Revegetation Workshop No. 3. Colorado State University. Information Series No. 28.

45. Berg, W.A., J.A. Brown, and R.L. Cuany. 1974. Proceedings of a Workshop on Revegetation of High-Altitude Disturbed Lands. Colorado State University. Information Series No. 10.

46. Beschel, R.E. 1963. Observations in the time factor in inter-actions of permafrost and vegetation. Pages 31-32 IN: E.B. Peterson and N.M. Peterson, eds. Revegetation information applicable to mining sites in northern Canada. Indian and Northern Affairs, Environmental Studies No. 3. (Annotation)

47. Best, K.F., J. Looman, and J.B. Campbell. 1971. Prairie Grasses. Canada Department of Agriculture, Publication 1413.

48. Billings, W.D. 1978. Aspects of the ecology of alpine and subalpine plants. Pages 1-15 IN: S.T. Kenny, ed. Proceedings: High Altitude Revegetation Workshop No. 3. Colorado State University. Information Series No. 28.
49. Blaser, R.E. 1963. Principles of making turf mixtures for roadside seedings. Page 33 IN: E.B. Peterson and N.M. Peterson, eds. Revegetation information applicable to mining sites in northern Canada. Indian and Northern Affairs. Environmental Studies No. 3. (Annotation)

50. Bleak, A.T., and W. Keller. 1973. Differential tolerance of some arid-range wheatgrasses to snow mold. J. Range Manage. 26(6): 434-435.

51. Bleak, A.T., W. Keller, and A.C. Hull, Jr. 1974. Range plant yield and species relationships in natural and partially controlled environments. J. Range Manage. 27(5): 396-399.

52. Bliss, L.C. and J.E. Cantlon. 1957. Succession on river alluvium in northern Alaska. Pages 35-36 IN: E.B. Peterson and N.M. Peterson, eds. Revegetation information applicable to mining sites in northern Canada. Indian and Northern Affairs, Environmental Studies No. 3. (Annotation)

53. Bliss, L.C. and R.W. Wein, eds. 1972. Botanical studies of natural and manmodified habitats in the eastern Mackenzie delta region and the arctic islands. Indian and Northern Affairs, ALUR 71-72-14.

54. Bliss, L.C. ed. 1973. Botanical studies of natural and man-modified habitats in the Mackenzie valley, eastern Mackenzie delta region and the arctic islands. Environmental-SocialCommitteeNorthern pipelines, Task Force on Northern Oil Development, Report No. 73-44.

55. Bliss, L.C., and R.W. Wein. 1972. Plant community responses to disturbances in the western Canadian arctic. Pages $37-$ 38 IN: E.B. Peterson and N.M. Peterson, eds. Revegetation information applicable to mining sites in northern Canada. Indian and Northern Affairs, Environmental Studies No. 3. (Annotation). 
56. Bliss, L.C., ed. 1975. Plant and surface responses to environmental conditions in the western high arctic. Indian and Northern Affairs, ALUR 74-75-73.

57. Bollen, W.B., K.C. Lu, J.M. Trappe, and R.F. Tarrant. 1969. Influence of Sitka alder on soil formation and microbiological succession on a landslide of alpine origin at Mount Rainier. USDA Forest Service, Research Note PNW-103.

58. Bond, G. 1957. Isotopic studies of nitrogen fixation in non-legume root nodules. Ann. Bot. 21: 513-521.

59. Bondurant, D.M., ed. 1971. Proceedings of the revegetation and economic use of surface-mined land and refuse symposium. West Virginia University. Morgantown, Va.

60. Bonham, C.D. 1972. Vegetation analysis of grazed and ungrazed alpine hairgrass meadows. J. Range Manage. 25(4): 276279.

61. Bookhout, T.A. 1977. Lessons from MidAppalachia strip mine reclamation efforts. Pages 154-166 IN: Reclamation for wildlife habitat: proceedings, reclamation workshop II. Ecology Consultants Inc. Ft. Collins, Colo.

62. Bradshaw, A.D. 1952. Populations of Agrostis tenuis resistant to lead and zinc poisoning. Page 42 IN: E.B. Peterson and N.M. Peterson, eds. Revegetation information applicable to mining sites in northern Canada. Indian and Northern Affairs, Environmental Studies No. 3. (Annotation)

63. Bradshaw, A.D., T.S. McNeilly, and R.P.G. Gregory. 1965. Industrialization, evolution and the development of heavy metal tolerance in plants. Pages 43-44 IN: E.B. Peterson and N.M. Peterson, eds. Revegetation information applicable to mining sites in northern Canada. Indian and Northern Affairs, Environmental Studies No. 3. (Annotation)

64. Brayshaw, T.C. 1976. Catkin bearing plants of British Columbia. British Columbia Provincial Museum, Occasional Paper No. 18. Victoria, B.C.
65.

Brenner, F.J., R.H. Crowley, M.J. Musaus, and J.H. Goth III. 1975. Evaluation and recommendations of strip mine reclamation procedures for maximum sediment-erosion control and wildlife potential. Pages 2-23 IN: Third Symposium on Surface Mining and Reclamation, Volume II, NCA/BCR Coal Conference and Expo II. National Coal Association. Washington, D.C.

66. Brink, V.C. n.d. Native sweetgrasses (Heirochloe spp.) for difficult environments. University of British Columbia. Vancouver, B.C.

67. Brink, V.C. 1974. A summary of comments on grasses and legumes for land reclamation. Pages 45-46 IN: E.B. Peterson and N.M. Peterson, eds. Revegetation information applicable to mining sites in northern Canada. Indian and Northern Affairs, Environmental Studies No. 3. (Annotation)

68. British Columbia Ministry of Mines and Petroleum Resources. 1977. Reclamation of lands disturbed by mining. Proceedings of the British Columbia mine reclamation symposium. Vernon, B.C.

69. British Columbia Ministry of Mines and Petroleum Resources. 1978. Reclamation of lands disturbed by mining. Proceedings of the second annual reclamation symposium. Vernon, B.C.

70. British Columbia Ministry of mines and Petroleum Resources. 1978. Revegetation of disturbances in the northeast coal block, current activities and state-of-theart. Inspection and Engineering Division, Paper 1978-6.

71. British Columbia Ministry of Energy, Mines and Petroleum Resources. 1979. Reclamation of lands disturbed by mining. Proceedings of the third annual British Columbia mine reclamation symposium. Vernon, B.C.

72. British Columbia Ministry of Energy, Mines and Petroleum Resources. 1979. Discussion group. Page 10 IN: Reclamation of lands disturbed by mining. Proceedings of the third annual British Columbia mine reclamation symposium. Vernon, B.C. 
73. Brown, J.A. 1974. Cultural practices for revegetation of high-altitude disturbed lands. Pages 59-63 IN: W.A. Berg, J.A. Brown, and R.L. Cuany, eds. Proceedings of a Workshop on Revegetation of High-Altitude Disturbed Lands. Colorado State University. Information Series No. 10.

74. Brown, R.W., and R.S. Johnston. 1976. Revegetation of an alpine mine disturbance: Beartooth Plateau, Montana. USDA Forest Service Research Note INT-206.

75. Brown, R.W., R.S.. Johnston. 1978. Rehabilitation of a high elevation mine disturbance. Pages 116-130 IN: S.T. Kenny, ed. Proceedings of a High Altitude Revegetation Workshop No. 3. Colorado State University. Information Series No. 28.

76. Brown, R.W., R.S. Johnston, B.Z. Richardson, and E.E. Farmer. 1976. Rehabilitation of alpine disturbances: Beartooth Plateau, Montana. Pages 58-73 IN: R.H. Zuck and C.F. Brown, eds. Proceedings: High Altitude Workshop No. 1. Colorado State University. Information Series No. 21.

77. Brummitt, R.A. 1976. Seeding of subsoils 1969-1975: final report. Pages 48-49 IN: E.B. Peterson and N.M. Peterson, eds. Revegetation information applicable to mining sites in northern Canada. Indian and Northern Affairs, Environmental Studies No. 3. (Annotation)

78. Budd, A.C. and K.F. Best. 1969. Wild plants of the Canadian prairies. Research Branch, Canada Department of Agriculture, Publication No. 983.

79. Bureau of Land Management. 1973. Influence of man-caused surface disturbance in permafrost areas of Alaska. Pages 50-51 IN: E.B. Peterson and N.M. Peterson, eds. Revegetation information applicable to mining sites in Northern Canada. Indian and Northern Affairs, Environmental Studies No. 3. (Annotation)

80. Cable, D.R. 1977. Western wheatgrass transplants grow well on raw mine spoil. USDA Forest Service Research Note RM346, Appendix B.
81. Calgary Power Ltd., and Fording Coal Ltd. 1978. Land reclamation research and demonstration at Camrose-Ryley 1978: third annual report. Calgary, AB.

82. Campbell, S.E., and G.W. Scotter. 1975. Subalpine revegetation and disturbance studies, Mount Revelstoke National Park. Prepared by Canadian Wildlife Service for Parks Canada. Edmonton, AB.

83. Canadian Arctic Gas Pipeline Ltd. 1974. Responses to pipeline application assessment group requests for supplementary information. Pages 52-53 IN: E.B. Peterson and N.M. Peterson, eds. Revegetation information applicable to mining sites in northern Canada. Indian and Northern Affairs, Environmental Studies No. 3. (Annotation)

84. Canadian Land Reclamation Association. 1976. Proceedings of the First Annual Meeting. University of Guelph. Guelph, Ont.

85. Canadian Land Reclamation Association. 1977. Proceedings of the Second Annual General meeting. August 17-20, 1977. University of Alberta. Edmonton, AB.

86. Canadian Land Reclamation Association. 1978. Proceedings of the Third Annual Meeting. May 29 - June 1, 1978. Laurentian University. Sudbury, Ont.

87. Canadian Land Reclamation Association. 1979. Proceedings: Fourth Annual Meeting. August $13-16,1979$. University of Regina. Regina, Sask.

88. Carpenter, P.L., and D.L. Hensley. 1979. Utilizing N2-fixing woody plant species for distressed soils and the effect of lime on survival. Botan. Gazette, 140: 576-581.

89. Chadwick, M.J. 1974. Variation in the chemical characteristics of colliery spoil and its relation to vegetational establishment. Page 54 IN: E.B. Peterson and N.M. Peterson, eds. Revegetation information applicable to mining sites in northern Canada. Indian and Northern Affairs, Environmental Studies No. 3. (Annotation) 
90. Chironis, N.P. 1977. Guide to plants for mine spoils. Pages $122-130$ IN: Reclamation Guidebook. Coal Age 82(7): 43-130.

91. Clark, W.F., ed. 1975. Proceedings of the Fort Union Coal Field symposium, Volume 3 - reclamation section. Montana Academy of Sciences. Billings, Ma.

92. Clebsch, E.E.C., and W.D. Billings. 1976. Seed germination and vivipary from a latitudinal series of populations of the arcticalpine grass Trisetum spicatum. Page 55 IN: E.B. Peterson and N.M. Peterson, eds. Revegetation information applicable to mining sites in northern Canada. Indian and Northern Affairs, Environmental Studies No. 3. (Annotation)

93. Cline, J.F., D.W. Uresk, and W.H. Rickard. 1977. Comparison of soil water used by a sagebrush-bunchgrass and a cheatgrass community. J. Range Manage. 30(3): 199201.

94. Coal Association of Canada. 1977. Coal Industry Reclamation Symposium: Proceedings, February $13-16$, Banff, Alberta. Calgary, AB.

95. Collins, O.B., F.E. Smeins, and D.H. Riskind. 1975. Plant communities of the Blackland prairie of Texas. Pages 75-88 IN: M.K. Wali, ed. Prairie: a multiple view. University of North Dakota Press. Grand Forks, N.D.

96. Como, B.A., L.M. Lavkulich, A.A. Bomke, and J.M. Robbins. 1978. Reclamation of abandoned mine spoils in British Columbia, 1977 - 1978. British Columbia Ministry of Mines and Petroleum Resources, Inspection and Engineering Division. Victoria, B.C.

97. Corns, I.G.W. 1972. Plant communities in the Mackenzie delta region. Pages $4-46$ IN: L.C. Bliss and R.W. Wein, eds. Botanical studies of natural and manmodified habitats in the eastern Mackenzie delta region and the arctic islands. Indian and Northern Affairs, ALUR 71-72-14.

98. Corns, W.G. 1974. Influence of time and frequency of harvests on productivity and chemical composition of fertilized and unfertilized awned sedge. Can. J. Plant Sci. 54: 493-498.
99.

Corns, W.G. 1978. Weed control research, 1978. Department of Plant Science, University of Alberta. Edmonton, AB. Unpublished Report.

100. Corns, W.G., and R.J. Schraa. 1962. Seasonal productivity and chemical composition of marsh reed grass (Calamagrostis canadensis) (Michx.) Beav. harvested periodically from fertilized and unfertilized native sod. Can. J. Plant Sci. 42: 651-659.

101. Cox, R.M. 1978. Multiple metal tolerance in the grass Deschampsia caespitosa. Pages 328-336 IN: Proceedings of the Third Annual Meeting, Canadian Land Reclamation Association. Sudbury, Ont.

102. Cram, W.H. 1976. 1975 annual report of the PFRA tree nursery. Canada Dept. of Regional Economic Expansion, Prairie Farm Rehabilitation Administration. Indian Head, Sask.

103. Cram, W.H. 1977. 1976 annual report of the PFRA tree nursery. Canada Dept. of Regional Economic Expansion, Prairie Farm Rehabilitation Administration. Indian Head, Sask.

104. Crocker, R.L., and B.A. Dickson. 1957. Soil development on the recessional moraines of the Herbert and Mendenhall glaciers, southeastern Alaska. Page 62 IN: E.B. Peterson and N.M. Peterson, eds. Revegetation information applicable to mining sites in northern Canada. Indian and Northern Affairs, Environmental Studies No. 3. (Annotation)

105. Crocker, R.L., and J. Major. 1955. Soil development in relation to vegetation and surface age at Glacier Bay, Alaska. pages 63-64 IN: E.B. Peterson and N.M. Peterson, eds. Revegetation information applicable to mining sites in northern Canada. Indian and Northern Affairs, Environmental Studies No. 3. (Annotation)

106. Cuany, R.L. 1974. Plant breeding and its role in supplying new plant materials. Pages 44-54 IN: W.A. Berg, J.A. Brown, and R.L. Cuany, eds. Proceedings of a Workshop on Revegetation of HighAltitude Disturbed Lands. Colorado State University. Information Series No. 10. 
107. Cuany, R.L. 1976. Plant materials. Pages 110-116 IN: R.H. Zuck and L.F. Brown, eds. Proceedings: High Altitude Revegetation Workshop No. 2. Colorado State University. Information Series No. 21.

108. Curtis, J.D. 1975. Seeds for reclamation. Pages 18-25 IN: Proceedings of the Inaugural Meeting of the Canadian Land Reclamation Association. Department of Crop Science, University of Guelph. Guelph, Ont.

109. Czaplowsky, M.M. 1970. Experimental planting of 14 tree species on Pennsylvania's anthracite strip-mine spoils. USDA Forest Service Research Paper NE155.

110. Dabbs, D.L. and W. Friesen. 1973. San Sault revegetation report. 1972. Prepared for Canadian Arctic Gas Study Limited by Northern Engineering Services Company Limited.

111. Dabbs, D.L., W. Friesen and S. Mitchell. 1974. Pipeline revegetation: Arctic Gas Biological Report Series, Volume Two. Prepared for Northern Engineering Services Company Ltd.

112. Dancer, W.S., and I.J. Jansen. 1978. Claypan soils and the reclamation of surfacemined land in southern Illinois. Pages 140154 IN: Proceedings: Canadian Land Reclamation Association, Fourth Annual Meeting. Regina, Sask.

113. de Jong, E. 1979. Reclamation problems in the oil industry. Pages 39-52 IN: Proceedings: Canadian Land Reclamation Association, Fourth Annual Meeting. Regina, Sask.

114. Demarchi, D.A. 1973. Relationships of range quality to range condition in the Chilcotin region, British Columbia. J. Range Manage. 26(5): 345-348.

115. Densmore, R., and J.C. Zasada. 1977. Germination requirements of Alaskan Rosa acicularis. Can. Field Naturalist 91(1): 5862.

116. Densmore, R., and J.C. Zasada. 1978. Rooting potential of Alaskan willow cuttings. Can. J. For. Res. 8: 477-479.
117. DePuit, E.J. and D.J. Dollhopf. 1978. Revegetation research on coal surfacemined lands at West Decker mine, Decker, Montana: progress report 1975. Montana Agricultural Experiment Station, Montana State University, Research Report 133.

118. Deveraux, D.G. 1978. Reclamation at the Dave Johnson mine. Pages 200-206 IN: Proceedings of the Third Annual Meeting, Canadian Land Reclamation Association. Sudbury, Ont.

119. Dick, John H. 1978. A management plant for the rehabilitation of surface mined coal lands in the East Kootenay, British Columbia. Unpublished M.Sc. Thesis. University of British Columbia.

120. Dick, J.H. 1974. Selection and propagation of woody plant species for reclamation in British Columbia. Presented at Land Reclamation Short Course E.M. 6672. Centre for Continuing Education, University of British Columbia. Vancouver, B.C.

121. Dittberner, P.L., and G. Bryant. 1978. The use of the plant information network (PIN) in high altitude revegetation. Pages 52-74 IN: S.T. Kenny, ed. Proceedings: High Altitude Revegetation Workshop No. 3. Colorado State University. Information Series No. 28.

122. Dormaar, J.F., A. Johnston, and S. Smoliak. 1977. Seasonal variation in chemical characteristics of soil organic matter of grazed and ungrazed mixed prairie and fescue grassland. J. Range Manage. 30(3): 195-198.

123. Down, C.G., and J. Stocks. 1977. Environmental impact of mining. John Wiley \& Sons Inc. New York and Toronto.

124. Drawe, D.L., J.B. Grumbles, and J.F. Hooper. 1975. Establishment of Russian wildrye on foothill ranges in Utah. J. Range Manage. 28(2): 152-155.

125. Ducks Unlimited (Canada). 1969. The health of the land - salinity. Based on material from: Principles and practices of commercial farming (5th edition). Faculty of Agriculture, University of Manitoba. Winnipeg, Man. 
126. Dunbar, G.A. 1970. Fertilizers, grasses and clover for high altitude revegetation. Tussock Grasslands and Mountain Lands Institute Review 18: 16-23.

127. Dunbar, G.A. 1970. Grasses in high altitude revegetation. Soil and Water, 6(3/4): 20-23.

128. Dunbar, G.A. 1971. The effectiveness of some herbaceous species for montane and subalpine revegetation. Proc. New Zealand Ecol. Soc. 18: 48-57.

129. Dusek, G.L. 1975. Vegetational responses by substrate, gradient, and aspect on a twelve acre test plot in the Bull Mountains, Pages 233-246 IN: W.F. Clark, ed. Proceedings of the Fort Union Coal Field Symposium, Volume 3 - reclamation section. Montana Academy of Sciences. Billings, Ma.

130. Dyrness, C.T. $1975 . \quad$ Grass-legume mixtures for erosion control along forest roads in western Oregon. J. Soil and Water Conserv. 30(4): 169-173.

131. Eaman, T.K. 1974. Plant species potentials for high-altitude revegetation. Pages 39-43 IN: W.A. Berg, J.A. Brown, and R.L. Cuany, eds. Proceedings of a Workshop on Revegetation of High-Altitude Disturbed Lands. Colorado State University. Information Series No. 10.

132. Echols, J.W., and R.L. Cuany. 1974. Seed supplies and plant materials work group summary. Pages 83-85 IN: W.A. Berg, J.A. Brown, and R.L. Cuany, eds. Proceedings of a Workshop on Revegetation of HighAltitude Disturbed Lands. Colorado State University. Information Series No. 10.

133. Ecology Consultants Inc. 1977. Reclamation for wildlife habitat. Proceedings of Reclamation Workshop II. Fort Collins, Colo.

134. Edwards, R.Y., and R.W. Ritcey. 1960. Foods of caribou in Wells Gray Park, British Columbia. Canadian Field-Naturalist, 74: 37.

135. Eis, S. 1978. Edaphological problems associated with deposits of incinerated municipal refuse. Reclamation Review, 1(3/4): 121-128.
136. Elkington, T.T., and S.R.J. Woodell. 1963. Potentilla fruticosa L. (Dasiphora fruticosa L. Rydb.). J. Ecol. 53: 769-781.

137. Elliott, C.R., and H. Baenziger. 1967. Creeping red fescue. Canada Department of Agriculture, Publication 1122.

138. Elliott, C.R., and J.L. Boton. 1970. Licensed varieties of cultivated grasses and legumes. Canada Department of Agriculture, Publication No. 1405.

139. Elliott, C.R., and M.E. Hiltz. 1974. Forage introductions. Northern Research Group, Canada Agriculture Research Branch, Publication No. NRG 74-16.

140. Epps, A.C. 1973. Uses of woody and herbaceous ornamental ground cover materials. Pages 45-50 IN: 1973 Alaska Revegetation Workshop Notes. Cooperative Extension Service, University of Alaska. Fairbanks, Al.

141. Erdman, J.A., and R.J. Ebens. 1979. Element content of crested wheatgrass grown on reclaimed coal spoils and on soils nearby. J. Range Manage. 32(2): 159-161.

142. Erdman, J.A., R.J. Ebens, and A.A. Case. 1978. Molybdenosis: a potential problem in ruminants grazing on coal mine spoils. J. Range Manage. 31(1): 34-36.

143. Errington, J.C. 1978. Evaluation of current revegetation techniques used in British Columbia. Pages 51-66 IN: Reclamation of lands disturbed by mining. Proceedings of the Second Annual British Columbia Mine Reclamation Symposium. Vernon, B.C.

144. Etter, H.M. 1973. Mined-land reclamation studies on bighorn sheep range in Alberta, Canada. Biol. Conserv. 5: 191 195.

145. Evans, F.C. 1975. A natural history of a Michigan field. Pages 27-51 IN: M.K. Wali, ed. Prairie: a multiple view. University of North Dakota Press. Grand Forks, N.D. 
146. Farmer, E.E. and W.G. Blue. 1978. Reclamation of lands mined for phosphate. Pages 585-608 IN: F.W. Schaller and P. Sutton, eds. Reclamation of drastically disturbed lands. American Society of Agronomy, Crop Science Society of America, Soil Science Society of America. Madison, Wis.

147. Farmer, E.E., B.Z. Richardson, and R.W. Brown. 1976. Revegetation of acid mining wastes in central Idaho. USDA Forest Service Research Paper INT-178.

148. Farmer, E.E., R.W. Brown, B.Z. Richardson, and P.E. Packer. 1974. Revegetation research on the Decker coal mine in southeastern Montana. USDA Forest Service, Research Paper INT-162.

149. Fedkenheuer, A.W. 1979. Propagation and establishment of native woody plants on oil sands reclamation areas. Syncrude Canada Ltd. Professional Paper 1979-6. Edmonton, AB.

150. Fedkenheuer, A.W. 1979. Native shrub research at Syncrude Canada Ltd. Pages 2-9 IN: P.F. Ziemkiewicz, C.A. Dermott, and H.P. Sims, eds. Proceedings: Workshop on Native Shrubs in Reclamation. Alberta Land Conservation and Reclamation Council Report No. RRTAC 79-2.

151. Fedkenheuer, A.W. 1979. Building soils using Athabasca oil sands tailings and soil amendments. Pages 165-193 IN: Proceedings: Canadian Land Reclamation Association, Fourth Annual Meeting. Regina, Sask.

152. Fedkenheuer, A.W., and A. Langevin. 1978. Revegetation practices at Syncrude Canada Ltd., Ft. McMurray, Alberta. Pages 173-183 IN: Proceedings of the Third Annual Meeting, Canadian Land Reclamation Association, Sudbury, Ont.

153. Fedkenheuer, A.W., and H.M. Heacock. 1979. Potential of soil amendments as sources of native plants for revegetation of Athabasca oil sands tailings. Pages 223237 IN: Proceedings: Canadian Land Reclamation Association, Fourth Annual Meeting. Regina, Sask.
154. Fessenden, R.J., and B.J. Sutherland. 1979. The effect of excess soil copper on the growth of black spruce and green alder seedlings. Botan. Gazette, 140:582587.

155. Fitter, A.H., and A.D. Bradshaw. 1974. Responses of Lolium perenne and Agrostis tenuis to phosphate and other nutritional factors in the reclamation of colliery shale. J. Appl. Ecol. 11(2): 597608.

156. Fitter, A.H., and A.D. Bradshaw. 1974. Root penetration of Lolium perenne on colliery shale in response to reclamation treatments. J. Appl. Ecol. 11 (2): 609615.

157. Fonda, R.W. 1974. Forest succession in relation to river terrace development in Olympic National Park, Washington. Ecology 55(5): 927-942.

159. Frischknecht, N.C. 1977. Use of shrubs for mined land reclamation and wildlife habitat. Pages 113-129 IN: Reclamation for wildlife habitat. Proceedings: Reclamation Workshop II. Ecology Consultants Inc., Ft. Collins, Colo.

160. Fyles, J.W. 1976. Vegetation of gravel bars on the western slope of the Rocky Mountains. Unpublished B.Sc. Thesis. University of Victoria.

161. Gadgil, R.L. 1971. The nutritional role of Lupinus arboreus in coastal sand dune forestry: I. The potential influence of undamaged lupine plants on nitrogen uptake by Pinus radiate. Plant and Soil, 34: 357-367.

162. Gardiner, R.T. 1972. Cominco approach to revegetation research. Pages 10-19 IN: Environmental Management: the mining scene, reclamation of disturbed land areas. Centre for Continuing Education, University of British Columbia. Vancouver, B.C.

163. Gardiner, R.T. $1977 . \quad$ Tailings revegetation experience at Cominco Ltd. metal mines in British Columbia and the Northwest Territories. Pages 35-53 IN: Reclamation of lands disturbed by mining. Proceedings of the British Columbia Mine Reclamation Symposium. Vernon, B.C. 
164. Gardner, I.C., and G. Bond. 1957. Observation on the root nodules of Shepherdia. Can. J. Bot. 35: 305-314.

165. Gavelin, L.A. 1978. Reclamation program to date. (Section of report of Craigmont Mines Ltd.) Merritt, B.C.

166. Gavelin, L.A. 1979. Current revegetation techniques at Craigmont Mines Ltd. Slide presentation given at the Third Annual British Columbia Mine Reclamation Symposium. Vernon, B.C.

167. Geyer, W.A., and N.F. Rogers. 1972. Spoils change and tree growth on coalmined spoils in Kansas. J. Soil and Water Conserv. 27(3): 114-116.

168. Gillespie, E. 1976. A review of cover crops as a biological control for weeds and woody growth incompatible with overhead electrical conductors. IN: Proceedings of the First Annual Meeting, Canadian Land Reclamation Association. University of Guelph. Guelph, Ont. (Abstr.)

169. Gillespie, E.D. 1978. Cover crops as a control for woody growth on electrical transmission rights-of-way. Reclamation Review 1(1): 31-35.

170. Godfread, C.S., and W.T. Baker. 1975. Vascular flora of Barnes and Stutsman counties, North Dakota. Pages 333-339 IN: M.K. Wali, ed. Prairie: a multiple view. University of North Dakota Press. Grand Forks, N.D.

171. Goplen, B.P., S.G. Bonin, W.E.P. Davis, and R.M. MacVicar. 1963. Reed canarygrass. Canada Department of Agriculture, Publication 805.

172. Gordon, J.C., and J.O. Dawson. 1979. Potential uses of nitrogen-fixing trees and shrubs in commercial forestry. Botan. Gazette, 140: 588-590.

173. Gould, W.L., D. Rai, and P.J. Wierenga. 1975. Problems in reclamation of coal mine spoils in New Mexico. Pages 107-121 IN: M.K. Wali, ed. Practices and problems of land reclamation in western North America. University of North Dakota Press. Grand Forks, N.D.
174.

Grainger, G. 1979. Native tree and shrub production. Pages 28-30 IN: P.F. Ziemkiewicz, C.A. Dermott, and H.P. Sims, eds. Proceedings: Workshop on Native Shrubs in Reclamation. Alberta Land Conservation and Reclamation Council Report No. RRTAC 79-2.

175. Grandt, A.F. 1977. Species trials on strip mine areas. Pages 347-352 IN: J.L. Thomas, ed. Reclamation and use of disturbed land in the southwest. The University of Arizona Press. Tucson, Ariz.

176. Gregg, J.W. 1976. Revegetation and stabilization of roadsides on Vail pass. Pages 92-101 IN: R.H. Zuck and L.F. Brown, eds. Proceedings: High Altitude Revegetation Workshop No. 2. Colorado State University. Information Series No. 21.

177. Greller, A.M. 1974. Vegetation of roadcut slopes in the tundra of Rocky Mountain National Park, Colorado. Biol. Conserv. 6(2): 84-93.

178. Groeneveld, D.P., and P.S. O'Boyle. 1978. Hazard identification, chemical removal, and revegetation of a toxic chemical spill on Lawson Hill, San Miguel County. Pages 142-153 IN: S.T. Kenny, ed. Proceedings: High Altitude Revegetation Workshop No. 3. Colorado State University. Information Series No. 28.

179. Hafenrichter, A.L., J.L. Schwendiman, H.L. Harris, R.S. MacLauchlan, and H.W. Miller. 1968. Grasses and legumes for soil conservation in the Pacific northwest and great basin states. USDA Soil Conservation Service, Agriculture Handbook No. 339.

180. Halland, C.M.A. 1972. Introduction of tree cover in the Estevan spoil banks: ninth interim report. Saskatchewan Department of Tourism and Renewable Resources, Forestry Branch. Prince Alberta, Sask.

181. Hammer, O.M. 1978. Subalpine revegetation. Western Region Office, Parks Canada. Calgary, AB. 
182. Hansen, J.E., and J.E. Mitchell. 1978. The role of terraces and soil amendments in revegetating steep, smelter-affected land. Reclamation Review, 1(3/4): 103-112.

183. Hanson, A.A. 1972. Grass varieties in the United States. USDA Agriculture Handbook No. 170.

184. Hanson, C.L., G.A. Schumaker, and C.J. Erickson. 1976. Influence of fertilization and supplemental runoff water on production and nitrogen content of western wheatgrass and smooth brome. J. Range Manage. 29(5): 406-409.

185. Harris, D.K. 1979. Rehabilitation of disturbed alpine areas. Wildland Recreation 271, Unpublished Technical Report. Selkirk College. Castlegar, B.C.

186. Harris, R.E. 1972. The Saskatoon. Canada Department of Agriculture, Publication No. 1246.

187. Hathorn, F.G. 1978. Reclamation planning at Hat Creek, B.C. Pages $109-131$ IN: Reclamation of lands disturbed by mining. Proceedings of the Second Annual British Columbia Mine Reclamation Symposium. Vernon, B.C.

188. Hathorn, F.G., D.L. Docksteader, and D.K McQueen. 1979. Hat Creek reclamation studies: results of the first year program. Pages 239 - 271 IN: Reclamation of Land Disturbed by Mining. Proceedings of the Third Annual British Columbia Mine Reclamation Symposium. Vernon, B.C.

189. Heath, M.E., D.S. Metcalf, and R.F. Barnes. 1973. The science of grassland agriculture. Third Edition. Iowa State University Press. Des Moines, lowa.

190. Heeney, C.J. 1974. Species suitability to various site conditions. Pages 11 - 13 IN: Ontario Cover Crop Committee: Proceedings 4th Annual Workshop. Department of Crop Science, University of Guelph. Guelph, Ont.

191. Heinrichs, D.H. 1969. Alfalfa in Canada. Canada Department of Agriculture, Publication 1377.
192.

Heitlinger, M.E. 1975. Burning a protected tallgrass prairie to suppress sweetclover, Melilotus alba Desr. Pages 123 - 132 IN: M.K. Wali, ed. Prairie: a multiple view. University of North Dakota Press. Grand Forks, N.D.

193. Hendzel, L. 1976. Forest Service highaltitude revegetation work. Pages 102 . 107 IN: R.H. Zuck and L.F. Brown, eds. Proceedings: High Altitude Revegetation Workshop No. 2. Colorado State University. Information Series No. 21.

194. Hernandez, H. 1972. Surficial disturbance and natural plant recolonization in the Mackenzie delta region. Pages 143 - 174 IN: L.C. Bliss and R.W. Wein, eds. Botanical studies of natural and man-modified habitats in the eastern Mackenzie delta region and the arctic islands. Indian and Northern Affairs, ALUR 71-72-14.

195. Hernandez, H. 1973. Revegetation studies - Norman Wells, Inuvik, and Tuktoyaktuk, N.W.T. and Prudhoe Bay, Alaska. Pages 77 - 149 IN: L.C. Bliss, ed. Botanical studies of natural and manmodified habitats in the Mackenzie valley, eastern Mackenzie delta region and the arctic islands. Environmental-Social Committee Northern Pipelines, TaskForce on Northern Oil Development, Report No. 73-44.

196. Hernandez, H. 1973. Interim report No. 3: Towards an environmental impact assessment of the portion of the Mackenzie gas pipeline from Alaska to Alberta, appendix V, revegetation. Prepared for the Environmental Protection Board.

197. Hilton, J.E., and A.W. Bailey. 1974. Forage production and utilization in a sprayed aspen forest in Alberta. J. Range Manage. 27(5): 375-380.

198. Hiratsuka, Y. 1977. Annotated checklist of tree and shrub diseases in the prairie provinces. Environment Canada, Forestry Service, Information Report NOR-X-178.

199. Hitchcock, A.S. 1971. Manual of the grasses of the United States. Second Edition revised by $\mathrm{A}$. Chase. Dover Publications, Inc. New York. 
200. Hitchcock, C.L. and A. Cronquist. 1973. Flora of the Pacific Northwest: an illustrated manual. University of Washington Press. Seattle, Washington.

201. Hocking, D., and W.R. MacDonald, eds. 1974. Proceedings of a Workshop on reclamation of disturbed lands in Alberta. Environment Canada, Forestry Service, Northern Forest Research Centre, Information Report NOR-X-116. Alberta Environment, Research Secretariat.

202. Hodgkinson, H.S., and A.E. Young. 1973. Rough fescue (Festuca scabrella Torr.) in Washington. J. Range Manage. 26(1): 2526.

203. Holloway, J.T. 1970. Control of erosion on the class VIII lands: the evolution of a research policy. Tussock Grasslands and Mountain Lands Institute Review, 18: 44-56.

204. Hordaway, J.E., D.B. Kimball, S.F. Lindsay, J. Schmidt, and L. Erickson. 1977. Subirrigated alluvial valley floors. Pages 61135 IN: Fifth Symposium on Surface Mining and Reclamation. NCA/BCR Coal Conference and Expo IV. National Coal Association. Washington, D.C.

205. Hosie, R.C. 1969. Native trees of Canada. Information Canada. Ottawa, Ont.

206. Howard, G.S., G.E. Schuman, and F. Rauzie. 1977. Growth of selected plants on Wyoming surface-mined soils and fly ash. J. Range Manage. 30(4): 306-310.

207. Howe, J.A.G. 1979. Nursery activities and production of native trees and shrubs. Pages 32-37 IN: P.F. Ziemkiewicz, C.A. Dermott, and H.P. Sims, eds. Proceedings: Workshop on Native Shrubs in Reclamation. Alberta Land Conservation and Reclamation Council Report No. RRTAC 79-2.

208. Howe, J.A.G. 1979. 1978 annual report of the PFRA tree nursery. Canada Dept. of Regional Economic Expansion, Prairie Farm Rehabilitation Administration. Indian Head, Sask.
209. Hubbard, W.F., and M.A.M. Bell. 1977. Reclamation of lands disturbed by mining in mountainous and northern areas: a selected bibliography and review relevant to British Columbia and adjacent areas. Prepared for B.C. Ministry of Mines and Petroleum Resources Inspection Branch by Biocon Research Ltd.

210. Hull, A.C. Jr. 1972. Growth characteristics of crested and fair-way wheatgrasses in southern Idaho. $\mathrm{J}$. Range Manage. 25(2): 123-125.

211. Hull, A.C. Jr. 1973. Germination of range plant seeds after long periods of uncontrolled storage. J. Range Manage. 26(3): 198-200.

212. Hull, A.C. Jr. 1973. Duration of seeded stands on terraced mountain lands, Davis County, Utah. J. Range Manage. 26(2): 133-136.

213. Hull, A.C. Jr. 1974. Species for seeding mountain rangelands in southeastern Idaho, northeastern Utah, and western Wyoming. J. Range Manage. 27(2): 150153.

214. Hulten, E. 1968. Flora of Alaska and neighboring territories. Stanford University Press. Stanford, Calif.

215. Hurd, R.M., and D.M. Christisen. 1975. Ecological study of Friendly Prairie, Missouri. Pages 89-101 IN: M.K. Wali, ed. Prairie: a multiple view. University of North Dakota Press. Grand Forks, N.D.

216. Hutchinson, T.C., and J.A. Hellebust. 1978. Vegetational recovery in the Canadian arctic after crude and diesel oil spills. Indian and Northern Affairs, ALUR 75-76-83.

217. Hutnik, R.J., and G. Davis, eds. 1973. Ecology and reclamation of devastated land. Proceedings of a N.A.T.O. Advanced Study Institute on the Ecology and Revegetation of Drastically Disturbed Areas. Pennsylvania State University. Gordon and Breach Scientific Publications. New York. 
218. Institute for Land Rehabilitation. 1978. Rehabilitation of western wildlife habitat: a review. Prepared for Fish and Wildlife Service, U.S. Dept. of the Interior. Utah State University. Logan, Utah.

219. Janzi, A. 1972. Soil survey in the Mackenzie Delta region. Pages 47-68 IN: L.C. Bliss and R.W. Wein, eds. Botanical studies of natural and man-modified habitats in the eastern Mackenzie delta region and the Arctic Islands. Indian and Northern Affairs, ALUR 71-72-14.

220. Jarvis, J.M., G.A. Steneker, R.M. Waldron, and J.C. Lees. 1966. Review of silvicultural research: white spruce and trembling aspen cover types, mixed wood forest section, boreal forest region, Alberta-SaskatchewanManitoba. Forestry Branch, Departmental Publication No. 1156.

221. Jeffrey, D.W., M. Maybury, and D. Levinge. 1975. Ecological approach to mining waste revegetation. Pages 159-160 IN: E.B. Peterson and N.M. Peterson, eds. Revegetation information applicable to mining sites in northern Canada. Indian and Northern Affairs, Environmental Studies No. 3. (Annotation)

222. Johnson, J.D., and G.L. Lesko. 1977. Recommendations for species selection and management in the amenity plantations of southern Saskatchewan. Environment Canada, Forestry Service, Information Report NOR-X-181.

223. Johnson, L., and K. Van Cleve. 1976. Revegetation in arctic and subarctic North America: a literature review. Cold Regions Research and Engineering Laboratory, Report 76-15. Hanover, N.H.

224. Johnson, M.S. 1976. Plant growth on fluorspar mine tailings. Page 169 IN: E.B. Peterson and N.M. Peterson, eds. Revegetation information applicable to mining sites in northern Canada. Indian and Northern Affairs, Environmental Studies No. 3. (Annotation)

225. Johnston, A., L.M. Bezeau, and S. Smoliak. 1968. Chemical composition and in vitro digestibility of alpine tundra plants. J. Wildl. Mgmt. 32(4): 773-777.
226.

Johnston, A., S. Smoliak, and R.A. Wroe. 1975. Poisonous and injurious plants of Alberta. Alberta Agriculture. Edmonton, AB.

227. Jones, J.N. Jr., W.H. Armiger, and O.L. Bennett. 1975. Forage grasses aid the transition from spoil to soil. Pages 185194 IN: Proceedings of the Third Symposium on Surface Mining and Reclamation, Volume II. NCA/BCR Coal Conference and Expo II. National Coal Association. Washington, D.C.

228. Jurgens, L. 1972. Suitable plant materials for various uses on reclaimed mined land in southeast Kansas. Pages 7-9 IN: Proceedings: Mined Land Redevelopment Workshop. University of Kansas, State Geological Survey, Special Distribution Publication 65.

229. Kagis, H. 1965. Possibilities of introducing tree cover in the Estevan spoil banks: project S-14, first interim report. Saskatchewan Department of Tourism and Renewable Resources, Forestry Branch. Prince Alberta, Sask.

230. Kagis, H. 1967. Introduction of tree cover in the Estevan spoil banks: third interim report. Saskatchewan Department of Tourism and Renewable Resources, Forestry Branch. Prince Albert, Sask.

231. Kamstra, L.D. 1973. Seasonal changes in quality of some important range grasses. J. Range Manage. 26(4): 289291.

232. Kay, B.L. 1973. Revegetation of mountain sites above $3000 \mathrm{ft}$. in California. University of California, Agricultural Experiment Station, Agronomy Progress Report No. 53.

233. Kay, B.L. 1978. Mulches for erosion control and plant establishments on disturbed sites. University of California, Agricultural Experiment Station, Agronomy Progress Report No. 87.

234. Kay, W.C. 1973. Greenhouse production of conifer seedlings. American Society of Agricultural Engineers. Winter Meeting, Paper No. 73-1550. 
235. Kenny, S.T., ed. 1978. Proceedings: High Altitude Revegetation Workshop No. 3. Colorado State University. Information Series No. 28.

236. Kenny, S.T., and R.L. Cuany. 1978. Grass and legume improvement for high altitude regions. Pages 84-100 IN: S.T. Kenny, ed. Proceedings: High Altitude Revegetation Workshop No. 3. Colorado State University. Information Series No. 28.

237. Kilcher, M.R., D.H. Heinrichs, and R.W. Lodge. 1976. Row spacings of Russian wildrye for fall pasture in southern Saskatchewan. J. Range Manage. 29(3): 237-240.

238. Kirby, C.L. 1975. Site index equations for lodgepole pine and white spruce in Alberta. Environment Canada, Forestry Service, Information Report NOR-X-142.

239. Klebesadel, L.J. 1971. Native Alaskan legumes studied. Pages 184-185 IN: E.B. Peterson and N.M. Peterson, eds. Revegetation information applicable to mining sites in northern Canada. Indian and Northern Affairs, Environmental Studies No. 3. (Annotation)

240. Klebesadel, L.J. 1973. Grasses and legumes for revegetation in Alaska. Pages 16-23 IN: Alaska revegetation workshop notes. Proceedings of Workshops Held in Anchorage and Fairbanks, April 1973. University of Alaska, Cooperative Extension Service, Publication RP-239.

241. Klebesadel, L.J. 1974. Sweet holy grass, a potentially valuable ally. Pages 196-197 IN: E.B. Peterson and N.M. Peterson, eds. Revegetation information applicable to mining sites in northern Canada. Indian and Northern Affairs, Environmental Studies No. 3. (Annotation).

242. Klebesadel, L.J., C.I. Branton, and J.J. Koranda. 1962. Seed characteristics of bluejoint and techniques for threshing. page 199 IN: E.B. Peterson and N.M. Peterson, eds. Revegetation information applicable to mining sites in northern Canada. Indian and Northern Affairs, Environmental Studies No. 3. (Annotation).
243. Klemmedson, J.O. 1979. Ecological importance of actinomycete-modulated plants in the western United States. Botan. Gazette, 140: 591-596.

244. Knipe, O.D. 1973. Western wheatgrass germination as related to temperature, light, and moisture stress. J. Range Manage. 26(1): 68-69.

245. Kufeld, R.C., O.C. Wallmo, and C. Feddema. 1973. Foods of the Rocky Mountain mule deer. USDA Forest Service, Research Paper RM-111.

246. Kuja, A.L., and T.C. Hutchinson. 1979. The use of native species in mine tailings revegetation. Pages 207-221 IN: Proceedings: Canadian Land Reclamation Association, Fourth Annual Meeting. Regina, Sask.

247. Laidlaw, T.F. 1977. The Camrose-Ryley project proposal (1975): a preliminary assessment of the surface reclamation potential on the Dodds-Roundhill coal field. Staff Report, Environment Conservation Authority. Edmonton, AB.

248. Laidlaw, T.F. 1974. The potential of trembling aspen for reclamation planting in Alberta: some techniques of propagation. Pages 88-92 IN: D. Hocking and W.R. MacDonald, eds. Proceedings: Workshop on Reclamation of Disturbed Lands in Alberta. Environment Canada, Forestry Service, Information Report NOR-X-116.

249. Langevin, A., and P.D. Lulman. 1977. Revegetation activities - 1976. Syncrude Canada Ltd. Edmonton, AB.

250. Lang, R.L. 1975. Strip mine rehabilitation problems and research in Wyoming. Pages 182-189 IN: M.K. Wali, ed. Practices and problems of land reclamation in western North America. University of North Dakota Press. Grand Forks, N.D. 
251. Lawrence, D.B., R.E. Schoenike, A. Quispel, and $\mathrm{G}$. Bond. 1967. The role of Dryas drummondii in vegetation development following ice recession at Glacier Bay, Alaska with special reference to its nitrogen fixation by root nodules. Pages 219-220 IN: E.B. Peterson and N.M. Peterson, eds. Revegetation information applicable to mining sites in northern Canada. Indian and Northern Affairs, Environmental Studies No. 3. (Annotation)

252. Lawrence, T., and D.H. Heinrichs. 1966. Russian wild ryegrass for western Canada. Canada Department of Agriculture, Publication No. 991.

253. Legge, A.H., D.R. Jacques, R.G. Amundson, and R.B. Walker. 1977. Field studies of pine, spruce and aspen periodically subjected to sulphur gas emissions. Water, Air, and Soil Pollution, 8: 105-129.

254. Lenderholm, W.A., and E.B. Hadley. 1975. Decomposition of natural and simulated litter in Oakville prairie. Pages 199-207 IN: M.K. Wali, ed. Prairie: a multiple view. University of North Dakota Press. Grand Forks, N.D.

255. Leresche, R.E., and J.L. Davis. 1973. Importance of non-browse foods to moose on the Kenai Peninsula, Alaska. J. Wildl. Manage. 37(3): 279-287.

256. LeRoy, J., and H. Keller. 1972. How to reclaim mined areas, tailings ponds, and dumps into valuable land. World Mining, January 1972: 34-41.

257. Lesko, G.L. 1974. Preliminary revegetation trials on tar sand tailings at Fort McMurray, Alberta. Environment Canada, Forestry Service, Information Report NOR-X-103.

258. Lesko, G.L. 1974. Species suitability for sand dune reclamation at Lesser Slave Lake, Alberta. Environment Canada, Forestry Service, Information Report NOR$\mathrm{X}-86$.

259. Lesko, G.L., H.M. Etter, and T.M. Dillon. 1975. Species selection, seedling establishment and early growth on coal mine spoils at Luscar, Alberta. Environment Canada, Forestry Service, Information Report NOR-X-117.
260. Linderman, R.G., and C.A. Call. 1977. Enhanced rooting of woody plant cuttings by mycorrhizal fungi. J. Am. Soc. Hort. Sci. 102(5): 629-632.

261. Louderback, T. 1975. Selenium and the environment. Mineral Industries Bulletin, 18(3): 1-14.

262. Lowry, G.L., F.C. Brokow, and C.H.J. Breeding. 1962. Alder for reforesting coal spoils in Ohio. Journal For. 60: 196199.

263. Ludwig, A., and S. Martin. 1977. The importance of non-game wildlife in mined land reclamation. Pages 40-45 IN: Reclamation for wildlife habitat. Proceedings, Reclamation Workshop II. Ecology Consultants Inc. Ft. Collins, Colo.

264. Ludwig, J.R., and W.J. McGinnies. 1978. Revegetation trials on a saltgrass meadow. J. Range Manage. 31(4): 308311.

265. Lynott, B. 1977. Critical wildlife habitats of North Dakota. Pages 28-39 IN: Reclamation for wildlife habitat. Proceedings, Reclamation Workshop II. Ecology Consultants Inc. Ft. Collins, Colo.

266. MacLaucklan, R.S. 1975. The role of the Soil Conservation Service's plant material centers in reclaiming surface-mined lands. Pages 131-139 IN: Third Symposium on Surface Mining and Reclamation, Volume II. NCA/BCR Coal Conference and Expo II. National Coal Association. Washington, D.C.

267. Macyk, T.M. 1972. Interim report: strip mine reclamation project, No. 8 mine, Grande Cache, Alberta. Alberta Research Council. Edmonton, AB.

268. Macyk, T.M. 1973. Progress report: strip mine reclamation project No. 8 mine, Grande Cache, Alberta. Alberta Institute of Pedology, Report M-73-14.

269. Macyk, T.M. 1974. Progress report: strip mine reclamation project, No. 8 mine, Grande Cache, Alberta. Alberta Institute of Pedology, Report M-74-16. 
270. Macyk, T.M. 1975. Progress report: strip mine reclamation project, No. 8 mine, Grande Cache, Alberta. Alberta Institute of Pedology, Report M-75-9.

271. Macyk, T.M. 1977. Progress report: strip mine reclamation project, No. 8 mine, Grande Cache, Alberta. Alberta Research Council, Soils Division, Edmonton, $A B$.

272. Macyk, T.M. and J. Steward. 1977. Reclamation at Mclntyre's No. 8 Mine. Pages 130-134 IN: Coal Industry Reclamation Symposium: Proceedings. The Coal Association of Canada. Calgary, AB.

273. Maddox, J.B., J.E. Brown, and G.N. Bartley, Jr. 1977. The effects of fertilizer and acid strip mine spoil on germination of grass seeds. Pages 245-254 IN: Fifth Symposium on Surface Mining and Reclamation. NCA/BCR Coal Conference and Expo IV. National Coal Association. Washington, D.C.

274. Magnusson, A., and D. Gaspe. 1979. Reclamation of exploration disturbances at the Isolation Ridge property, Fording Coal Ltd. Pages 39-48 IN: Reclamation of Land Disturbed by Mining. Proceedings of the Third Annual British Columbia Mine Reclamation Symposium. Vernon, B.C.

275. Maini, J.S., and K.W. Horton. 1966. Vegetative propagation of Populus spp.: I. influence of temperature on formation and initial growth of aspen suckers. Can. J. Bot. 44(9): 1183-1189.

276. Martens, H.E., and W.E. Nicholson. 1976. A soil and vegetation inventory of coal mining wastes in the Rocky Mountain region of Alberta and British Columbia. IN: Proceedings of the First Annual Meeting, Canadian Land Reclamation Association. University of Guelph. Guelph, Ont. (Abstr.)

277. Massey, D.L. 1972. Tailings sands to trees: a report on tailings sands revegetation at Fort McMurray, Alberta. Agricultural Soil and Feed Testing Laboratory. Edmonton, $\mathrm{AB}$.
278.

Mays, D.A., and G.W. Bengtson. 1978. Lime and fertilizer use in land reclamation in humid regions. Pages 307-328 IN: F.W. Schaller and P. Sutton, eds. Reclamation of drastically disturbed lands. American Society of Agronomy, Crop Science Society of America, Soil Science of America. Madison, Wis.

279. McAllister Environmental Services Ltd. 1979. Reclamation and revegetation demonstration and experimental program relative to a proposed coal strip mine in the Camrose-Ryley area: 1978 report and review of previous work. Prepared for Calgary Power Ltd. and Fording Coal Ltd.

280. McAllister Environmental Services Ltd. 1979. 1978 report: Field investigations and demonstrations on the reclamation of Whitewood Mine spoil for the production of agricultural crops. Prepared for Calgary Power Ltd.

281. McCann, S.A. 1975. The movement and occurrence of small mammals on a reclamation plot. Pages 318-324 IN: W.F. Clark, ed. Proceedings of the Fort Union Coal Field Symposium, Volume 3 reclamation section. Montana Academy of Sciences. Billings, Ma.

282. McGill, W.B. 1976. An introduction for field personnel to the effect of oil spills on soil and some general restoration and clean-up procedures. Alberta Institute of Pedology, Publication No. G-76-1.

283. McGinnies, W.J. 1976. Establishment methods work group summary. Pages 117-119 IN: R.H. Zuck and L.F. Brown, eds. Proceedings: High Altitude Revegetation Workshop No. 2. Colorado State University. Information Series No. 21.

284. McGrogan, J.F., A.C. Condo, and J. Neubauer. 1971. Tundra restoration: two-year response study of generic related grass types introduced onto disturbed Prudhoe Bay area tundra. Society of Petroleum Engineers of AIME, Paper No. SPE 324. 
285. McKell, C.M. 1978. Establishment of native plants for the rehabilitation of Paraho processed oil shale in an arid environment. IN: R.A. Wright, ed. The reclamation of disturbed arid land. University of New Mexico Press. Albuquerque, N. Mex.

286. McLean, A., and A.L. van Ryswyk. 1973. Mortality in crested wheatgrass and Russian wildrye. J. Range Manage. 26(6): 431-433.

287. McLean, A., and E.W. Tisdale. 1972. Recovery rate of depleted range sites under protection from grazing. J. Range Manage. 25(3): 178-184.

288. Megahan, W.F. 1974. Deep-rooted plants for erosion control on granitic road fills in the Idaho batholith. USDA Forest Service, Research Paper INT-161.

289. Meyn, R.L., J. Holechek, and E. Sundberg. 1975. Short and long term fertilizer requirements for reclamation of mine spoils at Colstrip, Montana. Pages 266-179 IN: W.F. Clark, ed. Proceedings of the Fort Union Coal Field Symposium, Volume 3 reclamation section. Montana Academy of Sciences. Billings, Ma.

290. Mickleborough, O. 1977. Strip mine planning and reclamation. Pages 135-158 IN: Coal Industry Reclamation Symposium: Proceedings. The Coal Association of Canada. Calgary, AB.

291. Miles, V.C., R.W. Ruble, and R.L. Bond. 1973. Performance of plants in relation to spoil classification in Pennsylvania. Pages 13-31 IN: R.J. Hutnik and G. Davis, eds. Ecology and reclamation of devastated land, Volume 2. Proceedings of a N.A.T.O. Advanced Study Institute on the Ecology and Revegetation of Drastically Disturbed Areas, Pennsylvania State University. Gordon and Breach Scientific Publications. New York.

292. Milligan, A.W., and R.J. Berdusco. 1977. Reclamation problems at high elevations. Pages 86-91 IN: Coal Industry Reclamation Symposium: Proceedings. The Coal Association of Canada. Calgary, AB.
293. Milstein, G.P., and D. Milstein. 1976. Collecting and cleaning of wildflower seed. Pages 41-53 IN: R.H. Zuck and L.F. Brown, eds. Proceedings: High Altitude Revegetation Workshop No. 2. Colorado State University. Information Series No. 21.

294. Mitchell, A. 1974. Plants and techniques used for sand dune reclamation in Australia. Int. J. of Biometeor. 18(2): 168-173.

295. Mitchell, D.L., and W.C. Kay. 1973. Growth of conifer seedlings in various peats and other mixtures. American Society of Agricultural Engineers. Winter Meeting, Paper No. 73-1551.

296. Mitchell, D.L., D. Hocking, and W.C. Kay. 1972. Reforestation with tree seedlings grown in extruded peat cylinders: part 1 mechanical aspects of the process. Trans. American Society of Agricultural Engineers, 15(1): 36-39.

297. Mitchell, W.W. 1974. Native bluejoint: a valuable forage and germplasm resource. Page 258 IN: E.B. Peterson and N.M. Peterson, eds. Revegetation information applicable to mining sites in northern Canada. Indian and Northern Affairs, Environmental Studies No. 3. (Annotation)

298. Mitchell, W.W. 1978. Development of plant materials for revegetation in Alaska. Pages 101-115 IN: S.T. Kenny, ed. Proceedings: High Altitude Revegetation Workshop No. 3 . Colorado State University. Information Series No. 21.

299. Mitchell, W.W., and J.D. McKendrick. 1973. Progress report 1973: tundra rehabilitation research, Prudhoe Bay and Palmer research center. Institute of Agricultural Sciences, University of Alaska. Palmer, Al.

300. Mitchell, W.W., J.D. McKendrick, and M.A. Barzee. 1973. Annual report 1972 73: tundra rehabilitation research, Prudhoe Bay, Palmer research center. Institute of Agricultural Sciences, University of Alaska. Palmer, Al. 
301. Moghaddam, M.R. 1977. Reseda lutea: a multipurpose plant for arid and semiarid lands. J. Range Manage. 30(1): 71-72.

302. Monsen, S.B. 1975. Selecting plants to rehabilitate disturbed areas. Pages $76-90$ IN: R.S. Campbell and C.H. Herbel, eds. Improved range plants. Proceedings of first range symposium. Society for Range Management. Denver, Colo.

303. Monsen, S.B., and A.P. Plummer. 1978. Plants and treatment of disturbed sites in the intermountain area. IN: R.A. Wright, ed. The reclamation of disturbed arid lands. University of New Mexico Press. Albuquerque, N. Mex.

304. Montreal Engineering Company Ltd. 1979. Highvale wildland reclamation trial plots. Prepared for Calgary Power Ltd.

305. Montreal Engineering Company Ltd. 1979. Wabamun ash lagoon reclamation studies, 1978. Prepared for Calgary Power Ltd.

306. Moore, A.W. 1964. Note on nonleguminous nitrogen-fixing plants in Alberta. Can. J. Bot. 42: 952-955.

307. Moore, R.T., D.A. Koehler, and C.L. Kling. 1975. Surface mine rehabilitation in northwestern Colorado. Pages 171-184 IN: third symposium on surface mining and reclamation, Volume II. NCA/BCR coal conference and expo II. National Coal Association. Washington, D.C.

308. Moore, R.T., S.L. Ellis, and D.R. Duba. 1977. Advantages of natural successional processes on western reclaimed lands. Pages 274-282 IN: Fifth symposium on surface mining and reclamation. NCA/BCR Coal Conference and Expo IV. National Coal Association. Washington, D.C.

309. Moore, T.R., and R.C. Zimmerman. 1976. The reclamation of asbestos mine wastes. IN: Proceedings of the first annual meeting, Canadian Land Reclamation Association. University of Guelph. Guelph, Ont. (Abstr.)

310. Moore, T.R., and R.C. Zimmerman. 1977. Establishment of vegetation on serpentine asbestos mine wastes, southern Quebec, Canada. J. Appl. Ecol. 14: 589-599.
311. Morrison, I.K. 1974. Mineral nutrition of conifers with special reference to nutrient status interpretation: a review of literature. Department of the Environment, Forest Service, Publication No. 1343.

312. Moss, E.H. 1983. Flora of Alberta (2nd edition). University of Toronto Press. Toronto, Ont.

313. Mueggler, W.F. 1972. Influence of competition on the response of bluebunch wheatgrass to clipping. J. Range Manage. 25(2): 88-92.

314. Mueggler, W.F. 1975. Rate and pattern of vigor recovery in Idaho fescue and bluebunch wheatgrass. J. Range Manage. 28(3): 198-204.

315. Murray, D.R. 1977. The influence of uranium mine tailings on tree growth at Elliot Lake, Ontario. IN: Proceedings of the Second Annual General Meeting, Canadian Land Reclamation Association. Edmonton, $\mathrm{AB}$.

316. Murray, D.R. 1977. Pit slope manual, reclamation by vegetation: vol. 1 - mine waste description and case histories. Canada Centre for Mineral and Energy Technology, Energy Mines and Resources, CANMET Report 77-31, Supplement 10-1.

317. Murray, D.R. 1978. Influence of uranium mill tailings on tree growth at Elliot Lake. C.I.M. Bulletin, December 1978: 79-81.

318. Murray, D.R., and D. Moffett. 1977. Vegetating the uranium mine tailings at Elliot Lake, Ontario. J. Soil and Water Conserv. 32(4): 171-174

319. Negusanti, J.J. 1978. Revegetation of deteriorated Sudbury sites through tree plant trails. Pages 14-24 IN: Proceedings of the Third Annual Meeting, Canadian Land Reclamation Association. Sudbury, Ont.

320. New Mexico State University, Cooperative Extension Service. 1964. Luna pubescent wheatgrass, Circular 368.

321. New Mexico State University, Cooperative Extension Service. 1977. Arriba western wheatgrass, Circular 475. 
322. New Mexico State University, Cooperative Extension Service. 1978. Paloma indian ricegrass, Circular 474.

323. Nishimura, J.Y. 1974. Soils and soil problems at high altitudes. Pages 5-9 IN: W.A. Berg, J.A. Brown, and R.L. Cuany, eds. Proceedings of a workshop on Revegetation of High-Altitude Disturbed Lands. Colorado State University. Information Series No. 10.

324. Nyhoff, J.J. 1975. The usage of Goose Lake Prairie State Park. Pages 383-387 IN: M.K. Wali, ed. Prairie: a multiple view. University of North Dakota Press. Grand Forks, N.D.

325. Oehmichen, F. 1976. Reclamation and stabilization of steep slopes by unrooted wood cutting. IN: Proceedings of the First Annual Meeting, Canadian Land Reclamation Association. University of Guelph. Guelph, Ont. (Abstr.)

326. Ogram, D.G., and W.W. Fraser. 1978. Reclamation of high sulfide tailings at Hudson Bay Mining and Smelting, Flin Flon, Manitoba. Reclamation Review, 1(1): 1925.

327. Packer, P.E., and E.F. Aldon. 1978. Revegetation techniques for dry regions. Pages 425-450 IN: F.W. Schaller and P. Sutton, eds. Reclamation of drastically disturbed lands. American Society of Agronomy, Crop Science Society of America, Soil Science Society of America. Madison, Wis.

328. Packer, P.E. 1974. Rehabilitation potentials and limitations of surface-mined land in the northern great plains. USDA Forest Service, General Technical Report INT-14.

329. Paul, E.A., R.J.K. Myers, and W.A. Rice. 1971. Nitrogen fixation in grassland and associated cultivated ecosystems. Pages 495-507 IN: Plant and Soil, Special Volume, Proceedings: Technical Meetings on Biological Nitrogen Fixation of the I.B.P. Prague and Wageningen.
330. Peepre, J. 1979. Interim report on selected landscape rehabilitation projects in the western National Parks. Pages 1727 IN: P.F. Ziemkiewicz, C.A. Dermott, and H.P. Sims, eds. Proceedings: workshop on native shrubs in reclamation. Alberta Land Conservation and Reclamation Council Report No. RRTAC 79-2.

331. Peterson, E.B., and H.B. Etter. 1970. A background for disturbed land reclamation and research in the Rocky Mountain region of Alberta. Environment Canada, Forestry Service, Information Report A-X-34.

332. Peterson, E.B., and N.M. Peterson. 1977. Revegetation information applicable to mining sites in northern Canada. Indian and Northern Affairs, Environmental Studies No. 3.

333. Pfister, R.D. n.d. Habitat types and regeneration. USDA Forest Service, Intermountain Forest and Range Experiment Station. Missoula, Ma.

334. Plass, W.T. 1975. Preliminary recommendations for seeding pine on surface mine spoils. Page 147 IN: Reclamation of coal mined-land: a bibliography with abstracts. Bituminous Coal Research, Inc. Monroeville, Pa.

335. Plass, W.T. 1975. An evaluation of trees and shrubs for planting surface-mine spoils. USDA Forest Service, Research Paper NE-317.

336. Plummer, A.P. 1970. Plants for revegetation of roadcuts and other disturbed or eroded areas. Range Improvement Notes, 15(10): 1-8.

337. Plummer, A.P. 1976. Shrubs for the subalpine zone of the Wasatch Plateau. Pages 33-40 IN: R.H. Zuck and L.F. Brown, eds. Proceedings: high altitude revegetation workshop No. 2. Colorado State University. Information Series No. 21. 
338. Plummer, A.P. 1977. Revegetation of disturbed intermountain area sites. Pages 302-339 IN: J.L. Thomas, ed. Reclamation and use of disturbed land in the southwest. The University of Arizona Press. Tucson, Ariz.

339. Plummer, A.P., D.R. Christenson, and S.B. Monsen. 1968 . Restoring biggame range in Utah. Utah Division of Fish and Game. Publication No. 68-3.

340. Plummer, A.P., A.C. Hull, Jr., G. Stewart, and J.H. Robertson. $1955 . \quad$ Seeding rangelands in Utah, Nevada, southern Idaho and western Wyoming. USDA Forest Service, Agriculture Handbook No. 71.

341. Pohl, R.W. 1968. How to know the grasses. Revised Edition. W.C. Brown Company Publishers. Dubuque, lowa.

342. Powell, J.L., R.I. Barnhisel, G.W. Akin, and M.W. Ebelhar. 1977. The state of the art of reclaiming land surface-mined for coal in the western Kentucky coal field. Pages 255-273 IN: Fifth Symposium on Surface Mining and Reclamation. NCA/BCR Coal Conference and Expo IV. National Coal Association. Washington, D.C.

343. Power, J.F., R.E. Ries, F.M. Sandoval, and W.O. Willis. 1975. Factors restricting revegetation of strip-mine spoils. Pages 336-346 IN: W.F. Clark, ed. Proceedings of the Fort Union Coal Field Symposium, Volume 3 - reclamation section. Montana Academy of Sciences. Billings, Ma.

344. Pratt, P.F., E.C. Nord, and F.L. Bair. 1971. Early growth tolerances of grasses, shrubs, and trees to boron in tunnel spoil. USDA Forest Service, Research Note PSW-232.

345. Radvanyi, A. 1976. Harmful small mammals - an unanticipated problem in the Alberta oil sands reclamation program. Environment Canada, Canadian Wildlife Service. Edmonton, AB.

346. Rafaill, B.L., and W.G. Vogel. 1978. A guide for revegetating surface-mined lands for wildlife in eastern Kentucky and West Virginia. Prepared for U.S. Department of the Interior, Fish and Wildife Service. Northeastern Forest Experiment Station. Berea, Ky.
347. Rawson, J.W. 1974. Willows. USDA Forest Service, General Technical Report, NE 9: 147-149.

348. Regier, H. 1973. Response to nitrogen, phosphorus, and potassium of alfalfa growing in coal refuse. Alberta Department of the Environment, Earth Sciences and Licensing Division. Edmonton, $\mathrm{AB}$.

349. Reid Collins Nurseries Ltd. n.d. Price list: seed of native tree and shrub species. Aldergrove, B.C.

350. Reynolds, J.F., M.J. Cwik, and N.E. Kelley. 1978. Reclamation at Anaconda's open pit uranium mine, New Mexico. Reclamation Review, 1(1): 9-17.

351. Richardson Seed Co. Ltd. n.d. Seed planting chart. Burnaby, B.C.

352. Richardson, B.Z., E.E. Farmer, R.W. Brown, and P.E. Packer. 1975. Rehabilitation research and its application on a surface mined area of eastern Montana. Pages 247-265 IN: W.F. Clark, ed. Proceedings of the Fort Union Coal Field Symposium, Volume 3 - reclamation section. Montana Academy of Sciences. Billings, Ma.

353. Richmond, H.A., S.J. Inytzki, and B.F. Vance. 1975. Forest pesticide handbook of British Columbia. Council of Forest Industries of British Columbia. Vancouver, B.C.

354. Rodiek, J., T.R. Verma, and J.L. Thames. 1976. Disturbed land rehabilitation in Lynx Creek watershed. Landscape Planning, 2: 265-282.

355. Roemer, H.L. 1975. Ecological impact of recreational use in the Magog area, Mount Assiniboine Provincial Park. Project 74A1. Prepared for the Parks Branch, Department of Recreation and Conservation by Biocon Research Ltd.

356. Ronco, F. 1976. Revegetation of forest lands at high elevations in the central Rocky Mountains. Pages 13-28 IN: R.H. Zuck and L.F. Brown, eds. Proceedings: High Altitude Revegetation Workshop No. 2. Colorado State University. Information Series No. 21. 
357. Root, J.D. 1976. Physical environment of an abandoned strip mine near Cadomin, Alberta. Alberta Research Council, Bulletin 34.

358. Rowell, M.J. 1977. Continued studies of soil improvement and revegetation of tailings sand slopes. Syncrude Canada Ltd., Environmental Research Monograph 1977-4.

359. Rowell, M.J. $1978 . \quad$ Revegetation and management of tailings sand slopes: 1977 results. Syncrude Canada Ltd., Environmental Research Monograph 1978-5.

360. Rowell, M.J., and W.B. McGill. 1978. Study into the reclamation of five oil spills in Alberta. Environment Research Control Committee, Canadian Petroleum Association. Calgary, AB.

361. Rowell, M.J., and J.M. Crepin. 1977. Brine spillage in the oil industry - the natural recovery of an area affected by a salt water spill near Swan Hills, Alberta. IN: Proceedings of the Second Annual General Meeting, Canadian Land Reclamation Association. Edmonton, AB.

362. Ruffner, J.D. 1973. Projecting the use of new plant materials for special reclamation problems. Pages 233-242 IN: Research and Applied Technology Symposium on Minedland Reclamation. National Coal Association. Pittsburgh, $\mathrm{Pa}$.

363. Rulli, J.F. 1971. Reclamation at Big Horn mine. Mining Congress Journal, 57(6): 4144.

364. Russell, W.B., and S.K. Takyi. 1979. The Cadomin reclamation research project: first year results (1978). Alberta Energy and Natural Resources, Report No. 121.

365. Russell, W.B. 1979. Survey of native shrubs on disturbed lands in the eastern slopes. Unpublished report prepared for Reforestation and Reclamation Branch, Alberta Forest Service, Alberta Energy and Natural Resources. Edmonton, AB.

366. Russell, W.B. 1979. Native grass reclamation research: container plantings in the eastern slopes of Alberta. Alberta Forest Service, Alberta Energy and Natural Resources Report 140.
367. Saeed, M. 1976. Use of sorptionisotherms for evaluating effect of leonardite on $P$ availability in surfacemined spoil materials. IN: Proceedings of the first annual meeting, Canadian Land Reclamation Association. University of Guelph. Guelph, Ont. (Abstr.)

368. Safaya, M.N., and A. Kollman. 1976. Responses of a grass-legume mixture to various amendments and nutrients on a sodic spoil material. IN: Proceedings of the first annual meeting, Canadian Land Reclamation Association. University of Guelph. Guelph, Ont. (Abstr.)

369. Sampson, E.J., and B.M.G. Jones. 1977. The productivity of Salix glauca in arctic Norway. Annals of Bot. 41(171): 155-161.

370. Schaller, F.W., and P. Sutton, eds. 1978. Reclamation of drastically disturbed lands. American Society of Agronomy, Crop Science Society of America, Soil Science Society of America. Madison, Wis.

371. Schier, G.A. 1978. Vegetative propagation of Rocky Mountain aspen. USDA Forest Service, General Technical Report INT 14: 1-13.

372. Schlatzer, G. 1973. Some experiments with various species in Danish reclamation work. Pages 33-64 IN: R.J. Hutnik and G. Davis, eds. Ecology and reclamation of devastated land, volume 2. Proceedings of a N.A.T.O. Advanced Study Institute on the Ecology and Revegetation of Drastically Disturbed Areas, Pennsylvania State University. Gordon and Breach Scientific Publications. New York.

373. Schlatterer, E.E., and M. Hironaka. 1972. Some factors influencing tolerance to moisture stress of three range grasses. J. Range Manage. 25(5): 364-367.

374. Schumacher, C.M. 1975. Rangeland - a proper prairie use. Pages 419-422 IN: M.K. Wali, ed. Prairie: a multiple view. University of North Dakota Press. Grand Forks, N.D.

375. Schuster, J.L., and R.C. De Leon Garcia. 1973. Phenology and forage production of cool season grasses in the southern plains. J. Range Manage. 26(5): 336-339. 
376. Echols, J.W., and R.L. Cuany. 1974. Seed supplies and plant materials work group summary. Pages 83-87 IN: W.A. Berg, J.A. Brown, and R.L. Cuany, eds. Proceedings of a Workshop on Revegetation of HighAltitude Disturbed Lands. Colorado State University. Information Series No. 10.

377. Selner, J. 1973. Surface mine reclamation research in Alberta: progress report for 1973. Forest Land Use Branch, Alberta Lands and Forests. Edmonton, AB.

378. Selner, J.E. 1975. Reclamation research in the Rocky Mountain foothills. Pages 1620 IN: Third symposium on surface mining and reclamation, Volume II. NCA/BCR coal conference and expo II. National Coal Association. Washington, D.C.

379. Selner, J., and P. King. 1977. Native grass study species adaptability trials. Alberta Energy and Natural Resources, Report No. 18.

380. Selner, J., P. King, and D. Hildebrandt. 1977. Progress report for Tent Mountain coal-mined land reclamation trials (1975-76). Alberta Forest Service, ENR Report No. 32.

381. Shinn, R., and T. Terrel. 1977. Problems of reclaiming for wildlife on private lands. Pages 74-85 IN: Reclamation for wildlife on private lands. Pages 74-85 IN: Reclamation for wildlife habitat: Proceedings, reclamation workshop II. Ecology Consultants Inc. Ft. Collins, Colo.

382. Sims, H.P. 1979. Land surface reclamation: an international bibliography. (Interim edition - April 1979). Alberta Department of Environment. Edmonton, $A B$.

383. Sinelor, B.W., and P.L. Plantenburg. 1979. Establishment, succession and stability of vegetation on surface mined lands in eastern Montana. Prepared for U.S. Department of Energy by Animal and Range Sciences Department, Montana State University. Bozeman, Ma.

384. Singleton, J.M. 1977. Natural succession on tailings ponds and associated sites at nine mine sites in British Columbia. Unpublished report, Directed Studies, University of Victoria. Victoria, B.C.
385. Sherstabetoff, J., B.G. Dunsworth, and S.K. Takyi. 1979. Interim report on reclamation for afforestation by suitable native and introduced tree and shrub species. Prepared by Reforestation and Reclamation Branch, Alberta Energy and Natural Resources for Alberta Oil Sands Environmental Research Program.

386. Smith, R.A.H., and A.D. Bradshaw. 1970. Reclamation of toxic metalliferous wastes using tolerant populations of grass. Nature, 227: 376-377.

387. Smith, R.A.H., and A.D. Bradshaw. 1972. Stabilization of toxic mine wastes by the use of tolerant plant populations. Inst. Mining and Metallurgy, 81: A230-A238.

388. Smithberg, M. 1974. Red-osier dogwood. USDA Forest Service, General Technical Report NE 9: 44-47.

389. Smoliak, S. 1974. Range vegetation and sheep production at three stocking rates on Stipa-Bouteloua prairie. J. Range Manage. 27(1): 23-26.

390. Smoliak, S., and S.B. Slen. 1974. Beef production on native range, crested wheatgrass and Russian wildrye pastures. J. Range Manage. 27(6): 433-436.

391. Smoliak, S., C.R. Elliott, and J. Willman. 1975. Hay and pasture crops for Alberta. Alberta Agriculture, Agdex 120/20-1.

392. Smoliak, S., J.F. Dormaar, and A. Johnston. 1972. Long-term grazing effects on Stipa-Bouteloua prairie soils. J. Range Manage. 25(4): 246-250.

393. Stanlake, E.A., D.S. Eastman, and M.G. Stanlake. 1978. Ungulate use of some recently reclaimed strip mines in southeastern British Columbia. Wildlife Research and Technical Services Section, Fish and Wildlife Branch, Ministry of Recreation and Conservation. B.C. Fish and Wildlife, Report No. R-1.

394. Stathers, J.E., and R.T. Gardiner. 1979. Operational reclamation experience at Cominco's Bluebell and Pinchi Lake mines. Pages 83-96 IN: Reclamation of Lands Disturbed by Mining. Proceedings of the Third Annual British Columbia Mine Reclamation Symposium. Vernon, B.C. 
395. Stevenson, K.E., and E.C. Garrett. 1974. Growth characteristics of bearberry in the Black Hills. USDA Forest Service, Rocky Mountain Forest and Range Experiment Station, Research Notes 254: 1-3.

396. Stranathan, S. 1978. Upper Colorado environmental plant center status report. Pages 75-82 IN: S.T. Kenny, ed. Proceedings: High Altitude Revegetation Workshop No. 3. Colorado State University. Information Series No. 28.

397. Stranathan, S.E., and L.J. Bruggeman. 1977. Developing plants compatible to wildlife and revegetation. Pages 148-153 IN: Reclamation for Wildlife Habitat. Proceedings, Reclamation Workshop II. Ecology Consultants Inc. Ft. Collins, Colo.

398. Strang, R.M. 1978. Land reclamation in Canada north of latitude $60^{\circ} \mathrm{N}$. Yukon and the Northwest Territories). Pages 64-68 IN: F.W. Schaller and P. Sutton, eds. Reclamation of drastically disturbed lands. American Society of Agronomy, Crop Science Society of America, Soil Science Society of America. Madison, Wis.

399. Stringer, P.W. 1976. A preliminary vegetation survey of the Alberta oil sands environmental research program studyarea, sub-project VE 2.2. Prepared for Vegetation Technical Research Committee, AOSERP, by Intraverda Plant Systems Ltd.

400. Sutherland, D.M. 1975. A vegetative key to Nebraska grasses. Pages 283-316 IN: M.K. Wali, ed. Prairie: a multiple view. University of North Dakota Press. Grand Forks, N.D.

401. Sutton, R., and C.W. Johnson. 1978. Landscape plants from Utah's mountains. Utah State University, Extension Service No. EC-368.

402. Svedarsky, W.D., and P.E. Buckley. 1975. Some interactions of fire, prairie and aspen in northwest Minnesota. Pages 115-121 IN: M.K. Wali, ed. Prairie: a multiple view. University of North Dakota Press. Grand Forks, N.D.
403.

Sylvester, T.W. 1975. Fuel characteristics of plant communities in the Mackenzie Delta region. Pages 63-91 IN: Vegetation recovery in Arctic tundra and forest-tundra after fire. Indian and Northern Affairs, ALUR 74-75-62.

404. Takyi, S.K., M.H. Rowell, W.B. McGill, and M. Nyborg. 1977. Reclamation and vegetation of surface mined areas in the Athabasca tar sands. Syncrude Canada Ltd., Environmental Research Monograph 1977-1.

405. Taylor, R.L., and B. MacBryde. 1977. Vascular plants of British Columbia: a descriptive resource inventory. The University of British Columbia Press, Technical Bulletin No. 4.

406. Tew, R.K. 1969. Water use, adaptability, and chemical composition of grasses seeded at high elevations. J. Range Manage. 22(4): 180-283.

407. Thames, J.L., and T.R. Verma. 1975. Coal mine reclamation on the Black Mesa and the Four Corners area of northeastern Arizona. Pages 48-64 IN: M.K. Wali, ed. Practices and problems of land reclamation in western North America. University of North Dakota Press. Grand Forks, N.D.

408. Thimm, H.F., G.J. Clark, and G. Baker. 1977. Combined overburden revegetation and wastewater disposal in the Southern Alberta foothills. IN: Proceedings of the Second Annual General Meeting, Canadian Land Reclamation Association. Edmonton, $\mathrm{AB}$.

409. Thirgood, J.V., and J.R. Matthews. 1971. Progress in reclamation research in British Columbia during 1970 . Fores. Chron. 47(6): 338-340.

410. Thirgood, J.V., and M.D. Meagher. 1972. Progress in reclamation research by mining companies in British Columbia during 1971. Fores. Chron. 48(6): 308311. 
411. Thirgood, J.V. 1978. Nature of disturbances and reclamation activities in British Columbia. Pages 58-64 IN: F.W. Schaller and $P$. Sutton, eds. Reclamation of drastically disturbed lands. American Society of Agronomy, Crop Science Society of America, Soil Science Society of America. Madison, Wis.

412. Thirgood, J.V., and P.F. Ziemkiewicz. 1978. Reclamation of coal surface-mined lands. American Society of Agronomy, Crop Science Society of America, Soil Science Society of America. Madison, Wis.

413. Thompson, P.W. 1975. The floristic composition of prairie stands in southern Michigan. Pages 317-331 IN: M.K. Wali, ed. Prairie: a multiple view. University of North Dakota Press. Grand Forks, N.D.

414. Thornburg, A.A., and S.H. Fuchs. 1978. Plant materials and requirements growth in dry regions. Pages 411-423 IN: F.W. Schaller and P. Sutton, eds. Reclamation of drastically disturbed lands. American Society of Agronomy, Crop Science Society of America, Soll Science Society of America. Madison, Wis.

415. Tiedeman, A.R., G.O. Klock, L.L. Mason, and D.E. Sears. 1976. Shrub plantings for erosion control in eastern Washington progress and research needs. USDA Forest Service, Research Note PNW-279.

416. Tiffney, W.N. Jr., D.R. Benson, and D.E. Eveleigh. 1978. Does Arctostaphylos uviursi (bearberry) have nitrogen-fixing root nodules? Am. J. Bot 65(6): 625-628.

417. Townsend, C.E. 1974. Legume selection and breeding research in Colorado. Pages 36-38 IN: W.A. Berg, J.A. Brown, and R.L. Cuany, eds. Proceedings of a Workshop on Revegetation of High-Altitude Disturbed Lands. Colorado State University. Information Series No. 10.

418. Turner, R.G., and C. Marshall. 1972. The accumulation of zinc by sub-cellular fractions of roots of Agrostis tenuis Sibth. in relation to zinc tolerance. New Phytol. 71: 671-676.
419. USDA, Forest Service. 1974. Seeds of woody plants in the United States. Agriculture Handbook No. 450.

420. USDA, Forest Service. 1975. Some important native shrubs of the west. Intermountain Forest and Range Experiment Station. Ogden, Utah.

421. USDA, Soil Conservation Service. n.d. Tree planting on alkaline and saline soils. Caspar, Wy.

422. USDA, Soil Conservation Service. 1971. Guidelines for reclamation of surfacemined areas in Montana. Bozeman, Ma.

423. USDA, Soil Conservation Service. 1973. Kentucky guide for classification, use and vegetative treatment of surface mine spoil. Lexington, Ky.

424. USDA, Soil Conservation Service. 1976. Standards and specifications: critical area planting. Technical Guide, Section IV. Denver, Colo.

425. USDA, Soil Conservation Service. 1976. National range handbook. Washington, D.C.

426. USDA, Soil Conservation Service. 1979. Plant materials for use on surface mined lands in western United States. Denver, Colo.

427. USDA, Soil Conservation Service. 1977. Planting guide for critical sites in northwestern Colorado. Denver, Colo.

428. USDA, Soil Conservation Service. 1977. Colorado plant materials: long range plan. Denver, Colo.

429. USDA, Soil Conservation Service. 1977. National plant materials handbook. Washington, D.C.

430. USDA, Soil Conservation Service. 1979. Improved plant materials cooperatively released by SCS through January, 1979.

431. Vaartnou and Sons Enterprises Ltd. 1977. Northern revegetation research: progress report - 1976. Prepared for Foothills Pipelines Ltd., Alberta Gas Trunkline Ltd., and Westcoast Transmission Ltd. 
432. Vaartnou and Sons Enterprises Ltd. 1977. Revegetation research proposal for continuing testing of native grasses and legumes for rehabilitating disturbed agricultural areas in Alberta: 1976 final report. Prepared for Alberta Agriculture.

433. Vaartnou and Sons Enterprises Ltd. 1978. 1977 progress report for VE 7.2, 7.3, and 7.4. Prepared for the Alberta Oil Sands Environmental Research Program.

434. Vaartnou, H. 1979. Working group I: propagation. Pages 38-56 IN: P.F. Ziemkiewicz, C.A. Dermott, and H.P. Sims, eds. Proceedings: Workshop on Native Shrubs in Reclamation. Alberta Land Conservation and Reclamation Council Report No. RRTAC 79-2.

435. Vaartnou, H., and G.W. Wheeler. 1974. Establishment and survival of ground cover plantings on disturbed areas in Alberta. Plant Industry Laboratory, Alberta Department of Agriculture. Edmonton, AB.

436. Vaartnou, M. 1979. Table 6 from unpublished M.Sc. Thesis (Yukon pipeline plot studies). University of British Columbia.

437. Van Adrichem, M.C.J. 1972. Variation among British Columbia and northern Alberta populations of raspberries, Rubus ideaus subspp. strigosus Michx. Can J. Plant Sci. 52: 1067-1072.

438. Van Cleve, K., L.A. Viereck, and R.L. Schlenter. 1971. Accumulation of nitrogen in Alder (Alnus) ecosystems near Fairbanks, Alaska. Arctic and Alpine Research, 3(2): 101-114.

439. van Drimmelen, B. 1979. Revegetation for wildlife use. Pages 169-178 IN: Reclamation of Lands Disturbed by Mining. Proceedings of the Third Annual British Columbia Mine Reclamation Symposium. Vernon, B.C.

440. Van Lear, D.H. 1971. Effects of spoil texture on growth of K-31 tall fescue.Page 63 IN: Reclamation of coal mined-land: a bibliography with abstracts. Bituminous Coal Research, Inc. Monroeville, $\mathrm{Pa}$. (Abstr.).
441. Viereck, L.A. 1966. Plant succession and soil development on gravel outwash of the Muldrow Glacier, Alaska. Ecological Monographs, 36: 181-199.

442. Viereck, L.A. 1970. Forest succession and soil development adjacent to the Chena River in interior Alaska. Arc. Alpine Res. 2(1): 1-26.

443. Viereck, L.A., and E.L. Little, Jr. 1972. Alaska trees and shrubs. USDA Forest Service, Agriculture Handbook No. 410.

444. Vogel, W.G., and W.A. Berg. 1968. Grasses and legumes for cover on acid strip-mine spoils. J. Soil and Water Conserv. 23(3): 89-91.

445. Vogel, W.G., and W.R. Curtis. 1978. Reclamation research on coal surfacemined lands in the humid east. Pages 379-397 IN: F.W. Schaller and P. Sutton, eds. Reclamation of drastically disturbed lands. American Society of Agronomy, Crop Science Society of America, Soil Science Society of America. Madison, Wis.

446. Vories, K.C., and P.L. Sims. 1977. The plant information network, volume II: reclamation and PIN in northwestern Colorado. U.S. Department of the Interior, Fish and Wildlife Service, Office of Biological Services, Report No. FWS/OBS-77/39.

447. Vories, K.C., and P.L. Sims. 1977. The plant information network volume III: reclamation and PIN in the Powder River basin of Montana and Wyoming. U.S. Department of the Interior, Fish and Wildlife Service. Office of Biological Services, Report No. FWS/OBS-77/40.

448. Waldron, R.M., and J.R. Dyck. 1975. Trees and shrubs on residential lots in Edmonton, 1973. Environment Canada, Forestry Service, Information Report NOR$\mathrm{X}-143$.

449. Wali, M.K., and F.M. Sandoval. 1975. Regional site factors and revegetation studies in western North Dakota. Pages 133-153 IN: M.K. Wali, ed. Practices and problems of land reclamation in western North America. University of North Dakota Press. Grand Forks, N.D. 
450. Wali, M.K., and P.B. Kannowski. 1975. Prairie ant mound ecology: interrelationships of microclimate, soils and vegetation. Pages 155-169 IN: M.K. Wali, ed. Prairie: a multiple view. University of North Dakota Press. Grand Forks, N.D.

451. Wali, M.K., ed. 1975. Prairie: a multiple view. University of North Dakota Press. Grand Forks, N.D.

452. Wali, M., ed. 1975. Practices and problems of land reclamation in western North America. University of North Dakota Press. Grand Forks, N.D.

453. Walker, D.G., R.S. Sadasivaiah, and J. Weijer. 1978. The utilization and genetic improvement of native grasses from the Alberta Rocky Mountains. Prepared for Alberta Environment, Alberta Fish \& Wildlife, Alberta Forestry, and Parks Canada. Department of Genetics, University of Alberta. Edmonton, AB.

454. Walker, D., and J. Weijer. 1974. The collection and maintenance of native grasses of the eastern slope of the Rocky Mountains. Prepared for Department of Lands and Forests, Division of Fish and Wildlife by Department of Genetics, University of Alberta. Edmonton, AB.

455. Walker, D., and J. Weijer. 1975. The collection, maintenance and utilization of native grasses of the eastern slopes of the Rocky Mountains. Prepared for Department of Recreation, Parks and Wildlife, Division of Fish and Wildlife and the Department of Energy and Natural Resources, Division of Forestry. Department of Genetics, University of Alberta. Edmonton, AB.

456. Walker, D., R.S. Sadasivaiah, and J. Weijer. 1977. The utilization and genetic improvement of native Alberta grasses from the eastern slopes of the Rocky Mountains. Department of Genetics, University of Alberta. Edmonton, AB.

457. Walmsley, J.R. 1977. Reclamation in the interior dry belt. Pages 25-33 IN: Reclamation of lands disturbed by mining. Proceedings of the British Columbia Mine Reclamation Symposium. Vernon, B.C.
458. Weber, M.G. 1975. Nutrient budget changes following fire in Arctic plant communities. Pages 92-115 IN: R.W. Wein, ed. Vegetation recovery in arctic tundra and forest-tundra after fire. Indian and Northern Affairs, ALUR 74-75-62.

459. Wein, R.W. 1971. Interim report No. 1: towards an environmental impact assessment of a gas pipeline from Prudhoe Bay, Alaska, to Alberta. Appendix IV, revegetation. Prepared for the Environment Protection Board.

460. Wein, R.W. 1975. Vegetation recovery in Arctic tundra and forest-tundra after fire. Indian and Northern Affairs, ALUR 74-7562.

461. Wein, R.W., and D.A. MacLean. 1973. Cotton grass (Eriophorum vaginatum) germination requirements and colonizing potential in the arctic. Can. J. Bot. 51: $2509-2513$.

462. Welin, C. 1974. Cultural problems and approaches in a ski area. Pages 64-70 IN: W.A. Berg, J.A. Brown, and R.L. Cuany, eds. Proceedings of a Workshop on Revegetation of High-Altitude Disturbed Lands. Colorado State University. Information Series No. 10.

463. Weston, S. 1973. Revegetation of mining waste areas under arid, temperate and permafrost conditions. Paper presented to 1973Pacific-Southwest Mineral Industry Conference, AIME. Phoenix, Ariz.

464. Weston, S. 1973. Report on developments and progress in reclaiming waste dumps and tailing ponds. Western Miner, August 1973: 29-37.

465. Whalley, R.D.B., and R.W. Brown. 1973. A method for the collection and transport of native grasses from the field to the greenhouse. J. Range Manage. 26(5): 376-377.

466. Whitby-Costescu, L., J. Shillabeer, and D.F. Coates. 1977. Pit slope manual, chapter 10: environmental planning. Canada Centre for Mineral and Energy Technology, Energy Mines and Resources, CANMET Report 77-2. 
467. White, L.M. 1977. Perenniality and development of shoots of 12 forage species in Montana. J. Range Manage. 30(2): 107110.

468. White, R.A., and E. de Jong. 1975. Reclamation of salt and oil damaged soils: a literature review of potential methods for use in oil fields in Saskatchewan. Saskatchewan Institute of Pedology, Publication M 27.

469. Whitman, W.C., and M.K. Wali. 1975. Grasslands of North Dakota. Pages 53-73 IN: M.K. Wali, ed. Prairie: a multiple view. University of North Dakota Press. Grand Forks, N.D.

470. Whysong, G.L., and A.W. Bailey. 1975. Production and nitrogen content of herbage in a silverberry (Elaeagnus commutata) community compared to adjacent grassland and forest communities. Can. J. Plant Sci. 55(3): 801-808.

471. Willard, E.E., and J.L. Schuster. 1973. Chemical composition of six southern great plains grasses as related to season and precipitation. J. Range Manage. 26(1): 3738.

472. Williams, Dean Elder. 1976. Growth, production, and browse utilization characteristicsofserviceberrry(Amelanchier alnifolia Nutt.) in the bad-lands of southwestern North Dakota. M.S. Thesis. North Dakota State University. (Summary)

473. Williams, D.E., and H. Goetz. 1975. Growth, production and browse utilization characteristics of serviceberry Amelanchier alnifolia in the badlands of southwestern North Dakota. Proceed. of the North Dakota Academy of Science. 27(2): 50-58.

474. Wilson, A.M. 1973. Responses of crested wheatgrass seeds to environment. J. Range Manage. 26(1): 43-46.

475. Wilson, A.M. D.E. Wondercheck, and C.J. Goebel. 1974. Responses of range grass seeds to winter environments. J. Range Manage. 27(2): 120-122.
476. Winterhalder, K. 1974. Reclamation studies on industrial barrens in the Sudbury area. Pages 2-3 IN: Ontario Cover Crop Committee: Proceedings, 4th Annual Workshop. Department of Crop Science, University of Guelph. Guelph, Ont.

477. Winterhalder, K. 1975. Reclamation of industrial barrens in the Sudbury area. Pages 64-72 IN: Transactions - Annual Meeting Ontario Chapter, the Canadian Society of Environmental Biologists. Laurentian University. Sudbury, Ont.

478. Winterhalder, K. 1976. Reclamation studies on industrial barrens in the Sudbury region - a progress report. Pages 65-68 IN: Proceedings of the Inaugural Meeting, Canadian Land Reclamation Association. University of Guelph. Guelph, Ont.

479. Winterhalder, K. 1978. $\mathrm{pH}$ and phosphorus as factors limiting plant establishment on the industrially denuded soils of the Sudbury area, Ontario, Canada. Presented at a joint meeting of the British Ecological Society (Industrial Ecology Group) and the British Soil Science Society entitled "Soil-Plant Relationships in the Reclamation of Derelict Land". University of York, U.K.

480. Winterhalder, K. 1978. A historical perspective of mining and reclamation in Sudbury. Pages 1-13 IN: Proceedings of the Third Annual Meeting, Canadian Land Reclamation Association. Sudbury, Ont.

481. Wolff, J.O. 1978. Burning and browsing effects on willow growth in interior Alaska. J. Wildl. Manage. 42(1): 135-140.

482. Woodhouse, W.W., Jr. 1978. Dune building and stabilization with vegetation. U.S. Army, Corps of Engineers, Coastal Engineering Research Centre, Special Report No. 3.

483. Wright, R.A., ed. 1978. The reclamation of disturbed arid land. University of New Mexico Press. Albuquerque, N. Mex. 
484. Younkin, W. 1973. Autecological studies of native species potentially useful for revegetation, Tuktoyaktuk region. Pages 45-76 IN: L.C. Bliss, ed. Botanical studies of natural and man-modified habitats in the Mackenzie valley, eastern Mackenzie delta region and the arctic islands. Environmental-Social Committee Northern Pipelines, Task Force on Northern Oil Development, Report No. 73-44.

485. Younkin, W., and W. Friesen. 1974. Progress report on CAGSL revegetation studies north of $60^{\circ}$. Prepared by Northern Engineering Services Co. Ltd.

486. Younkin, W.E. 1972. Revegetation studies of disturbances in the Mackenzie Delta region. Pages 175-229 IN: L.C. Bliss and R.W. Wein, eds. Botanical studies of natural and man-modified habitats in the eastern Mackenzie delta region and the arctic islands. Indian and Northern Affairs, ALUR 71-72-14.

487. Younkin, W.E. 1975. The effects of winter methanol spills on forest-tundra vegetation. Prepared for Canadian Arctic Gas Study Limited by Northern Engineering Services Company Ltd.

488. Younkin, W.E. 1975. Preliminary pipeline revegetation specifications for areas north of $60^{\circ}$. Prepared for Canadian Arctic Gas Pipeline Ltd. by Northern Engineering Services Company Ltd.

489. Younkin, W.E. 1976. Seeding trials in the Mackenzie Delta region, N.W.T. IN: Proceedings of the First Annual Meeting, Canadian Land Reclamation Association. University of Guelph. Guelph, Ont. (Abstr.)

490. Younkin, Walter E. 1974. Ecological studies of Arctagrostis latifolia (R.Br.) Griseb. and Calamagrostis canadensis (Michx.) Beauv. in relation to their colonization potential in disturbed areas, Tuktoyaktuk region, N.W.T. Unpublished Ph.D. Thesis. University of Alberta.

491. Zuck, R.H., and L.F. Brown, eds. 1976. Proceedings: High Altitude Revegetation Workshop No. 1. Colorado State University. Information Series No. 21.
492.

Zasada, J.C., and R.A. Densmore. 1977. Change in seed viability during storage for selected Alaskan Salicaceae. Seed Science and Technology, 5(3): 509-518.

493. Zasada, J.C., and L.A. Viereck. 1975. Effect of temperature and stratification on germination of Alaskan Salicaceae seeds. Can. J. Forest Res. 5: 333-337.

494. Ziemkiewicz, P.F. 1977. A comprehensive reclamation research program on coal mining disturbed lands. Pages 119-132 IN: Reclamation of lands disturbed by mining. Proceedings of the British Columbia Mine Reclamation Symposium. Vernon, B.C.

495. Ziemkiewicz, P.F., C.A. Dermott, and H.P. Sims, eds. 1978. Proceedings: Workshop on Native Shrubs in Reclamation. Alberta Land Conservation and Reclamation Council, Report No. RRTAC 79-2. Edmonton, AB.

496. Ziemkiewicz, P.F. 1979. The capacity of reclamation plant communities to supply their own nutrients: when does maintenance fertilization become unnecessary? Pages 195-206 IN: Proceedings: Canadian Land Reclamation Association, fourth annual meeting. Regina, Sask.

497. Ziemkiewicz, P.F., and S.M. Northway. 1976. Statistical models predicting the success of thirteen revegetation species on coal-mining disturbed lands in southeastern British Columbia. IN: Proceedings of the first annual meeting, Canadian Land Reclamation Association. Guelph, Ont.

498. Ziemkiewicz, P.F., and S.M. Northway. 1978. A species selection technique for reclamation in British Columbia. Reclamation Review, 1(3/4): 163-166.

499. Zufa, L. 1971. A rapid method for vegetative propagation of aspens and their hybrids. Fores. Chron. 47(2): 36-39. 
Additional References

500. Buckerfield's Ltd. 1980. Seeds for revegetating disturbed land: descriptive manual. Buckerfield's Seed Division. Vancouver, B.C.

501. Porsild, A.E. 1974. Rocky Mountain wild flowers. Natural History Series No. 2. Published by National Museum of Natural Sciences and Parks Canada.

502. Hudson, J.H. 1979. Carex in Saskatchewan. Bison Publishing House, Saskatoon, Sask.

503. Herman, F.J. 1970. Manual of Carices of the Rocky Mountains and Colorado Basin. Agricultural Handbook No. 374 . USDA. Forest Service.

505. Campbell, J.B., K.F. Best, and A.C. Budd. 1973. Ninety-nine range forage plants of the Canadian prairies. Canada Department of Agriculture, Publication No. 964.

506. Taylor, T.M.C. 1974. The pea family of British Columbia. British Columbia Provincial Museum Handbook No. 32.

507. Hitchcock, C.L., and A. Cronquist. 1973. Flora of the Pacific Northwest. University of Washington Press, Seattle and London.

\section{Species Manual Update - July 1989 References Cited}

600. Acharya, S.N., C.B. Chu and R. Hermesh. 1989. Effects of population environment and their interaction on Saskatoon berry (Amelanchier alnifolia Nutt.) Seed germination. Can. J. Plant Sci. 69: 277284.

601. Acharya, S.N., R.N. Coleman, M.E. Neuwirth and M. Dalpe. 1989. Why are the grasses green in alpine meadows? IN: Proceedings of the Conference "Reclamation, A Global Perspective". Alberta Land Conservation and Reclamation Council Report RRTAC 89-2. pp. 69-79.
602. Adams, B.W. and C.J. Richardson. 1990. Control of western snowberry. Range Notes 6: 2 - 3. Alberta Forestry, Lands and Wildlife Publication No. T/207.

603. Allen, E.B. J.C. Chambers, K.F. Connor, M.F. Allen and R.W. Brown. 1987. Natural reestablishment of mycorrhizae in disturbed alpine ecosystems. Arctic and Alpine Research 19 (1): 11-20.

604. Anderson, H.G. and A.W. Bailey. 1980. Effects of annual burning on grassland in the aspen parkland of east-central Alberta, Canada. Can. J. Bot. 58 (8): 985-996.

605. Asay, K.H., and R.P. Knowles. 1985. The wheatgrasses. Chapter 18 IN: M.E. Heath, R. Barnes and D.S. Metcalfe, Eds. Forages. The science of grassland agriculture. 4th Edition. lowa State University Press. Ames, lowa.

606. Belcher, E. 1985. Handbook on Seeds of browse shrubs and forbs. Association of Official Seed Analysts in cooperation with USDA Forest Service, Southern Region, Atlanta, Ga. Technical Publication . R8TP8. 19-20.

607. Bishop, B.H. and S.H. Nelson. 1980. Propagation and transplanting of Saskatoons (Amelanchier alnifolia Nutt.) softwood cuttings. Can. J. Plant Sci. 60: 883-890.

608. Bitterroot Native Growers, Inc. 1989. 1989 wholesale nursery catalogue. Bitterroot Native Growers, Inc., Corvallis, Montana. $16 \mathrm{pp}$.

609. Bjugstad, A.J., T.Yamamoto and D.W. Uresk. 1981. Shrub establishment on coal and bentonite clay mine spoils. Pages 104-122. IN: Shrub establishment on disturbed arid and semi-arid lands. Wyoming Game and Fish Dept., Laramie.

610. Bliss, L.C. and J.M. Mayo. 1980. An ecophysical investigation of the jackpine woodland with reference to revegetation of mixed sands. Alberta Oil Sands Environmental Research Program V.E. 6.1 . 
611. Blundon, D. and K. Winterhalder. 1983. Choosing between metal-tolerant Deschampsia caespitosa and agronomic grasses in the revegetation of toxic, metalliferous tailings in the Yukon Territory. IN: Proceedings of the eighth annual meeting of the Canadian Land Reclamation Association. University of Waterloo, Waterloo, Ontario, Canada. August 21 to 24, 1983. pp. $174-200$.

612. Brinkman, K.A. 1974. Amelanchier Med. serviceberry. Pages 212-125. IN: C.S. Schopmeyer, ed. Seeds of woody plants in the United States. USDA Forest Service, Washington, D.C. Agriculture Handbook 450.

613. Brooke, B.M., R.E. McDiarmid and W. Majak. 1988. The cyanide potential in two varieties of Amelanchier alnifolia. Can. J. Plant. Sci. 68 (2): 543-548.

614. Campbell, J.B., K.F. Best and A.C. Budd. 1956. 99 range forage plants of the Canadian Prairies. Can. Dep. Agriculture Publication. 964. Ottawa, Ontario. 102 pp.

615. Cayford, J.H., Z. Chrosciewicz and H.P. Sims. 1967. A review of silviculture research in jackpine. Forestry Branch, Departmental Publication No. 1173.

616. Clark, K.W. and D.H. Heinrichs. 1957. Grass-legume mixture trials. Can. Dep. Agriculture Proc. Dull. p. 27.

617. Crocker, W. and L. V. Barton. 1931. Afterripening, germination, and storage of certain rosaceous seeds. Boyce Thompson Inst. Contrib. 3: 385-404.

618. Crowle, W.L. 1970. Revenue slender wheatgrass. Can. J. Plant Sci. 50: 748749 .

619. Davidson, J.G.N. 1986. The saskatoon industry. Agriculture Canada, Beaverlodge NRG News. 86-11. 3 pp.

620. Davidson, J.G.N. 1987. The prinicipal diseases of commercial saskatoons. Agriculture and Forestry Bulletin, University of Alberta, Edmonton, Canada. 10(1): 6-9.

621. Davidson, J.G.N. (in preparation). Saskatoon fruit production guide.
622. Danielson, R.M. and S. Visser. 1988. Ectomycorrhizae of jack pine and green alder: Assessment of the need for inoculation, development of inoculation techniques and outplanting trials on oil sand tailings. Alberta Land Conservation and Reclamation Council Report RRTAC 88-5. $186 \mathrm{pp}$.

623. Davis, A.M. 1982. The occurrence of anagyrine in a collection of Western American lupines. Journal of Range Management. 35: 81-84.

624. Davis, A.M. and D.M. Stout. 1986. Anagyrine in Western American lupines. Journal of Range Management. 39 (1): 29-30.

625. Department of Energy and Natural Resources. 1982. Summaries of current reclamation studies (updated 1982). Alberta Forest Service, Reforestation and Reclamation Branch. Edmonton, AB.

626. Depuit, E.J., C.L. Skilbred and J.G. Coenenberg. 1982. Effects of two years of irrigation on revegetation of coal surface-mined land in southeastern Montana. J. Range Management. 35 (1): 67-74.

627. Dewey, D.R. 1969. Synthetic hybrids of Agropyron albicans $\times \underline{A}$. dasystachyum, Sitanon hystrix, and Elymus canadensis. Amer. J. Bot. 56(6): 664-670.

628. Dietz, D.R. 1975. Germination, survival and growth of selected browse species in the Black Hills of South Dakota, USA. In. Proceed. Symposium and Workshop Wildand Shrubs. Provo, Utah. Pages: 158-159.

629. Erickson, D.O., W.T. Barker, S. Wanapat and R.L. Williamson. 1981. Nutritional composition of common shrubs in North Dakota, USA. Proceedings North Dakota Academy of Science. 35.4 .

630. Ettala, M.O., K.M. Yrjonen and E.J. Rossi. 1988. Vegetation coverage at sanitary landfills in Finland. Waste Management \& Research 6: 281 - 289.

631. Everett, R.E., R.O. Meeuwig, and J.H. Robertson. 1978. Propagation of Nevada shrubs by stem cuttings. J. Range Management. 13: 426-429. 
632. Fahey, T.J., J.B.Yavitt, J.A. Pearson and D.H. Knight. 1984. The nitrogen cycle in lodgepole pine forests, southeastern Wyoming. Biogeochemistry. 1(3): 257275.

633. Fairey, D.T., and J.L. Dobb. 1989. Red fescue an ideal conservation grass. A species widely adapted in North America. Technology Transfer Publication. Fine seeds committee, British Columbia. Grain Producers Association and Alberta Forage Seed Council.

634. Fedkenheuer, A.W. and H.M. Heacock. 1980. Native plant propagation: analysis of 1977 -1979 data. Syncrude Canada Ltd. Edmonton, Alberta. 83 pp.

635. Fiander, K. 1983. Meadow Foxtail - its use for reclamation and conservation areas. IN: Proceedings of the Eighth Annual Meeting of the Canadian Land Reclamation Association. University of Waterloo, Waterloo, Ontario, Canada. August 21 to 24, 1983.

636. Forsyth, J.K. 1980. Principal component analysis of subalpine vegetation on the east slopes of the Colorado Rocky Mountains. Dissertation Abstracts International. 41(4): 1224-1225.

637. Fowells, H.A. 1965. Silvics of forest trees of the United States. USDA Forest Service Division of Timber Management Research. Agriculture Handbook No. 271. Washington.

638. Friesen, L.J. and C. Stushnoff. 1987. The relationship of moisture content and adenine nucleotide levels with cold hardiness and cryopreservability of Amelanchier alnifolia Nutt. Cryobiology. 24(6). 568.

639. Granite Seed. 1989. 1989-90 wholesale seed catalog. Granite Seed, Lehi, Utah. 32 pp.

640. Hafenrichter, A.L., J.L. Schwendiman, H.L. Harris, R.S. MacLauchlan and H.W. Miller. 1968. Grasses and legumes for soil conservation in the Pacific Northwest and Great Basin States. USDA Soil Conservation Agric. Handbook 339. 69 pp.
641. Hardy BBT Ltd. 1989. Oil sands soil reconstruction project: annual report 1988-89. Prepared for Industry and Government Steering Committee on Oil Sands Reclamation. $33 \mathrm{pp}$.

642. Hardy BBT Ltd. 1988. Judy Creek test mine reclamation status. Prepared for Esso Resources Canada Limited.

643. Hardy BBT Ltd. 1988. Vegetation and soil characteristics in reclaimed areas on the Suncor Lease. 1987 annual report. Prepared for Suncor Inc. Resources Group, Oil Sands Division. 10 pp.

644. Hardy BBT Ltd. 1988. 1987 revegetation monitoring of the Interprovincial Pipe Line (NW) Ltd. Norman Wells to Zama Pipeline. Prepared for Interprovincial Pipe Line (NW) Ltd. 36 pp.

645. Hardy Associates (1978) Ltd. 1983. Vegetation and soil characteristics from 1977 - 1982 in reclaimed areas on the Suncor Lease. 1982 annual report. Prepared for Suncor Inc. Resources Group Oil Sands Division. 80 pp.

646. Hardy Associates (1978) Ltd. 1983. 1983 reclamation program Judy Creek test pit. Prepared for Esso Minerals Canada, a Division of Esso Resources Canada Ltd.

647. Hardy Associates (1978) Ltd. 1982. Reclamation monitoring at the Luscar open pit mine. 1982 report. Prepared for Cardinal River Coals Ltd. 44 pp.

648. Hardy Associates (1978) Ltd. 1980. Vegetation and soil characteristics in reclaimed areas on the Suncor Lease. 1980 annual report. Prepared for Suncor Inc., Resources Group Oil Sands Division. $30 \mathrm{pp}$.

649. Harris, R.E. 1961. The vegetative propagation of Amelanchier alnifolia. Can. J. Plant Science 41: 728 - 731.

650. Harris, R.E. and E.B.B. Mason. 1983. Two machines for invitro propagation of plants in liquid media. Can. J. Plant Science 63: 311 - 316. 
651. Harrison, G. 1980. Revegetation research, Windy Point, Jasper National Park. Parks Canada Western Region Office.

652. Harrison, G. 1981. Seeding trials, Flints Park fire road. 1978 - 1980. Parks Canada Western Region Office.

653. Hartmann, H.T. and D.E. Kester. 1975. Plant propagation principles and practices. Third edition. Prentice Hall Inc., Englewood Cliffs, N.J.

654. Heit, C.E. 1971. Propagation from seed. Part 22 testing and growing western desert and mountain shrub species. American Nurseryman. 133: 10-2, 76 - 89.

655. Hermesh, R. 1989. Report on the native species for reclamation program (1988 1989). A progress report for: The Reclamation Division of Alberta Environment, The Reclamation Research Technical Advisory Committee, The Canadian Parks Service. Vegetation Branch, Alberta Environmental Centre. Vegreville.

656. Hermesh, R. and L.M. Cole. 1983. Propagation study: use of shrubs for oil sands mine reclamation. Alberta Land Conservation and Reclamation Council. Edmonton, Alberta. Report No. RRTAC 842. $58 \mathrm{pp}$.

657. Hess, L.W. and D.B. Dunn. 1970. Nomenclature of the Lupinus argenteus and L. caudatus complexes. Rhodora 72 (789): $110-114$.

658. Hewitt, G.B. 1980. Tolerance of ten species of Agropyron to feeding by Labops hesperius. J. Econ. Entomol. 73(6): 779 782.

659. Hilditch, T.W., G.A. Sinclair and C.P. Hughes. 1988. Rehabilitation of pits and quarries for forest production. Prepared by Gartner Lee Limited for the Aggregate Resources Section, Ontario Ministry of Natural Resources, Toronto, Ontario. 28 pp.

660. Hosie, R.C. 1979. Native trees of Canada. Canadian Forestry Service, Department of Fisheries and Forestry.
661. Humphrey, L.D. 1984. Patterns and mechanisms of plant succession after fire on Artemisia-grass sites in southeastern Idaho. Vegetatio. 57: $91-101$.

662. Irving, R.B. and T. Lawrence. 1982. Grazing cattle preference of alfalfa as influenced by slender wheatgrass. Can. J. Plant Science. 62: 241 - 247.

663. Johnson A., S. Smoliak and D.B. Wilson. 1972. Seedling growth of four Agropyron species. Can. J. Plant Sci. 52: 763 768.

664. Johnson, D.A. 1978. Environmental effects on turgor pressure response in range grasses. Crop. Sci. 18(6): 945 948.

665. Johnson, D.A., T.M.J. Ford, M.D. Rumbaugh and B.Z. Richardson. 1989. Morphological and physiological variation among ecotypes of sweetvetch (Hedysarum boreale Nutt.). Journal of Range Management 42(6): 496-501.

666. Johnson, D.A. and M.D. Rumbaugh. 1986. Field nodulation and acetylene reduction activity of high altitude legumes in the western USA. Arctic and Alpine Research. 18(2): $171-179$.

667. Jones, C.E. and B. McTavish. 1986. Economic and biological feasibility of native plants for land reclamation in western Canada. IN: Proceedings of the eleventh annual meeting of the Canadian Land Reclamation Association. Univ. of British Columbia, Vancouver, B.C. June 3 to $6,1986$.

668. Juntilla, O., C. Stushnoff and L.V. Gusta. 1983. Dehardening in flower buds of Saskatoon berry, Amelanchier alnifolia in relation to temperature, moisture content, and spring bud development. Can. J. Bot. 61: $164-170$.

669. Kennedy, A.J. 1985. Reforestation studies at the Judy Creek Test Mine overview and preliminary results. IN: Revegetation methods for Alberta's mountains and foothills. Proceedings of a workshop held 30 April -1 May 1984, Edmonton, Alberta. Alberta Land Conservation and Reclamation Council. Report RRTAC 85-1. pp. 270-300. 
670. King, P.J., G. Grainger and A. Straka. 1985. Testing of seed pre-germination treatments for selected native shrub species. Alberta Energy and Natural Resources. Edmonton, Alberta. ENR Rep. T/43. 80 pp.

671. King, P.J. $1985 . \quad W o o d y$ plant demonstrations and trials on disturbances in the eastern slopes. IN: Revegetation methods for Alberta's mountains and foothills. Proceedings of a workshop Held 30 April - 1 May 1984, Edmonton, Alberta. Alberta Land Conservation and Reclamation Council, Report RRTAC 85-1. pp. 318 - 352.

672. King, P.J., G. Grainger and A. Straka. 1975. Pre-germination treatments for selected woody plant species native to the eastern slopes. IN: Revegetation methods for Alberta's mountains and goothills. Proceedings of a workshop held 30 April 1 May 1984, Edmonton, Alberta. Alberta Land Conservation and Reclamation Council, Report RRTAC 85-1. pp. 227 - 269.

673. Kittleson, D. 1985. Methodology and initial results of the Bryan Mountain reclamation test plots. IN: Revegetation methods for Alberta's mountains and foothills. Proceedings of a workshop held 30 April 1 May 1984, Edmonton, Alberta. Alberta Land Conservation and Reclamation Council. Report RRTAC 85-1. pp. 301-317.

674. Lawrence, T. 1978. An evaluation of thirty grass populations as forage crops for southwestern Saskatchewan. Can. J. Plant Science 58: $107-115$.

675. Lloyd, D.A. and S.M. Smoliak. 1983. Revegetation and reclamation of sandy regosols -a preliminary report. IN: Proceedings of the eighth annual meeting of the Canadian Land Reclamation Association. University of Waterloo, Waterloo, Ontario, Canada. August 21 to 24, 1983.

676. Looman, J. and K.F. Best. 1979. Budd's flora of the Canadian prairies. Research Branch, Agriculture Canada Pub. 1662. Ottawa. 363 pp.

677. Louda, S.M., P.M. Dixon and N.J. Huntly. 1987. Herbivory in sun versus shade at a natural meadow-woodland ecotone in the Rocky Mountains. Vegetatio. 72(3): 141150.
678. Lowen, K. and D.G. Walker, 1989. Buying seed: The pitfalls and blunders and how to avoid them. IN: Alberta Conservation and Reclamation Conference '88. C.B. Powter (Compiler). Proceedings of a conference sponsored by the Alberta chapters of the Canadian Land Reclamation Association and the Soil and Water Conservation Society. pp. 139-144.

679. Macyk, T.M. and B.A. Skirrow. 1984. Reclamation research at no. 8 and no. 9 mines. Grand Cache, Alberta. IN: revegetation methods for the mountains and foothills. P.F. Ziemkiewicz (Ed.). Report \# RRTAC 85-1. Reclamation Research Technical Advisory Committee. Edmonton, Alberta.

680. Majak, W., B. Pink, J. Hall and J.S. McKenzie. 1982. A rapid method for determining cyanide potential in Saskatoon (Amelanchier alnifolia). Can. J. Plant Sci. 62: 439 - 443.

681. Majak, W., D.A. Quinton and K. Broersma. 1980. Cyanogenic glycoside levels in Saskatoon serviceberry. J. Range Management. 33(3): 197 - 199.

682. Marchand, D.E. 1973. Edaphic control of plant distribution in the White Mountains, eastern California. Ecology 54(2): 233 250.

683. Marks, J.S. and V.S. Marks. 1988. Winter habitat use by Columbian sharp-tailed grouse in western Idaho. J. Wildlife Management. 52(4): $743-746$.

684. Mazza, G. and M.W. Hodgins. 1985. Benzaldehyde, a major aroma component of Saskatoon berries. Hort. Science. 20(4): 724 - 744.

685. McCabe, D. and A.J. Kennedy. 1989. An evaluation of non-seeding reclamation techniques on an oil sands pipeline rightof-way. IN: Alberta Conservation and Reclamation Conference '88. C.B. Powter, compiler. Proceedings of a symposium sponsored by the Alberta chapters of the Canadian Land Reclamation Association and the Soil and Water Conservation Society. pp. 34-56. 
686. McConkey, M. 1979. What's a Saskatoon? The pioneering and popularizing of native fruit. The North American Pomona XII (1): $2-10$.

687. McElgunn, J.D., and T. Lawrence. 1973. Salinity tolerance of Altai wild ryegrass and other forage grasses. Can. J. Plant Science. 53: $303-307$.

688. Michalski, M.F.P., D.R. Gregory and A.J. Usher. 1987. Rehabilitation of pits and quarries for fish and wildlife. Prepared by Michael Michalski Associates for the Aggregate Resources Section, Ontario Ministry of Natural Resources, Toronto, Ontario. 59 pp.

689. Miller, W.S. and C. Stushnoff. 1970. A description of Amelanchier species in regard to cultivar development. Fruit Var. Hort. Digest. 25: $3-10$.

690. Moss, E.H.,1983. Flora of Alberta. A manual of flowering plants, conifers, ferns, and fern allies found growing without cultivation in the province of Alberta, Canada. 2nd Edition revised by J.G. Packer. University of Toronto Press. Toronto, Ontario.

691. Mueller, D.M. and R.A. Bowman. 1989. Emergence and root growth of three pregerminated cool-season grasses under salt and water stress. Journal of Range Management 42(6): 490 - 495.

692. Nelson, S.H. 1987. Effects of stock plant etiolation on the rooting of Saskatoon berry Amelanchier alnifolia Nutt. cuttings. Can. J. Plant Science 67(1): 299 - 304.

693. Nelson, S.H. and B.H. Bishop. 1980. Rootstock studies on Saskatoons (Amelanchier alnifolia Nutt.). Can. J. Plant Science 60(3): $879-882$.

694. Nelson, S.H., J.R. Sawatzky 1988. Etiolation of stock plants as an aid in the rooting of Saskatoon berry (Amelanchier alnifolia Nutt.) cuttings. Proc. West Can. Sci. Hortic: $39-41$.

695. Nicholas, P.J. and W.J. McGinnies. 1982. An evaluation of 17 grasses and 2 legumes for revegetation of soil and spoil on a coal strip mine. J. Range Management 35(3): $288-293$.
696.

Oddie, T.A. $1986 . \quad$ Revegetation and reclamation of ash lagoon surfaces in central Alberta. IN: Proceedings of the eleventh annual meeting of the Canadian Land Reclamation Association. University of British Columbia, Vancouver, B.C. June 3 - 6, 1986 . Canadian Land Reclamation Association, Guelph, Ont. Pages 205 - 218.

697. Parkinson, D. (ed). 1984. Mycorrhizal studies regarding the reclamation of oil sand tailings: production and outplanting of jackpine seedlings and amounts of VAand ectomycorrhizal inoculum in stockpiled peat. Department of Biology, University of Calgary, Calgary, AB.

698. Pease, J.L., R.H. Vowles and L.B. Keith. 1979. Interaction of snowshoe hares and woody vegetation. J. Wildlife Management. $43(1)$ : $43-60$.

699. Plummer, A.P., D.R. Christensen and S.B. Monsen. 1968. Restoring big game range in Utah. Publication No. 68-3. Utah Division of Fish and Game. Ephrain, Utah. $183 \mathrm{p}$.

700. Pringle, W.L., C.R. Elliott and K.J. Degenhardt. 1975. The effect of photoperiod and temperature on northern Canadian ecotypes of Agropyron trachycaulum var trachycaulum (slender wheatgrass). Can. J. Bot. 53: 18 - 24.

701. Pruski K., J. Nowak and G. Grainger 1990. Micropropagation of four cultivars of Saskatoon berry (Amelanchier alnifolia Nutt.) Plant, Cell, Organ and Tissue Culture Journal (In Press).

702. Pruski, K., M. Mohyuddin and G. Grainger 1990., Saskatoon (Amelanchier alnifolia Nutt.) IN: Y.P.S. Bajaj Ed. "Biotechnology in Agriculture and Forestry - Trees III - Saskatoons (Amelanchier alnifolia Nutt.). Springer - Verlag, Berlin.

703. Riffle, J.W. and G.W. Peterson. 1986. Diseases of trees in the great plains. USDA Forest Service. General technical report RM-129. Fort Collins, Colo.

704. Rowell, M.J. 1980. The evaluation of soil mixture plots established in 1970 on a tailings sand dyke slope. Suncor Ltd., Fort McMurray, AB. 84 pp. 
705. Russell Ecological Consultants. 1986. Reclamation with native grasses in Alberta: field trial results. Prepared for Alberta Energy and Natural Resources, Forest Service by Russell Ecological Consultants, Edmonton, Alberta. Technical Report No. $\mathrm{T} / 115.57 \mathrm{pp}$.

706. Russell Ecological Consultants. 1987. Evaluation of trees and shrubs for oil sands reclamation: field trial results. Reforestation and Reclamation Branch. Alberta Forest Service, Alberta Energy/Forestry, Lands and Wildlife. Edmonton, Alberta. Report No. $T / 149$. $42 \mathrm{pp}$.

707. Russell, W.B. 1984. Evaluation of trees and shrubs for coal mine reclamation in the eastern slopes: a summary of Alberta Forest Service field demonstration plantings 197377. Alberta Energy and Natural Resources, Forest Service, Edmonton, Alberta. ENR Technical Report T/76. 55 pp.

708. Russel, W.B. 1984. Natural vegetation and ecology of abandoned coal mined land at Sterco-Coal Valley, Alberta. IN: P.F. Ziemkiewicz Ed. Revegetation methods for the mountains and foothills. P.F. Ziemkiewicz (Ed.). Report RRTAC 85-1. Reclamation Research Technical Advisory Committee. Edmonton.

709. Ryerson, D.E. A new Montana grass variety "critana" thickspike wheatgrass.

710. Schwartz, P.A. and W.M. Safaya. 1978. Some nutrient deficiency and toxicity symptoms in slender wheatgrass. Proceedings North Dakota Academy of Science. 31(1): $50-57$.

711. Schuman, G.E., F. Rauzi and D.T. Booth. 1982. Production and competition of crested wheatgrass-native grass mixures. Agron. J. 74(1): 23 - 26.

712. Skousen, J. 1988a. Species for revegetation: grasses. Green Lands 18(1): 41-44.

713. Skousen, J. 1988b. Species for revegetation: legumes. Green Lands 17(4): 35-39.
714. Smith, J.A., E.J. DePuit and G.E. Schuman. 1986. Wood residue and fertilizer amendment of bentonite mine spoils: II Plant species responses. J. Environ. Qual. 15: 427 - 435.

715. Smoliak, S. and A. Johnston. 1975. Seedling competition of some grasses in mono- and mixed culture under greenhouse conditions. Can. J. Plant Science 55: 935-940.

716. Smoliak, S. and A. Johnston 1980. Elbee northern wheatgrass Can. J. Plant Sci. 60: $1473-75$.

717. Smoliak, S. and A. Johnston. 1983. Walsh western wheatgrass (notes). Can. J. Plant Sci. 63: 759 - 61.

718. Spurr, S.H. and B.V. Barnes. 1973. Forest ecology. Second edition. The Ronald Press Company. New York, N.Y.

719. St. Pierre, R.G. 1989. Magnitude, timing and causes of immature fruit loss in Amelanchier alnifolia (Rosaceae). Can. J. Bot. 67: 726 - 731 .

720. Stroh, J.R., A.A. Thornburg and D.E. Ryerson. 1972. Registration of critana thickspike wheatgrass (Reg. No. 9). Crop Science 12: 394.

721. Strong, W.L., and K.R. Leggat. 1981. Ecoregions of Alberta. Alberta Energy and Natural-Resources, Resource Evaluation and Planning Division. ENR Technical Report Number: T/4.

722. Takyi, S.K. 1984. Role of topsoil, fertilizers and companion crops in revegetation of two severe sites in the Alberta foothills and mountains. Alberta Department of Energy and Natural Resources, Forest Service, Edmonton, Alberta. ENR Technical Report No. T/67. $29 \mathrm{pp}$.

723. Takyi, S.K. and R.M. Islam. 1984. Performance of native grasses and cultivated legumes and grasses on disturbances in the eastern slopes of the Rockies. Alberta Department of Energy and Natural Resources, Forest Service, Edmonton, Alberta. ENR Technical Report No. T/68. 30 pp. 
724. Thomm, H. 1982. Progress report on the Tent Mountain grass and legume reclamation trials. Alberta Forest Service, Reforestation and Reclamation Branch. Edmonton, $\mathrm{AB}$.

725. Thornburg, A.A. 1982. Plant materials for use on surface-mined lands in arid and semi arid regions. USDA Soil Conservation Service. Report 505-TP-157.

726. Tucker, R., A. McLean and D.E. Waldern. 1977. Relative preference by mule deer Odocoileus hemionus hemionus for six shrubs from range near Kamloops, British Columbia, Canada. Can. J. Animal Science. 57(2): $375-378$.

727. USDA 1961. Seeds. The Yearbook of Agriculture. Washington, D.C.

728. Visser, S. and R.M. Danielson. 1988. Revegetation of oil sands tailings: Growth improvement of silver-berry and buffaloberry by inoculation with mycorrhizal fungi and $\mathrm{N}_{2}$-fixing bacteria. Alberta Land Conservation and Reclamation Council Report RRTAC 88-3. 98 pp.

729. Wali, M.K. and S.M. Jalal. 1971. Analysis of a saline tall grass prairie ecosystem. II. Vegetation-soil relationships along a transect. Proceedings North Dakota Academy of Science. 25(1): 30

730. Wali, M.K. and P.B. Kannowski. 1971. Analysis of a saline tall grass prairie ecosystem. III. A study of soil-plant-ant interactions. Proceedings North Dakota Academy of Science. 25(1): 30.

731. Walker, D.G. 1982. Alpine revegetation research and techniques at the Lake Louise ski area. IN: R.L. Cuany and J. Etra Eds. Proceedings: high altitude revegetation workshop No. 5. Fort Collins, Colorado, March 8 - 9, $1982 . \quad$ Colorado State University, Fort Collins, Colorado. Pages 190-194.

732. Walker, D.G. and G. Harrison. 1985. Bow Valley revegetation trials. IN: Revegetation methods for Alberta's mountains and foothills. Proceedings of a workshop. 30 April - 1 May 1984. Edmonton, Alberta. Alberta Land Conservation and Reclamation Council. Report RRTAC 85-1. pp. 33-49.
733. Walker, N.R., and H.P. Sims 1984. Jack pine seed dispersal from slash and seedling performance on prepared seedbeds. Northern Forest Research Centre, Information Report NOR-X-259, Canadian Forestry Service, Environment Canada.

734. Williamson, R.L. 1978. Improving species composition and seasonal variety on reclaimed strip mined grasslands through selective grazing intensities and time periods. Proceedings North Dakota Academy of Science. 35(0): 5 .

735. Williamson, R.L., W.T. Barker and D.O. Erickson. $1978 . \quad$ Seasonal fluctuations in the nutrient quality of 9 selected shrubs. Proceedings North Dakota Academy Science. 32(1): 16.

736. Williamson, R.L., J.L. Richardson, G.Clambey, B.J. Bermes and E.W. Keamm. 1981. Physical and environmental factors of woodland ecosystems on the Glenharold mine reserve in western North Dakota USA. Proceedings North Dakota Academy Science. 35: 8.

737. Wishart, D.M. 1984. Montane grassland revegetation trails. IN: Proceedings of the ninth annual meeting of Canadian Land Reclamation Association. Calgary, Alberta. August 21 - 24, 1984. Canadian Land Reclamation Association, Guelph, Ont. $17 \mathrm{pp}$.

738. Wright, S. 1989. Advances in plant material and revegetation technology in Alaska. IN: Proceedings of the conference "Reclamation, A Global Perspective". Alberta Land Conservation and Reclamation Council Report RRTAC 89-2. pp. 107-116.

739. Younkin, W. and H. Martens. 1985. Evaluation of selected reclamation studies in Northern Canada. Prepared for Department of Indian and northern Affairs, Northern Environmental Protection Branch. 
740. Ziemkiewicz, P.F. 1985. Effects of topsoiling, maintenance fertilization and species selection on long-term revegetation success. IN: Revegetation methods for Alberta's mountains and foothills. Proceedings of a workshop. 30 April 1 May 1984. Edmonton, Alberta. Alberta Land Conservation and Reclamation Council. Report RRTAC 85-1. pp. 50-77. 


\section{Personal Communications}

1. A. Fedkenheuer, Syncrude Canada Ltd. February, 1980.

2. P. King, Reclamation Division, Reforestation and Reclamation Branch, Forest Service, Alberta Department of Energy and Natural Resources. February, 1980.

3. D. Klym, Suncor Inc. February, 1980.

4. T. Laidlaw, Research Management Division, Alberta Department of the Environment. July, 1980.

5. P. Lulman, LGL Limited. February, 1980.

6. J. Packer, Department of Botany, University of Alberta. July, 1980.

7. R. Sadisivaiah, Department of Genetics, University of Alberta. February, 1980.

8. J. Sherstabetoff, Reclamation Division, Reforestation and Reclamation Branch, Forest Service, Alberta Department of Energy and Natural Resources. February, 1980.

9. P. Sims, Research Management Division, Alberta Department of the Environment, July, 1980.

10. J. Weijer, Department of Genetics, University of Alberta. February, 1980.

11. D.R. Wooley, Scientific and Engineering Services and Research Division, Alberta Department of Energy and Natural Resources. July, 1980.

12. P.F. Ziemkiewicz, Advisory Services and Research Division, Alberta Department of Energy and Natural Resources. July, 1980.

\section{Personal Communications}

\section{Update}

1. Dr. S. Takyi

Alberta Forest Service

Alberta Department of Energy and Natural

Resources

Edmonton, Alberta.

October, 1989.
2. Mr. G. Howe

Manager, Shelterbelt Centre

Prairie Farm Rehabilitation Administration Indianhead, Saskatchewan.

November, 1989.

3. Mr. D. Wishart

Interprovincial Pipe Line Limited

Regina, Saskatchewan.

October, 1989.

4. Mr. G. Grainger

Alberta Tree Nursery and Horticulture Centre

Oliver, Alberta

November, 1989.

5. Dr. M. Vaartnou

M. Vaartnou and Associates

11520 Kestrel Drive

Richmond, B.C.

October, 1989.

6. Mr. J. Hayes

Interprovincial Pipe Line Limited

Edmonton, Alberta

October, 1989.

$7 . \quad$ Dr. J. Davidson

Beaverlodge Research Station

Agriculture Canada

Beaverlodge, Alberta

November, 1989.

8. Ms. G. Harrison

Western Region Office

Canadian Parks Service

Calgary, Alberta

November, 1989.

9. Dr. W. Willms

Agriculture Canada Research Station

Lethbridge, Alberta

October, 1989.

$10 . \quad$ Mr. R. Hermesh

Plant Materials Division

Alberta Environmental Centre

Vegreville, Alberta

November, 1989.

11. Ms. A. Smreciu

Plant Materials Division

Alberta Environmental Centre

Vegreville, Alberta

November, 1989. 
12. Mr. B. Adams

Alberta Forestry, Lands and

Wildlife

Public Lands Division

Lethbridge, Alberta

January, 1990. 
APPENDIX 


\section{Appendix}

The following is a summary of additional species of grasses, forbs, shrubs and trees that have or may have potential for reclamation in Alberta.

\begin{tabular}{|c|c|c|c|c|c|}
\hline Species & Common Name & $\begin{array}{l}\text { Natural } \\
\text { Distribution }\end{array}$ & $\begin{array}{l}\text { Commercially } \\
\text { Available }\end{array}$ & $\begin{array}{l}\text { Reclamation } \\
\text { Information }\end{array}$ & Comments \\
\hline \multicolumn{6}{|l|}{ HERBS } \\
\hline Typha latifolia & Common cattail & $\begin{array}{l}\text { Widespread in wetlands } \\
\text { of grassland, parkland } \\
\text { and boreal forest }\end{array}$ & No & Yes & $\begin{array}{l}\text { Fast growing, wildlife habitat, } \\
\text { sewage treatment }\end{array}$ \\
\hline Carex aquatilis & Sedge & $\begin{array}{l}\text { Widespread in wetlands } \\
\text { throughout Alberta }\end{array}$ & No & None & Fast growing, wildlife habitat \\
\hline \multicolumn{6}{|l|}{ GRASSES } \\
\hline Bouteloua gracilis & Blue grama & Dry grasslands & Yes & Yes & Drought and grazing tolerant \\
\hline Stipa comata & Spear grass & Grasslands & Yes & Yes & Dominant prairie grass, drought tolerant \\
\hline Eestuca scabrella & Rough fescue & Aspen parkland & Yes & Yes & $\begin{array}{l}\text { Dominant grass of parkland, and } \\
\text { Cypress Hills, palatable }\end{array}$ \\
\hline Festuca saximontana & Fescue & $\begin{array}{l}\text { Foothills and aspen } \\
\text { parkland }\end{array}$ & Yes & None & Winter hardy and palatable \\
\hline Agropyron latiglume & $\begin{array}{l}\text { Broad glumed } \\
\text { wheatgrass }\end{array}$ & Subalpine and alpine & No & None & Cold tolerant, erosion control \\
\hline
\end{tabular}

SHRUBS

Ribes spp

Currents and gooseberries

Blueberries

laccinium spp.

Salix exigua

Sandbar willow

Caragana arborescens Common caragana

Introduced hedges and windbreaks in grasslands and parkland

Dwarf birch and bog birch

Boreal forest and

foothills wetlands

Beaked hazelnut

Boreal forest

Low-bush cranberry

Widespread throughout forest areas

Widespread throughout forest areas

\begin{tabular}{|c|}
\hline $\begin{array}{l}\text { Yes (several } \\
\text { varieties) }\end{array}$ \\
\hline Yes \\
\hline
\end{tabular}

Yes

Yes

No

No

Yes

Yes

Yes

Yes

No

No
Hardy, shade tolerant, wildlife habitat ornamental value

Hardy, shade tolerant, wildlife habitat, ornamental value

Fast growing, erosion control, flood tolerant, sandy soil

Drought tolerant, hardy, aggressive, wildlife habitat

Flood tolerant, hardy, wildlife habitat

Hardy, wildife habitat, omamental value

Shade and chinook tolerant, wildlife habitat, ornamental value

Harcly, shade and acid tolerant, erosion control 
Appendix (Continued)

\begin{tabular}{|c|c|c|c|c|c|}
\hline Species & Common Name & $\begin{array}{l}\text { Natural } \\
\text { Distribution }\end{array}$ & $\begin{array}{l}\text { Commercially } \\
\text { Available }\end{array}$ & $\begin{array}{l}\text { Reclamation } \\
\text { Information }\end{array}$ & Comments \\
\hline \multicolumn{6}{|l|}{ TREES } \\
\hline Picea mariana & Black spruce & Widespread throughout & No & Yes & $\begin{array}{l}\text { Hardy, shade, acid and cold soil tolerant, } \\
\text { wildlife habitat }\end{array}$ \\
\hline Populus deltoides & Western cottonwood & $\begin{array}{l}\text { River floodplains in } \\
\text { grassland }\end{array}$ & Yes & Yes & $\begin{array}{l}\text { Flood tolerant, fast growing, wildlife } \\
\text { habitat }\end{array}$ \\
\hline Hybrid $\underline{P}$. deltoides & Brooks poplar & - & Yes & Yes & $\begin{array}{l}\text { Hardy, drought tolerant, fast growing, } \\
\text { ornamental value }\end{array}$ \\
\hline Hybrid P. deltoides & Walker poplar & - & Yes & Yes & $\begin{array}{l}\text { Hardy, fast growing, ornamental } \\
\text { value }\end{array}$ \\
\hline Picea engelmannii & Engelman spruce & Subalpine & Yes & Yes & $\begin{array}{l}\text { Hardy, shade and cold soil tolerant, } \\
\text { wildlife habitat, ornamental value }\end{array}$ \\
\hline Pseudosuga menziesii & Douglas fir & Montane & Yes & Yes & $\begin{array}{l}\text { Chinook and drought tolerant, wildlife } \\
\text { habitat and ornamental value }\end{array}$ \\
\hline
\end{tabular}




\section{Reclamation Research Reports}

1. RRTAC 79-2: Proceedings: Workshop on Native Shrubs in Reclamation. P.F. Ziemkiewicz, C.A. Dermott and H.P. Sims (Editors). 104 pp. No longer available.

The Workshop was organized as the first step in developing a Native Shrub reclamation research program. The Workshop provided a forum for the exchange of information and experiences on three topics: propagation; outplanting; and, species selection. Seven papers and the results of three discussion groups are presented.

2. RRTAC 80-1: Test Plot Establishment: Native Grasses for Reclamation. R.S. Sadasivaiah and J. Weijer. 19 pp. No longer available.

The report details the species used at three test plots in Alberta's Eastern Slopes (one at Caw Creek Ridge and two at Cadomin). Site preparation, experimental design, and planting method are also described.

\section{RRTAC 80-3: The Role of Organic Compounds in Salinization of Plains Coal Mining Sites.} N.S.C. Cameron et al. 46 pp. $\$ 10.00$

This is a literature review of the chemistry of sodic mine spoil and the changes expected to occur in groundwater.

\section{RRTAC 80-4: Proceedings: Workshop on Reconstruction of Forest Soils in Reclamation. P.F. Ziemkiewicz, S.K. Takyi and H.F. Regier (Editors). 160 pp. $\$ 10.00$}

Experts in the field of forestry and forest soils report on research relevant to forest soil reconstruction and discuss the most effective means of restoring forestry capability of mined lands.

\section{RRTAC 80-5: Manual of Plant Species Suitability for Reclamation in Alberta. L.E. Watson, R.W. Parker and D.F. Polster. 2 vols, 541 pp. No longer available.}

Forty-three grass, fourteen forb, and thirty-four shrub and tree species are assessed in terms of their suitability for use in reclamation. Range maps, growth habit, propagation, tolerance, and availability information are provided.

\section{RRTAC 81-2: 1980 Survey of Reclamation Activities in Alberta. D.G. Walker and R.L. Rothwell. 76 pp. $\$ 10.00$}

This survey is an update of a report prepared in 1976 on reclamation activities in Alberta, and includes research and operational reclamation, locations, personnel, etc.

\section{RRTAC 81-3: Proceedings: Workshop on Coal Ash and Reclamation. P.F. Ziemkiewicz, R. Stein, R. Leitch and G. Lutwick (Editors), 253 pp. $\$ 10.00$}

Presents nine technical papers on the chemical, physical, and engineering properties of Alberta fly and bottom ashes, revegetation of ash disposal sites, and use of ash as a soil amendment. Workshop discussions and summaries are also included.

8. RRTAC 82-1: Land Surface Reclamation: An International Bibliography. H.P. Sims and C.B. Powter. 2 vols, 292 pp. $\$ 10.00$

Literature to 1980 pertinent to reclamation in Alberta is listed in Vol. 1 and is also on the University of Alberta computing system (in a SPIRES database called RECLAIM). Vol. 2 comprises the keyword index and computer access manual. 


\section{RRTAC 82-2: A Bibliography of Baseline Studies in Alberta: Soils, Geology, Hydrology and Groundwater. C.B. Powter and H.P. Sims. 97 pp. $\$ 5.00$}

This bibliography provides baseline information for persons involved in reclamation research or in the preparation of environmental impact assessments. Materials, up to date as of December 1981, are available in the Alberta Environment Library.

\section{RRTAC 83-1: Soil Reconstruction Design for Reclamation of Oil Sand Tailings. Monenco} Consultants Ltd. 185 pp. No longer available

Volumes of peat and clay required to amend oil sand tailings were estimated based on existing literature. Separate soil prescriptions were made for spruce, jack pine, and herbaceous cover types. The estimates form the basis of field trials.

11. RRTAC 83-3: Evaluation of Pipeline Reclamation Practices on Agricultural Lands in Alberta. Hardy Associates (1978) Ltd. 205 pp. No longer available.

Available information on pipeline reclamation practices was reviewed. A field survey was then conducted to determine the effects of pipe size, age, soil type, construction method, etc. on resulting crop production.

\section{RRTAC 83-4: Proceedings: Effects of Coal Mining on Eastern Slopes Hydrology.}

P.F. Ziemkiewicz (Editor). 123 pp. $\$ 10.00$

Technical papers are presented dealing with the impacts of mining on mountain watersheds, their flow characteristics, and resulting water quality. Mitigative measures and priorities were also discussed.

13. RRTAC 83-5: Woody Plant Establishment and Management for Oil Sands Mine Reclamation. Techman Engineering Ltd. 124 pp. No longer available.

This is a review and analysis of information on planting stock quality, rearing techniques, site preparation, planting, and procedures necessary to ensure survival of trees and shrubs in oil sand reclamation.

14. RRTAC 84-1: Land Surface Reclamation: A Review of the International Literature. H.P. Sims, C.B. Powter and J.A. Campbell. 2 vols, 1549 pp. $\$ 20.00$

Nearly all topics of interest to reclamationists including mining methods, soil amendments, revegetation, propagation and toxic materials are reviewed in light of the international literature.

15. RRTAC 84-2: Propagation Study: Use of Trees and Shrubs for Oil Sand Reclamation. Techman Engineering Ltd. 58 pp. $\$ 10.00$

This report evaluates and summarizes all available published and unpublished information on large-scale propagation methods for shrubs and trees to be used in oil sand reclamation.

16. RRTAC 84-3: Reclamation Research Annual Report - 1983. P.F. Ziemkiewicz. 42 pp. $\$ 5.00$

This report details the Reclamation Research Program indicating priorities, descriptions of each research project, researchers, results, and expenditures.

17. RRTAC 84-4: Soil Microbiology in Land Reclamation. D. Parkinson, R.M. Danielson, C. Griffiths, S. Visser and J.C. Zak. 2 vols, 676 pp. $\$ 10.00$

This is a collection of five reports dealing with re-establishment of fungal decomposers and mycorrhizal symbionts in various amended spoil types. 
18. RRTAC 85-1: Proceedings: Revegetation Methods for Alberta's Mountains and Foothills. P.F. Ziemkiewicz (Editor). 416 pp. $\$ 10.00$

Results of long-term experiments and field experience on species selection, fertilization, reforestation, topsoiling, shrub propagation and establishment are presented.

19. RRTAC 85-2: Reclamation Research Annual Report - 1984. P.F. Ziemkiewicz. 29 pp. $\$ 5.00$

This report details the Reclamation Research Program indicating priorities, descriptions of each research project, researchers, results, and expenditures.

20. RRTAC 86-1: A Critical Analysis of Settling Pond Design and Alternative Technologies. A. Somani. 372 pp. $\$ 10.00$

The report examines the critical issue of settling pond design, and sizing and alternative technologies. The study was co-funded with The Coal Association of Canada.

\section{RRTAC 86-2: Characterization and Variability of Soil Reconstructed after Surface Mining in} Central Alberta. T.M. Macyk. 146 pp. $\$ 10.00$

Reconstructed soils representing different materials handling and replacement techniques were characterized, and variability in chemical and physical properties was assessed. The data obtained indicate that reconstructed soil properties are determined largely by parent material characteristics and further tempered by materials handling procedures. Mining tends to create a relatively homogeneous soil landscape in contrast to the mixture of diverse soils found before mining.

22. RRTAC 86-3: Generalized Procedures for Assessing Post-Mining Groundwater Supply Potential in the Plains of Alberta - Plains Hydrology and Reclamation Project. M.R. Trudell and S.R. Moran. 30 pp. $\$ 5.00$

In the Plains region of Alberta, the surface mining of coal generally occurs in rural, agricultural areas in which domestic water supply requirements are met almost entirely by groundwater. Consequently, an important aspect of the capability of reclaimed lands to satisfy the needs of a residential component is the post-mining availability of groundwater. This report proposes a sequence of steps or procedures to identify and characterize potential post-mining aquifers.

23. RRTAC 86-4: Geology of the Battle River Site: Plains Hydrology and Reclamation Project. A. Maslowski-Schutze, R. Li, M. Fenton and S.R. Moran. 86 pp. $\$ 10.00$

This report summarizes the geological setting of the Battle River study site. It is designed to provide a general understanding of geological conditions adequate to establish a framework for hydrogeological and general reclamation studies. The report is not intended to be a detailed synthesis such as would be required for mine planning purposes.

24. RRTAC 86-5: Chemical and Mineralogical Properties of Overburden: Plains Hydrology and Reclamation Project. A. Maslowski-Schutze. 71 pp. $\$ 10.00$

This report describes the physical and mineralogical properties of overburden materials in an effort to identify individual beds within the bedrock overburden that might be significantly different in terms of reclamation potential.

25. RRTAC 86-6: Post-Mining Groundwater Supply at the Battle River Site: Plains Hydrology and Reclamation Project. M.R. Trudell, G.J. Sterenberg and S.R. Moran. 49 pp. $\$ 5.00$

The report deals with the availability of water supply in or beneath cast overburden to support post-mining land use, including both quantity and quality considerations. The study area is in the Battle River Mining area in east-central Alberta. 
26. RRTAC 86-7: Post-Mining Groundwater Supply at the Highvale Site: Plains Hydrology and Reclamation Project. M.R. Trudell. 25 pp. $\$ 5.00$

This report evaluates the availability of water supply in or beneath cast overburden to support post-mining land use, including both quantity and quality considerations. The study area is the Highvale mining area in west-central Alberta.

27. RRTAC 86-8: Reclamation Research Annual Report - 1985. P.F. Ziemkiewicz. 54 pp. $\$ 5.00$

This report details the Reclamation Research Program indicating priorities, descriptions of each research project, researchers, results, and expenditures.

28. RRTAC 86-9: Wildlife Habitat Requirements and Reclamation Techniques for the Mountains and Foothills of Alberta. J.E. Green, R.E. Salter and D.G. Walker. 285 pp. $\$ 10.00$

This report presents a review of relevant North American literature on wildlife habitats in mountain and foothills biomes, reclamation techniques, potential problems in wildlife habitat reclamation, and potential habitat assessment methodologies. Four biomes (Alpine, Subalpine, Montane, and Boreal Uplands) and 10 key wildlife species (snowshoe hare, beaver, muskrat, elk, moose, caribou, mountain goat, bighorn sheep, spruce grouse, and white-tailed ptarmigan) are discussed. The study was co-funded with The Coal Association of Canada.

29. RRTAC 87-1: Disposal of Drilling Wastes. L.A. Leskiw, E. Reinl-Dwyer, T.L. Dabrowski, B.J. Rutherford and H. Hamilton. 210 pp. No longer available.

Current drilling waste disposal practices are reviewed and criteria in Alberta guidelines are assessed. The report also identifies research needs and indicates mitigation measures. A manual provides a decision-making flowchart to assist in selecting methods of environmentally safe waste disposal.

30. RRTAC 87-2: Minesoil and Landscape Reclamation of the Coal Mines in Alberta's Mountains and Foothills. A.W. Fedkenheuer, L.J. Knapik and D.G. Walker. 174 pp. $\$ 10.00$

This report reviews current reclamation practices with regard to site and soil reconstruction and re-establishment of biological productivity. It also identifies research needs in the Mountain-Foothills area. The study was co-funded with The Coal Association of Canada.

\section{RRTAC 87-3: Gel and Saline Drilling Wastes in Alberta: Workshop Proceedings. D.A. Lloyd (Compiler). 218 pp. $\$ 10.00$}

Technical papers were presented which describe: mud systems used and their purpose; industrial constraints; government regulations, procedures and concerns; environmental considerations in waste disposal; and toxic constituents of drilling wastes. Answers to a questionnaire distributed to participants are included in an appendix.

\section{RRTAC 87-4: Reclamation Research Annual Report - 1986. 50 pp. $\$ 5.00$}

This report details the Reclamation Research Program indicating priorities, descriptions of each research project, researchers, results, and expenditures.

\section{RRTAC 87-5: Review of the Scientific Basis of Water Quality Criteria for the East Slope Foothills of Alberta. Beak Associates Consulting Ltd. 46 pp. $\$ 10.00$}

The report reviews existing Alberta guidelines to assess the quality of water drained from coal mine sites in the East Slope Foothills of Alberta. World literature was reviewed within the context of the East Slopes environment and current mining operations. The ability of coal mine operators to meet the various guidelines is discussed. The study was co-funded with The Coal Association of Canada. 
34. RRTAC 87-6: Assessing Design Flows and Sediment Discharge on the Eastern Slopes. Hydrocon Engineering (Continental) Ltd. and Monenco Consultants Ltd. 97 pp. $\$ 10.00$

The report provides an evaluation of current methodologies used to determine sediment yields due to rainfall events in well-defined areas. Models are available in Alberta to evaluate water and sediment discharge in a post-mining situation. SEDIMOT II (Sedimentology Disturbed Modelling Techniques) is a single storm model that was developed specifically for the design of sediment control structures in watersheds disturbed by surface mining and is well suited to Alberta conditions. The study was co-funded with The Coal Association of Canada.

\section{RRTAC 87-7: The Use of Bottom Ash as an Amendment to Sodic Spoil. S. Fullerton. 83 pp. No longer available.}

The report details the use of bottom ash as an amendment to sodic coal mine spoil. Several rates and methods of application of bottom ash to sodic spoil were tested to determine which was the best at reducing the effects of excess sodium and promoting crop growth. Field trials were set up near the Vesta mine in East Central Alberta using ash readily available from a nearby coal-fired thermal generating station. The research indicated that bottom ash incorporated to a depth of $30 \mathrm{~cm}$ using a subsoiler provided the best results.

\section{RRTAC 87-8: Waste Dump Design for Erosion Control. R.G. Chopiuk and S.E. Thornton. 45 pp. $\$ 5.00$}

This report describes a study to evaluate the potential influence of erosion from reclaimed waste dumps on downslope environments such as streams and rivers. Sites were selected from coal mines in Alberta's mountains and foothills, and included resloped dumps of different configurations and ages, and having different vegetation covers. The study concluded that the average annual amount of surface erosion is minimal. As expected, erosion was greatest on slopes which were newly regraded. Slopes with dense grass cover showed no signs of erosion. Generally, the amount of erosion decreased with time, as a result of initial loss of fine particles, the formation of a weathered surface, and increased vegetative cover.

\section{RRTAC 87-9: Hydrogeology and Groundwater Chemistry of the Battle River Mining Area. M.R. Trudell, R.L. Faught and S.R. Moran. 97 pp. No longer available.}

This report describes the premining geologic conditions in the Battle River coal mining area including the geology as well as the groundwater flow patterns, and the groundwater quality of a sequence of several water-bearing formations extending from the surface to a depth of about 100 metres.

\section{RRTAC 87-10: Soil Survey of the Plains Hydrology and Reclamation Project - Battle River Project Area. T.M. Macyk and A.H. MacLean. 62 pp. plus 8 maps. $\$ 10.00$}

The report evaluates the capability of post-mining landscapes and assesses the changes in capability as a result of mining, in the Battle River mining area. Detailed soils information is provided in the report for lands adjacent to areas already mined as well as for lands that are destined to be mined. Characterization of the reconstructed soils in the reclaimed areas is also provided. Data were collected from 1979 to 1985 . Eight maps supplement the report.

39. RRTAC 87-11: Geology of the Highvale Study Site: Plains Hydrology and Reclamation Project. A. Maslowski-Schutze. 78 pp. $\$ 10.00$

The report is one of a series that describes the geology, soils and groundwater conditions at the Highvale Coal Mine study site. The purpose of the study was to establish a summary of site geology to a level of detail necessary to provide a framework for studies of hydrogeology and reclamation. 
40. RRTAC 87-12: Premining Groundwater Conditions at the Highvale Site. M.R. Trudell and R. Faught. 83 pp. $\$ 10.00$

This report presents a detailed discussion of the premining flow patterns, hydraulic properties, and isotopic and hydrochemical characteristics of five layers within the Paskapoo Geological Formation, the underlying sandstone beds of the Upper Horseshoe Canyon Formation, and the surficial glacial drift.

\section{RRTAC 87-13: An Agricultural Capability Rating System for Reconstructed Soils. T.M. Macyk. 27 pp. $\$ 5.00$}

This report provides the rationale and a system for assessing the agricultural capability of reconstructed soils. Data on the properties of the soils used in this report are provided in RRTAC 86-2.

\section{RRTAC 88-1: A Proposed Evaluation System for Wildlife Habitat Reclamation in the Mountains and Foothills Biomes of Alberta: Proposed Methodology and Assessment Handbook. T.R. Eccles, R.E. Salter and J.E. Green. 101 pp. plus appendix. $\$ 10.00$}

The report focuses on the development of guidelines and procedures for the assessment of reclaimed wildlife habitat in the Mountains and Foothills regions of Alberta. The technical section provides background documentation including a discussion of reclamation planning, a listing of reclamation habitats and associated key wildlife species, conditions required for development, recommended revegetation species, suitable reclamation techniques, a description of the recommended assessment techniques and a glossary of basic terminology. The assessment handbook section contains basic information necessary for evaluating wildlife habitat reclamation, including assessment scoresheets for 15 different reclamation habitats, standard methodologies for measuring habitat variables used as assessment criteria, and minimum requirements for certification. This handbook is intended as a field manual that could potentially be used by site operators and reclamation officers. The study was co-funded with The Coal Association of Canada.

\section{RRTAC 88-2: Plains Hydrology and Reclamation Project: Spoil Groundwater Chemistry and its Impacts on Surface Water. M.R. Trudell (Compiler). 135 pp. $\$ 10.00$}

Two reports comprise this volume. The first "Chemistry of Groundwater in Mine Spoil, Central Alberta," describes the chemical make-up of spoil groundwater at four mines in the Plains of Alberta. It explains the nature and magnitude of changes in groundwater chemistry following mining and reclamation. The second report, "Impacts of Surface Mining on Chemical Quality of Streams in the Battle River Mining Area," describes the chemical quality of water in streams in the Battle River mining area, and the potential impact of groundwater discharge from surface mines on these streams.

\section{RRTAC 88-3: Revegetation of Oil Sands Tailings: Growth Improvement of Silver-berry and Buffalo-berry by Inoculation with Mycorrhizal Fungi and $\mathrm{N}_{2}$-Fixing Bacteria. S. Visser and R.M. Danielson. 98 pp. $\$ 10.00$}

The report provides results of a study: (1) To determine the mycorrhizal affinities of various actinorrhizal shrubs in the Fort McMurray, Alberta region; (2) To establish a basis for justifying symbiont inoculation of buffalo-berry and silver-berry; (3) To develop a growing regime for the greenhouse production of mycorrhizal, nodulated silver-berry and buffalo-berry; and, (4) To conduct a field trial on reconstructed soil on the Syncrude Canada Limited oil sands site to critically evaluate the growth performance of inoculated silver-berry and buffalo-berry as compared with their uninoculated counterparts. 
45. RRTAC 88-4: Plains Hydrology and Reclamation Project: Investigation of the Settlement Behaviour of Mine Backfill. D.R. Pauls (compiler). 135 pp. $\$ 10.00$

This three part volume covers the laboratory assessment of the potential for subsidence in reclaimed landscapes. The first report in this volume, "Simulation of Mine Spoil Subsidence by Consolidation Tests," covers laboratory simulations of the subsidence process particularly as it is influenced by resaturation of mine spoil. The second report, "Water Sensitivity of Smectitic Overburden: Plains Region of Alberta," describes a series of laboratory tests to determine the behaviour of overburden materials when brought into contact with water. The report entitled "Classification System for Transitional Materials: Plains Region of Alberta," describes a lithological classification system developed to address the characteristics of the smectite rich, clayey transition materials that make up the overburden in the Plains of Alberta.

46. RRTAC 88-5: Ectomycorrhizae of Jack Pine and Green Alder: Assessment of the Need for Inoculation, Development of Inoculation Techniques and Outplanting Trials on Oil Sand Tailings. R.M. Danielson and S. Visser. 177 pp. $\$ 10.00$

The overall objective of this research was to characterize the mycorrhizal status of Jack Pine and Green Alder which are prime candidates as reclamation species for oil sand tailings and to determine the potential benefits of mycorrhizae on plant performance. This entailed determining the symbiont status of container-grown nursery stock and the quantity and quality of inoculum in reconstructed soils, developing inoculation techniques and finally, performance testing in an actual reclamation setting.

\section{RRTAC 88-6: Reclamation Research Annual Report - 1987. Reclamation Research Technical} Advisory Committee. 67 pp. No longer available.

This annual report describes the expenditure of $\$ 500,000.00$ of Alberta Heritage Savings Trust Fund monies on research under the Land Reclamation Program. The report outlines the objectives and research strategies of the four program areas, and describes the projects funded under each program.

48. RRTAC 88-7: Baseline Growth Performance Levels and Assessment Procedure for Commercial Tree Species in Alberta's Mountains and Foothills. W.R. Dempster and Associates Ltd. 66 pp. $\$ 5.00$

Data on juvenile height development of lodgepole pine and white spruce from cut-over or burned sites in the Eastern Slopes of Alberta were used to define reasonable expectations of early growth performance as a basis for evaluating the success of reforestation following coal mining. Equations were developed predicting total seedling height and current annual height increment as a function of age and elevation. Procedures are described for applying the equations, with further adjustments for drainage class and aspect, to develop local growth performance against these expectations. The study was co-funded with The Coal Association of Canada.

\section{RRTAC 88-8: Alberta Forest Service Watershed Management Field and Laboratory Methods.}

A.M.K. Nip and R.A. Hursey. 4 Sections, various pagings. $\$ 10.00$

Disturbances such as coal mines in the Eastern Slopes of Alberta have the potential for affecting watershed quality during and following mining. The collection of hydrometric, water quality and hydrometeorologic information is a complex task. A variety of instruments and measurement methods are required to produce a record of hydrologic inputs and outputs for a watershed basin. There is a growing awareness and recognition that standardization of data acquisition methods is required to ensure data comparability, and to allow comparison of data analyses. The purpose of this manual is to assist those involved in the field of data acquisition by outlining methods, practices and instruments which are reliable and recognized by the International Organization for Standardization. 
50. RRTAC 88-9: Computer Analysis of the Factors Influencing Groundwater Flow and Mass Transport in a System Disturbed by Strip Mining. F.W. Schwartz and A.S. Crowe. 78 pp. $\$ 10.00$

Work presented in this report demonstrates how a groundwater flow model can be used to study a variety of mining-related problems such as declining water levels in areas around the mine as a result of dewatering, and the development of high water tables in spoil once resaturation is complete. This report investigates the role of various hydrogeological parameters that influence the magnitude, timing, and extent of water level changes during and following mining at the regional scale. The modelling approach described here represents a major advance on existing work.

\section{RRTAC 88-10: Review of Literature Related to Clay Liners for Sump Disposal of Drilling Wastes. D.R. Pauls, S.R. Moran and T. Macyk. 61 pp. $\$ 5.00$}

The report reviews and analyses the effectiveness of geological containment of drilling waste in sumps. Of particular importance was the determination of changes in properties of clay materials as a result of contact with highly saline brines containing various organic chemicals.

\section{RRTAC 88-11: Highvale Soil Reconstruction Project: Five Year Summary. D.N. Graveland, T.A. Oddie, A.E. Osborne and L.A. Panek. 104 pp. $\$ 10.00$}

This report provides details of a five year study to determine a suitable thickness of subsoil to replace over minespoil in the Highvale plains coal mine area to ensure return of agricultural capability. The study also examined the effect of slope and aspect on agricultural capability. This study was funded and managed with industry assistance.

53. RRTAC 88-12: A Review of the International Literature on Mine Spoil Subsidence. J.D. Scott, G. Zinter, D.R. Pauls and M.B. Dusseault. 36 pp. $\$ 10.00$

The report reviews available engineering literature relative to subsidence of reclaimed mine spoil. The report covers methods for site investigation, field monitoring programs and lab programs, mechanisms of settlement, and remedial measures.

\section{RRTAC 89-1: Reclamation Research Annual Report - 1988. 74 pp. $\$ 5.00$}

This annual report describes the expenditure of $\$ 280,000.00$ of Alberta Heritage Savings Trust Fund monies on research under the Land Reclamation Program. The report outlines the objectives and research strategies of the four program areas, and describes the projects funded under each program.

55. RRTAC 89-2: Proceedings of the Conference: Reclamation, A Global Perspective. D.G. Walker, C.B. Powter and M.W. Pole (Compilers). 2 Vols., 854 pp. $\$ 10.00$

Over 250 delegates from all over the world attended this conference held in Calgary in August, 1989. The proceedings contains over 85 peer-reviewed papers under the following headings: A Global Perspective; Northern and High Altitude Reclamation; Fish \& Wildlife and Rangeland Reclamation; Water; Herbaceous Revegetation; Woody Plant Revegetation and Succession; Industrial and Urban Sites; Problems and Solutions; Sodic and Saline Materials; Soils and Overburden; Acid Generating Materials; and, Mine Tailings.

\section{RRTAC 89-3: Efficiency of Activated Charcoal for Inactivation of Bromacil and Tebuthiuron Residues in Soil. M.P. Sharma. 38 pp. $\$ 5.00$}

Bromacil and Tebuthiuron were commonly used soil sterilants on well sites, battery sites and other industrial sites in Alberta where total vegetation control was desired. Activated charcoal was found to be effective in binding the sterilants in greenhouse trials. The influence of factors such as herbicide:charcoal concentration ratio, soil texture, organic matter content, soil moisture, and the time interval between charcoal incorporation and plant establishment were evaluated in the greenhouse. 

